\title{
Análise estrutural de edifícios de paredes de concreto com a incorporação da interação solo-estrutura e das ações evolutivas
}

\author{
VERSÃO CORRIGIDA
}

A versão original encontra-se na Escola de Engenharia de São Carlos

Tese apresentada ao Departamento de Engenharia de Estruturas da Escola de Engenharia de São Carlos, Universidade de São Paulo, como parte dos quesitos necessários para obtenção do título de Doutor em Engenharia Civil (Estruturas).

Orientador: Prof. Dr. Márcio Roberto Silva Corrêa 
AUTORIZO A REPRODUÇÃO TOTAL OU PARCIAL DESTE TRABALHO, POR QUALQUER MEIO CONVENCIONAL OU ELETRÔNICO, PARA FINS DE ESTUDO E PESQUISA, DESDE QUE CITADA A FONTE.

Ficha catalográfica elaborada pela Biblioteca Prof. Dr. Sérgio Rodrigues Fontes da EESC/USP com os dados inseridos pelo(a) autor(a).

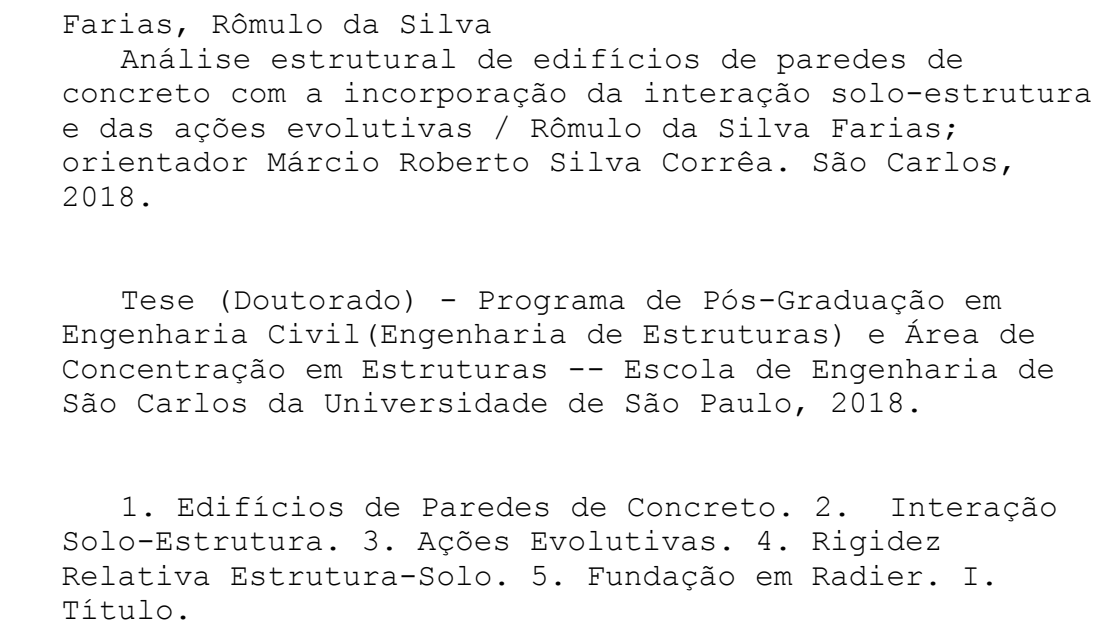

Eduardo Graziosi Silva - CRB - 8/8907 


\section{POLHA DE JULGAMENTO}

Candidato: Engenheiro RÔMULO DA SILVA FARIAS.

Título da tese: "Análise estrutural de edifícios de paredes de concreto com a incorporação da interação solo-estrutura e das ações evolutivas".

Data da defesa: 06/12/2018

Comissão Julgadora:

Resultado:

Prof. Associado Marcio Roberio Silva Corrêa (Orientador)

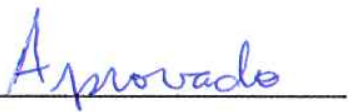

(Escola de Engenharia de São Carlos/EESC)

Prof. Associado Vladimir Guilherme Haach

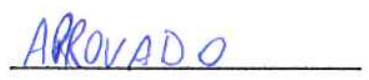

(Escola de Engenharia de São Carlos/EESC)

Prof. Associado Alexandre Duarłe Gusmão

(Universidade de Pernambuco/UPE)

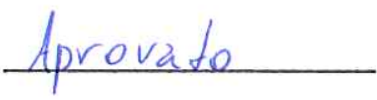

Prof. Titular Moacir Kripka

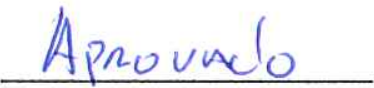

(Universidade de Passo Fundo/UPF)

Prof. Tiłular Túlio Nogueira Bitłencourł

(Escola Politécnica/EP-USP)

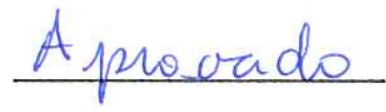

Coordenador do Programa de Pós-Graduação em Engenharia Civil (Engenharia de Estruturas):

Prof. Titular Humberto Breves Coda

Presidente da Comissão de Pós-Graduação:

Prof. Associado Luís Fernando Cosła Alberio 

Dedico este trabalho ao meu irmão André (in memoriam) e a minha família 



\section{AGRADECIMENTOS}

Agradeço a minha família. Aos meu pais, João e Luzinete, e aos meus irmãos, André (in memoriam) e Keroh. Agradeço a minha esposa Andresa pelo apoio em todos os momentos e por estar ao meu lado nessa caminhada. Aos meus sobrinhos, Gabriel e Arthur, e a Raquel Remígio.

Ao meu orientador Prof. Márcio Corrêa, pela dedicação e paciência na orientação desse trabalho e pela amizade e apoio fornecido.

Ao Eng. Marcos de carvalho, pelo apoio e pela amizade que foram fundamentais para a realização desse trabalho.

Ao prof. Alexandre Duarte de Gusmão pelas indicações e contribuições dadas que foram essenciais para o desenvolvimento do trabalho e a concessão das medições experimentais dos edifícios analisados.

Aos professores do Departamento de estruturas da EESC. Ao Prof. Vladimir Haach, pelo auxílio na modelagem numérica. A Professora Ana Lúcia El Debs e ao Professor Samuel Giongo. Aos funcionários do Departamento de estruturas da EESC.

Aos Engenheiros Denis Delazari, Vínicius Pereira, Paulo Vitor Santos, Thales Braguim e Jonny Dantas, pelas discussões e contribuições diretas e indiretas fornecidas.

Aos amigos da OSMB Engenheiros Associados. Aos amigos e colegas do SET. Aos amigos do Jaça.

Agradeço a todos que contribuíram no desenvolvimento deste trabalho. 



\section{RESUMO}

FARIAS, Rômulo da Silva. Análise estrutural de edifícios de paredes de concreto com a incorporação da interação solo-estrutura e das ações evolutivas. 2018. 263p. Tese de doutorado - Departamento de Estruturas, Escola de Engenharia de São Carlos, Universidade de São Paulo, São Carlos-SP, 2018.

As análises estruturais têm como procedimento usual considerar apoios rígidos nas fundações e aplicar as ações de maneira instantânea. Essas duas simplificações podem induzir a uma configuração de esforços não condizentes com a estrutura real. Este trabalho investiga a interação solo-estrutura (ISE) em edifícios de paredes de concreto apoiados em fundação do tipo radier. O presente estudo considera a sequência construtiva da edificação, denominada por ações evolutivas, objetivando obter resultados mais condizentes com a estrutura real. A investigação é realizada mediante simulação numérica utilizando o Método dos Elementos Finitos (MEF) por meio do pacote computacional DIANA ${ }^{\circledR}$. A tipologia do modelo numérico é baseada em um conjunto de edifícios já construídos. São utilizados dados de monitoramento de recalques geotécnicos ao longo da construção dos edifícios para aferir as propriedades constitutivas do solo no modelo numérico. São analisados os efeitos da deformação da fundação na redistribuição de esforços e tensões das paredes da superestrutura, a contribuição da rigidez da estrutura na uniformização dos recalques e demais parâmetros que envolvem a ISE na estrutura e na fundação. A NBR-16055 (ABNT, 2012) obriga que seja incorporado a interação solo-estrutura nas análises de edifícios de paredes de concreto acima de 5 pavimentos. O presente estudo indica que os efeitos da ISE na estrutura têm uma maior dependência da rigidez relativa estrutura-solo. Deste modo, é proposto um coeficiente específico de rigidez relativa estrutura-solo para edifícios de paredes de concreto. São realizados estudos paramétricos que indicam que o coeficiente proposto pode ser utilizado como um parâmetro para análise da ISE em edifícios de paredes de concreto.

Palavras-chave: Edifícios de Paredes de Concreto; Interação Solo-Estrutura; Ações Evolutivas; Rigidez Relativa Estrutura-solo; Fundação em Radier. 



\begin{abstract}
FARIAS, Rômulo da Silva. Structural analysis of concrete wall buildings including soilstructure interaction and progressive loading 2018. 263p. Thesis (Ph.D.) - Departament of Structural Engineering, São Carlos School of Engineering, University of São Paulo, São CarlosSP, 2018.

The usual procedure in structural analysis neglects the deformation of the foundations and the load sequence of the building. These simplifications can provide inaccurate results. This work deals with the structural analysis of concrete wall buildings settled on raft foundations taking into account the soil-structure interaction (SSI) and the progressive vertical loading. The numerical simulation was performed using the finite element method (FEM) in the DIANA ${ }^{\circledR}$ software. The numerical model is based on a set of buildings already constructed. During the construction process, the settlement of many points were measured and are used here to evaluate the constitutive soil parameters to feed the numerical models. The obtained results show a redistribution of the walls' internal forces and the loss of uniformity of their vertical normal stress. The progressive vertical loading during the construction reduces the influences of the soil-structure interaction. The Brazilian code for concrete wall buildings (NBR-16055, 2012) requires that the soil/structure interaction be incorporated into the structural model in the buildings with more than 5 stories. A specific relative stiffness structural-soil factor is proposed for concrete wall buildings. The present study indicates that the SSI results are not related to the number of floors of the building. The SII have a larger dependence on soil stiffness and relative stiffness structure-soil.
\end{abstract}

Keywords: Concrete Wall Buildings; Soil-Structure Interaction; Progressive loads; Relative Stiffness Structure-Soil; Raft Foundations. 



\section{LISTA DE SÍMBOLOS}

\section{Letras maiúsculas}
AR
Fator de recalque absoluto
B
Base da fundação
$C V_{\sigma}$
Coeficiente de variação das tensões normais
$C V_{w}$
Coeficiente de variação dos recalques
$E_{c}$
Módulo de elasticidade do concreto
$E_{s}$
Módulo de elasticidade do solo
$F_{c}$
Fator de contribuição à uniformização do recalque
$G_{c}$
Energia de Fratura na compressão
$G_{f}$
Energia de Fratura na tração
H
Profundidade do maciço do solo
$I_{b}$
Rígidez à flexão do radier
$I_{f}$
Rígidez à flexão da superestrutura
$K_{r}$
Coeficiente de rigidez relativa estrutura-solo (ACI)
$K_{r P A R}$
Coeficiente de rigidez relativa estrutura-solo em edifícios de paredes
$L$
Largura da fundação
Mxd $d_{\text {res }}$
Momento fletor resistente de cálculo - Direção x
Myd $d_{\text {res }}$
Momento fletor resistente de cálculo - Direção y
$M x d_{\text {sol }}$
Momento fletor solicitante de cálculo - Direção x
Mxdres
Momento fletor solicitante de cálculo - Direção y
$N_{d, r e s}$
Esforço normal resistente de cálculo
$N_{d, \text { sol }}$
Esforço normal solicitante de cáculo
$N_{I S E}$
$N_{R E F}$
Esforço normal com a consideração da interação solo- estrutura
$N_{S P T}$
Esforço normal com a consideração de apoios fixos
Índice de resistência à penetração do SPT

\section{Letras minúsculas}

$c$
$e_{\text {min }}$
$f_{c d}$
$f_{c k}$
$f_{s c d}$

Coesão do solo

Excentricidade mínima

Resistência à compressão de cálculo do concreto

Resistência característica à compressão do concreto

Resistência de cálculo do aço 
$m_{x x}$

$m_{y y}$

$m_{x y}$

$m_{x x}^{*}$

$m_{y y}^{*}$

$u_{x}$

$u_{y}$

$u_{Z}$

w

$W_{\max }$

$W_{\text {min }}$

$\bar{W}$

\section{Letras gregas}

$\beta$

$\gamma_{n}$

$\gamma / n$

$\triangle A R$

$\delta w$

$\varepsilon_{x x}$

$\varepsilon_{y y}$

$\varepsilon_{z z}$

$\eta$

$\eta_{d, r e s i s t}$

$\eta_{G R U}$

$\eta_{P A R}$
Resistência característica à tração do concreto

Altura das paredes/pavimentos

Vão médio entre as paredes

Comprimento efetivo da parede

Espessura da parede

Momento fletor - Direção x

Momento fletor - Direção y

Momento volvente

Momentos normais - Direção x

Momentos normais - Direção y

Deslocamento - Eixo global x

Deslocamento - Eixo global y

Deslocamento - Eixo global z

Recalque absoluto

Recalque máximo

Recalque mínimo

Recalque médio
Distorção angular

Coeficiente de majoração de esforços

Coeficiente adicional de majoração de esforços

Variação do fator de recalque absoluto

Recalque diferencial

Deformação - Eixo global x

Deformação - Eixo global y

Deformação - Eixo global z

Coeficiente de redistribuição de esforços normais

Esforço normal resistente por metro (NBR-16055)

Coeficiente de redistribuição de esforços normais - Grupo de Paredes

Coeficiente de redistribuição de esforços normais - Paredes individualizadas 


$\begin{array}{ll}\eta_{\text {Pav,gru }} & \begin{array}{l}\text { Coeficiente de redistribuição de esforços normais médios no } \\ \text { pavimento - Grupo de Paredes }\end{array} \\ \eta_{\text {Pav,par }} & \begin{array}{l}\text { Coeficiente de redistribuição de esforços normais médios no } \\ \text { pavimento - Paredes individualizadas }\end{array} \\ \theta & \text { Desaprumo (Estrutural) } \\ \lambda & \text { Índice de esbeltez da parede } \\ v_{c} & \text { Coeficiente de Poisson do concreto } \\ v_{s} & \text { Coeficiente de Poisson do solo } \\ \rho & \text { Taxa de armadura na parede } \\ \sigma_{c o n t, d} & \text { Tensões de contato de cálculo } \\ \sigma_{x x} & \text { Tensão normal - Eixo global x } \\ \sigma_{y y} & \text { Tensão normal - Eixo global y } \\ \sigma_{z z} & \text { Tensão normal - Eixo global z } \\ \phi & \text { Ângulo de atrito do solo } \\ \omega & \text { Desaprumo (Geotécnico) }\end{array}$



CAPÍTULO 1 - INTRODUÇÃO................................................................................ 21

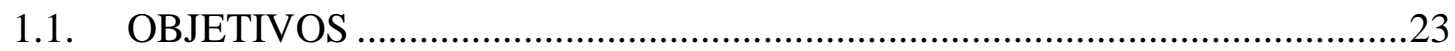

1.1.1. Objetivos específicos.........................................................................24

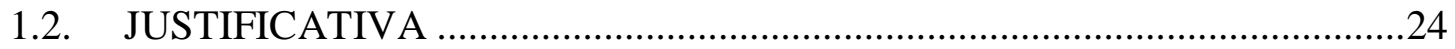

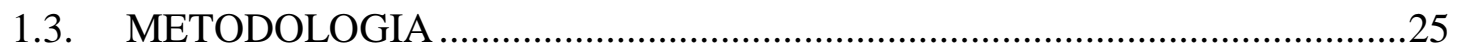

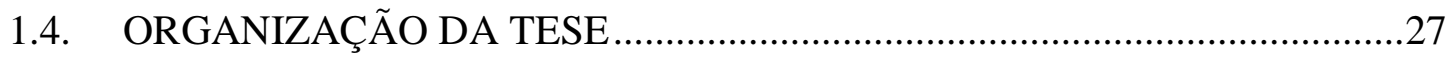

CAPÍTULO 2 - REVISÃO BIBLIOGRÁFICA......................................................29

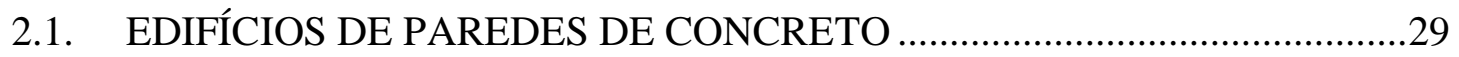

2.1.1. Introdução do sistema estrutural no brasil e aspectos construtivos................29

2.1.2. Comportamento estrutural...........................................................................31

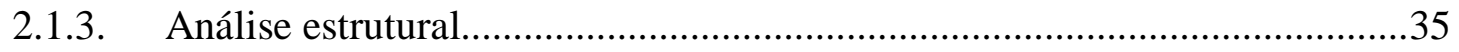

2.2. ANÁLISE ESTRUTURAL COM A INCLUSÃO DA INTERAÇÃO SOLO-

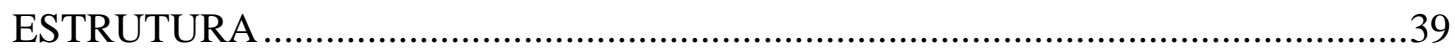

2.2.1. Ise em edifícios de paredes .........................................................................51

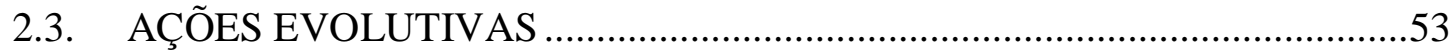

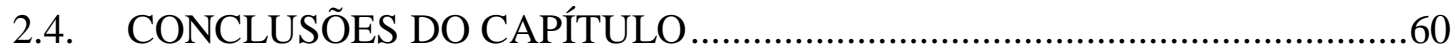

CAPÍTULO 3 - DESENVOLVIMENTO DO MODELO NUMÉRICO.................... 61

3.1. CARACTERÍSTICAS DO PROBLEMA......................................................61

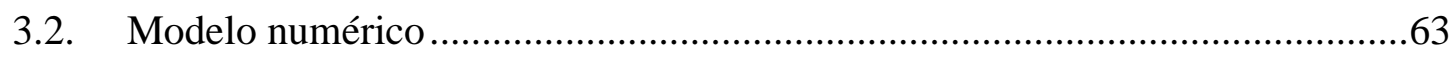

3.2.1. Estratégia para aferir as propriedades do solo ……………………………......64

3.2.2. Modelos constitutivos - superestrutura …………………………...................68

3.2.3. Geometria do modelo proposto....................................................................71

3.2.4. Elementos finitos utilizados.......................................................................72

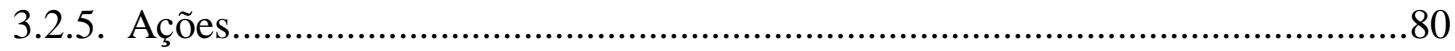

3.3. ANÁLISE COMPARATIVA DOS RECALQUES NUMÉRICOS E

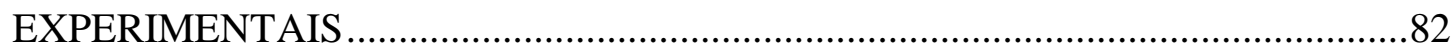

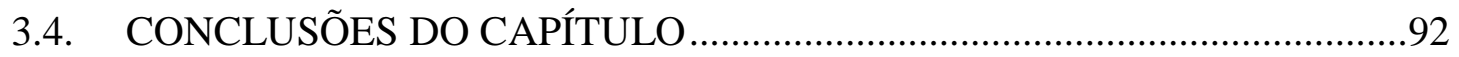

CAPÍTULO 4 -INTERAÇÃO SOLO-ESTRUTURA NOS EDIFÍCIOS DE PAREDE DE CONCRETO...................................................................................95

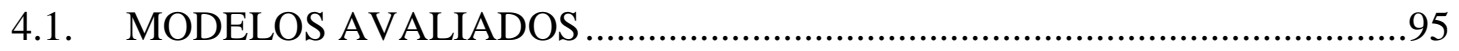

4.2. REDISTRIBUIÇÃO DE ESFORÇOS E TENSÕES NA SUPERESTRUTURA EM EDIFÍCIOS DE PAREDES DE CONCRETO COM A INCLUSÃO DA ISE ....97

4.2.1. Análise da redistribuição de cargas nas paredes 
4.2.2. Distribuição das tensões normais nas paredes 109

4.3. ANÁLISE DAS AÇÕES EVOLUTIVAS

4.4. ASPECTOS CONCLUSIVOS SOBRE O COMPORTAMENTO DA ISE EM EDIFÍCIOS DE PAREDES

4.5. DEMAIS ASPECTOS DA ISE EM EDIFÍCIOS DE PAREDES DE CONCRETO 130

4.5.1. Fissuração nos elementos de paredes. 130

4.5.2. Dimensionamento dos elementos de paredes 134

4.6. CONCLUSÕES DO CAPÍTULO 139

CAPÍTULO 5 - I.S.E. EM EDIFÍCIOS DE PAREDES: INFRAESTRUTURA E

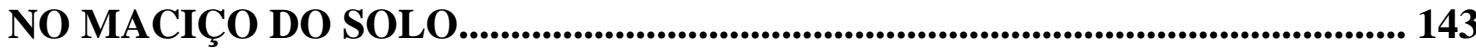

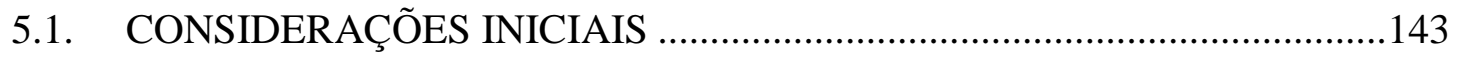

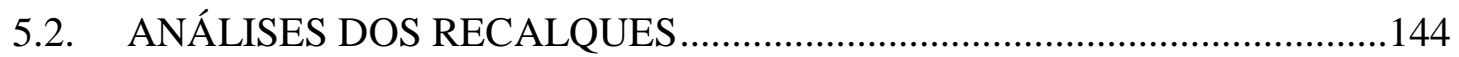

5.3. AÇÕES EVOLUTIVAS E UNIFORMIZAÇÃO DOS RECALQUES...........155

5.4. ASPECTOS CONCLUSIVOS SOBRE A DISTRIBUIÇÃO DOS

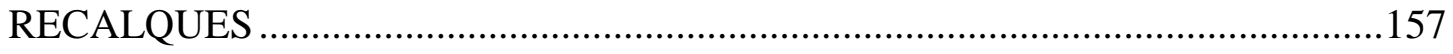

5.5. ANÁLISE DOS ESFORÇOS NA FUNDAÇÃO ............................................160

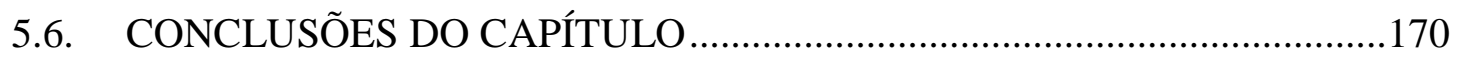

CAPÍTULO 6 - ANÁLISE PARAMÉTRICA............................................................173

6.1. RIGIDEZ RELATIVA ESTRUTURA-SOLO EM EDIFÍCIOS DE PAREDES 173

6.2. ALTURA DA EDIFICAÇÃO E RIGIDEZ DO SOLO..................................178

6.2.1. Construção do edifício e limite de rigidez ....................................................178

6.2.2. Pressões de contato e rigidez relativa estrutura-solo ....................................181

6.2.3. Análise comparativa da variação do número de pavimentos e rigidez do

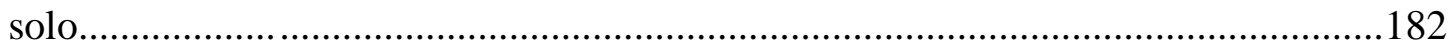

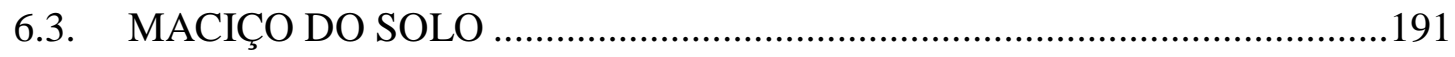

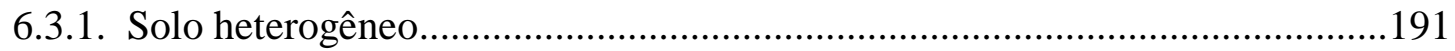

6.3.2. Maciço do solo - profundidade da base rígida ...............................................197

6.4. ANÁLISE DO DESEMPENHO ESTRUTURAL - VARIAÇÃO DO NÚMERO DE PAVIMENTOS E RIGIDEZ DO SOLO ..........................................204

6.4.1. Edifício de 5 pavimentos ................................................................................206

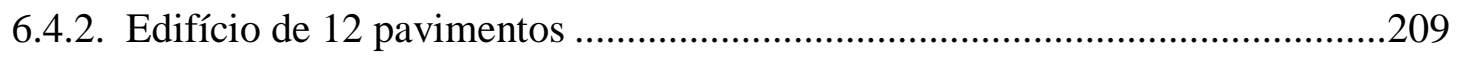

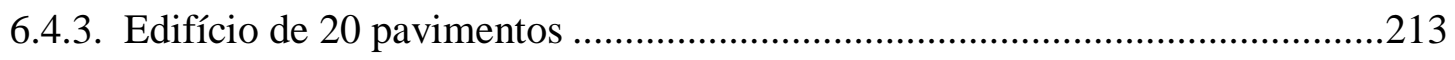

6.4.4. Dimensionamento das paredes pela NBR:6118 (2014) ................................217

6.5. ASPECTOS CONCLUSIVOS SOBRE O DIMENSIONAMENTO DOS EDIFÍCIOS DE PAREDES DE CONCRETO COM A ISE 


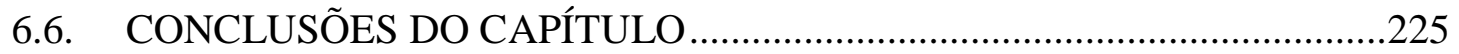

CAPÍTULO 7 - CONCLUSÃO .......................................................................229

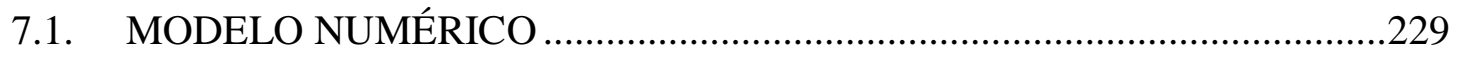

7.2. ISE EM EDIFÍCIOS DE PAREDES .......................................................230

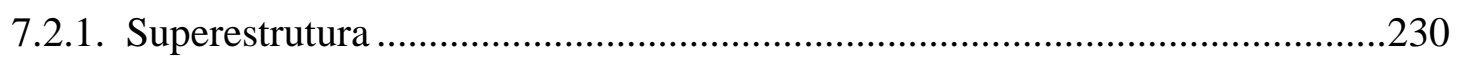

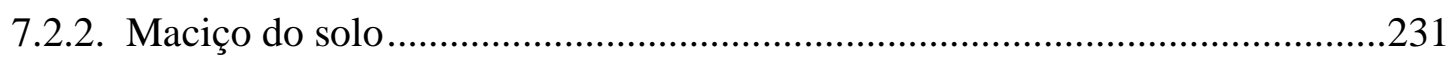

7.3. CONSIDERAÇÕES SOBRE A ISE EM EDIFÍCIOS DE PAREDES DE

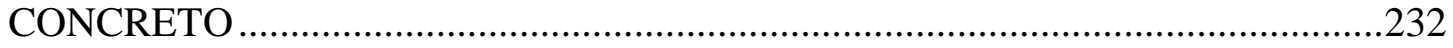

7.4. RECOMENDAÇÕES PARA A NBR-16055 (ABNT, 2012) ........................234

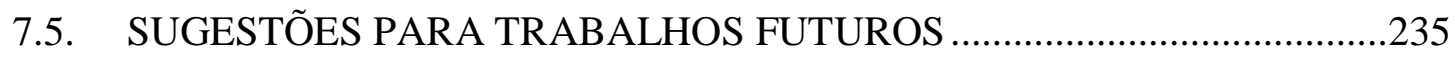

REFERÊNCIAS BIBLIOGRÁFICAS................................................................2237

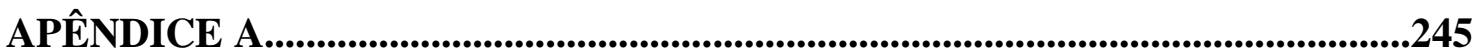

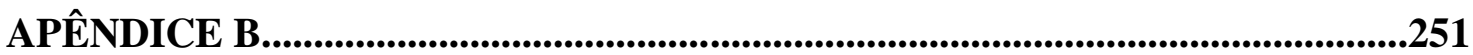

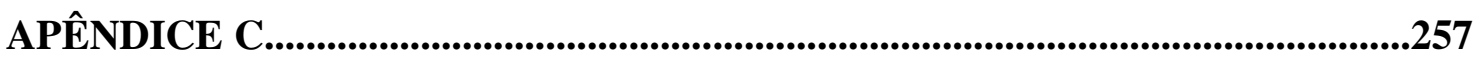

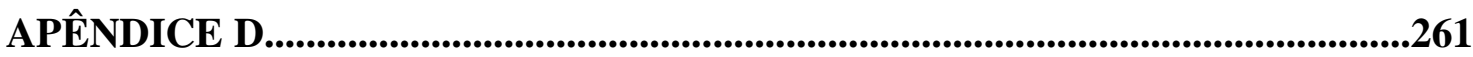





\section{CAPÍTULO 1 - INTRODUÇÃO}

O déficit habitacional é um dos grandes problemas sociais brasileiros, principalmente na faixa populacional de menor renda e poder aquisitivo. Para suprir esta demanda, as construtoras estão optando por sistemas construtivos mais competitivos. Os edifícios de paredes de concreto possuem qualidades que os tornam uma alternativa atraente. O reaproveitamento das fôrmas aliado com o alto grau de repetição dos pavimentos permitem reduções de custos, devida à produção em escala, e à melhoria do processo construtivo.

A ampla utilização dos edifícios de paredes de concreto (Figura 1.1) é recente no Brasil, usualmente utilizados em edificações habitacionais de pequeno e médio porte. Estudos e pesquisas sobre o sistema ganharam força a partir de 2007 numa parceria entre a ABCP (Associação Brasileira de Cimento Portland), ABESC (Associação Brasileira das empresas de serviços de concretagem) e o IBTS (Instituto Brasileiro de Telas Soldadas). Esses institutos desenvolveram em conjunto pesquisas sobre as edificações de parede de concreto moldado in loco (BRAGUIM, 2013).

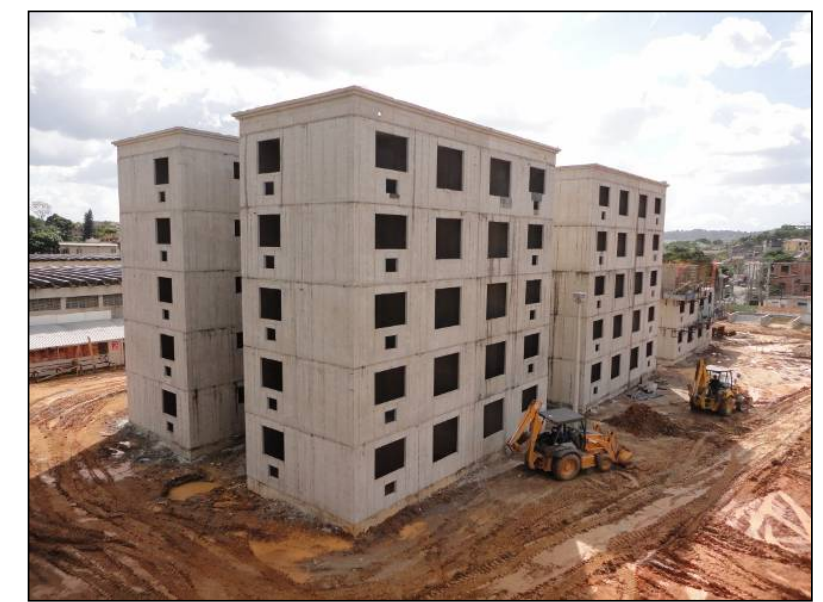

Figura 1.1 Edifícios de paredes de concreto. Fonte: Autor (2012)

No ano de 2012 o surgimento da norma brasileira de paredes de concreto NBR 16055 (ABNT, 2012) evidenciou a necessidade e o interesse do meio técnico sobre o tema. A escassez de referências bibliográficas sobre o tema, a publicação recente da norma de paredes de concreto e o aumento do emprego do referido sistema estrutural são fatores que indicam a necessidade do surgimento de novos estudos e publicações sobre o assunto.

Em relação aos projetos de edifícios de paredes de concreto, alguns aspectos necessitam de estudos e avanços. Esses avanços podem permitir o aprimoramento dos métodos 
de cálculo e, consequentemente, a construção de edifícios mais econômicos e seguros. A interação solo-estrutura é um aspecto particular que carece de pesquisas.

Nas análises estruturais e em projetos de edifícios é usual a idealização dos apoios na fundação como indeslocáveis (Figura 1.2a). Ao realizar esta idealização todos os efeitos da deformação da fundação na superestrutura são desprezados. De modo similar, o cálculo convencional dos recalques nas fundações é realizado desprezando-se a contribuição da rigidez da superestrutura (Figura 1.2b).

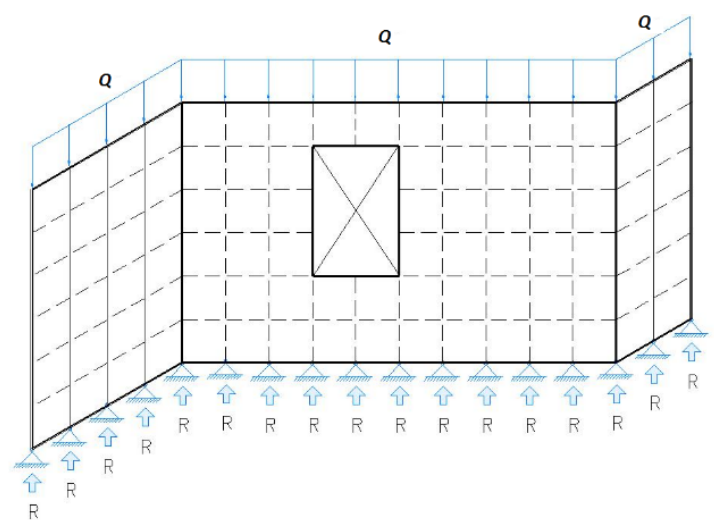

a) Modelo estrutural convencional

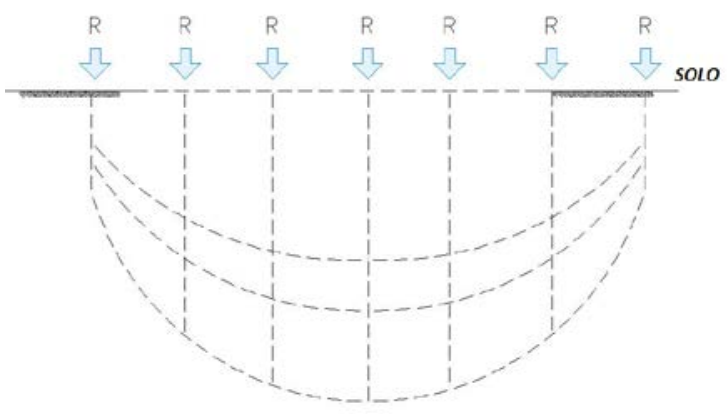

b) Modelo geotécnico convencional

Figura 1.2 - Modelos convencionais

Contudo, para os dois modelos convencionais apresentados, essas idealizações podem não ser satisfatórias. Em uma análise estrutural, os recalques diferenciais nos elementos de fundação podem redistribuir significativamente os esforços nos elementos da superestrutura. $\mathrm{O}$ surgimento de esforços adicionais oriundos dos recalques diferenciais, pode ter como consequência o dimensionamento equivocado dos elementos que compõem a estrutura.

Em relação as análises geotécnicas, estudos desenvolvidos por Chamecki (1954), Poulos (1975) e Gusmão (1994) indicaram que a inclusão da rigidez da superestrutura na estimativa dos recalques na fundação, tendem a uniformizar a distribuição dos recalques. Desta forma, um dos objetivos almejados na consideração da interação solo-estrutura é a possibilidade de reduzir a estimativa dos recalques diferenciais.

Assim sendo, pode-se afirmar que o emprego de uma metodologia que permita acoplar a superestrutura, a infraestrutura e o maciço de solo em um único modelo (Figura 1.3) pode produzir resultados mais representativos da estrutura real. 


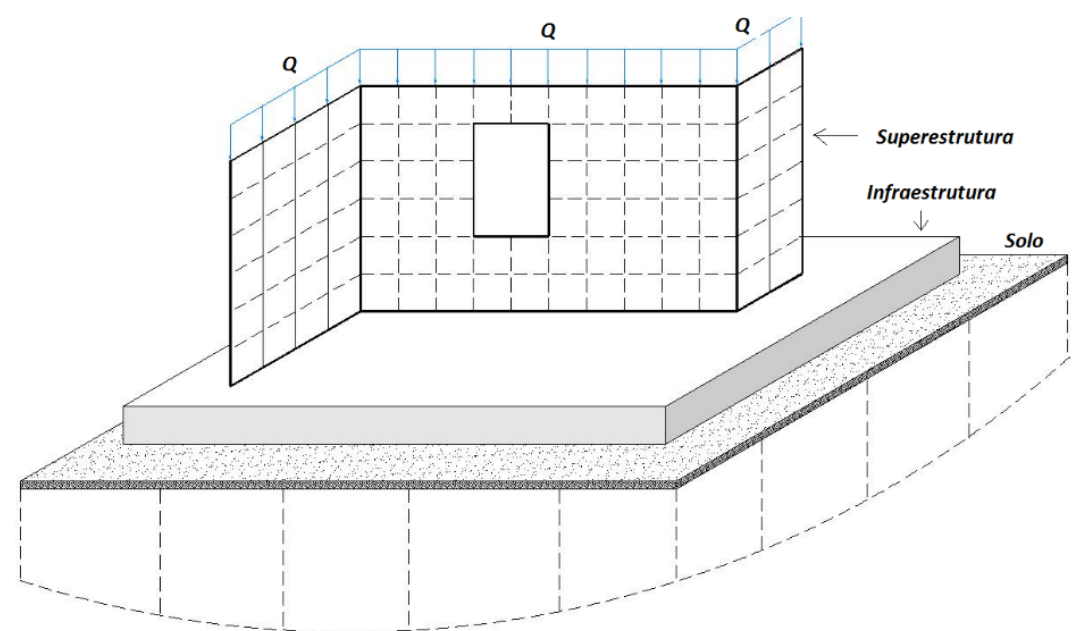

Figura 1.3- Modelo estrutural e geotécnico acoplado

Em uma análise estrutural usual (com ou sem a consideração da interação soloestrutura), as ações são consideradas como aplicadas em sua totalidade de forma instantânea. As ações atuantes em uma estrutura real apresentam uma dependência direta da sequência construtiva, com a atuação progressiva do peso próprio dos elementos para que em uma etapa posterior ocorra a atuação das ações variáveis. A consideração da sequência construtiva, por meio da realização de uma análise evolutiva, tende a modificar a redistribuição dos esforços devido à redução do deslocamento diferencial entre os elementos da estrutura (KRIPKA, 1990). Entende-se que a consideração da sequência construtiva pode vir então a reduzir o nível dos esforços adicionais originários da interação solo-estrutura.

Algumas metodologias que tratam da incorporação da superestrutura na aferição dos recalques na fundação podem ser encontradas na literatura. A ampla maioria destas pesquisas abordam as estruturas convencionais aporticadas, como as desenvolvidas por Poulos (1975) e Aoki (1997), indicando uma carência de trabalhos enfocando especificamente os edifícios de paredes, sobretudo quanto às consequências na superestrutura. É importante afirmar também que o uso da interação solo-estrutura não deva ser necessariamente uma regra estabelecida para todas as análises estruturais. Devido à complexidade e ao custo computacional, esse tipo de análise pode não ser viável. Infelizmente faltam na literatura parâmetros que possam indicar a necessidade do seu emprego, em especial no que se refere aos edifícios de paredes.

\subsection{OBJETIVOS}

O presente trabalho objetiva avaliar a análise estrutural de edifícios de paredes de concreto considerando a interação solo-estrutura e as ações evolutivas. O enfoque do trabalho é em fundações do tipo radier, bastante empregada na atualidade. 


\subsubsection{OBJETIVOS ESPECÍFICOS}

A partir das análises realizadas pretende-se esclarecer uma série de questões relativas aos modelos com a incorporação da interação solo estrutura. Dentre os objetivos específicos podem-se citar:

a). Investigar os efeitos da interação solo-estrutura nas paredes da superestrutura. A inclusão da interação solo-estrutura modifica a distribuição de esforços nas paredes, tornando-se necessário verificar como se manifesta a redistribuição de esforços e tensões nesses elementos. Verificar os efeitos da ISE no dimensionamento das paredes da estrutura.

b). Analisar a uniformização dos recalques na fundação pela inclusão da ISE e a redistribuição de esforços no radier.

c). Investigar a influência dos efeitos da sequência construtiva nos modelos de análise estrutural com a inclusão da ISE. A sequência construtiva pode alterar de forma significativa o comportamento das estruturas reticuladas de concreto, mas ainda não se tem clareza sobre tais efeitos em edifícios de paredes, e a sua contribuição na interação solo-estrutura.

d). Investigar os fatores inerentes à interação solo-estrutura tais como: rigidez do solo, número de pavimentos da edificação, profundidade do maciço do solo e a heterogeneidade do solo.

e). Propor um parâmetro de rigidez relativa estrutura-solo para edifícios de paredes de concreto.

Almeja-se que o trabalho proposto venha a adicionar ao meio técnico, parâmetros e conclusões para as análises usuais em escritórios de projetos estruturais em edifícios de paredes de concreto.

\subsection{JUSTIFICATIVA}

Por mais que os efeitos da interação solo-estrutura possam ocasionar alterações no comportamento da superestrutura para edifícios de paredes de concreto, poucos trabalhos a respeito deste tipo de análise foram desenvolvidos, como se mostrará na revisão bibliográfica. 
Os trabalhos desenvolvidos por Testoni (2013) e Santos (2016) esclarecem alguns pontos a respeito da interação solo-estrutura em edifícios de parede. O presente estudo adiciona aspectos não avaliados nos trabalhos anteriores. Dentre esses aspectos podem-se destacar as não-linearidades físicas dos materiais, a consideração da sequência construtiva e a inclusão das lajes dos pavimentos como elemento para a redistribuição de esforços nas paredes.

A norma de parede de concreto, NBR 16055 (ABNT, 2012), estabelece no item 11.5:

A consideração no modelo estrutural da interação solo-estrutura é obrigatória no caso de edifícios com mais de cinco pavimentos, considerando a deformabilidade da fundação (inclusive vigas de apoio) conforme parâmetros geotécnicos definidos por especialista em mecânica de solos. Deve-se, no mínimo, considerar o modelo de molas discretas independentes localizadas nos pontos de apoio das vigas de fundação.

A obrigatoriedade estabelecida pela referida norma é bastante rigorosa e parece não se basear em critério cientifico, em especial no que se refere ao limite de cinco pavimentos. A inclusão da interação solo-estrutura em práticas corriqueiras de projetos é bastante dispendiosa, acreditando-se que tal prática não seja realizada corriqueiramente e/ou, quando realizada, seja feita de forma muito simplificada.

Corrêa (2005) questiona quais são os parâmetros do conjunto solo-estrutura para indicar a necessidade da consideração da interação solo-estrutura nas análises estruturais de tais edifícios. O autor contesta se é necessário o abandono dos modelos convencionais de apoios rígidos em todas as análises estruturais nos edifícios de parede e indaga quais são os elementos estruturais mais afetados diante da inclusão da deformação do solo.

A escassez de pesquisas a respeito desses sistemas estruturais e o aumento recente de seu uso sinalizam a necessidade do aprofundamento de investigações que contribuam para o crescimento do conhecimento técnico a seu respeito.

\subsection{METODOLOGIA}

Para que os objetivos sejam atingidos, o desenvolvimento da tese é baseado em um estudo realizado em um conjunto de edifícios já construídos, no qual foram realizadas medições de recalques durantes a sua execução.

O edifício modelo faz parte de um empreendimento residencial construído na cidade de São Lourenço da Mata no estado de Pernambuco. O edifício tem 8 pavimentos e fundação 
do tipo radier. O empreendimento estudado possui 64 edifícios com a mesma tipologia na superestrutura (Figura 1.4).

Os edifícios estudados possuem características típicas aos da ampla maioria das construções de paredes de concreto do Brasil. Por este motivo os resultados apresentados são representativos para cumprir os objetivos almejados.
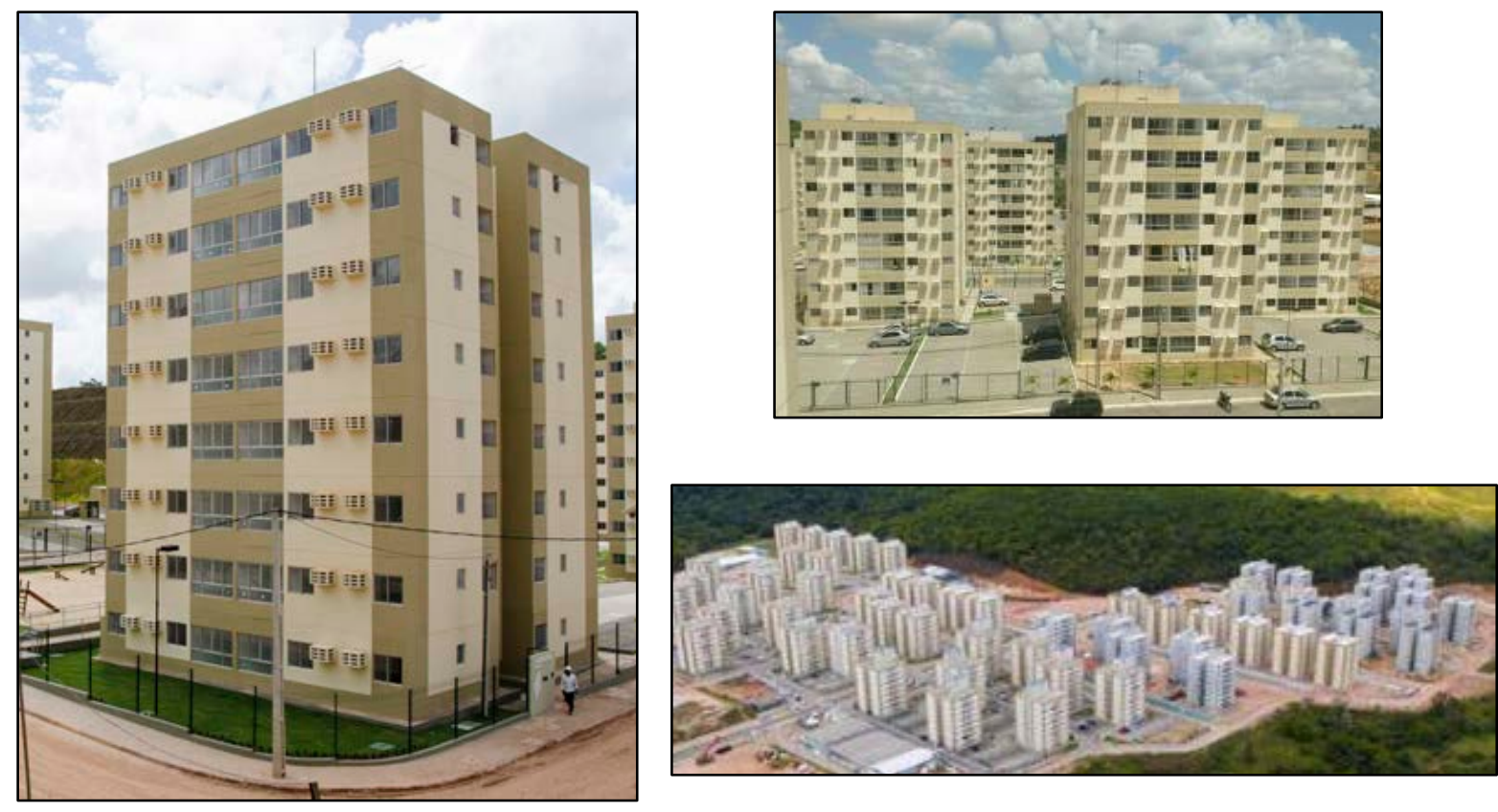

Figura 1.4- Empreendimento estudado

O estudo é realizado por meio de análise numérica com o emprego do método dos elementos finitos. É utilizado o pacote computacional DIANA versão 9.6 para a modelagem e o processamento do modelo. O modelo numérico da superestrutura é desenvolvido com base no projeto estrutural da superestrutura. São analisados três maciços de solo com distintas rigidez. As propriedades do maciço do solo são aferidas por meio dos resultados das medições de recalques realizadas durante a construção do edifício, com o complemento dos ensaios de sondagem do terreno.

O estudo dos efeitos da interação solo-estrutura ocorre por meio de análises comparativas entre modelos numéricos que acoplam o modelo estrutural e o maciço do solo (Modelos ISE-EVO) com modelos numéricos de referência. Os modelos acoplados consideram a sequência construtiva do edifício, denominada no decorrer da tese como "ações evolutivas”. Os resultados dos recalques do modelo numérico são confrontados com o das medições experimentais, para que se comprove a sua representatividade.

O modelo estrutural de referência (REF-AP) é composto apenas pela superestrutura com a consideração de apoios rígidos na base. O modelo de referência considera as ações 
aplicadas de modo instantâneo. Estas simplificações são realizadas visando representar uma análise convencional.

O modelo de referência geotécnico (REF-GEO) considera o maciço do solo como um meio continuo, entretanto, as ações são aplicadas na superfície do maciço, desprezando deste modo a rigidez da superestrutura.

Por fim é realizada uma análise paramétrica com modificações no modelo numérico, como por exemplo o número de pavimentos e a rigidez do solo, visando estudar o papel da rigidez estrutura-solo na interação solo-estrutura.

\subsection{ORGANIZAÇÃO DA TESE}

O capítulo 2 apresenta a revisão bibliográfica dos temas vinculados à tese. Apresentase brevemente uma introdução sobre os edifícios de paredes de concreto, seu comportamento estrutural e os modelos usuais para a análise estrutural desse tipo de edificação. Posteriormente são apresentados trabalhos sobre os efeitos da interação solo-estrutura e sobre as metodologias para contemplar a ISE. Também são expostos estudos a respeito da consideração da sequência construtiva.

No capítulo 3 é descrita a construção do modelo numérico proposto. São concebidos três modelos numéricos similares na superestrutura e distintas propriedades do solo. Os resultados numéricos obtidos são comparados com as medições de recalque da estrutura real. Essa análise tem como objetivo confirmar a representatividade do modelo numérico.

No capítulo 4 são apresentadas as consequências da interação solo-estrutura na superestrutura, mais especificamente nas paredes estruturais. Neste capítulo são investigados o fenômeno da transferência de esforços e as modificações do fluxo de tensões das paredes estruturais. A influência das ações evolutivas no comportamento devido à ISE também é avaliada.

O capítulo 5 mostra os efeitos da interação solo-estrutura no radier e no maciço do solo. São apresentadas as modificações de esforços no radier devidas à inclusão da rigidez da estrutura. No maciço do solo, o principal fator investigado é a influência da rigidez da estrutura na uniformização dos recalques do maciço e na redução das distorções angulares nas bases das paredes.

O capítulo 6 é destinado a um estudo paramétrico baseado no edifício modelo. São investigados os efeitos da ISE com as modificações da rigidez do maciço do solo e do número de pavimento da edificação. É proposto um coeficiente específico de rigidez relativa estrutura- 
solo em edifícios de paredes. Análises são realizadas com variações deste coeficiente. São apresentados estudos com modificações na profundidade do maciço do solo e com a consideração simplificada da heterogeneidade do maciço. Por fim, é avaliado o dimensionamento das paredes com modificações no número de pavimentos e na rigidez do solo.

O capítulo 7 mostra um resumo de todos as conclusões obtidas ao longo da tese, apresentando sugestões para trabalhos futuros e apontando pontos que devem ser observados pelo meio técnico para a evolução dos estudos sobre os edifícios de paredes de concreto. São apresentadas algumas sugestões para a revisão da norma de parede de concreto NBR 16055 (ABNT, 2012). 


\section{CAPÍTULO 2 - REVISÃO BIBLIOGRÁFICA}

O presente estudo investiga o comportamento de estruturas de paredes de concreto com o emprego da ISE e das ações evolutivas. Usualmente esses assuntos são tratados separadamente pelos pesquisadores. O sistema estrutural dos edifícios de paredes de concreto ganhou destaque nos últimos anos. Deste modo, estudos sobre a interação solo-estrutura (ISE) são aplicados na ampla maioria das vezes em estruturas aporticadas. Semelhantemente, o mesmo ocorre nos poucos estudos existentes sobre as ações evolutivas. Desta forma, a revisão bibliográfica desenvolvida neste capítulo é subdividida nos temas envolvidos.

Inicialmente é apresentado resumidamente o desenvolvimento do sistema de parede de concreto no Brasil. São abordadas algumas de suas vantagens e características. São levantados alguns estudos referentes ao comportamento estrutural e ao desenvolvimento da análise estrutural dos edifícios de parede de concreto.

$\mathrm{Na}$ sequência são apresentados alguns dos trabalhos mais relevantes sobre o desenvolvimento da análise da interação solo-estrutura abordando as metodologias de análise, as variáveis influentes e suas implicações na estrutura e no solo. Neste item são mostrados alguns estudos sobre a interação solo-estrutura em edifícios de paredes.

Finalmente alguns trabalhos sobre a aplicação das ações sequenciais, ou ações evolutivas, são abordados.

\subsection{EDIFÍCIOS DE PAREDES DE CONCRETO}

\subsubsection{INTRODUÇÃO DO SISTEMA ESTRUTURAL NO BRASIL E ASPECTOS CONSTRUTIVOS}

O surgimento do sistema estrutural de paredes de concreto no Brasil ocorreu por volta dos anos 2000, embora já existissem edificações com o uso dessa tecnologia na década de 1980. Nesta época, o mercado da construção civil habitacional tinha como demanda um sistema construtivo que fosse ágil e com um custo adequado. Essa demanda ocorreu pelo surgimento de programas habitacionais, em especial o Minha Casa Minha Vida. Em 2007, ocorreu a formação do GPC (Grupo de Parede de Concreto) que tinha como objetivo implementar esse sistema no país. O grupo foi formado pela ABCP (Associação Brasileira de Cimento Portland), 
ABESC (Associação Brasileira das Empresas de Serviços de Concretagem) e pelo IBTS (Instituto Brasileiro de Telas Soldadas). O GPC implementou ciclos de estudos sobre temas relacionados ao sistema e em 2008 publicou a primeira coletânea de ativos em paredes de concreto (MONGE et al., 2018). Em 2012, embora o sistema já estivesse em uso no Brasil, foi lançada a Norma Brasileira de Paredes de Concreto moldada in loco pela ABNT (NBR-16055; ABNT, 2012).

Os elementos de parede de concreto têm funcionamento tanto de vedação como de estrutura portante. Esses elementos são monolíticos, sem juntas aparentes, sendo as instalações (elétricas e hidráulicas) e elementos de esquadrias embutidas. O sistema é utilizado preferencialmente em empreendimentos que possuam alta repetitividade, como condomínios residenciais (Figura 2.1), devido ao alto custo do sistema de formas.

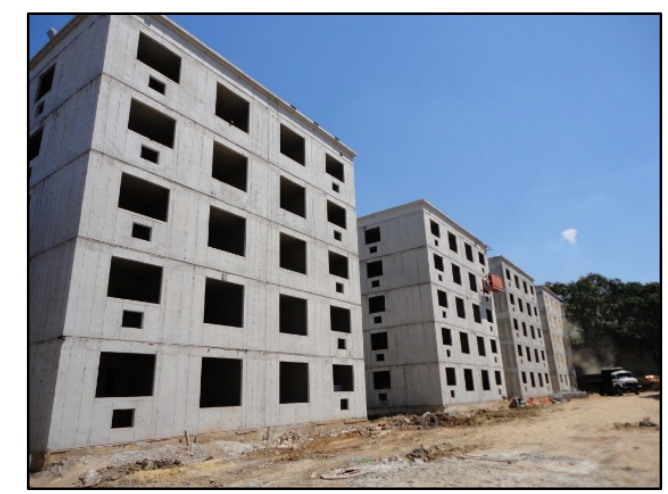

Figura 2.1 - Edifícios de Paredes de concreto - Fonte: Autor (2012)

O sistema de formas usualmente utilizado é de formas metálicas (Figura 2.2). O alto custo das formas é diluído pelo seu ótimo fator de reaproveitamento. O alto reaproveitamento permite que com um mesmo conjunto de formas possam ser executadas diversas unidades idênticas. Ocasionalmente, são utilizados outros tipos de formas como o sistema mistos de formas (quadros metálicos com chapas de madeira compensadas) e as formas de plástico reciclado.
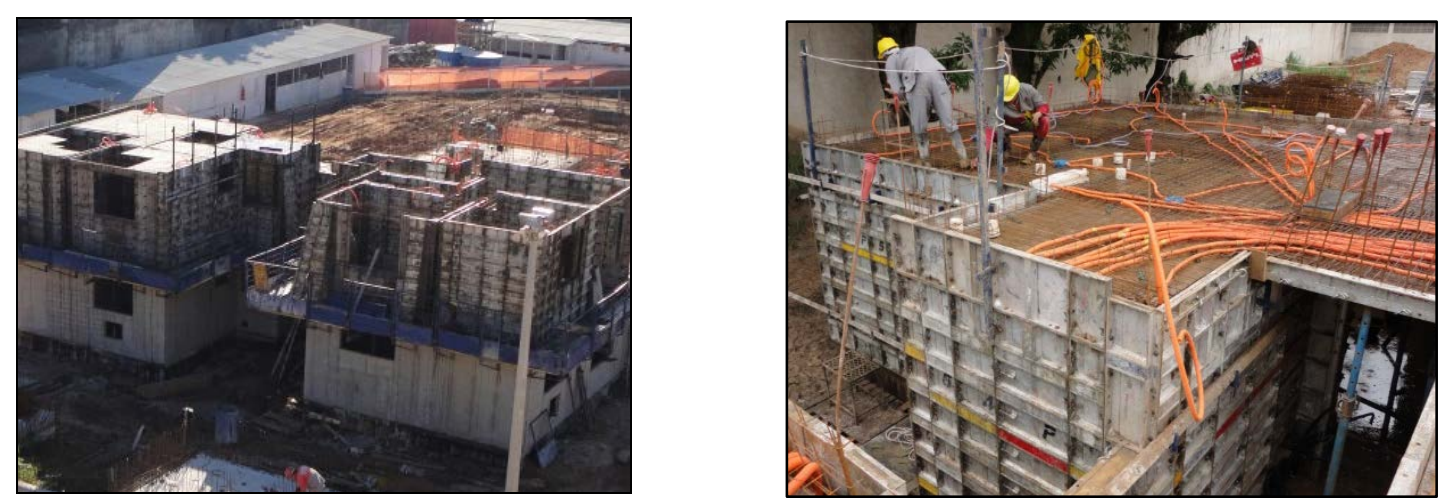

Figura 2.2 - Sistemas de formas metálicas - Fonte: Autor (2012) 
É necessário para o correto funcionamento do sistema de paredes de concreto um bom controle tecnológico do concreto. O concreto utilizado deve possuir boa trabalhabilidade. $\mathrm{O}$ concreto auto-adensável é uma solução frequentemente empregada para facilitar a concretagem das paredes. O controle da resistência à compressão do concreto, “ $f c k$ ”, nas etapas de desforma das paredes também deve ser realizado.

Para aumentar a velocidade e a produtividade do sistema são utilizadas telas soldadas nas armações das lajes e paredes (Figura 2.3). São empregadas telas simples (centralizadas nas paredes) ou telas duplas (posicionadas nas faces das paredes, respeitando o cobrimento). Vergalhões comuns são utilizados em reforços de aberturas, furos e shafts.
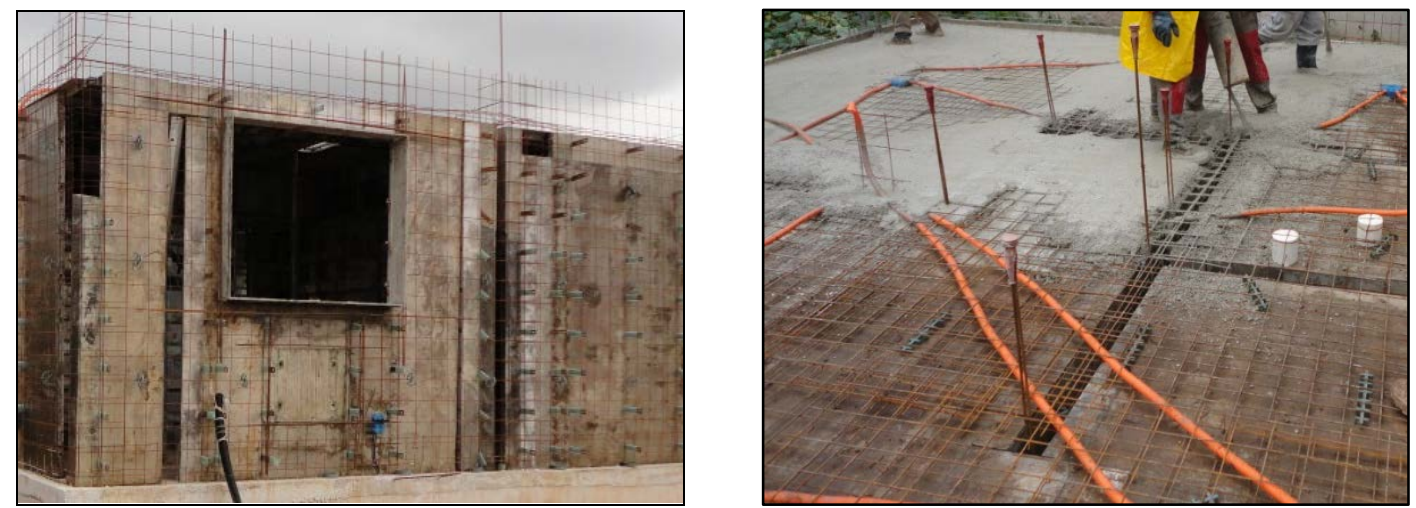

Figura 2.3 - Armação das paredes e lajes de um edifício de parede - Fonte: Autor (2012)

Todas as características citadas tornam o processo construtivo racionalizado. O pouco desperdício e o baixo descarte de materiais inerentes ao processo construtivo dos edifícios de paredes o tornam uma solução sustentável. O uso do mesmo conjunto de formas em inúmeras unidades impõe que haja um planejamento prévio em todas as etapas de projeto (concepção arquitetônica, projetos de formas, projetos de instalações e projetos complementares). Esse procedimento reduz os improvisos em obra e acarreta no emprego de mão de obra especializada (ABCP, 2008).

\subsubsection{COMPORTAMENTO ESTRUTURAL}

As paredes de concreto eram utilizadas inicialmente apenas como componentes adicionais em estruturas aporticadas para compor a estrutura de contraventamento da edificação. Em edifícios de paredes de concreto, os próprios elementos têm como função resistir aos esforços normais provenientes das cargas verticais da estrutura (peso próprio dos pavimentos e ações acidentais) e as ações laterais (vento ou do desaprumo). O próprio elemento estrutural também tem função de elemento de vedação. 
A NBR 16055 (ABNT, 2012) define o elemento de parede de concreto no item 3.1 como:

\footnotetext{
Elemento estrutural autoportante, moldado no local, com comprimento maior que dez vezes sua espessura e capaz de suportar carga no mesmo plano da parede.
}

Os elementos de paredes de concreto possuem espessura menor que as utilizadas em pilares de concreto armado. A taxa de armadura utilizada também é menor que a presente em edificações convencionais de concreto armado. Basicamente esses elementos são submetidos a esforços normais na sua seção transversal (cargas verticais) e momentos fletores originários das ações laterais do vento.

O comportamento estrutural das paredes de concreto foi estudado experimentalmente por diversos autores. Saheb e Desayi (1989) estudaram a resistência de paredes de concreto submetidas a esforços axiais aplicados com pequenas excentricidades. A excentricidade da carga aplicada era o equivalente a $1 / 6$ da espessura da parede. Foram analisadas experimentalmente 24 paredes de concreto. Comprimento, altura dos painéis e as taxas de armaduras horizontais e verticais da parede foram os parâmetros variados no estudo. Todos os exemplares analisados possuíam $5 \mathrm{~cm}$ de espessura. A altura variava de $45 \mathrm{~cm}$ a $135 \mathrm{~cm}$ e o comprimento de $30 \mathrm{~cm}$ a $90 \mathrm{~cm}$. As taxas de armaduras analisadas foram variadas de $0,16 \%$ a 0,85\%. Todos os modelos possuíam vinculações apenas no topo e na base. Os autores chegaram às seguintes conclusões:

- A resistência última dos painéis decresce não-linearmente com o aumento da relação altura/espessura.

- Aumento da resistência do painel com a ampliação da taxa de armadura vertical.

- Pouca influência das armaduras horizontais no comportamento da parede.

Posteriormente Saheb e Desayi (1990) estudaram modelos com dimensões idênticas ao do estudo anterior, sendo agora modificadas as vinculações. Foram dispostos travamentos nas extremidades laterais dos painéis, formando dois planos de flexão ao invés de um plano como no estudo anterior. Os resultados indicaram: 
- A resistência última dos painéis aumenta linearmente com o aumento da relação altura/comprimento.

- Comportamento similar ao estudo anterior em relação à altura/espessura e a taxa vertical de armadura.

- Acréscimo da carga de ruptura com o aumento da taxa de armadura horizontal.

De um modo geral os resultados dos dois estudos apresentaram comportamento distinto na ruptura. Os exemplares do segundo estudo apresentaram carga de ruptura superior em todos os ensaios em comparação aos exemplares do primeiro estudo. A vinculação é um dos pontos mais importantes no comportamento estrutural das paredes de concreto. Dependendo da inclusão ou não das vinculações laterais são formados um ou dois planos de flexão na parede (Figura 2.4).

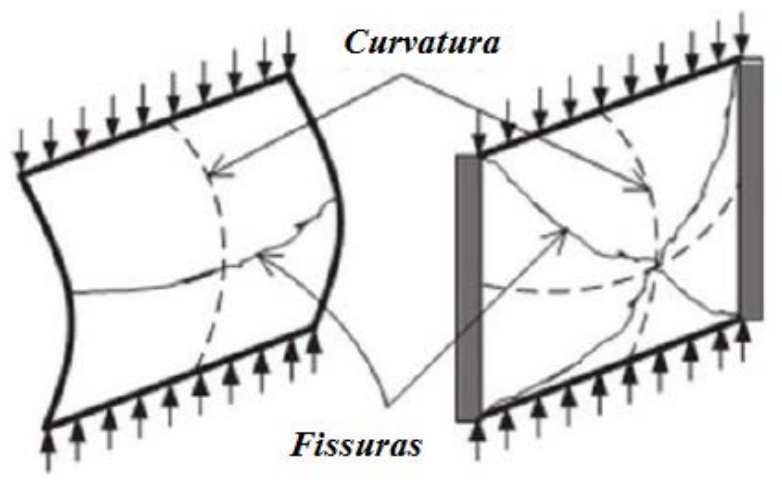

Figura 2.4 - Planos de flexão e vinculações - Adaptado de Braguim (2013)

Os estudos realizados nos trabalhos de Saheb e Desayi (1989 e 1990) serviram como base para o equacionamento utilizado pelo código americano ACI318 (American concrete Institute, 2011) para paredes de concreto submetidas a esforços normais.

Outros códigos normativos internacionais prescrevem expressões especificas similares para o cálculo da resistência axial das paredes de concreto. Dentre esses códigos pode-se citar o Britânico BS810 (British Standard, 1997), que utilizou em suas expressões os estudos experimentais de Seddon (1956), e o Australiano AS3600 (Australian concrete Standard, 2001), que similarmente empregou a pesquisa de Fragomeni (1996) (DOH, 2012). Esses códigos utilizam expressões simplificadas que relacionam as características geométricas do elemento estrutural (altura e espessura da parede), vinculações e taxa de armadura com coeficientes de redução da resistência à compressão do elemento. Essas expressões incluem a consideração automática de excentricidades e os efeitos da instabilidade nas paredes. 
Doh (2012) apresentou questionamentos quanto aos equacionamentos prescritos pelos códigos internacionais. O autor destacou as possíveis falhas dos estudos experimentais que serviram como base para as formulações simplificadas:

- Pouco aprofundamento em elementos com travamentos laterais (Flexão em dois planos).

- Exemplares com limites de resistência característica à compressão entre 25 e $30 \mathrm{MPa}$.

- $\quad$ Limites da razão altura/espessura das paredes menores que 30.

O autor estudou experimental e numericamente paredes de concreto submetidas a esforços normais com excentricidades. Foram avaliados modelos com e sem a inclusão das vinculações laterais. $\mathrm{Na}$ análise numérica foi utilizado o método dos elementos finitos laminados e foram inclusas as não-linearidades físicas do concreto e do aço. Foram utilizados elementos de cascas para a modelagem das paredes. O estudo paramétrico desenvolvido pelo pesquisador consistia na variação das dimensões das paredes, taxa de armadura e excentricidades consideradas. Os resultados numéricos foram confrontados com resultados experimentais (Figura 2.5-a) e foram avaliados exemplares com a flexão ocorrida em um e dois planos (Figura 2.5-b).

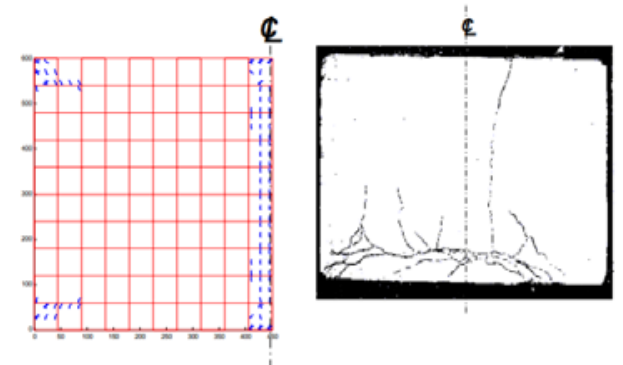

a) Comparação modelo numérico (fissuração) e resultado experimental - Flexão em um plano
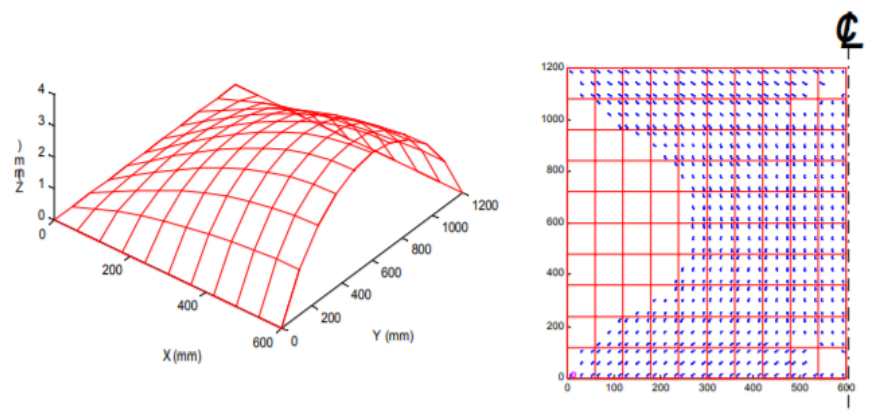

b) Deslocamento e panorama de fissuração - Flexão em dois planos Figura 2.5 - Estudo experimental e numérico - Doh (2012) 
O modelo numérico desenvolvido por Doh (2012) apresentou resultados semelhantes aos ensaiados experimentalmente. Os resultados indicaram que o aumento da resistência à compressão do concreto (Para exemplares com resistência acima de $30 \mathrm{MPa}$ ) não apresentavam necessariamente em um aumento proporcional na carga de ruptura da parede. Fato este considerado nas equações simplificadas dos códigos normativos.

\subsubsection{ANÁLISE ESTRUTURAL}

Um dos primeiros modelos desenvolvidos para a análise estrutural de edifícios de paredes de concreto foi o proposto por Colotti e Vulcano (1987). O modelo denominado como MVLE (Multiple Vertical Line Element) consistia na representação da parede de concreto por elementos uniaxiais conectados por elementos lineares de molas verticais e horizontais. A Figura 2.6 mostra o modelo MVLE proposto pelos autores.

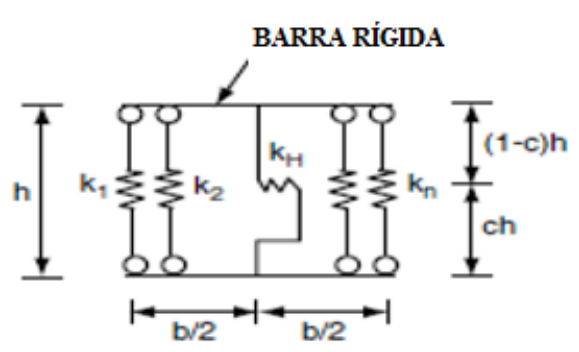

Figura 2.6 - Modelo MVLE - Colotti e Vulcano (2012)

O topo e a base da parede são simulados por vigas de grande rigidez. A rigidez axial das paredes é simulada pelas molas $K_{1}$ até $K_{n}$. A região “ch” e a mola horizontal $K_{H}$ são responsáveis pela rigidez transversal (ações laterais). O modelo sugerido pelos autores apresentou algumas deficiências na representação dos elementos de paredes. Posteriormente, Colotti (1993) argumentou que não existe uma proporção linear entre a carga aplicada e a deformação da parede dificultando o uso de molas lineares. O autor sugeriu modificações no modelo, na qual atrela a rigidez das molas à resposta de uma micro-modelagem não-linear em elementos planos da parede.

O uso de modelos com elementos lineares para a análise de edifícios de paredes de concreto é permitido pela NBR-16055 (ABNT, 2012). Dentre as hipóteses básicas da análise estrutural a referida norma cita no item 14.1.3. 
A Parede componente do sistema estrutural de contraventamento pode ser representada por elemento linear, desde que se considere, além da deformação por flexão, a deformação por cisalhamento. A interação de paredes que se interceptam deve ser incluída no modelo, representado de forma adequada a eventual distinção entre a posição do centro de gravidade e do centro de cisalhamento da seção transversal composta (T, L, C, etc.)

O uso de elementos de barra para representar as paredes estruturais é fundamentado na hipótese de que as tensões devidas às ações verticais apresentam uma distribuição de tensões homogêneas na base da parede. Essa hipótese é permitida pela NBR-16055 (ABNT, 2012) que considera a redistribuição das cargas aplicadas nas paredes seguindo um caminhamento inclinado de 45 graus ao longo da altura do elemento (Figura 2.7).

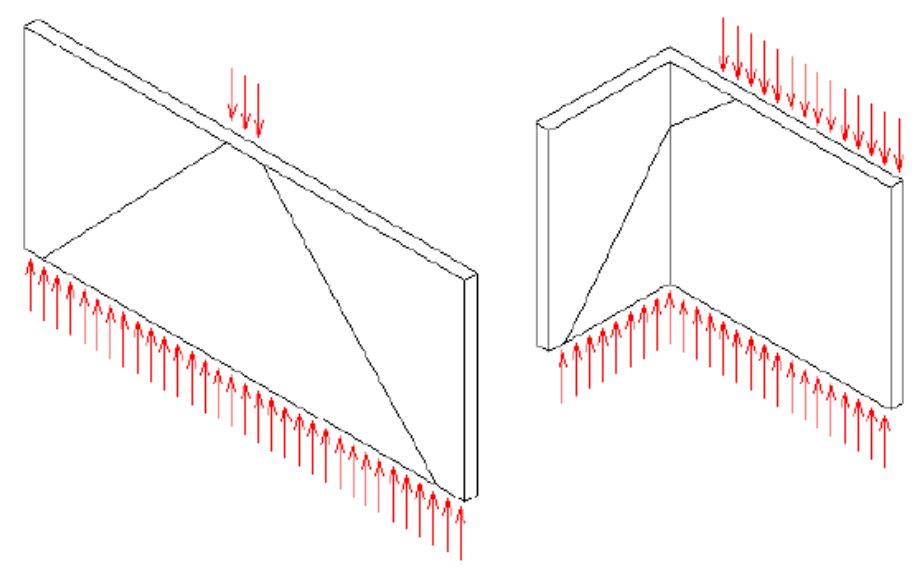

Figura 2.7 - Distribuição de carregamento vertical - Nunes (2011)

Nascimento Neto (1999) utilizou um modelo de pórtico tridimensional para a análise de edifícios de alvenaria estrutural. O modelo foi adaptado do desenvolvido por Yagui (1978) para a análise de núcleos de concreto armado. O pórtico tridimensional representa as paredes por meio elementos de barras verticais flexíveis. O eixo da barra vertical é posicionado no centro geométrico da parede. A barra vertical é fixada em barras horizontais rígidas nos níveis dos pavimentos (base e topo). A ligação entre as paredes conectadas é realizada por meio das barras horizontais rígidas articuladas nas extremidades. Os linteis são simulados por barras horizontais flexíveis. Neste tipo de modelagem é necessário incluir a deformação por cisalhamento nas barras. A Figura 2.8 ilustra o modelo de pórtico tridimensional desenvolvido pelo autor. 


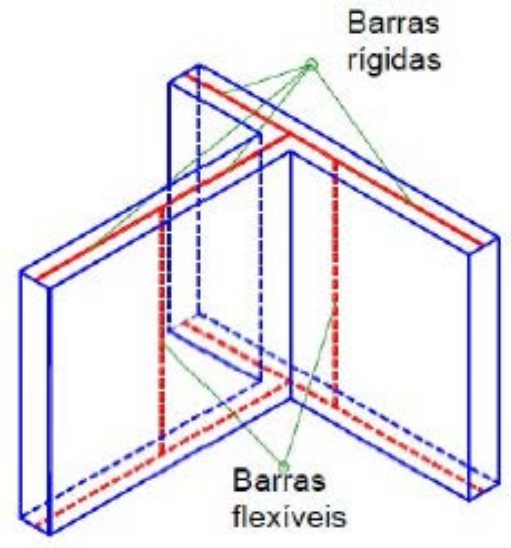

a) Grupos de paredes

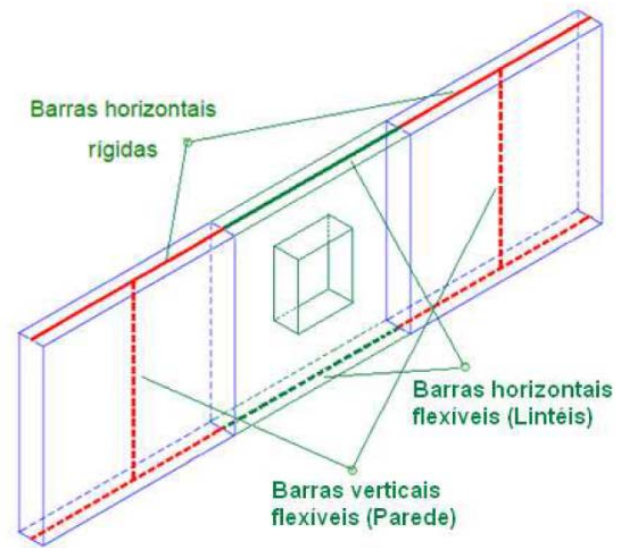

b) Paredes com aberturas

Figura 2.8 - Modelo de Pórtico Tridimensional - Edifícios de Alvenaria estrutural (Nascimento Neto, 1999)

Esse modelo apresenta vantagens relacionadas à simplicidade de sua construção e permite incluir aspectos como a formação de grupos de paredes para as cargas verticais e a adição de linteis sobre as aberturas. O modelo de pórtico tridimensional é suficientemente preciso para análises em que se considera a distribuição dos esforços normais na base das paredes uniforme. Entretanto, esse tipo de investigação numérica pode também não ser viável para a inclusão dos efeitos da ISE. A curvatura da base da edificação, por consequência da deformação do solo, pode originar modificações das tensões nas paredes. Deste modo, a hipótese da homogeneização de esforços não pode ser considerada.

O uso de elementos finitos planos para representar as paredes é um procedimento mais refinado e que permite avaliar as consequências da deformação da base nas paredes. Com o avanço dos microcomputadores dos últimos anos o uso deste método é tecnicamente viável. Entretanto, as inúmeras dificuldades para a construção do modelo e a quantidade de resultados obtidos dificultam sua utilização em casos práticos.

Deste modo, Nunes (2011) propôs o uso de um modelo misto composto por elementos finitos planos de casca e elementos lineares de barra (pórtico tridimensional). O estudo foi baseado em um edifício de parede de concreto apoiado em uma estrutura de transição de concreto armado. O elemento de casca foi utilizado apenas nas paredes dos dois primeiros pavimentos. O pesquisador avaliou a eficiência do modelo misto por meio da comparação de resultados com um modelo de referência. O modelo de referência foi construído com o uso de elementos de cascas em todos os pavimentos. O objetivo almejado era analisar as decorrências do efeito arco nas paredes dos primeiros pavimentos. O uso do modelo misto simplificou a análise ao considerar elementos de barra nos pavimentos superiores, supondo que nesses pavimentos a distribuição de esforços nas paredes é uniforme. 


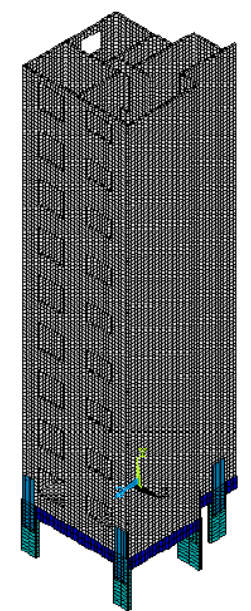

a) Modelo - Elementos finitos - Casca

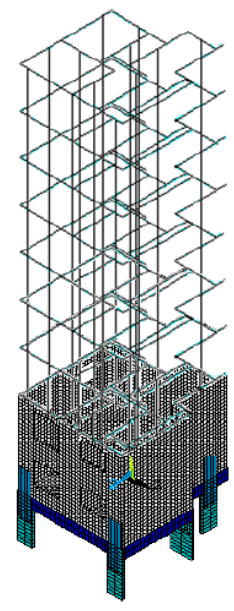

b) Modelo Casca + Pórtico tridimensional

Figura 2.9 - Análise de edifícios de paredes de concreto com transição (Nunes, 2011)

Os resultados obtidos pelo autor mostraram que o uso do modelo misto (Figura 2.9-b) forneceu resultados semelhantes nos pavimentos superiores. A maior diferença percentual de esforços entre os dois modelos oriundos do carregamento vertical foi de $8 \%$. O autor também destacou que o uso de apenas dois pavimentos modelados com elementos de casca foi suficiente para contabilizar o efeito arco nas paredes e nas vigas de transição. Pode-se concluir pela análise do estudo de Nunes (2011) que o uso de elementos planos é necessário apenas nos pavimentos afetados pela deformação da base das paredes.

Braguim (2013) comparou a análise estrutural de um edifício de parede com 16 pavimentos em um modelo de pórtico tridimensional com um modelo composto por elementos de membrana (Figura 2.10). O estudo realizado considerou os edifícios sobre apoios fixos. A comparação de esforços entre os modelos foi realizada com e sem a consideração da interação das paredes no modelo de pórtico tridimensional. O autor avaliou aspectos como a distribuição de esforços normais, a distribuição de momentos devido a ação do vento e o dimensionamento dos elementos.

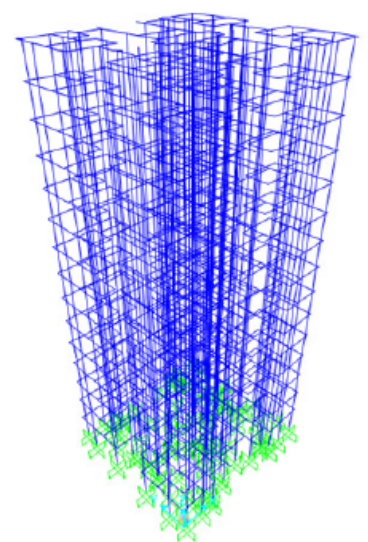

a) Pórtico tridimensional

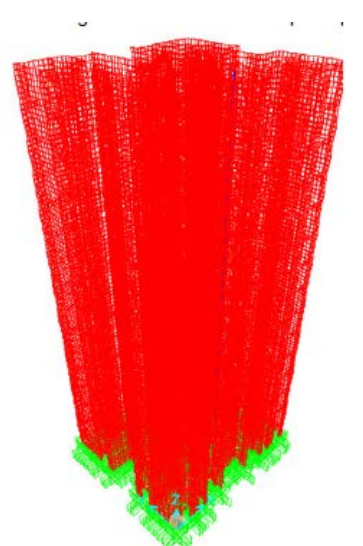

b) Elementos de chapa

Figura 2.10 - Análise de edifícios de paredes de concreto (Braguim, 2012) 
O estudo de Braguim (2013) indicou que o modelo de pórtico tridimensional é confiável para avaliar a distribuição de cargas nas paredes, isto quando considerada a interação entre esses elementos. Na análise dos esforços oriundos das ações horizontais ocorreram diferenças consideráveis entre os modelos (acima de 50\% em alguns elementos). Entretanto, o autor destacou que na verificação do dimensionamento das paredes essas diferenças foram irrelevantes devido à combinação de carregamentos.

\subsection{ANÁLISE ESTRUTURAL COM A INCLUSÃO DA INTERAÇÃO SOLO- ESTRUTURA}

O surgimento do primeiro método com a finalidade de contemplar a deformação do solo em uma análise estrutural foi desenvolvido por Winkler (1867, apud VESIC, 1961) ${ }^{1}$. A hipótese é baseada na representação do maciço do solo com o uso de apoios elásticos (Figura 2.11). Os apoios elásticos simulam a proporcionalidade entre as pressões de contato no solo (“q”) com os respectivos deslocamentos verticais (“w”)

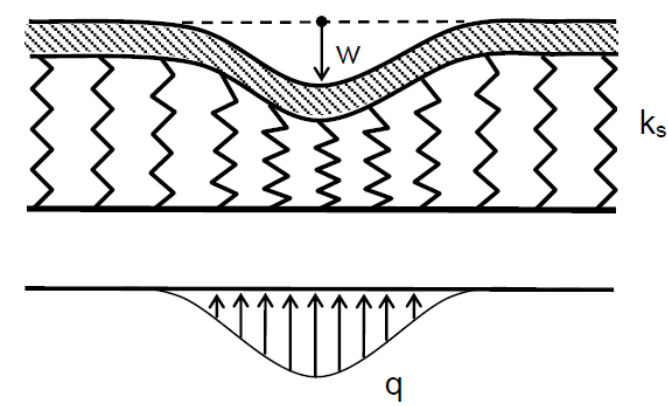

Figura 2.11 - Método de Winkler

Dentre as desvantagens da hipótese pode-se salientar a representação pobre da deformação do solo, distorcendo os resultados quando comparado com a consideração do solo como um meio contínuo. Os aspectos destacados que contribuem na baixa representatividade do método são listados abaixo:

- Falta de interação entre os elementos de mola.

- Dificuldade na definição da rigidez das molas

- Dependência do refinamento da malha

- Dificuldade da representação das diversas camadas do maciço de solo

- Impossibilidade de representar os deslocamentos laterais da fundação e do maciço de solo.

\footnotetext{
${ }^{1}$ Winkler, E. Die Lehre von Elasticität und Festigkeit. Kessinger Publishing. Praga. 1987
} 
Um modo mais eficiente consiste na representação do maciço do solo como um meio continuo e por um modelo que seja acoplado à superestrutura. A Figura 2.12 mostra um esquema comparativo dos dois diferentes procedimentos.

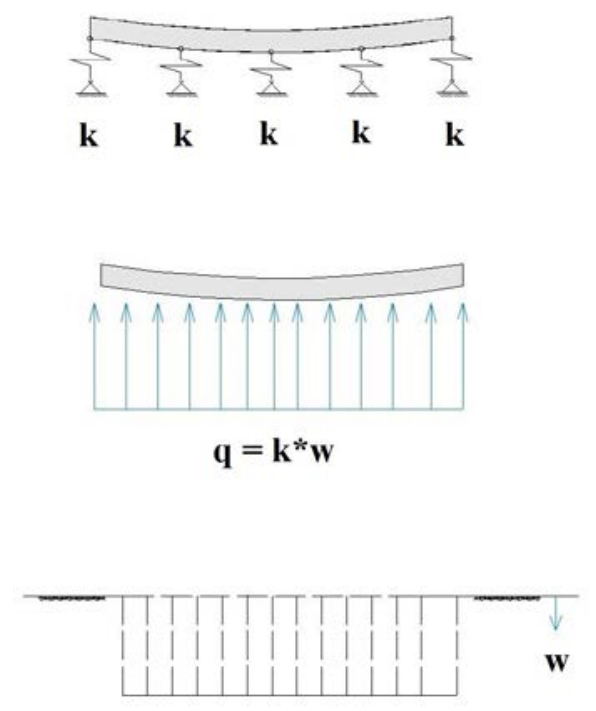

a) Modelo de Winkler - Pressões de contato e recalques
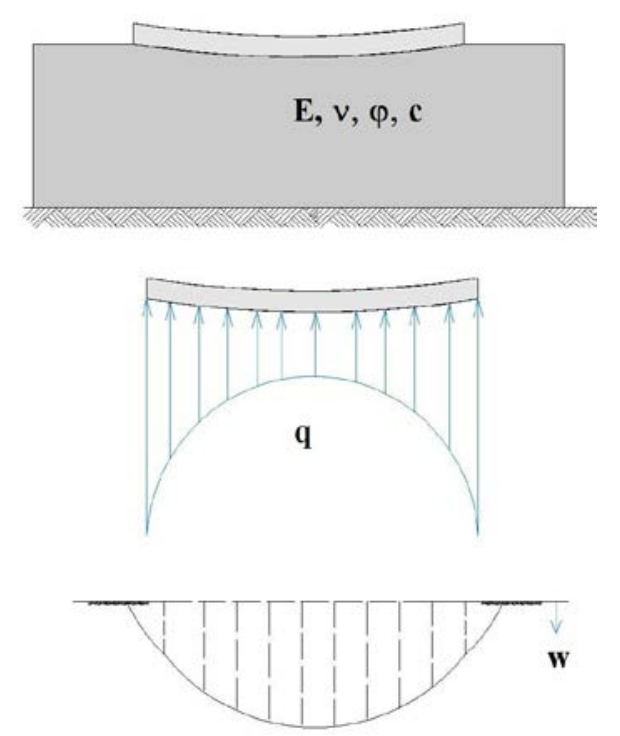

b) Modelo de contínuo - Pressões de contato e recalques

Figura 2.12- Modelos para a interação solo-estrutura - Adaptado de Velosso e Lopes (2010)

A representação do maciço do solo como um modelo contínuo pode ser feita por equacionamento analítico ou com análises numéricas. A reprodução das propriedades constitutivas do maciço do solo é de fato um dos pontos mais complexos da interação soloestrutura, sendo que a resposta do solo às cargas aplicadas possui um papel fundamental neste tipo de problema. O uso da teoria da elasticidade com a finalidade de representar a relação tensão-deformação do material do maciço é comum, mas pode fornecer respostas não precisas. Plastificações localizadas (frequentemente presentes nas bordas dos elementos de fundação) podem alterar a distribuição das pressões de contato nos elementos de fundação, isto, é claro, em altos níveis de solicitação.

Meyerhof (1947) desenvolveu um dos primeiros trabalhos que incorporava os recalques diferenciais nas fundações na análise estrutural de pórticos planos. O autor desenvolveu uma formulação especifica para pórticos rígidos e semi-rígidos. Devido às particularidades da metodologia proposta foi apresentada uma maneira simplificada de incorporar a análise em outros tipos de pórticos. O pesquisador avaliou a aplicação do método em dois tipos de estruturas: uma edificação industrial metálica de apenas um pavimento e um edifício comercial de concreto armado de cinco pavimentos. Ambas edificações utilizavam sapatas isoladas como elementos de fundação. A estimativa dos recalques nos apoios foi 
realizada por meio de uma equação analítica aproximada relacionando a pressão nas sapatas com os recalques. $\mathrm{O}$ autor observou que os recalques diferenciais induziram o surgimento de acréscimos de esforços nas vigas, nas ligações externas e nos pilares externos da estrutura. Os esforços adicionais foram mais acentuados no primeiro pavimento. $\mathrm{O}$ estudo também avaliou o efeito das ligações entre as vigas e os pilares. Com isto, o autor observou que a redução da rigidez nas ligações aumentou os recalques diferenciais.

Posteriormente, o mesmo autor (Meyerhof, 1953) apresentou um dos primeiros estudos relacionando o deslocamento vertical nas fundações com o surgimento de fissuras na estrutura. As observações foram realizadas por meio de resultados de ensaios experimentais de uma parede de alvenaria submetida a atuação de cargas verticais. Foram realizados ensaios com e sem a presença das vigas na base. O estudo experimental da parede de alvenaria sem a presença de vigas de fundação, indicou o surgimento das primeiras fissuras com valor de deslocamento vertical no meio do vão em torno de $0,1 \mathrm{~mm}$, correspondendo a uma rotação na base de 1/20000. Com a inclusão de vigas de concreto armado na base da parede, o valor do deslocamento vertical máximo para o surgimento das primeiras fissuras ficou em torno de 0,6mm, correspondente a uma rotação de 1/5000. Esses resultados já indicavam o papel da rigidez relativa entre a estrutura e a fundação.

Meyerhof (1953), a partir da Equação 2.1 desenvolvida por Borowick (1936), analisou o comportamento de radiers com carregamento uniformemente distribuído.

$$
K_{f}=\frac{E_{f} I_{f}}{E_{S} B^{3} L}
$$

Equação 2.1

$K_{f}:$ Rigidez relativa solo - fundação

$E_{f}$ : Módulo de elasticidade do radier

$I_{f}:$ Momento de Inercia da fundação

$E_{s}:$ Módulo de elasticidade do solo

B: Comprimento do Radier

L: Largura do Radier

Foram avaliados o papel da variação das dimensões do radier e da rigidez relativa solofundação, na grandeza dos recalques máximos e diferenciais dos elementos. Os resultados obtidos mostraram que a modificação da rigidez do radier pouco alterou os recalques médios dos elementos, mas modificou significativamente os recalques diferenciais. O aumento dos recalques diferenciais ocorreu à medida que acontece um decréscimo da rigidez do radier.

Neste mesmo trabalho o autor propôs a inclusão da rigidez da superestrutura na formulação utilizada para o cálculo da rigidez relativa solo-fundação. A proposta foi realizada de maneira simplificada, fazendo uma analogia da rigidez da estrutura por meio de uma viga de rigidez equivalente (Figura 2.13). 

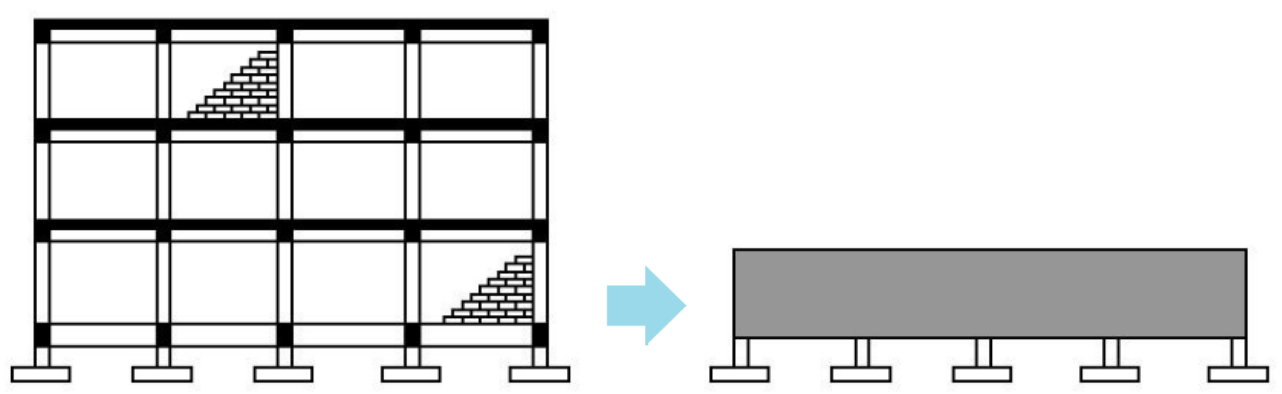

Figura 2.13- Viga de rigidez equivalente - Meyerhof (1953) (Adaptado de Velloso e Lopes, 2000)

A justificativa do autor é que esta consideração pode representar melhor o problema, principalmente em quando elementos de fundação são flexíveis em relação à superestrutura. Também foram desenvolvidas equações adicionais para a inclusão da rigidez dos pilares e dos elementos de alvenaria de vedação.

No Brasil, um dos trabalhos pioneiros sobre o tema foi o desenvolvido por Chamecki (1954), sendo umas das primeiras tentativas de incluir a interação solo estrutura tanto nas análises estruturais como nas análises geotécnicas. Neste estudo o autor ressaltou a importância da consideração da rigidez da estrutura para o cálculo dos recalques na fundação. Para este fim foi desenvolvida uma metodologia relacionando a transferência de esforços entre os apoios com os recalques dos elementos. O método proposto consistia inicialmente na definição de coeficientes de transferência de cargas entre os apoios, a partir da imposição de recalques unitários. A proposta desenvolvida por Chamecki (1954) destacou a separação de funções para o emprego da metodologia, cabendo ao engenheiro de estruturas fornecer na planta de cargas os coeficientes de transferência de esforços entre os apoios. Desta maneira, o engenheiro geotécnico poderia aferir os recalques com a consideração da rigidez da estrutura. Por meio de um exemplo estudado foi concluído que a inclusão da interação solo-estrutura induz à recalques diferenciais menos acentuados e mais próximos da realidade. O exemplo apontou alterações nas reações finais nos pilares da edificação. A pesquisa permitiu observar a tendência da redistribuição de cargas nos pontos de apoio da estrutura, com a redução de esforços nos pilares centrais do edifício e acréscimo de esforços nos pilares da periferia.

Chamecki (1969) estudou o papel da rigidez da estrutura nas pressões de contato na fundação e na distribuição dos recalques. O autor destacou que a rigidez da estrutura pode alterar de forma significativa a distribuição dos recalques e a das pressões de contato na fundação. A Figura 2.14 exemplifica duas situações, uma com a estrutura de rigidez infinita e a outra com a estrutura de rigidez nula. A estrutura de rigidez infinita tende a apresentar recalques uniformes, com pressões de contato maiores nos cantos e menores no centro. Essa 
diferença de pressões provoca a redistribuição de esforços nos pilares, sendo que os pilares da periferia sofrem acréscimo de esforços, enquanto os pilares localizados nas regiões centrais da estrutura tendem a apresentar redução nos esforços solicitantes. A situação oposta, em que a estrutura apresenta uma rigidez nula, as pressões de contato são distribuídas de maneira uniforme, não alterando os esforços nos pilares da edificação. A estrutura se adapta à deformação no solo e não ocorrem alterações na distribuição dos recalques devido à sua rigidez.

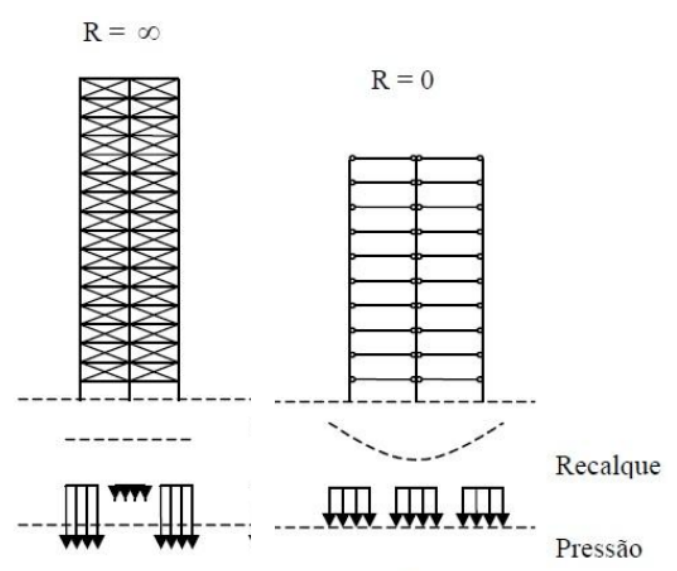

Figura 2.14- Rigidez da superestrutura - (Chamecki, 1956 apud Iwamoto, 2000)

Poulos (1975) desenvolveu uma metodologia de extrema relevância para a incorporação da interação solo-estrutura nas análises estruturais. O método desenvolvido pelo autor consistia no estabelecimento de uma equação para a representação da interação entre a superestrutura e o maciço do solo. Para a resolução do problema é necessário primeiramente calcular a matriz de flexibilidade da fundação e a matriz de rigidez da estrutura. A matriz de flexibilidade relaciona os recalques nos apoios com cargas unitárias aplicadas em cada um dos pontos de apoio. A matriz de rigidez da estrutura relaciona as reações de apoio, aos deslocamentos unitários nos mesmos. Desta maneira, a partir da Equação 2.2 é possível obter o vetor de reação final nos pontos de apoios, considerando a interação solo-estrutura. Por fim os recalques finais na estrutura podem ser obtidos utilizando a equação Equação 2.3.

A metodologia desenvolvida pelo autor pode ser utilizada e adaptada para qualquer tipo de estrutura de apoios pontuais. Os deslocamentos no maciço de solo podem ser estimados por meio de equações da teoria da elasticidade considerando o solo como um meio semiinfinito. O método foi utilizado para a investigação de diversos aspectos referentes à interação solo-estrutura, como o tipo de fundação utilizada, influência da interação entre os apoios e o número de pavimentos nas edificações. 
$\left\{V_{o}\right\}=[I-[S M] *[F M]] *\{V\}$

Equação 2.2

$\{\delta\}=[F M] *\{V\}$

Equação 2.3

$\{\delta\}:$ Vetor dos recalques de apoio

[FM]: Matriz de flexibilidade na fundação

[SM]: Matriz de rigidez da estrutura

$\{V\}:$ Vetor de cargas finais no apoios

$\{$ Vo\}:Vetor de cargas obtidos no modelo com apoios indeslocáveis

[I]: Matriz identidade

Os resultados da pesquisa realizada por Poulos (1975) indicaram:

- Recalques diferenciais em radiers rígidos foram menores do que outras opções como radiers flexíveis, sapatas e fundação profunda em estacas.

- A não consideração da interação entre os pontos de apoio forneceu recalques menores, sendo estes resultados contra a segurança

- A variação do número de pavimentos dos exemplos analisados indicou que o aumento do número de pavimentos acarreta na tendência de redução dos recalques diferenciais. O autor ressalta que esta diminuição se deve possivelmente ao acréscimo de rigidez da superestrutura.

Goschy (1978) apresentou uma investigação de diversos fatores influentes na interação solo-estrutura. O autor destacou as hipóteses da distribuição das pressões de contato e dos recalques conforme a rigidez relativa estrutura-solo. Essas hipóteses são similares às apresentadas por Chamecki (1969). O autor incluiu neste caso os efeitos da geometria da edificação em planta. O modo que a rigidez da estrutura influencia no comportamento da ISE depende das dimensões em planta da edificação (Relação Largura/comprimento). Deste modo, o autor destacou que edificações com geometrias alongadas são mais suscetíveis aos efeitos da ISE, pois a direção de menor comprimento acaba funcionando como rígida enquanto a de maior comprimento como flexível. O estudo também ressaltou que os efeitos da ISE são mais acentuados nos primeiros pavimentos, no qual o autor faz uma analogia de viga-parede com o comportamento estrutural de uma edificação sobre o efeito da ISE. Goshy (1978) também apresentou o efeito da sequência construtiva em um edifício por meio de medições de deslocamentos. As medições foram mantidas com a edificação construída, para analisar os recalques ao longo do tempo. 
O uso de medições experimentais ao longo da construção para a confrontação de resultados com modelo numéricos foi feito por Landva et al. (1987). Os pesquisadores realizaram medições de recalques ao longo da construção de duas estruturas aporticadas de concreto. Os resultados medidos foram confrontados com os resultados obtidos por meio de um modelo numérico. As duas estruturas possuíam fundação do tipo radier. O modelo numérico foi confeccionado com o uso da analogia de grelha de vigas para a representação do radier. Foram dispostos apoios elásticos nas grelhas para a simulação da interação solo-estrutura, no qual o coeficiente de reação vertical foi estimado por meio de resultados experimentais. O comportamento experimental indicou que os maiores recalques foram localizados no centro do radier, ocorrendo uma redução de forma progressiva até as bordas. A partir da comparação de resultados, foi possível observar que os recalques experimentais foram bastante inferiores aos estimados numericamente. Deve-se salientar que os autores não realizaram a interação soloestrutura com a inclusão da rigidez da superestrutura, sendo que este aspecto tem grande influência na uniformização dos recalques.

Gusmão (1990) indicou que a rigidez relativa solo-estrutura governa o comportamento de uma edificação. O pesquisador ressalta que uma estrutura apoiada em um maciço rochoso pode se comportar como flexível, enquanto a mesma estrutura sobre uma argila mole pode ter um comportamento rígido. O autor observou que quando a edificação é flexível, as reações de apoio com a interação solo-estrutura tendem a ser as mesmas obtidas por meio do procedimento convencional, não necessitando da inclusão do fenômeno da interação solo-estrutura para a avaliação estrutural. O mesmo é valido na investigação dos recalques, em que os valores obtidos da maneira convencional, sem a inclusão da estrutura, tendem a ser similares aos obtidos com a sua inclusão. Para uma estrutura rígida, os valores dos recalques obtidos da maneira convencional tendem a ser bastante diferentes dos obtidos com a sua inclusão. A consideração da rigidez da estrutura permite a uniformização dos recalques, entretanto a interação soloestrutura tende a gerar alterações nos esforços finais da estrutura neste caso.

Gusmão (1994) utilizou o método desenvolvido por Poulos (1975) para avaliar a influência da interação solo-estrutura no recalque de edifícios. O autor realizou uma análise paramétrica em torno da rigidez relativa solo-estrutura. As análises indicaram que o desempenho da edificação é governado por esta rigidez e que o acréscimo de rigidez com o aumento do número de pavimentos tende a produzir a uniformização dos recalques. Do mesmo modo, foi observado que a uniformização dos recalques não cresce de forma constante com o aumento do número de pavimentos, ocorrendo uma contribuição maior dos primeiros pavimentos e sendo influenciado cada vez menos com a construção dos pavimentos 
subsequentes. Gusmão (1994) afirmou que o recalque médio da edificação pode ser associado ao modelo de tensão-deformação do solo, que é função das cargas aplicadas e das propriedades do solo. A configuração da distribuição dos recalques pode ser relacionada ao modelo de interação solo-estrutura (Figura 2.15).

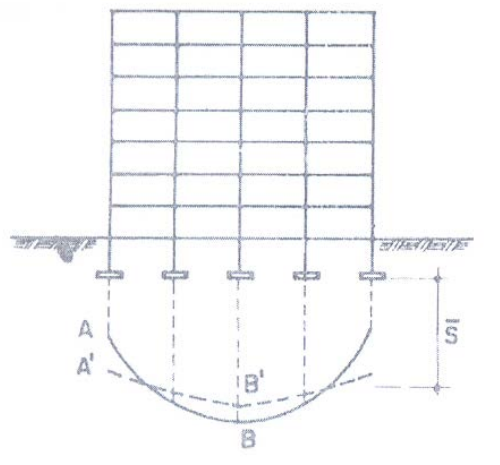

$$
\begin{gathered}
\text { ESTIMADO CONVENCIONALMENTE } \\
S=\bar{S} \pm \Delta S i \\
\bar{S}=f \text { (modelo de tensão }- \text { deformação do solo) } \\
\Delta S i=f(\text { modelo de interação solo - estrutura) }
\end{gathered}
$$

Figura 2.15 - Estimativa de recalques na edificação (Gusmão, 1994)

Dessa forma, o autor destacou que a consideração da interação solo-estrutura tende a suavizar a distribuição dos recalques, com a permanência do recalque absoluto médio praticamente inalterado, já que este é função do maciço do solo e das cargas aplicadas. Utilizando esse conceito, o autor fez uma análise comparativa entre os valores obtidos do monitoramento de recalques em estruturas, com os resultados estimados com e sem o uso da interação solo-estrutura. A partir destas análises foi possível confirmar a influência da interação solo-estrutura na uniformização dos recalques. Os valores de recalques obtidos a partir das medições foram inferiores aos estimados convencionalmente, além de apresentar uma suavização da distribuição dos recalques, indicando dessa maneira a influência da interação solo-estrutura.

Zhang e Small (1994) desenvolveram um procedimento numérico baseado no método das faixas finitas para avaliar a interação solo-estrutura. Foram modificados a rigidez do solo e da estrutura. Os resultados obtidos indicaram:

- Para um solo com alta rigidez, os recalques diferenciais tendem a ser baixos, independentemente da rigidez da superestrutura. 
- Para um solo de rigidez flexível, a configuração da distribuição dos recalques dependerá da rigidez da superestrutura

- Para uma superestrutura muito rígida os recalques diferenciais são baixos, independentemente da rigidez da fundação

Badie et al. (1997) desenvolveram um método simplificado para a consideração da interação solo-estrutura em elementos de parede. A metodologia consistia na substituição do maciço do solo por um elemento de interface. O elemento de interface desenvolvido foi baseado no "Método de Winkler”, com a inclusão da interação entre as molas por meio de uma função para representar o cisalhamento (Figura 2.16).

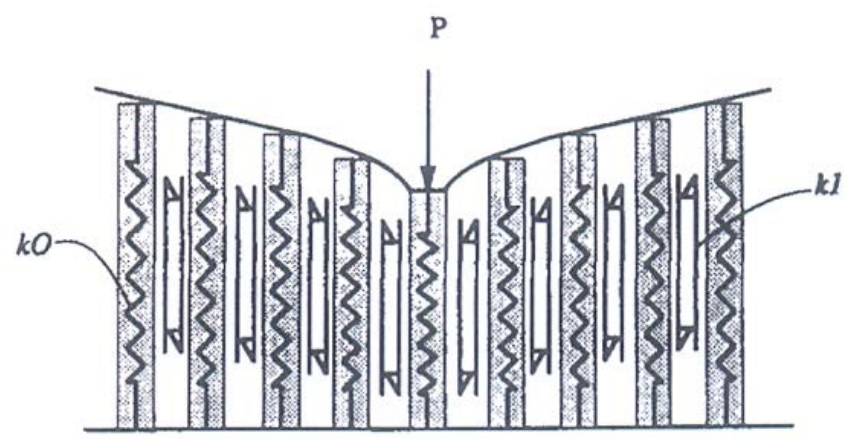

Figura 2.16 - Representação do elemento de interface de Badie et al. (1997)

Dois parâmetros de rigidez foram necessários para o elemento proposto, uma rigidez axial da mola, rigidez “ $k 0$ ” (similar ao "Método de Winkler”) e um parâmetro de rigidez que representa a interação entre as molas (rigidez “ $k 1$ ”). Os autores destacaram que a vantagem do elemento de interface está na redução do custo computacional, quando comparado com o maciço de solo modelado por meio de elementos sólidos.

Badie et al. (1997) utilizaram o elemento proposto para avaliar elementos de paredes, na simulação de núcleos estruturais de edifícios de concreto. Foram consideradas situações com apoios fixos, e com a interação solo-estrutura, variando a rigidez do solo. A consideração da interação solo-estrutura, acarretou em acréscimos das tensões normais provenientes das ações horizontais em até 25\%. Outra consequência foi o aumento dos esforços de flexão nos linteis. Os linteis dos pavimentos inferiores foram os mais solicitados devido a inclusão da interação solo-estrutura.

Ta e Small (1997) propuseram uma modelagem simplificada baseada no método dos elementos finitos para a modelagem do maciço de solo em edifícios com radiers. A justificativa dos autores foi reduzir o custo computacional, em comparação com uma análise com elementos finitos sólidos para a representação do maciço do solo. O maciço do solo é analisado pelo 
método das faixas finitas permitindo desta forma uma grande redução na dimensão da matriz de rigidez do modelo numérico. O estudo indicou uma boa aproximação dos resultados, quando comparado com o uso de elementos sólidos para a representação do maciço do solo.

Aoki (1997) apresentou um método para a consideração da interação entre a superestrutura com o maciço do solo. O método consistia na interação entre os diversos elementos envolvidos na análise estrutural. Foram consideradas a interação entre as estacas e o maciço do solo, a interação entre os blocos de fundação e as estacas e finalmente a interação da superestrutura com os blocos de fundação. A interação das estacas com maciço do solo foi realizada por meio da solução de Mindlin (1936). A simplificação de Steinbrenner (1934) foi considerada para a inclusão das inúmeras camadas do solo. Para a estimativa dos recalques no bloco rígido foi proposta uma adaptação do modelo de Schiel (1957), adicionando o efeito de grupo do recalque das estacas nos blocos rígidos. Por fim, para a consideração da interação solo-estrutura no modelo da superestrutura foi utilizada uma rotina iterativa. A estrutura inicialmente é avaliada com os apoios indeslocáveis e a partir das reações de apoio em cada estaca, os recalques são estimados para cada ponto de apoio. Os pontos de apoios no modelo estrutural são substituídos por uma mola de rigidez equivalente ao recalque calculado. A estrutura é reprocessada e os valores das reações são recalculados. O procedimento é repetido inúmeras vezes até que todas as reações de apoio coincidam com as respectivas reações da iteração anterior. O modelo proposto por Aoki (1997) apresenta as vantagens de considerar o efeito de grupo das fundações, a continuidade do maciço do solo e a possibilidade de incorporar o método na análise estrutural utilizando rotinas computacionais.

Gusmão Filho e Guimarães (1997) sugeriram que deve ser considerado um limite de rigidez da superestrutura para a avaliação da interação solo-estrutura. Esse limite de rigidez foi associado à construção da edificação. Ao longo da construção, após a estrutura atingir este limite de rigidez, os efeitos da interação solo-estrutura na redistribuição de esforços tendem a reduzir. A pesquisa abordou principalmente os efeitos da interação solo-estrutura nas reações de apoio, em que os autores propuseram a Equação 2.4 para avaliar a variação de cargas nos pilares, comparando as análises com e sem a consideração da interação solo-estrutura.

$$
\eta=\frac{Q_{s s i}-Q_{c o n v}}{Q_{c o n v}}
$$

$\eta$ : Coefeciente de variação de carga

$Q_{\text {conv }}:$ Reação de apoio em um análise convencional

$Q_{s s i}:$ Reação de apoio com a consideração da interaçao solo - estrutura 
A Figura 2.17-a mostra a hipótese adotada pelos autores, na qual após atingido o limite de rigidez da estrutura, a redistribuição de esforços entre os pilares começa a reduzir conforme se acrescenta novos pavimentos na estrutura. A hipótese foi avaliada por meio de análise numérica e do monitoramento de recalques de uma edificação. A Figura 2.17-b exibe o acréscimo de cargas no pilar localizado na região periférica da estrutura, ao longo da construção da edificação, sendo que a curva representa os resultados da análise numérica e os pontos se referem aos resultados obtidos por meio das medições de recalques realizadas na estrutura.

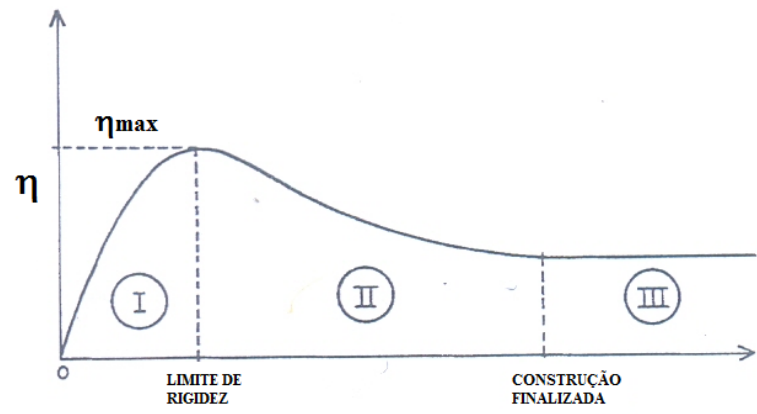

NÚMERO DE PAVIMENTOS

a) Limite de rigidez ao longo da construção

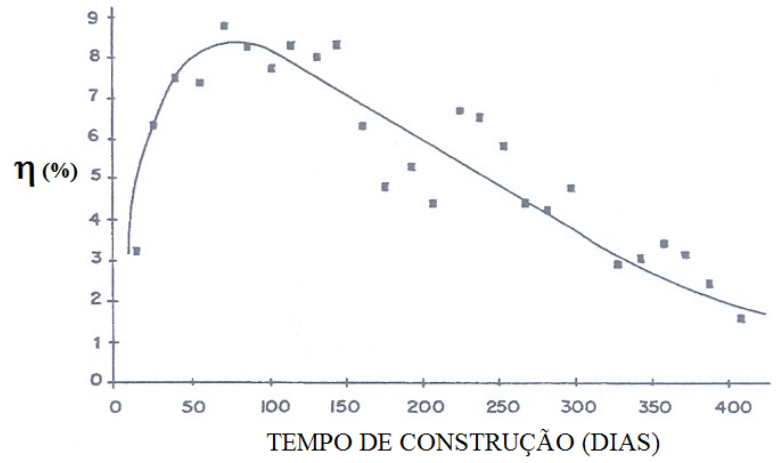

b) Verificação do pilar da periferia da estrutura (experimental e numérico)

Figura 2.17- Limite de rigidez (Adaptado de Gusmão Filho e Guimarães, 1994)

Esses resultados permitiram verificar a hipótese de Gusmão Filho e Guimarães (1994). Durante a sequência de construção, após ser atingido o limite de rigidez da estrutura, ocorre redução na redistribuição das cargas devida à interação solo-estrutura.

Entretanto, pode-se observar que alguns estudos indicam que a influência da interação solo-estrutura é maior nos pavimentos iniciais da estrutura. Desta forma à medida que os pavimentos vão sendo construídos, as reações nos pilares provenientes dos pavimentos superiores tendem a ser similares às reações obtidas em uma análise convencional. Por fim, a diferença das reações finais nos pilares entre um modelo convencional e um modelo com a consideração da interação solo-estrutura, tendem a diminuir à medida que são adicionados mais pavimentos na estrutura.

Iwamoto (2000) avaliou o uso da interação solo-estrutura na análise estrutural de edifícios de concreto armado. O modelo proposto consiste na representação da superestrutura pelo método dos elementos finitos, no qual todos os elementos da estrutura foram considerados, como as lajes, vigas e pilares. Em relação à superestrutura foram incluídas as excentricidades das vigas em relação aos apoios e o comportamento de diafragma rígido nas lajes dos pavimentos para avaliar a distribuição das ações horizontais. Para a consideração da ISE foi 
utilizado o método de Aoki (1987). A pesquisa avaliou três exemplos de edifícios, sendo dois deles com fundação profunda em estaca e o último com fundação do tipo tubulão. Em relação aos resultados obtidos, Iwamoto (2000) afirmou que a consideração da interação solo-estrutura reduziu os recalques diferenciais e as distorções angulares nas fundações. Do mesmo modo foi observado que a redistribuição de esforços ocorre de maneira mais acentuada nos primeiros pavimentos, sendo influenciada pela rigidez solo-estrutura.

Poulos (2000) apontou os inúmeros métodos da literatura para o cálculo de recalques e para a consideração da interação solo-estrutura. O autor destacou quais os métodos que podem ser utilizados e os que devem ser evitados. Entre os métodos adequados, o pesquisador destaca a análise elástica para radiers considerando o meio continuo. Dentre os métodos inadequados, o autor sugeriu evitar o uso do método de "Winkler” para fundações superficiais. Para a análise de um elemento isolado, o método consegue uma aproximação adequada, entretanto para a análise que envolve vários elementos de fundações, a representação do coeficiente de reação é precária, pois negligencia a interação dos elementos.

Starvrids (2002) propôs uma metodologia para incorporar a interação solo-estrutura em uma análise estrutural. O procedimento consistia na criação da matriz de rigidez do solo, com a aplicação de cargas unitárias em cada nó. Os recalques são obtidos por meio de uma resolução analítica, baseada na solução clássica de Boussinesq e Streibrenner (1934). Posteriormente deve ser aferida a matriz de rigidez dos pontos de apoio, por meio da imposição de deslocamentos unitários nos mesmos. Finalmente a estrutura é analisada com apoios indeslocáves. Utilizando Equação 2.5 é possível estimar os recalques nos apoios. A partir da estimativa dos recalques nos apoios, estes são impostos no modelo afim de aferir a nova configuração da estrutura com os recalques. Utilizando a metodologia proposta, o referido autor apresentou alguns exemplos de estruturas de concreto apoiadas diretamente no solo, e comparou os seus resultados com a aplicação do método clássico de Winkler. Starvrids (2002) ressalta que a metodologia proposta consegue representar de forma superior o maciço do solo em comparação com a aplicação do método de Winkler, e que a metodologia é de fácil aplicação, podendo ser incorporado a qualquer rotina baseada no método dos elementos finitos. É possível observar a semelhança da metodologia do autor com o método de Poulos (1975), concluindo que, apesar da diferença de décadas entre os respectivos trabalhos, não ocorreram grandes evoluções na criação de metodologias simplificadas para a consideração da ISE na análise estrutural. 


$$
\left(K_{\text {soil }}+K_{\text {sup }}\right) \Delta=-R_{0}
$$

$K_{\text {soil }}:$ Matriz de rigidez do maciço do solo para cargas unitárias

$K_{\text {sup }}:$ Matriz de rigidez dos pontos de apoio para deslocamentos unitários

$\Delta:$ Vetor de recalques nos pontos de apoio

$R_{0}:$ Vetor de cargas obtidos no modelo com apoios indeslocáveis

Borges (2009) avaliou o comportamento estrutural de edifício altos de concreto com a inclusão da interação solo-estrutura. O enfoque principal do trabalho foi o comportamento global do edifício, avaliado por meio de indicadores de desempenho. Dentre os parâmetros avaliados, se destacam a consideração da não-linearidade geométrica, a não-linearidade física e a verificação do conforto humano perante a ação dinâmica do vento. O estudo foi realizado em três edifícios altos construídos na região de Recife/PE. A partir dos resultados obtidos foi possível observar o efeito da interação solo-estrutura no aumento dos efeitos de segunda ordem dos edifícios analisados.

\subsubsection{ISE EM EDIFÍCIOS DE PAREDES}

Testoni (2013) avaliou a análise estrutural de edifícios de parede de concreto com a consideração de apoios elásticos. Para a superestrutura o autor utilizou dois modelos distintos, sendo um modelo de referência com o uso de elementos de casca para representar as paredes e um modelo proposto simplificado de pórtico tridimensional. As paredes do primeiro pavimento do modelo proposto foram representadas por elementos de treliça (Figura 2.18). Os demais pavimentos foram construídos com um modelo de barras equivalentes (Pórtico tridimensional)

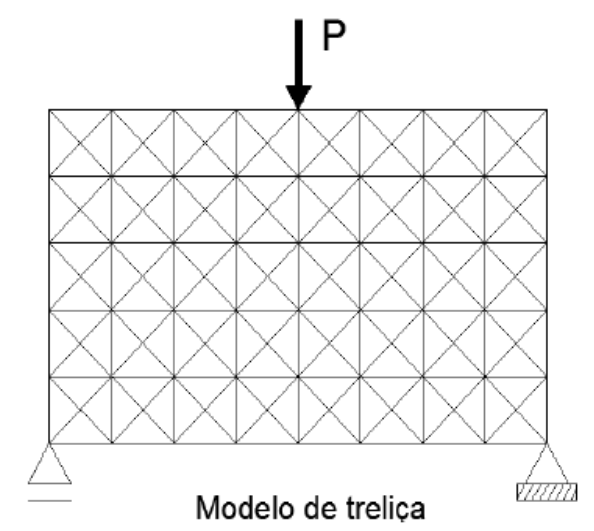

Figura 2.18 - Modelos para parede de concreto (Testoni, 2013)

Para a estimativa dos recalques na fundação, Testoni (2013) utilizou o método de Aoki e Lopes (1975). O autor estudou três edifícios de parede de concreto, sendo dois com 15 
pavimentos e um com 10 pavimentos. A solução de fundação dos edifícios analisados era de fundação profunda. Por meio dos resultados obtidos foi observado que a consideração dos recalques de apoio acarretou em alterações consideráveis nos esforços das vigas baldrame da fundação. A consideração da interação solo-estrutura além disso alterou o fluxo de tensões nas paredes e as reações de apoio obtidas em relação ao modelo sem a interação solo-estrutura. Testoni (2013) destacou a homogeneização das cargas, com a redução das reações nos apoios mais carregados e acréscimos nos apoios menos carregados.

Santos (2016) deu continuidade ao trabalho realizado por Testoni (2013). O trabalho além de analisar soluções em estacas profundas incluiu o estudo em fundações superficiais do tipo sapata. Os modelos da superestrutura foram construídos utilizando o MEF e o procedimento para a consideração da ISE foi também utilizando o método desenvolvido por Aoki e Lopes (1975). Neste estudo foram utilizados elementos de casca para a representação das paredes dos pavimentos. Foi proposto um procedimento simplificado, utilizando o "Modelo Yagui” para a modelagem das paredes dos pavimentos superiores. Esse procedimento foi similar ao apresentado por Nunes (2011) no item 2.1.3 com a confrontação de resultados entre um modelo completo (Elementos de casca) e um modelo misto (Elementos de casca com pórtico tridimensional) (Figura 2.19).

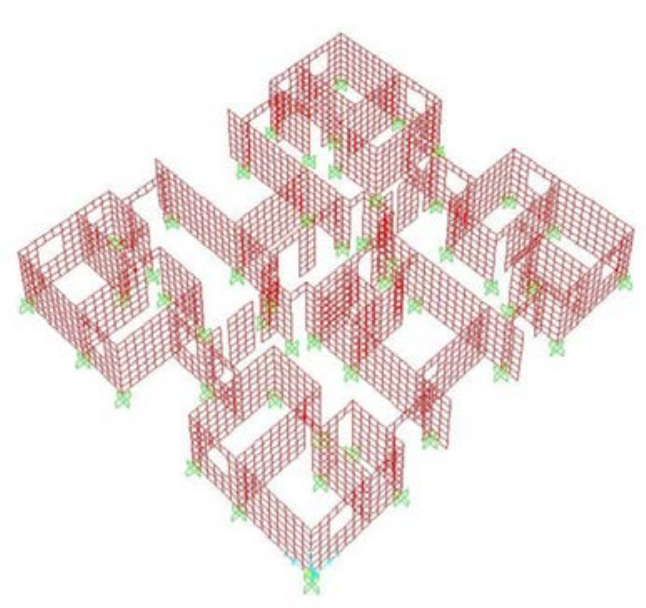

a) Modelo de casca

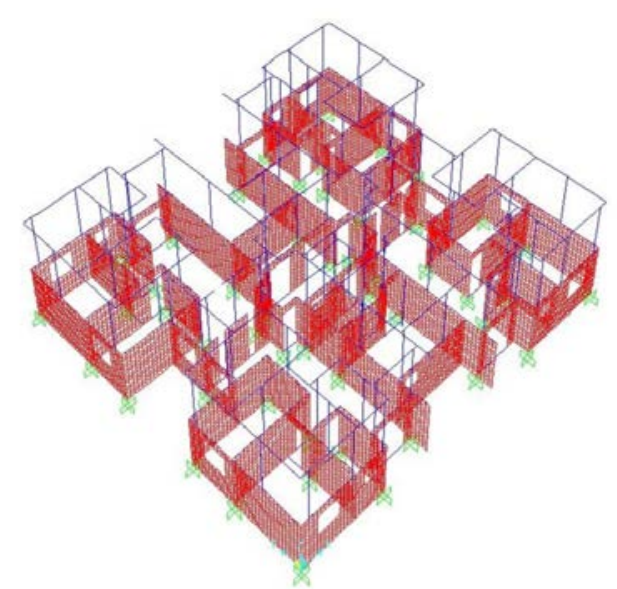

b) Modelo mistos - Casca + Pórtico tridimensional

Figura 2.19 - Modelos de ISE em edifícios de paredes - Santos (2016)

Os resultados indicaram a uniformização dos recalques na fundação nos modelos com a consideração da interação solo-estrutura. Ocorreram alterações significativas nos esforços normais nas paredes com a consideração da interação solo-estrutura. As redistribuições de esforços nas paredes foram superiores a 18\%, valor este considerado relevante pelo pesquisador. Os resultados indicaram que a consideração de apenas 5 pavimentos seria 
suficiente para avaliar o efeito da interação solo-estrutura, sendo que a inclusão dos demais pavimentos poderia ser feita apenas com o acréscimo das cargas referentes aos mesmos.

Santos (2016b) estudou a interação solo-estrutura em edifícios de paredes de concreto e de alvenaria estrutural considerando a sequência construtiva. As simulações numéricas foram realizadas por meio do MEF. Foi considerada a solução de fundações profundas em estacas. Neste estudo o autor simulou o maciço do solo por meio de elementos sólidos. As estacas foram simuladas por meio de elementos de barra e as paredes da superestrutura utilizando elementos de casca. Os resultados indicaram que os edifícios de paredes de concreto foram mais suscetíveis aos efeitos da ISE na redistribuição de esforços do que os edifícios de alvenaria. O autor credita essa ocorrência à rigidez superior dos edifícios de paredes de concreto. Por fim o autor destacou que esses efeitos foram mais significativos nos primeiros pavimentos das edificações.

\subsection{AÇÕES EVOLUTIVAS}

Os modelos numéricos para análise estrutural convencionalmente contemplam a aplicação das ações de modo instantâneo. Nesta hipótese, as ações são aplicadas com a estrutura completa. Essa simplificação não é verdadeira, pois as ações são aplicadas progressivamente na estrutura, de acordo com o processo construtivo da edificação. O procedimento convencional pode conduzir a resultados poucos aproximados aos da estrutura real.

A sequência construtiva da edificação faz com que as ações devidas ao peso próprio dos elementos da estrutura atuem e sejam distribuídos nos apoios à medida que o escoramento é retirado. Este processo permite que as cargas atuem com a estrutura parcialmente construída, ou seja, sem a contribuição da rigidez estrutural completa. Apenas as ações acidentais atuam com a construção completa, sendo que esta normalmente não é ação preponderante em edifícios convencionais.

A aplicação de uma análise estrutural que contemple a sequência construtiva (alteração de geometria progressiva e aplicação das cargas por etapa) é um tipo de análise mais acurada que a convencional, que aproxima a resposta do modelo estrutural do modelo real. No método convencional, a matriz de rigidez $(\mathrm{K})$ é calculada com a consideração da rigidez total da estrutura e o vetor de forças (P) assume as cargas aplicadas em sua totalidade. Deste modo o vetor de deslocamentos da estrutura é avaliado por intermédio de uma única análise (Figura 2.20). 


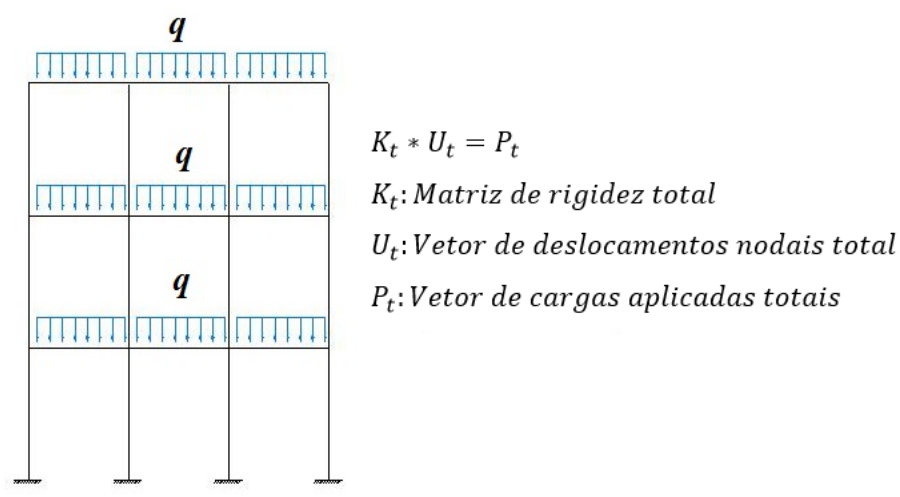

Figura 2.20- Modelo convencional - Ações instantâneas

O procedimento para o emprego das ações evolutivas assume que cada pavimento construído defina uma etapa da análise, sendo necessário um processamento em cada fase. Em cada etapa da construção, a rigidez das regiões não construídas é desprezada, obtendo-se uma matriz de rigidez diferente em cada fase. A dimensão da matriz de rigidez assume valores distintos em cada fase. A mesma variação ocorre em relação às dimensões dos vetores de deslocamentos e de forças externas. Esse processo acarreta deslocamentos nodais nulos nas regiões não construídas. A partir do cálculo dos deslocamentos nodais ocorridos em cada fase, os esforços na estrutura são calculados. Por fim, em uma análise linear (física e geométrica) os esforços e deslocamentos da estrutura em sua etapa final podem ser alcançados mediante a superposição dos resultados de cada uma das fases do processamento. Os vetores nodais de cada fase devem ser reordenados na dimensão vetorial atualizada e tomados como referencial à fase final da construção do modelo (Figura 2.21).

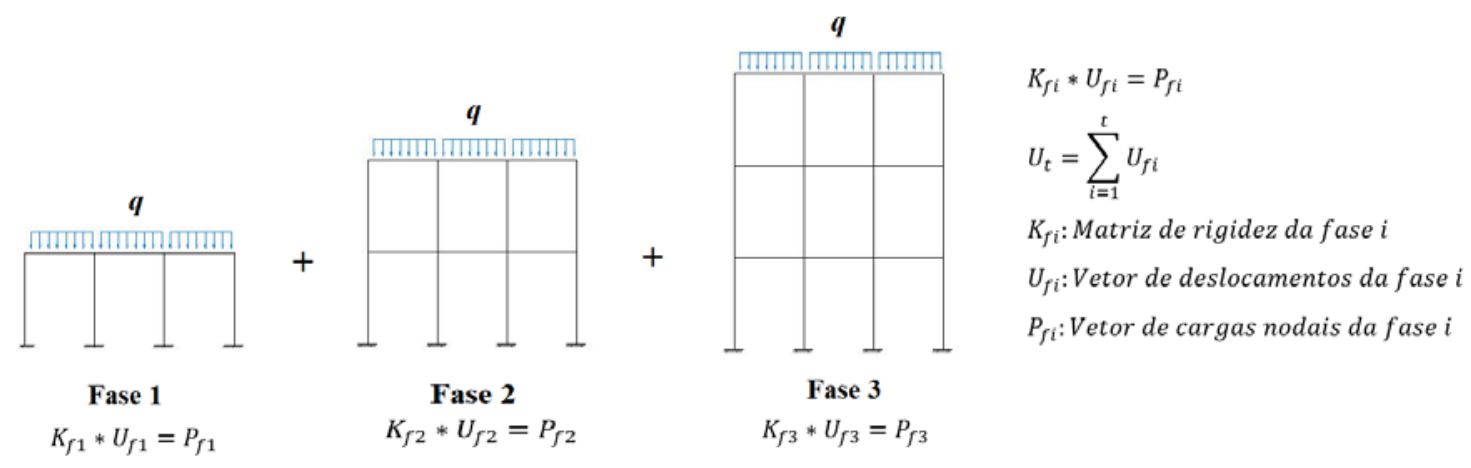

Figura 2.21- Ações por fases com alteração de geometria

O procedimento descrito pode sofrer também influência do processo de escoramento dos pavimentos. Ações provenientes do peso próprio das lajes incidem nos pavimentos inferiores devido à presença de escoramento. Este fator inclui mais uma variável na análise por fases, na qual o processo de colocação e retirada de escoramento acrescenta uma fase adicional 
para cada etapa ocorrida no processo construtivo do escoramento. Esta consideração acarreta no conhecimento prévio do cronograma de obra para a sua correta aplicação. Outras considerações ainda podem ser inclusas para um refinamento do modelo, como a evolução das propriedades dos materiais com o tempo.

Grundy e Kabaila (1963) avaliaram as ações de construção em edifícios de concreto. Os pesquisadores justificam que não considerar as ações devido à construção pode negligenciar o surgimento de esforços nas lajes dos pavimentos devidos ao sistema de escora da edificação. Para tal, os autores propuseram uma metodologia para a consideração da atuação das cargas das lajes dos pavimentos superiores nas lajes dos pavimentos inferiores. A metodologia proposta por Grundy e Kabaila (1963) tem algumas simplificações, como a consideração de elementos de escoramento rígidos e a sua distribuição uniforme no pavimento. O método consiste na avaliação do ciclo de escoramento da edificação para a definição de fatores de carga das ações atuantes dos pavimentos superiores nos pavimentos inferiores (Figura 2.22).

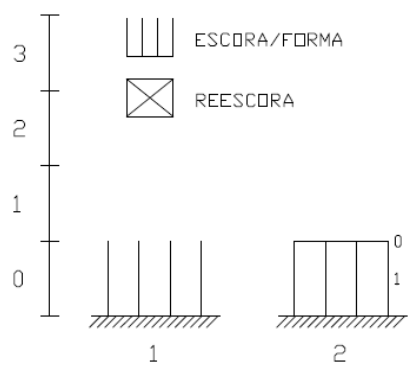

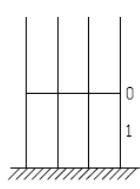

3

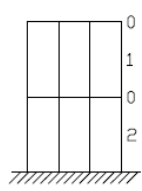

4

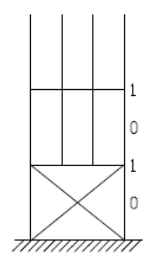

5

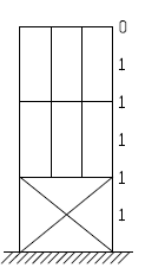

6

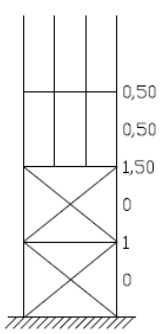

7

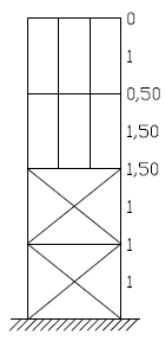

8

Figura 2.22 - Fatores carga para a consideração das ações de construção (Grundy e Kabaila, 1963) - Fonte: Prado (1999)

Selvaraj e Sharma (1974) avaliaram a consideração da sequência construtiva nos esforços solicitantes em pórticos planos. Os autores utilizaram uma análise sequencial direta, em que a geometria do modelo estrutural é confeccionada por fases e as ações são aplicadas no modelo de acordo com a sequência da construção. Foram avaliados modelos com e sem a consideração do escoramento e das deformações axiais dos pilares da estrutura. A Figura 2.23 mostra um dos pórticos estudados e os resultados finais obtidos por Selvaraj e Sharma (1974). 


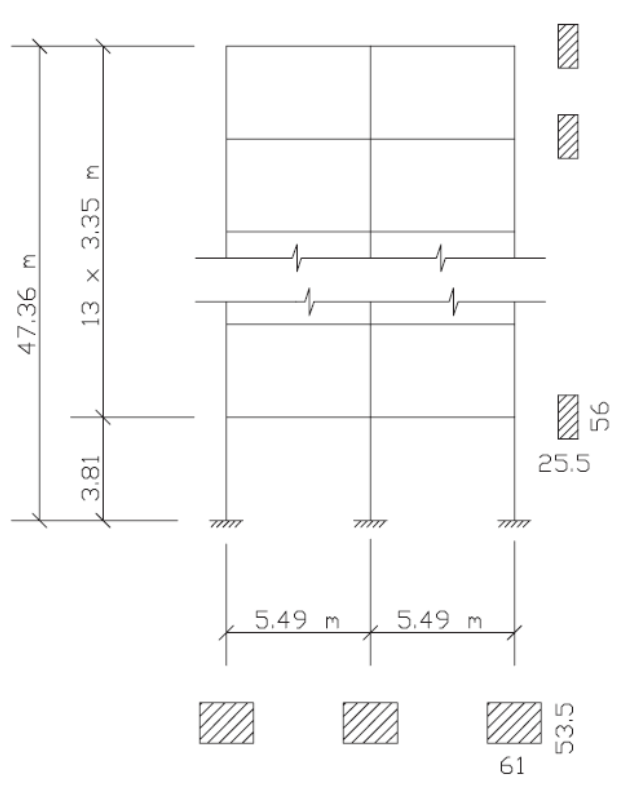

VIGAS: $25,5 \times 56 \mathrm{~cm}$

PILARES: $61 \times 53,5 \mathrm{~cm}$

PESO PRÓPRIO DA

ESTRUTURA POR

PAVIMENTO $=9,23 \mathrm{kN} / \mathrm{m}$

$\mathbf{E I}=$ CONSTANTE

a) Pórtico plano analisado
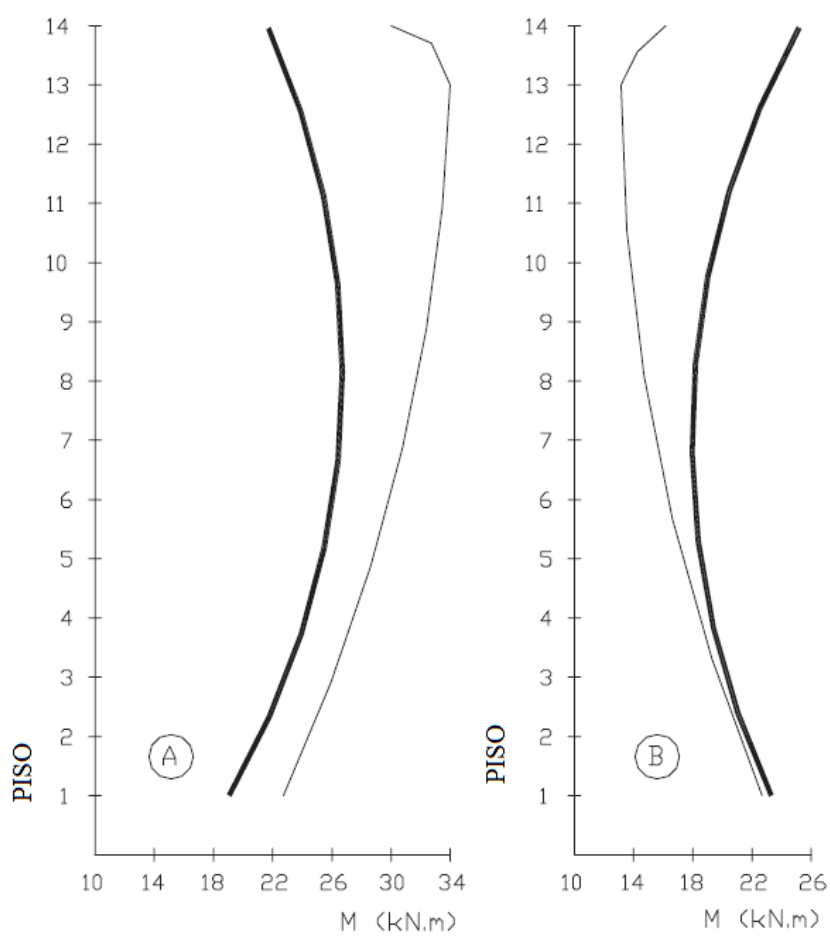

SEQUÊNCIA CONSTRUTIVA MODELO CONVENCIONAL

b) Momento nas vigas dos pavimentos Figura 2.23 - Pórtico de concreto (Adaptado de Selvaraj e Sharma, 1974)

O procedimento permitiu verificar alterações significativas nos esforços de flexão das vigas do pavimento, quando considerada a análise sequencial. Os resultados permitem visualizar que a consideração da sequência construtiva reduz o momento fletor nas extremidades das vigas e aumenta na região do apoio central. Essas alterações são mais significativas nos últimos pavimentos. As alterações nos esforços da viga devem-se à consideração gradual da deformação axial dos pilares. Quando a sequência construtiva é negligenciada, as deformações axiais nos pilares centrais são superiores, afetando a distribuição dos esforços nos pavimentos subsequentes. Selvaraj e Sharma (1974) indicaram que a sequência construtiva altera também as reações finais nos pilares. Os resultados indicaram que os pilares localizados no interior da edificação sofreram acréscimo nas suas reações finais, enquanto os pilares da periferia do pórtico obtiveram redução desses valores. Observe-se que esse fenômeno ocorre no sentido oposto ao da influência da interação solo-estrutura, indicando que a sua consideração, em tese, pode atenuar os efeitos da rigidez relativa estrutura-solo. A diferença percentual das reações dos pilares, quando considerada a sequência evolutiva, chegaram a valores de até $20 \%$. Outras tipologias foram analisadas, e os resultados tiveram implicações semelhantes. 
Brown e Yu (1986) analisaram a interação solo-estrutura em função da rigidez relativa solo-fundação, da rigidez relativa solo-estrutura e da sequência construtiva. Os autores não incluíram a rigidez da estrutura em conjunto com a rigidez da fundação, avaliando-as de forma separada. A Equação 2.6 e a Equação 2.7 mostram os coeficientes adotados por Bronw e Yu (1986), para a rigidez relativa solo-fundação e rigidez relativa solo-estrutura, respectivamente.

$$
\begin{aligned}
& K_{r s}=\frac{16 * E_{f} * I_{f}\left(1-v_{s}^{2}\right)}{\pi * E_{s} * L^{4}} \\
& K_{s b}=\frac{E_{s} * l^{4}}{n E_{v} I_{v}\left(1-v_{s}^{2}\right)} \\
& K_{r s}: \text { Rigidez solo }- \text { fundação } \\
& K_{s b}: \text { Rigidez solo }- \text { estrutura } \\
& E_{f}: \text { Módulo de elasticidade do radier } \\
& E_{s}: \text { Módulo de elasticidade do solo } \\
& E_{v}: \text { Módulo de elasticidade das vigas da superestrutura } \\
& v_{s}: \text { Coeficiente de poisson do solo } \\
& I_{f}: \text { Momento de Inercia da fundação } \\
& I_{v}: \text { Momento de Inercia das vigas da superestrutura } \\
& \text { L: Largura do radier } \\
& l: \text { Vão entre as vigas da superestrutura } \\
& n: \text { Número de pavimentos }
\end{aligned}
$$

Deve-se observar que a Equação 2.7 relaciona a rigidez do solo com a rigidez da estrutura, o que pode causar erro de interpretação quando comparado com as equações usuais da rigidez relativa entre o solo-fundação. Um valor de rigidez relativa solo-estrutura alto, representa uma estrutura flexível em relação ao maciço do solo e uma rigidez relativa baixa indica que a estrutura é bastante rígida em relação ao maciço do solo. O estudo avaliou a forma de atuação das ações, considerando-as de forma instantânea ou aplicadas por pavimentos, seguindo a evolução da construção. O procedimento para a consideração da interação soloestrutura foi realizado com base na metodologia apresentada por Poulos (1975).

Para o estudo apresentado, Brown e Yu (1986) variaram valores da rigidez relativa solo-fundação de 0,001 (radier flexível) até 0,1 (radier rígido). As análises foram feitas por meio de um pórtico plano de um edifício de estrutura metálica. A variação da rigidez relativa solo-estrutura foi feita com a variação do número de pavimento e da rigidez do solo. Foram considerados valores de rigidez relativa solo-estrutura entre 1 (edifício de 20 pavimentos sobre argila mole) até 100 (edifício com um pavimento sobre argila dura)

A Figura 2.24 aponta a percentagem de carga atuante no pilar da extremidade em relação à carga total nos pilares, com a variação dos coeficientes de rigidez relativa solofundação e rigidez relativa solo-estrutura propostos pelo autor 


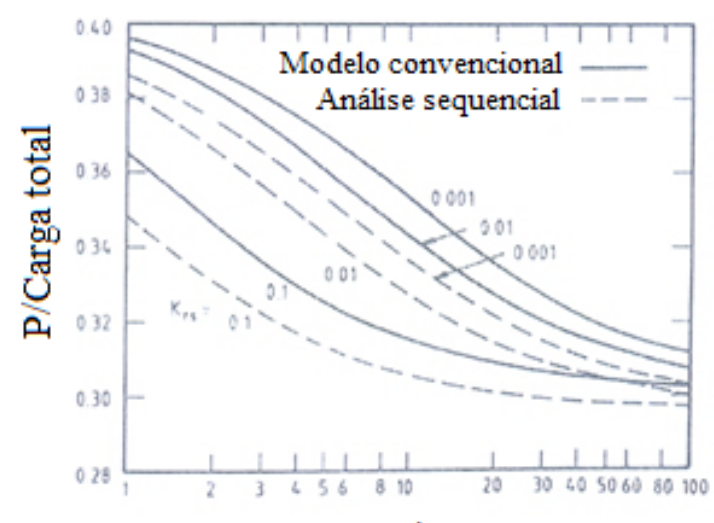

$\mathrm{Ksb}$

Figura 2.24 - Transferência de cargas e recalques diferenciais (Brown and YU, 1986)

Por meio da Figura 2.24 é possível vislumbrar que quanto mais flexível é a estrutura perante o solo, a transferência de esforços para o pilar da periferia é menor, indicando uma menor influência da interação solo-estrutura. Observa-se que a inclusão das ações evolutivas reduziu a transferência de esforços para o pilar da periferia. A redução da transferência ocorreu para todos os níveis avaliados de rigidez relativa solo-estrutura e fundação-solo.

Kripka (1990) desenvolveu um procedimento numérico para avaliar a análise incremental construtiva em edifícios de concreto. O procedimento proposto considera os efeitos do escoramento e a sequência de construção das alvenarias de vedação. O autor destacou o papel do deslocamento diferencial nas vigas na análise incremental. Tal ocorrência origina o aparecimento de esforços com sinais opostos nas duas extremidades da viga, aumentando o esforço final em um dos extremos e igual redução no extremo oposto (Figura 2.25).

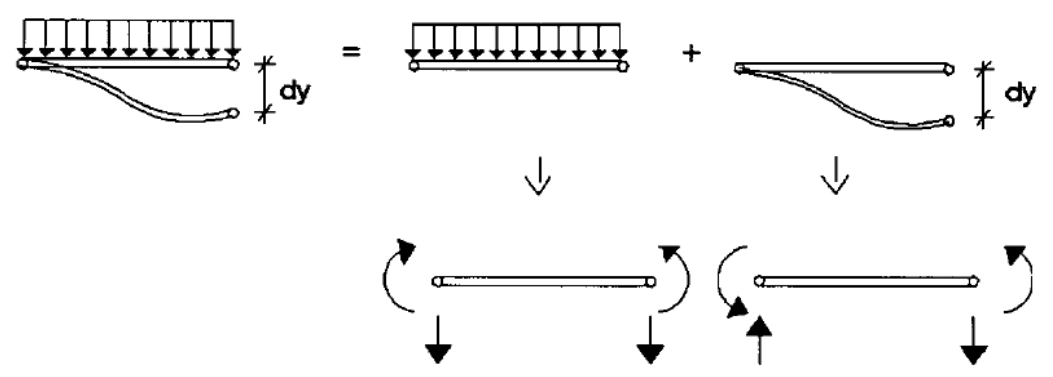

Figura 2.25 - Deslocamento diferencial em vigas (Kripka, 1990)

Kripka (1990) estudou 4 edifícios, buscando os efeitos da análise construtiva nos deslocamentos verticais diferenciais entre os pilares e as alterações dos momentos fletores nos elementos. Sobre os deslocamentos diferenciais nos pilares, o pesquisador afirma que o uso de procedimentos convencionais provoca o acúmulo de deslocamentos verticais nos andares superiores, o que gera o aumento do deslocamento diferencial ao longo da altura da edificação, sendo máximo no ultimo pavimento. Na consideração do procedimento incremental, os 
deslocamentos diferenciais máximos ocorrem a meia altura da edificação. Essas diferenças acarretam mudanças nos esforços finais quando comparados com os modelos convencionais. O autor sugere o uso de procedimentos que considerem a sequência construtiva nas análises estruturais, devido às alterações nos esforços.

Prado et al. (2003) sugeriram uma alteração do método proposto por Grundy e Kabaila (1963), evitando por exemplo a consideração das escoras com rigidez infinita e a transferência das ações nos pavimentos inferiores de forma uniformemente distribuída. O método proposto foi baseado na criação de modelos básicos do pavimento, considerando o sistema de escora, de modo a obter a proporção de cargas transmitidas ao sistema de escora e aos pilares, para as situações de carregamento e descarregamento do pavimento. A partir destas análises foi possível alterar os fatores de cargas utilizados no método de Grundy e Kabaila (1965). O método proposto permite incluir fatores como as propriedades dos elementos de escoramento, a influência da distribuição aproximada dos elementos de escora e a consideração das propriedades do concreto no momento da retirada do escoramento. Para avaliar a eficiência do método, foi analisado um edifício de concreto armado em que os resultados foram comparados com um modelo considerando a análise sequencial de forma direta. Os resultados obtidos indicaram que o método proposto apresentou resultados similares aos obtidos com a análise sequencial direta.

\subsection{CONCLUSÕES DO CAPÍTULO}

A análise dos trabalhos citados permite destacar algumas conclusões:

- Os edifícios de paredes de concreto constituem um sistema de uso recente no Brasil. Existe uma escassez de trabalhos sobre essas edificações, principalmente em relação à ISE.

- Os estudos voltados para a análise estrutural de elementos de paredes de concreto indicam que elementos lineares de barra são suficientemente precisos para análises usuais de edifícios de paredes. Entretanto, a deformação da base na estrutura sugere que para inclusão da ISE torna-se necessário o emprego de elementos planos para a representação das paredes da estrutura.

- Sobre a interação solo-estrutura, percebe-se que a ampla maioria dos trabalhos realizados abordam metodologias sobre a aplicação da ISE. Percebe-se uma carência de análises voltadas para a redistribuição de esforços nos elementos.

- A rigidez relativa solo-estrutura tem um papel fundamental no comportamento conjunto estrutura/maciço do solo. Alguns desses trabalhos destacam a 
diferença de comportamento com as mudanças da relação de rigidez entre a estrutura e o solo.

- Estudos sobre ações evolutivas, ou progressivas, foram brevemente abordados. Os estudos sugerem que a consideração dessas ações, que representam de forma mais aproximada a estrutura real, modifica a distribuição de esforços nos elementos da estrutura. Por fim, percebe-se que esta consideração pode alterar os efeitos da interação solo-estrutura na redistribuição de esforços, se as duas considerações forem utilizadas de forma conjunta. 


\section{CAPÍTULO 3 - DESENVOLVIMENTO DO MODELO NUMÉRICO}

Este capítulo aborda aspectos referentes à construção do modelo numérico empregado ao longo da tese. O desenvolvimento da pesquisa é baseado em um edifício modelo. O edifício modelo pertence a um empreendimento residencial construído na cidade de São Lourenço da Mata no estado de Pernambuco. Durante a execução do edifício, foram efetivadas medições de recalques em diversos pontos da edificação, que são utilizadas para comparações aos resultados do modelo numérico proposto. Por intermédio do balizamento das medições de recalques é possível a consolidação da estratégia numérica adotada.

A metodologia utilizada consiste na consideração das ações atuando por fases, com alterações progressivas na geometria da edificação, que é denominada ao longo do texto como ações evolutivas. O modelo numérico é fundamentado no Método dos Elementos Finitos. A aplicação do método é executada com o uso do pacote computacional DIANA $9.6^{\circledR}$.

São apresentadas as características do problema estudado e a estratégia utilizada para aferir as propriedades constitutivas do maciço do solo. Conceitos sobre a construção do modelo numérico (elementos empregados, ações e condições de contorno) são discutidos.

Por fim, as medições experimentais dos recalques nas paredes são confrontadas com as soluções obtidas numericamente.

\subsection{CARACTERÍSTICAS DO PROBLEMA}

O edifício modelo empregado no desenvolvimento do trabalho tem 8 pavimentos tipo, com 4 apartamentos em cada pavimento. As paredes de concreto possuem 12 centímetros de espessura. A solução de fundação utilizada é superficial do tipo radier, com 40 centímetros de espessura. A estrutura do radier é prolongada 50 centímetros da projeção das paredes da estrutura em todo o perímetro da edificação. Os elementos de laje dos pavimentos foram modelados com 10 centímetros de espessura.

Deve-se ter em mente que os edifícios de paredes de concreto são empregados, em sua ampla maioria, em edificações residenciais populares, onde geralmente não se tem a presença de grandes vãos e nem soluções estruturais arrojadas. Entende-se, assim, que a tipologia do edifício modelo é representativa da grande maioria de edifícios de paredes de concreto construídos no Brasil. 
O empreendimento possui inúmeras unidades do mesmo edifício, sendo elas idênticas na superestrutura. A tipologia do pavimento tipo é ilustrada na Figura 3.1 (Vista em planta) e na Figura 3.2 (Perspectiva tridimensional de um pavimento).

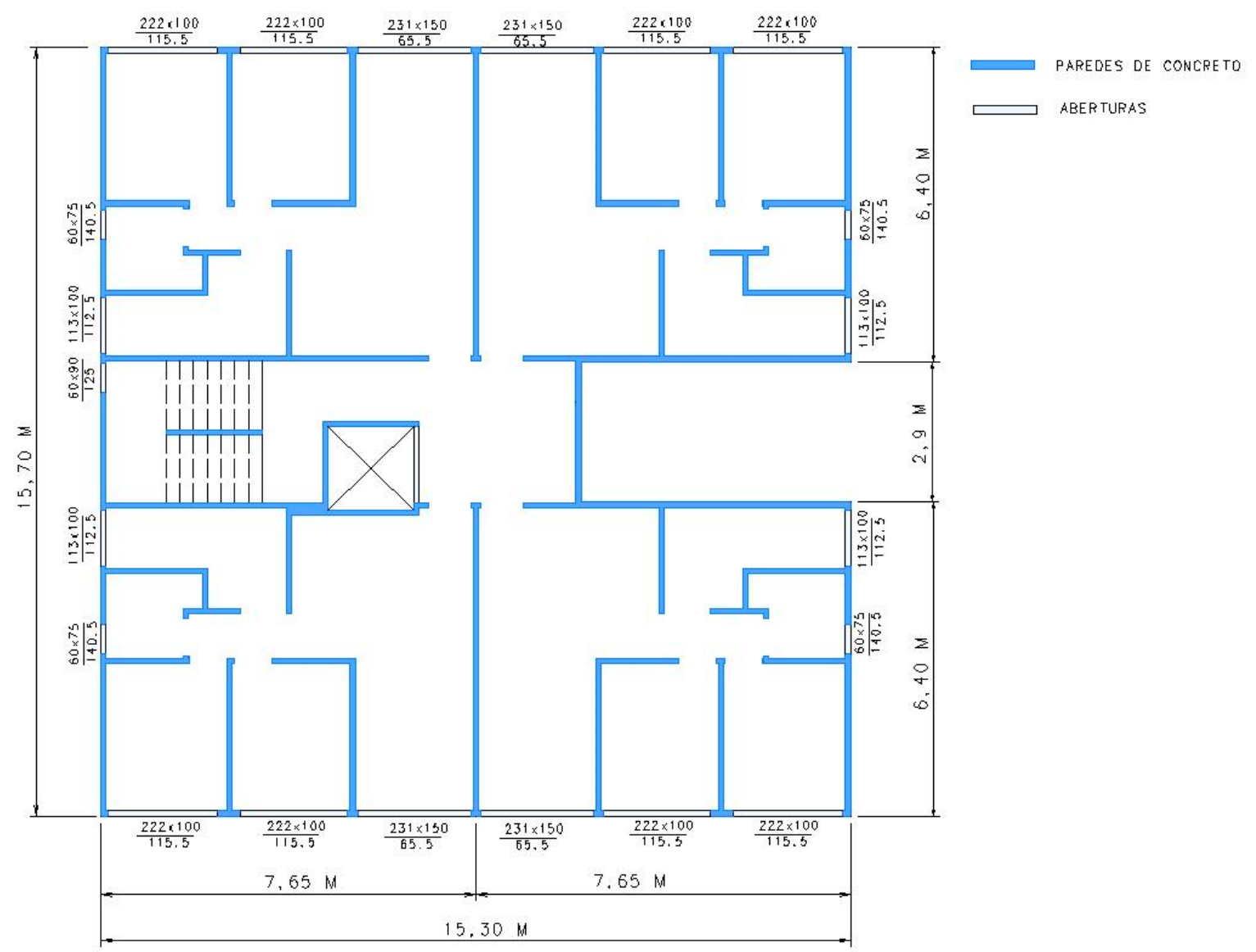

Figura 3.1- Tipologia do edifício modelo

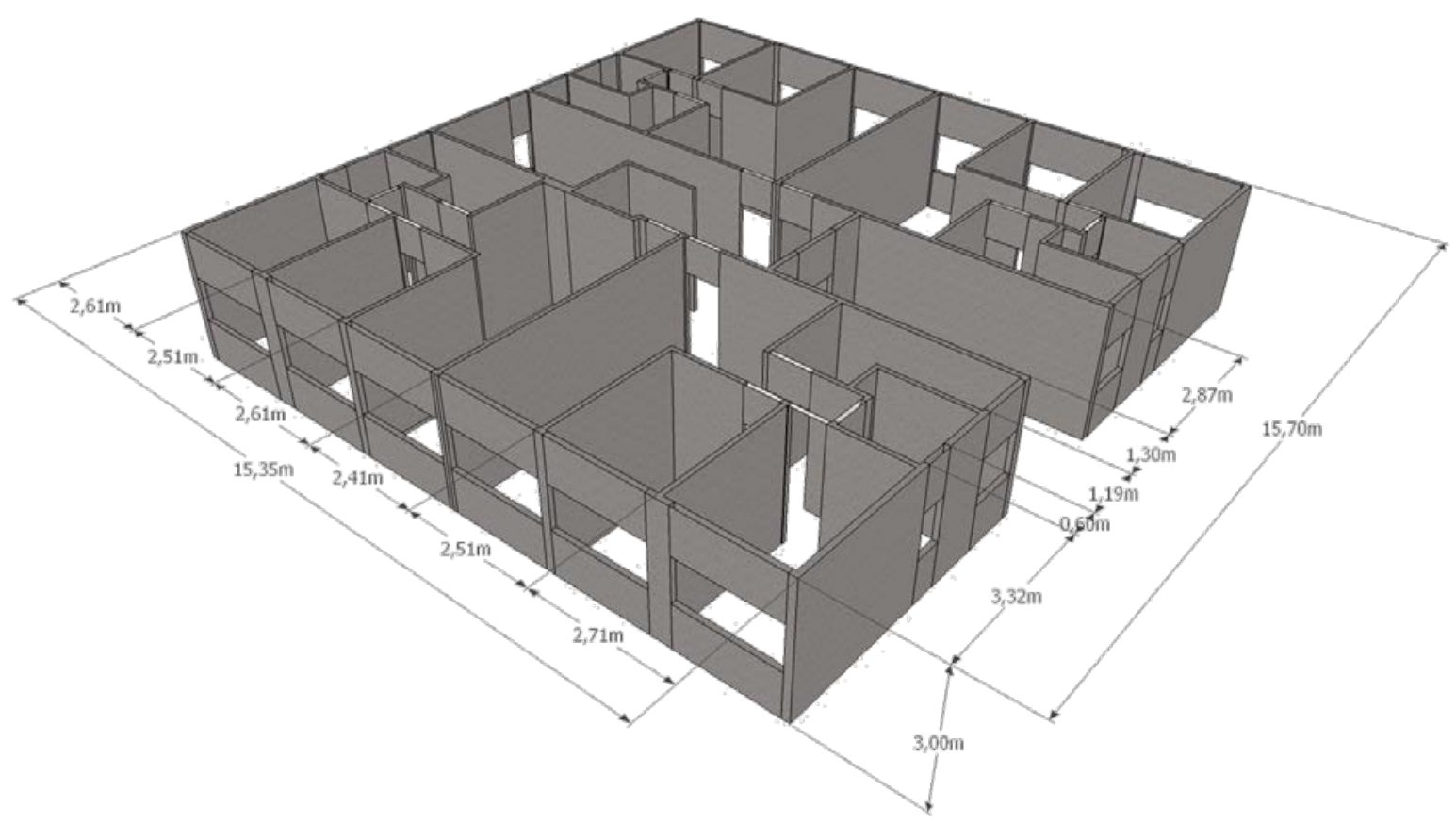

Figura 3.2- Perspectiva tridimensional de um pavimento 
As medições dos recalques foram executadas por intermédio de um nível ótico que mensura o deslocamento relativo entre os pontos de medições, dispostos em determinados locais específicos da estrutura, em relação a um ponto de referencial de nível indeslocável (localizado em uma área externa da construção). Os pontos de medições são pinos metálicos fixados na base da estrutura do pavimento térreo. Os pinos de medições dos recalques foram dispostos nas paredes externas da edificação, o que favoreceu a leitura.

Todas as medições foram realizadas com a obra em andamento, sendo que as ações atuantes na estrutura, correspondentes aos recalques medidos, foram estimadas a partir da porcentagem de construção da edificação no instante da medição.

As sondagens possibilitaram identificar diferentes perfis de solos ao longo do empreendimento. Os resultados das medições indicam grande variabilidade na grandeza dos recalques médios. Os valores finais médios obtidos variaram entre 1 e 35mm. Assim sendo, são selecionados três tipos diferentes de solo visando contemplar distintos níveis de recalques. Visando que a heterogeneidade do solo tivesse baixa influência nos resultados procurou-se utilizar casos com baixos níveis de desaprumos, indicados nas medições de recalques em conjunto com os relatórios de sondagem. Outro parâmetro na seleção dos edifícios analisados se refere à qualidade das medições de recalque, aferida pela reduzida ou inexistente perda de dados.

\subsection{MODELO NUMÉRICO}

O modelo numérico desenvolvido é baseado no Método dos Elementos Finitos. O Método dos elementos finitos (MEF) consiste na discretização de um meio contínuo em um número finito de elementos, no qual, com o uso do princípio da energia potencial, podem ser obtidos os deslocamentos nodais e consequentemente as inúmeras variáveis envolvidas no problema analisado (tensões, deformações e esforços). O Método teve seu início e desenvolvimento por volta dos anos 50 e 60 do século XX e é amplamente utilizado em inúmeros problemas da Engenharia de Estruturas e por não fazer parte do escopo da tese, os conceitos a respeito da formulação do método não são debatidos no presente texto. Algumas bibliografias como Bathe (1982), Assan (2001) e Liu e Quek (2013) foram consultadas com o intuito de servir como fundamento no desenvolvimento do modelo numérico.

Sobre o uso do MEF em problemas de interação solo-estrutura, poucos trabalhos são encontrados na literatura, provavelmente devido ao elevado custo computacional. O maciço do solo é um meio semi-infinito, o que ocasiona que para o uso do MEF neste tipo de problema 
deve-se utilizar um domínio suficientemente grande de forma que se minimize a sua influência nos resultados. A escolha do método dos elementos finitos deu-se pela possibilidade de incorporar em um único modelo as ações sequenciais de construção, um modelo constitutivo nas paredes de concreto que permitisse avaliar a fissuração do concreto e a interação soloestrutura.

\subsubsection{ESTRATÉGIA PARA AFERIR AS PROPRIEDADES DO SOLO}

A partir das medições de recalques dos 64 edifícios, são selecionados três exemplares e desenvolvidos os seus respectivos modelos numéricos, denominados como modelos M1, M2 e M3. O modelo M1, que apresentou uma das menores intensidades dos recalques do empreendimento, obteve na etapa final da construção um recalque médio final de 4,12mm. Em contrapartida, o modelo M3 alcançou um recalque médio dentre os mais altos dos edifícios observados, com um valor final de 32,55mm. O modelo M2 apresentou um recalque médio final de 15,59mm. Os exemplares escolhidos permitem, desta maneira, abranger toda a faixa de recalques levantada nos edifícios do empreendimento estudado.

A estratégia para aferir as propriedades de rigidez do maciço do solo é fundamentada na teoria de elasticidade. O solo em si não é um material de comportamento elástico, já que os recalques imediatos não são recuperados com o descarregamento da estrutura. Cintra et al. (2011) afirmam que é razoável admitir o uso da teoria da elasticidade em análise geotécnicas devido a relação linear entre a carga aplicada e os recalques obtidos em fundações superficiais.

A estratégia na definição das propriedades elásticas do solo consiste no emprego dos próprios valores obtidos nas medições experimentais na estimativa destes parâmetros. Parte-se da premissa que os recalques médios da edificação dependem apenas do carregamento aplicado e das propriedades de deformação do solo.

Gusmão (1990) afirma que a interação solo-estrutura atua na uniformização dos recalques, fazendo com que pilares mais carregados tendam a recalcar menos que o previsto sem a ISE e os menos carregados mais do que o previsto, mas por fim o recalque médio absoluto tende a permanecer inalterado. Deste modo, pode-se afirmar que a magnitude média dos recalques medidos na edificação analisada possa ser utilizada na estimativa do módulo de elasticidade do maciço do solo.

A solução para o cálculo do recalque na superfície de uma massa tridimensional em um meio semi-infinito (Equação 3.1) sendo esse material homogêneo, isotrópico e de comportamento elástico, foi inicialmente proposta por Boussinesq (Timoshenko e Goodier, 1934). A solução clássica exposta pelo autor permite calcular o recalque em qualquer ponto da 
superfície de um maciço de solo com uma carga concentrada "P” localizada na origem de um sistema de coordenadas, como ilustrado pela Figura 3.3.

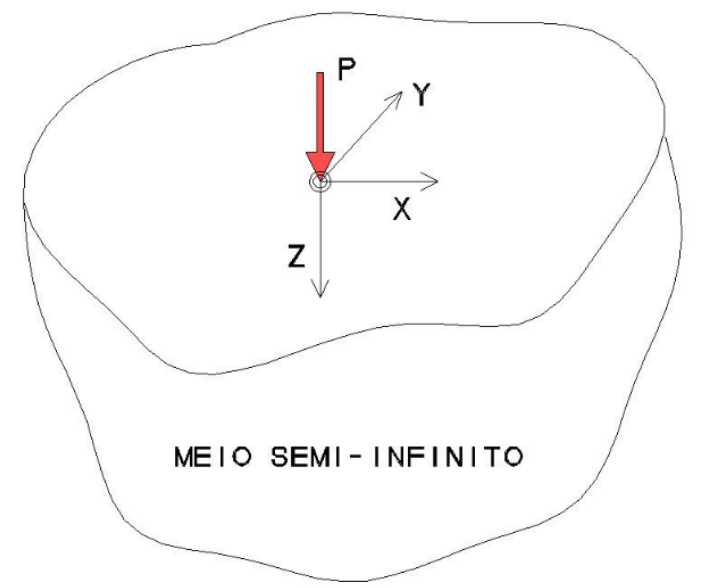

Figura 3.3 - Solução clássica de Boussinesq - Recalque no meio semi-infinito

$$
w(x, y)=\frac{P *\left(1-\mu s^{2}\right)}{E_{s} * \pi * \sqrt{x^{2}+y^{2}}}
$$

$w(x, y):$ Recalque na coordenada $(x, y)$

Es: Módulo de elasticidade do solo

$P:$ Carga concentrada

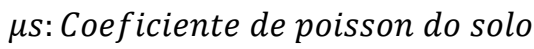

x e y: Coordenadas cartesianas com a origem localizada no centro de aplicação da carga

Posteriormente, diversos autores deduziram a partir da solução clássica de Boussinesq formulações para o cálculo de deslocamentos e tensões em inúmeras condições de contornos e tipos de carregamentos. A solução clássica de Boussinesq é baseada em um domínio semiinfinito. Harr (1966) apresentou adaptações de algumas situações especificas da Equação 3.1. Dentre elas a solução tridimensional considerando o maciço do solo como um meio de espessura vertical finita sobre uma base estimada rígida (Equação 3.2).

$$
w=\frac{2 a q *\left(1-\mu s^{2}\right) * K}{E_{s}}
$$

A Equação 3.2 possibilita o cálculo do recalque no centro de uma superfície com carregamento retangular distribuído. Os valores referentes ao coeficiente $\mathrm{K}$ foram baseados na 
hipótese do elemento de fundação funcionando como um elemento rígido. Esta suposição é bastante plausível devido às dimensões do radier e a rigidez da superestrutura.

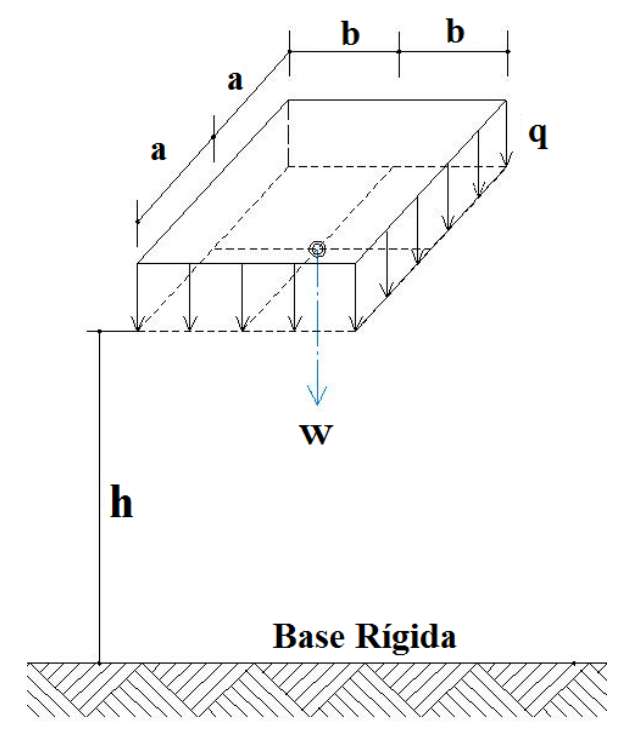

\begin{tabular}{|c|c|c|c|c|c|c|r|}
\hline \multirow{2}{*}{$\mathrm{h} / \mathrm{a}$} & \multicolumn{7}{|c|}{$\mathrm{b} / \mathrm{a}$} \\
\cline { 2 - 8 } & 1 & 2 & 3 & 5 & 7 & 10 & $\infty$ \\
\hline 0,2 & 0,096 & 0,098 & 0,098 & 0,099 & 0,099 & 0,099 & 0,100 \\
\hline 0,5 & 0,226 & 0,231 & 0,233 & 0,236 & 0,237 & 0,238 & 0,239 \\
\hline 1 & 0,403 & 0,427 & 0,435 & 0,441 & 0,444 & 0,446 & 0,452 \\
\hline 2 & 0,609 & 0,698 & 0,727 & 0,748 & 0,757 & 0,764 & 0,784 \\
\hline 3 & 0,711 & 0,856 & 0,910 & 0,952 & 0,964 & 0,982 & 1,018 \\
\hline 5 & 0,800 & 1,010 & 1,119 & 1,201 & 1,238 & 1,256 & 1,323 \\
\hline 7 & 0,842 & 1,094 & 1,223 & 1,346 & 1,402 & 1,442 & 1,532 \\
\hline 10 & 0,875 & 1,155 & 1,309 & 1,475 & 1,556 & 1,619 & 1,758 \\
\hline$\infty$ & 0,946 & 1,300 & 1,527 & 1,826 & 2,028 & 2,246 & $\infty$ \\
\hline
\end{tabular}

Figura 3.4 - Recalque em meio finito com carregamento distribuido - Harr (1966)

O maciço do solo é composto por diversas camadas horizontais de materiais distintos. A estratégia proposta consiste em definir a rigidez do maciço como de um material único que pudesse representar as diversas camadas do problema, permitindo assim simplificar o problema.

A partir da manipulação da Equação 3.2 é possível relacionar o módulo de elasticidade do solo com as cargas aplicadas e o recalque médio da edificação. Juntamente com os recalques medidos, foram fornecidos dados para a estimativa das ações atuantes na estrutura (Peso próprio dos elementos construídos).

Desta maneira, por intermédio dos dados fornecidos (Recalques medidos e carga atuante estimada) é possível estimar o Módulo de Elasticidade do maciço do solo abaixo da edificação estudada. O coeficiente de Poisson empregado em todos os modelos foi de 0,3 , valor este usual na ampla maioria dos solos.

Além da rigidez do solo foi definido critérios para simular a plastificação do solo. Deve-se deixar claro que o nível de carga utilizado nas análises realizadas tem associação com a boa capacidade resistente do solo, já que os modelos aqui representam estruturas reais já executadas. Assim, é interessante destacar que a ruptura do solo não será atingida no nível de carga empregado nos problemas analisados. Entretanto, optou-se pelo uso de um critério nãolinear objetivando simular a plastificação de zonas com grandes concentrações de tensões e consequentemente redistribuir as deformações de maneira mais realista.

Caputo (1967) indica que o critério de plastificação de Mohr-Coulomb é uma das hipóteses tradicionalmente mais utilizadas para representar a ruptura na mecânica dos solos. 
Este critério é usualmente empregado com o intuito de representar a ruptura de materiais frágeis, relacionando o aumento da resistência ao cisalhamento com a compressão hidrostática. A ruptura do maciço ocorre quando em todos os pontos ao longo da superfície de ruptura, a tensão de cisalhamento atuante atinge a tensão de cisalhamento resistente (Figura 3.5).
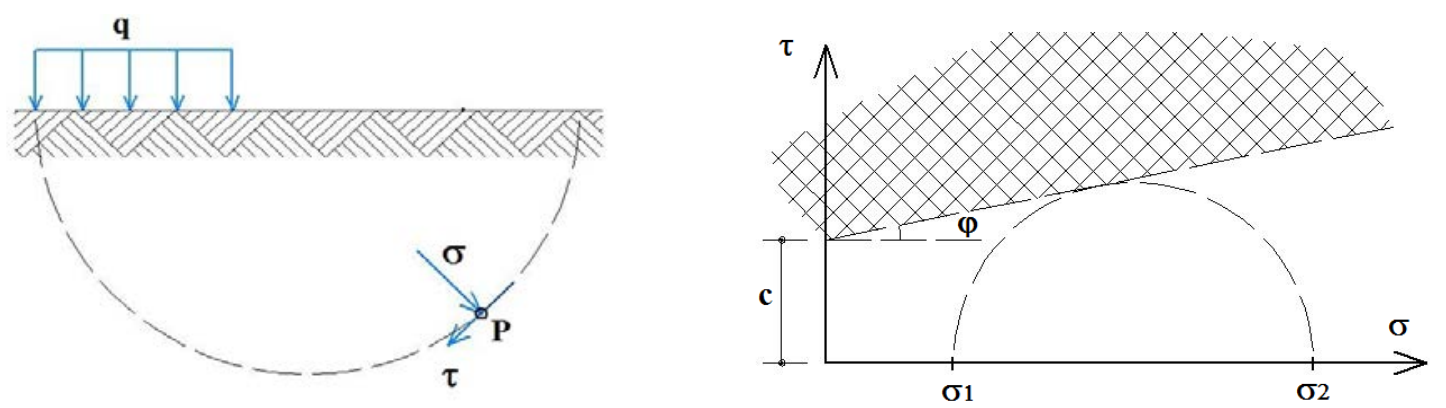

Figura 3.5 - Critério de ruptura de Mohr-Coulomb - Adaptado de CAPUTO (1967)

Devido à ausência de ensaios experimentais do solo presente nas edificações estudadas, a definição das propriedades não-lineares do maciço foi realizada a partir de indicações de Teixeira e Godoy (1996) em conjunto com os relatórios de sondagens dos edifícios. Os autores definiram relações entre o ângulo de atrito interno e a coesão do solo, na condição não-drenada, com o índice de resistência à penetração do SPT. Deste modo, mediante os relatórios de sondagens das edificações estudadas, essas variáveis foram estimadas. A Equação 3.3 e a Equação 3.4 apresentam as expressões propostas pelos autores.

$$
\begin{aligned}
& c=10 N_{S P T}(\mathrm{KPa}) \\
& \varphi=\sqrt{20 * N_{S P T}}+15^{\circ}
\end{aligned}
$$
Equação 3.3

c: Coesão

$\varphi$ : Ângulo de atrito interno do solo

$N_{S P T}$ : Índice de resistência à penetração do SPT

A Tabela 3.1 mostra os dados de recalques médios finais obtidos por meio das medições, o valor de resistência à penetração SPT e as propriedades do solo calculados de acordo com o modelo adotado. As espessuras dos maciços do solo em ambos dos modelos são de 8 metros de profundidade.

Tabela 3.1 - Propriedades do solo dos modelos propostos

\begin{tabular}{|c|c|c|c|c|c|c|}
\multicolumn{1}{c|}{ Tabela 3.1 - Propriedades do solo dos modelos propostos } \\
\cline { 2 - 7 } \multicolumn{1}{c|}{} & $\begin{array}{c}\text { Recalque final } \\
\text { medido (mm) }\end{array}$ & $N_{S P T}$ & $\begin{array}{c}E_{s}-\text { Módulo de } \\
\text { Elasticidade }\left(\mathrm{kN} / \mathrm{m}^{2}\right)\end{array}$ & $\begin{array}{c}v_{s} \text { - Coeficiente } \\
\text { de poisson }\end{array}$ & $\begin{array}{c}c \text { - Coesão } \\
\left(\mathrm{kN} / \mathrm{m}^{2}\right)\end{array}$ & $\begin{array}{c}\varphi \text { - Ângulo de } \\
\text { Atrito }\end{array}$ \\
\hline M1 & 4,12 & 17 & 42000 & 0,3 & 170 & $33^{\circ}$ \\
\hline M2 & 13,86 & 14 & 19300 & 0,3 & 147 & $30^{\circ}$ \\
\hline M3 & 32,55 & 13 & 8200 & 0,3 & 135 & $29^{\circ}$ \\
\hline
\end{tabular}




\subsubsection{MODELOS CONSTITUTIVOS - SUPERESTRUTURA}

As propriedades dos materiais utilizadas são fundamentadas nos valores solicitados nos projetos do edifício modelo. Para o concreto é empregada resistência característica à compressão de 35 MPa para o radier e de 25 MPa nas paredes e lajes dos pavimentos.

Em relação ao radier e as lajes dos pavimentos, adota-se comportamento elástico-linear do concreto. Esta simplificação é realizada, pois o enfoque principal do problema é referente às paredes de concreto da superestrutura, para as quais o concreto é simulado com não-linearidades como explicado a seguir. Para a estimativa do módulo de elasticidade do concreto e do coeficiente de Poisson são utilizadas as prescrições da norma NBR 6118 (ABNT, 2014).

Emprega-se comportamento não-linear físico do concreto, com o objetivo de avaliar o surgimento de fissuração do concreto nas paredes estruturais causada pela interação soloestrutura. O modelo constitutivo do concreto utilizado para a consideração das não-linearidades físicas é baseado no modelo de fissuração distribuída “Total strain crack model”. O modelo constitutivo é fundamentado em estudos desenvolvidos na universidade de Toronto, no qual foram executadas uma variedade ampla de ensaios que permitiram avaliar o desempenho tensão-deformação do concreto fissurado sujeito ao cisalhamento. O critério citado permite avaliar o surgimento de fissuras localizadas e estimar o comportamento tensão-deformação localizado após o surgimento da fissura, tanto por tração como por esmagamento do concreto. A teoria original do modelo foi proposta por Vecchio e Collins (1986). O procedimento possibilita relacionar o comportamento do concreto com base nos conceitos da energia de fratura. O modelo utilizado considera a formação de fissuras fixas.

Os diagramas tensão-deformação do concreto são baseados nas recomendações realizadas por Lourenço (1996). O pesquisador apresentou o desempenho típico de materiais quase-frágeis sob carregamento uniaxial, com possibilidade de modelagem pós-pico. A Figura 3.6 ilustra as curvas de tensão versus deslocamento propostas por Lourenço (1996). 

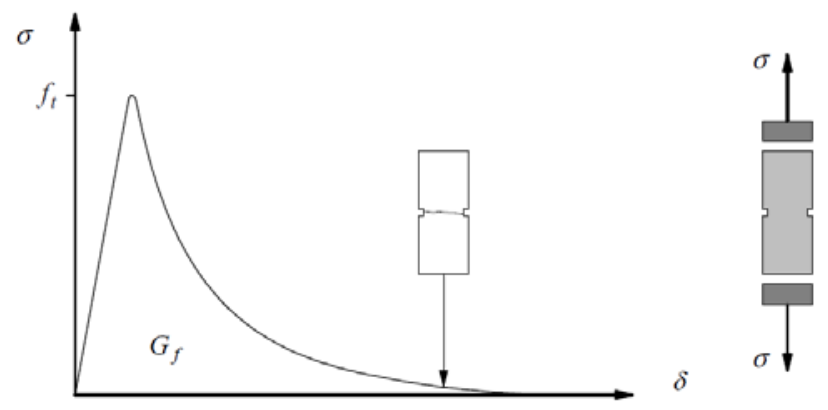

a) Comportamento na tração
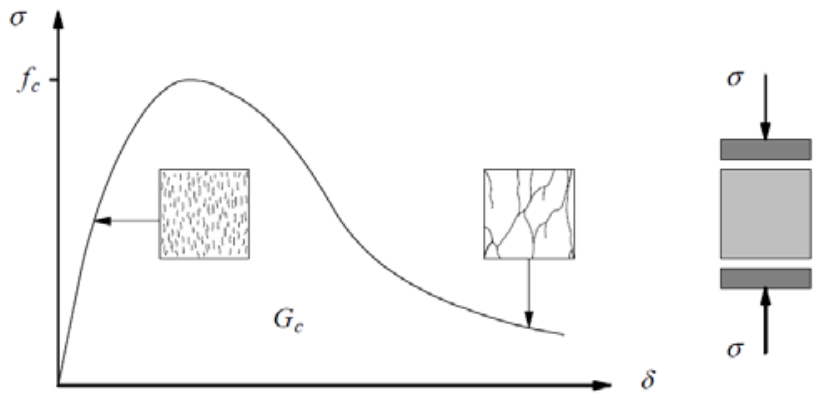

b) Comportamento na compressão

Figura 3.6 - Comportamento de materiais quase-frágeis sob carregamento uniaxial (Lourenço, 1996)

Por meio da integral desses diagramas são definidas as propriedades referentes à energia de fratura dos materiais (na compressão e na tração). A energia de fratura é aquela necessária para a formação da primeira fissura. O “modo I” (Figura 3.7) corresponde à fissura no plano analisado, com direção normal à face da fissura (Lourenço, 1996).

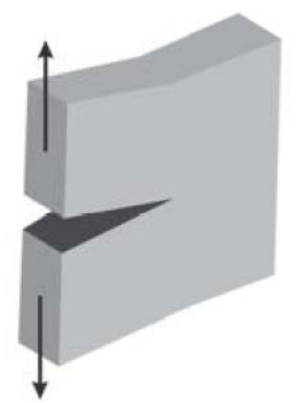

Figura 3.7 - Energia de fratura - MODO I

A partir dessas recomendações, utiliza-se para o diagrama tensão versus deformação na tração uma curva composta por trechos lineares, baseada na resistência à tração do concreto e na energia de fratura na tração "Ğ” (Modo I). O comportamento do concreto na compressão é estimado mediante da adoção de uma curva parabólica relacionando tensão e deformação. A curva é construída com base na resistência característica à compressão do concreto e na energia de fratura na compressão “ $G_{c}$ ” (Modo I). A Figura 3.8 indica os diagramas adotados no modelo não-linear do concreto. 


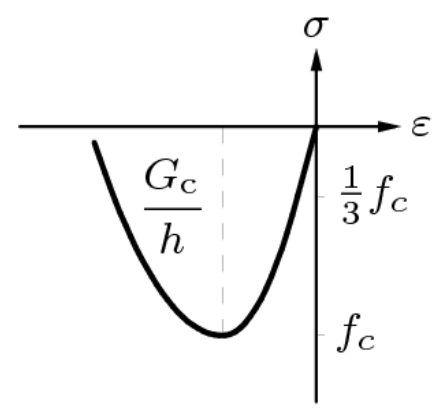

a) Compressão

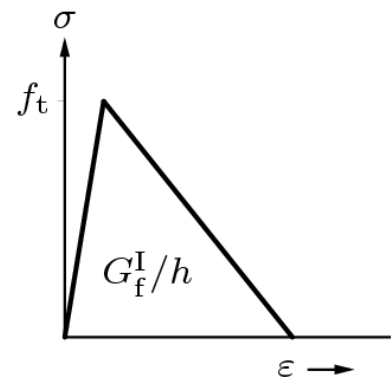

b) Tração

Figura 3.8 - Modelos não-lineares para o concreto - "Total Strain Crack Model”

A estimativa da intensidade da energia de fratura na compressão e na tração (Modo I) é executada por meio da proposta do CEB-FIP (2010). A variável “ $h$ ” é a largura de banda da fissura, que é calculada automaticamente pelo software a partir da raiz quadrada da área de cada elemento finito. A resistência característica à tração do concreto é estimada utilizando as prescrições da norma NBR-6118 (ABNT, 2014).

Em referência ao cisalhamento, pode-se definir um comportamento visando penalizar a rigidez após a ocorrência da fissura no elemento finito. A penalização da rigidez é realizada com a utilização do coeficiente de retenção ao cisalhamento. Adota-se um valor de 0,01 constante para o coeficiente de retenção ao cisalhamento (“ $\beta$ ”). A Tabela 3.2 exibe as propriedades constitutivas do concreto adotadas, tanto para os modelos lineares como os nãolineares.

Tabela 3.2 - Propriedades do concreto

\begin{tabular}{|c|c|c|}
\hline \multicolumn{3}{|c|}{ Radier } \\
\hline $\begin{array}{l}f_{c k} \text { - Resistência à compressão } \\
(\mathrm{MPa})\end{array}$ & $\begin{array}{c}\text { Ec - Módulo de Elasticidade } \\
(\mathrm{MPa})\end{array}$ & $v_{c}$ - Coeficiente de poisson \\
\hline 35 & 33130 & 0,2 \\
\hline \multicolumn{3}{|c|}{ Lajes dos pavimentos } \\
\hline $\begin{array}{l}\text { fck - Resistência à compressão } \\
(\mathrm{MPa})\end{array}$ & $\begin{array}{c}\text { Ec - Módulo de Elasticidade } \\
(\mathrm{MPa})\end{array}$ & $v_{c}$ - Coeficiente de poisson \\
\hline 25 & 28000 & 0,2 \\
\hline \multicolumn{3}{|c|}{ Paredes de concreto } \\
\hline $\begin{array}{l}\text { fck - Resistência à compressão } \\
\text { (MPa) }\end{array}$ & $\begin{array}{c}\text { Ec - Modulo de elasticidade } \\
(\mathrm{MPa})\end{array}$ & $v_{c}$ - Coeficiente de poisson \\
\hline 25 & 28000 & 0,2 \\
\hline ftk -Resistência à Tração (MPa) & $\begin{array}{c}G_{c} \text {-Energia de fratura - } \\
\text { compressão }\left(\mathrm{Nm} / \mathrm{m}^{2}\right)\end{array}$ & $\begin{array}{c}G_{f} \text { Energia de fratura - tração } \\
\left(\text { Modo I) }\left(\mathrm{Nm} / \mathrm{m}^{2}\right)\right.\end{array}$ \\
\hline 2,54 & 490 & 49 \\
\hline
\end{tabular}

Em conjunto com a incorporação da não-linearidade física do concreto, é necessário o uso de elementos de armaduras em todas as paredes e linteis da superestrutura com o objetivo de simular as barras de aço presentes nas paredes de concreto. Considera-se o comportamento elástico-linear para o aço, utilizando o módulo de elasticidade de 210 GPa (NBR 6118, 2014). 
Por simplicidade, adota-se aderência perfeita entre os elementos de armadura e as paredes de concreto.

\subsubsection{GEOMETRIA DO MODELO PROPOSTO}

Algumas simplificações referentes à geometria da estrutura e as dimensões das aberturas são adotadas, com o objetivo de facilitar a construção do modelo e a análise dos resultados. São alinhadas algumas aberturas e desprezados pequenos trechos de paredes entre essas aberturas. Este procedimento é utilizado para evitar regiões com grande concentração de tensões e, consequentemente, atrapalhasse a convergência dos resultados.

Utiliza-se a simetria da edificação para a redução do custo computacional. A consideração da simetria é executada por meio da imposição das adequadas condições de contorno. A Figura 3.9 exibe a geometria do pavimento, a numeração das paredes adotadas, bem como o sistema de coordenadas adotado.

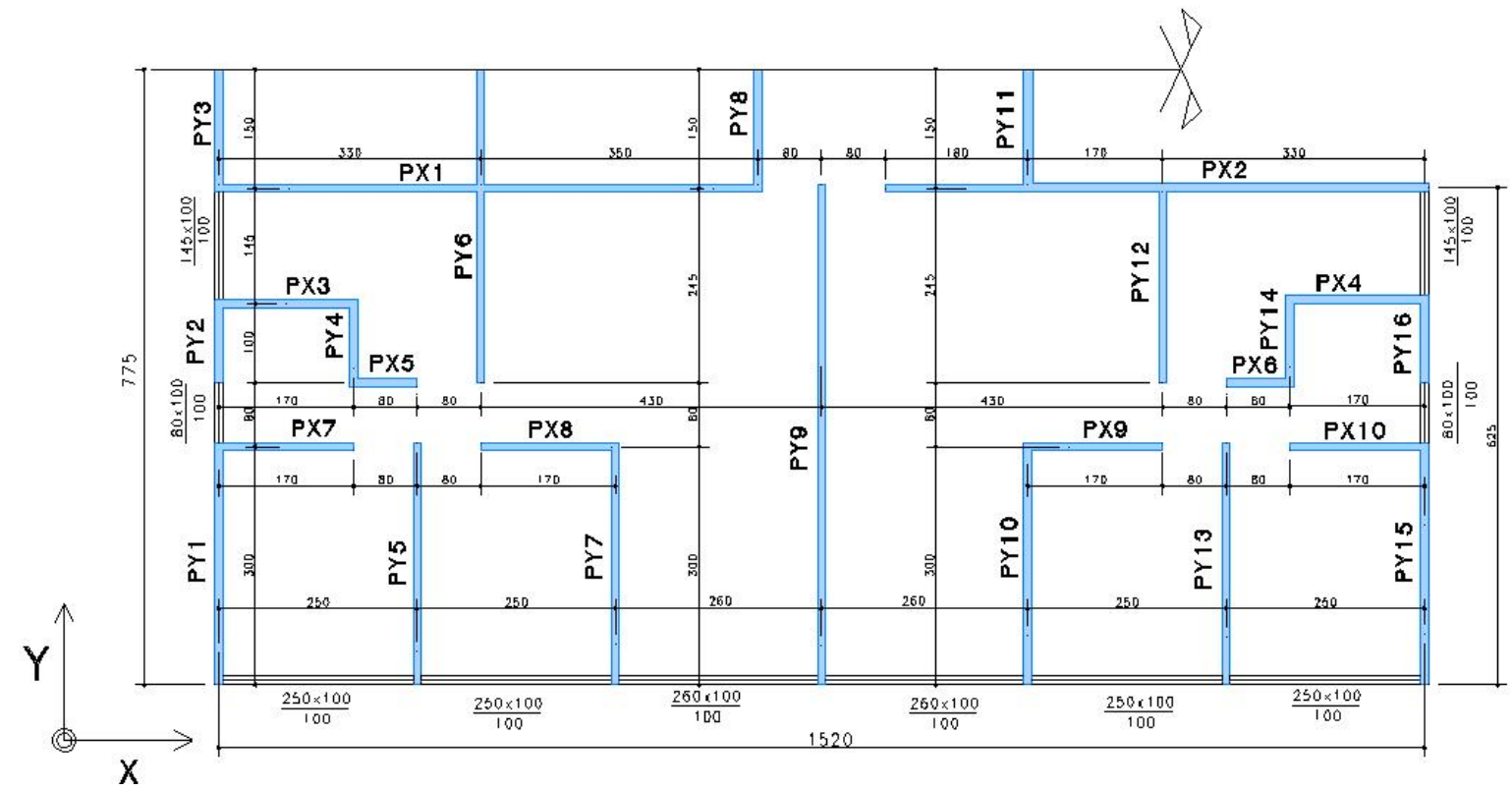

Figura 3.9 - Geometria e numeração das paredes adotadas

A profundidade vertical do maciço do solo é definida até a camada considerada indeformável, de acordo com os relatórios de sondagem fornecidos. O limite horizontal do domínio do maciço do solo é definido como o valor da metade do maior comprimento da edificação em planta. No Apêndice A é descrito o procedimento realizado em análises preliminares simplificadas para a verificação desse limite. 
Foi desenvolvido um estudo preliminar para avaliar o grau de refinamento da malha nas paredes. Quanto ao domínio do solo, é executada a redução progressiva da densidade da malha à medida que o maciço do solo se afastava da edificação. As avaliações referentes ao refinamento da malha estão expostas no ANEXO A.

\subsubsection{ELEMENTOS FINITOS UTILIZADOS}

São empregados diversos tipos de elementos finitos, sempre de acordo com as simplificações geométricas convenientes de cada elemento estrutural analisado. As variáveis exibidas neste item são referentes aos eixos locais de cada elemento finito. Os resultados expostos ao longo da presente tese utilizam o eixo global do modelo como referência.

Para a simulação das paredes da superestrutura considera-se o estado plano de tensões, ou seja, as tensões perpendiculares ao plano das paredes são nulas. Assim sendo, é adotado um elemento plano de chapa, ou membrana. A simplificação é válida, pois a espessura das paredes $(12 \mathrm{~cm})$ é muito inferior às duas outras dimensões. A formulação do elemento finito de chapa possui dois graus de liberdade nodais nas direções do seu plano e as ações são aplicadas sempre no seu plano médio. A Figura 3.10 mostra as características e variáveis do elemento de chapa, lembrando que mesmo sendo um elemento plano é utilizada uma formulação tridimensional.

O emprego de elementos de casca na representação das paredes da superestrutura é possível, e até recomendável para o caso da aplicação de ações horizontais. Optou-se por utilizar elementos de chapa, ou membrana, com o objetivo de reduzir o custo computacional. Testoni (2013) e Braguim (2013) utilizaram elementos planos de chapa em suas análises em edifícios de paredes de concreto com resultados suficientemente precisos. 


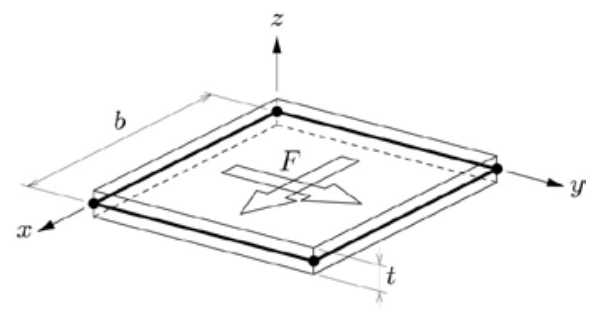

a) Características

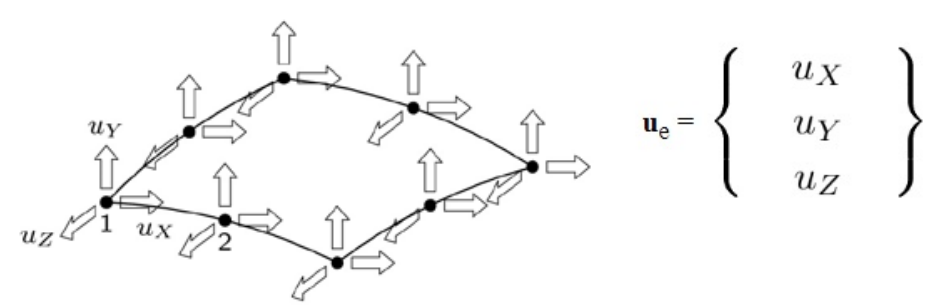

b) Deslocamentos nodais

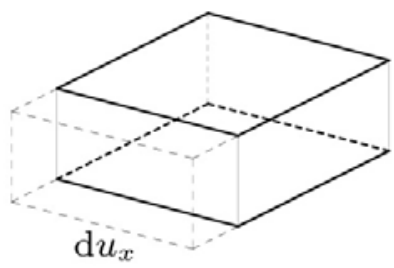

$$
\begin{gathered}
\varepsilon=\left\{\begin{array}{l}
\varepsilon_{x x} \\
\varepsilon_{y y} \\
\varepsilon_{z z} \\
\gamma_{x y}
\end{array}\right\} \\
\varepsilon_{x x}=\frac{\partial u_{x}}{\partial x} \quad \varepsilon_{y y}=\frac{\partial u_{y}}{\partial y} \\
\varepsilon_{z z}=\frac{\nu\left(\varepsilon_{x x}+\varepsilon_{y y}\right)}{1-\nu} \quad \gamma_{x y}=\frac{\partial u_{x}}{\partial y}+\frac{\partial u_{y}}{\partial x}
\end{gathered}
$$

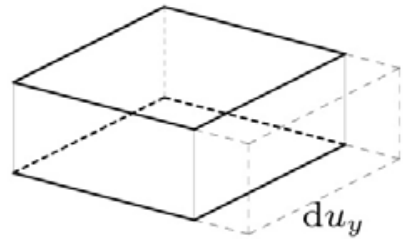

c) Deformações

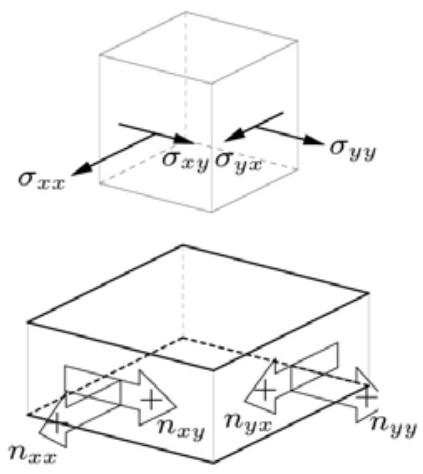

$$
\begin{gathered}
\boldsymbol{\sigma}=\left\{\begin{array}{c}
\sigma_{x x} \\
\sigma_{y y} \\
\sigma_{z z}=0 \\
\sigma_{x y}=\sigma_{y x}
\end{array}\right\} \\
\mathbf{n}=\left\{\begin{array}{l}
n_{x x} \\
n_{y y} \\
n_{x y}=n_{y x}
\end{array}\right\}
\end{gathered}
$$

d) Tensões de Cauchy e Esforços

Figura 3.10 - Estado plano de tensões e Elemento finito de chapa

O desprezo do deslocamento nodal na direção perpendicular ao plano da parede pode ser utilizado, já que no presente estudo são consideradas apenas ações verticais no edifício. A distribuição de esforços entre paredes interconectadas é realizada por intermédio da compatibilização do deslocamento vertical na interface comum.

O elemento de chapa adotado da biblioteca de elementos do DIANA é designado como “Q24GME”, que é um elemento retangular com oito nós, com interpolação quadrática dos deslocamentos. Este é um elemento plano específico para modelagens numéricas tridimensionais. A Figura 3.11 ilustra a descrição do elemento finito "Q24GME” e a função de interpolação dos deslocamentos nodais. A Figura 3.12 mostra a visão tridimensional isométrica da malha de elementos finitos de um pavimento do edifício modelo. 


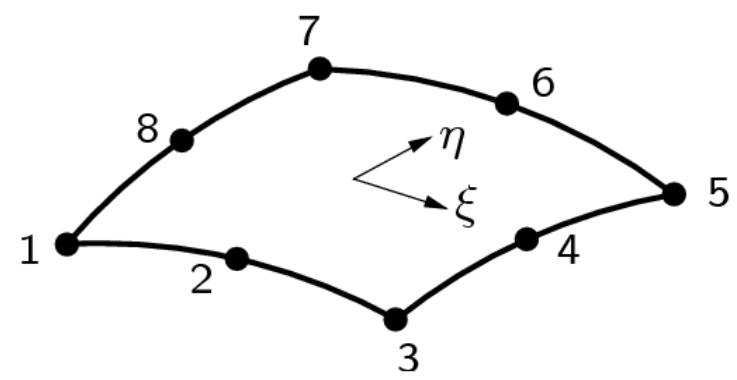

$u_{\mathrm{i}}(\xi, \eta)=a_{0}+a_{1} \xi+a_{2} \eta+a_{3} \xi \eta+a_{4} \xi^{2}+a_{5} \eta^{2}+a_{6} \xi^{2} \eta+a_{7} \xi \eta^{2}$

Figura 3.11 - Elemento Q24GME

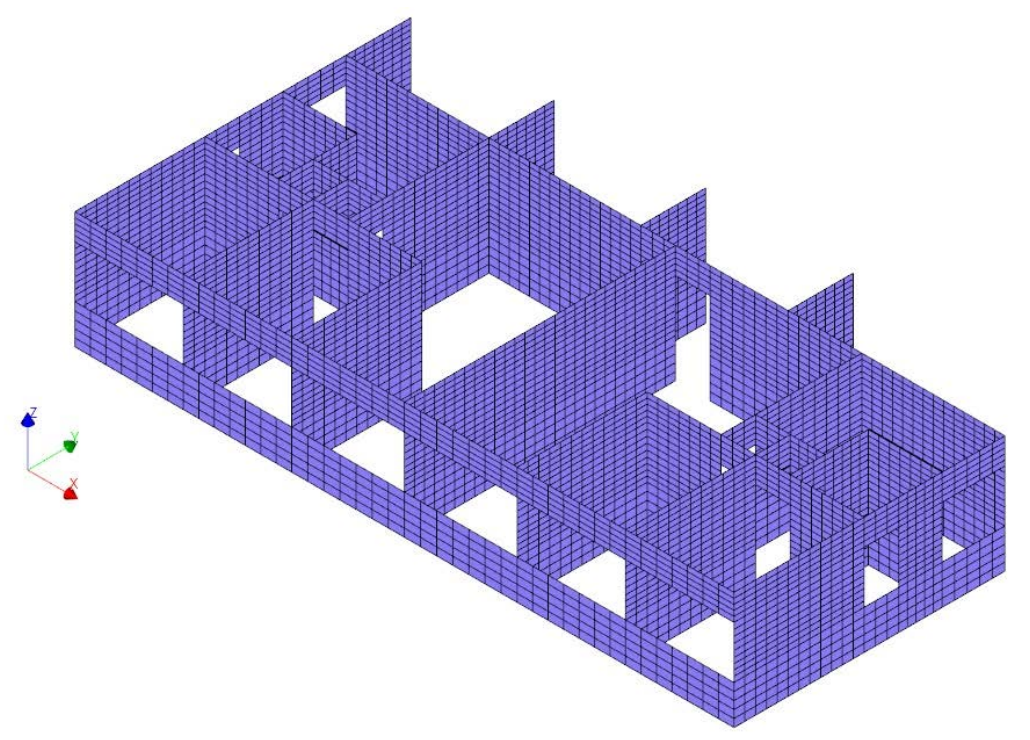

Figura 3.12 - Malha de elemento finitos de um pavimento

As armaduras nas paredes são representadas por elementos específicos para os reforços, denominados no DIANA ${ }^{\circledR}$ por embedded reinforcement. O embedded reinforcement não é um elemento finito discreto, mas sim um recurso que permite o uso de reforços embutidos nos demais elementos do modelo. Os reforços nas paredes adicionam rigidez de acordo com as propriedades das armaduras aos elementos nos quais elas estão inseridas. Este recurso possui vantagens em comparação ao uso discreto de elementos para as armaduras, pois não necessita de alterações de geometria na malha de elementos finitos.

A distribuição de armadura nas paredes foi feita uniformemente com a taxa mínima de armadura definida pela norma NBR-16055 (ABNT, 2012). São consideradas armaduras distribuídas, nas direções vertical e horizontal, de armaduras de $5 \mathrm{~mm}$ de diâmetro com um espaçamento entre as barras de 12 cm. Esta simplificação é razoável, já que convencionalmente são empregadas malhas de telas-soldadas com taxa de armadura similar para a armação desses elementos. A Figura 3.13 mostra a distribuição de armaduras em um dos pavimentos do modelo numérico. 


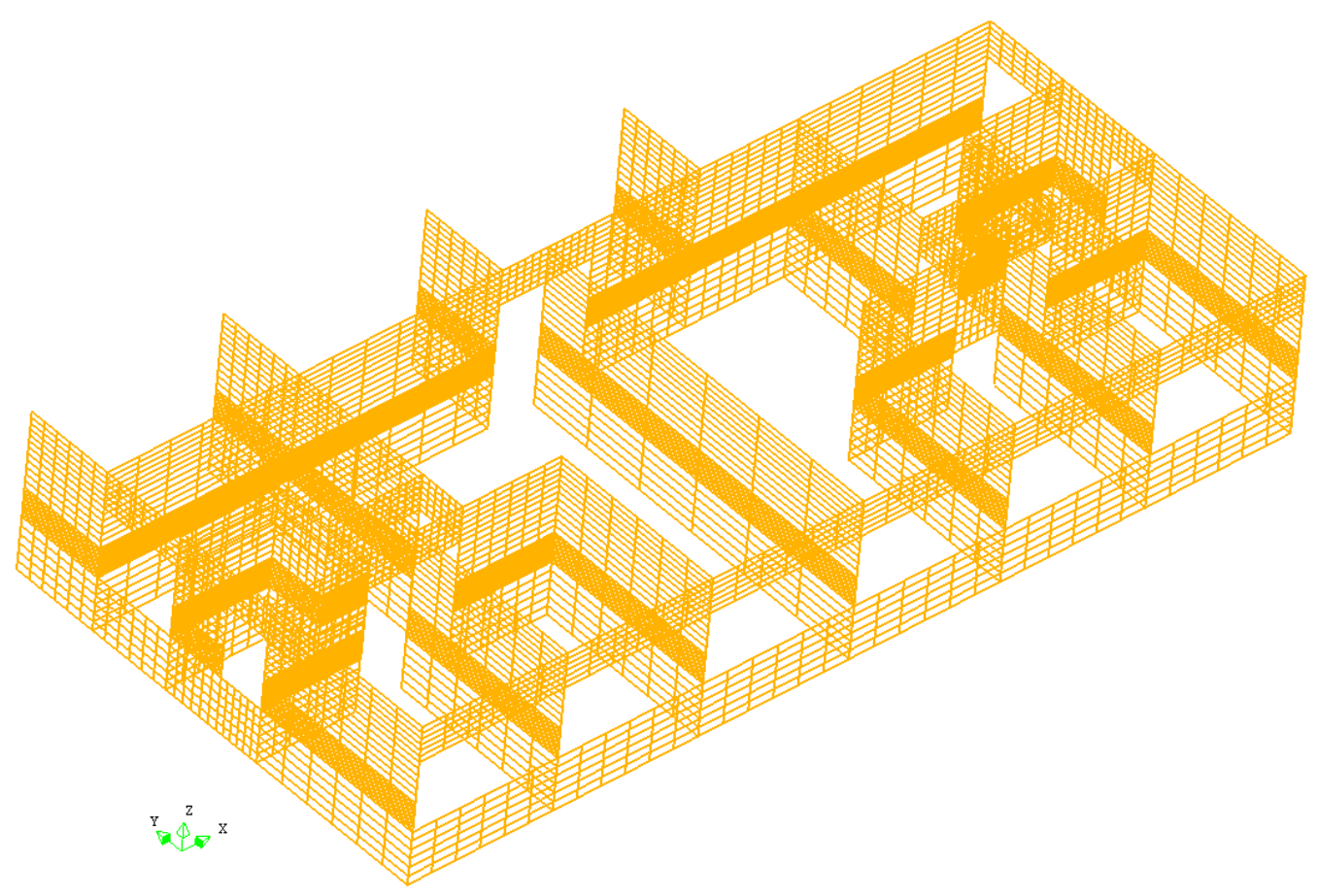

Figura 3.13 - Distribuição de armaduras em um dos pavimentos (REINFORCE)

A modelagem das lajes do pavimento e do radier, é fundamentada na teoria de placas de "Reissner-Mindlin”. A teoria de placa considera as ações atuantes perpendiculares ao plano do elemento. São utilizados três graus de liberdades por nó, sendo eles o deslocamento perpendicular ao plano da placa e as rotações em torno de duas direções no plano. O elemento finito de placa de Reissner-Mindlin trata o deslocamento e a rotação da placa no plano de forma independente (Figura 3.14).

A teoria de placa de "Reissner-Mindlin" é ideal em elementos de placa de grande espessura, no qual é contemplada a deformação por cisalhamento da placa, sendo adequada na simulação do radier. Nas lajes dos pavimentos, o uso de tal elemento não seria necessário, podendo ser utilizado um elemento mais simples baseado por exemplo na teoria de placas de “Kirchoff”. Utilizou-se o elemento de placa de Reissner-Mindlin para manter a conformidade entre os elementos do modelo, já que os elementos utilizados na simulação das paredes da superestrutura possuem interpolação quadrática dos deslocamentos. 


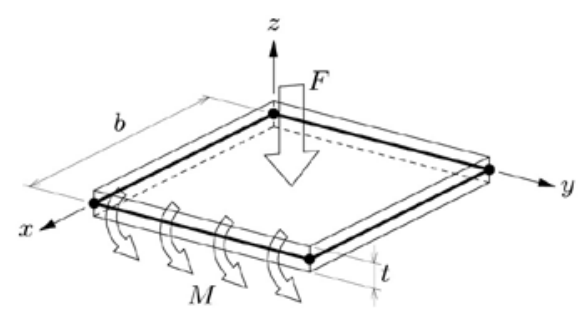

a) Características

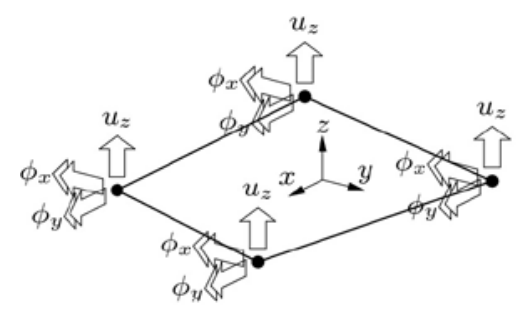

b) Deslocamentos e rotações nodais

$$
\mathbf{u}_{\mathrm{e}}=\left\{\begin{array}{c}
u_{z} \\
\phi_{x} \\
\phi_{y}
\end{array}\right\}
$$

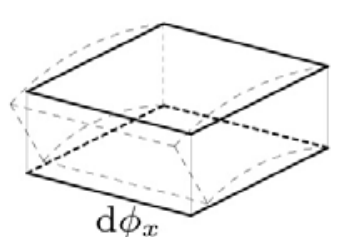

$$
\varepsilon=\left\{\begin{array}{c}
\kappa_{x x} \\
\kappa_{y y} \\
\kappa_{x y} \\
\Psi_{y z} \\
\Psi_{z x}
\end{array}\right\}
$$

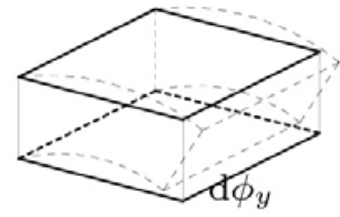

$\kappa_{x x}=-\frac{\partial \phi_{x}}{\partial x} \quad \kappa_{y y}=-\frac{\partial \phi_{y}}{\partial y}$

$\kappa_{x y}=-\left(\frac{\partial \phi_{x}}{\partial y}+\frac{\partial \phi_{y}}{\partial x}\right)$

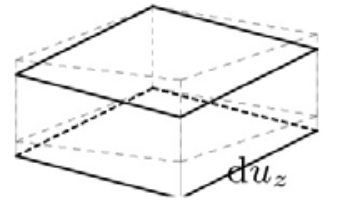

$\Psi_{y z}=\frac{\partial u_{z}}{\partial y}-\phi_{y}$

$\Psi_{z x}=\frac{\partial u_{z}}{\partial x}-\phi_{x}$

c) Deformações

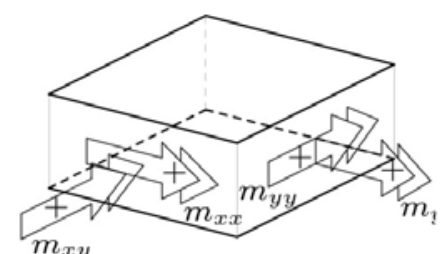

$\mathbf{m}=\left\{\begin{array}{l}m_{x x} \\ m_{y y} \\ m_{x y}=m_{y x}\end{array}\right\}$

$\mathbf{f}=\left\{\begin{array}{l}q_{x z} \\ q_{y z}\end{array}\right\}$

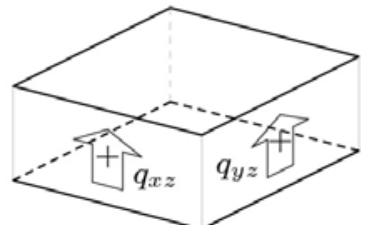

d) Momentos e forças

Figura 3.14 - Características e variáveis - Elementos de placa

O elemento de placa utilizado no radier e nas lajes dos pavimentos é o triangular isoparamétrico com seis nós e interpolação quadrática dos deslocamentos e rotações, indicado na biblioteca de elementos do DIANA por “CT18P” (Figura 3.15). A subdivisão da malha foi executada de forma a garantir a coincidência de nós entre os elementos das paredes com os nós dos elementos das lajes e do radier. Para a geração da malha das lajes utiliza-se um algoritmo do DIANA baseado na "triangulação de Delaunay". Esse procedimento permite a criação de uma malha não estruturada. A malha gerada atende aos critérios relacionados aos ângulos internos mínimos e máximos específicos para bom funcionamento do elemento finito. A Figura 
3.16 mostra a malha das lajes do primeiro pavimento e do radier em conjunto com a malha das paredes da superestrutura do $1^{\circ}$ pavimento.

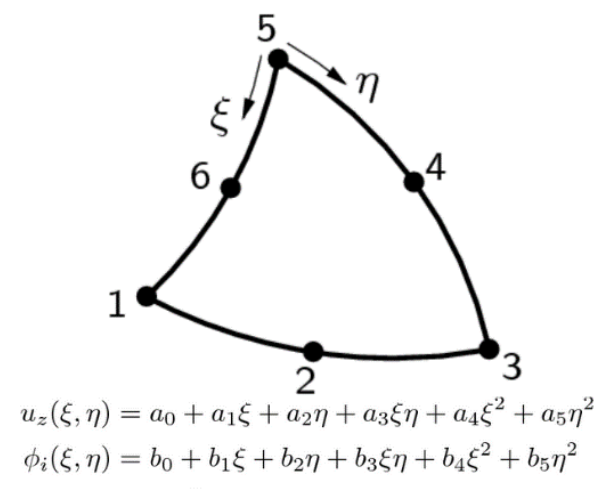

Figura 3.15 - Elemento CT18P

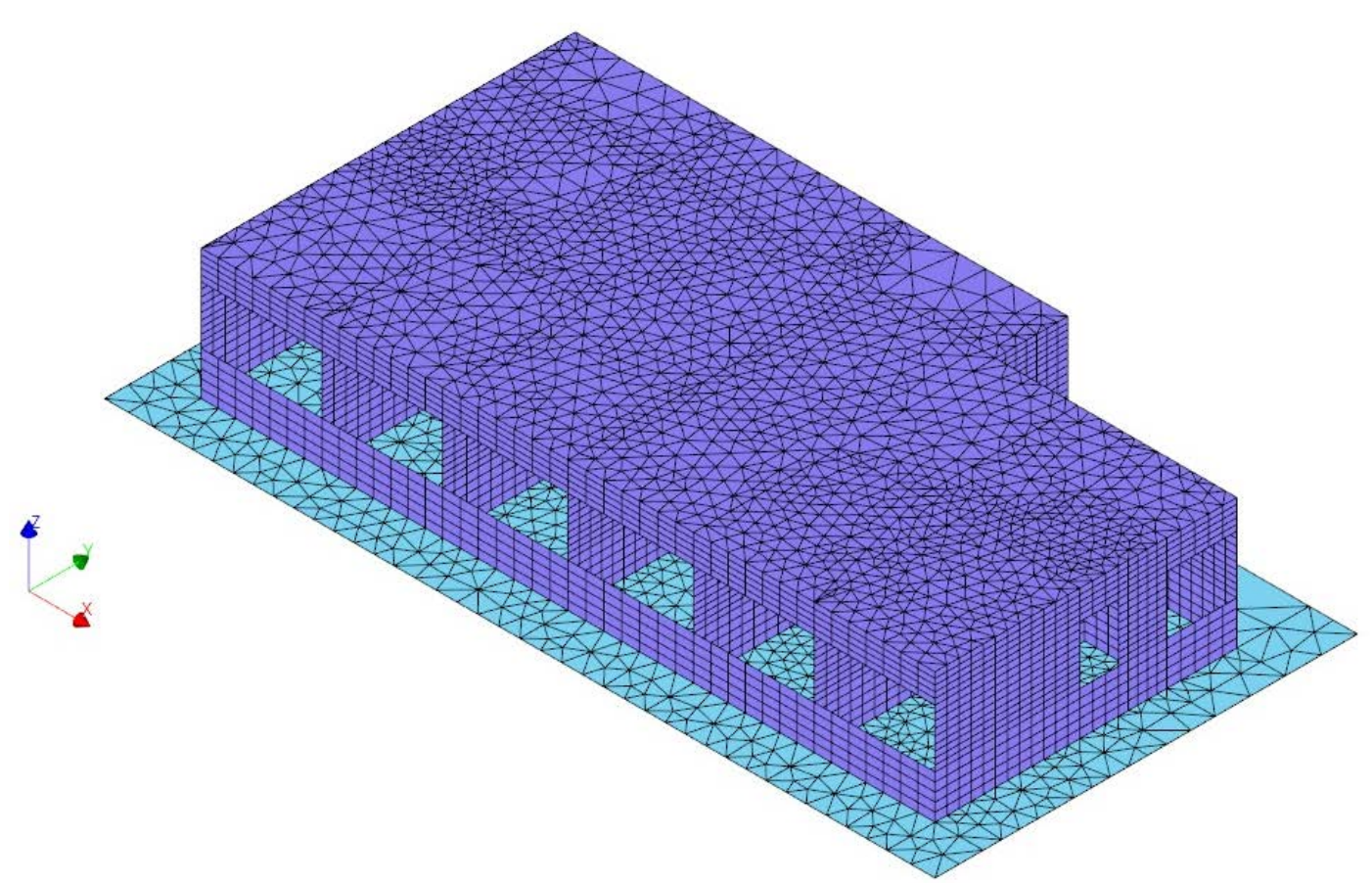

Figura 3.16 - Lajes do $1^{\circ}$ pavimento e do radier em conjunto com paredes estruturais

Não são utilizados elementos de contato ou interface entre o radier e o maciço do solo. O elemento de interface poderia simular o deslizamento (atrito) e o deslocamento entre as superfícies do radier e do maciço do solo. Esse procedimento foi descartado de acordo com as soluções alcançadas em análises preliminares, nas quais ficou comprovado que no presente estudo não ocorreriam diferenças significativas com ou sem o uso dos elementos de interface.

O maciço de solo é representado por elementos sólidos, utilizando o elemento da biblioteca do DIANA denominado “CTE30”. O elemento sólido possui 3 graus de liberdade por nó, sendo estes os deslocamentos nodais nas três direções. O elemento CTE30 é um elemento piramidal isoparamétrico com dez nós, com aproximação quadrática nos 
deslocamentos. A Figura 3.17 mostra as variáveis do elemento sólido e a Figura 3.18 ilustra o elemento finito CTE30 e sua função de aproximação dos deslocamentos.

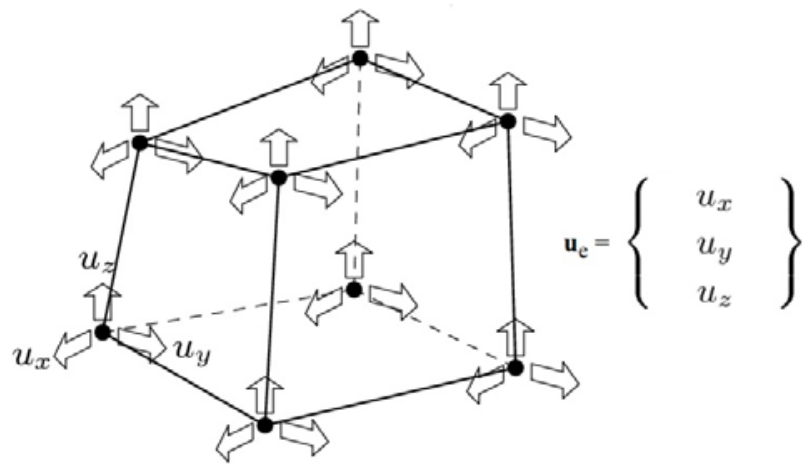

a) Deslocamentos nodais

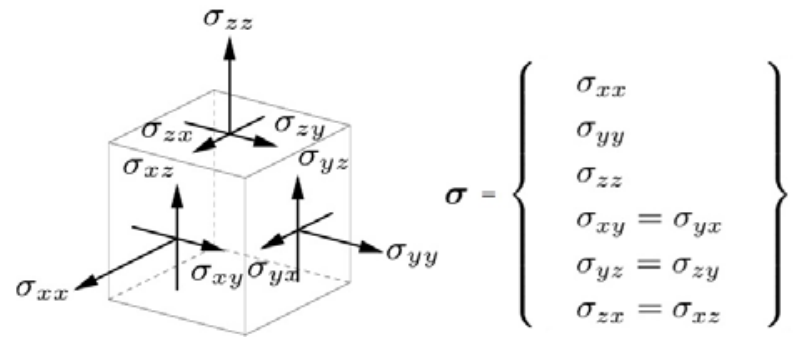

b) Tensões de Cauchy
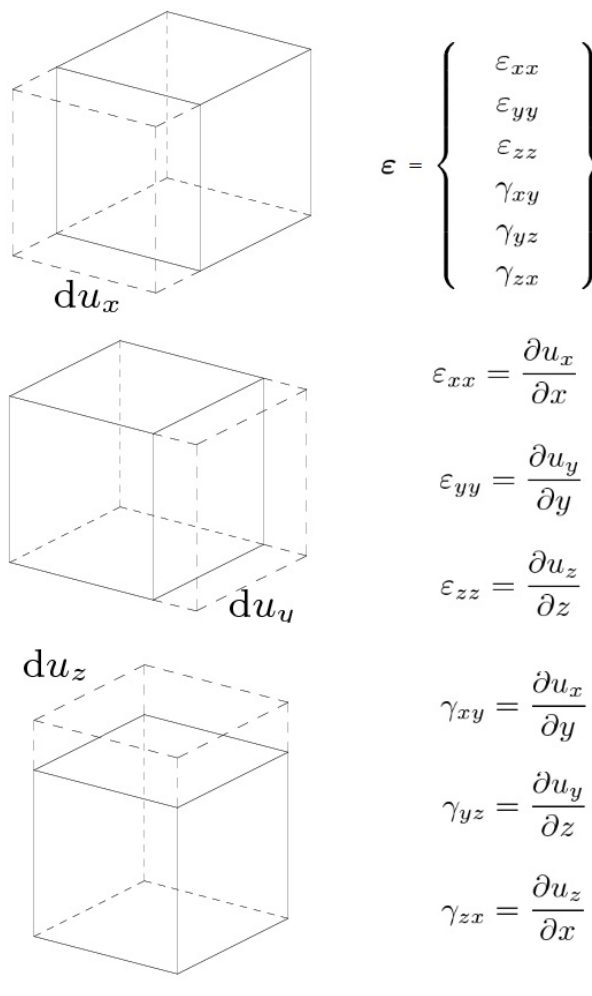

$$
\begin{aligned}
\gamma_{x y} & =\frac{\partial u_{x}}{\partial y}+\frac{\partial u_{y}}{\partial x} \\
\gamma_{y z} & =\frac{\partial u_{y}}{\partial z}+\frac{\partial u_{z}}{\partial y} \\
\gamma_{z x} & =\frac{\partial u_{z}}{\partial x}+\frac{\partial u_{x}}{\partial z}
\end{aligned}
$$

c) Deformações

Figura 3.17 - Elemento Sólido - Características e variáveis

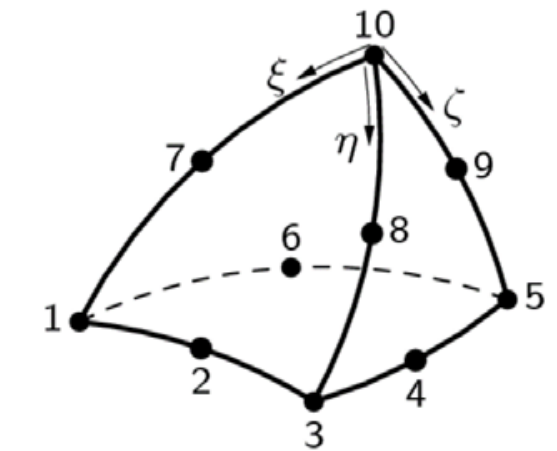

$u_{i}(\xi, \eta, \zeta)=a_{0}+a_{1} \xi+a_{2} \eta+a_{3} \zeta+a_{4} \xi \eta+a_{5} \eta \zeta+$ $a_{6} \xi \eta+a_{7} \xi^{2}+a_{8} \eta^{2}+a_{9} \zeta^{2}$

Figura 3.18 - Elemento CTE30

O maciço de solo consiste na região do modelo numérico que apresenta maior número de nós e de elementos finitos. Além disso, o elemento finito solido é o que possui maior custo computacional dentre os elementos finitos utilizados no problema. Desta forma, executa-se um procedimento para a redução da densidade da malha nas regiões mais afastadas do edifício. A malha de elementos finitos do maciço do solo, similar à utilizada nas lajes da estrutura, é gerada 
de forma não estruturada por meio do algoritmo do software DIANA baseado na "Triangulação de Delaunay”. A Figura 3.19 exibe o modelo numérico final utilizado para avaliação da interação solo-estrutura do edifício analisado. O modelo final completo possui um total de 262465 nós e 125779 elementos.

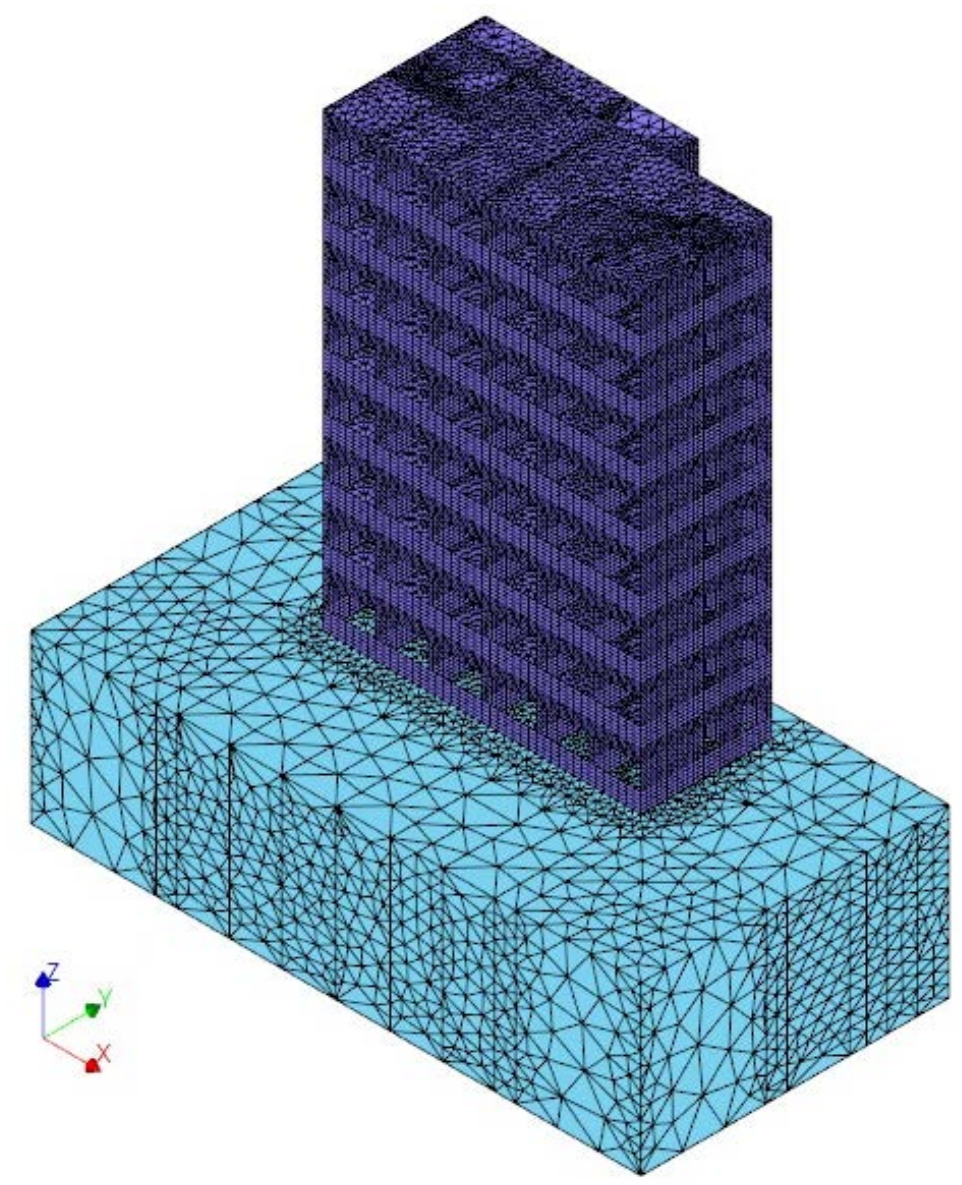

Figura 3.19 - Modelo com interação solo-estrutura

Deve-se salientar que o modelo numérico exposto possui um plano de simetria perpendicular à $\mathrm{Y}$, na região central da edificação. Este fato é essencial para o melhor aprofundamento dos resultados que serão divulgados ao longo da tese. A consideração do plano de simetria é realizada mediante a imposição de condições de contorno nos nós localizados neste plano. Restringe-se o deslocamento nodal na direção Y e a rotação nas direções X e Z em toda a face externa no plano perpendicular ao eixo X-Z do modelo numérico (Superestrutura e maciço do solo).

As condições de contorno impostas no maciço do solo são a restrição dos deslocamentos nodais na sua face inferior, região estimado como rígido, e suas extremidades laterais. A Figura 3.20 mostra as condições de contorno adotadas. 


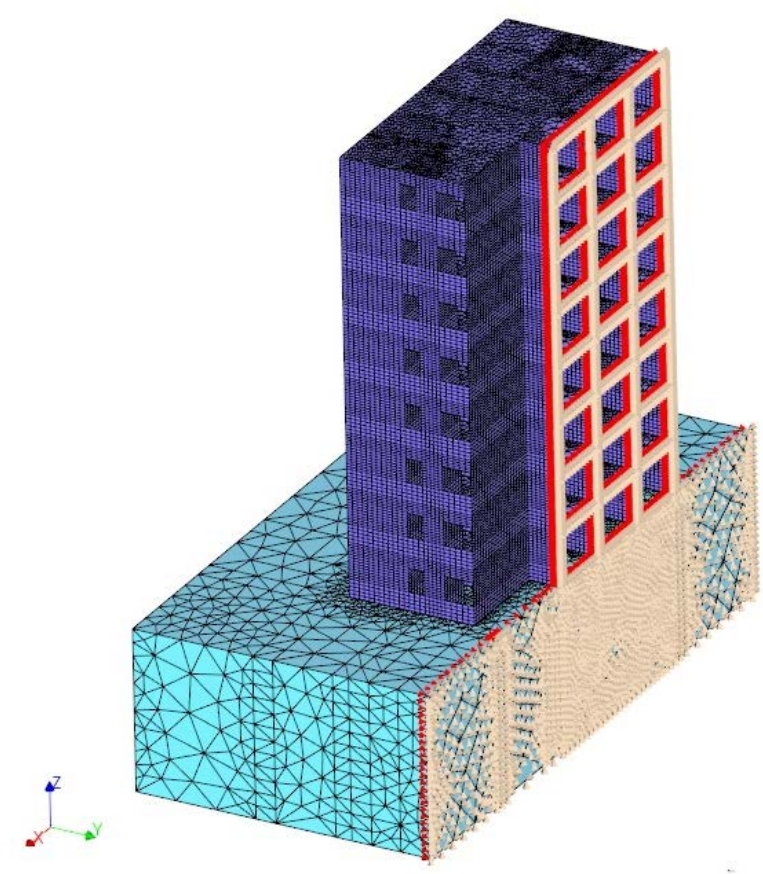

a) Plano de simetria - Plano Y

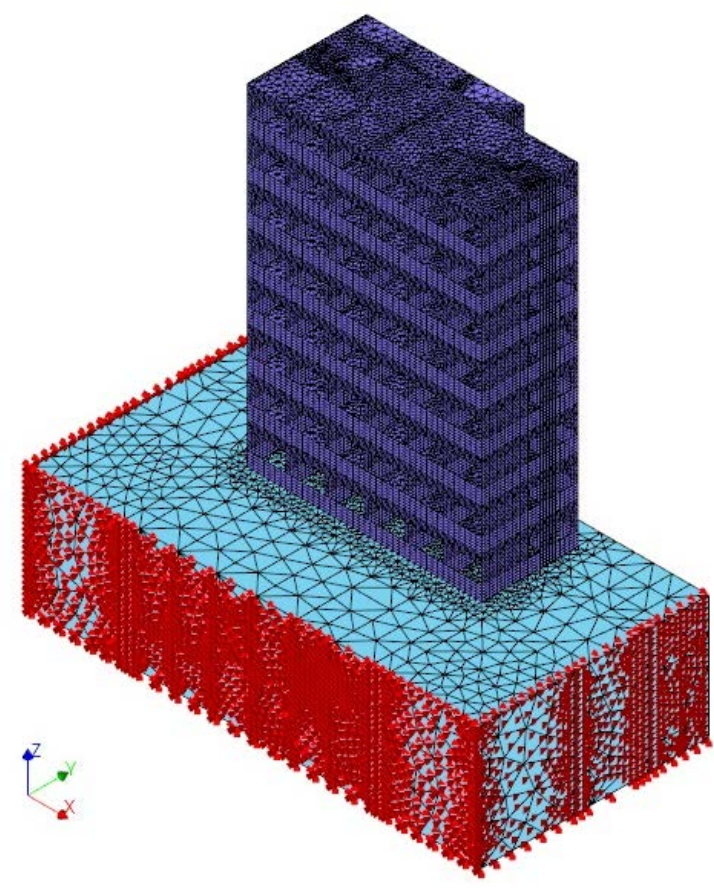

b) Restrições ao deslocamento - Maciço do solo

Figura 3.20 - Condições de contorno no modelo.

\subsubsection{AÇÕES}

Quanto às ações verticais atuantes, são consideradas o peso próprio das paredes, das lajes e dos revestimentos. Para a comparação dos recalques experimentais e os do modelo numérico, as ações acidentais não são utilizadas, pois o edifício real não se encontrava em uso quando se realizam as medições. Os valores adotados são os prescritos pela norma NBR 6120 (ABNT, 1998). Para o concreto utiliza-se o peso especifico de $25 \mathrm{kN} / \mathrm{m}^{3}$ e $1,0 \mathrm{kN} / \mathrm{m}^{2}$ de carga distribuída nos pavimentos na consideração do peso próprio do revestimento. A ação relativa ao peso próprio das paredes da superestrutura é empregada por intermédio da aplicação de uma carga distribuída uniformemente nos elementos de chapa do pavimento na direção vertical (Figura 3.21a). O peso próprio do revestimento e o peso próprio das lajes são aplicados por meio de uma ação vertical uniformemente distribuída perpendicular ao plano das lajes de cada pavimento (Figura 3.21b). O procedimento é similar ao utilizado para a aplicação do peso próprio do radier. Deve-se se salientar que neste tipo de edificação as ações permanentes representam quase que a totalidade das ações atuantes na edificação. A Figura 3.21 mostra as ações aplicadas nas paredes e lajes do pavimento da superestrutura. 

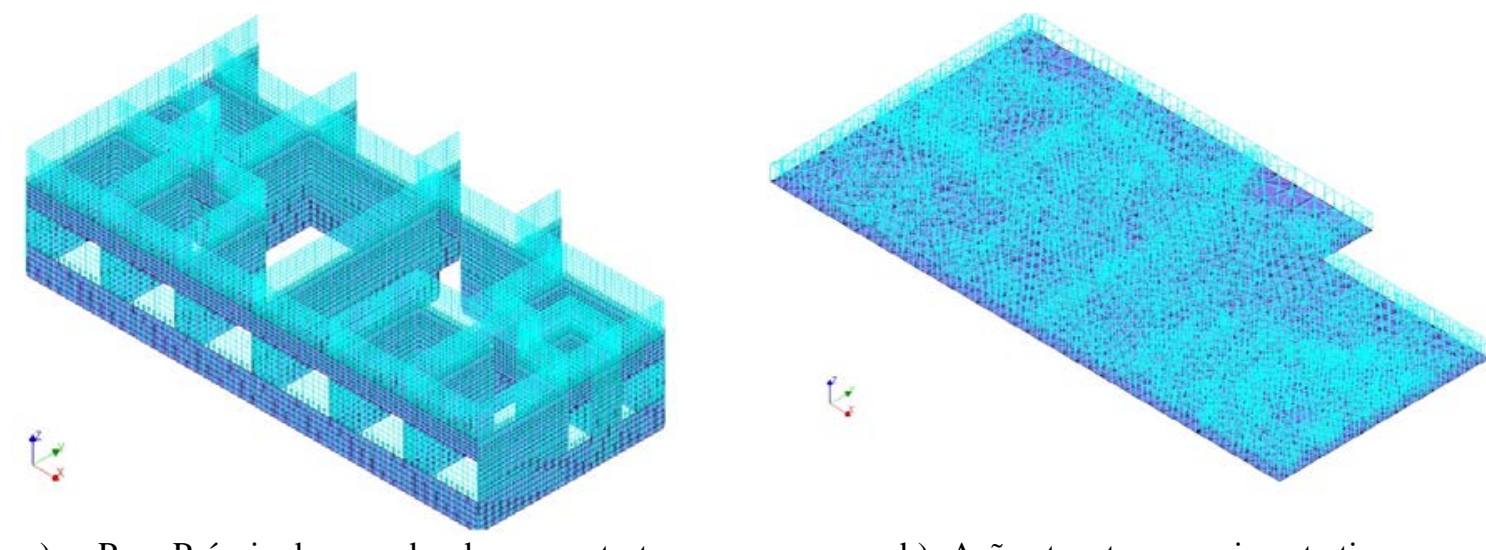

a) Peso Próprio das paredes da superestrutura

b) Ação atuante no pavimento tipo Figura 3.21 - Ações aplicadas no modelo numérico.

O uso das ações evolutivas aumenta o grau de representatividade do modelo numérico em relação à estrutura real. Deve-se ressaltar que algumas variáveis não estão sendo contabilizadas, como o sistema de escoramento da edificação.

Na presente análise são necessárias 9 fases para o processamento completo da estrutura. Na primeira fase da análise sequencial, são avaliados apenas o radier de concreto armado e o maciço do solo, com os seus pesos próprios e as ações permanentes no pavimento térreo (Figura 3.22-a). Após a obtenção da configuração deformada, os deslocamentos, tensões e deformações do radier e do maciço do solo são armazenados e reaplicados após a construção da geometria do $1^{\circ}$ pavimento, na etapa inicial da segunda fase (Figura 3.22-b). Após a imposição da configuração deformada da primeira fase, o peso próprio e demais ações permanentes do primeiro pavimento são aplicadas na etapa final da segunda fase (Figura 3.22c). Os resultados da configuração deformada da segunda fase são armazenados e importados para a aplicação na etapa inicial da terceira fase com a construção do $2^{\circ}$ pavimento (Figura 3.22d). Este procedimento continua nos pisos subsequentes até a construção do $8^{\circ}$ pavimento na nona fase (Figura 3.23).

O método iterativo de resolução do sistema de equações não-lineares utilizado no processamento do modelo é o de Newton-Raphson Regular. Utiliza-se o recurso line-search com a finalidade de reduzir o tempo de processamento. A tolerância utilizada no critério de convergência é de $0,1 \%$ para a norma de energia. O processamento do modelo proporcionou poucas dificuldades associadas à convergência, sendo necessário apenas reduzir os passos de cargas nas 3 últimas fases da análise, devido ao surgimento de algumas fissuras nos elementos de paredes do $1^{\circ}$ pavimento e pela plastificação localizada de alguns pontos do maciço do solo. 


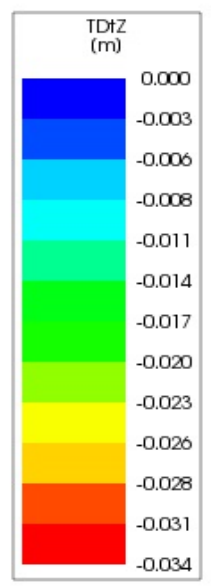

a) Fase 1 - Maciço de solo + Radier

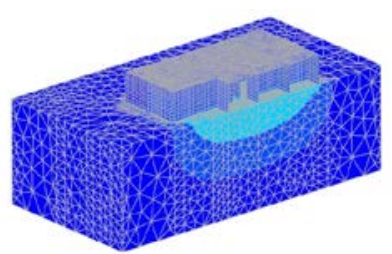

c) Fase 2 - Maciço de solo + Radier + $1^{\mathrm{o}}$ Pavimento - Etapa Final

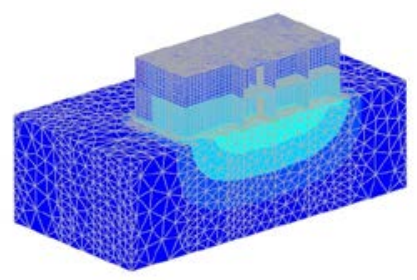

e) Fase 3 - Maciço de solo + Radier + $1^{\circ}$ e $2^{\circ}$ Pavimento - Etapa Final

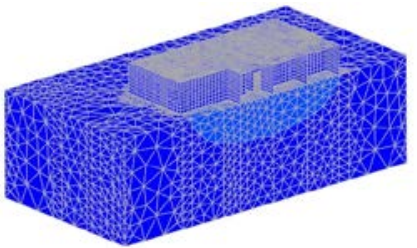

b) Fase 2 - Maciço de solo + Radier $+1^{\circ}$ Pavimento - Etapa inicial

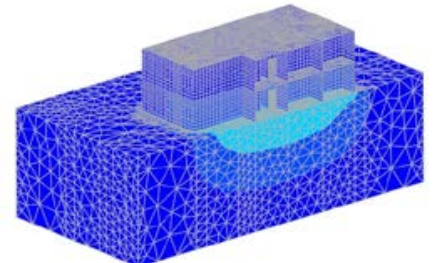

d) Fase 3 - Maciço de solo + Radier $+1^{\circ}$ e $2^{\circ}$ Pavimento - Etapa Inicial

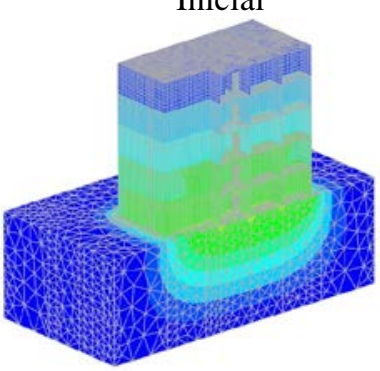

f) Fase 6 - Etapa Final

Figura $3.22-\mathrm{u}_{\mathrm{z}}(\mathrm{m})$ - Sequência de construção adotada e deslocamento vertical da estrutura - Modelo M3
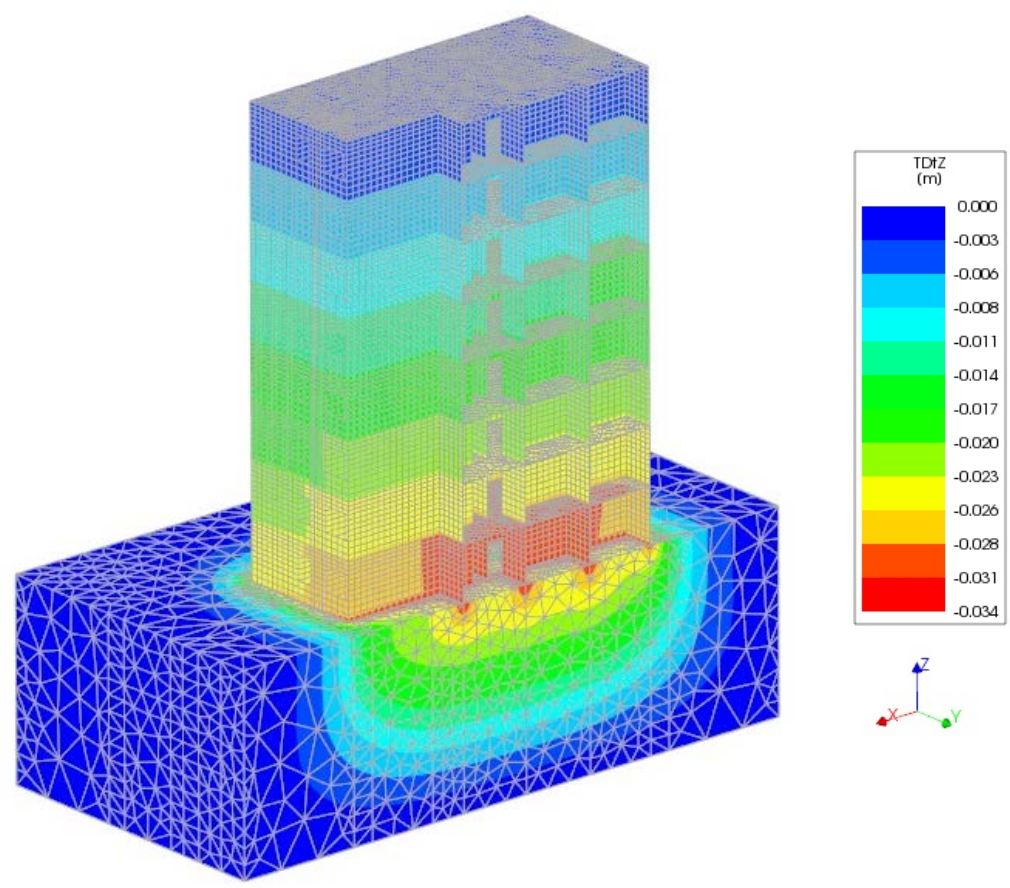

Figura $3.23-\mathrm{u}_{\mathrm{z}}(\mathrm{m})$ - Fase 9 - Modelo M3 


\subsection{ANÁLISE COMPARATIVA DOS RECALQUES NUMÉRICOS E EXPERIMENTAIS}

Neste item são avaliadas as soluções alcançadas pela análise numérica e confrontados com os obtidos na medição experimental das estruturas reais estudadas. Todos os resultados mostrados para a comparação com os recalques medidos, são obtidos com o emprego das ações evolutivas. Os resultados numéricos são expostos fase a fase, o que não ocorre necessariamente com os valores apresentados nas medições de recalques.

As soluções numéricas contemplam a simetria da edificação, o que experimentalmente não ocorre de maneira rigorosa. Dessa forma a comparação nos pontos simétricos são realizadas em relação aos dois pontos medidos da estrutura. Outro ponto fundamental que deve ser enfatizado é que as medições foram iniciadas com uma parte da estrutura já construída. Dessa forma os recalques medidos sempre são nivelados, por meio de interpolação, para que se possa ter coerência na confrontação dos resultados.

A Figura 3.24 ilustra o posicionamento dos pinos de medições de recalque do edifício analisado (P1 a P10). Adicionalmente, as soluções são analisadas utilizando as vistas idealizadas (Vistas VA a VD), que são ilustradas também na Figura 3.24. A Figura 3.25 ilustra o deslocamento vertical final do maciço do solo do modelo M2.

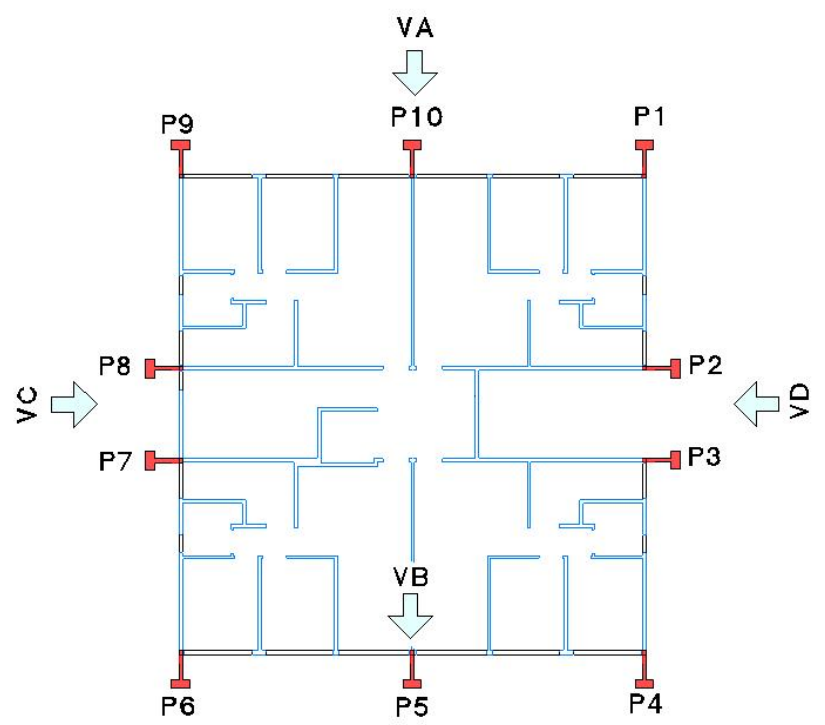

Figura 3.24 - Pontos de medições de recalques nas edificações estudadas 


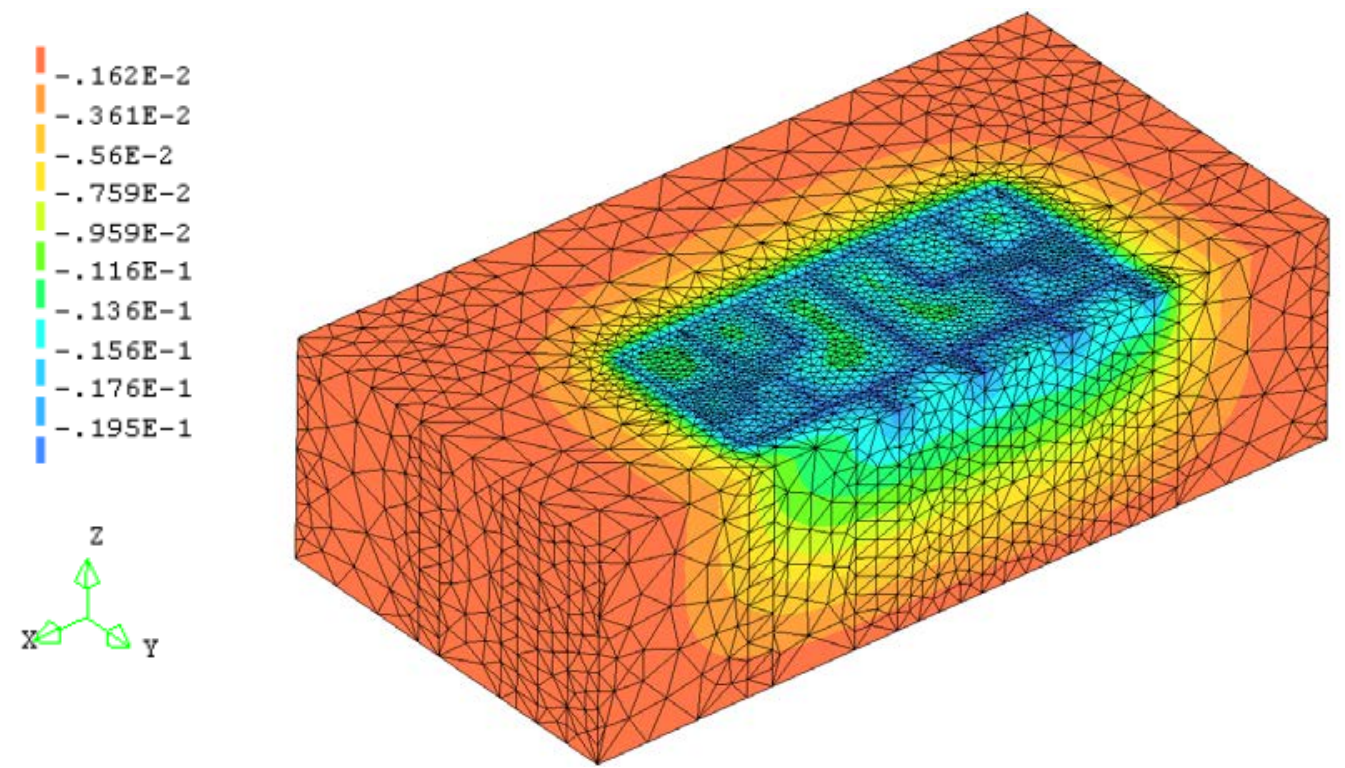

Figura 3.25 - $\mathrm{u}_{\mathrm{z}}(\mathrm{m})$ - Deslocamento vertical - Recalque final do Modelo numérico

A partir da Figura 3.25 é possível observar que os recalques maiores ocorrem diretamente na projeção da base das paredes, como esperado. Pode-se observar por meio da intensidade dos valores do fluxo dos deslocamentos do maciço que os níveis dos recalques nas bases das paredes são semelhantes, o que indica o baixo recalque diferencial nas paredes da estrutura. Ao longo da altura do maciço pode-se observar a propagação do bulbo de recalques, que acaba limitada pela altura reduzida do maciço do solo, devido à presença de uma base rígida. O comportamento é bastante similar aos resultados obtidos com os modelos do perfil M1 e M3, alterando, obviamente, a intensidade dos recalques.

Nos itens seguintes são confrontados os resultados entre as medições dos recalques e os obtidos pelo modelo numérico. A Figura 3.26 aponta os resultados das medições dos recalques nos pinos e as soluções numéricas, ao longo da construção do edifício, referente ao modelo M1. Como ressaltado anteriormente, devido à simetria do modelo numérico, os resultados são comparados com os respectivos pontos simétricos da estrutura real. 


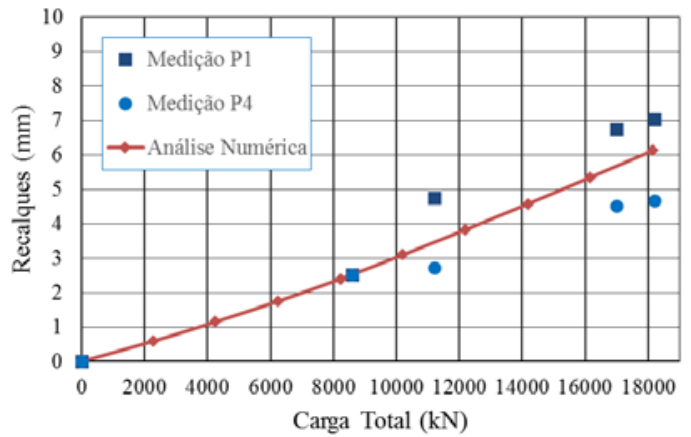

a) Pinos P1 e P4

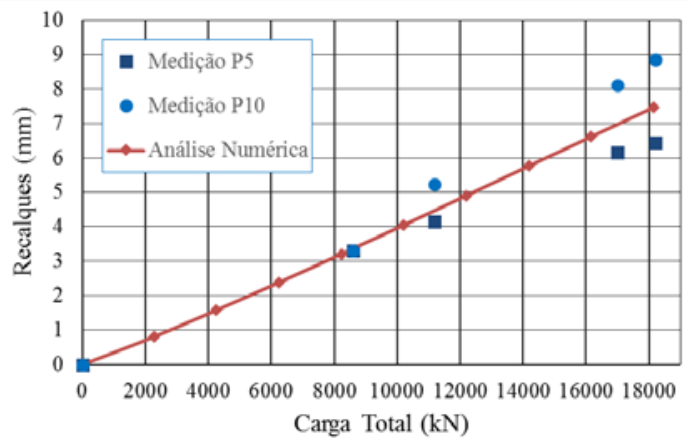

c)

Pinos P5 e P10

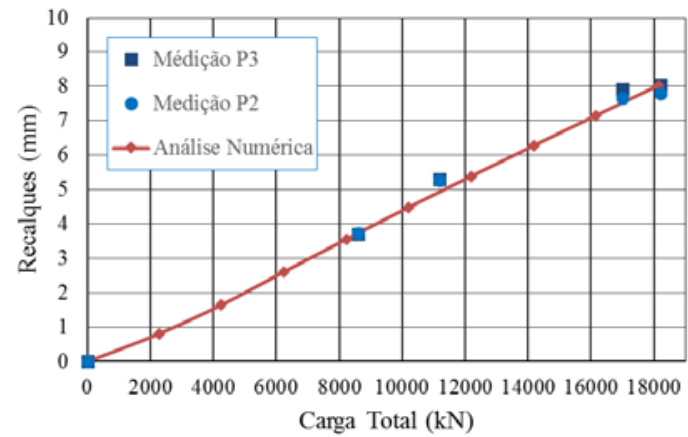

b) Pinos P3 e P2

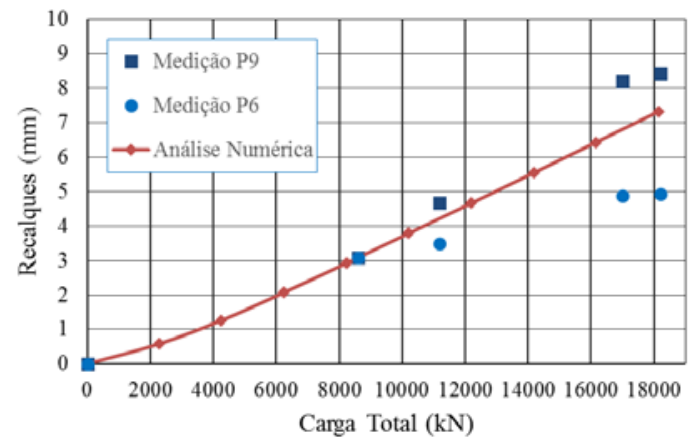

d) Pinos P9 e P6

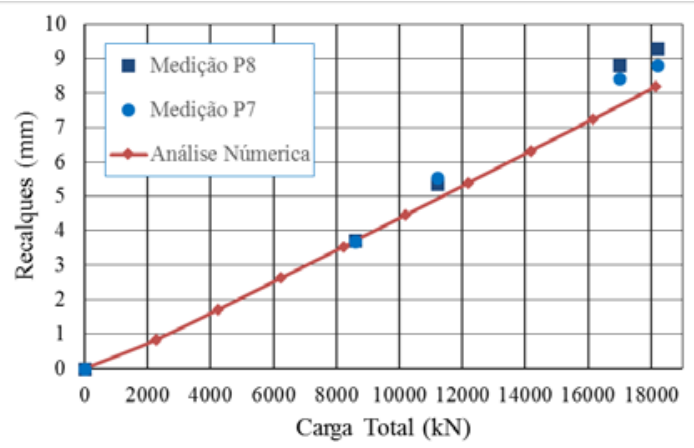

e) Pinos P8 e P7

Figura 3.26 - Recalques experimentais x Recalques numéricos - Modelo M1

A partir da confrontação dos resultados é possível observar semelhanças entre os recalques medidos e os adquiridos mediante emprego de análise numérica. As soluções numéricas ao longo da construção da edificação possuem boa aproximação com as medições, principalmente nos pinos P2/P3 e nos pinos P7/P8.

Nos pinos P5/P10, P9/P6, P1/P4 observa-se que a curva relacionada ao modelo numérico permanece geralmente na região média entre os pinos simétricos. Esta ocorrência indica a presença de um desaprumo na edificação, fato este que pode ser observado também pela diferença relevante entre as medições nos pinos citados. A Tabela 3.3 apresenta comparações entre os valores medidos e os alcançados por meio do modelo numérico na fase final (construção finalizada). 
Tabela 3.3 - Recalques numéricos x Recalques medidos - Etapa Final - Modelos M1

\begin{tabular}{|c|c|c|c|}
\hline \multicolumn{3}{|c|}{ Modelo M1 } \\
\hline Pinos & Medição (mm) & Análise Numérica (mm) & $\begin{array}{c}\text { Aproximação } \\
\text { Percentual (\%) }\end{array}$ \\
\hline P1 & 7,03 & 6,13 & $87,2 \%$ \\
\hline P2 & 7,80 & 8,03 & $97,1 \%$ \\
\hline P3 & 8,06 & 8,03 & $99,6 \%$ \\
\hline P4 & 4,69 & 6,13 & $69,3 \%$ \\
\hline P5 & 6,45 & 7,46 & $84,3 \%$ \\
\hline P6 & 4,93 & 7,32 & $51,5 \%$ \\
\hline P7 & 8,79 & 8,18 & $93,1 \%$ \\
\hline P8 & 9,28 & 8,18 & $88,1 \%$ \\
\hline P9 & 8,42 & 7,32 & $86,9 \%$ \\
\hline P10 & 8,85 & 7,46 & $84,3 \%$ \\
\hline Média & 7,43 & 7,42 & $99,9 \%$ \\
\hline
\end{tabular}

O resultado numérico médio na etapa final apresenta aproximação percentual de 99,9\% em relação ao valor médio das medições. Individualmente o melhor resultado obtido é no Pino P3 com uma aproximação de 99,6\% entre o resultado numérico e o resultado experimental.

A maior diferença é no pino P6, com aproximação percentual de 51,5\% entre o resultado numérico e experimental. A medição final do recalque no pino P6 é de 4,96mm, muito inferior às demais medições da tipologia analisada, que possui média de 7,43mm, inclusive com valores distantes do pino P9 (ponto simétrico da estrutura) que possui um recalque experimental de 8,42 mm. Esses valores indicam a ocorrência de uma possível heterogeneidade do solo na região do pino P6.

A mesma conclusão pode ser efetivada sobre o pino P5 (próximo ao pino P6) que exibe recalques inferiores ao medido no seu ponto simétrico da estrutura (Pino P10). Interessante reforçar que os resultados numéricos nesses casos forneceram valores localizados na média entre os pinos das medições experimentais. A Figura 3.27 mostra as vistas dos recalques numéricos e experimentas na etapa final de construção. 


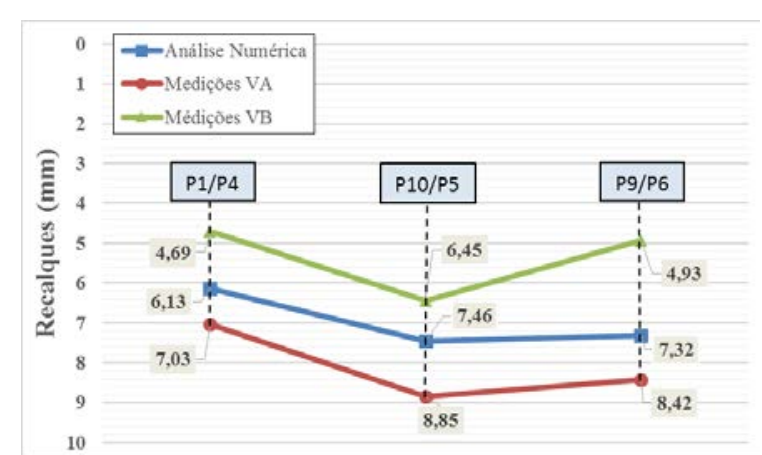

a) Vistas VA e VB

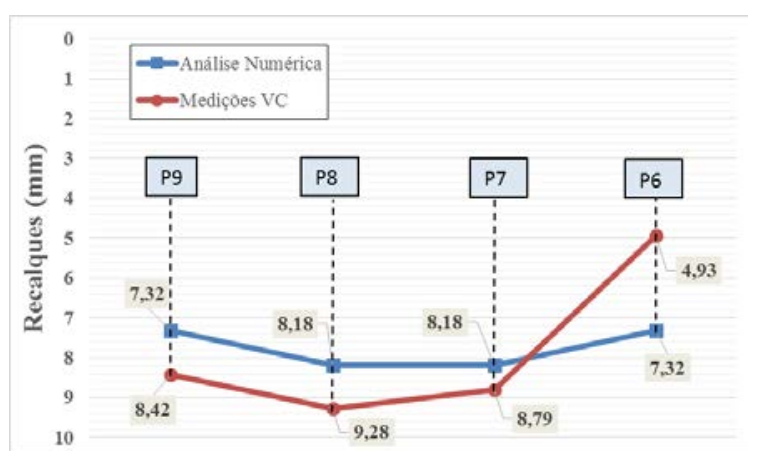

b)

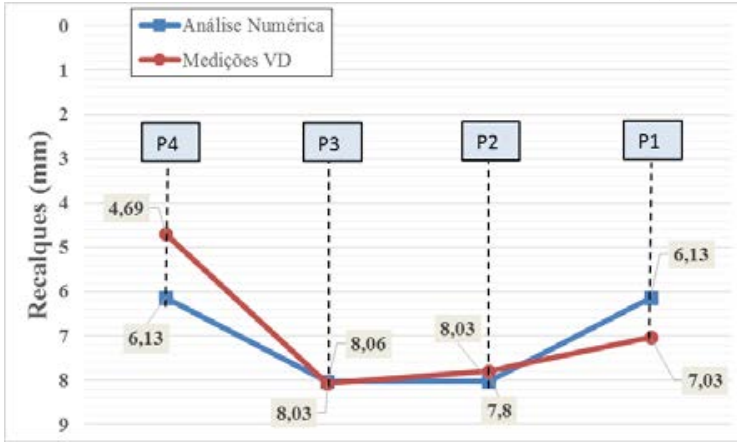

c) Vista VD

Figura 3.27 - Recalques experimentais x Recalques numéricos - Vistas - Modelo M1

A conclusão sobre a heterogeneidade do solo, que provoca um desaprumo na edificação, pode ser reforçada pela observação da Figura 3.27-a. Observa-se que o recalque numérico localizado na vista VA e VB alcança valores intermediários em relação às duas vistas medidas experimentalmente.

A Figura 3.28 exibe a comparação entre os resultados numéricos e os medidos experimentalmente ao longo da construção da estrutura referente ao modelo M2.

Os resultados numéricos referentes ao modelo M2 alcançam uma ótima aproximação, na maioria dos pontos, principalmente na etapa final da construção. Ao contrário do modelo M1, os valores experimentais apresentam maior homogeneidade nos pontos simétricos da estrutura. 


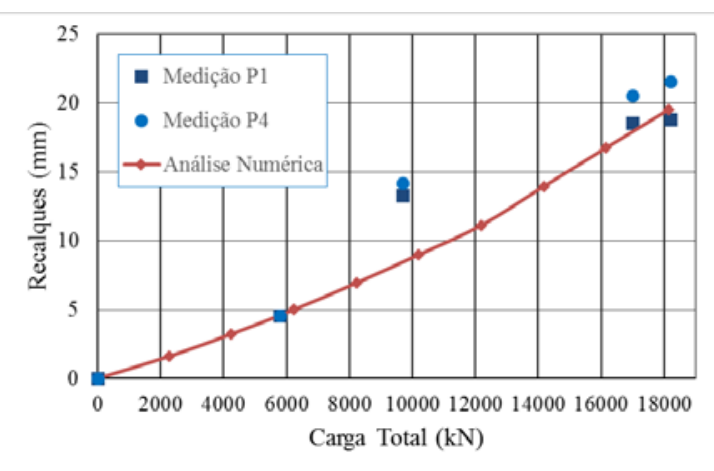

a) Pinos P1 e P4

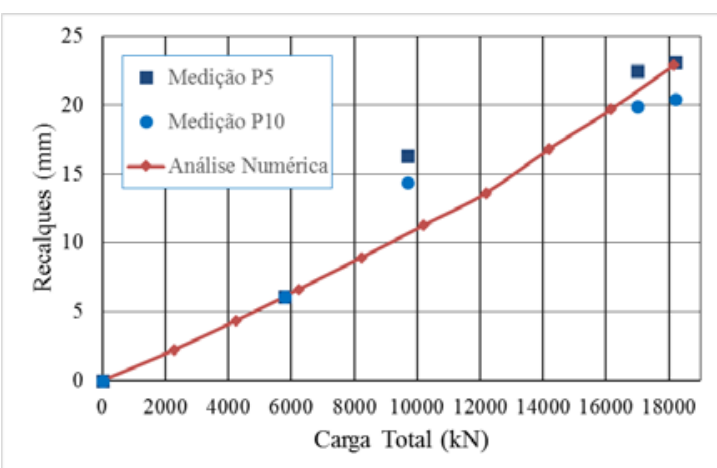

e)

Pinos P5 e P10

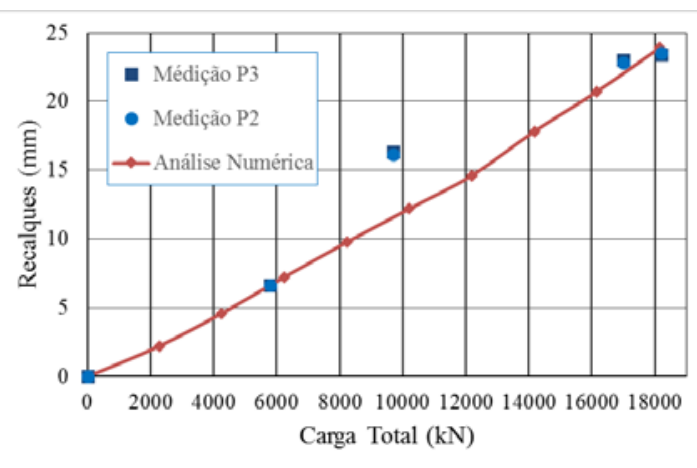

d) Pinos P3 e P2

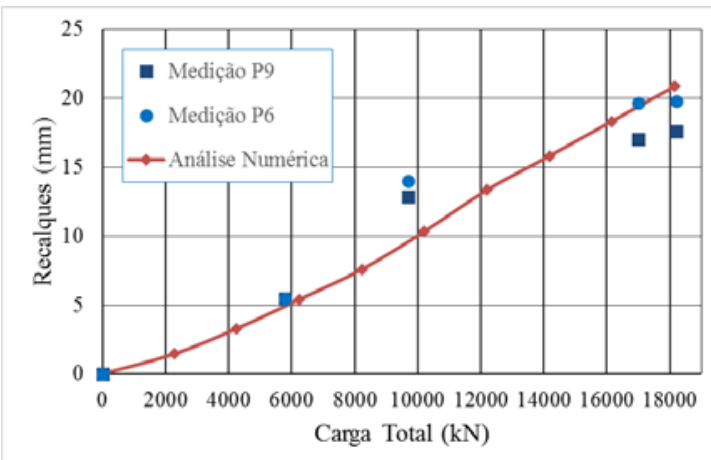

f) Pinos P9 e P6

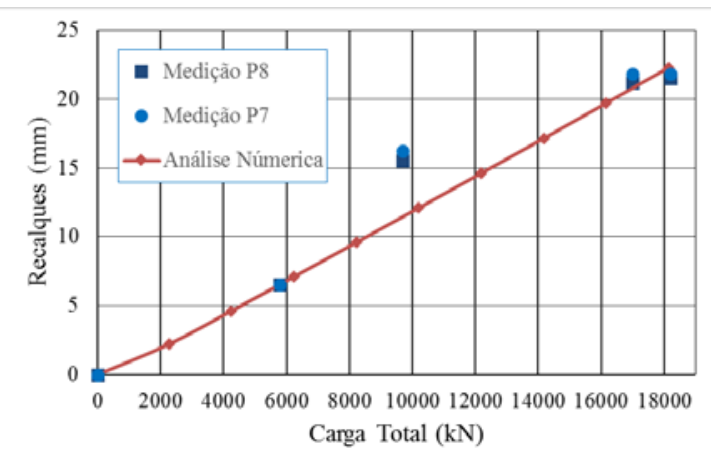

g) Pinos P8 e P7

Figura 3.28 - Recalques experimentais x Recalques numéricos - Modelo M2

Os resultados medidos exibem divergências nas medições com a carga total aplicada na estrutura em 10.000 kN, início da construção do $5^{\circ}$ pavimento da estrutura. Pode-se explicar este fato pela imprecisão do carregamento estimado no momento da medição experimental. Mas a comparação das soluções numéricas finais e das últimas medições (Estrutura finalizada) indica essa ótima aproximação entre o modelo e a estrutura real. A Tabela 3.4 mostra a confrontação entre os resultados numéricos e os medidos no modelo M2 na etapa final de construção. 
Tabela 3.4 - Recalques numéricos x Recalques medidos - Etapa Final - Modelos M2

\begin{tabular}{|c|c|c|c|}
\hline \multicolumn{3}{|c|}{ Modelo M2 } \\
\hline Pinos & $\begin{array}{c}\text { Medição } \\
(\mathrm{mm})\end{array}$ & $\begin{array}{c}\text { Análise Numérica } \\
(\mathrm{mm})\end{array}$ & $\begin{array}{c}\text { Aproximação Percentual } \\
(\%)\end{array}$ \\
\hline P1 & 18,82 & 19,54 & $96,1 \%$ \\
\hline P2 & 23,51 & 23,89 & $98,4 \%$ \\
\hline P3 & 23,38 & 23,89 & $97,8 \%$ \\
\hline P4 & 21,58 & 19,54 & $90,6 \%$ \\
\hline P5 & 23,07 & 22,86 & $99,1 \%$ \\
\hline P6 & 19,8 & 20,84 & $94,7 \%$ \\
\hline P7 & 21,81 & 22,27 & $97,9 \%$ \\
\hline P8 & 21,47 & 22,27 & $96,3 \%$ \\
\hline P9 & 17,58 & 20,84 & $81,5 \%$ \\
\hline P10 & 20,37 & 22,86 & $87,7 \%$ \\
\hline Média & 21,13 & 21,88 & $96,5 \%$ \\
\hline
\end{tabular}

Os pinos P5 e P2 alcançam valores acima de 98\% de aproximação no recalque final entre o resultado numérico e o experimental. A maioria dos pinos possuem aproximação percentual acima de 90\%, não ocorrendo apenas nos pinos P9 e P10. O pino P9 obteve a menor aproximação entre o numérico e o experimental, com 81,5\%.

A homogeneidade dos resultados em pontos simétricos e a proximidade entre os valores medidos e os valores da análise numérica podem ser verificados nas vistas dos recalques exibidos na Figura 3.29.

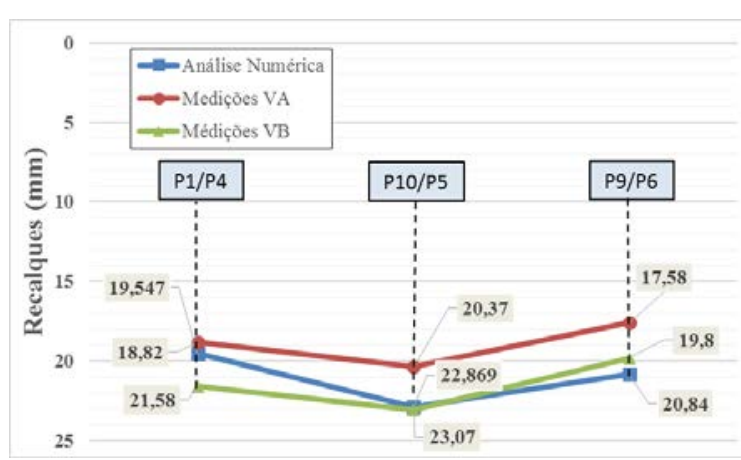

a) Vistas VA e VB

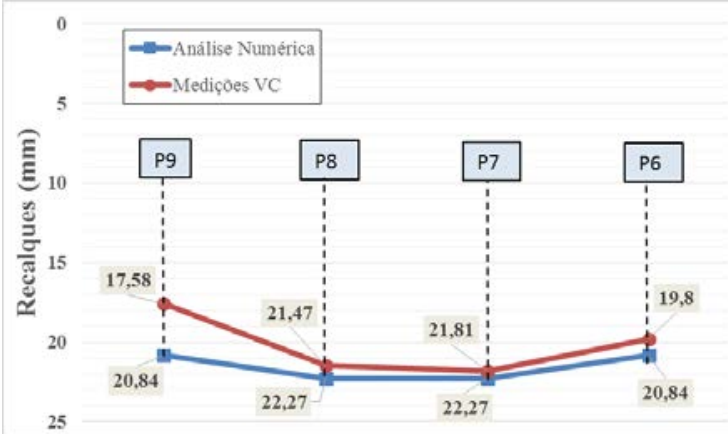

b) Vista VC

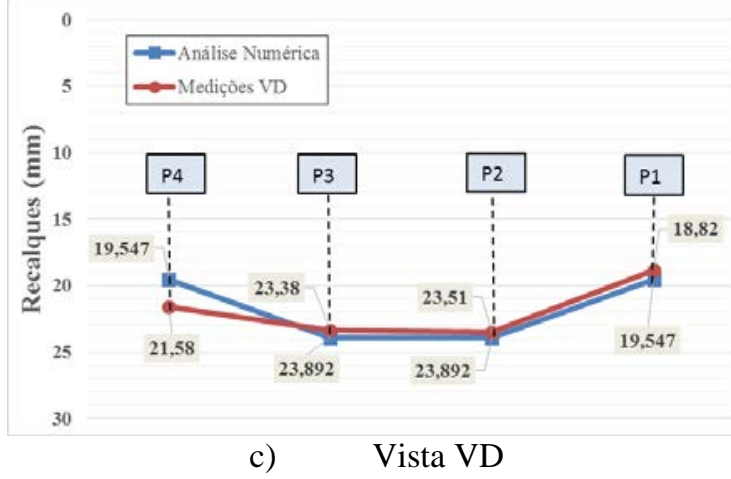

Figura 3.29 - Recalques experimentais x Recalques numéricos - Vistas - Modelo M2 
Os gráficos de recalques observados nos pontos de vista na Figura 3.29 permitem visualizar a boa aproximação das respostas obtidas pelo modelo numérico. Esses resultados apresentaram de um modo geral recalques mais elevados que as medições experimentais. A vista da Figura 3.29a permite também observar a presença de desaprumo na edificação, embora com uma menor intensidade do que o ocorrido no modelo M1.

A Figura 3.30 aponta os resultados referentes aos recalques medidos e os alcançados no modelo numérico M3.

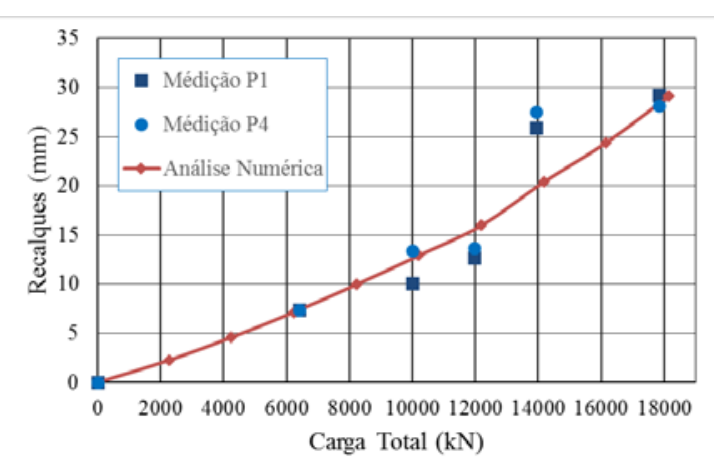

a) Pinos P1 e P4

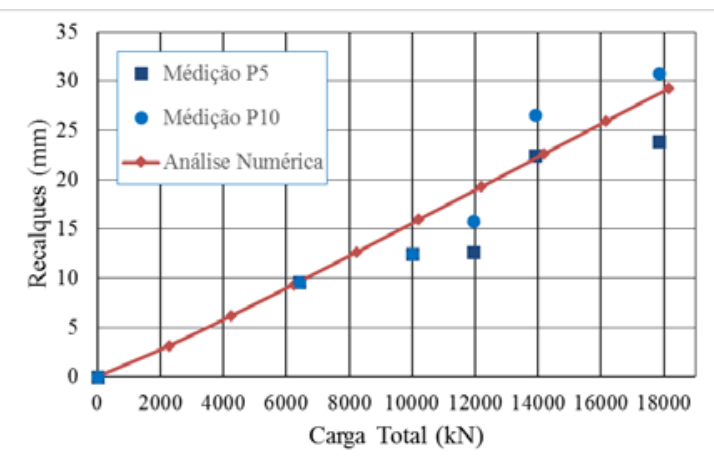

c)

Pinos P5 e P10

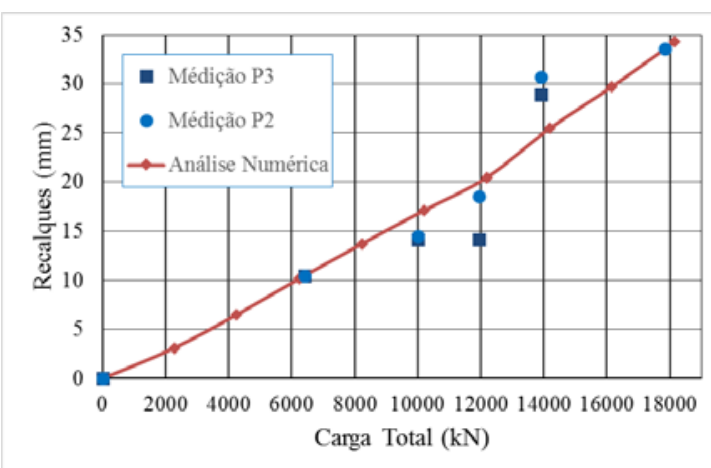

b) $\quad$ Pinos P3 e P2

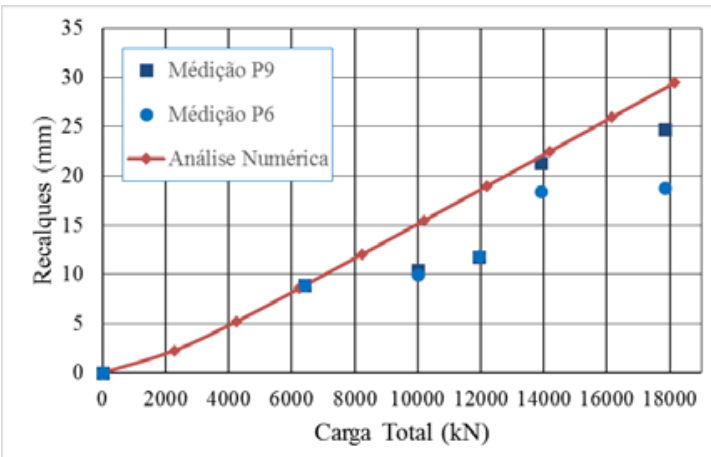

d) Pinos P9 e P6

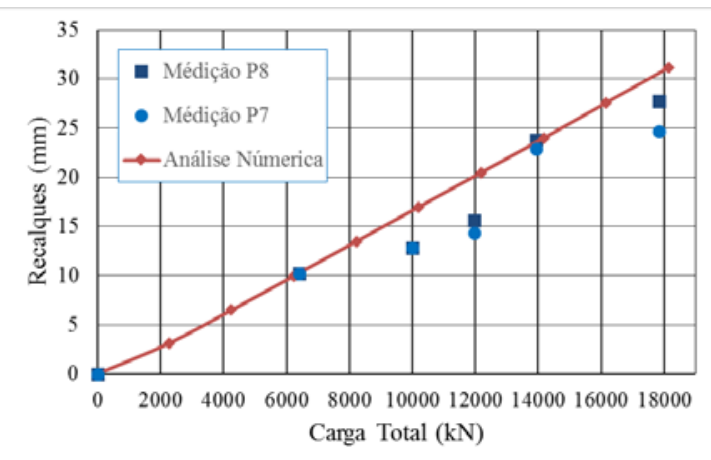

e) Pinos P8 e P7

Figura 3.30 - Recalques experimentais x Recalques numéricos - Modelo M3

Os resultados numéricos referentes ao modelo M3 mostraram-se adequados. A observação das medições desses pontos evidencia a presença de diferenças no próprio levantamento experimental, em pontos simétricos (como ocorrido no modelo M1). 
Ao longo da construção, o modelo M3 é o que possui maior variabilidade nos resultados experimentais. Observa-se que ocorrem diferenças significativas de recalques medidos com pouco acréscimo de carga, entre as cargas de 10.000 kN e 12.000 kN. Acreditase que esta ocorrência pode estar relacionada com a imprecisão na estimativa da carga aplicada no instante da medição do recalque. Outra possibilidade pode ter ligação com a qualidade do solo, que possui menos rigidez que as apresentadas pelos modelos M1 e M2, apresentando comportamento não-linear com cargas inferiores aos dos demais modelos.

Embora ao longo da construção do edifício ocorram diferenças significativas entre os recalques medidos e os recalques numéricos, os resultados na etapa final da construção são adequados. A Tabela 3.5 mostra um resumo comparativo entre os valores numéricos e os mensurados na etapa final de construção.

Tabela 3.5 - Recalques numéricos x Recalques medidos - Etapa Final - Modelos M3

\begin{tabular}{|c|c|c|c|}
\hline \multicolumn{3}{|c|}{ Modelo M3 } \\
\hline Pinos & $\begin{array}{c}\text { Medição } \\
(\mathrm{mm})\end{array}$ & $\begin{array}{c}\text { Análise Numérica } \\
(\mathrm{mm})\end{array}$ & $\begin{array}{c}\text { Aproximação Percentual } \\
(\%)\end{array}$ \\
\hline P1 & 29,27 & 29,12 & $99,5 \%$ \\
\hline P2 & 33,54 & 34,25 & $97,9 \%$ \\
\hline P3 & 31,66 & 34,25 & $91,8 \%$ \\
\hline P4 & 28,18 & 29,12 & $96,7 \%$ \\
\hline P5 & 23,9 & 29,26 & $77,6 \%$ \\
\hline P6 & 18,78 & 29,44 & $43,2 \%$ \\
\hline P7 & 24,66 & 31,17 & $73,6 \%$ \\
\hline P8 & 27,78 & 31,17 & $87,8 \%$ \\
\hline P9 & 24,74 & 29,44 & $81,0 \%$ \\
\hline P10 & 30,83 & 29,26 & $94,9 \%$ \\
\hline Média & 27,33 & 30,64 & $87,9 \%$ \\
\hline
\end{tabular}

Alguns pontos apresentam aproximação acima de $90 \%$, como os pontos P1/P4 e P3/P2. Os resultados menos precisos são nos pinos P5, P6 e P7. A aproximação percentual média final é de quase $90 \%$, sendo este um resultado bastante adequado. A presença de um desaprumo na edificação, que pode ser observado melhor pela Figura 3.31 prejudicou o desempenho final entre a comparação entre o modelo numérico e o levantamento experimental. 


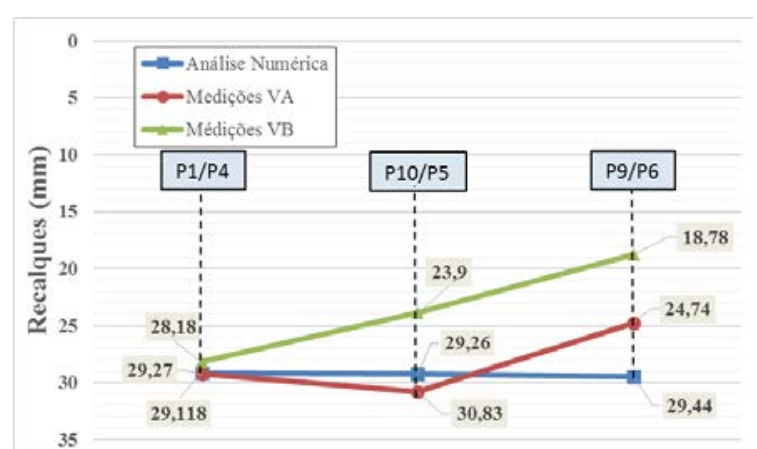

a) Vistas VA e VB

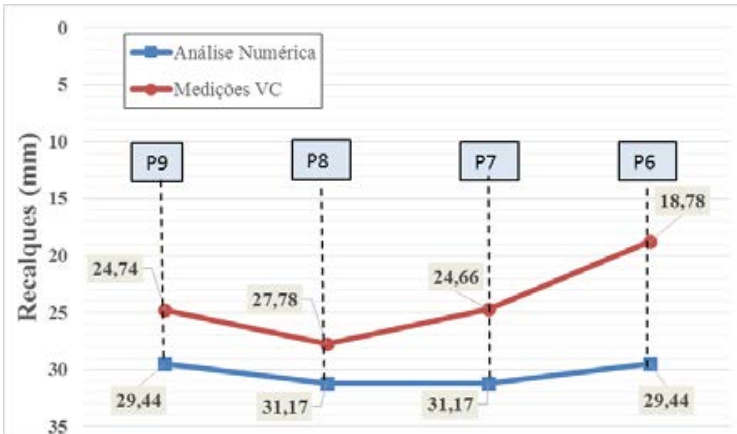

b) Vistas VC

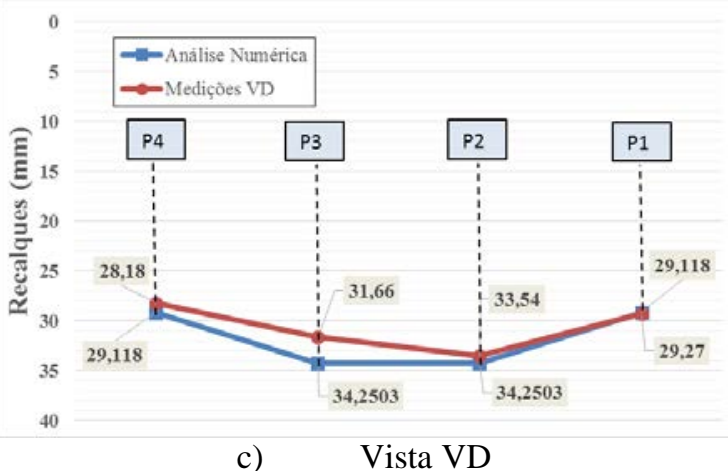

Figura 3.31 - Recalques experimentais x Recalques numéricos - Vistas - Modelo M3

A observação das medições dos pontos P10 e P5 evidencia a ocorrência de diferença no próprio levantamento experimental, em pontos simétricos. O mesmo ocorre entre os pontos P9 e P6. Esse desempenho indica a não-homogeneidade do perfil do solo, característica que não está sendo contemplada na análise numérica. A Figura 3.31 reforça essa hipótese indicando recalques superiores na região da vista VA em referência à vista VB. A região da Vista VD obteve-se uma melhor proximidade entre os modelos numéricos e experimentais.

\subsection{CONCLUSÕES DO CAPÍTULO}

O modelo proposto proporcionou resultados adequados, com um bom grau de aproximação em comparação aos mensurados em obra. São encontradas algumas diferenças pontuais entre os recalques numéricos e os recalques medidos. Essas diferenças em sua totalidade são associadas à heterogeneidade do solo, que faz com que ocorra um desaprumo na edificação. A representação do maciço no modelo numérico não contempla a heterogeneidade do solo. Pode-se observar que os recalques experimentais forneceram valores que indicam a não-homogeneidade do perfil do solo, o que é de certa forma esperada, devido à condição intrínseca desse material.

A estratégia para definir as propriedades do maciço do solo se mostrou interessante, já que no presente estudo não foi coletado material com a finalidade de aferir melhor tais propriedades. A estratégia é simplista, pois elimina a necessidade de representação do maciço 
do solo por camadas distintas e os resultados médios obtidos ficaram próximos dos valores médios finais medidos. Reforça-se que as maiores diferenças entre os valores numéricos e experimentais ocorrem em virtude de desaprumos na edificação em consequência da nãohomogeneidade do solo.

Deve-se observar que outros aspectos contribuem na falta de precisão dos valores analisados. A incerteza do nível de carga atuante na estrutura no instante das medições é um desses aspectos. Assim sendo, o nível de ação atuante no modelo numérico não necessariamente é o mesmo da estrutura real. Sobre o modelo proposto, são concretizadas algumas simplificações relacionadas ao maciço do solo que foi concebido com geometria e domínio regular e com estimativas na idealização do modelo constitutivo.

Embora existam inúmeras incertezas e simplificações utilizadas, as soluções obtidas nos três perfis apresentam intensidades suficientemente próximas do modelo real, principalmente se for observado o grande número de variáveis que envolvem o problema. Devido a esses fatores, é possível afirmar que o modelo numérico desenvolvido pode representar de maneira consistente o problema real e com isto avaliar os efeitos da ISE no comportamento estrutural das paredes. 



\section{CAPÍTULO 4 - INTERAÇÃO SOLO-ESTRUTURA NOS EDIFÍCIOS DE PAREDES DE CONCRETO}

O modelo numérico provou-se adequado para a avaliação da interação solo-estrutura em edifícios de paredes de concreto, conforme comprovado no estudo exposto no capítulo 3. Os resultados apresentaram magnitudes adequadas com as medições realizadas ao longo da construção da edificação. Neste capítulo são levantadas e elucidadas as implicações da interação solo-estrutura nos elementos da superestrutura.

Sobre as consequências da interação solo-estrutura (ISE) na superestrutura, geralmente dois aspectos são mais relevantes. O primeiro deles é a redistribuição de esforços nos elementos estruturais e o segundo é a possibilidade do surgimento de patologias por decorrência das distorções angulares iniciadas pelas deformações na base dos elementos.

As consequências da ISE são analisadas com base nos modelos desenvolvidos no capítulo 3. Aspectos como as modificações das reações nos elementos e no fluxo das tensões normais nas paredes sobre o efeito da interação solo-estrutura são abordados. A influência das ações evolutivas em conjunto com a ISE é estudada por meio de comparações com modelos que utilizam as ações instantâneas. Por fim, são apresentados os aspectos conclusivos sobre o funcionamento da ISE em edifícios de paredes de concreto.

\subsection{MODELOS AVALIADOS}

A avaliação da interação solo-estrutura é efetivada a partir da comparação do modelo proposto com um similar de referência, sendo este concebido com apoios fixos. Os estudos realizados nesse capitulo têm como base os modelos concebidos no capitulo 3, denominados como modelos M1, M2 e M3. A Figura 4.1 exibe o modelo de referência. 


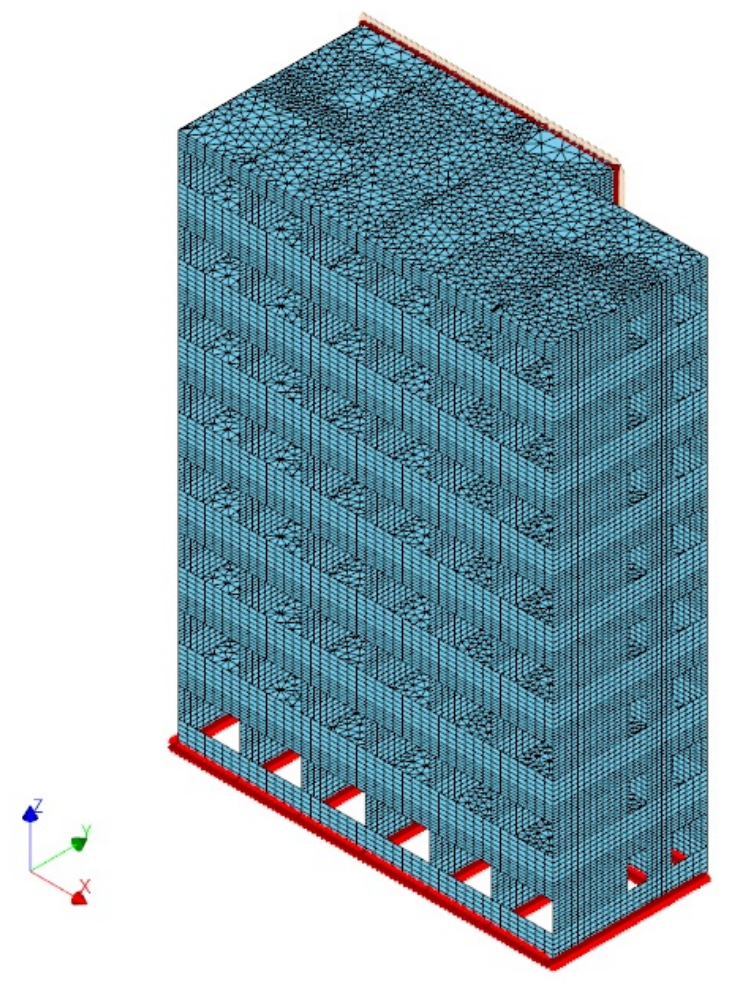

Figura 4.1 - Modelo de referência - REF - Apoios fixos na base das paredes

A influência das ações evolutivas é realizada por meio da confrontação de resultados com modelos de referência, sendo estes com a consideração da estrutura completa, representando o modelo convencionalmente utilizado. Por simplicidade, o termo "ações instantâneas” será utilizado para diferenciar os modelos que consideram o procedimento convencional (estrutura completa) dos modelos que consideram a sequência construtiva (ações evolutivas). Pretende-se enfatizar nesse ponto a influência da consideração das ações evolutivas em conjunto com a interação solo-estrutura.

A Tabela 4.1 mostra um resumo da nomenclatura dos modelos. No modelo denominado ISE-INS, as ações são aplicadas com a estrutura completa, e nos modelos ISEEVO, são consideradas as etapas de construção, ou seja, são utilizadas as ações atuando por fases. O modelo REF-AP é o modelo de referência, sem o maciço do solo.

Tabela 4.1 - Nomenclatura dos modelos

\begin{tabular}{|c|c|c|}
\hline Nomenclatura & Condição de apoio & Ações \\
\hline REF-AP & $\begin{array}{c}\text { Modelo de referência - Estrutura } \\
\text { - Apoios Rígidos }\end{array}$ & Instantâneas \\
\hline M1-ISE-INS & Solo - M1 & Instantâneas \\
\hline M1-ISE-EVO & Solo - M1 & Evolutivas \\
\hline M2-ISE-INS & Solo - M2 & Instantâneas \\
\hline M2-ISE-EVO & Solo - M2 & Evolutivas \\
\hline M3-ISE-INS & Solo -M3 & Instantâneas \\
\hline M3-ISE-EVO & Solo -M3 & Evolutivas \\
\hline
\end{tabular}


Mais especificamente, são avaliados os seguintes aspectos listados abaixo:

- Reações nas paredes em virtude da redistribuição das ações verticais.

- Fluxo das tensões normais nas paredes devido às ações verticais.

- Análise da consideração das ações evolutivas.

- Alterações nas tensões e esforços nas paredes ao longo da altura da edificação.

\subsection{REDISTRIBUIÇÃO DE ESFORÇOS E TENSÕES NA SUPERESTRUTURA EM EDIFÍCIOS DE PAREDES DE CONCRETO COM A INCLUSÃO DA ISE}

As paredes de concreto são elementos estruturais concebidos e dimensionados para suportar predominantemente esforços normais de compressão devido às cargas verticais do edifício, provenientes das lajes e do peso próprio do elemento estrutural em si. Obviamente as paredes estruturais também são utilizadas como painéis de contraventamento para combater os esforços provenientes do vento e desaprumo da edificação, que ocasionam o surgimento de flexão no plano da seção da parede, caso este que não é objeto de estudo no presente trabalho.

No presente item avalia-se principalmente a redistribuição dos esforços normais nas paredes da estrutura em consequência da interação solo-estrutura, já que como salientado este é o esforço predominante neste tipo de elemento estrutural. A redistribuição do esforço normal é avaliada considerando as paredes como elementos isolados e como grupo de paredes. Posteriormente são investigados o fluxo das tensões normais com o intuito de elucidar a perda de homogeneidade na distribuição em virtude da ISE.

\subsubsection{ANÁLISE DA REDISTRIBUIÇÃO DE CARGAS NAS PAREDES}

Este item inicialmente aborda a redistribuição dos esforços normais nas paredes de concreto. A Figura 4.2 ilustra a numeração de paredes adotada e metade da geometria em planta da edificação. 


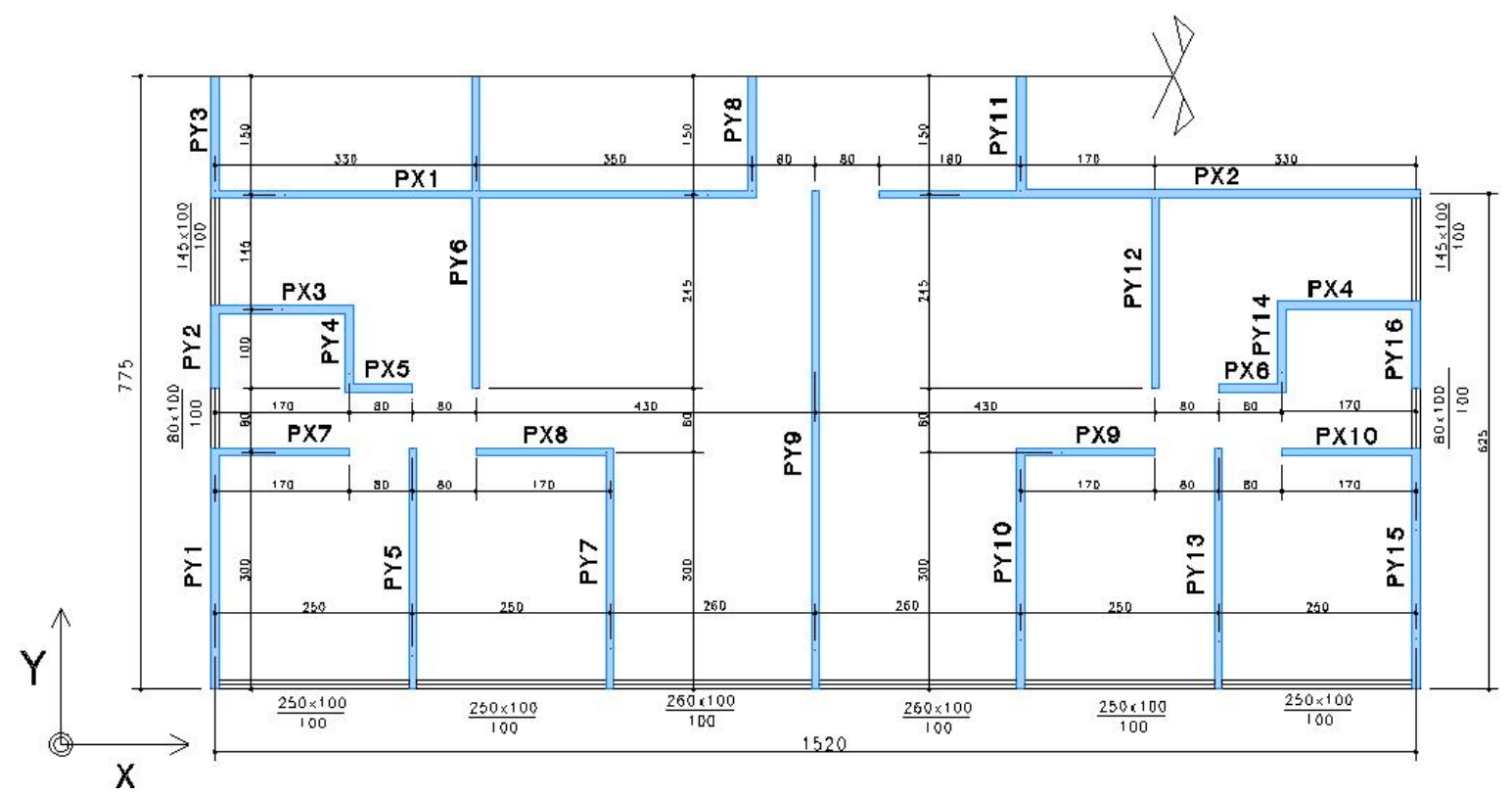

Figura 4.2 - Geometria e numeração das paredes adotadas

A conexão ou interação das paredes causa uma uniformização de esforços ao longo da altura do edifício nos elementos interligados, fato este comprovado em diversas pesquisas realizadas, como os estudos desenvolvidos para alvenaria estrutural por Capuzzo Neto (200) e Corrêa e Page (2001). A análise da redistribuição de esforços também é realizada com a consideração da formação de grupos de paredes, permitindo complementar a análise anterior. A delimitação do grupo de paredes é realizada pela presença de aberturas (portas e janelas). A Tabela 4.2 apresenta os grupos de paredes que compõem o edifício analisado.

Tabela 4.2 - Grupo de Paredes

\begin{tabular}{|c|c|}
\hline Nomenclatura & Paredes \\
\hline G1 & PX1, PY3, PY6 e PY8 \\
\hline G2 & PX2, PY11 e PY12 \\
\hline G3 & PX3, PX5, PY2 e PY4 \\
\hline G4 & PX4, PX6, PY14 e PY16 \\
\hline G5 PY1 \\
\hline G6 & PY5 \\
\hline G7 & PX8 e PY7 \\
\hline G8 & PY9 \\
\hline G9 & PX9 e PY10 \\
\hline G10 & PY13 \\
\hline G11 & PX10 e PY15 \\
\hline
\end{tabular}

A modificação das cargas nos elementos estruturais em razão da ISE tem relação com a ocorrência de recalques na edificação. Para o melhor entendimento do funcionamento obtido na redistribuição de esforços nas paredes torna-se necessário observar os recalques ocorridos na base da estrutura. A Figura 4.3 mostra a distribuição de deslocamentos verticais do $1^{\circ}$ 
pavimento (Paredes estruturais e lajes) da edificação em conjunto com o maciço do solo do mesmo modelo.

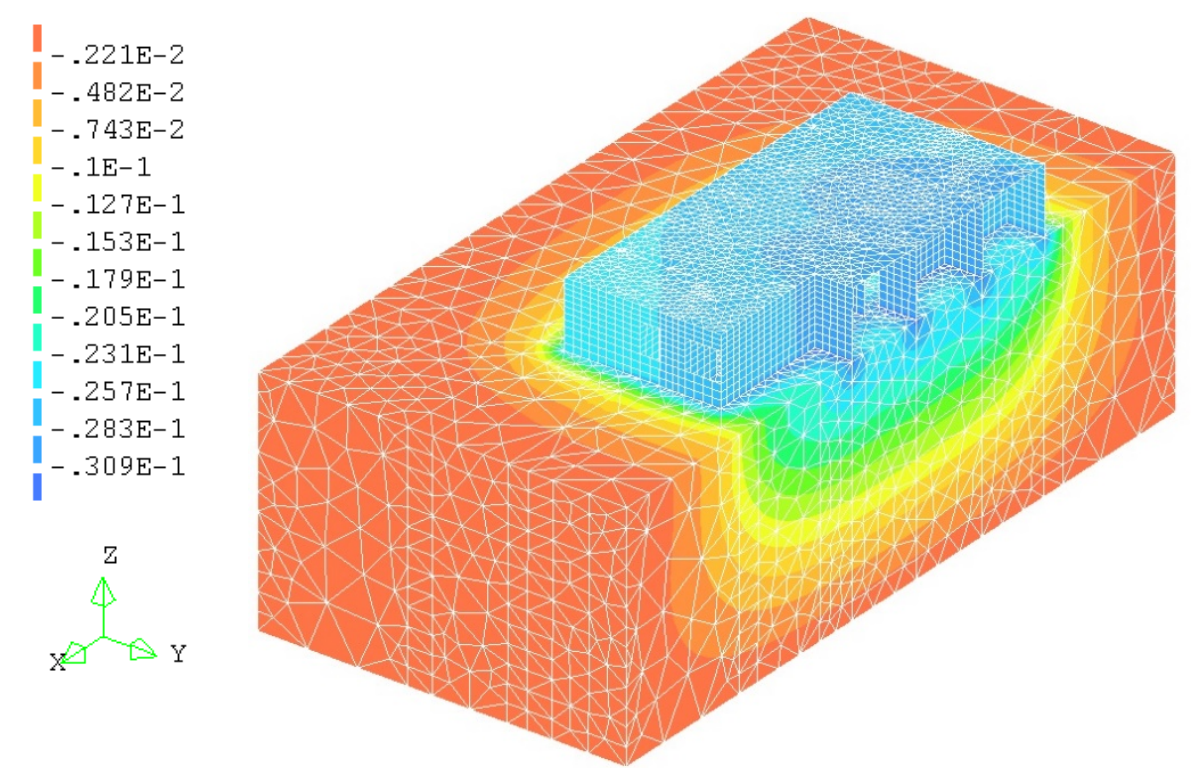

Figura $4.3-\mathrm{u}_{\mathrm{z}}(\mathrm{m})$ - Deslocamento vertical do conjunto primeiro pavimento e maciço do solo - Modelo M3ISE-EVO - Fase Final

A partir da Figura 4.3 é possível observar que os recalques tendem a ser superiores no centro da edificação (O modelo apresenta plano de simetria perpendicular ao Eixo-y) e inferiores na região periférica. Para entender o comportamento da redistribuição dos esforços, deve também ser observado o deslocamento vertical isolado das paredes estruturais. A Figura 4.4 exibe o deslocamento vertical apenas dos pontos das paredes estruturais do $1^{\circ}$ pavimento no modelo M1-ISE-EVO.
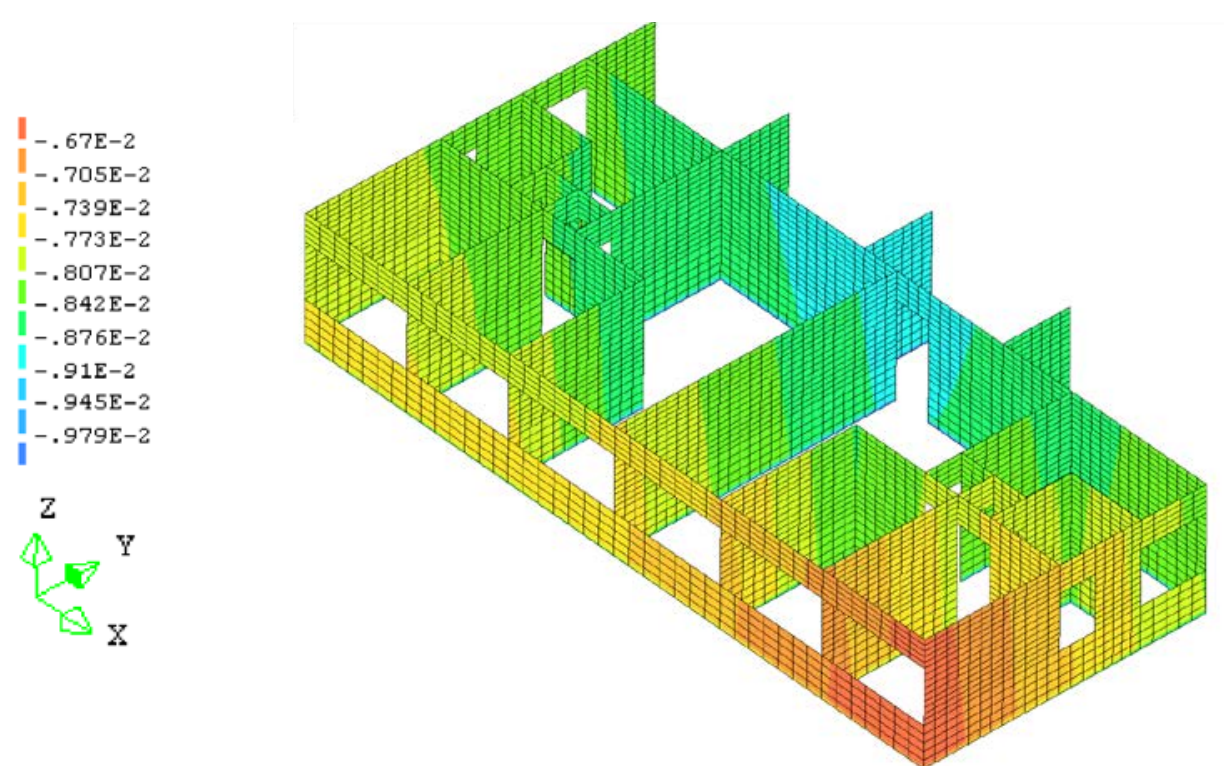

Figura $4.4-\mathrm{u}_{\mathrm{z}}(\mathrm{m})$ - Deslocamento vertical das paredes estruturais do primeiro pavimento - Modelo M1-ISEEVO - Fase Final 
O deslocamento vertical dos pontos das paredes, ilustrado na Figura 4.4, mostra que além dos recalques diferenciais entre os elementos da superestrutura, na base de cada parede estrutural o seu recalque também não é uniforme. Esse resultado indica a possível ocorrência de distorções angulares nesses elementos.

A distribuição do deslocamento vertical nas paredes apresenta comportamento distinto nas direções x e y. Em relação ao Eixo-Y, os elementos localizados mais ao centro sofrem recalques superiores em comparação com as paredes das regiões periféricas. Em relação ao Eixo-X, por não haver simetria da edificação neste sentido, verificam-se diferenças na distribuição de recalques em planta na direção X. Observa-se, por exemplo, que o recalque mínimo ocorre na extremidade da parede PY15. Desta maneira alguns grupos de paredes que possuem semelhança geométrica, apresentam diferenças relevantes no deslocamento vertical de seus pontos (G3 e G4; G5 e G15).

De uma maneira geral, as paredes localizadas na região central da edificação sofrem deslocamentos superiores, como as pertencentes aos grupos G1, G2, G3. As paredes localizadas nas regiões periféricas apresentam menores deslocamentos verticais como as paredes dos grupos G9, G10 e G11.

A distribuição de recalques nas edificações nos modelos M2-ISE-EVO e M3-ISEEVO são semelhantes as apresentadas pela Figura 4.3 e pela Figura 4.4, alterando, obviamente, a grandeza dos recalques.

O primeiro aspecto abordado é a alteração das cargas nas paredes da superestrutura. Para esta avaliação utiliza-se o coeficiente “ $\eta$ ”, denominado no presente trabalho como coeficiente de redistribuição de esforços. Esse coeficiente é adaptado da sugestão feita por Gusmão Filho e Guimarães (1994). Os autores utilizaram a Equação 4.1 para avaliar percentualmente o acréscimo ou alívio de cargas em pilares entre os modelos com e sem o uso da ISE.

$$
\eta=\frac{N_{i s e}-N_{c o n v}}{N_{c o n v}}
$$

$N_{\text {ise }}:$ Reação com a consideração da interação solo - estrutura

$N_{\text {conv }}$ : Reação com a consideração de apoio fixos

O uso do coeficiente é adaptado no presente trabalho, para os elementos de paredes de concreto, no qual os mesmos são modelados por elementos de chapa. Como descrito 
anteriormente, o cálculo das reações finais nas paredes é realizado com o uso de duas simplificações distintas. A primeira com a consideração das paredes isoladas e a segunda com a hipótese da interação entre as paredes. A Equação 4.2 mostra o cálculo do coeficiente de redistribuição de cargas para o caso de paredes isoladas e a Equação 4.3 para o caso de grupos de paredes. O cálculo do coeficiente de redistribuição é feito a partir do somatório dos esforços normais nos elementos finitos que compõem o elemento de análise. Desta maneira é possível obter o esforço normal total atuante no elemento estrutural que está sendo analisado.

$$
\begin{array}{lr}
\eta_{P A R}=\frac{\sum_{P a r} N_{I S E}-\sum_{P a r} N_{R E F}}{\sum_{P a r} N_{R E F}} & \text { Equação } 4.2 \\
\eta_{G R U}=\frac{\sum_{G R U} N_{I S E}-\sum_{G R U} N_{R E F}}{\sum_{G R U} N_{R E F}} & \text { Equação } 4.3 \\
N_{I S E}: \text { Esforço normal (compressão) no elemento finito no modelo com a ISE } & \\
N_{R E F}: \text { Esforço normal (compressão) no elemento finito no modelo de referência } &
\end{array}
$$

A vantagem de expressar o desempenho do edifício por meio do coeficiente proposto deve-se ao fato de valores positivos do coeficiente de redistribuição de esforços indicarem acréscimo de cargas no elemento investigado em virtude da aplicação da interação soloestrutura. Os valores negativos indicam alívios de esforços nos elementos em virtude da interação solo-estrutura. Além disso, os acréscimos ou decréscimos por consequência da ISE são obtidos percentualmente em relação à carga atuante no elemento avaliado no modelo de referência.

Além das alterações dos esforços nos elementos estruturais, nas paredes individuais e nos grupos de paredes, avalia-se também o valor médio absoluto do coeficiente de redistribuição de esforços por pavimento. O objetivo é apenas ter um parâmetro indicativo para que se possam comparar pisos diferentes do mesmo modelo ou de modelos distintos. A Equação 4.4 e a Equação 4.5 mostram respectivamente o coeficiente de redistribuição de esforços por pavimento para as duas situações consideradas. 


$$
\begin{aligned}
\eta_{\text {Pav,par }}=\frac{\sum_{\text {Pav }}\left|\eta_{\text {Par }}\right|}{\text { Número de paredes do pavimento }} & \text { Equação } 4.4 \\
\eta_{\text {Pav,gru }}=\frac{\sum_{\text {Pav }}\left|\eta_{\text {gru }}\right|}{\text { Número de grupos de paredes do pavimento }} & \text { Equação } 4.5
\end{aligned}
$$

As células das tabelas de resultados mostrados ao longo da tese possuem uma separação em escala de cores para facilitar a visualização dos resultados. Esse procedimento permite melhorar a identificação dos elementos mais afetados, tanto no acréscimo (Cores vermelhas) como na redução de esforços (Cores azuis), isto nas análises da variável “ $\eta$ ”. Esta análise é estendida para outras variáveis ao longo da tese. Os níveis de referência são sempre os valores máximos e mínimos da série de resultados avaliados em questão. A Tabela 4.3 indica a escala de cores utilizadas nas tabelas de resultados ao longo da tese.

Tabela 4.3 - Escala de cor na análise de resultados

\begin{tabular}{|l|l|}
\hline Cor & \multicolumn{1}{|c|}{ Descrição } \\
\hline & Maiores acréscimos Percentuais da série de resultados avaliados \\
\hline & Acréscimos percentuais intermediários da série de resultados avaliados \\
\hline & Menores acréscimos percentuais da série de resultados avaliados \\
\hline & Menores reduções percentuais da série de resultados avaliados \\
\hline & Reduções percentuais intermediarias da série de resultados avaliados \\
\hline & Maiores reduções percentuais da série de resultados avaliados \\
\hline
\end{tabular}

A primeira avaliação da redistribuição de cargas é realizada na base do edifício considerando as paredes como elementos individualizados. A Tabela 4.4 exibe a redistribuição de cargas na base das paredes para os modelos M1, M2 e M3. São mostrados os valores individuais de cada elemento e por fim o valor médio absoluto do $1^{\circ}$ pavimento.

Por meio da visualização da Tabela 4.4 é possível observar que as paredes PY1 e PY16 são as que denotaram maiores acréscimos de cargas. Observa-se que a PY1 é a parede mais distante da região central, onde verificam-se os maiores recalques. Comportamento equivalente pode ser observado nas paredes PY5 e PY15. A redução das reações ocorre normalmente nos elementos localizados em regiões com maiores recalques, como nas paredes PY6 e PY8. 
Tabela 4.4 - $\eta_{\text {PAR }}$ - Redistribuição de cargas nas paredes

\begin{tabular}{|c|c|c|c|}
\hline \multirow{2}{*}{ PAREDE } & \multicolumn{3}{|c|}{$\eta_{P A R}$} \\
\hline & M1-ISE-EVO & M2-ISE-EVO & M3-ISE-EVO \\
\hline PX1 & $-17 \%$ & $-21 \%$ & $-23 \%$ \\
\hline PX2 & $5 \%$ & $1 \%$ & $1 \%$ \\
\hline PX3 & $-2 \%$ & $1 \%$ & $1 \%$ \\
\hline $\mathrm{PX} 4$ & $9 \%$ & $11 \%$ & $12 \%$ \\
\hline PX5 & $-17 \%$ & $-18 \%$ & $-19 \%$ \\
\hline PX6 & $-20 \%$ & $-19 \%$ & $-19 \%$ \\
\hline PX7 & $6 \%$ & $13 \%$ & $14 \%$ \\
\hline PX8 & $-30 \%$ & $-33 \%$ & $-34 \%$ \\
\hline PX9 & $-42 \%$ & $-49 \%$ & $-49 \%$ \\
\hline PX10 & $2 \%$ & $9 \%$ & $9 \%$ \\
\hline PY1 & $29 \%$ & $32 \%$ & $33 \%$ \\
\hline PY2 & $19 \%$ & $19 \%$ & $19 \%$ \\
\hline PY3 & $0 \%$ & $-2 \%$ & $-2 \%$ \\
\hline PY4 & $-46 \%$ & $-53 \%$ & $-54 \%$ \\
\hline PY5 & $23 \%$ & $26 \%$ & $28 \%$ \\
\hline PY6 & $-32 \%$ & $-42 \%$ & $-43 \%$ \\
\hline PY7 & $8 \%$ & $9 \%$ & $10 \%$ \\
\hline PY8 & $-23 \%$ & $-35 \%$ & $-37 \%$ \\
\hline PY9 & $-4 \%$ & $-5 \%$ & $-5 \%$ \\
\hline PY10 & $2 \%$ & $2 \%$ & $4 \%$ \\
\hline PY11 & $-10 \%$ & $-16 \%$ & $-16 \%$ \\
\hline PY12 & $-13 \%$ & $-18 \%$ & $-20 \%$ \\
\hline PY13 & $10 \%$ & $13 \%$ & $14 \%$ \\
\hline PY14 & $-48 \%$ & $-58 \%$ & $-60 \%$ \\
\hline PY15 & $14 \%$ & $18 \%$ & $19 \%$ \\
\hline PY16 & $20 \%$ & $21 \%$ & $21 \%$ \\
\hline$\eta_{P a v}$ & $17 \%$ & $21 \%$ & $22 \%$ \\
\hline
\end{tabular}

As modificações dos esforços expostas na Tabela 4.4 são referentes à base da edificação. É interessante também analisar como transcorre a redistribuição dos esforços normais nos pavimentos superiores. A Tabela 4.5 aponta a redistribuição de cargas nas paredes do $1^{\circ}$ ao $8^{\circ}$ nível dos modelos pesquisados, com enfoque no valor médio absoluto.

Os recalques da estrutura são maiores na região central, diminuindo de forma gradativa até as extremidades. Os resultados indicam a tendência das paredes localizadas nas regiões com menores recalques, apresentarem acréscimo de cargas e as localizadas nas regiões de maiores recalques apresentarem redução. Apesar desta tendência, não se deve estabelecer esta observação como uma regra absoluta, pois nem todas as paredes apresentaram este desempenho. Isto se deve, possivelmente, ao fato destes elementos possuírem comprimento suficientemente grande, abrangendo tanto regiões com grandes recalques como regiões de 
pequenos recalques. Outro motivo é a conexão ou interligação entre as paredes, fazendo com que ocorra um funcionamento de grupo.

Tabela 4.5 - Pav,Par - Redistribuição de cargas nas paredes - Pavimentos 1 a 8 - Valor médio absoluto

\begin{tabular}{|c|c|c|c|}
\hline \multirow{2}{*}{ Pavimento } & \multicolumn{3}{|c|}{$\eta_{\text {Pav,Par }}$} \\
\cline { 2 - 4 } & M1-ISE-EVO & M2-ISE-EVO & M3-ISE-EVO \\
\hline 1 & $17,38 \%$ & $20,92 \%$ & $21,62 \%$ \\
\hline 2 & $13,50 \%$ & $14,58 \%$ & $14,91 \%$ \\
\hline 3 & $9,85 \%$ & $10,19 \%$ & $10,69 \%$ \\
\hline 4 & $6,77 \%$ & $6,96 \%$ & $7,26 \%$ \\
\hline 5 & $4,42 \%$ & $4,73 \%$ & $4,84 \%$ \\
\hline 6 & $2,88 \%$ & $3,12 \%$ & $3,15 \%$ \\
\hline 7 & $1,77 \%$ & $1,96 \%$ & $2,01 \%$ \\
\hline 8 & $1,12 \%$ & $1,23 \%$ & $1,26 \%$ \\
\hline
\end{tabular}

Os resultados mostram que a redistribuição média absoluta de esforços normais reduz gradativamente nos níveis superiores. Observa-se por exemplo que a partir do quinto pavimento o valor médio absoluto de “ $\eta$ ” nas paredes assume valores inferiores a cinco por cento nos três modelos estudados.

Outro aspecto interessante é a semelhança apresentada nos três modelos, ocorrida acima do terceiro piso, mesmo com diferenças significativas na rigidez do solo e consequentemente nos recalques na fundação.

Esses resultados, mesmo sendo médios, já são um indício de que a interação soloestrutura afeta sobretudo os primeiros níveis. Essa hipótese pode ser melhor pesquisada por meio do estudo individual de algumas paredes dos modelos investigados. A evolução do coeficiente de redistribuição de cargas de algumas paredes ao longo da altura do edifício pode ser observada na Figura 4.5. Os valores de redistribuição de esforços de todos os elementos e todos os pavimentos são expostos no Apêndice B. 


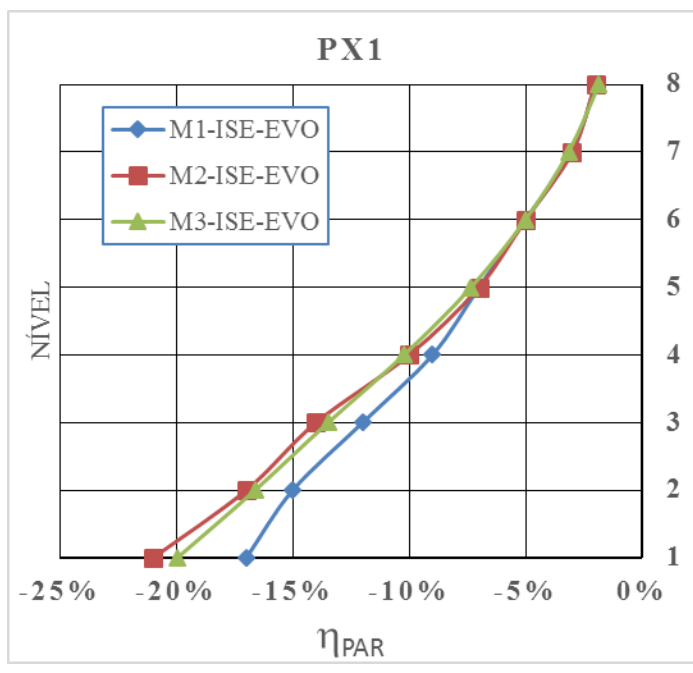

a) Parede PX1

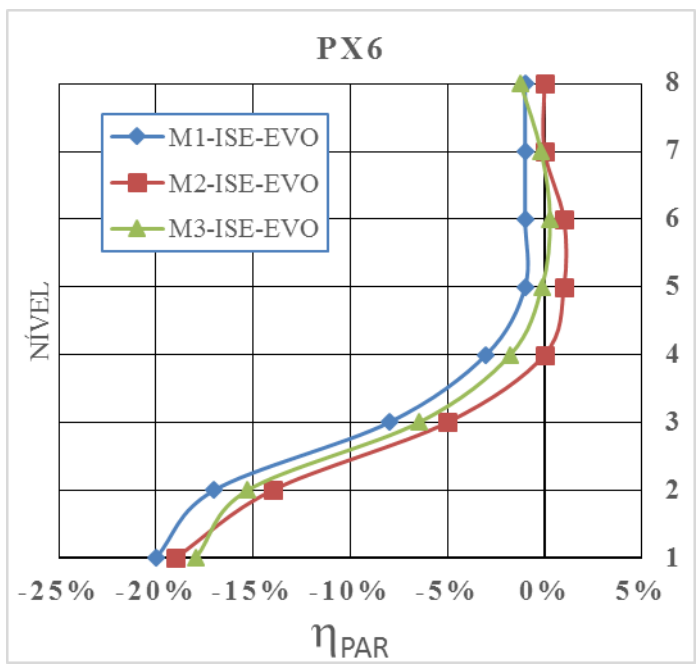

c) Parede PX6

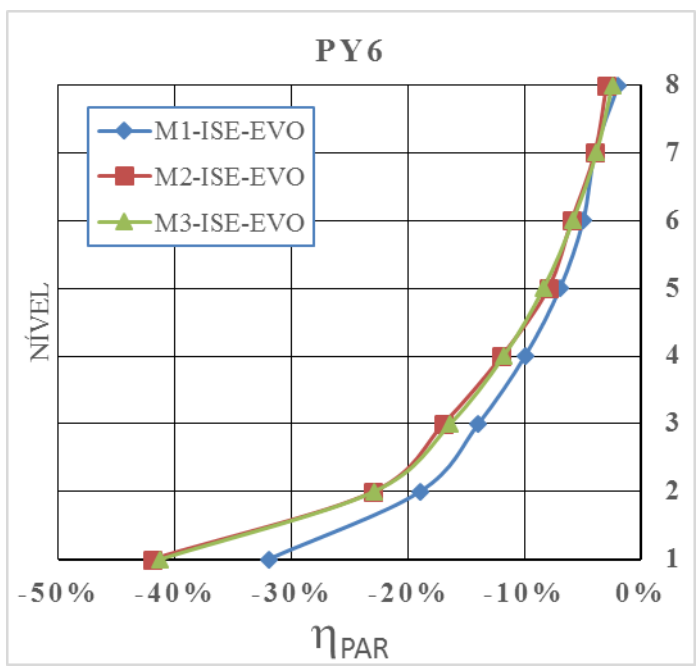

e) Parede PY6

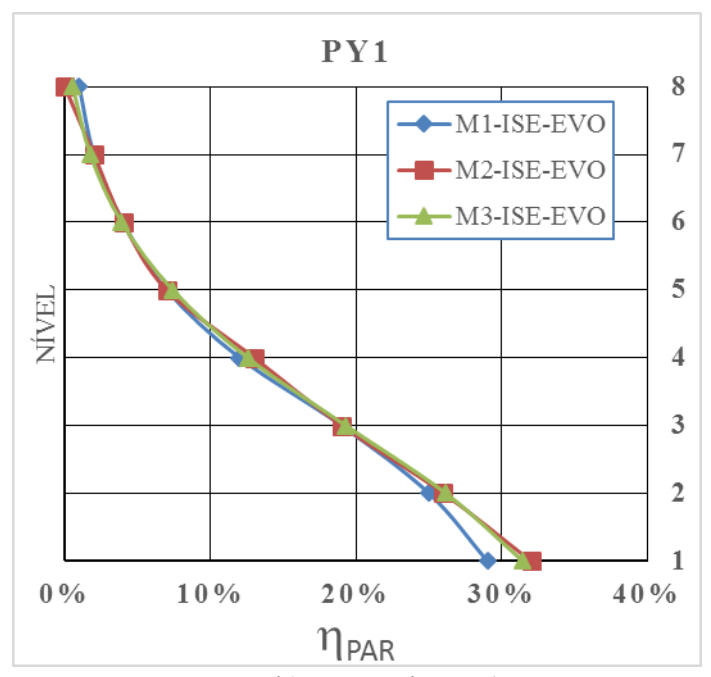

b) Parede PY1

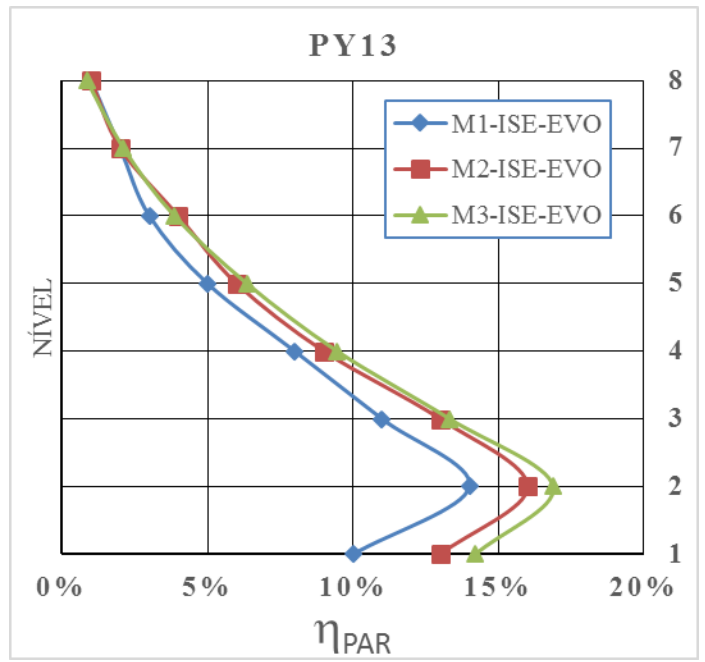

d) Parede PY13

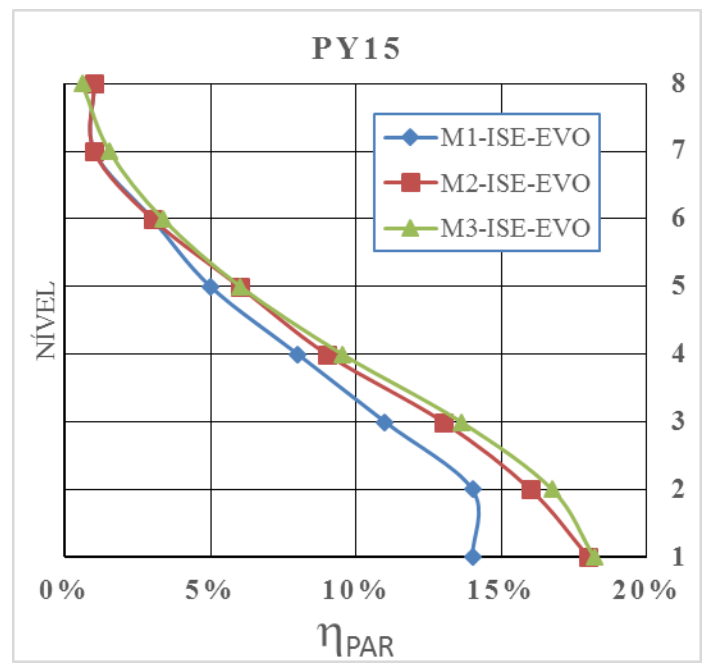

f) Parede PY15

Figura 4.5 - ๆPAR - Redistribuição de cargas ao longo dos pavimentos

Observa-se por meio da Figura 4.5 a redução gradativa do coeficiente “ $\eta$ ” à medida que a análise evolui para os pavimentos superiores, indicando que as cargas tendem a se 
aproximar dos valores obtidos com o modelo convencional de apoios fixos. Esta constatação indica, como suposto anteriormente, que a redistribuição de cargas é de um modo geral maior nos primeiros níveis e se atenua nos pavimentos superiores. Como destacado anteriormente, independentemente da rigidez do solo, nos modelos analisados, os três modelos apresentam funcionamento semelhante nos pisos superiores, e de forma similar ao modelo de referência (Apoios fixos).

Os resultados obtidos são reavaliados considerando a interação entre os elementos. Essa avaliação permite obter um panorama geral da redistribuição dos esforços normais. A Tabela 4.6 exibe os resultados nos grupos de paredes da edificação.

Tabela 4.6 - $\eta_{\text {GRU }}$ - Redistribuição de cargas nos grupos de paredes

\begin{tabular}{|c|c|c|c|}
\hline \multirow{2}{*}{ Grupo } & \multicolumn{3}{|c|}{$\eta_{\text {GRU }}$} \\
\cline { 2 - 4 } & M1-ISE-EVO & M2-ISE-EVO & M3-ISE-EVO \\
\hline G1 & $-19 \%$ & $-24 \%$ & $-25 \%$ \\
\hline G2 & $-1 \%$ & $-5 \%$ & $-5 \%$ \\
\hline G3 & $-1 \%$ & $-1 \%$ & $-2 \%$ \\
\hline G4 & $-2 \%$ & $-2 \%$ & $-3 \%$ \\
\hline G5 & $22 \%$ & $25 \%$ & $26 \%$ \\
\hline G6 & $23 \%$ & $26 \%$ & $26 \%$ \\
\hline G7 & $-1 \%$ & $-1 \%$ & $-1 \%$ \\
\hline G8 & $-4 \%$ & $-5 \%$ & $-5 \%$ \\
\hline G9 & $-9 \%$ & $-9 \%$ & $-9 \%$ \\
\hline G10 & $10 \%$ & $13 \%$ & $14 \%$ \\
\hline G11 & $10 \%$ & $15 \%$ & $15 \%$ \\
\hline$\eta_{\text {Pav }}$ & $9 \%$ & $12 \%$ & $13 \%$ \\
\hline
\end{tabular}

Observa-se que a consideração dos grupos de paredes apresenta valores inferiores da redistribuição de esforços em comparação com os resultados supondo os elementos de forma individualizada. A análise por grupos de paredes permite observar uma melhor separação das regiões nas quais ocorrem os acréscimos e os decréscimos de esforços na estrutura. A Figura 4.6 exibe, como caráter ilustrativo, um esquema da edificação em planta indicando as regiões de acréscimos e alívios de esforços para o modelo M3. 


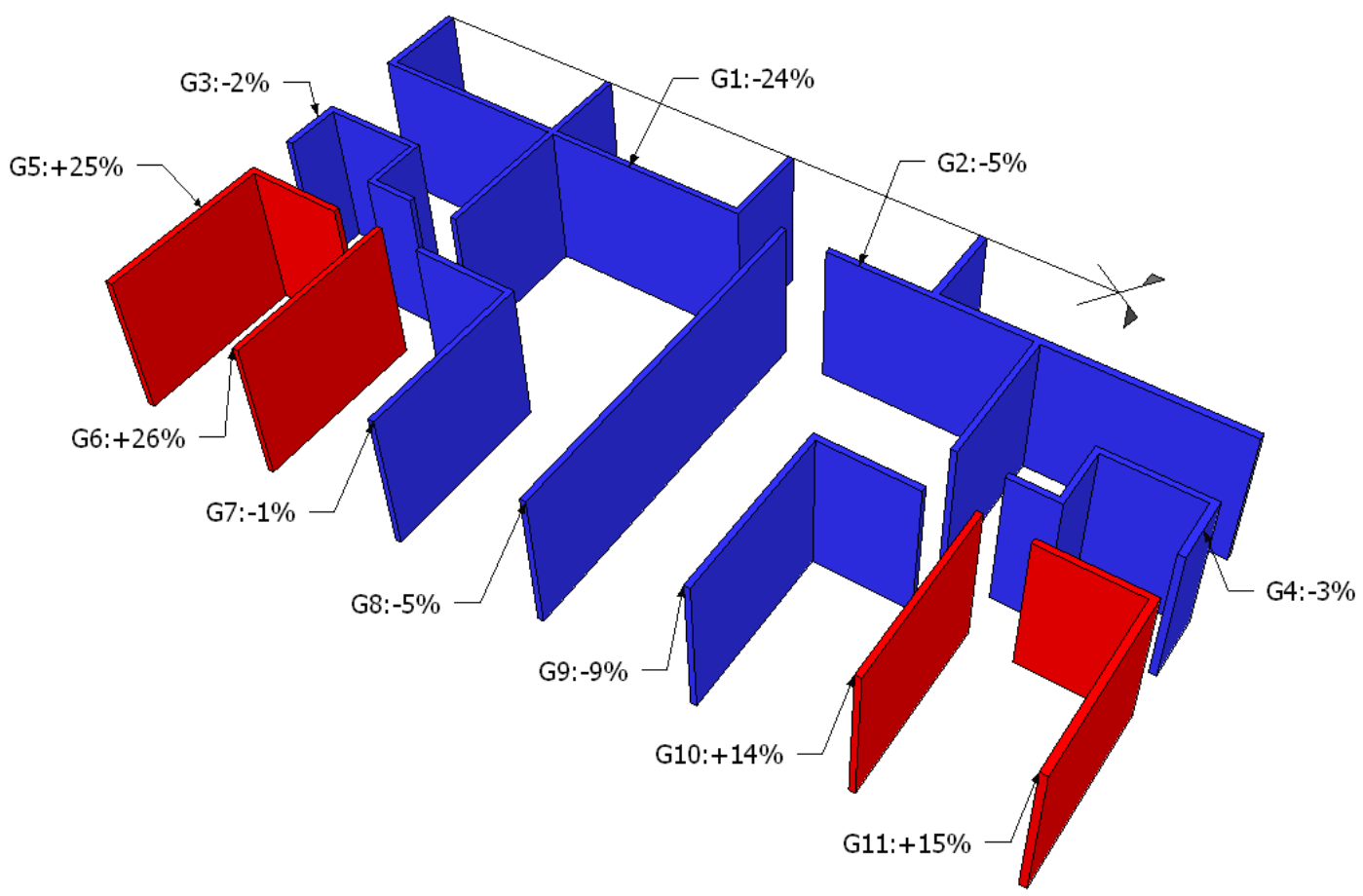

Figura 4.6 - ךGRU - Redistribuição de cargas nos grupos de paredes - Esquema ilustrativo - Modelo M3-ISEEVO

Observa-se pela Figura 4.6 que os acréscimos de cargas totais pela análise de grupos de paredes ocorrem nos quatro grupos localizados nas regiões periféricas, Grupos G5, G6, G10 e G15. Os alívios nos esforços normais ocorrem nos demais grupos, localizados majoritariamente na região central da edificação. O grupo de parede localizado mais ao centro da edificação, grupo G1, é o que apresenta maior alívio de esforços em razão da ISE, sendo este localizado na região central da edificação.

Os resultados mostrados correspondem à base do primeiro pavimento. De maneira similar ao realizado na análise individualizada das paredes, a redistribuição média absoluta dos grupos de paredes nos pisos superiores são também levantadas. A Tabela 4.7 exibe esses resultados nos três modelos estudados.

Os resultados da Tabela 4.7 apontam que a redução do efeito da interação soloestrutura nos pavimentos superiores ocorre de modo análogo ao mostrado na análise de paredes individualizadas. De maneira similar as consequências da interação solo-estrutura na redistribuição de esforços assumem valores abaixo de 5\% a partir do quinto nível. A Figura 4.7 mostra a redistribuição de cargas nos grupos de paredes mais importantes do edifício, ao longo de sua altura. Os resultados nos demais grupos de paredes são expostos no Apêndice B. 
Tabela 4.7 - Pav,gru - Redistribuição de cargas nos grupos de paredes - Pavimentos 1 a 8 - Valor médio absoluto

\begin{tabular}{|c|c|c|c|}
\hline \multirow{2}{*}{ Pavimento } & \multicolumn{3}{|c|}{$\eta_{\text {Pav,Gru }}$} \\
\cline { 2 - 4 } & M1-ISE-EVO & M2-ISE-EVO & M3-ISE-EVO \\
\hline 1 & $9,32 \%$ & $11,76 \%$ & $11,80 \%$ \\
\hline 2 & $9,24 \%$ & $10,72 \%$ & $10,80 \%$ \\
\hline 3 & $7,33 \%$ & $8,09 \%$ & $8,24 \%$ \\
\hline 4 & $5,39 \%$ & $6,05 \%$ & $6,12 \%$ \\
\hline 5 & $3,90 \%$ & $4,35 \%$ & $4,41 \%$ \\
\hline 6 & $2,66 \%$ & $2,99 \%$ & $3,04 \%$ \\
\hline 7 & $1,71 \%$ & $1,94 \%$ & $1,98 \%$ \\
\hline 8 & $1,08 \%$ & $1,16 \%$ & $1,22 \%$ \\
\hline
\end{tabular}

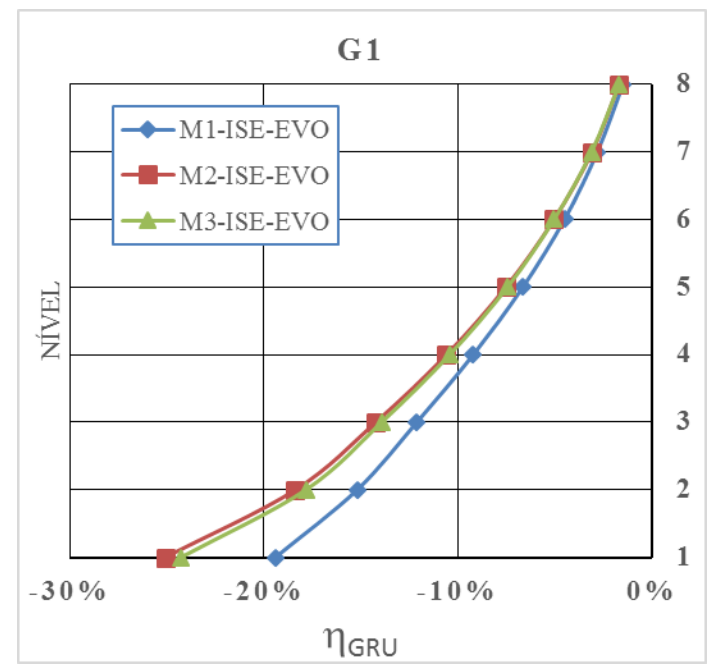

a) G1

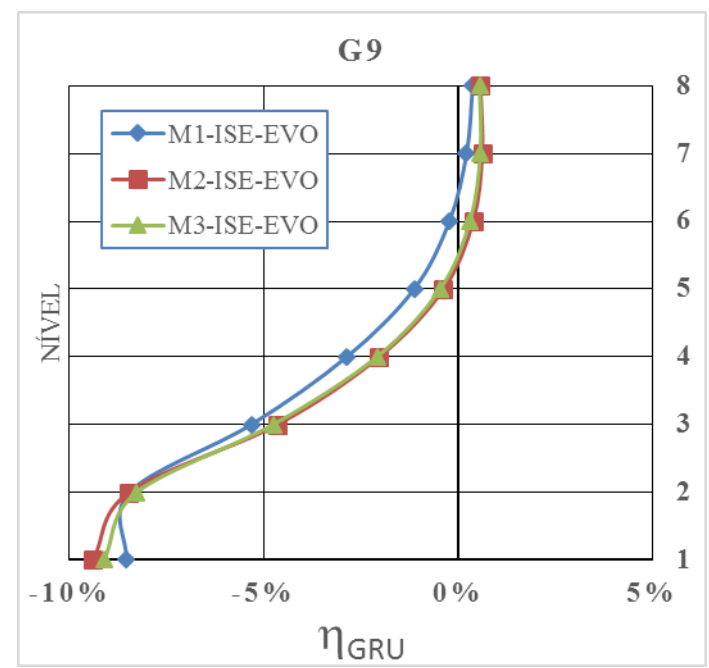

c) G9

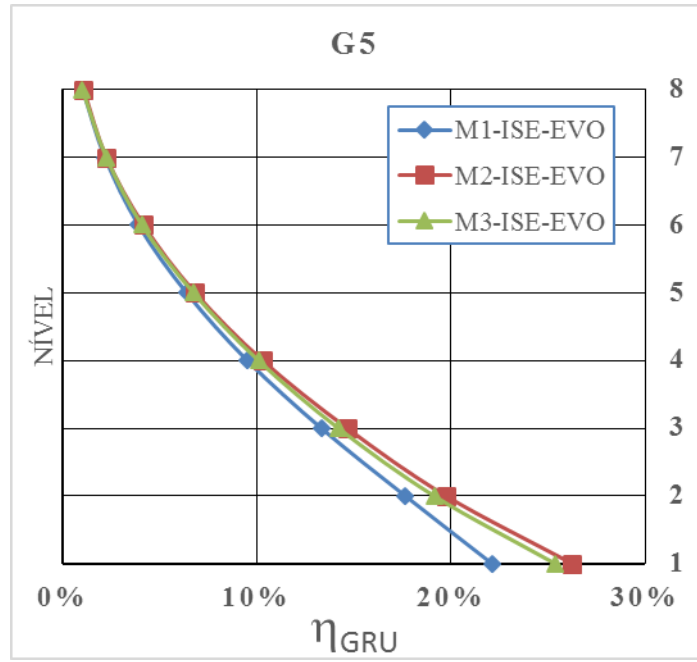

b) G5

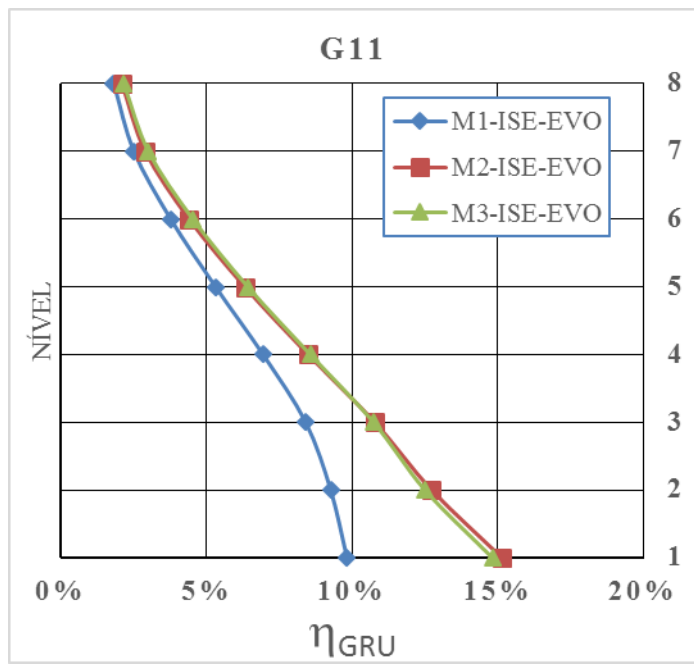

d) G11

Figura 4.7 - ךGRU - Redistribuição de cargas ao longo dos pavimentos 
Os resultados mostrados na Figura 4.7 (grupo de paredes) apresentam comportamento similar ao obtido com as análises das paredes individualizadas, em que nos pisos superiores as alterações das cargas produzidas pela interação solo-estrutura vão reduzindo progressivamente ao longo da altura, indicando novamente que a interação solo-estrutura reduz sua influência nos pavimentos superiores, como esperado pelo distanciamento progressivo do solo. Observa-se que no quinto piso, na ampla maioria dos grupos de paredes, o coeficiente “ $\eta$ ” já apresenta valores muito próximos de zero.

Outro ponto interessante a se destacar é a baixa diferença entre os coeficientes “ $\eta$ ” nas soluções dos esforços obtidos entre os modelos M1, M2 e M3. Estes resultados indicam que a diferença de rigidez do solo, neste estudo realizado, pouco interfere no comportamento estrutural. Deve-se isto provavelmente à baixa rigidez solo-estrutura, independente da rigidez utilizada para o solo, ou seja, a superestrutura possui uma rigidez muito superior à rigidez do solo. Santos (2016) indicou que o limite de contribuição de rigidez da estrutura na uniformização dos recalques em edifícios de paredes de concreto com fundação superficial em sapata foi de cinco pavimentos. Esse comportamento se repete nos modelos analisados nesse capítulo, sendo este edifício com fundação do tipo radier. Para níveis de rigidez do solo diferentes dos modelos estudados a contribuição da rigidez pode se apresentar de forma distinta à descrita acima, sendo que esse aspecto será melhor avaliado no capitulo 6 .

\subsubsection{DISTRIBUIÇÃO DAS TENSÕES NORMAIS NAS PAREDES}

As análises apresentadas no item anterior focalizaram os resultados finais das reações nas paredes individualizadas e nos grupos de paredes. Avaliar apenas as reações finais na base desses elementos pode levar a erros de interpretação no comportamento da ISE, já que as paredes podem ter comprimentos grandes em planta. Esse tipo de análise parte da suposição que a distribuição de esforços normais nas paredes apresenta uniformidade. Essa simplificação pode ser aceitável para elementos de pequeno comprimento, como pilares, ou até paredes de pequenas dimensões. Para elementos usuais dos edifícios de paredes de concreto essa simplificação pode não ser verdadeira. Alguns elementos, graças ao seu comprimento, podem sofrer acréscimos e reduções de esforços localizados e dessa forma o uso de um resultado médio da reação da parede pode mascarar a influência da interação solo-estrutura.

Como descrito anteriormente, a uniformização das tensões normais de compressão em paredes (Alvenaria estrutural) já foi comprovada numérica e experimentalmente. As soluções obtidas no presente estudo mostram que quando considerada a ISE os recalques nas bases das 
paredes não apresentam distribuição uniforme ao longo do seu comprimento, o que já é um indício de que as tensões de compressão na base da parede possam perder uniformidade.

A análise das modificações das tensões normais sobre o efeito da interação soloestrutura é realizada por meio da observação do seu fluxo nos planos dos elementos das paredes estruturais.

O fluxo das tensões normais de alguns elementos podem ser observados por meio das Figura 4.8, Figura 4.9 e Figura 4.10, que ilustram respectivamente essa distribuição nas paredes PY1, PY5 e PY9 com e sem o emprego da interação solo-estrutura no $1^{\circ}$ pavimento do modelo M3-ISE-EVO.

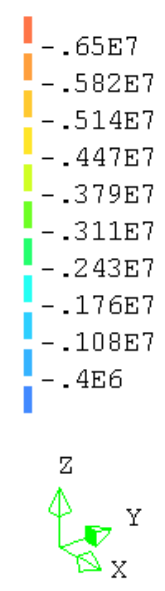

$\mathrm{X}$

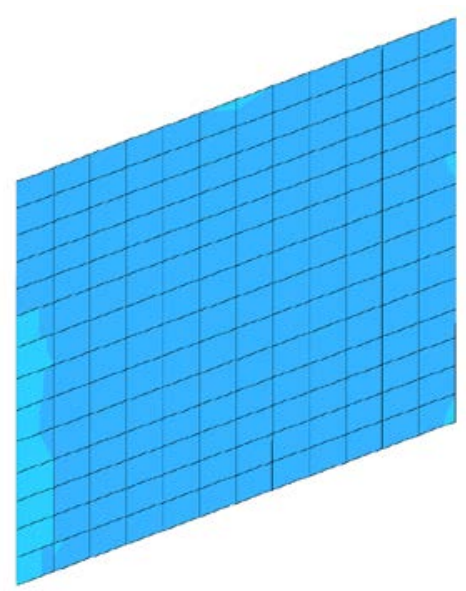

a) REF-AP

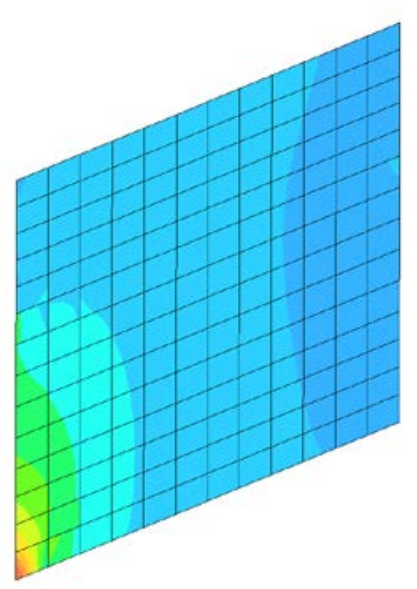

b) M3-ISE-EVO

Figura $4.8-\sigma_{\mathrm{zz}}\left(\mathrm{N} / \mathrm{m}^{2}\right)$ - Tensões normais - PY1 - $1^{\circ}$ Pavimento - Modelo M3

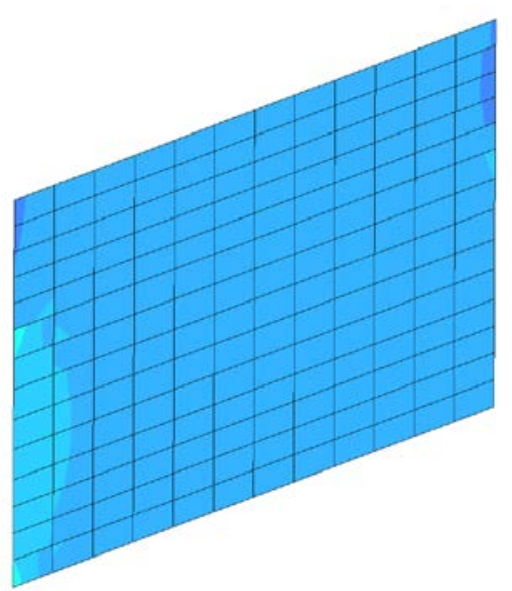

a) REF-AP

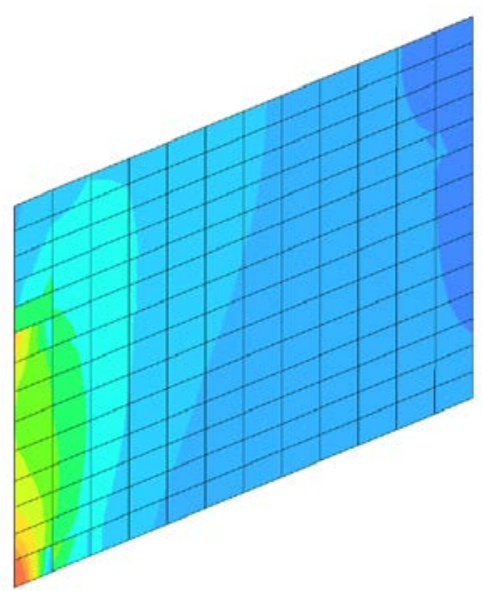

b) M3-ISE-EVO

Figura $4.9-\sigma_{\mathrm{zz}}\left(\mathrm{N} / \mathrm{m}^{2}\right)$ - Tensões normais - PY5 - $1^{\circ}$ Pavimento - Modelo M2 


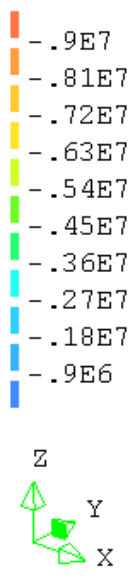

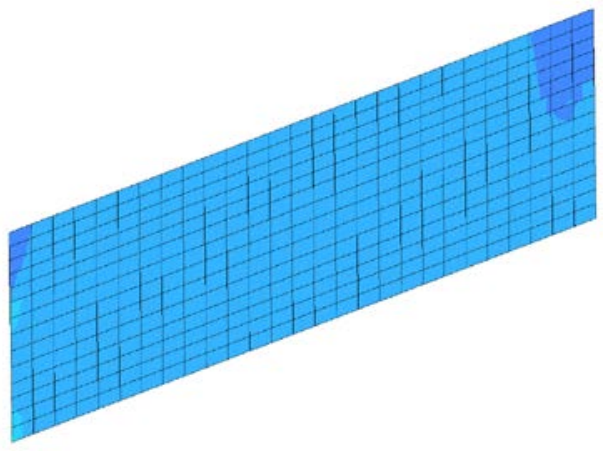

a) REF-AP

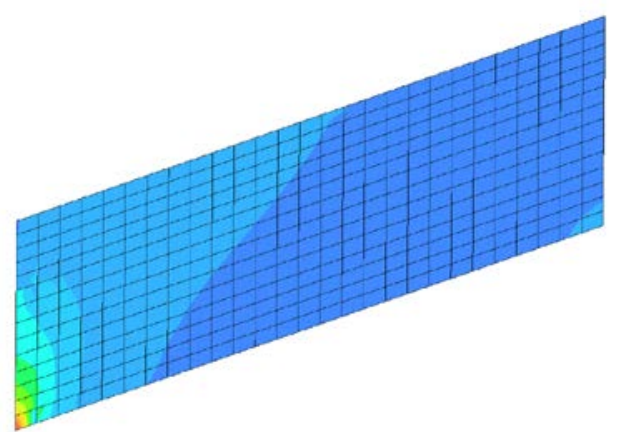

b) M3-ISE-EVO

Figura $4.10-\sigma_{\mathrm{zz}}\left(\mathrm{N} / \mathrm{m}^{2}\right)$ - Tensões normais - PY9 $-1^{\circ}$ Pavimento - Modelo M1

A Figura 4.8 aponta que na parede PY1 o modelo com o emprego da ISE não apresentou uma distribuição de tensões uniforme, ao contrário do alcançado com a aplicação de apoios fixos (Modelo de referência). O acréscimo das tensões ocorre na extremidade esquerda da parede, localizada na região externa da estrutura, onde se encontram os menores recalques. As tensões normais de compressão sofrem redução à medida que se distancia do ponto de menor recalque, até a outra extremidade da parede (região com maior deslocamento vertical).

O desempenho é similar na PY5 (Figura 4.9), na qual os maiores acréscimos das tensões de compressão ocorrem nas regiões localizadas mais próximas da periferia do edifício, sendo esta a região que possui os menores recalques. É possível supor que a alteração do fluxo de tensões nas paredes tem relação com a distribuição de recalques em sua base.

Na PY9 (Figura 4.10) a consideração da interação solo-estrutura promoveu perturbações no fluxo de tensões normais nas duas extremidades. Quando comparada com o modelo de referência, observa-se que a parede PY9 apresenta uma das extremidades com acréscimo de tensões de compressão e a outra extremidade com alívio nas tensões de compressão. Os trechos localizados junto à região central da edificação apresentam reduções nas tensões de compressão, quando comparados com o modelo de referência, sendo esses trechos localizados nas regiões de maiores recalques.

Os resultados foram similares nas demais paredes da edificação, como apresentado na Figura 4.11, que ilustra as tensões normais nas bases de algumas paredes dos modelos analisados, ao longo do seu comprimento. 


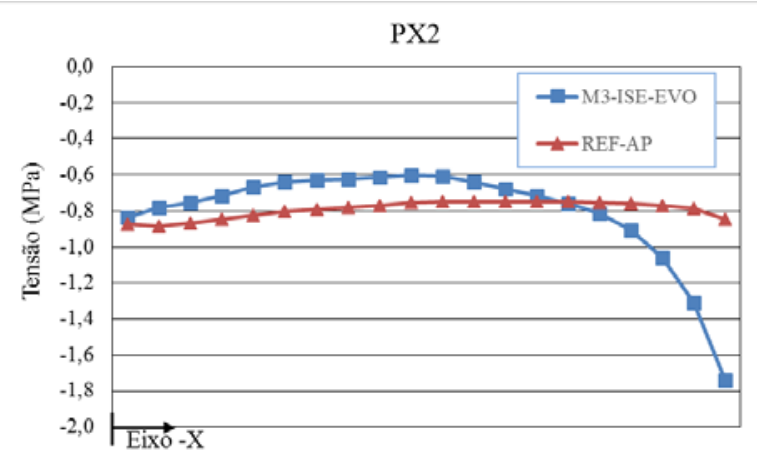

a) Parede PX2 - Modelo M3

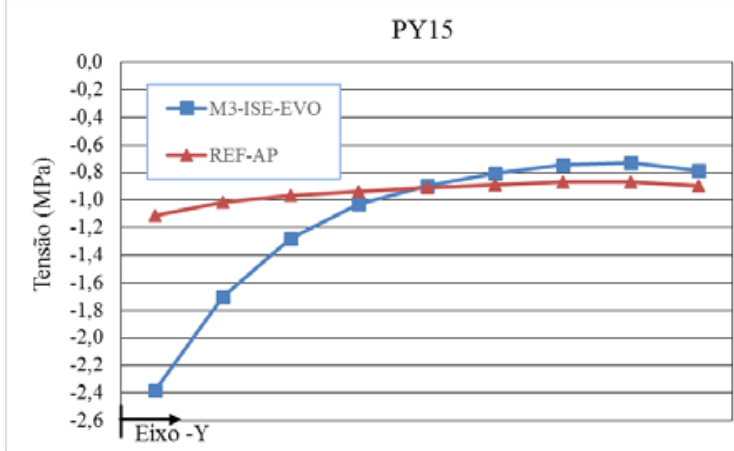

c) Parede PY15- Modelo M3

PX4

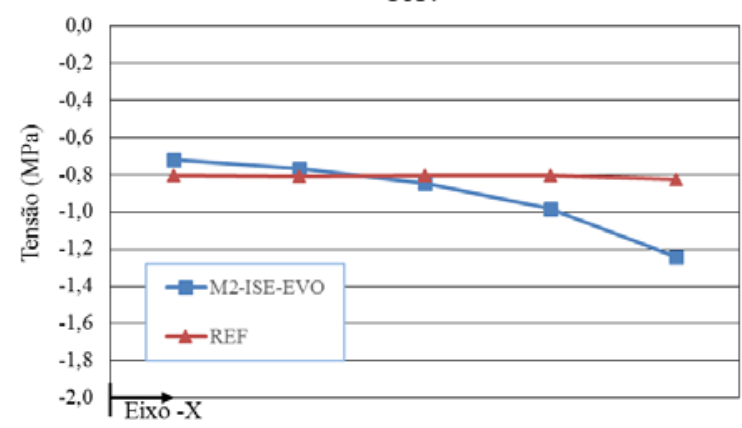

e) Parede PX4 - Modelo M2

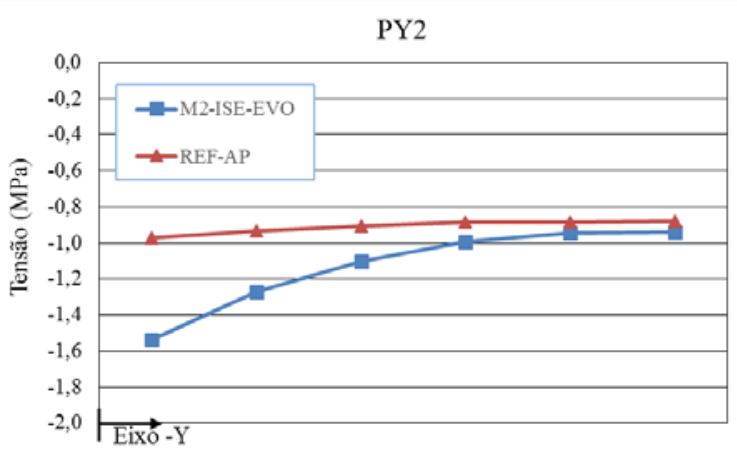

b) Parede PY2 - Modelo M2

PY7

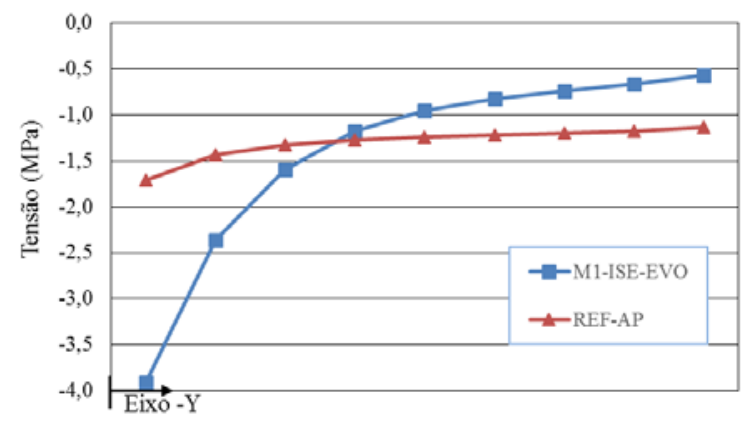

d) Parede PY7 - Modelo M1

PX8

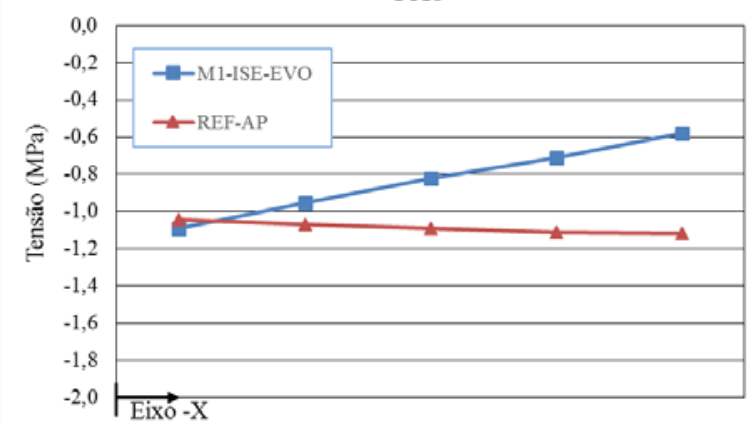

f) Parede PX8 - Modelo M1

Figura $4.11-\sigma_{\mathrm{zz}}(\mathrm{MPa})$ - Distribuição de tensões normais nas bases das paredes- ISE-EVO x REF-AP

Os gráficos da Figura 4.11 indicam que a distribuição das tensões normais da base das paredes nos modelos em que são considerados os efeitos da ISE apresentam variações significativas ao longo do seu comprimento. Claramente se percebe que no modelo de referência as respostas das tensões possuem uma menor variabilidade, indicando também que o critério da homogeneidade dos esforços normais nas paredes sobre apoios fixos é válido.

O coeficiente de variação é um índice estatístico que possibilita avaliar a uniformidade de uma variável qualquer. No caso específico, pode-se calcular o coeficiente de variação das medições das tensões normais nas paredes estudadas e desta forma analisar a sua uniformidade. O coeficiente de variação das tensões é denominado como " $C V_{\sigma}$ ” no presente texto. A Tabela 4.8 exibe o coeficiente de variação das tensões normais na base das paredes dos modelos pesquisados e do modelo de referência. O cálculo do coeficiente de variação foi realizado por 
meio dos valores de tensões normais médias de cada elemento finito na base do referido elemento estrutural.

Tabela 4.8 - $C V_{\sigma}$ - Coeficiente de variação - Tensões normais - Base $1^{\circ}$ pavimento

\begin{tabular}{|c|c|c|c|c|}
\hline \multicolumn{5}{|c|}{$C V_{\sigma}-$ Tensões Normais nas paredes (\%) } \\
\hline Parede & REF-AP & M1-ISE-EVO & M2-ISE-EVO & M3-ISE-EVO \\
\hline PX1 & $2,2 \%$ & $19,6 \%$ & $21,3 \%$ & $21,5 \%$ \\
\hline PX2 & $6,1 \%$ & $34,4 \%$ & $35,3 \%$ & $34,9 \%$ \\
\hline PX3 & $1,2 \%$ & $12,4 \%$ & $6,0 \%$ & $7,8 \%$ \\
\hline $\mathrm{PX} 4$ & $1,2 \%$ & $26,5 \%$ & $23,1 \%$ & $22,7 \%$ \\
\hline PX5 & $2,9 \%$ & $27,1 \%$ & $41,3 \%$ & $37,3 \%$ \\
\hline PX6 & $3,1 \%$ & $22,8 \%$ & $35,4 \%$ & $36,4 \%$ \\
\hline PX7 & $3,2 \%$ & $13,0 \%$ & $19,8 \%$ & $19,5 \%$ \\
\hline PX8 & $2,7 \%$ & $24,1 \%$ & $25,7 \%$ & $24,2 \%$ \\
\hline PX9 & $2,8 \%$ & $19,5 \%$ & $19,8 \%$ & $20,7 \%$ \\
\hline PX10 & $3,0 \%$ & $12,6 \%$ & $17,7 \%$ & $17,5 \%$ \\
\hline PY1 & $6,1 \%$ & $50,3 \%$ & $52,2 \%$ & $52,6 \%$ \\
\hline PY2 & $4,0 \%$ & $16,1 \%$ & $20,7 \%$ & $20,0 \%$ \\
\hline PY3 & $2,9 \%$ & $23,1 \%$ & $23,2 \%$ & $22,6 \%$ \\
\hline PY4 & $1,7 \%$ & $12,8 \%$ & $30,0 \%$ & $25,3 \%$ \\
\hline PY5 & $14,6 \%$ & $82,5 \%$ & $83,2 \%$ & $85,0 \%$ \\
\hline PY6 & $3,6 \%$ & $7,9 \%$ & $7,9 \%$ & $8,5 \%$ \\
\hline PY7 & $13,6 \%$ & $77,0 \%$ & $79,4 \%$ & $79,1 \%$ \\
\hline PY8 & $1,6 \%$ & $4,8 \%$ & $9,4 \%$ & $10,0 \%$ \\
\hline PY9 & $16,5 \%$ & $68,1 \%$ & $71,8 \%$ & $71,8 \%$ \\
\hline PY10 & $14,6 \%$ & $75,7 \%$ & $78,0 \%$ & $78,6 \%$ \\
\hline PY11 & $0,2 \%$ & $3,0 \%$ & $2,7 \%$ & $2,5 \%$ \\
\hline PY12 & $9,7 \%$ & $13,7 \%$ & $12,0 \%$ & $10,4 \%$ \\
\hline PY13 & $17,2 \%$ & $81,5 \%$ & $83,8 \%$ & $84,1 \%$ \\
\hline PY14 & $2,8 \%$ & $7,2 \%$ & $20,6 \%$ & $21,3 \%$ \\
\hline PY15 & $8,6 \%$ & $46,2 \%$ & $46,4 \%$ & $48,5 \%$ \\
\hline PY16 & $4,3 \%$ & $19,0 \%$ & $17,4 \%$ & $17,6 \%$ \\
\hline
\end{tabular}

Os valores exibidos na Tabela 4.8 mostram grandes variações das tensões na base de uma mesma parede quando considerada a ISE. O modelo de referência possui uma uniformidade das tensões de compressão na maioria das paredes. A PY13 é a que apresenta maior variação na distribuição de tensões no modelo de referência, mas esse valor ainda é muito baixo quando comparado com os calculados por meio do emprego da ISE. Nota-se também que na ampla maioria das paredes os coeficientes de variação são similares nos três modelos que consideram a ISE evidenciando que a variação das tensões de compressão pode não possuir tanta dependência da rigidez do solo, mas apenas pelo fato de ser deformável. 
Os resultados apresentados anteriormente correspondem ao $1^{\circ}$ pavimento da edificação. A Figura 4.12 amplifica a análises para os níveis superiores, mostrando a comparação do fluxo das tensões da parede PY9 em alguns dos demais pavimentos superiores do edifício com e sem o uso da ISE.

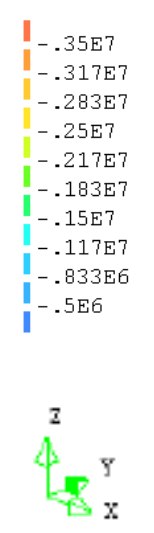

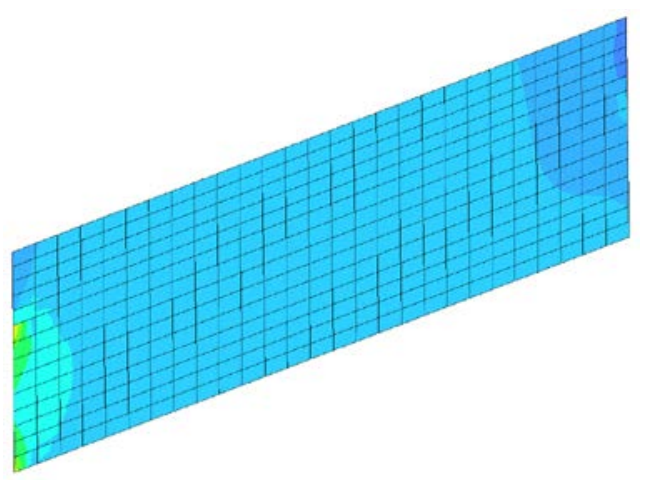

REF-AP

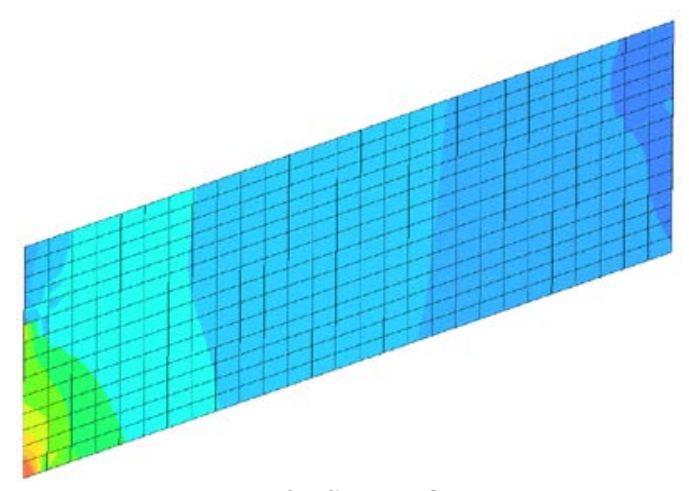

M2-ISE-EVO

a) $\sigma_{\mathrm{zz}}\left(\mathrm{N} / \mathrm{m}^{2}\right)-$ Tensões normais $-2^{\circ}$ Pavimento

$-.3 \mathrm{E} 7$
$-.27 \mathrm{E} 7$
$-.24 \mathrm{E} 7$
$-.21 \mathrm{E} 7$
$-.18 \mathrm{E} 7$
$-.15 \mathrm{E} 7$
$-.12 \mathrm{E} 7$
$-.9 \mathrm{E} 6$
$-.6 \mathrm{E} 6$
$-.3 \mathrm{E} 6$
$\mathrm{z}$
$\mathrm{Y} \triangle \mathrm{X}$

$-.25 \mathrm{E} 7$

$-.227 \mathrm{E} 7$

$-.203 \mathrm{E} 7$

$1-.18 \mathrm{E} 7$

$-.157 \mathrm{E} 7$

$-.133 \mathrm{E} 7$

$-.11 \mathrm{E} 7$

$-.867 \mathrm{E} 6$

$-.633 \mathrm{E} 6$

$-.4 \mathrm{E} 6$

$\mathrm{Y}_{\rightarrow \mathrm{I}} \mathrm{X}$

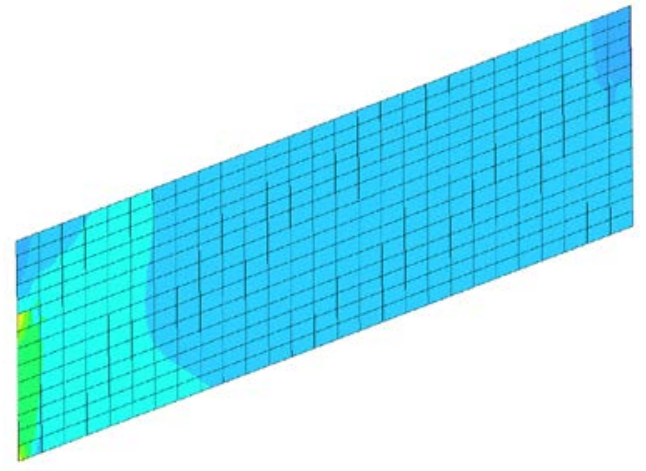

REF-AP

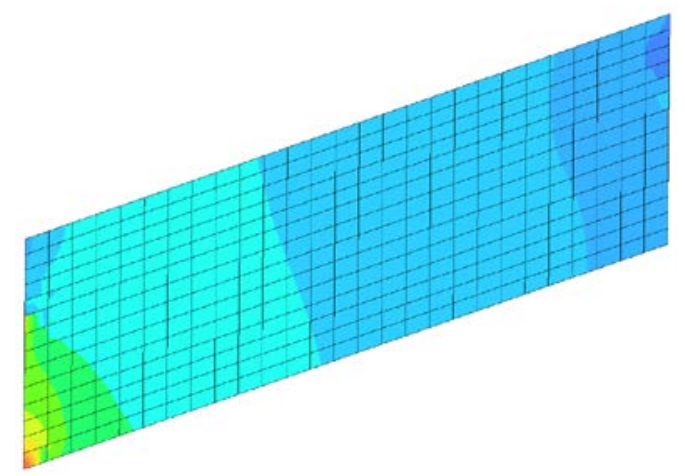

M2-ISE-EVO

b) $\sigma_{\mathrm{zz}}\left(\mathrm{N} / \mathrm{m}^{2}\right)$ - Tensões normais - $3^{\circ}$ Pavimento

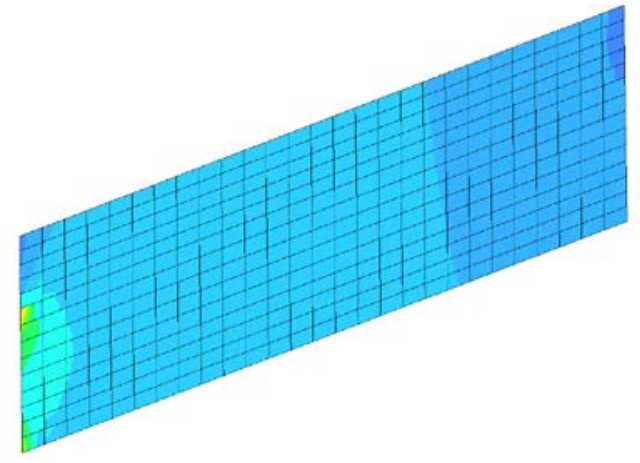

REF-AP

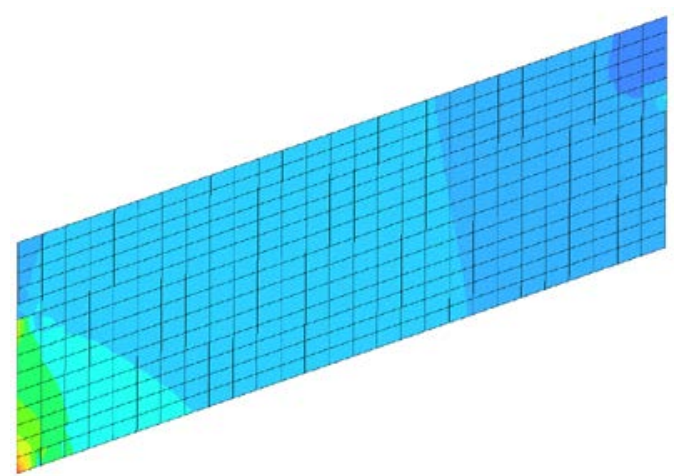

M2-ISE-EVO

c) $\sigma_{\mathrm{zz}}\left(\mathrm{N} / \mathrm{m}^{2}\right)$ - Tensões normais $-4^{\circ}$ Pavimento

Figura $4.12-\sigma_{\mathrm{zz}}\left(\mathrm{N} / \mathrm{m}^{2}\right)$-Tensões normais - PY9 $-2^{\circ}$, $3^{\circ}$ e $4^{\circ}$ Pavimento

A comparação do fluxo de tensões no $1^{\circ}$ pavimento na parede PY9 entre os dois modelos já foi mostrada anteriormente na Figura 4.10. A Figura 4.12 evidencia que as diferenças entre os modelos com a aplicação da ISE e de referência reduzem à medida que a análise é realizada nos pisos superiores. No segundo pavimento a Figura 4.12a indica que o modelo com o emprego da ISE apresenta uma configuração mais heterogênea que o modelo de 
referência. No terceiro pavimento (Figura 4.12b) a distribuição das tensões de compressão entre os dois modelos exibe valores mais aproximados em relação aos resultados apresentados no $2^{\circ}$ piso. No $4^{\circ}$ pavimento é possível afirmar que os modelos possuem comportamentos similares, com algumas pequenas diferenças no fluxo de tensões. A Figura 4.13 exibe a análise da distribuição das tensões de compressão na parede PY1 sendo agora no $3^{\circ}, 5^{\circ}$ e $7^{\circ}$ pisos com e sem o uso da ISE.

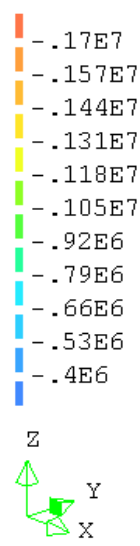

$-.14 \mathrm{E} 7$

$-.129 \mathrm{E} 7$

$-.118 \mathrm{E} 7$

$-.107 \mathrm{E} 7$

$-.964 \mathrm{E} 6$

$-.855 \mathrm{E} 6$

$-.745 \mathrm{E} 6$

$-.636 \mathrm{E} 6$

$-.527 \mathrm{E} 6$

$-.418 \mathrm{E} 6$

$-.309 \mathrm{E} 6$

$-.2 \mathrm{E} 6$

乙

4

$\operatorname{SO}_{\mathrm{X}}^{\mathrm{Y}}$

$-.7 \mathrm{E} 6$

$-.7 \mathrm{E} 6$
$-.639 \mathrm{E} 6$

$-.578 \mathrm{E} 6$

$-.517 \mathrm{E} 6$

$-.456 \mathrm{E} 6$

$-.395 \mathrm{E} 6$

$-.335 \mathrm{E} 6$

$-.274 \mathrm{E} 6$

$-.213 \mathrm{E} 6$

$-.152 \mathrm{E} 6$

$-.909 \mathrm{E} 5$

$-.3 \mathrm{E} 5$

z

$4 \underbrace{Y}_{X}$

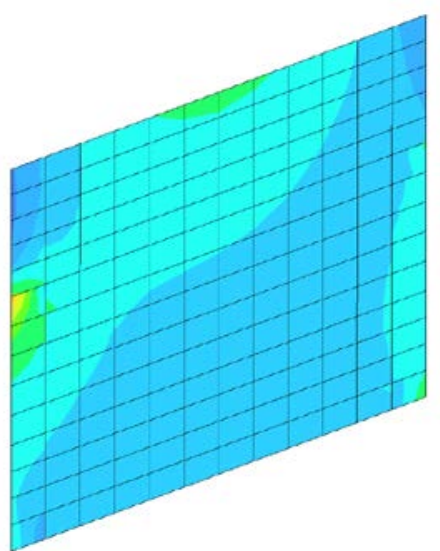

REF-AP

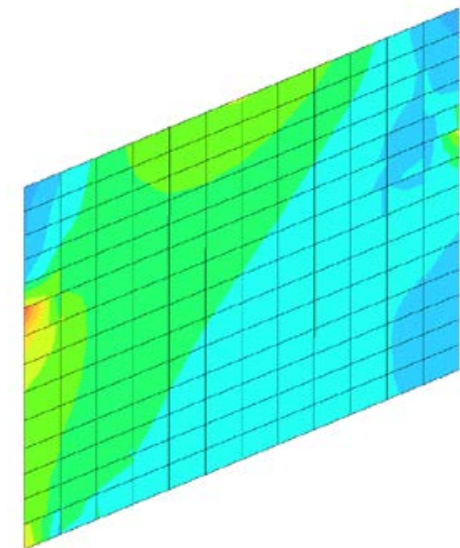

M1-ISE-EVO

a) $\sigma_{\mathrm{zz}}\left(\mathrm{N} / \mathrm{m}^{2}\right)-$ Tensões normais $-3^{\circ}$ Pavimento

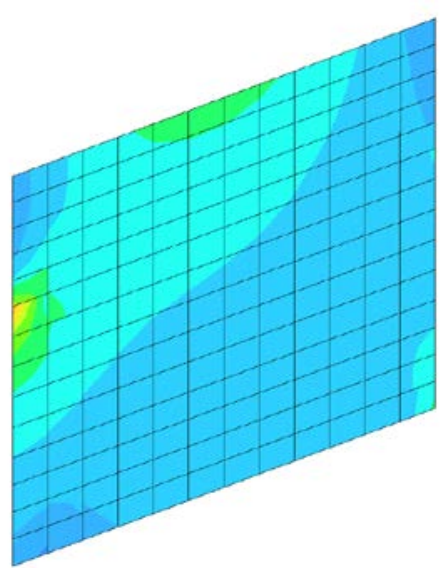

REF-AP

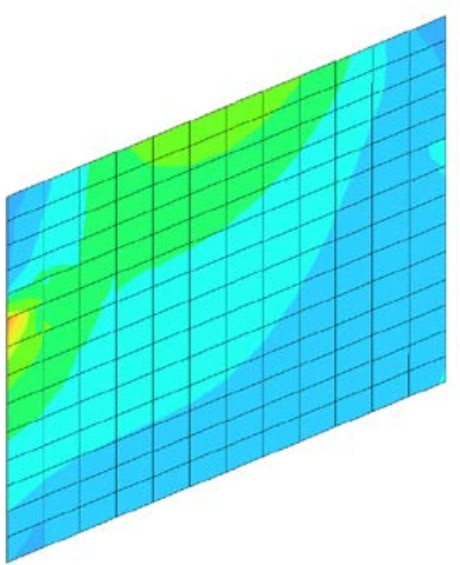

M1-ISE-EVO

b) $\sigma_{z z}\left(\mathrm{~N} / \mathrm{m}^{2}\right)-$ Tensões normais $-5^{\circ}$ Pavimento

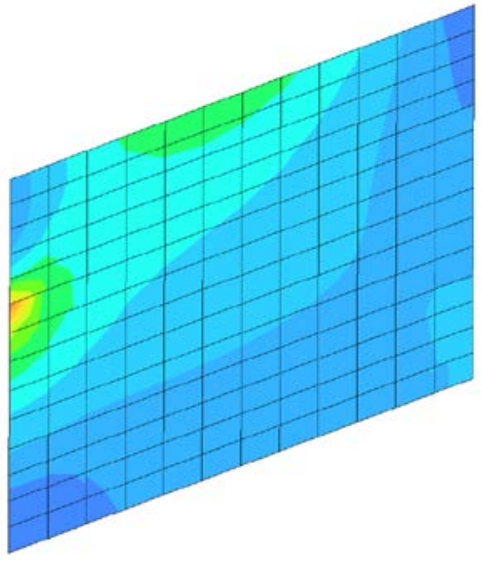

REF-AP

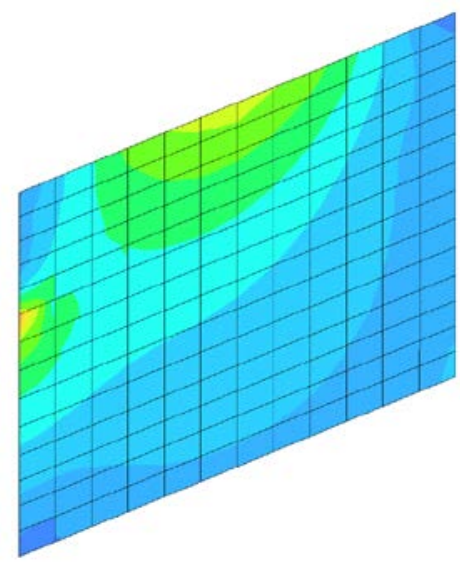

M1-ISE-EVO

c) $\sigma_{\mathrm{zz}}\left(\mathrm{N} / \mathrm{m}^{2}\right)$ - Tensões normais $-7^{\circ}$ Pavimento

Figura $4.13-\sigma_{z z}\left(\mathrm{~N} / \mathrm{m}^{2}\right)$ - Tensões normais - PY $1-3^{\circ}, 5^{\circ}$ e $7^{\circ}$ Pavimentos 
A análise da parede PY1 indica que ainda no $3^{\circ}$ piso do edifício ocorrem diferenças significativas no fluxo de tensões de compressão entre os modelos com e sem consideração da ISE. No $5^{\circ}$ pavimento o modelo com o uso da ISE apresenta uma distribuição mais uniforme, em relação ao que ocorre no $3^{\circ}$ e $1^{\circ}$ pavimentos (mostrados anteriormente na Figura 4.8), mas a intensidade da tensão de compressão ainda se difere da obtida pelo modelo de referência. Contudo, no $7^{\circ}$ piso os fluxos das tensões entre os dois modelos são similares, indicando que neste elemento estrutural e neste pavimento a influência da interação solo-estrutura é praticamente nula.

A análise da Figura 4.12 e da Figura 4.18 sugere que a distribuição de tensões no modelo com o emprego da ISE se aproxima do modelo de referência, à medida que a análise evolui para os pavimentos superiores. Observa-se que no $2^{\circ}$ e no $3^{\circ}$ pavimentos ainda ocorrem diferenças perceptíveis. Essa diferença reduz nos pavimentos seguintes ( $4^{\circ}$ ao $5^{\circ}$ pavimento). A partir do $6^{\circ}$ pavimento os dois modelos apresentam fluxo de tensões similares. Os resultados indicam que a influência da ISE vai reduzindo de forma gradativa nos pavimentos superiores.

Outro aspecto relevante é a percepção da ocorrência de uniformização das tensões de compressão nas paredes nos pavimentos superiores nos modelos que consideram a ISE. A homogeneização das tensões normais ocorre gradativamente. Essa hipótese pode ser verificada por meio da avaliação do coeficiente de variação das tensões nas paredes, “ $C V_{\sigma}$ ”, nos demais pisos da superestrutura. A Tabela 4.9 mostra o coeficiente de variação das tensões de compressão nos elementos do modelo M2-ISE-EVO nos oitos pavimentos da estrutura.

Os resultados nos modelos M1-ISE-EVO e M3-ISE-EVO apresentam desempenho similar aos apresentados pela Tabela 4.9 (com pequenas variações de intensidade dos coeficientes). Esses resultados são mostrados no Apêndice B. A Tabela 4.9 mostra que os coeficientes de variação das tensões normais nas paredes da estrutura são nitidamente superiores na base do $1^{\circ}$ pavimento. 
Tabela 4.9-CV - Tensões normais - Pavimentos - Modelo M2-ISE-EVO

\begin{tabular}{|c|c|c|c|c|c|c|c|c|}
\hline \multicolumn{9}{|c|}{$C V_{\sigma}$ - Tensões Normais nas paredes } \\
\hline \multirow{2}{*}{ Parede } & \multicolumn{8}{|c|}{ Pavimento } \\
\hline & 10 & 20 & 30 & 40 & 50 & 60 & 70 & 80 \\
\hline PX1 & $21,52 \%$ & $7,35 \%$ & $3,99 \%$ & $3,62 \%$ & $4,57 \%$ & $6,07 \%$ & $8,38 \%$ & $14,52 \%$ \\
\hline PX2 & $35,33 \%$ & $12,45 \%$ & $5,10 \%$ & $8,50 \%$ & $12,76 \%$ & $16,98 \%$ & $23,06 \%$ & $39,02 \%$ \\
\hline PX3 & $6,04 \%$ & $6,57 \%$ & $4,92 \%$ & $3,28 \%$ & $2,80 \%$ & $2,65 \%$ & $2,83 \%$ & $6,30 \%$ \\
\hline $\mathrm{PX} 4$ & $23,05 \%$ & $4,51 \%$ & $1,77 \%$ & $2,50 \%$ & $3,23 \%$ & $3,68 \%$ & $4,27 \%$ & $8,22 \%$ \\
\hline PX5 & $41,27 \%$ & $3,36 \%$ & $5,77 \%$ & $8,67 \%$ & $9,72 \%$ & $10,34 \%$ & $11,59 \%$ & $15,53 \%$ \\
\hline PX6 & $35,42 \%$ & $7,28 \%$ & $8,43 \%$ & $11,39 \%$ & $12,76 \%$ & $13,71 \%$ & $15,38 \%$ & $20,02 \%$ \\
\hline PX7 & $19,81 \%$ & $13,55 \%$ & $6,14 \%$ & $7,35 \%$ & $9,46 \%$ & $11,66 \%$ & $15,24 \%$ & $24,43 \%$ \\
\hline PX8 & $25,69 \%$ & $13,85 \%$ & $4,49 \%$ & $6,99 \%$ & $7,27 \%$ & $7,85 \%$ & $9,24 \%$ & $14,27 \%$ \\
\hline PX9 & $19,82 \%$ & $12,64 \%$ & $5,88 \%$ & $8,94 \%$ & $9,20 \%$ & $9,37 \%$ & $10,24 \%$ & $15,00 \%$ \\
\hline PX10 & $17,69 \%$ & $10,20 \%$ & $7,26 \%$ & $10,00 \%$ & $12,47 \%$ & $14,61 \%$ & $18,02 \%$ & $27,52 \%$ \\
\hline PY1 & $52,18 \%$ & $22,50 \%$ & $10,52 \%$ & $7,18 \%$ & $6,94 \%$ & $7,93 \%$ & $10,27 \%$ & $14,80 \%$ \\
\hline PY2 & $20,74 \%$ & $24,22 \%$ & $20,78 \%$ & $16,46 \%$ & $13,26 \%$ & $11,08 \%$ & $9,88 \%$ & $11,46 \%$ \\
\hline PY3 & $23,20 \%$ & $8,23 \%$ & $7,62 \%$ & $7,60 \%$ & $7,50 \%$ & $7,30 \%$ & $7,02 \%$ & $5,87 \%$ \\
\hline PY4 & $29,96 \%$ & $4,16 \%$ & $0,63 \%$ & $0,39 \%$ & $0,46 \%$ & $0,52 \%$ & $0,77 \%$ & $2,26 \%$ \\
\hline PY5 & $83,16 \%$ & $38,35 \%$ & $24,31 \%$ & $18,61 \%$ & $17,46 \%$ & $18,89 \%$ & $21,70 \%$ & $22,20 \%$ \\
\hline PY6 & $7,90 \%$ & $4,52 \%$ & $3,80 \%$ & $2,67 \%$ & $2,77 \%$ & $4,35 \%$ & $7,66 \%$ & $17,22 \%$ \\
\hline PY7 & $79,42 \%$ & $45,74 \%$ & $30,73 \%$ & $23,10 \%$ & $18,96 \%$ & $16,80 \%$ & $15,64 \%$ & $13,83 \%$ \\
\hline PY8 & $9,39 \%$ & $6,12 \%$ & $4,92 \%$ & $3,72 \%$ & $2,90 \%$ & $2,44 \%$ & $2,41 \%$ & $4,06 \%$ \\
\hline PY9 & $71,77 \%$ & $40,13 \%$ & $30,83 \%$ & $24,99 \%$ & $21,10 \%$ & $18,49 \%$ & $16,56 \%$ & $12,54 \%$ \\
\hline PY10 & $78,02 \%$ & $44,89 \%$ & $29,69 \%$ & $22,03 \%$ & $18,09 \%$ & $16,10 \%$ & $15,06 \%$ & $13,46 \%$ \\
\hline PY11 & $2,72 \%$ & $0,79 \%$ & $1,52 \%$ & $1,96 \%$ & $2,47 \%$ & $3,37 \%$ & $5,48 \%$ & $14,32 \%$ \\
\hline PY12 & $12,00 \%$ & $11,79 \%$ & $11,50 \%$ & $11,92 \%$ & $12,55 \%$ & $13,78 \%$ & $16,53 \%$ & $23,38 \%$ \\
\hline PY13 & $83,81 \%$ & $37,13 \%$ & $24,76 \%$ & $20,23 \%$ & $19,24 \%$ & $20,12 \%$ & $22,07 \%$ & $21,86 \%$ \\
\hline PY14 & $20,64 \%$ & $1,00 \%$ & $0,68 \%$ & $0,31 \%$ & $1,10 \%$ & $2,11 \%$ & $3,97 \%$ & $8,90 \%$ \\
\hline PY15 & $46,44 \%$ & $19,63 \%$ & $13,45 \%$ & $12,48 \%$ & $12,23 \%$ & $12,26 \%$ & $13,20 \%$ & $16,60 \%$ \\
\hline PY16 & $17,41 \%$ & $7,61 \%$ & $12,14 \%$ & $11,89 \%$ & $11,22 \%$ & $10,52 \%$ & $9,78 \%$ & $9,76 \%$ \\
\hline
\end{tabular}

A maioria dos elementos apresenta redução progressiva do coeficiente de variação das tensões ao longo da altura, indicando a tendência de uniformização das tensões de compressão nos níveis superiores. A parede PY9, por exemplo, em virtude do seu comprimento apresenta uma grande variação na distribuição de tensões de compressão ao longo de sua maior dimensão horizontal. Observar-se que este elemento apresenta um coeficiente de variação das tensões de compressão de $72 \%$ no $1^{\circ}$ pavimento e esse valor reduz gradativamente ao longo dos pisos superiores chegando a $12,54 \%$ no $8^{\circ}$ pavimento.

Alguns elementos apresentam valores inferiores do coeficiente de variação nos pisos intermediários, com um aumento do coeficiente de variação nos pavimentos superiores. Contudo, no $8^{\circ}$ pavimento esses ainda são menores dos que os apresentados na base do edifício. A explicação para este fato é a aproximação do modelo com a consideração da ISE com a 
hipótese de apoios rígidos nos níveis superiores. Nos pisos superiores as ações aplicadas no topo das paredes possuem diferentes intensidades devido à distribuição de cargas das lajes nos pavimentos. Desta maneira a uniformização das tensões nos últimos pisos do edifício ainda é reduzida, até para o caso da estrutura sobre apoios rígidos.

Essa afirmação pode ser esclarecida por meio da comparação das soluções mostradas na Figura 4.14, que exibe os gráficos do coeficiente de variação das tensões normais em alguns elementos da estrutura ao longo dos níveis da edificação, confrontado os resultados entre os modelos com e sem o uso da ISE.

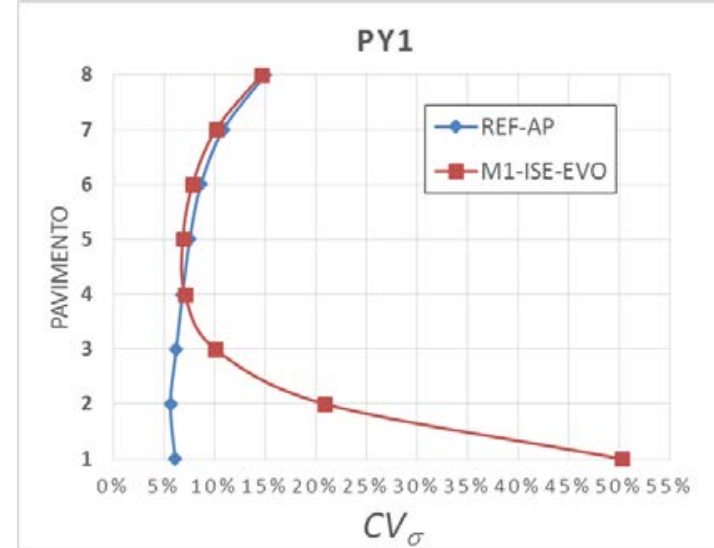

a) Parede PY1 - Modelo M1-ISE-EVO

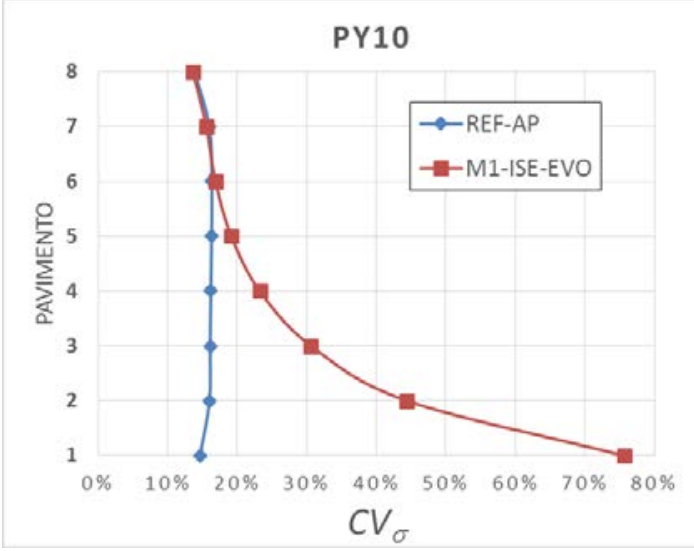

c) Parede PY10 - Modelo M1-ISE-EVO

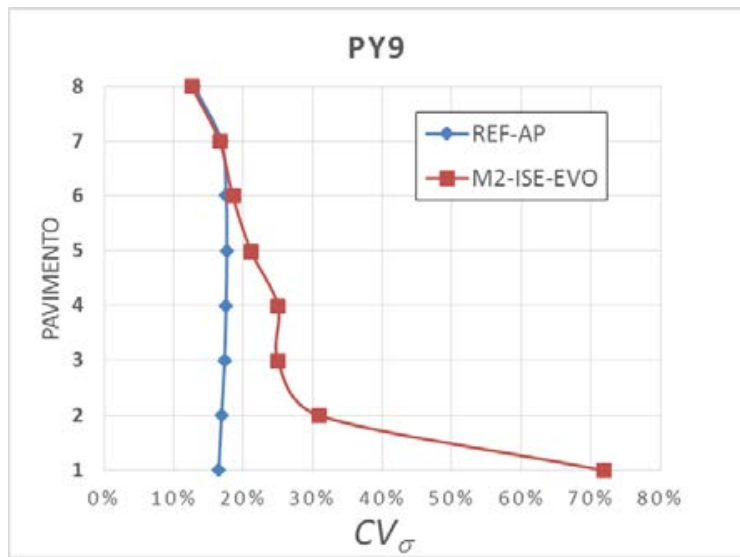

b) Parede PY9 - Modelo M2-ISE-EVO

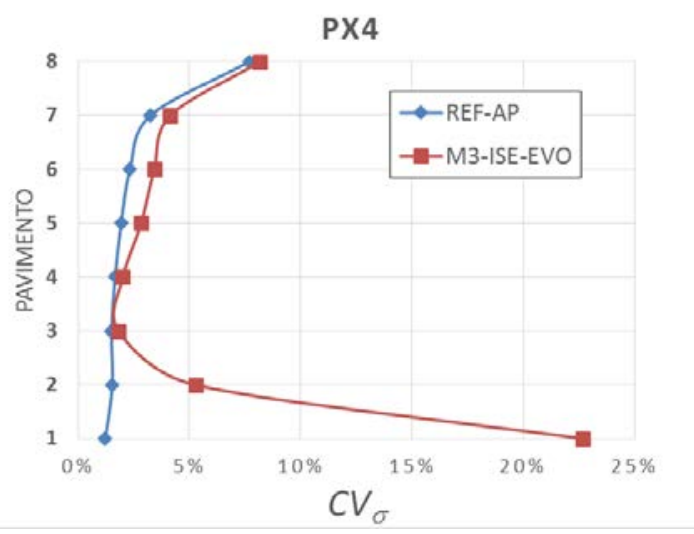

d) Parede PX4 - Modelos M3-ISE-EVO

Figura $4.14-C V_{\sigma}$ - Coeficiente de variação das tensões normais

Os gráficos da Figura 4.14 mostram que o coeficiente de variação das tensões de compressão reduz conforme a região de análise se distancia da base da estrutura, indicando a uniformização das tensões nos elementos superiores. O comportamento é o inverso do que ocorre nos modelos convencionais (Apoio rígidos). Nos modelos convencionais observa-se pelos gráficos da Figura 4.14 que os coeficientes de variação das tensões são superiores nos últimos pavimentos. 
Essa análise de resultados reforça os aspectos conclusivos já indicados neste capítulo, de que o efeito da interação solo-estrutura é superior na base da estrutura e vai reduzindo a sua influência nos pavimentos superiores, como esperado.

\subsection{ANÁLISE DAS AÇÕES EVOLUTIVAS}

As análises realizadas nos itens anteriores do presente capítulo consideraram a atuação das ações na estrutura e a construção por fases, como já descrito no capítulo 3. Esse procedimento não é usual, em virtude do surgimento de dificuldades na confecção de um modelo numérico que possa contemplar a construção da geometria do modelo em etapas e os procedimentos numéricos na importação das configurações deformadas fase a fase no modelo.

A hipótese levantada é que o uso do procedimento das ações sequenciais pudesse reduzir o efeito da interação solo-estrutura. Este item avalia a influência desse procedimento. Para este fim utiliza-se um modelo de referência idêntico ao concebido na avaliação da interação solo-estrutura, sendo que neste não são consideradas as ações sequenciais e nem a construção por etapas, com o intuito de representar os modelos usuais de interação soloestrutura.

A primeira análise é referente à alteração das cargas na estrutura por consequência da ISE, analisados por meio do coeficiente “ $\eta_{P A R}$ ”. A Figura 4.15 exibe o coeficiente de redistribuição de esforços (definido no item 4.2) ao longo dos pavimentos do edifício em algumas de suas paredes (isoladas).

Os resultados da Figura 4.15 indicam que o emprego de um modelo que contemple a sequência construtiva reduz os efeitos da interação solo-estrutura na redistribuição de cargas entre as paredes. Essa redução ocorre tanto na base do edifício como ao longo de toda a sua altura.

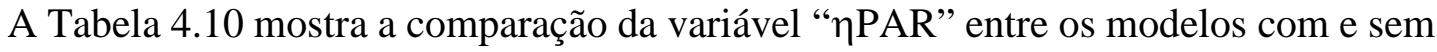
a consideração das ações evolutivas na base do primeiro pavimento. 


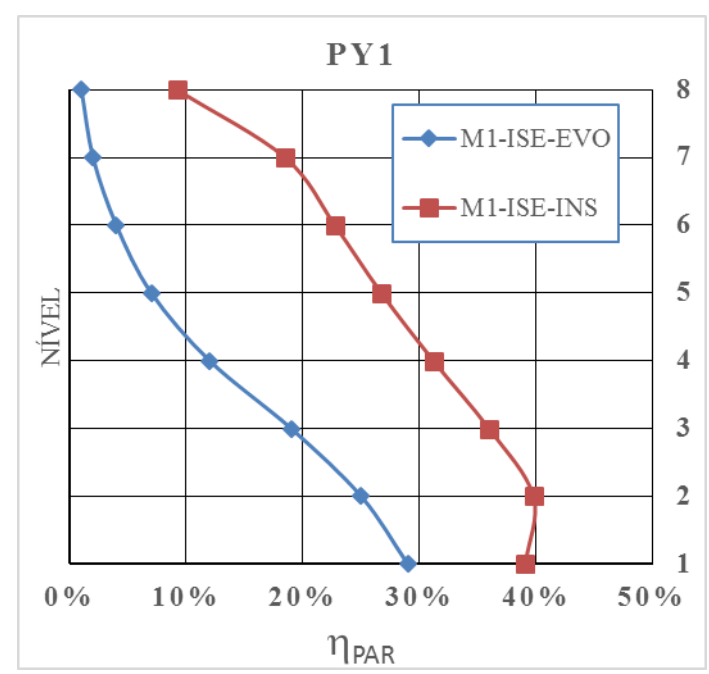

a) Parede PY1 - Modelo M1

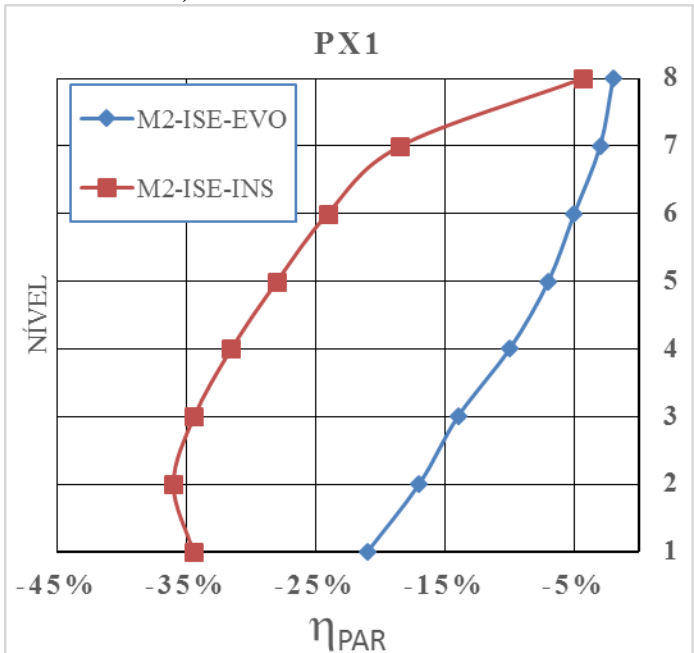

c) Parede PX1 - Modelo M2

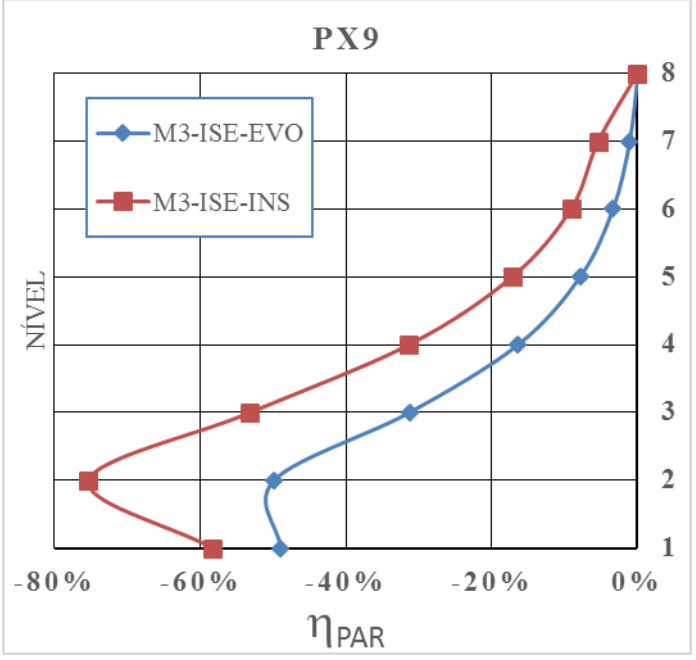

e) Parede PX9 - Modelo M3

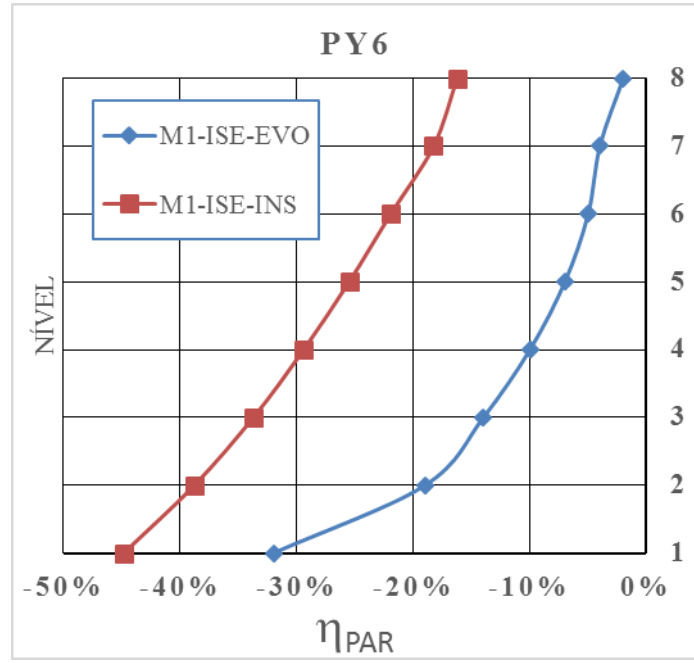

b) Parede PY6 - Modelo M1

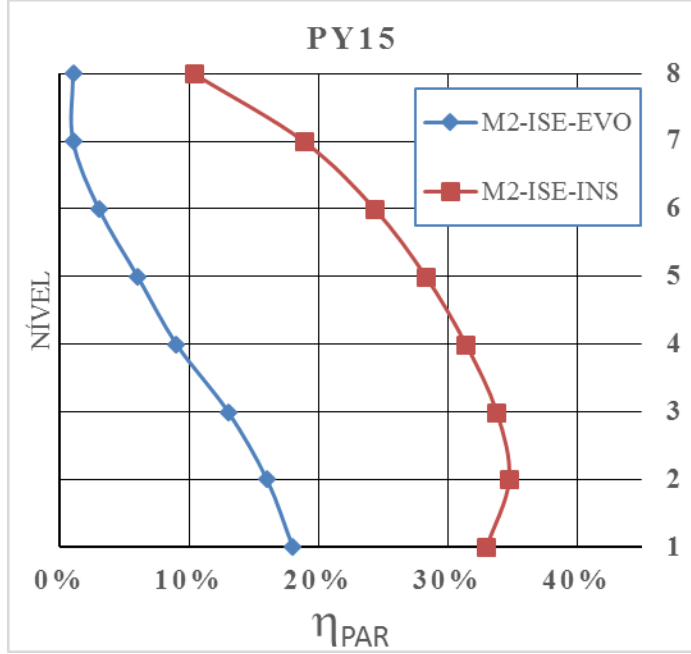

d) Parede PY15 - Modelo M2

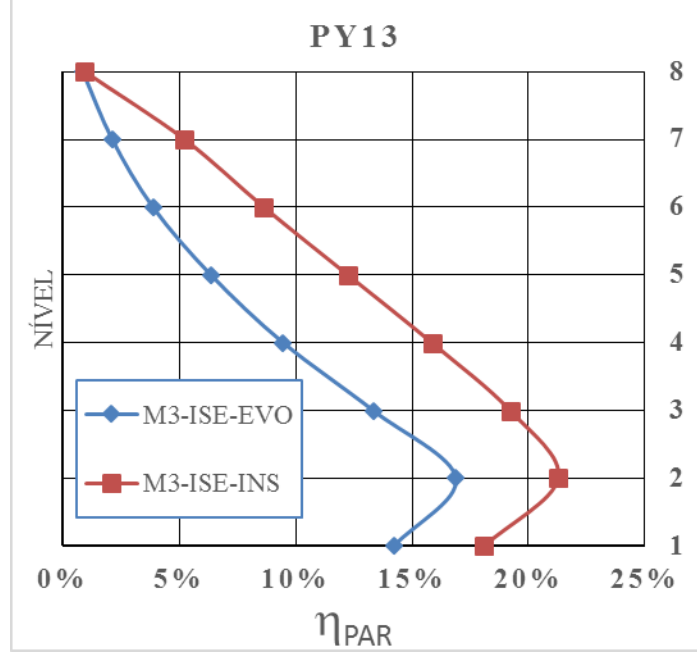

f) Parede PY13 - Modelo M3

Figura 4.15 - ךPAR - Coeficiente de distribuição de esforços - Ações instantâneas x Ação sequenciais 
Tabela 4.10 - “ $\eta_{P A R}$ ” - Ações evolutivas x Ações instantâneas

\begin{tabular}{|c|c|c|c|c|c|c|}
\hline PAREDE & M1-ISE-EVO & M1-ISE-INS & M2-ISE-EVO & M2-ISE-INS & M3-ISE-EVO & M3-ISE-INS \\
\hline PX1 & $-17 \%$ & $-28 \%$ & $-21 \%$ & $-34 \%$ & $-23 \%$ & $-36 \%$ \\
\hline PX2 & $5 \%$ & $0 \%$ & $1 \%$ & $-6 \%$ & $1 \%$ & $-7 \%$ \\
\hline PX3 & $-2 \%$ & $-2 \%$ & $1 \%$ & $1 \%$ & $1 \%$ & $0 \%$ \\
\hline PX4 & $9 \%$ & $4 \%$ & $11 \%$ & $6 \%$ & $12 \%$ & $8 \%$ \\
\hline PX5 & $-17 \%$ & $-26 \%$ & $-18 \%$ & $-28 \%$ & $-19 \%$ & $-31 \%$ \\
\hline PX6 & $-20 \%$ & $-29 \%$ & $-19 \%$ & $-27 \%$ & $-19 \%$ & $-28 \%$ \\
\hline PX7 & $6 \%$ & $6 \%$ & $13 \%$ & $11 \%$ & $14 \%$ & $11 \%$ \\
\hline PX8 & $-31 \%$ & $-42 \%$ & $-33 \%$ & $-48 \%$ & $-34 \%$ & $-51 \%$ \\
\hline PX9 & $-42 \%$ & $-53 \%$ & $-49 \%$ & $-61 \%$ & $-49 \%$ & $-62 \%$ \\
\hline PX10 & $2 \%$ & $0 \%$ & $9 \%$ & $7 \%$ & $9 \%$ & $9 \%$ \\
\hline PY1 & $29 \%$ & $39 \%$ & $32 \%$ & $42 \%$ & $33 \%$ & $44 \%$ \\
\hline PY2 & $19 \%$ & $23 \%$ & $19 \%$ & $25 \%$ & $19 \%$ & $27 \%$ \\
\hline PY3 & $0 \%$ & $7 \%$ & $-2 \%$ & $7 \%$ & $-2 \%$ & $9 \%$ \\
\hline PY4 & $-46 \%$ & $-57 \%$ & $-53 \%$ & $-63 \%$ & $-54 \%$ & $-61 \%$ \\
\hline PY5 & $23 \%$ & $24 \%$ & $26 \%$ & $27 \%$ & $28 \%$ & $31 \%$ \\
\hline PY6 & $-32 \%$ & $-45 \%$ & $-42 \%$ & $-55 \%$ & $-43 \%$ & $-56 \%$ \\
\hline PY7 & $8 \%$ & $11 \%$ & $9 \%$ & $11 \%$ & $10 \%$ & $14 \%$ \\
\hline PY8 & $-23 \%$ & $-36 \%$ & $-35 \%$ & $-50 \%$ & $-37 \%$ & $-52 \%$ \\
\hline PY9 & $-4 \%$ & $-4 \%$ & $-5 \%$ & $-7 \%$ & $-5 \%$ & $-9 \%$ \\
\hline PY10 & $2 \%$ & $5 \%$ & $2 \%$ & $6 \%$ & $4 \%$ & $8 \%$ \\
\hline PY11 & $-10 \%$ & $-28 \%$ & $-16 \%$ & $-40 \%$ & $-16 \%$ & $-42 \%$ \\
\hline PY12 & $-13 \%$ & $-28 \%$ & $-18 \%$ & $-35 \%$ & $-20 \%$ & $-37 \%$ \\
\hline PY13 & $10 \%$ & $14 \%$ & $13 \%$ & $18 \%$ & $14 \%$ & $19 \%$ \\
\hline PY14 & $-48 \%$ & $-62 \%$ & $-58 \%$ & $-68 \%$ & $-60 \%$ & $-70 \%$ \\
\hline PY15 & $14 \%$ & $28 \%$ & $18 \%$ & $33 \%$ & $19 \%$ & $34 \%$ \\
\hline PY16 & $20 \%$ & $23 \%$ & $21 \%$ & $25 \%$ & $21 \%$ & $27 \%$ \\
\hline
\end{tabular}

A aplicação das ações sequencias reduz os efeitos da interação solo-estrutura nas cargas presentes na base das paredes. Ambas as análises apresentam reduções com valores semelhantes. Os resultados indicam diminuição da influência da ISE na redistribuição de esforços, mas não foi possível relacionar a tendência desta redução com a rigidez do solo.

Similarmente ao item anterior é avaliada a distribuição das tensões normais nas paredes com e sem a consideração da sequência construtiva. A Figura 4.16 exibe o estudo comparativo do fluxo de tensões na PY15 entre os modelos com o emprego da ISE, sem e com o uso das ações evolutivas, em diversos pavimentos do modelo M2. 
$-.3 \mathrm{E} 7$
$-.272 \mathrm{E} 7$
$-.244 \mathrm{E}$
$-.217 \mathrm{E}$
$-.189 \mathrm{E}$
$-.161 \mathrm{E}$
$-.133 \mathrm{E}$
$-.106 \mathrm{E}$
$-.778 \mathrm{E}$
$-.5 \mathrm{E} 6$

$\Delta \mathrm{Y}$
$\mathrm{Y}$

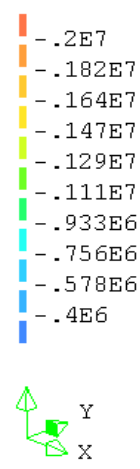

$-.2 \mathrm{E} 7$

$-.2 \mathrm{E} 7$
$-.179 \mathrm{E} 7$

$-.158 \mathrm{E}$ ?

$-.137 \mathrm{E} 7$

$-.116 \mathrm{E} 7$

$-.944 \mathrm{E} 6$

$-.733 \mathrm{E} 6$

$-.522 \mathrm{E} 6$

$-.311 \mathrm{E} 6$

$-.1 \mathrm{E} 6$

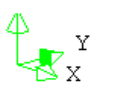

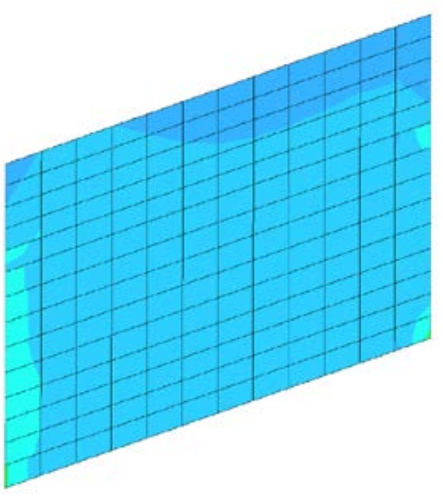

REF-AP

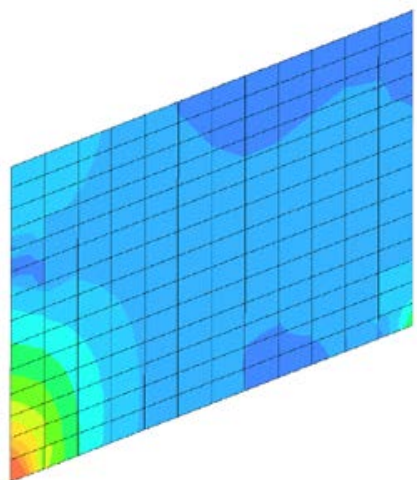

M2-ISE-EVO

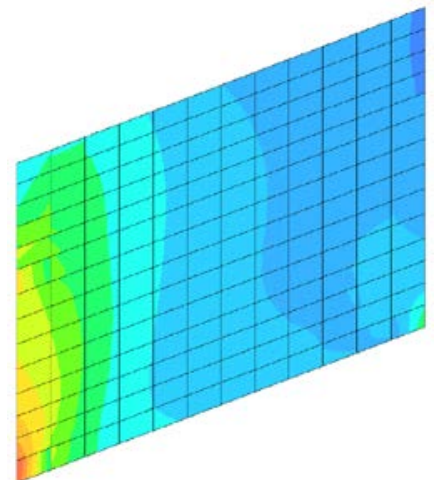

M2-ISE-INS

a) $\sigma_{\mathrm{zz}}\left(\mathrm{N} / \mathrm{m}^{2}\right)$ - Tensões normais $-1^{\circ}$ pavimento

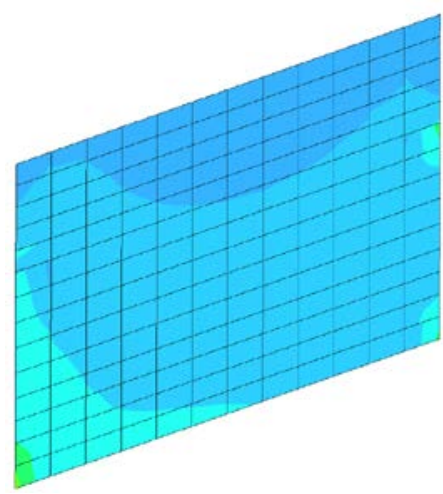

REF-AP

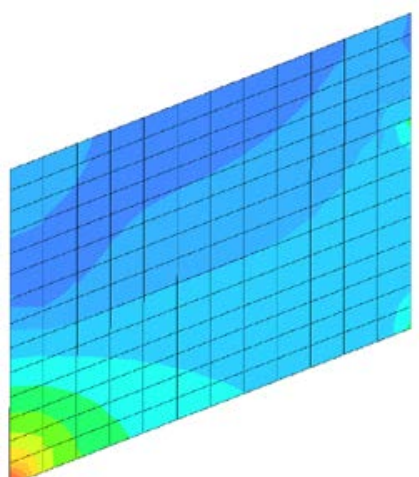

M2-ISE-EVO

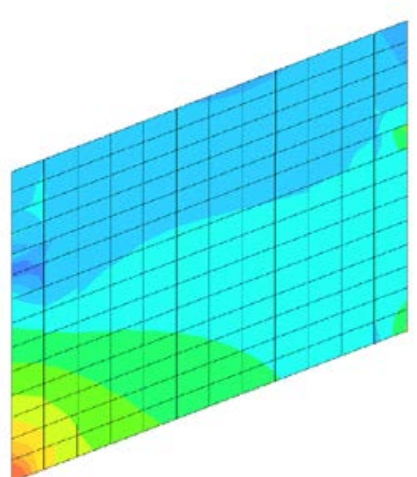

M2-ISE-INS

b) $\sigma_{\mathrm{zz}}\left(\mathrm{N} / \mathrm{m}^{2}\right)-$ Tensões normais $-3^{\circ}$ pavimento

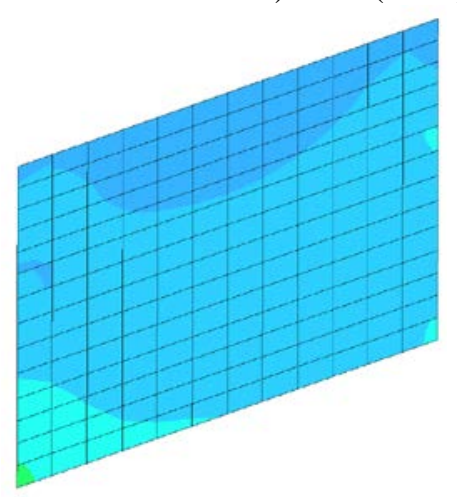

REF-AP

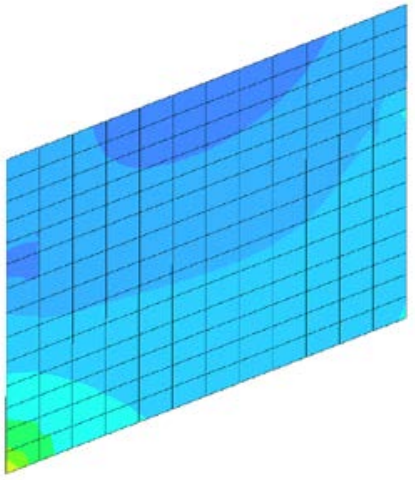

M2-ISE-EVO

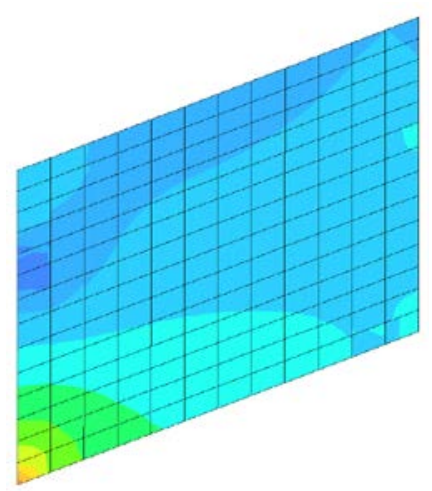

M2-ISE-INS

c) $\sigma_{\mathrm{zz}}\left(\mathrm{N} / \mathrm{m}^{2}\right)$ - Tensões normais $-5^{\circ}$ pavimento

Figura $4.16-\sigma_{\mathrm{zz}}\left(\mathrm{N} / \mathrm{m}^{2}\right)$ - Tensões normais - Parede PY15 - Ações sequenciais x Ações evolutivas

Além de influenciar na redução de valores finais de esforços, a aplicação das ações evolutivas permite a uniformização das tensões de forma mais efetiva nos pavimentos superiores. Os resultados expostos na Figura 4.16 mostram, por exemplo, que no quinto piso da parede PY15 a distribuição das tensões já apresenta semelhanças com o modelo de referência. Este fato não ocorre com o uso das ações instantâneas, em que no $5^{\circ}$ pavimento os efeitos da interação solo-estrutura ainda são expressivos.

Essas implicações indicam que o benefício de considerar as ações evolutivas na redução na transferência de esforços é mais expressivo nos pavimentos superiores da estrutura. Essa afirmação pode ser reforçada pela análise da Figura 4.17, que mostra a distribuição do 
coeficiente de variação das tensões normais em alguns elementos da estrutura ao longo da altura do edifício.

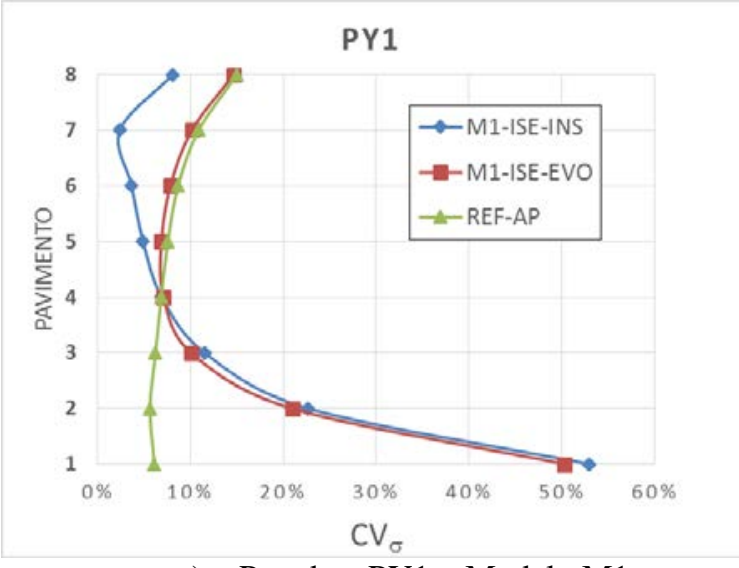

a) Parede - PY1 - Modelo M1

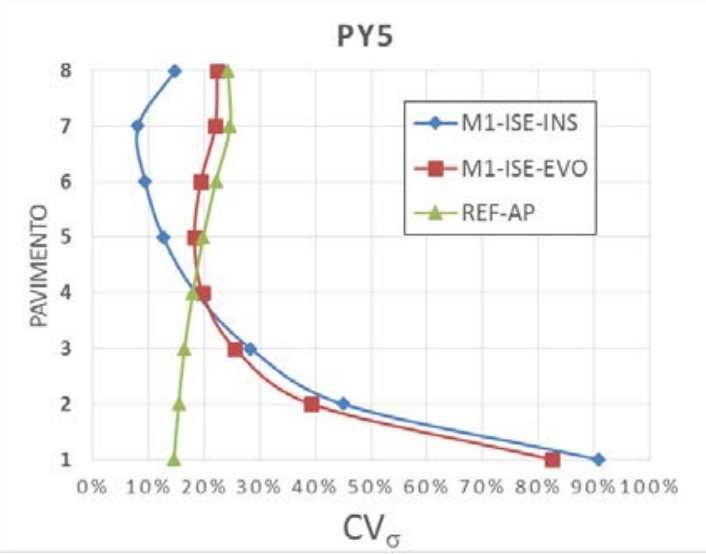

c) Parede - PY5 - Modelo M1

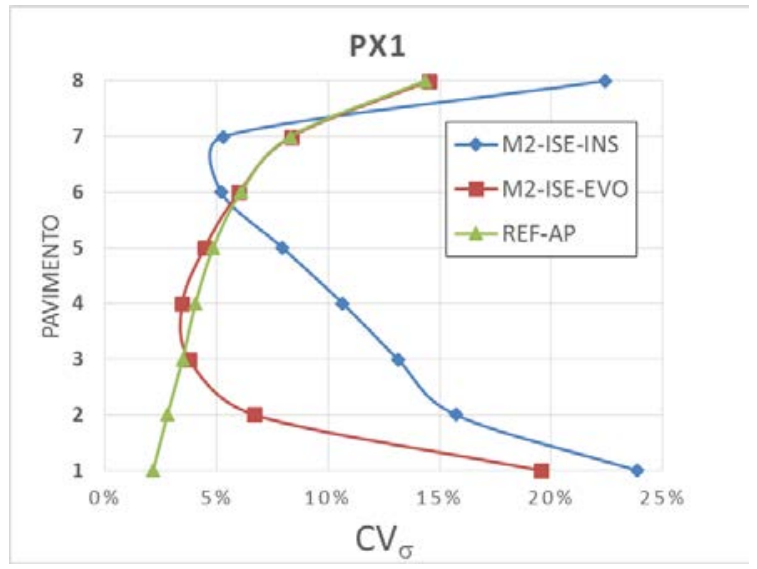

b) Parede - PX1 - Modelo M2

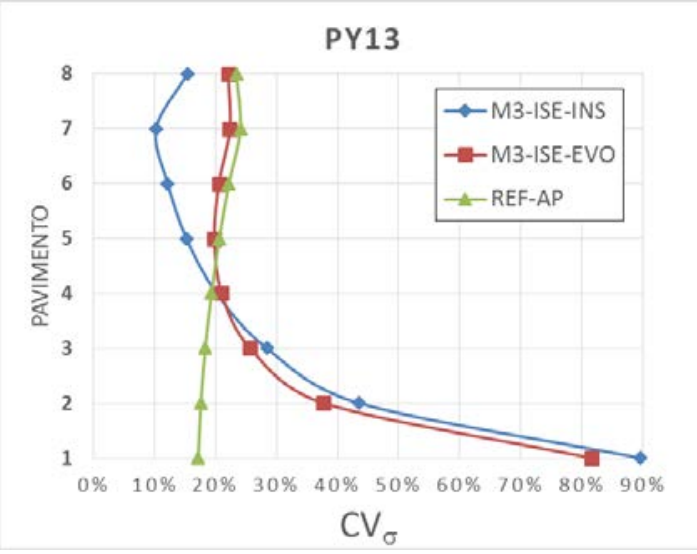

d) Parede - PY13 - Modelo M3

Figura $4.17-C V_{\sigma}$ - Coeficiente de variação das tensões normais - Ações instantâneas x Ações evolutivas

A variação das tensões normais nas paredes mostrada na Figura 4.17, indica que o emprego das ações evolutivas reduz a influência da ISE. Os modelos que consideram as ações evolutivas apresentam, na ampla maioria dos elementos estruturais, no $4^{\circ}$ ou $5^{\circ}$ pavimento comportamento semelhante ao modelo de referência, fato este que não ocorre quando se considera as ações aplicadas de modo instantâneo.

\subsection{ASPECTOS CONCLUSIVOS SOBRE O COMPORTAMENTO DA ISE EM EDIFÍCIOS DE PAREDES}

A análise de resultados realizada indicou que o emprego da ISE altera de maneira significativa o comportamento dos elementos da superestrutura e também a distribuição da deformação no maciço do solo. Esses resultados acabam indicando que considerar apoios fixos conduz a um funcionamento distinto de quando a deformação do solo é incluída no modelo 
numérico, sendo que a aplicação da ISE é uma hipótese que tenta aproximar a solução numérica do comportamento da estrutura real.

O primeiro aspecto a ser exposto é a relação entre os recalques e a distribuição de esforços na superestrutura. Seria equivocado afirmar que a configuração dos recalques ocorre devido às cargas provenientes das paredes ou que a redistribuição de esforços nos elementos incide em virtude dos recalques diferenciais na fundação. O modo mais coerente de tratar o problema é destacar o funcionamento conjunto entre os dois meios, formando um sistema único.

A partir dessa reflexão, o que deve ser levantado é a relação entre os recalques com as alterações de esforços nas paredes, quando comparados com o modelo convencional sobre apoios fixos.

Os recalques na fundação do presente modelo são superiores no centro e inferiores na periferia, o que ocasionou que os elementos da estrutura mais próximos ao centro apresentassem um alívio de cargas em relação ao modelo convencional. Consequentemente os mais próximos à periferia obtiveram um acréscimo nessas cargas. Isso está relacionado ao fato de que as regiões internas são, em geral, mais carregadas, levando a recalques maiores e, portanto, algum alívio nas reações, ao se computar os seus efeitos.

As cargas utilizadas nas análises do item 4.2.1 são reações totais, mas a redistribuição dessas cargas não ocorre de maneira uniforme o que pôde ser observado pelo fluxo de tensões nas paredes da estrutura. A configuração do fluxo das tensões normais apresenta a mesma linha de tendência proporcionada pela distribuição de cargas, ocorrendo concentração de tensões nos pontos onde os recalques são inferiores e, similarmente nas regiões onde os recalques são maiores, apresentam uma tendência de alívio de tensões. Esse comportamento pode ser observado por meio das Figura 4.18 e Figura 4.19, que ilustram a relação entre o fluxo das tensões normais e o deslocamento vertical respectivamente nas paredes PY11 e PY7 no $1^{\circ}$ pavimento, ambas no modelo M3-ISE-EVO. 

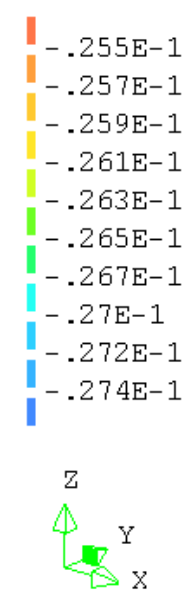

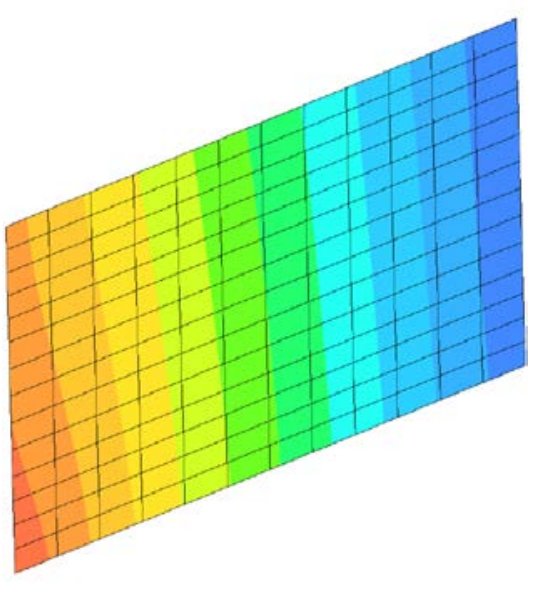

a) $\mathrm{u}_{\mathrm{z}}(\mathrm{m})$ - Deslocamento vertical
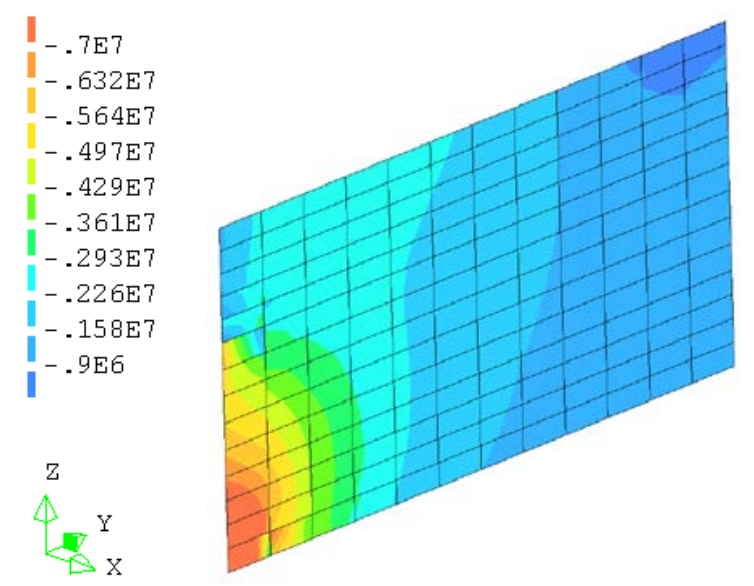

b) $\sigma_{\mathrm{zz}}\left(\mathrm{N} / \mathrm{m}^{2}\right)$ - Tensões Normais

Figura 4.18 - Parede PY11 - Deslocamento vertical e Tensões normais de compressão - $1^{\circ}$ Pavimento - Modelo M3-ISE-EVO
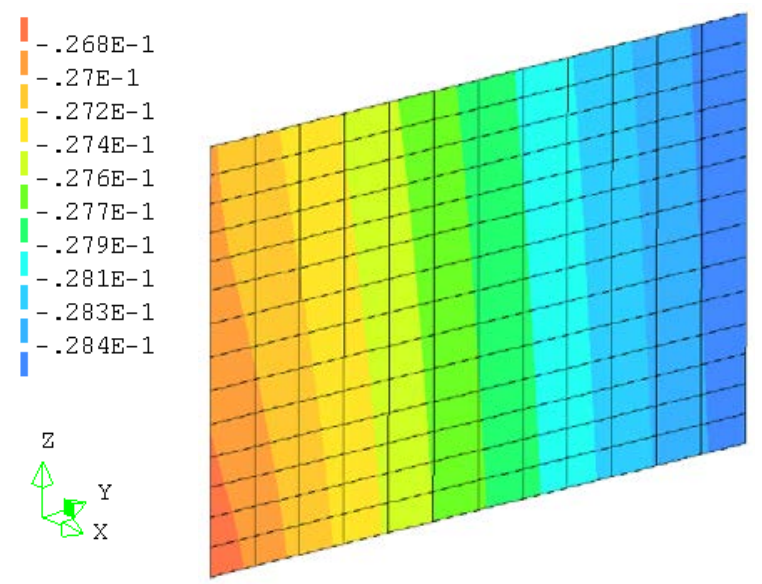

a) $\mathrm{u}_{\mathrm{z}}(\mathrm{m})$ - Deslocamento vertical
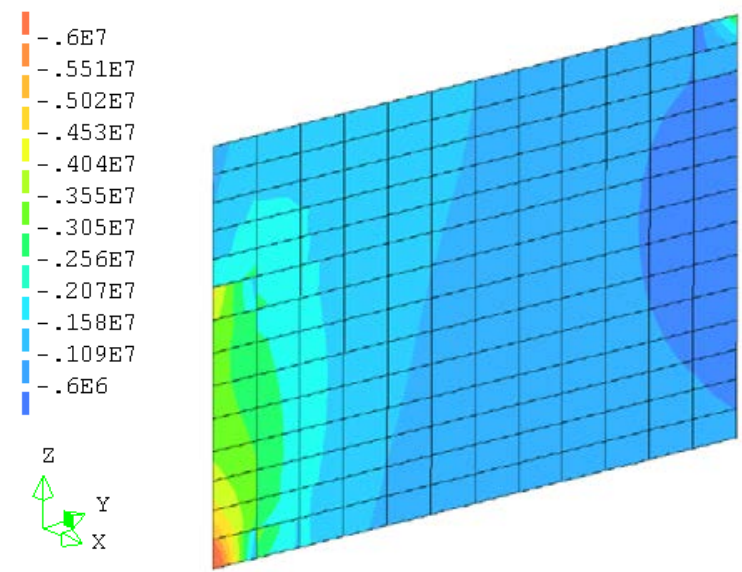

b) $\sigma_{\mathrm{zz}}\left(\mathrm{N} / \mathrm{m}^{2}\right)$ - Tensões Normais

Figura 4.19 - Parede PY7 - Deslocamento vertical e Tensões normais de compressão - $1^{\circ}$ Pavimento - Modelo M3-ISE-EVO

A Figura 4.18 mostra que as regiões com os menores recalques são as que apresentam maiores concentração de tensões de compressão na parede. O mesmo comportamento pode ser observado na Figura 4.19. Esses resultados indicam que a alteração do fluxo de tensões normais de compressão nas paredes apresenta relação direta com a deformação vertical. As regiões com menores recalques, tendem a ter um acréscimo de tensões de compressão enquanto regiões com maiores recalques tendem a ter um alívio dessas tensões.

A perda de homogeneidade das tensões nas paredes é diretamente ligada ao padrão dos recalques ocorridos em sua base. O acréscimo tende a ocorrer em paredes que possuem deslocamentos verticais de seus pontos de apoio inferiores aos demais elementos da estrutura. De forma similar, paredes localizadas em regiões com recalques superiores em relação ao restante da estrutura, tendem a sofrer alívio das tensões de compressão. 
O efeito de grupo tem um papel importante na configuração do fluxo das tensões normais da ISE. Alguns grupos de paredes apresentam comportamento conjunto, não devendo ser analisado como paredes isoladas. Esta influência pode ser observada no grupo de parede G5, constituídos pelas paredes PY1 e PX7 (Figura 4.20).

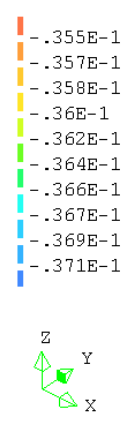

a) $\mathrm{u}_{\mathrm{z}}(\mathrm{m})$ - Deslocamento vertical - PY1+PX7

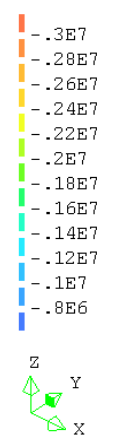

b) $\sigma_{\mathrm{zz}}\left(\mathrm{N} / \mathrm{m}^{2}\right)$ - Tensões Normais (M3-ISE$\mathrm{EVO})-\mathrm{PY} 1+\mathrm{PX} 7$

Figura 4.20 - Comportamento de grupo de parede

Os recalques na PX7 são superiores na extremidade direita da parede, o que poderia indicar um possível acréscimo de tensões de compressão em sua extremidade esquerda. A distribuição na PX7 ocorre inversamente, com acréscimo de tensões na região de maior deslocamento vertical. Avaliando-se a parede PX7 em conjunto com a PY1, pode-se observar que o alívio das tensões na região de maior recalque da parede PY1 afeta a distribuição na parede PX7. O comportamento de grupo fica mais evidente em elementos de pequeno comprimento interligados em paredes com comprimento maior.

Os resultados do item 4.2.2 mostram que a distribuição das tensões de compressão nas paredes começa a apresentar uma uniformidade crescente nos pavimentos superiores, assemelhando-se ao modelo de referência. Esse desempenho pode ser elucidado por meio da análise da Figura 4.21, que exibe o deslocamento vertical e as tensões de compressão de pontos da parede $\mathrm{PY} 7$ no $3^{\circ}$ e $5^{\circ}$ pavimentos. 


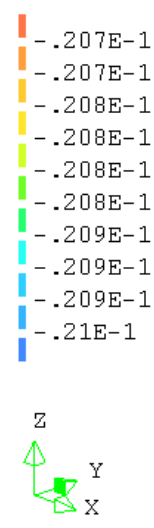

a) $\mathrm{u}_{\mathrm{z}}(\mathrm{m})$ - Deslocamento vertical - PY7 - $3^{\circ}$ pavimento - M3-ISE-EVO

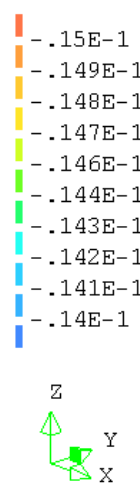

c) $\mathrm{u}_{\mathrm{z}}(\mathrm{m})$ - Deslocamento vertical - PY7 - $5^{\circ}$ pavimento - M3-ISE-EVO

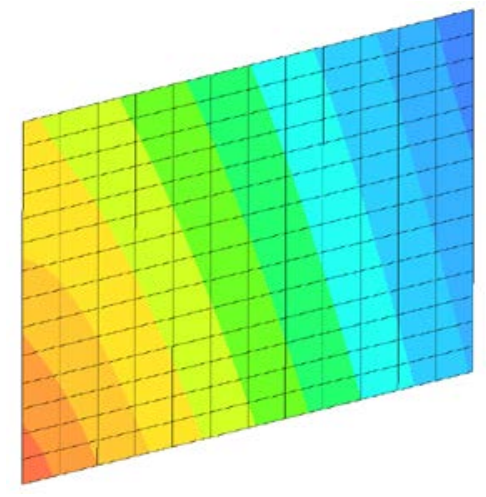

$-.3 \mathrm{E} 7$

$-.268 \mathrm{E} 7$

$-.235 \mathrm{E} 7$

$-.202 \mathrm{E} 7$

$-.17 \mathrm{E} 7$

$-.138 \mathrm{E} 7$

$-.105 \mathrm{E} 7$

$-.725 \mathrm{E} 6$

$-.4 \mathrm{E} 6$

z

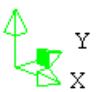

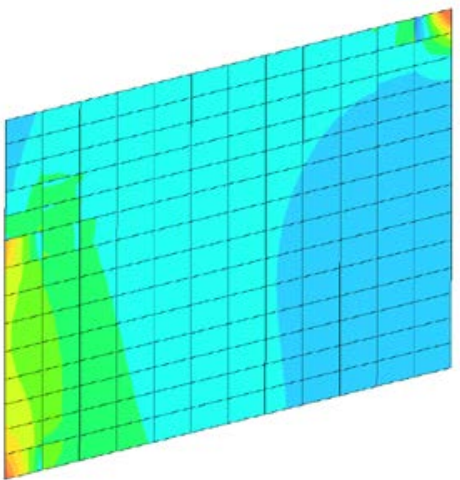

b) $\quad \sigma_{\mathrm{zz}}\left(\mathrm{N} / \mathrm{m}^{2}\right)$ - Tensões Normais - PY7 - $3^{\mathrm{o}}$ pavimento - M3-ISE-EVO
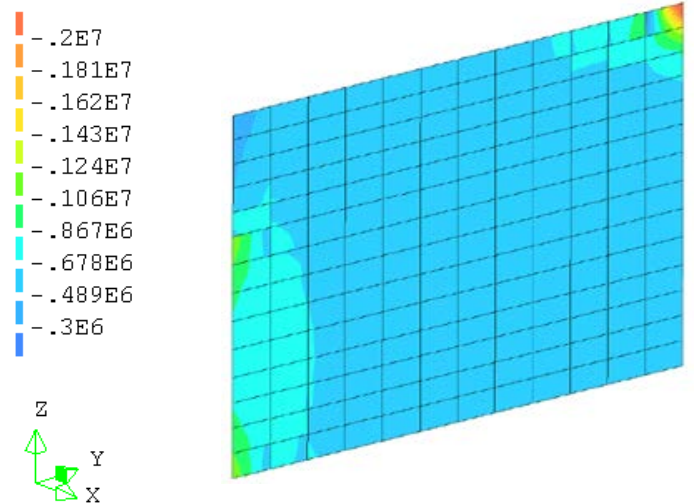

d) $\sigma_{\mathrm{zz}}\left(\mathrm{N} / \mathrm{m}^{2}\right)$ - Tensões Normais - PY7 - $5^{\circ}$ pavimento - M3-ISE-EVO

Observa-se que o deslocamento diferencial ao longo do comprimento da parede sofre uma redução gradativa nos pavimentos superiores e, como consequência, a distribuição das tensões de compressão neste elemento começa a apresentar maior uniformidade, de modo semelhante ao comportamento em modelos convencionais com apoios fixos.

Pode-se concluir que a redistribuição de cargas nas paredes mostradas no item anterior está diretamente ligada à perda de uniformidade das tensões normais que ocorre ao longo do seu comprimento. Na grande maioria das paredes, a partir do $4^{\circ}$ pavimento a diferença de tensões de compressão entre os modelos com e sem interação solo-estrutura foi menor que 15\%.

A consideração das ações evolutivas mostra que os efeitos da ISE na estrutura são menores do que aparentam como comprovado no item 4.3. A diminuição dos deslocamentos diferenciais nas paredes ao longo da construção de cada etapa da análise reduz as consequências da ISE nos pavimentos inferiores. O uso de um modelo que não considera a sequência construtiva (modelos convencionais) despreza a redução dos deslocamentos diferencias entre os modelos, deste modo superestimando os efeitos da ISE. 
O funcionamento conjunto maciço/estrutura promove alterações nos deslocamentos verticais dos pontos dos elementos. Essas alterações são as responsáveis pela modificação das tensões e governam a redistribuição das cargas das lajes dos pavimentos e nas paredes da estrutura. Para esclarecer melhor essa conclusão, a Figura 4.22 exibe a comparação do deslocamento das lajes de alguns pavimentos do modelo de referência com o modelo M1-ISEEVO.

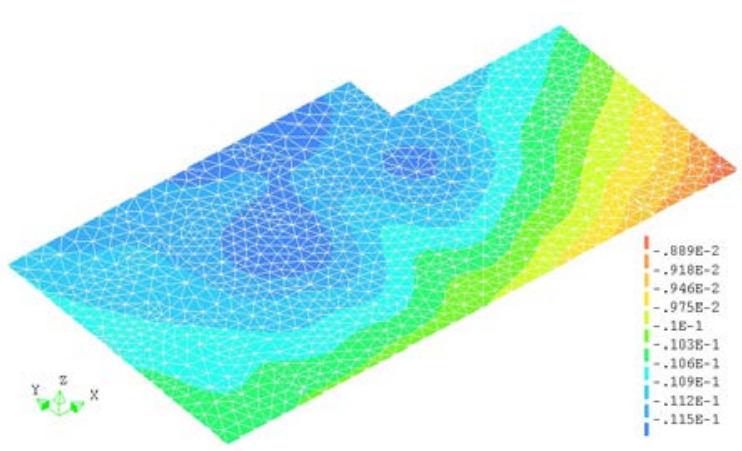

MODELO M1-ISE-EVO

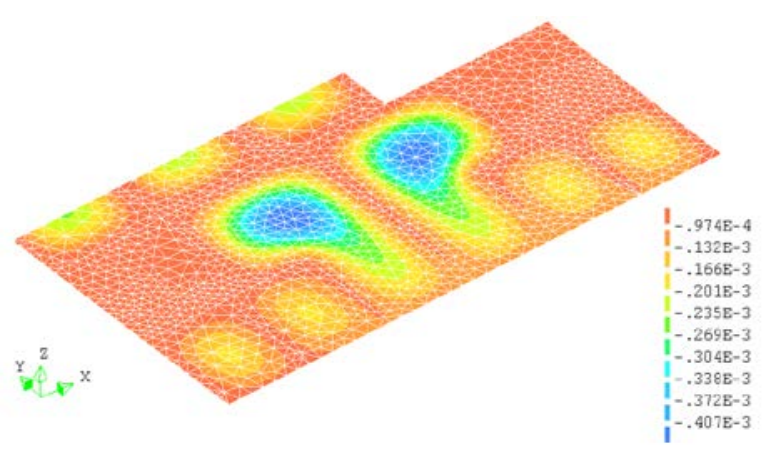

MODELO REF-AP

a) $\mathrm{u}_{\mathrm{z}}(\mathrm{m})$ - Deslocamento Vertical - Lajes $-1^{\circ} \mathrm{Pav}$.

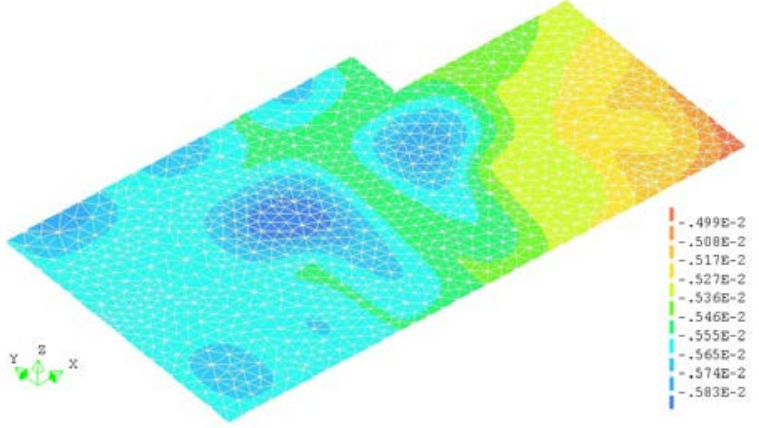

MODELO M1-ISE-EVO

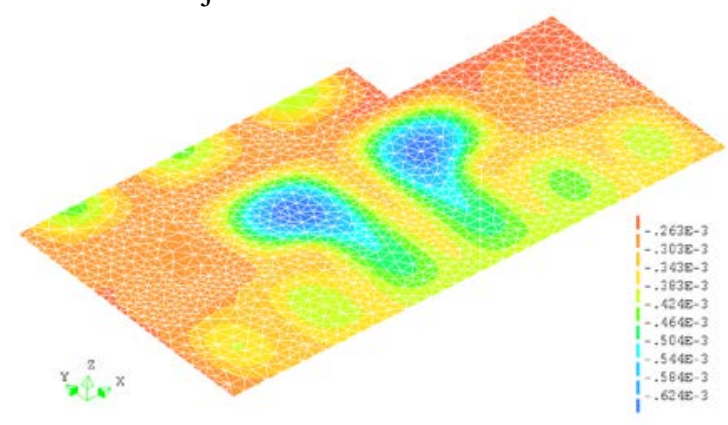

MODELO REF-AP

b) $\mathrm{u}_{\mathrm{z}}(\mathrm{m})$ - Deslocamento Vertical - Lajes $-5^{\circ}$ Pav.

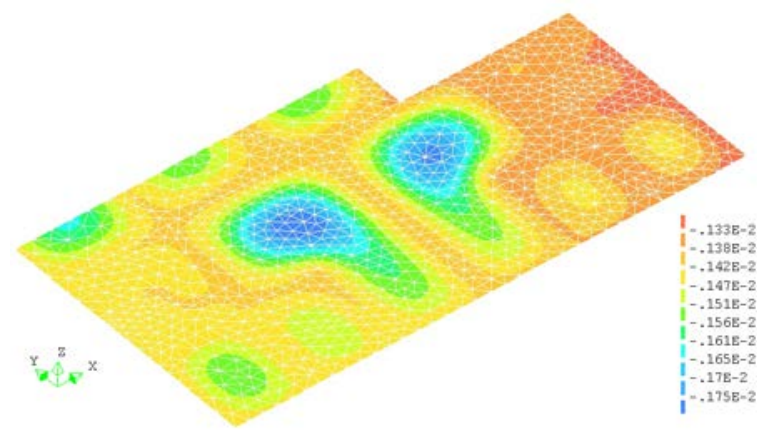

MODELO M1-ISE-EVO

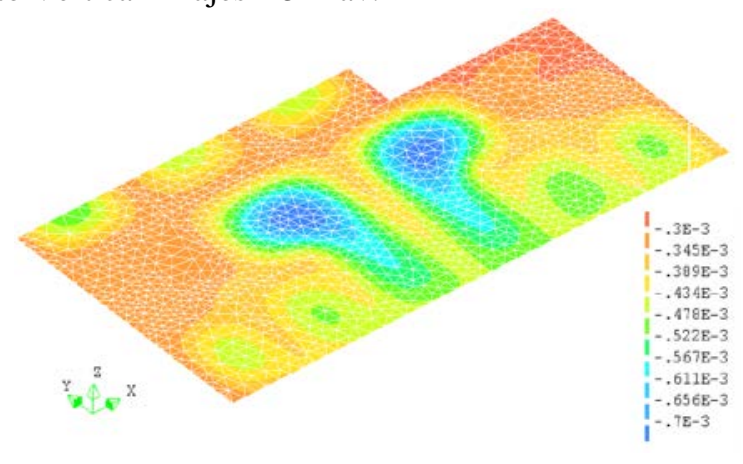

MODELO REF-AP

c) $\mathrm{u}_{\mathrm{z}}(\mathrm{m})$ - Deslocamento Vertical - Lajes $-8^{\circ}$ Pav.

Figura $4.22-\mathrm{u}_{\mathrm{z}}(\mathrm{m})$ - Modelo REF-AP x Modelo M1-ISE-EVO 
A configuração do deslocamento dos pontos das lajes expostos na Figura 4.22, apesar das diferentes intensidades, ilustra bem a hipótese sugerida. As diferentes intensidades têm relação com o referencial global, já que no modelo M1-ISE-EVO o modelo está com a consideração dos recalques na base e no modelo de referência o deslocamento na base é nulo. No $1^{\mathrm{o}}$ pavimento a configuração do deslocamento vertical da laje no modelo M1-ISE-EVO apresenta comportamento bem distante do modelo de referência (Figura 4.22-a). Nos pavimentos intermediários, exemplificado pelos $5^{\circ}$ e $8^{\circ}$ pavimentos (Figura 4.22-b e Figura 4.22-c), o deslocamento da laje começa a se aproximar gradativamente da configuração do modelo de referência. Assim sendo, a redistribuição das cargas entre os elementos nos pisos pode ser explicada pela alteração do deslocamento diferencial entre as paredes

As ações atuantes em um pavimento tendem a migrar para os elementos que possuem maior rigidez. Desta forma, elementos com menores recalques, acabam recebendo parcelas adicionais das ações atuantes nos pavimentos, em razão dos recalques superiores das paredes mais próximas.

A partir dessas observações, pode-se afirmar que o deslocamento diferencial ocorrido entre as paredes governa a migração de cargas entre esses elementos. A transferência de cargas entre os elementos é possível graças à sua interligação com as lajes e linteis, compondo um sistema hiperestático complexo, no qual o solo tem influência significativa nos pavimentos inferiores.

Nos pavimentos superiores ocorre uma redução desse deslocamento diferencial, o que acarreta similaridade entre as cargas provenientes desses pavimentos e as do modelo usual com apoios fixos. A Tabela 4.11 mostra um esquema comparativo com os principais aspectos observados entre os modelos com e sem o uso da interação solo-estrutura em edifícios de parede. 
Tabela 4.11 - Resumo comparativos - Modelo usual x ISE

\begin{tabular}{|c|c|c|}
\hline & Modelo Usual - Apoios Rígidos & Interação solo-estrutura e Ações evolutivas \\
\hline $\begin{array}{c}\text { Deslocamento } \\
\text { vertical }\end{array}$ & $\begin{array}{l}\text { - Deslocamento nulo na base - Apoios } \\
\text { rígidos. } \\
\text { - Deslocamento máximo no topo do último } \\
\text { pavimento. }\end{array}$ & $\begin{array}{l}\text { - Deslocamento maior na base - Conforme } \\
\text { recalques do maciço do solo. } \\
\text { - Deslocamento mínimo no topo do último } \\
\text { pavimento - Redução progressiva por } \\
\text { decorrência das ações evolutivas. }\end{array}$ \\
\hline $\begin{array}{r}\text { Reaç } \\
\text { pa }\end{array}$ & $\begin{array}{l}\text { - Distribuição de cargas decorrente do } \\
\text { modelo Hiperestático conforme a } \\
\text { geometria e/ ou rigidez das paredes. } \\
\text { - Proporção das reações por pavimento } \\
\text { similar. }\end{array}$ & $\begin{array}{l}\text { - Alteração na distribuição das ações } \\
\text { conforme a rigidez e posicionamento dos } \\
\text { elementos } \\
\text { - Redistribuição das ações conforme os } \\
\text { recalques na base. Elementos com maiores } \\
\text { recalques sofrem alívio nas reações finais e } \\
\text { elementos com menores recalques sofrem } \\
\text { acréscimo nas reações finais. } \\
\text { - Modificações na distribuição das reações } \\
\text { ao longo dos pavimentos. }\end{array}$ \\
\hline $\begin{array}{c}\text { Tensões } \\
\text { normais - } \\
\text { Base das } \\
\text { paredes }\end{array}$ & $\begin{array}{l}\text { - Homogeneidade das tensões normais. } \\
\text { - Presença de uma leve concetração de } \\
\text { tensões nas extremidades das paredes - } \\
\text { Teoria da elasticidade. }\end{array}$ & $\begin{array}{l}\text { - Distribuição heterogênea das tensões } \\
\text { normais. } \\
\text { - Acréscimos de tensões nas extremidades } \\
\text { com menores níveis de recalques e alívio } \\
\text { de tensões nas extremidades com maiores } \\
\text { níveis de recalque. }\end{array}$ \\
\hline $\begin{array}{c}\text { Variação das } \\
\text { tensões } \\
\text { normais }\end{array}$ & $\begin{array}{l}\text { - Homogeneidade das tensões normais. } \\
\text { - Tensões normais mais uniformes nos } \\
\text { primeiros pavimentos (baixo coeficiente de } \\
\text { variação) e menos uniforme nos últimos } \\
\text { pavimentos (médio coeficiente de } \\
\text { variação). }\end{array}$ & $\begin{array}{l}\text { - Distribuição heterogênea das tensões } \\
\text { normais. } \\
\text { - Tensões normais desuniforme nos } \\
\text { primeiros pavimentos (alto coeficiente de } \\
\text { variação) e com uniformidade similar ao } \\
\text { modelo usual nos pavimentos superiores } \\
\text { (médio coeficiente de variação). }\end{array}$ \\
\hline
\end{tabular}

\subsection{DEMAIS ASPECTOS DA ISE EM EDIFÍCIOS DE PAREDES DE CONCRETO}

\subsubsection{FISSURAÇÃO NOS ELEMENTOS DE PAREDES}

O desenvolvimento do trabalho nos itens anteriores teve enfoque principal na distribuição de esforços normais e tensões normais verticais nas paredes, já que são os esforços preponderantes e utilizados para o dimensionamento de tais elementos. Nas paredes de concreto a manifestação das patologias em virtude da ISE ocorre pelo surgimento de fissuras, mais precisamente na região da base.

A origem das fissuras nos elementos devidas à ISE (Elementos de vedação e estruturais) ocorre pela distorção desses elementos graças ao deslocamento diferencial na base. A distorção na parede pode causar o surgimento de tensões de tração em sua região inferior que consequentemente pode ocasionar aparecimento fissuras, caso as tensões de tração ultrapassem 
os limites de resistência do material. Essas situações têm frequência maior em elementos de vedação, pois esses na ampla maioria das vezes não possuem capacidade resistente na absorção desses esforços.

As fissuras no concreto são inevitáveis quando o elemento é submetido às tensões de tração. Após a perda da capacidade resistente do concreto na tração, a formação das fissuras e as dimensões das aberturas de fissuras dependem do alongamento axial das armaduras.

A distribuição das tensões normais nas paredes (Eixo Z ou direção vertical do plano das paredes) já foi abordado nos itens anteriores. Os resultados indicaram que o uso da ISE promove alterações nas tensões normais nos elementos, mas estes ainda são totalmente comprimidos. O surgimento do recalque diferencial nas paredes acarreta em modificações na distribuição das tensões na direção horizontal do elemento. A Figura 4.23 mostra o deslocamento da parede PY1 na direção vertical, as deformações e tensões na direção horizontal. As deformações e tensões mostradas ilustram apenas valores positivos, para uma melhor compreensão do problema.
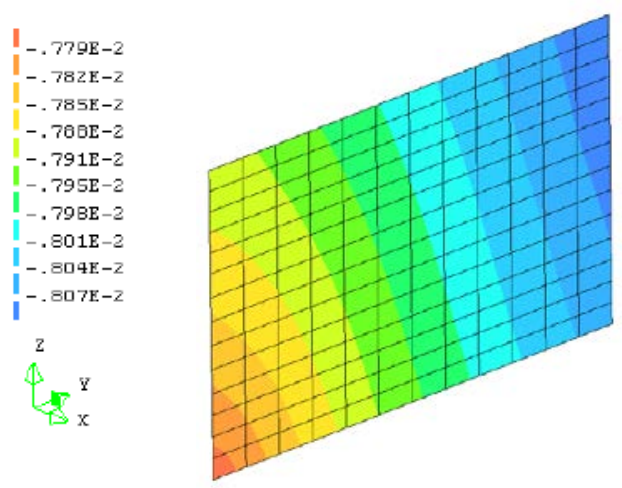

a) $\mathrm{u}_{\mathrm{z}}(\mathrm{m})$ - Deslocamento vertical

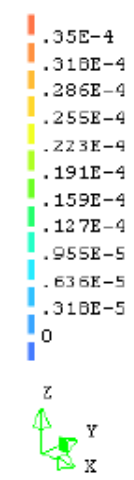

(1)

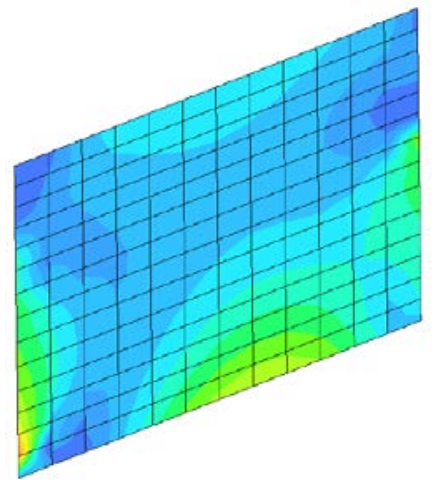

b) $\varepsilon_{\mathrm{yy}}-$ Deformação
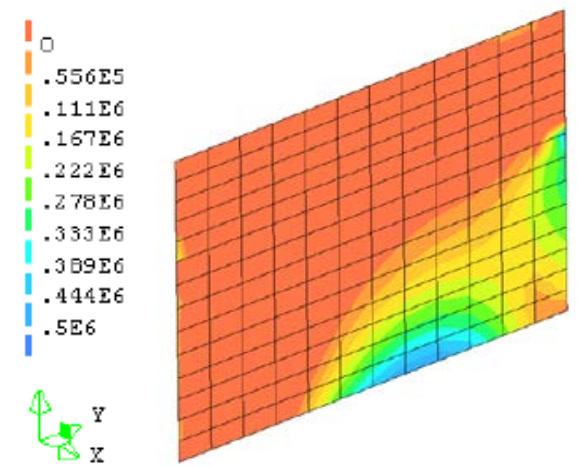

c) $\sigma_{\mathrm{yy}}\left(\mathrm{N} / \mathrm{m}^{2}\right)$ - Tensões normais de tração - Direção Y

Figura 4.23 - Deslocamendo vertical, tensões e deformações na direção Y - Parede PY1 - Modelo ISE-EVO-3

O fluxo de tensões horizontais da Figura 4.23 indica claramente o surgimento de tensões de tração na parede. O recalque diferencial ao longo do comprimento do elemento promove a ocorrência de distorções angulares na base do mesmo. A ocorrência das distorções 
nas paredes será melhor aprofundada no capítulo 5. Comportamento similar ao apresentado pode ser observado na parede PY9 (Figura 4.24).

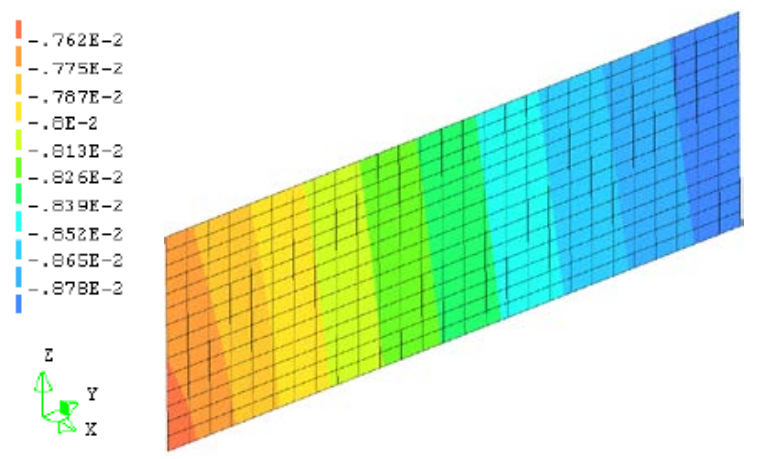

a) $\mathrm{u}_{\mathrm{z}}(\mathrm{m})$ - Deslocamento vertical
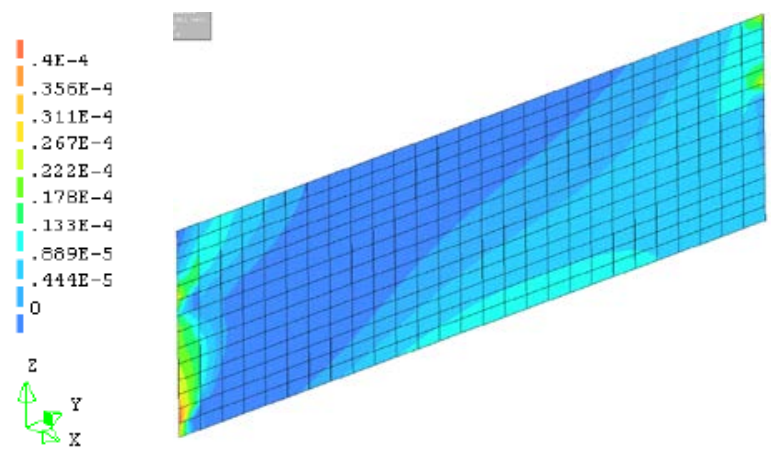

b) $\varepsilon_{y y}-$ Deformação

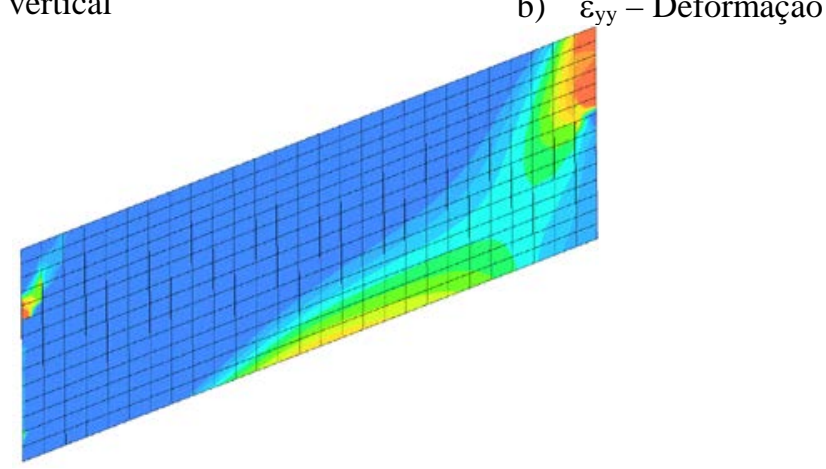

c) $\sigma_{y y}\left(\mathrm{~N} / \mathrm{m}^{2}\right)$ - Tensões normais de tração - Direção $\mathrm{Y}$

Figura 4.24 -Deslocamendo vertical, tensões e deformações na direção Y - Parede PY9 - Modelo ISE-EVO-3

Embora ocorram tensões de tração na base dos elementos dos modelos estudados devido a ISE, deve ser observado que a intensidade da tensão de tração presente nessas paredes são menores que a resistência característica à tração do concreto. Na presente análise considerase 2,5MPa de resistência à tração do concreto, conforme mostrado no capítulo 3.

Contudo, uma das paredes da estrutura apresentou-se com tensões de tração acima do limite resistente estipulado. Esta ocorrência se deu na parede PY3 nos modelos M2-ISE-EVO e M3-ISE-EVO. A Figura 4.25 mostra as deformações de fissuração apresentadas na parede PY3 no modelo M3-ISE-EVO. 

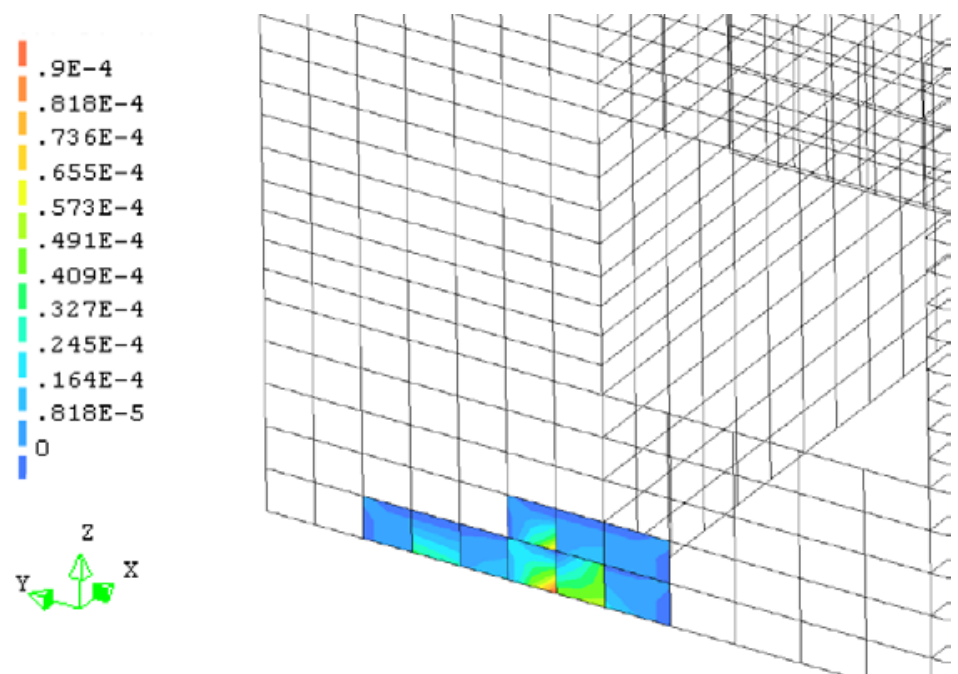

Figura 4.25 - $\varepsilon_{\text {kyy }}$ - Deformação de fissuração (Strain Crack) - Parede PY3 - M3-ISE-EVO

As tensões de tração localizadas nas extremidades das paredes são similares ao comportamento apresentado por Goshy (1978). O referido autor faz uma analogia de vigaparede com o edifício sujeito aos efeitos da ISE, considerando a presença de tensões de tração na base da edificação (Figura 4.26).
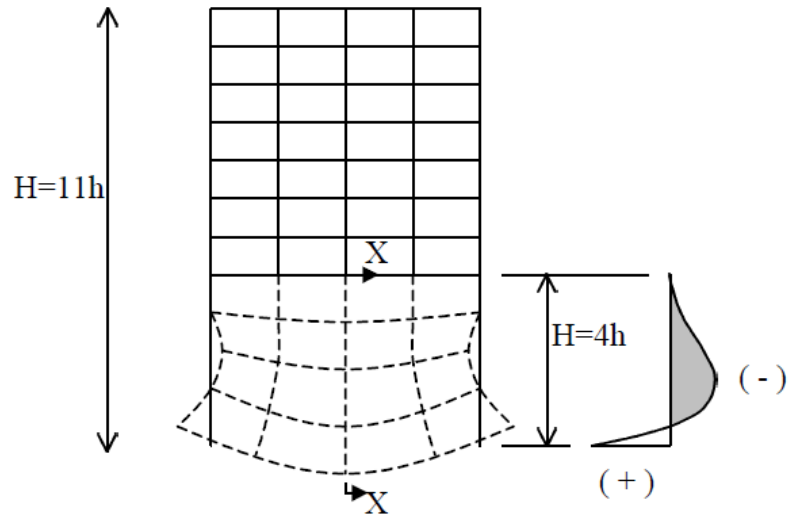

Deformada da estrutura

Distribuição de tensões

Figura 4.26 - Analogia de Viga-Parede de Goshy (1978) - Fonte: Iwamoto (2000)

Nota-se pela Figura 4.25 que embora as deformações presentes na base da parede PY3 encontram-se acima da deformação limite para que se ultrapasse a resistência do concreto à tração, o valor dessa deformação ainda assim é muito baixo. Esse resultado indica que o nível de fissuração presente é irrisório, que pode ser confirmado pela verificação das aberturas de fissuras. A Figura 4.27 indica as aberturas de fissuras na mesma região apresentada da parede PY3 no modelo M2-ISE-EVO.

A Tabela 4.12 mostra o levantamento das aberturas de fissuras máximas neste elemento nos dois modelos destacados. 

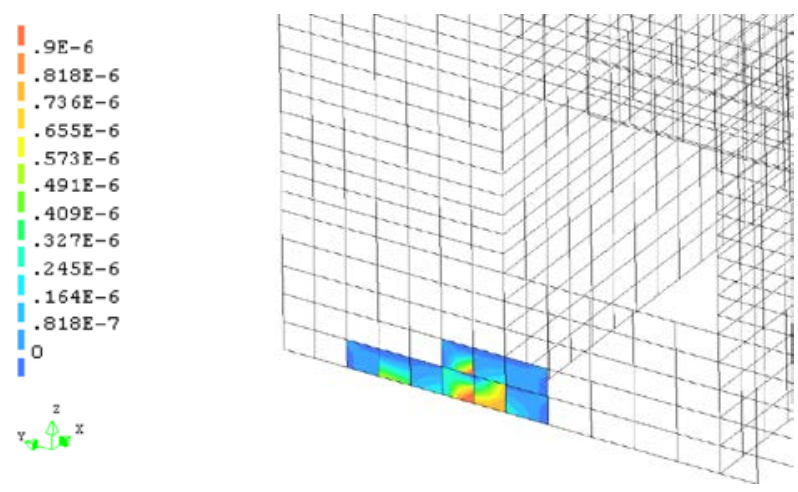

Figura $4.27-\varepsilon_{\mathrm{kwyy}}-$ Abertura de fissura (m)

Tabela 4.12 - Abertura de fissuras

\begin{tabular}{|c|c|c|}
\hline \multirow{2}{*}{ Parede } & \multicolumn{2}{|c|}{ Abertura de fissuras (mm) } \\
\cline { 2 - 3 } & M2-ISE-EVO & M3-ISE-EVO \\
\hline PY3 & 0,00116 & 0,00231 \\
\hline
\end{tabular}

As aberturas de fissuras apresentadas nos dois modelos são irrisórias. A norma brasileira de concreto (NBR-6118, 2014) apresenta limites de abertura de fissura para o atendimento dos estados limites de serviço. Os limites de aberturas de fissuras admitidos pela referida norma dependem da agressividade ambiental considerada no projeto. A Tabela 4.13 apresenta os limites de aberturas de fissuras da NBR-6118 (2014).

Tabela 4.13 - Abertura de fissuras admissíveis

\begin{tabular}{|c|c|}
\hline \multicolumn{2}{|c|}{ NBR-6118 (2014) } \\
\hline Classe de agressividade ambiental & Limite admissível (mm) \\
\hline CAA I & $0,4 \mathrm{~mm}$ \\
\hline CAA II e CAAIII & $0,3 \mathrm{~mm}$ \\
\hline CAA IV & $0,2 \mathrm{~mm}$ \\
\hline
\end{tabular}

As aberturas de fissuras obtidas nos modelos M2-ISE-EVO e M3-ISE-EVO, em especial na parede PY3, são bastante inferiores aos limites apresentados pela NBR-6118 (2014). Esses resultados são coerentes, pois as deformações presentes nessas regiões são baixas. Devese atentar que as paredes são elementos totalmente comprimidos e as tensões de tração são originarias da distorção angular devido a deformação da base. O baixo nível da deformação de tração pode indicar deste modo uma baixa distorção angular nesses elementos. Esse assunto será melhor avaliado no capítulo 5.

Os resultados indicam que o surgimento de fissuras decorrentes da ISE nestas tipologias não é um aspecto preocupante, pois na ampla maioria dos elementos as tensões de tração na base das paredes não ultrapassam o limite de resistência do concreto e nos elementos que esse limite é ultrapassado as dimensões das aberturas de fissuras são bastante inferiores aos 
limites normativos. No capítulo 6 são analisadas o surgimento de fissuras em tipologias com um número maior de pavimentos.

\subsubsection{DIMENSIONAMENTO DOS ELEMENTOS DE PAREDES}

São avaliados neste item o efeito prático, da alteração dos esforços nas paredes, sob o ponto de vista do dimensionamento dos elementos. Essa análise é realizada utilizando as prescrições para o dimensionamento dos elementos de paredes da norma NBR-16055 (2012). O dimensionamento é realizado neste item por meio de duas verificações:

- Resistência de cálculo sob solicitação normal de compressão

- Dimensionamento devido a cargas localizadas (tensão de contato)

Como salientado no capítulo 2 as diversas normas de paredes de concreto prescrevem procedimentos simplificados para a análise da resistência destes elementos sob esforços de compressão. A resistência de cálculo sob a solicitação normal de compressão é avaliada por meio do equacionamento simplificado da NBR-16055 (ABNT, 2012). O procedimento da referida norma contempla a minoração da resistência referente a instabilidade localizada com a a consideração de uma excentricidade mínima conforme a Equação 4.6.

$$
\begin{aligned}
& e_{\text {min }}=1,5+0,03 * t \\
& e_{\text {min }}: \text { excentricidade mínima }(\mathrm{cm}) \\
& t: \text { Espessura da parede }(\mathrm{cm})
\end{aligned}
$$

A NBR-16055 (2012) prescreve que a resistência de cálculo das paredes submetidas à esforços de compressão pode ser calculada por meio da Equação 4.7.

$$
\eta_{d, \text { resist }}=\frac{(0,85 f c d+\rho f s c d) t}{k 1[(1+3 k 2(2-k 2)]} \leq \frac{(0,85 f c d+\rho f s c d) t}{1,643} \leq 0,4 * f c d * t \quad \text { Equação } 4.7
$$

fcd: Resistência de calculo do concreto: $\gamma_{c}=1,68$

fscd: Resistência de calculo do aço

$\rho$ : Taxa de armadura da parede: Adotado armadura mínima $=0,09 \%$

t: Espessura da parede 
A Equação 4.7 fornece a normal resistente de cálculo por unidade de comprimento. A primeira parcela da equação é utilizada para elementos mais esbeltos, no qual os coeficientes “ $k 1$ ” e "k2”consideram a perda de resistência dos elementos devido à instabilidade local e localizada. A última parcela é o limite máximo de resistência ao esforço normal admitido pela NBR-16055. Este limite é o equivalente à 40\% da tensão resistente de cálculo da seção de concreto. Observa-se também que o coeficiente de minoração da resistência do concreto é 1,68, valor este superior ao utilizado em estrutura convencionais de concreto armado. A Equação 4.8 e a Equação 4.9 mostram respectivamente as expressões para a obtenção dos coeficientes “ $k 1$ ” e “ $k 2$ ” que dependem do índice de elbeltez da parede. A Equação 4.10 mostra a expressão para calcular o índice de esbeltez da parede.

$$
\begin{array}{ll}
k 1=\frac{\lambda}{35} ; 35 \leq \lambda \leq 86 & \text { Equação } 4.8 \\
k 2=\frac{(\lambda-86)}{120} ; \quad 35 \leq \lambda \leq 86 & \text { Equação } 4.9 \\
k 2=0 ; 86<\lambda \leq 120 & \\
\lambda=\frac{l_{e} * \sqrt{12}}{t} & \text { Equação } 4.10 \\
\lambda: \text { Índice de esbeltez do elemento } & \\
l_{e}: \text { Comprimento equivalente da parede } &
\end{array}
$$

O procedimento para a obtenção do comprimento equivalente da parede é idêntico ao realizado em pilares-paredes da NBR-6118 (ABNT, 2014). A Figura 4.28 mostra um esquema ilustrativo, retirado na NBR-16055 (ABNT, 2012), para o cálculo do comprimento equivalente da parede. 


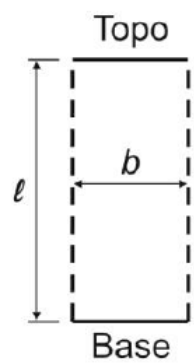

$\ell_{\mathrm{e}}=\ell$

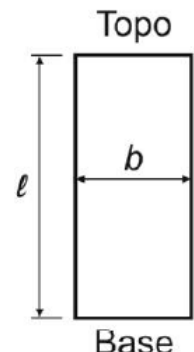

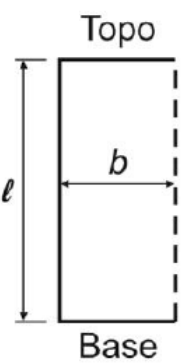

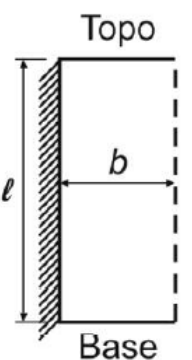

$$
\ell_{\mathrm{e}}=\frac{\ell}{1+(\beta / 3)^{2}} \geq 0,3 \ell
$$$$
\beta=\ell / b
$$

$$
\ell_{\mathrm{e}}=2 b \leq \ell
$$

$$
\begin{aligned}
& \ell_{\mathrm{e}}=\frac{\ell}{2 \beta} \text { se } \beta>1 \\
& \beta=\ell / b
\end{aligned}
$$

Figura 4.28 - Comprimento equivalente - NBR 16055 (ABNT, 2012)

As verificações são todas realizadas utilizando-se os esforços de cálculo para o estado limite último, ou seja, são aplicados os devidos coeficientes de segurança nas análises. São observados apenas os modelos com a consideração das ações evolutivas (ISE-EVO). A distribuição das tensões nas paredes possui uma distribuição desuniforme, como mostrado anteriormente neste capítulo. Para cada elemento é utilizado o esforço normal total solicitante.

A Tabela 4.14 exibe os índices de eslbeltez das paredes, esforço normal resistente da parede, o esforço normal solicitante de cálculo com o emprego da ISE nos três modelos pesquisados. O equacionamento proposto pela norma fornece o esforço normal resistente por unidade de comprimento. Os resultados expostos na Tabela 4.14 mostram os esforços normais

\begin{tabular}{|c|c|c|c|c|c|c|c|c|}
\hline \multirow{2}{*}{ PAREDE } & \multirow{2}{*}{$\lambda$} & \multirow{2}{*}{$\begin{array}{l}\mathrm{Nd}_{\text {res }} \\
(\mathrm{kN})\end{array}$} & \multicolumn{2}{|c|}{ M1-ISE-EVO } & \multicolumn{2}{|c|}{ M2-ISE-EVO } & \multicolumn{2}{|c|}{ M3-ISE-EVO } \\
\hline & & & $\mathrm{Nd}_{\text {sol }}(\mathrm{kN})$ & $\mathrm{Nd}_{\text {sol }} / \mathrm{Nd}_{\text {res }}$ & $\mathrm{Nd}_{\mathrm{sol}}(\mathrm{kN})$ & $\mathrm{Nd}_{\mathrm{sol}} / \mathrm{Nd}_{\mathrm{res}}$ & $\mathrm{Nd}_{\mathrm{sol}}(\mathrm{kN})$ & $\mathrm{Nd}_{\text {sol }} / \mathrm{Nd}_{\text {res }}$ \\
\hline PX1 & 67,2 & 4857 & 1011 & $20,8 \%$ & 980 & $20,2 \%$ & 987 & $20,3 \%$ \\
\hline $\mathrm{PX} 2$ & 67,2 & 4857 & 1101 & $22,7 \%$ & 1057 & $21,8 \%$ & 1057 & $21,8 \%$ \\
\hline PX3 & 24,5 & 1214 & 275 & $22,6 \%$ & 283 & $23,3 \%$ & 279 & $23,0 \%$ \\
\hline PX4 & 24,5 & 1214 & 292 & $24,0 \%$ & 299 & $24,7 \%$ & 295 & $24,3 \%$ \\
\hline PX5 & 11,5 & 571 & 122 & $21,3 \%$ & 121 & $21,2 \%$ & 119 & $20,9 \%$ \\
\hline PX6 & 11,5 & 571 & 118 & $20,6 \%$ & 119 & $20,8 \%$ & 120 & $21,0 \%$ \\
\hline PX7 & 60,6 & 1214 & 313 & $25,8 \%$ & 339 & $27,9 \%$ & 333 & $27,5 \%$ \\
\hline PX8 & 60,6 & 1214 & 273 & $22,5 \%$ & 268 & $22,0 \%$ & 266 & $21,9 \%$ \\
\hline PX9 & 60,6 & 1214 & 253 & $20,8 \%$ & 241 & $19,8 \%$ & 241 & $19,8 \%$ \\
\hline PX10 & 60,6 & 1214 & 303 & $24,9 \%$ & 328 & $27,0 \%$ & 322 & $26,5 \%$ \\
\hline PY1 & 71,2 & 2143 & 729 & $34,0 \%$ & 762 & $35,5 \%$ & 754 & $35,2 \%$ \\
\hline
\end{tabular}
solicitantes $\left(N d_{\text {sol }}\right)$ e resistentes $\left(N d_{r e s}\right)$ de cada parede, ou seja, os comprimentos dos elementos estão contemplados.

Tabela 4.14 - Relação tensão de cálculo atuante nas paredes com e sem ISE. 


\begin{tabular}{|l|r|r|r|r|r|r|r|r|}
\cline { 1 - 3 } PY2 & 43,0 & 714 & 216 & $30,3 \%$ & 219 & $30,6 \%$ & 218 & $30,5 \%$ \\
\hline PY3 & 43,0 & 2143 & 514 & $24,0 \%$ & 506 & $23,6 \%$ & 513 & $23,9 \%$ \\
\hline PY4 & 14,4 & 714 & 115 & $16,1 \%$ & 109 & $15,3 \%$ & 110 & $15,4 \%$ \\
\hline PY5 & 77,9 & 2089 & 886 & $42,4 \%$ & 919 & $44,0 \%$ & 921 & $44,1 \%$ \\
\hline PY6 & 77,9 & 5502 & 1055 & $19,2 \%$ & 981 & $17,8 \%$ & 983 & $17,9 \%$ \\
\hline PY7 & 71,2 & 2143 & 822 & $38,4 \%$ & 828 & $38,6 \%$ & 832 & $38,8 \%$ \\
\hline PY8 & 43,0 & 2143 & 425 & $19,8 \%$ & 387 & $18,1 \%$ & 391 & $18,2 \%$ \\
\hline PY9 & 77,9 & 4353 & 1390 & $31,9 \%$ & 1371 & $31,5 \%$ & 1375 & $31,6 \%$ \\
\hline PY10 & 71,2 & 2143 & 788 & $36,8 \%$ & 792 & $37,0 \%$ & 794 & $37,1 \%$ \\
\hline PY11 & 43,0 & 2143 & 415 & $19,4 \%$ & 394 & $18,4 \%$ & 400 & $18,7 \%$ \\
\hline PY12 & 68,3 & 1750 & 373 & $21,3 \%$ & 357 & $20,4 \%$ & 354 & $20,2 \%$ \\
\hline PY13 & 77,9 & 2089 & 787 & $37,7 \%$ & 816 & $39,1 \%$ & 826 & $39,6 \%$ \\
\hline PY14 & 14,4 & 714 & 110 & $15,4 \%$ & 103 & $14,5 \%$ & 102 & $14,3 \%$ \\
\hline PY15 & 71,2 & 2143 & 632 & $29,5 \%$ & 665 & $31,0 \%$ & 667 & $31,1 \%$ \\
\hline PY16 & 43,0 & 714 & 209 & $29,2 \%$ & 211 & $29,6 \%$ & 207 & $29,0 \%$ \\
\hline
\end{tabular}

Embora os resultados anteriormente mostrados no capítulo indiquem uma alta redistribuição de esforços entre os elementos, estes não foram suficientes para não possibilitar o dimensionamento dos elementos aos esforços normais de compressão.

Os elementos presentes nas regiões periféricas foram os mais afetados, como por exemplo as paredes PY1, PY5 e PY7. A PY5 apresentou a pior situação, e mesmo assim a razão entre os esforços normais solicitantes e resistentes ficaram abaixo de $45 \%$ nos três modelos.

A segunda verificação realizada é o atendimento das tensões máximas de contato. Usualmente essa verificação é realizada na análise de introdução de cargas localizadas. A consideração da ISE acarretou em uma distribuição de tensões desuniformes e concentração de tensões, sendo normalmente mais intensas nas extremidades. É razoável realizar essa análise nos modelos com a consideração da ISE, principalmente devido a região de contato entre a base da parede e o radier. Essa análise verifica se a concentração de tensões ultrapassa o limite estipulado pela norma. A Equação 4.11 mostra o limite estipulado pela NBR 16055 (ABNT, 2012) para as tensões de contato de cálculo. A Tabela 4.15 mostra a razão entre a tensão máxima atuante de contato e a tensão resistente de contato de cálculo.

$\sigma_{c o n t, d} \leq 0,85 * f c d$

Equação 4.11

$\sigma_{\text {cont }, d}:$ Tensão de contato de cálculo

fcd: Resistência de calculo do concreto: $\gamma_{c}=1,68$ 
Tabela 4.15 - Razão entre tensão de cálculo atuante e tensão resistente de cálculo

\begin{tabular}{|l|r|r|r|}
\hline \multirow{2}{*}{ Parede } & \multicolumn{3}{|c|}{$\sigma_{\text {cont } d} \leq 12,64 \mathrm{MPa}$} \\
\cline { 2 - 4 } & \multicolumn{3}{|c|}{$\sigma_{\text {cont }, d}$} \\
\cline { 2 - 4 } & M1-ISE-EVO & M $f$ C \\
\hline & $16,2 \%$ & $16,0 \%$ & \multicolumn{1}{c|}{} \\
\hline PX1 & $22,7 \%$ & $22,2 \%$ & $22,2 \%$ \\
\hline PX2 & $12,5 \%$ & $11,9 \%$ & $12,1 \%$ \\
\hline PX3 & $15,9 \%$ & $15,8 \%$ & $15,5 \%$ \\
\hline PX4 & $12,7 \%$ & $14,1 \%$ & $13,5 \%$ \\
\hline PX5 & $11,9 \%$ & $13,2 \%$ & $13,5 \%$ \\
\hline PX6 & $14,3 \%$ & $16,6 \%$ & $16,2 \%$ \\
\hline PX7 & $13,9 \%$ & $13,8 \%$ & $13,5 \%$ \\
\hline PX8 & $12,2 \%$ & $11,6 \%$ & $11,7 \%$ \\
\hline PX9 & $13,9 \%$ & $15,8 \%$ & $15,5 \%$ \\
\hline PX10 & $34,0 \%$ & $35,9 \%$ & $35,8 \%$ \\
\hline PY1 & $18,3 \%$ & $19,6 \%$ & $19,4 \%$ \\
\hline PY2 & $15,8 \%$ & $15,5 \%$ & $15,7 \%$ \\
\hline PY3 & $8,6 \%$ & $9,7 \%$ & $9,3 \%$ \\
\hline PY4 & $56,4 \%$ & $58,7 \%$ & $59,6 \%$ \\
\hline PY5 & $9,7 \%$ & $9,2 \%$ & $9,3 \%$ \\
\hline PY6 & $49,8 \%$ & $51,1 \%$ & $51,2 \%$ \\
\hline PY7 & $9,8 \%$ & $9,3 \%$ & $9,5 \%$ \\
\hline PY8 & $51,3 \%$ & $52,4 \%$ & $52,5 \%$ \\
\hline PY9 & $47,4 \%$ & $48,4 \%$ & $48,8 \%$ \\
\hline PY10 & $9,4 \%$ & $8,9 \%$ & $9,0 \%$ \\
\hline PY11 & $12,1 \%$ & $11,1 \%$ & $10,8 \%$ \\
\hline PY12 & $49,7 \%$ & $52,4 \%$ & $53,1 \%$ \\
\hline PY13 & $7,8 \%$ & $8,4 \%$ & $8,4 \%$ \\
\hline PY14 & $28,1 \%$ & $29,4 \%$ & $30,3 \%$ \\
\hline PY15 & $17,1 \%$ & $16,9 \%$ & $16,7 \%$ \\
\hline PY16 & & & \\
\hline
\end{tabular}

Os resultados obtidos mostram que apesar da concentração das tensões nas paredes, essas são inferiores ao limite imposto pela NBR-16055 (ABNT, 2012). A parede PY5 é o elemento que apresenta a maior aproximação, com razão entre a tensão solicitante e a tensão resistente de quase $60 \%$.

Em virtude dos critérios normativos, nos quais existe a imposição de valores mínimos para as espessuras das paredes, o dimensionamento das paredes de concreto no modelo apresenta esforços atuantes bem abaixo dos seus esforços resistentes. Desta maneira, o surgimento de esforços adicionais por consequência da ISE, apesar de serem elevados em alguns elementos estruturais, permitem dimensionamento das paredes do edifício nos três modelos analisados, sem maiores problemas. As tensões de contatos, embora acentuadas devido 
a desunifomização das tensões as paredes, apresentam-se com valores inferiores aos limites normativos. Edifícios com números maiores de pavimentos e diferentes são avaliados no capítulo 6.

\subsection{CONCLUSÕES DO CAPÍTULO}

A partir das análises e levantamentos realizados é possível destacar as seguintes conclusões sobre a influência da ISE na superestrutura.

- A interação solo-estrutura promove modificações significativas nas reações finais nas paredes da superestrutura. Elementos localizados em regiões com menores recalques tendem a receber um acréscimo de cargas, enquanto as paredes localizadas em regiões com recalques maiores, tendem a apresentar um alívio nos valores das suas reações verticais.

- A redistribuição das cargas é maior nos primeiros pavimentos, diminuindo de forma gradativa nos pisos superiores. Nos últimos níveis, os esforços atuantes nas paredes dos modelos com ISE se assemelham aos resultados de referência (apoios fixos).

- O uso das ações evolutivas, que considera o processo construtivo da edificação, reduz os efeitos da ISE na redistribuição de cargas nas paredes. Essa redução é mais expressiva nos pavimentos superiores.

- A interação solo-estrutura modifica o fluxo das tensões normais nas paredes devido às ações verticais. Em trechos com recalques menores, ocorre a tendência de acréscimo das tensões normais de compressão, e nos trechos com recalques maiores ocorre o alívio dessas tensões.

- O uso das ações evolutivas reduziu de forma significativa a perda de homogeneidade nas tensões normais nas paredes em virtude da ISE, principalmente nos pisos superiores.

- Os deslocamentos verticais diferenciais entre as paredes modificam a migração de cargas. Essa transferência é possível graças à conexão entre os elementos pelas lajes e linteis. A formação de grupo de paredes pode afetar o comportamento da redistribuição de tensões, principalmente nas paredes que têm baixa rigidez e estão acopladas em elementos de alta rigidez. 
- A consideração da não-linearidade física do concreto possibilita avaliar o aparecimento de fissuras nas regiões inferiores dos elementos. Destaca-se que poucos elementos apresentaram algum panorama de fissuração. As aberturas de fissuras foram irrisórias e distantes dos limites impostos pela NBR-6118 (2014).

- O emprego da ISE nos três perfis investigados não inviabiliza o dimensionamento dos elementos estruturais pelas prescrições da NBR-16055 (2012). Para o edifício em estudo, em razão da exigência de espessura mínima das paredes, os elementos possuem uma reserva de resistência considerável. Em um edifício de maior porte, a consideração da ISE pode modificar o seu dimensionamento.

Tendo em vista as diversas variáveis citadas que possam afetar a perda de uniformidade nas tensões nas paredes, avaliar apenas os valores de recalques na base pode não fornecer indícios de como se manifestará essa consequência. A redistribuição das tensões deve ser observada por meio de uma análise estrutural que possa indicar como está ocorrendo a transferência de cargas entre os elementos, por razão do deslocamento vertical diferencial entre as paredes.

Em um edifício de estrutura reticulada convencional (concreto armado, estruturas metálicas e etc.) esse tipo de análise pode ser mais simples, principalmente em uma tipologia com a geometria regular. Para um edifício de paredes, esse tipo de avaliação ganha complexidade, pois a geometria deste tipo de edifício segue um padrão irregular, com elementos de comprimentos muitos distintos e com inúmeras interligações entres os mesmos (grupos de paredes). Outro aspecto é que, diferentemente de edifícios reticulados, a interação soloestrutura não altera apenas a reação final no elemento, mas a distribuição das tensões normais ao longo da sua seção transversal.

O emprego da interação solo-estrutura nos edifícios investigados não inviabilizaria o projeto estrutural de tal edificação feito com apoios fixos. Os elementos poderiam ser dimensionados normalmente. 



\section{CAPÍTULO 5 - I.S.E. EM EDIFÍCIOS DE PAREDES: INFRAESTRUTURA E MACIÇO DO SOLO}

\subsection{MODELOS ANALISADOS}

Neste capítulo são abordados os efeitos da interação solo-estrutura no radier e no maciço do solo. Aspectos como a redistribuição de esforços no radier e o papel da rigidez da estrutura na deformação do maciço são avaliados. A análise comparativa de resultados é realizada por meio de um modelo de referência.

O modelo de referência, denominado REF-GEO, simula apenas o conjunto maciço do solo com o radier. Essa simulação despreza toda a rigidez da superestrutura. As cargas provenientes da superestrutura são aplicadas diretamente no radier. Essas cargas são estimadas por meio do modelo de referência REF-AP (Capítulo 4). Esse procedimento é similar ao utilizado em casos práticos, nos quais as cargas aplicadas na fundação são provenientes de uma solução sobre apoios fixos. A Figura 5.1 mostra o modelo de referência concebido para avaliar a ausência da ISE nos modelos geotécnicos. O modelo possui um plano de simetria perpendicular ao Eixo-Y, como descrito nos capítulos anteriores.

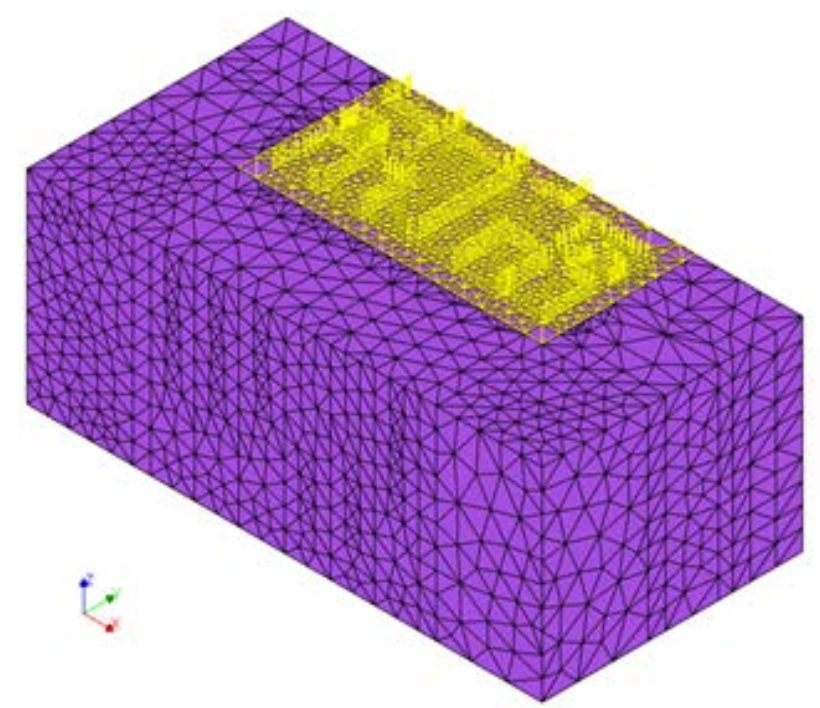

Figura 5.1 - Modelo de referência - REF-GEO

Deve-se ressaltar que o modelo de referência (REF-GEO) considera o maciço do solo como um meio contínuo. Este procedimento é mais refinado que os rotineiramente empregados em escritórios de projeto no dimensionamento de fundação do tipo radier. Usualmente são 
utilizados modelos baseados em molas discretas (Hipótese de Winkler), que devem ser evitados como parâmetros qualitativos em função de sua enorme simplificação.

Os estudos realizados têm como base as tipologias e características dos respectivos solos apresentadas no capítulo 3. A Tabela 5.1 mostra as nomenclaturas dos modelos de referência deste capítulo.

Tabela 5.1 - Nomenclatura dos modelos

\begin{tabular}{|c|c|c|}
\hline Nomenclatura & Condição de apoio & Ações \\
\hline M1-REF-GEO & Modelo de referência - Geotécnico - Solo M1 & Instantâneas \\
\hline M2-REF-GEO & Modelo de referência - Geotécnico - Solo M2 & Instantâneas \\
\hline M3-REF-GEO & Modelo de referência - Geotécnico - Solo M2 & Instantâneas \\
\hline
\end{tabular}

Os demais modelos que contemplam a ISE são os mesmos apresentados no Capítulo 4. As nomenclaturas destes modelos estão indicadas na tabela 4.1. Os resultados deste capítulo são enfocados no maciço do solo e no radier. São avaliados especificamente a redistribuição dos momentos fletores atuantes no radier e a uniformização dos recalques no maciço do solo ambos com a contribuição da superestrutura.

\subsection{ANÁLISES DOS RECALQUES}

Diversos estudos indicam que a consideração da ISE tende a uniformizar os recalques na fundação. A partir do modelo de referência (REF-AP), com a superestrutura sobre apoios fixos, as reações nas bases das paredes são obtidas e reaplicadas em um modelo sem a incorporação da superestrutura (REF-GEO).

São avaliadas a distribuição dos recalques no radier, os recalques diferenciais e as distorções angulares na base das paredes. A convenção utilizada dessas variáveis é baseada nas sugestões de Burland e Wroth (1974). A Figura 5.2 mostra as convenções para essas variáveis sugeridas pelos autores.

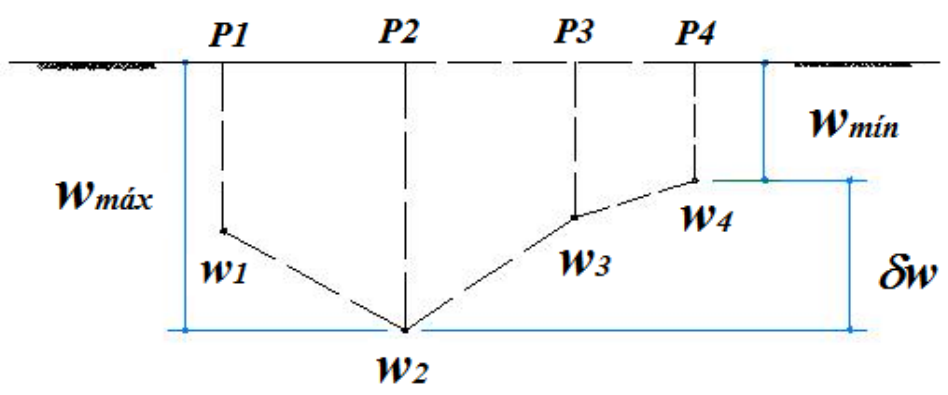

Figura 5.2 - Recalques - Burland e Wroth (1974)

O recalque absoluto " $w$ ” ou recalque total representa o deslocamento absoluto em um ponto qualquer da fundação. O valor máximo do recalque é representado por “wmáx” e o mínimo 
de "wmin". A diferença do deslocamento vertical entre dois pontos é chamada de recalque diferencial, representado pela variável “ $\delta w$ ”.

O recalque médio, “ $\bar{w}$ ”, depende sempre da referência utilizada. Quando associado ao radier ele é obtido por meio dos deslocamentos em todos os nós do radier. Se o recalque médio é referenciado à superestrutura, este é obtido pela média dos nós na base das paredes estruturais.

Outras variáveis comumente utilizadas na associação dos danos nas estruturas são o desaprumo “ $\omega$ ” e a distorção angular “ $\beta$ ”. O desaprumo “ $\omega$ ” indica a rotação de uma estrutura, similar a um movimento de corpo rígido na direção estudada. A distorção angular “ $\beta$ ” é a rotação entre dois pontos de referência. Comumente a distorção angular é chamada de rotação relativa. No cálculo da distorção angular deve-se descontar o valor do movimento de corpo rígido. Essas variáveis são interessantes para avaliar os efeitos dos recalques ao longo de uma linha reta, como, por exemplo, a base de uma parede. A distorção angular é utilizada na avaliação das paredes no presente capítulo. O desaprumo é calculado para descontar o movimento do corpo rígido na avaliação da distorção angular. A Figura 5.3 exibe um esquema ilustrativo adaptado de Burland e Wroth (1974) que descreve as duas variáveis.

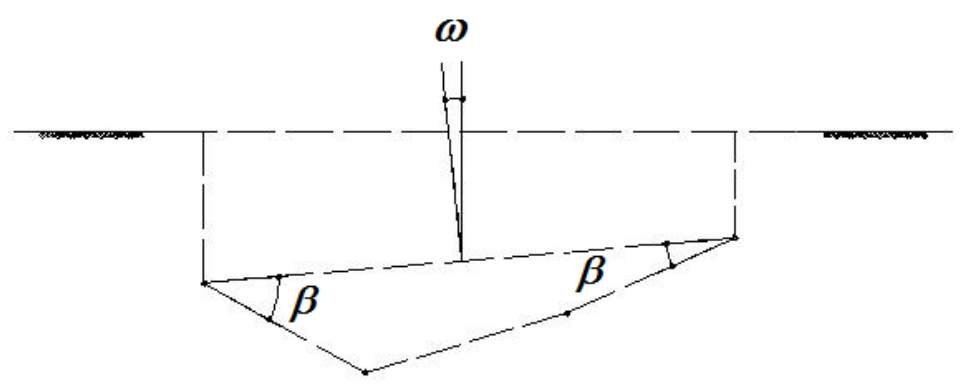

Figura 5.3 - Distorção angular e desaprumo - Burland e Wroth (1974)

A confrontação dos recalques entre os modelos com ISE e o de referência, possibilita avaliar o papel da rigidez da estrutura na sua homogeneização. A visualização dos recalques no radier por meio dos modelos numéricos é representada pelo deslocamento vertical “ $u_{\mathrm{z}}$ ”. A diferença do deslocamento vertical " $u_{z}$ ” e o recalque “ $w$ ” é apenas a convenção de sinais. Neste caso, o deslocamento vertical “ “ $u_{z}$ ” utiliza a convenção do sistema global de eixos da estrutura. A comparação dos recalques no radier com e sem o uso da ISE no perfil M1 pode ser observada na Figura 5.4. 

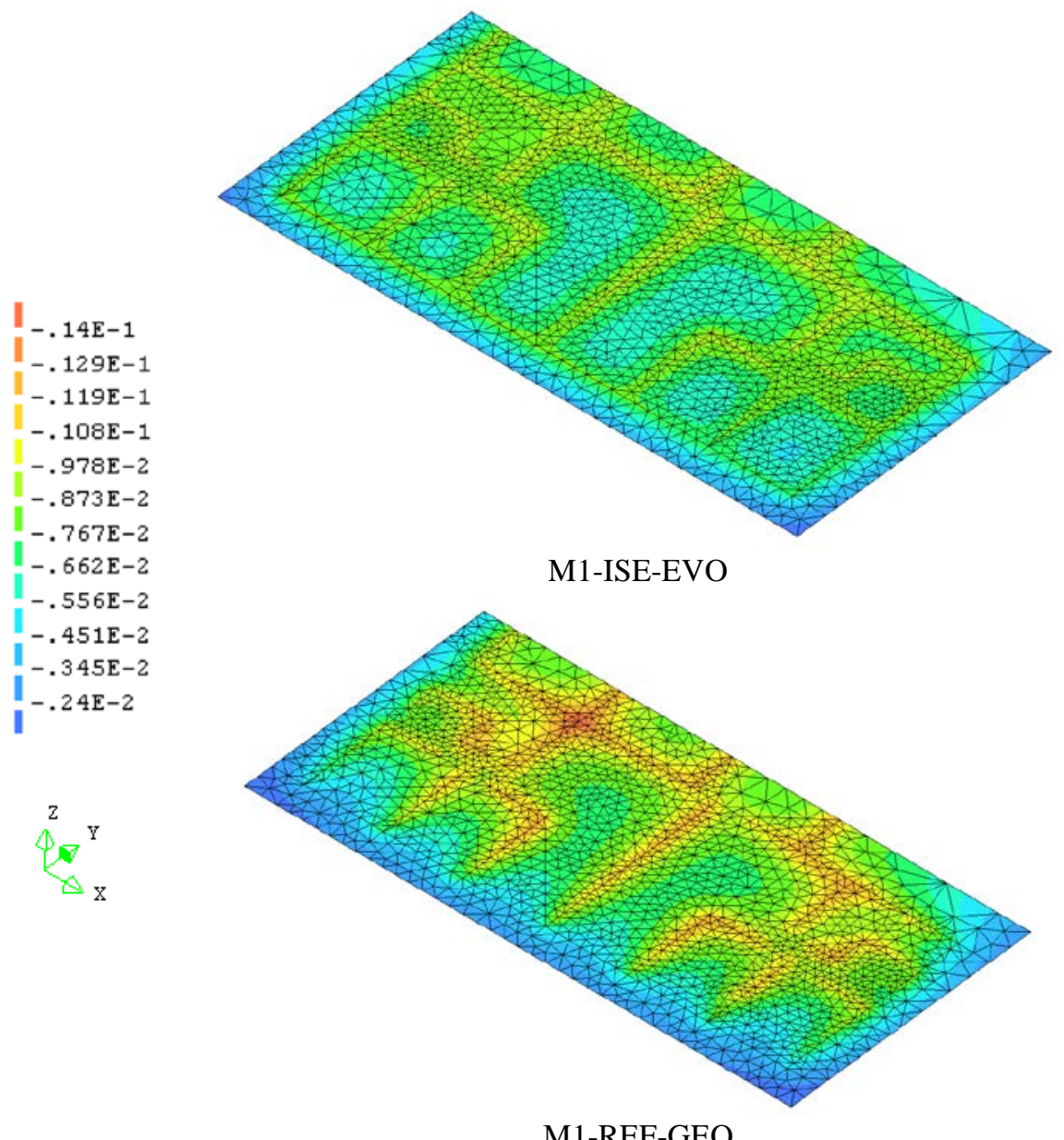

Figura 5.4 - Recalques - $\mathrm{u}_{\mathrm{z}}(\mathrm{m})$ - Modelos M1

A Figura 5.4 evidencia que o modelo de referência M1-REF-GEO apresenta recalques superiores aos obtidos pelo M1-ISE-EVO. Os recalques no modelo M1-REF-GEO são superiores no centro do radier, com valores bem reduzidos nas extremidades. Embora o padrão da deformada de recalques seja similar ao do modelo M1-ISE-EVO, sua distribuição é menos homogênea.

A Tabela 5.2 aponta o levantamento dos recalques no modelo M1. São expostos os recalques máximos, mínimos, diferenciais e médios. Além disso, o desvio padrão e o coeficiente de variação também são expostos. O desvio padrão e o coeficiente de variação servem como um indicativo da uniformidade dos recalques no radier. O coeficiente de variação dos recalques é representado pela variável “ $C V_{w}$ ”.

Tabela 5.2 - Recalques médios, diferenciais e máximos com e sem a ISE - Modelos M1

\begin{tabular}{|c|c|c|c|}
\hline Modelo/Perfil & M1-ISE-EVO & M1-REF-GEO & Diferença Percentual (\%) \\
\hline $\bar{w}(\mathrm{~mm})$ & 7,47 & 7,52 & - \\
\hline$w_{\operatorname{máx}}(\mathrm{mm})$ & 10,11 & 13,34 & $-25 \%$ \\
\hline$w_{\min }(\mathrm{mm})$ & 1,61 & 1,20 & $+49 \%$ \\
\hline Desvio padrão $(\mathrm{mm})$ & 1,39 & 2,18 & $-36 \%$ \\
\hline $\mathrm{CV}_{\mathrm{w}}$ & $18,6 \%$ & $29,2 \%$ & $-39 \%$ \\
\hline
\end{tabular}


Os resultados expostos pela Tabela 5.2 indicam que a aplicação da ISE modifica a uniformização dos recalques. A inclusão da rigidez estrutural reduziu o recalque máximo em 25\% e aumentou o mínimo em 49\%. Os dois modelos apresentam recalques médios em torno de 7,5 mm, sendo irrisória a diferença percentual entre eles. Essa análise indica claramente que a ISE conduz à uniformização dos recalques no radier. Essa afirmação é evidenciada pela redução do desvio padrão e do coeficiente de variação quando incorporada a ISE.

Os resultados dos modelos M2 e M3 apresentaram comportamento similar, com alterações na intensidade dos recalques, como pode ser observado pela Figura 5.5 e pela Figura 5.6.
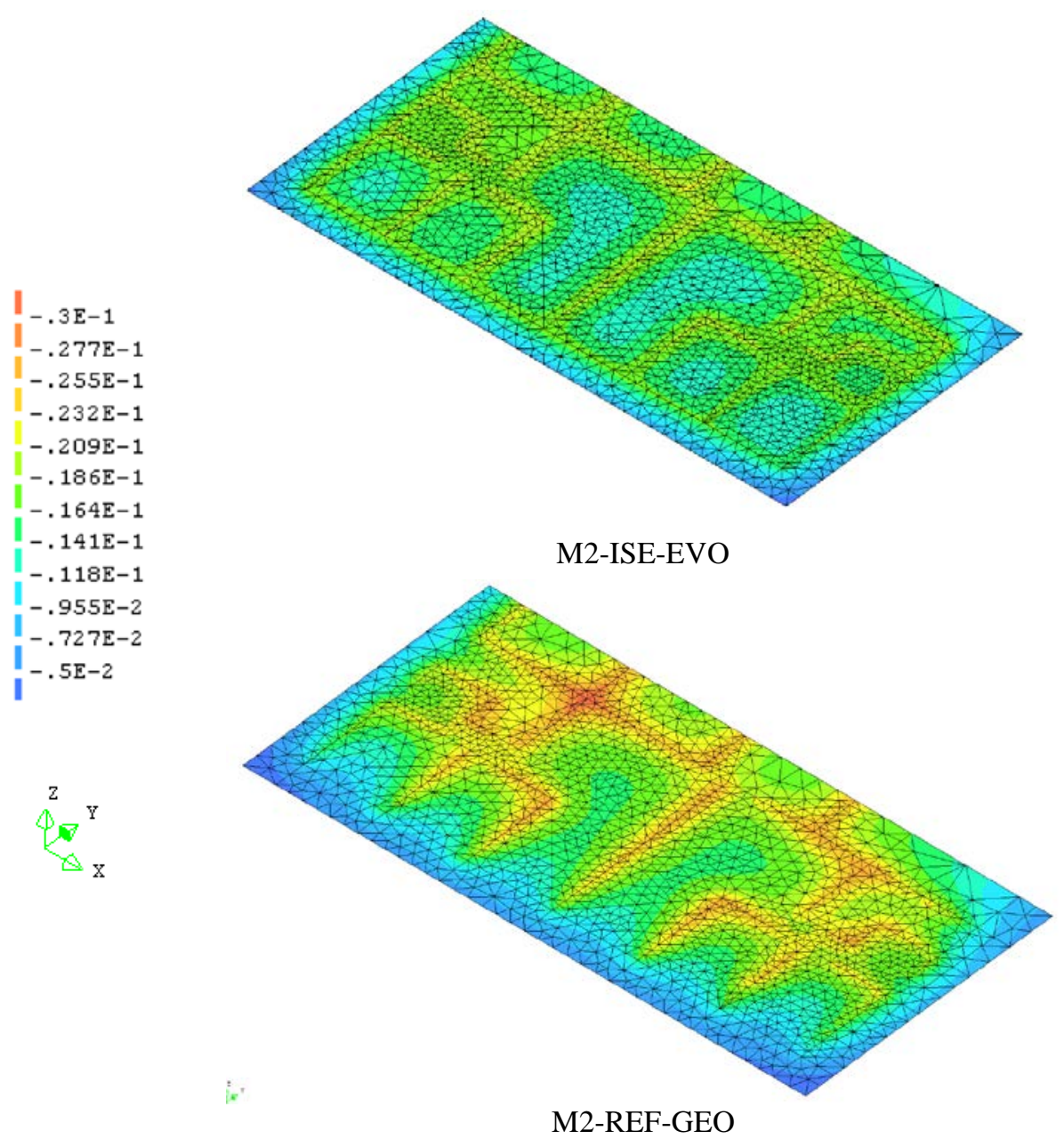

Figura 5.5 - Recalques - $\mathrm{u}_{\mathrm{z}}(\mathrm{m})$ - Modelos M2 


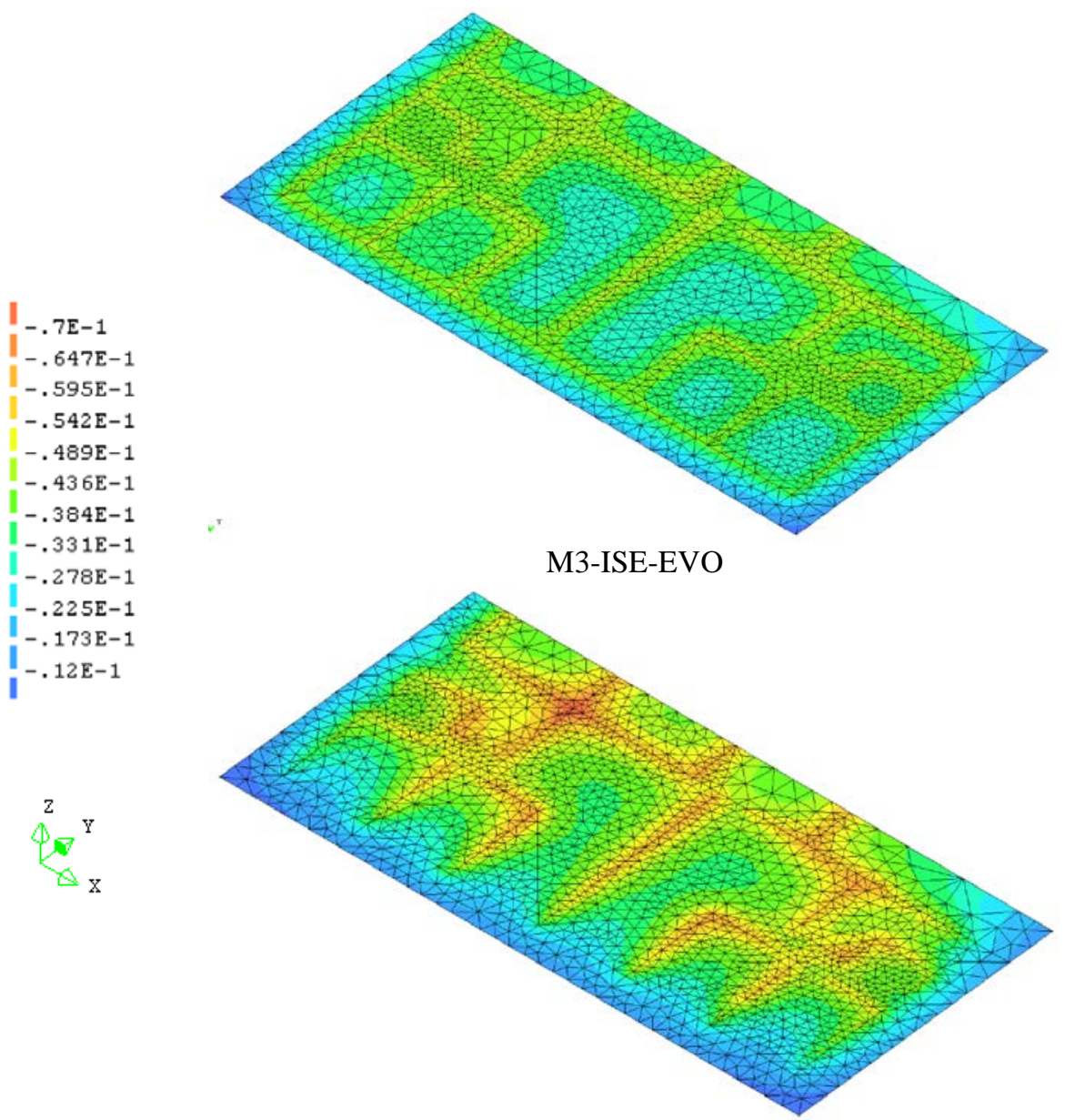

M3-REF-GEO

Figura 5.6 - Recalques - $\mathrm{u}_{\mathrm{z}}(\mathrm{m})$ - Modelos M3

A inclusão da estrutura conduziu a homogeneização dos recalques nas outras duas tipologias de solos analisadas. Os maiores recalques permanecem sempre na região central da edificação, independente da rigidez do solo. Esse Comportamento é semelhante ao descrito anteriormente na análise do modelo M1. A Tabela 5.3 apresenta as soluções obtidas do modelo M2 com e sem a inclusão ISE e a Tabela 5.4 os mesmos resultados referentes ao modelo M3.

Tabela 5.3 - Recalques médios, diferenciais e máximos com e sem a ISE - Modelo M2

\begin{tabular}{|c|c|c|c|}
\hline Modelo/Perfil & M2-ISE-EVO & M2-REF-GEO & Diferença Percentual (\%) \\
\hline $\bar{w}(\mathrm{~mm})$ & 16,21 & 16,27 & - \\
\hline$w_{\operatorname{máx}}(\mathrm{mm})$ & 21,51 & 29,12 & $-26 \%$ \\
\hline$w_{\min }(\mathrm{mm})$ & 3,61 & 2,34 & $+54 \%$ \\
\hline Desvio padrão $(\mathrm{mm})$ & 2,92 & 4,71 & $-38 \%$ \\
\hline $\mathrm{CV}_{\mathrm{w}}$ & $17,9 \%$ & $29,2 \%$ & $-38 \%$ \\
\hline
\end{tabular}

Tabela 5.4 - Recalques médios, diferenciais e máximos com e sem a ISE - Modelo M3

\begin{tabular}{|c|c|c|c|}
\hline Modelo/Perfil & M3-ISE-EVO & M3-REF-GEO & Diferença Percentual (\%) \\
\hline $\bar{w}(\mathrm{~mm})$ & 37,71 & 37,93 & - \\
\hline$w_{\text {máx }}(\mathrm{mm})$ & 49,41 & 67,93 & $-27 \%$ \\
\hline$w_{\min }(\mathrm{mm})$ & 8,68 & 5,45 & $+59 \%$ \\
\hline Desvio padrão $(\mathrm{mm})$ & 6,59 & 11,10 & $-40 \%$ \\
\hline $\mathrm{CV}_{\mathrm{w}}$ & $17,5 \%$ & $29,2 \%$ & $-40 \%$ \\
\hline
\end{tabular}


A inclusão da estrutura nos modelos M2 e M3 possibilita a atenuação dos recalques máximos e o aumento dos mínimos e, consequentemente, a tendência de uniformização dos recalques. Essa hipótese é confirmada também pela redução do coeficiente de variação nos três modelos.

A inclusão da superestrutura pouco modifica a diferença percentual relativa das variáveis expostas na comparação entre as três tipologias do solo. Ocorreram diferenças percentuais similares nos recalques máximos entre os modelos com e sem a ISE, mesmo com diferença na rigidez do solo.

As modificações da distribuição dos recalques ocorrem também ao longo da parede, sendo esta mais importante do que o comportamento mostrado anteriormente no radier como um todo. Os recalques diferenciais nas paredes modificam o seu comportamento perante a ISE, como destacado no capítulo 4.

Existem três principais modos de deformação de uma estrutura sujeita a um recalque. Os modos de deformação são os recalques uniformes, recalques desuniformes sem distorção e os recalques desuniformes com distorção (LOPES e VELLOSO, 2010). A Figura 5.7 ilustra os modos de deformação de uma parede estrutural sobre os efeitos de recalques.

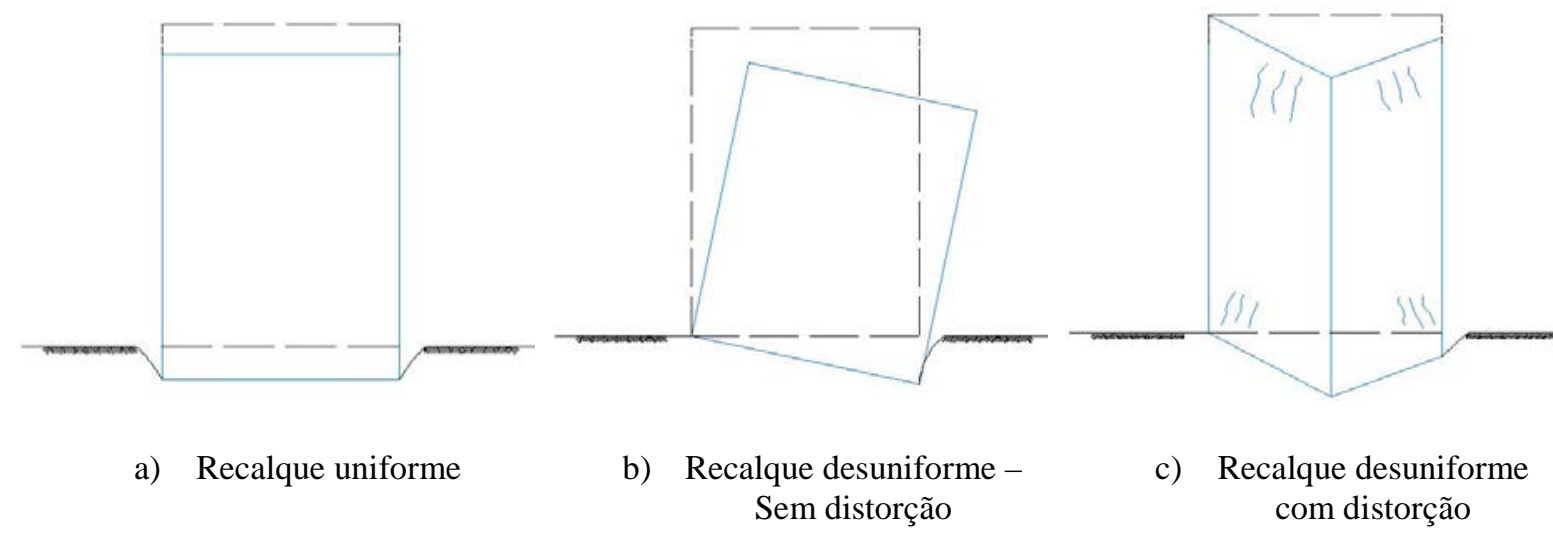

Figura 5.7 - Modos de deformação - Adaptado de Lopes e Velloso (2010)

Geralmente existe uma ligação dos possíveis efeitos ou danos da estrutura com os modos de deformação. O recalque uniforme é o menos grave, sendo prejudicial apenas quando for excessivo. O recalque desuniforme sem distorção, ou desaprumo, pode acarretar em danos estéticos ou funcionais (nivelamento de pisos). A situação mais agravante é quando o recalque desuniforme está associado com a distorção, o que pode ocasionar o surgimento de fissuras. A partir dessas informações podem-se analisar os recalques nas bases das paredes. A Tabela 5.5 exibe tais recalques diferenciais com e sem a interação solo-estrutura. São exibidas também as reduções percentuais dos resultados com o emprego da ISE. 
Tabela $5.5-\delta w(\mathrm{~mm})$ - Recalques diferenciais nas bases das paredes

\begin{tabular}{|c|c|c|c|c|c|c|c|c|c|}
\hline \multirow[b]{2}{*}{ Parede } & \multicolumn{9}{|c|}{$\delta w(\mathrm{~mm})$} \\
\hline & $\begin{array}{l}\text { M1-REF- } \\
\text { GEO }\end{array}$ & $\begin{array}{l}\text { M1-ISE- } \\
\text { EVO }\end{array}$ & $(\%)$ & $\begin{array}{l}\text { M2-REF- } \\
\text { GEO }\end{array}$ & $\begin{array}{l}\text { M2-ISE- } \\
\text { EVO }\end{array}$ & (\%) & $\begin{array}{c}\text { M3-REF- } \\
\text { GEO }\end{array}$ & $\begin{array}{c}\text { M3-ISE- } \\
\text { EVO }\end{array}$ & (\%) \\
\hline PX1 & 1,93 & 0,69 & $-64 \%$ & 4,80 & 1,58 & $-67 \%$ & 10,53 & 2,74 & $-74 \%$ \\
\hline PX2 & 3,00 & 0,82 & $-73 \%$ & 7,07 & 1,67 & $-76 \%$ & 15,79 & 3,57 & $-77 \%$ \\
\hline PX3 & 1,82 & 0,32 & $-83 \%$ & 3,84 & 0,56 & $-86 \%$ & 8,62 & 1,19 & $-86 \%$ \\
\hline PX4 & 1,82 & 0,38 & $-79 \%$ & 3,67 & 0,83 & $-77 \%$ & 8,62 & 1,79 & $-79 \%$ \\
\hline PX5 & 0,64 & 0,13 & $-80 \%$ & 1,05 & 0,56 & $-47 \%$ & 2,69 & 0,95 & $-65 \%$ \\
\hline PX6 & 0,12 & 0,11 & $-6 \%$ & 0,22 & 0,19 & $-16 \%$ & 0,45 & 0,43 & $-4 \%$ \\
\hline PX7 & 0,70 & 0,25 & $-64 \%$ & 1,75 & 0,46 & $-73 \%$ & 3,81 & 1,07 & $-72 \%$ \\
\hline PX8 & 1,05 & 0,19 & $-82 \%$ & 2,52 & 0,37 & $-85 \%$ & 3,36 & 0,48 & $-86 \%$ \\
\hline PX9 & 0,53 & 0,32 & $-40 \%$ & 2,36 & 0,65 & $-72 \%$ & 5,49 & 1,19 & $-78 \%$ \\
\hline PX10 & 0,53 & 0,38 & $-28 \%$ & 1,40 & 0,74 & $-47 \%$ & 3,02 & 1,67 & $-45 \%$ \\
\hline PY1 & 3,20 & 0,38 & $-88 \%$ & 6,92 & 0,74 & $-89 \%$ & 16,02 & 1,43 & $-91 \%$ \\
\hline PY2 & 0,76 & 0,06 & $-92 \%$ & 1,75 & 0,19 & $-89 \%$ & 5,38 & 0,32 & $-94 \%$ \\
\hline PY3 & 0,11 & 0,05 & $-55 \%$ & 0,18 & 0,16 & $-11 \%$ & 0,28 & 0,23 & $-18 \%$ \\
\hline PY4 & 0,82 & 0,16 & $-80 \%$ & 0,94 & 0,19 & $-80 \%$ & 1,12 & 0,24 & $-79 \%$ \\
\hline PY5 & 3,32 & 0,82 & $-75 \%$ & 6,81 & 1,30 & $-81 \%$ & 16,02 & 2,50 & $-84 \%$ \\
\hline PY6 & 0,11 & 0,05 & $-55 \%$ & 0,19 & 0,15 & $-21 \%$ & 0,29 & 0,21 & $-28 \%$ \\
\hline PY7 & 3,67 & 1,07 & $-71 \%$ & 7,77 & 1,76 & $-77 \%$ & 20,05 & 3,33 & $-83 \%$ \\
\hline PY8 & 0,10 & 0,04 & $-60 \%$ & 0,17 & 0,14 & $-18 \%$ & 0,26 & 0,19 & $-27 \%$ \\
\hline PY9 & 3,59 & 1,26 & $-65 \%$ & 6,90 & 2,50 & $-64 \%$ & 15,34 & 5,00 & $-67 \%$ \\
\hline PY10 & 4,22 & 1,07 & $-75 \%$ & 8,56 & 2,04 & $-76 \%$ & 20,05 & 3,81 & $-81 \%$ \\
\hline PY11 & 0,09 & 0,04 & $-56 \%$ & 0,18 & 0,13 & $-28 \%$ & 0,29 & 0,22 & $-24 \%$ \\
\hline PY12 & 2,93 & 0,32 & $-89 \%$ & 5,67 & 0,74 & $-87 \%$ & 13,66 & 1,43 & $-90 \%$ \\
\hline PY13 & 3,11 & 1,01 & $-67 \%$ & 6,37 & 1,95 & $-69 \%$ & 15,01 & 3,69 & $-75 \%$ \\
\hline PY14 & 0,19 & 0,16 & $-16 \%$ & 0,26 & 0,28 & $6 \%$ & 0,32 & 0,23 & $-28 \%$ \\
\hline PY15 & 3,11 & 0,90 & $-71 \%$ & 6,66 & 1,76 & $-74 \%$ & 15,90 & 3,21 & $-80 \%$ \\
\hline PY16 & 3,95 & 0,25 & $-94 \%$ & 4,57 & 0,46 & $-90 \%$ & 5,15 & 0,71 & $-86 \%$ \\
\hline $\begin{array}{c}\text { Valor } \\
\text { máximo }\end{array}$ & 4,22 & 1,26 & - & 8,56 & 2,5 & & 20,00 & 5,00 & - \\
\hline
\end{tabular}

Observa-se, por intermédio da Tabela 5.5, a ocorrência de recalques diferenciais com e sem o uso da ISE na base das paredes. Esses resultados mostram que o emprego da ISE promove reduções expressivas nos recalques diferenciais.

Para fins práticos, a observação apenas do recalque diferencial pode fornecer poucas informações do comportamento deste elemento. A análise da configuração da deformada do recalque pode ser um melhor parâmetro de avaliação. A comparação dos recalques na projeção de algumas paredes selecionadas com e sem a interação solo-estrutura pode ser observada na Figura 5.8. 


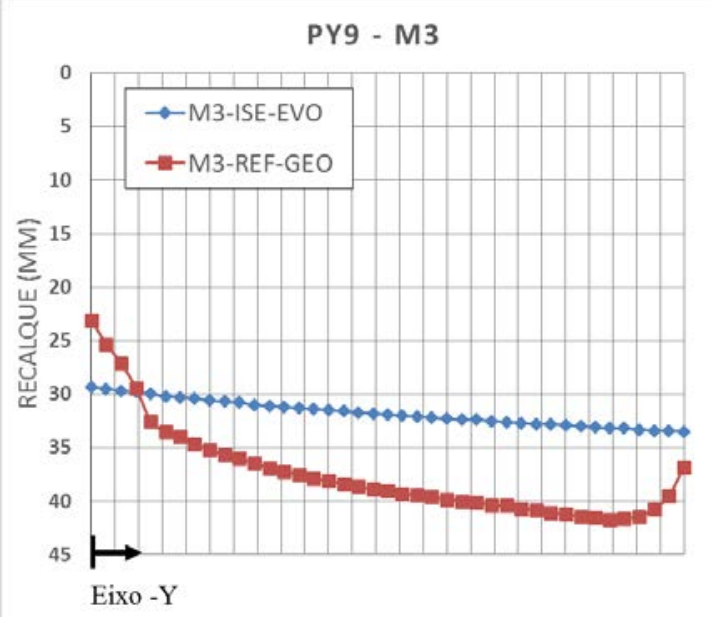

a) Parede PY9 - Modelo M3

PY10 - M2

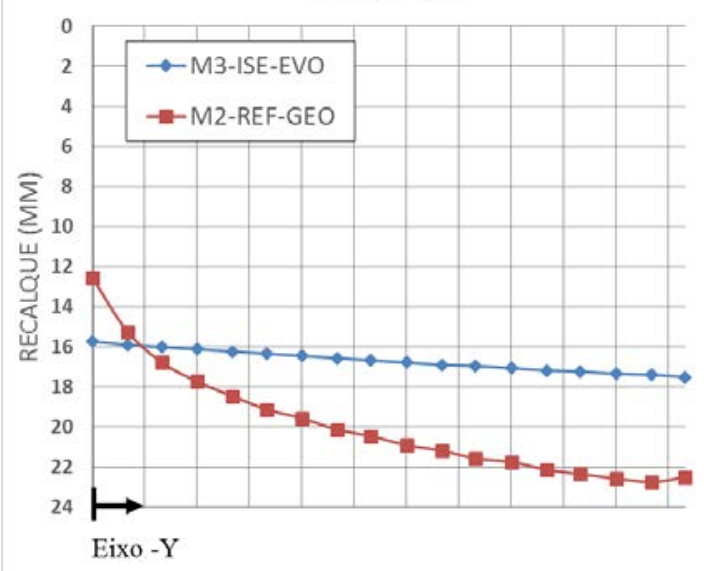

c) Parede PY10 - Modelo M2

PY1 - M1

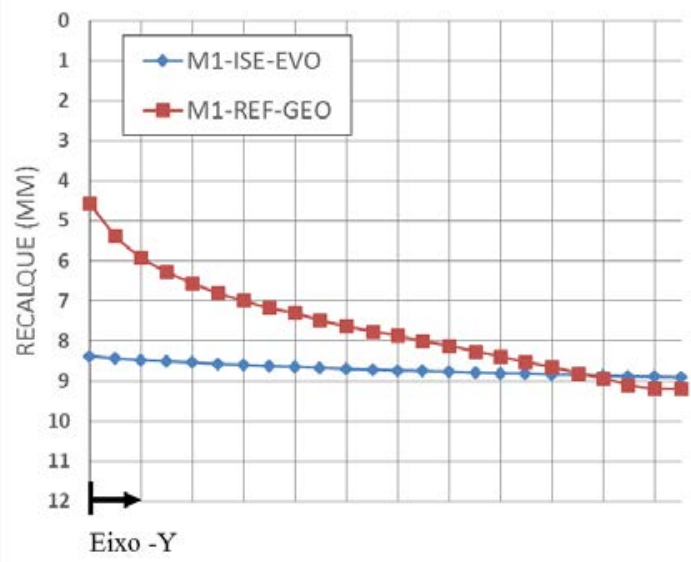

e) Parede Py1 - Modelo M1

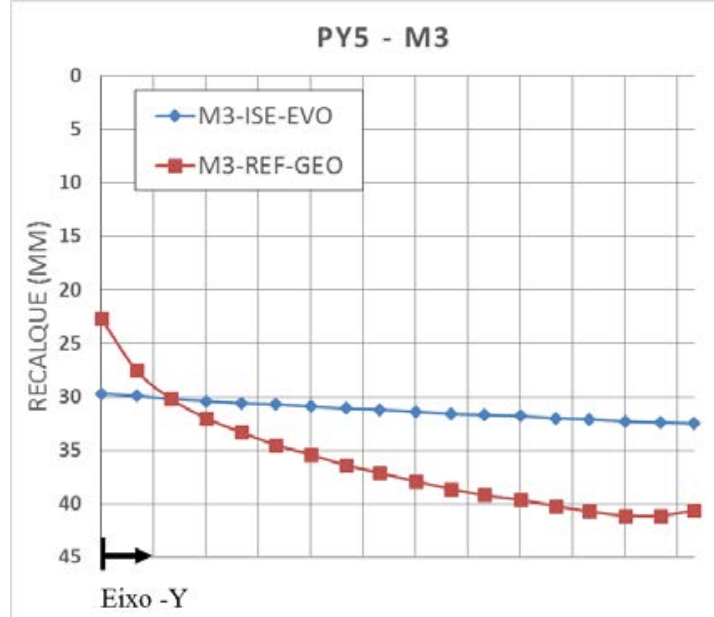

b) Parede PY5 - Modelo M3

PY15 - M1

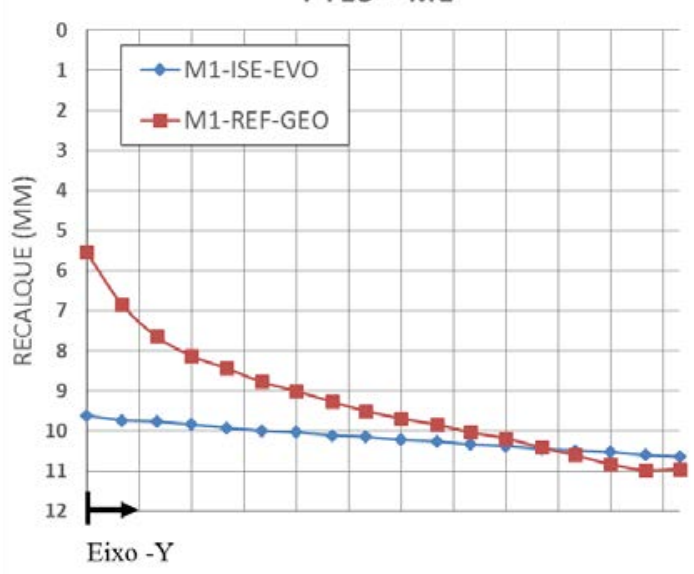

d) Parede PY15 - Modelo M1

PX5 - M2

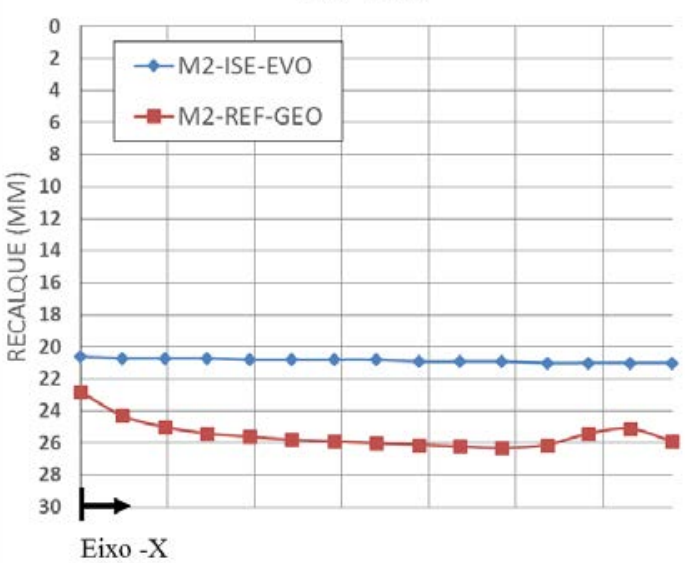

f) Parede Px5 - Modelo M2

Figura 5.8 - Recalques com e sem a ISE

Os resultados mostrados pela Figura 5.8 indicam claramente a atenuação da curvatura da deformada dos recalques na base das paredes quando contemplada a ISE. A curvatura reduzida indica a ocorrência de baixa distorção angular nos elementos da superestrutura. A 
quantificação da distorção angular é importante, já que o seu efeito pode vir a causar fissuras e patologias.

A Figura 5.9 exibe uma comparação de recalques entre os modelos M2-ISE-EVO e M2-REF-GEO, destacando apenas a base das paredes. Embora apresentem intensidades diferentes, os resultados são ilustrados com o mesmo fator de escala no deslocamento vertical, para facilitar a comparação.

$$
\begin{aligned}
& \begin{array}{l}
--.165 \mathrm{E}-1 \\
--.171 \mathrm{E}-1 \\
--.176 \mathrm{E}-1 \\
-.182 \mathrm{E}-1 \\
--.187 \mathrm{E}-1 \\
--.193 \mathrm{E}-1 \\
--.199 \mathrm{E}-1 \\
--.204 \mathrm{E}-1 \\
-{ }_{-}-.21 \mathrm{E}-1
\end{array} \\
& \sum_{x}^{2} \nabla^{\mathrm{Y}}
\end{aligned}
$$
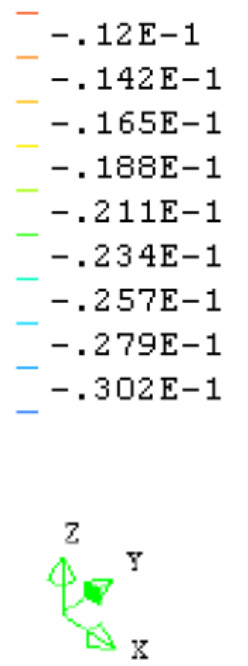

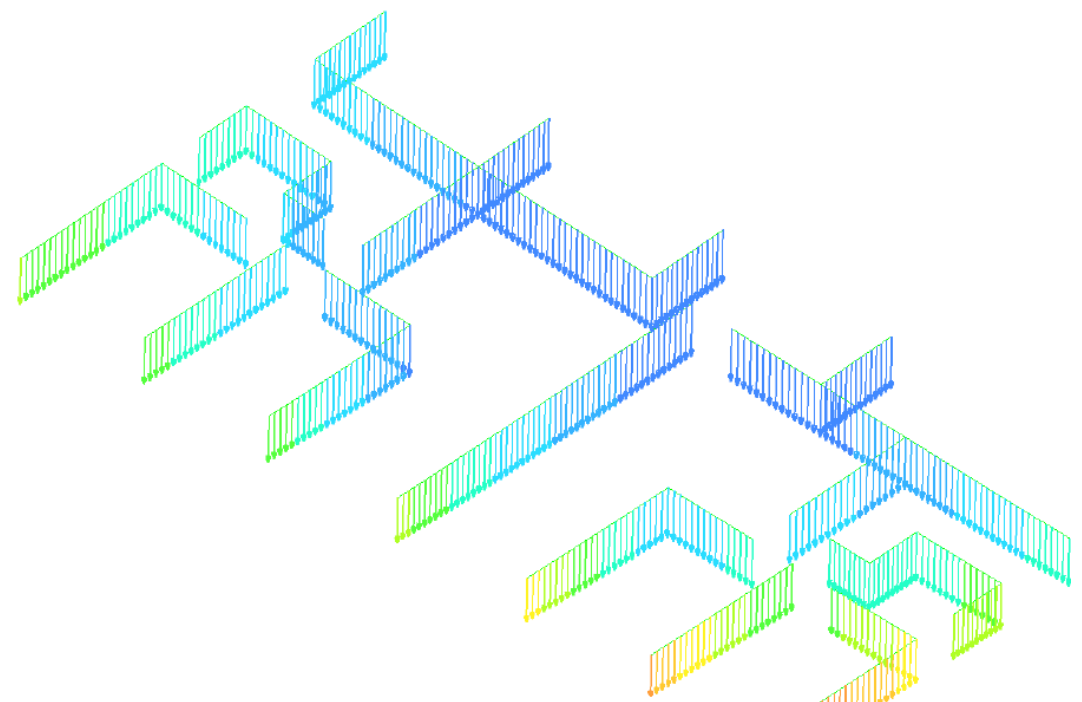

a) M2-ISE-EVO

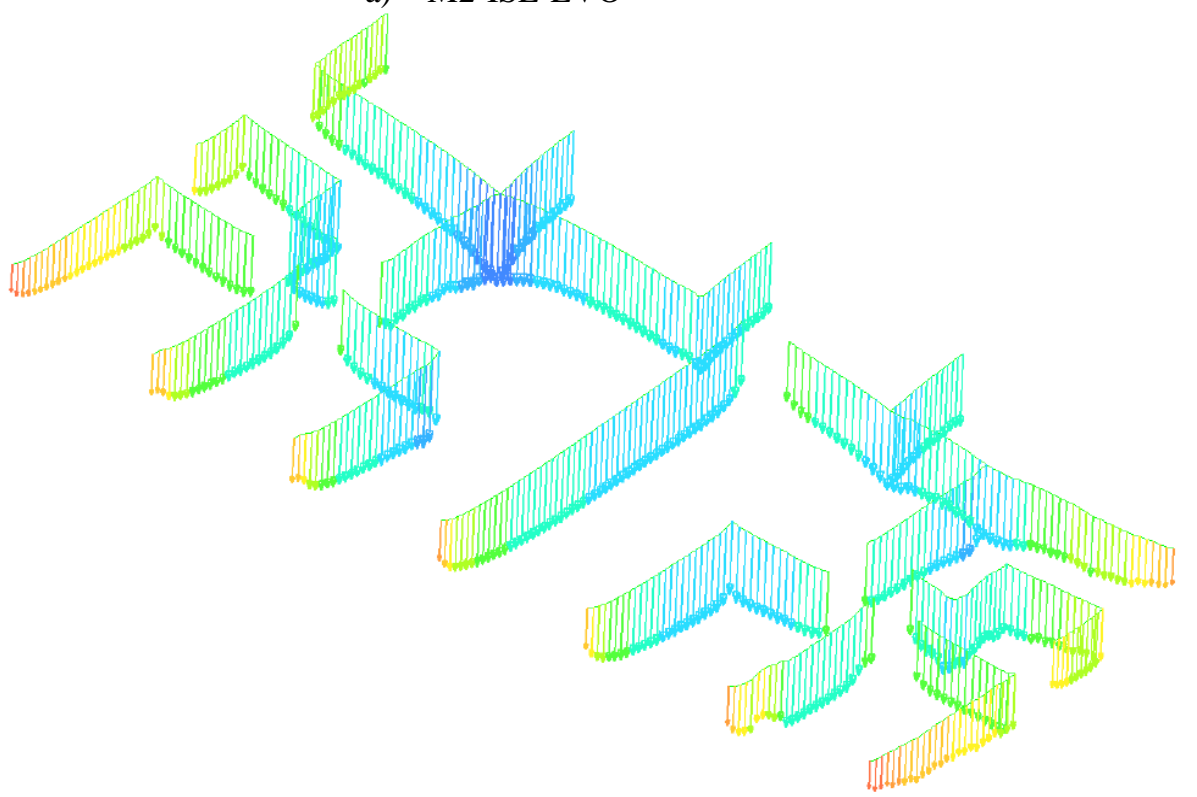

b) M2-REF-GEO

Figura $5.9-\mathrm{u}_{\mathrm{z}}(\mathrm{m})$ - Modelos M2 - Resultados vetoriais

A Figura 5.9 mostra a presença de curvaturas na distribuição do deslocamento vertical na base das paredes no modelo M2-REF-GEO. Quando a rigidez da superestrutura é incorporada, observa-se a redução da curvatura da deformada do recalque. Pode-se afirmar que a ISE beneficia não apenas a uniformização dos recalques, mas reduz a distorção angular dos 
elementos analisados. A Figura 5.10 exibe um diagrama de Lopes e Velosso (2010) com um resumo das consequências da distorção angular em edifícios estudados por Bejrrum (1963) e Vargas e Silva (1973).

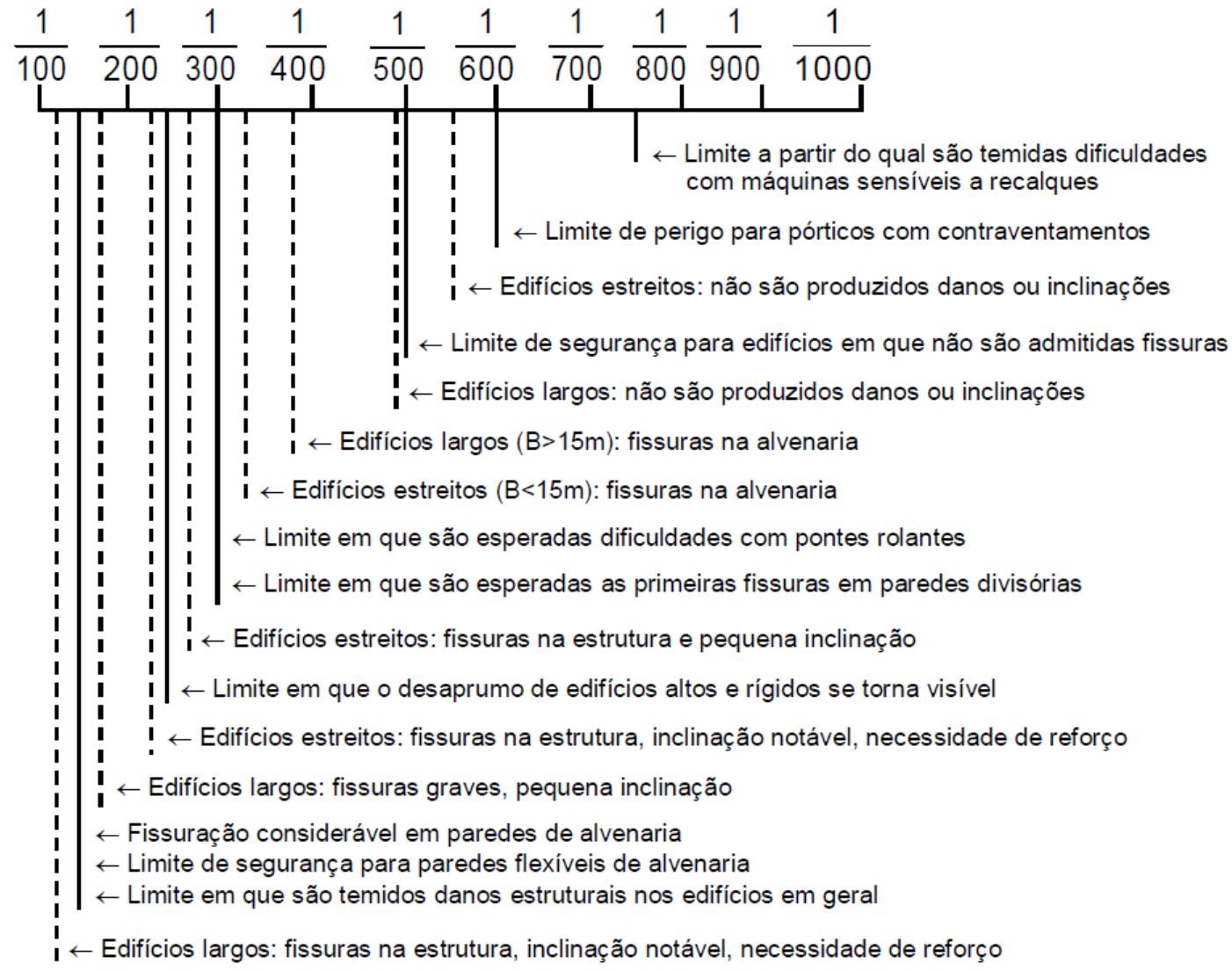

Bjerrum (1963) Vargas e Silva (1973)

Figura 5.10 - Distorção angular e danos estruturais

Tendo em vista essas consequências, pode-se destacar a importância da limitação da distorção angular nos edifícios. Esses valores estão atrelados ao comportamento conjunto da estrutura convencional com os elementos de vedação. Em edifícios de paredes de concreto a própria estrutura tem finalidade de vedação. Deste modo, parece mais coerente fazer a análise ao longo do comprimento de cada elemento. A Tabela 5.6 mostra a quantificação da distorção angular nas bases desses elementos com e sem a ISE. 
Tabela 5.6 - $\beta$ - Distorção angular nas paredes com e sem a ISE

\begin{tabular}{|c|c|c|c|c|c|c|}
\hline \multirow{3}{*}{ PAREDE } & \multicolumn{6}{|c|}{$\beta$} \\
\hline & \multicolumn{2}{|c|}{ M1 } & \multicolumn{2}{|c|}{ M2 } & \multicolumn{2}{|c|}{ M3 } \\
\hline & GEO & ISE-EVO & GEO & ISE-EVO & GEO & ISE-EVO \\
\hline PX1 & 2,71E-03 & $0,00 \mathrm{E}+00$ & $3,65 E-03$ & 2,35E-04 & 4,82E-03 & $7,06 \mathrm{E}-04$ \\
\hline PX2 & 1,53E-03 & $0,00 \mathrm{E}+00$ & 2,82E-03 & $3,53 E-04$ & $4,18 \mathrm{E}-03$ & $8,24 \mathrm{E}-04$ \\
\hline PX3 & 2,88E-03 & $0,00 \mathrm{E}+00$ & 3,50E-03 & 5,00E-04 & 4,00E-03 & 7,50E-04 \\
\hline PX4 & $1,00 \mathrm{E}-03$ & $0,00 \mathrm{E}+00$ & 1,38E-03 & $0,00 \mathrm{E}+00$ & $2,50 \mathrm{E}-03$ & $0,00 \mathrm{E}+00$ \\
\hline PX5 & $1,76 \mathrm{E}-03$ & $1,18 \mathrm{E}-04$ & 2,35E-03 & $1,48 \mathrm{E}-04$ & 4,59E-03 & $1,68 \mathrm{E}-04$ \\
\hline PX6 & $4,71 \mathrm{E}-04$ & $5,88 \mathrm{E}-05$ & $1,76 \mathrm{E}-03$ & 6,78E-05 & $2,16 \mathrm{E}-03$ & 7,98E-05 \\
\hline PX7 & 1,00E-03 & 4,78E-05 & 1,47E-03 & 5,88E-05 & 2,76E-03 & 1,15E-04 \\
\hline PX8 & 1,35E-03 & 1,18E-04 & 1,76E-03 & $1,26 \mathrm{E}-04$ & 3,35E-03 & $1,56 \mathrm{E}-04$ \\
\hline PX9 & 5,53E-04 & 5,37E-05 & 6,43E-04 & 6,67E-05 & 1,37E-03 & 1,33E-04 \\
\hline PX10 & 2,30E-03 & $1,00 \mathrm{E}-04$ & 3,00E-03 & $1,00 \mathrm{E}-04$ & 3,80E-03 & $1,00 \mathrm{E}-04$ \\
\hline PY1 & 8,00E-04 & $0,00 \mathrm{E}+00$ & 1,07E-03 & $0,00 \mathrm{E}+00$ & 1,73E-03 & $0,00 \mathrm{E}+00$ \\
\hline PY2 & 2,60E-03 & $0,00 \mathrm{E}+00$ & 5,00E-04 & $0,00 \mathrm{E}+00$ & $1,80 \mathrm{E}-03$ & $0,00 \mathrm{E}+00$ \\
\hline PY3 & 1,82E-03 & 1,00E-04 & 2,27E-03 & 1,33E-04 & 4,30E-03 & 2,33E-04 \\
\hline PY4 & 1,27E-04 & 2,53E-05 & 2,78E-04 & 5,06E-05 & 4,30E-04 & 7,59E-05 \\
\hline PY5 & 2,36E-03 & 1,17E-04 & 2,77E-03 & 1,67E-04 & 4,17E-03 & 2,00E-04 \\
\hline PY6 & 1,53E-03 & $0,00 \mathrm{E}+00$ & 1,80E-03 & $0,00 \mathrm{E}+00$ & 2,60E-03 & $0,00 \mathrm{E}+00$ \\
\hline PY7 & 1,11E-03 & 1,60E-04 & 1,55E-03 & 1,90E-04 & 3,09E-03 & 2,24E-04 \\
\hline PY8 & 1,80E-03 & $0,00 E+00$ & $1,87 \mathrm{E}-03$ & $0,00 \mathrm{E}+00$ & 4,03E-03 & $6,67 \mathrm{E}-05$ \\
\hline PY9 & 6,67E-04 & $0,00 \mathrm{E}+00$ & 8,67E-04 & $0,00 \mathrm{E}+00$ & 1,33E-03 & $0,00 \mathrm{E}+00$ \\
\hline PY10 & $4,08 \mathrm{E}-04$ & $4,08 \mathrm{E}-05$ & 4,49E-04 & $8,16 \mathrm{E}-05$ & 1,47E-03 & $8,16 \mathrm{E}-05$ \\
\hline PY11 & $1,43 \mathrm{E}-03$ & $6,67 \mathrm{E}-05$ & $1,77 \mathrm{E}-03$ & $6,87 \mathrm{E}-05$ & $3,55 \mathrm{E}-03$ & 6,89E-05 \\
\hline PY12 & $1,60 \mathrm{E}-03$ & $1,00 \mathrm{E}-04$ & 2,90E-03 & $1,00 \mathrm{E}-04$ & 4,40E-03 & $1,00 \mathrm{E}-03$ \\
\hline PY13 & 1,37E-03 & $7,67 \mathrm{E}-05$ & 1,41E-03 & $3,33 E-05$ & 2,53E-03 & 3,33E-05 \\
\hline PY14 & 1,80E-03 & $0,00 \mathrm{E}+00$ & 1,80E-03 & $0,00 \mathrm{E}+00$ & $1,80 \mathrm{E}-03$ & $0,00 \mathrm{E}+00$ \\
\hline PY15 & $2,71 \mathrm{E}-03$ & $0,00 \mathrm{E}+00$ & $3,65 \mathrm{E}-03$ & $2,35 \mathrm{E}-04$ & $4,82 \mathrm{E}-03$ & $7,06 \mathrm{E}-04$ \\
\hline PY16 & 1,53E-03 & $0,00 \mathrm{E}+00$ & $2,82 \mathrm{E}-03$ & 3,53E-04 & $4,18 \mathrm{E}-03$ & $8,24 \mathrm{E}-04$ \\
\hline $\begin{array}{c}\text { Valor } \\
\text { Máximo }\end{array}$ & 2,88E-03 & $1,60 \mathrm{E}-04$ & $3,65 \mathrm{E}-03$ & $5,00 \mathrm{E}-04$ & 4,75E-03 & 1,00E-03 \\
\hline
\end{tabular}

Observa-se que alguns elementos apresentam distorções angulares próximas de 1/200 quando não incorporada a ISE. A inclusão da ISE reduziu significativamente esses valores nas bases das paredes. Alguns elementos não apresentam distorção angular quando considerada a ISE, indicando recalques desuniformes sem distorção. Essa ocorrência é mais suscetível nas paredes de menor comprimento, como por exemplo, as PX3, PX4 e PY16.

A redução dos recalques e da distorção angular nas bases das paredes com o uso da ISE ocorre devido ao acréscimo da rigidez da superestrutura. No trabalho desenvolvido por Gusmão (1994) fica evidente a uniformização dos recalques em edifícios convencionais. No presente estudo a mesma hipótese mostra-se verdadeira para edifícios de paredes de concreto. 
Além disso, os resultados apresentados mostram que quanto à distorção angular, as reduções destes valores foram bastante expressivas.

\subsection{AÇÕES EVOLUTIVAS E UNIFORMIZAÇÃO DOS RECALQUES}

Avalia-se os efeitos das ações evolutivas na distribuição dos recalques e sua homogeneização. Esse estudo é realizado com base nos resultados da aplicação das ações instantâneas, descritos no capítulo 4, no modelo ISE-INS. A Figura 5.11 mostra a comparação dos iso-recalques entre os modelos M2-ISE-EVO e M2-ISE-INS.

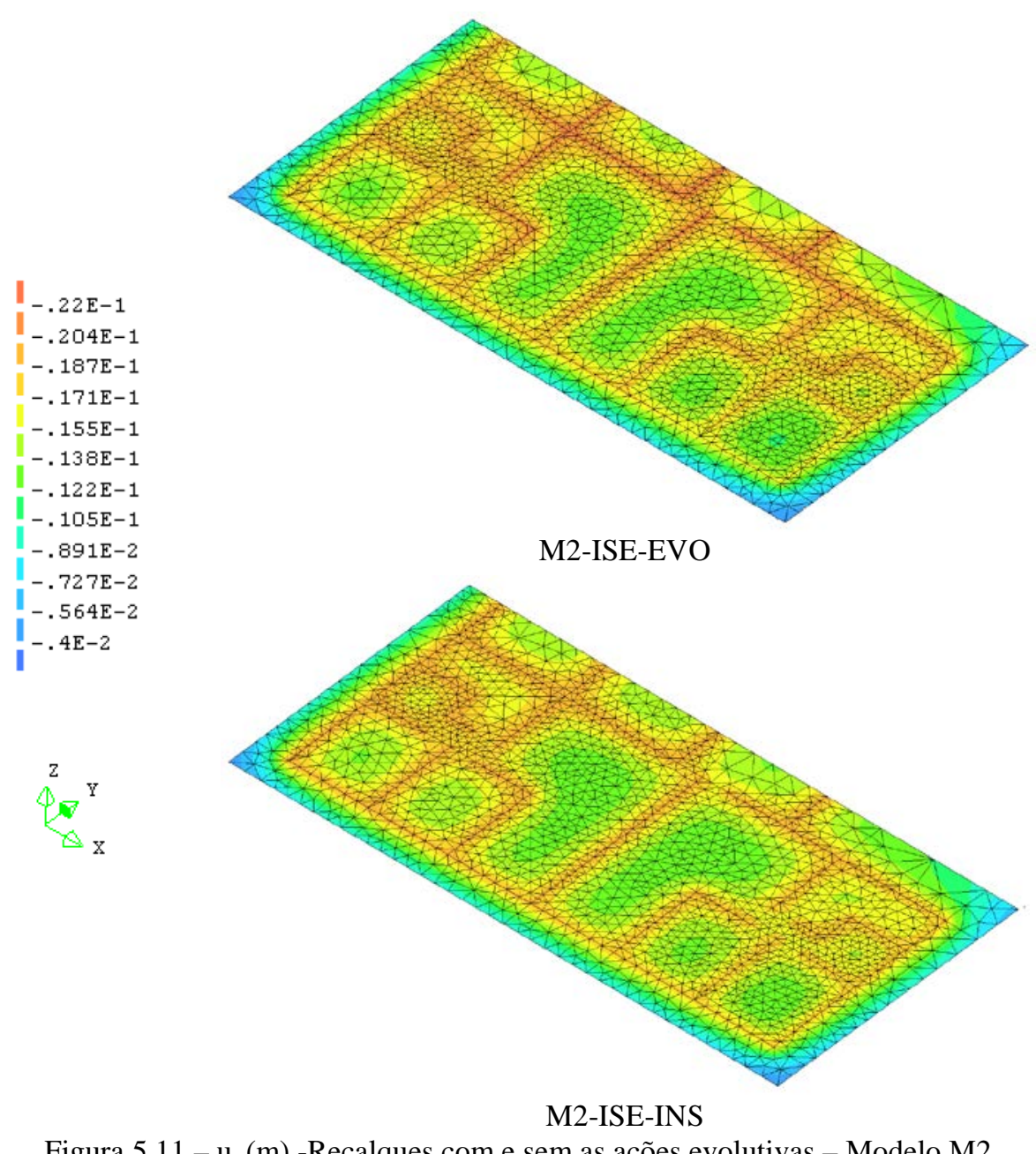

Figura $5.11-\mathrm{u}_{\mathrm{z}}(\mathrm{m})$-Recalques com e sem as ações evolutivas - Modelo M2

Os iso-recalques exibidos na Figura 5.11 indicam que o uso das ações instantâneas (M2-ISE-INS) fornece uma configuração mais homogênea, embora de modo sutil. Percebe-se também redução nos recalques máximos do radier. A Tabela 5.7 mostra um resumo das variáveis relacionadas aos recalques do radier, comparando-se os modelos com e sem a aplicação das ações evolutivas. 
Tabela 5.7 - Recalques - Modelos ISE-EVO x ISE-INS

\begin{tabular}{|c|c|c|c|c|c|c|}
\hline \multirow{2}{*}{ Modelo/Perfil } & \multicolumn{2}{|c|}{ M1 } & \multicolumn{2}{c|}{ M2 } & \multicolumn{2}{c|}{ M3 } \\
\cline { 2 - 7 } & ISE-EVO & ISE-INS & ISE-EVO & ISE-INS & ISE-EVO & ISE-INS \\
\hline $\bar{w}(\mathrm{~mm})$ & 7,47 & 7,39 & 16,21 & 16,13 & 37,71 & 37,74 \\
\hline$w_{\operatorname{máx}}(\mathrm{mm})$ & 10,10 & 9,39 & 21,51 & 20,32 & 49,42 & 47,42 \\
\hline$w_{\min }(\mathrm{mm})$ & 1,61 & 1,78 & 3,61 & 3,97 & 8,68 & 9,41 \\
\hline $\begin{array}{c}\text { Desvio padrão } \\
(\mathrm{mm})\end{array}$ & 1,39 & 1,25 & 2,91 & 2,66 & 6,59 & 6,16 \\
\hline $\mathrm{CV}_{\mathrm{w}}$ & $18,6 \%$ & $17,0 \%$ & $17,9 \%$ & $16,7 \%$ & $17,5 \%$ & $16,5 \%$ \\
\hline
\end{tabular}

Os valores mostrados na Tabela 5.7 mostram que o uso das ações instantâneas fornece recalques mais homogêneos do que as ações evolutivas. Os resultados apontados no Capítulo 4 possibilitaram concluir que o procedimento evolutivo reduziu os efeitos da ISE na superestrutura. Partindo dessa premissa, considerar a ISE com a aplicação de ações instantâneas poderia resultar em uma distribuição de esforços a favor da segurança na superestrutura, desde que o modelo de apoios rígidos também seja utilizado no dimensionamento dos elementos.

Sobre os recalques, a premissa é inversa. O uso do procedimento evolutivo reduz o efeito da homogeneização dos recalques. Deste modo, utilizar as ações instantâneas em conjunto com ISE pode fornecer uma maior uniformização dos recalques.

O procedimento evolutivo redistribui os esforços a cada fase da construção, reduzindo o recalque diferencial entre os elementos em sua base e a influência da ISE. Esta aproximação reduz a uniformização dos recalques. A Figura 5.12 mostra um gráfico com a evolução do coeficiente de variação dos recalques ao longo da construção dos pavimentos. São exibidos também os resultados finais do coeficiente de variação dos modelos com o uso das ações instantâneas.

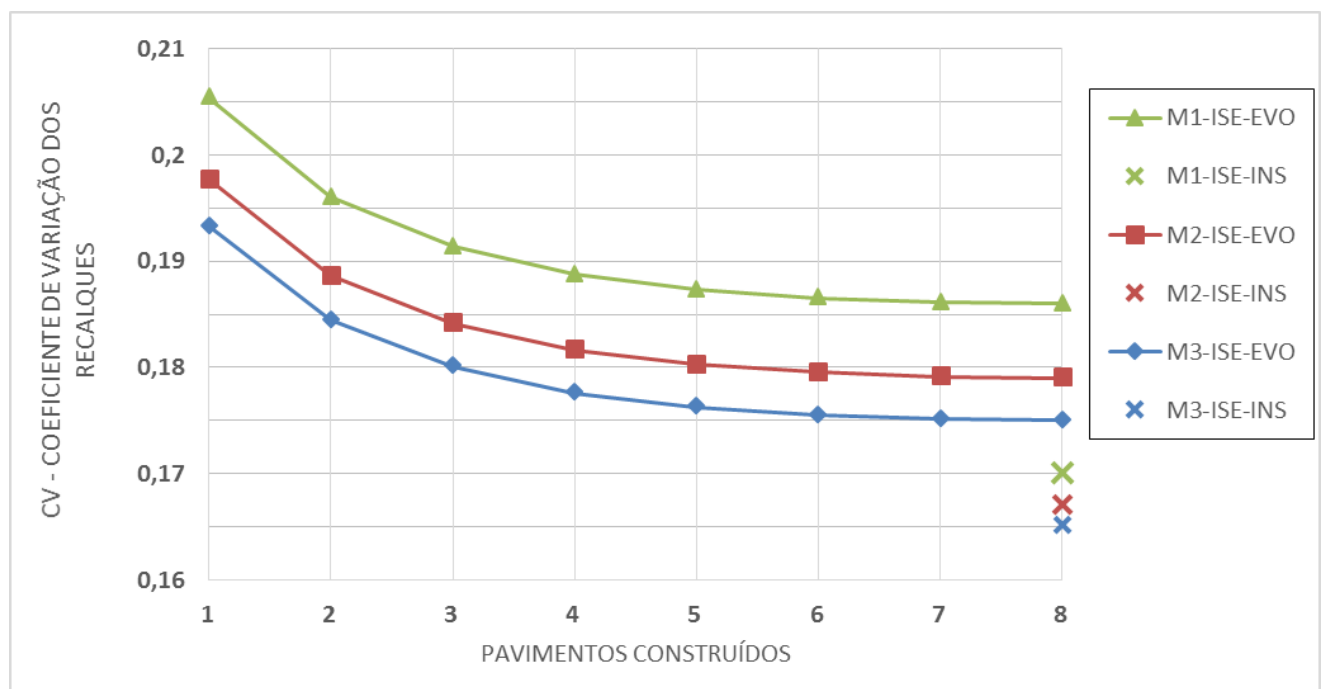

Figura 5.12 - Coeficiente de Variação dos recalques - Ações evolutivas x Ações instantâneas. 
A Figura 5.12 indica atenuações do coeficiente de variação dos recalques conforme são construídos os pavimentos subsequentes da estrutura. A cada fase de construção é adicionada a rigidez do pavimento e, com a consequente redistribuição de cargas, ocorre a homogeneização dos recalques.

No entanto, observa-se que a redução do coeficiente não é linear com a construção de novos pavimentos. Este fato indica que a contribuição da rigidez dos pavimentos superiores é menor em relação aos pavimentos inferiores. Não ocorrem grandes mudanças no coeficiente de variação após a construção do $5^{\circ}$ pavimento. Os coeficientes de variação, com a inserção do procedimento evolutivo, foram superiores aos apresentados com o procedimento convencional de ações instantâneas.

\subsection{ASPECTOS CONCLUSIVOS SOBRE A DISTRIBUIÇÃO DOS RECALQUES}

Os resultados apresentados indicam a uniformização dos recalques quando incorporada a ISE e consequentemente atenuações das distorções angulares na base das paredes. Trechos próximos ao centro sofrem reduções dos recalques com a inclusão da ISE e nas regiões periféricas ocorre um aumento desses valores.

Tendo em vista a homogeneização dos recalques, pode-se fazer uma relação desta com a modificação dos esforços nos elementos. Como apresentado no capítulo 4, a redistribuição das cargas ocorre com o acréscimo em paredes localizadas próximas da periferia da edificação e o alívio nas regiões próximas ao centro.

Gusmão (1990) propôs o parâmetro “AR”, denominado como fator de recalque absoluto, para avaliar a uniformização dos recalques e a tendência de redistribuição de cargas nos pilares. O parâmetro (Equação 5.1) foi utilizado pelo autor em análises comparativas dos valores medidos dos recalques com os estimados via modelo numérico.

$$
\begin{aligned}
& A R=\frac{W i}{\bar{W}} \\
& \text { AR: Fator de Recalque Absoluto } \\
& \text { Wi: Recalque absoluto do apoio } i \\
& \bar{W}: \text { Recalque absoluto médio }
\end{aligned}
$$

$O$ “ $A R$ ” examina se o recalque do elemento analisado possui valor superior ou inferior à média do recalque da edificação. Objetivando relacionar a uniformização dos recalques com as modificações de esforços por consequência da ISE é realizada uma alteração no “AR”. A 
Equação 5.2 mostra a modificação proposta. O “ $\triangle A R$ ” estima percentualmente a alteração do fator de recalque perante a inclusão da rigidez da superestrutura.

$$
\triangle A R=\frac{\text { Wiref }- \text { Wise }}{\bar{W}}
$$

$\triangle A R:$ Variação do Fator de Recalque Absoluto

Wiref: Recalque médio absoluto da parede

Wise: Recalque médio absoluto da parede

$\bar{W}:$ Recalque absoluto médio

Como o recalque médio entre os dois procedimentos são similares, o parâmetro permite avaliar se a inclusão da ISE aproximou ou afastou os recalques da parede estrutural do valor médio da estrutura. O coeficiente positivo indica o afastamento percentual perante o recalque médio. O coeficiente negativo indica que a inclusão da ISE aumentou percentualmente os recalques naquele elemento perante o valor médio.

A avaliação deste parâmetro é realizada em conjunto com o coeficiente de redistribuição de cargas apresentado no capítulo 4. Os recalques sem a incorporação da ISE são obtidos por meio dos modelos REF-GEO. Os recalques com a inserção da ISE adquiridos por intermédio dos modelos ISE-EVO. Os valores das modificações dos esforços são os mesmos expostos anteriormente, no qual são confrontados os resultados entre os modelos ISE-EVO e REF-AP. O comportamento dos modelos quanto a esta variável foram similares, deste modo são apresentados os resultados no modelo M3. Os resultados nos modelos M1 e M2 são mostrados no Apêndice C. A Figura 5.13 mostra a relação dos dois coeficientes na tipologia M3 para as paredes na direção do Eixo X.

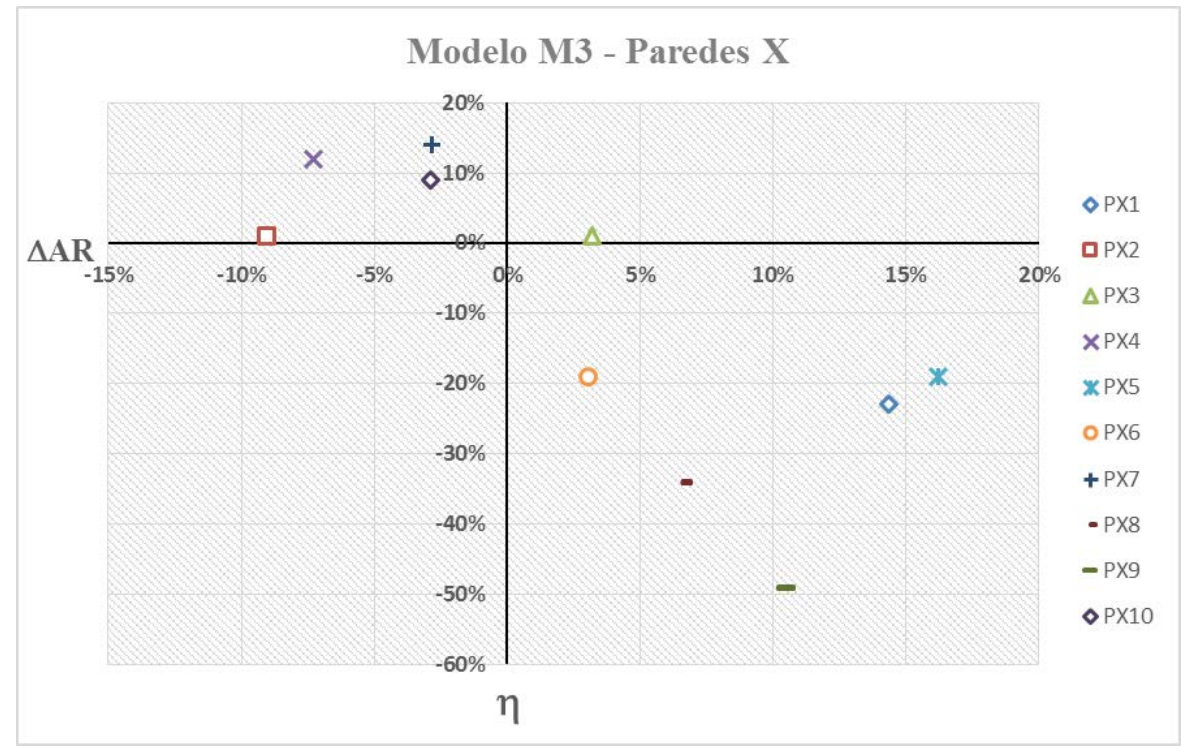

Figura $5.13-\Delta$ AR x $\eta$ - Modelo M3 - Paredes X 
A observação da Figura 5.13 mostra a relação entre a uniformização dos recalques com a redistribuição de esforços em decorrência da ISE. A tendência dessa uniformização tem ligação direta com o aumento e com o alivio das cargas nas paredes.

Os elementos que apresentam variação positiva do fator de recalque com a inclusão da ISE têm como decorrência o alívio de esforços normais. A inclusão da ISE proporciona de forma conjunta a redução das reações normais com a aproximação dos seus recalques com o valor médio da edificação. Os elementos que apresentam variação negativa do fator de recalque têm como consequência o acréscimo de esforços. A Figura 5.14 mostra os resultados nas paredes da direção Y e a Figura 5.15 esses valores por grupo de parede.

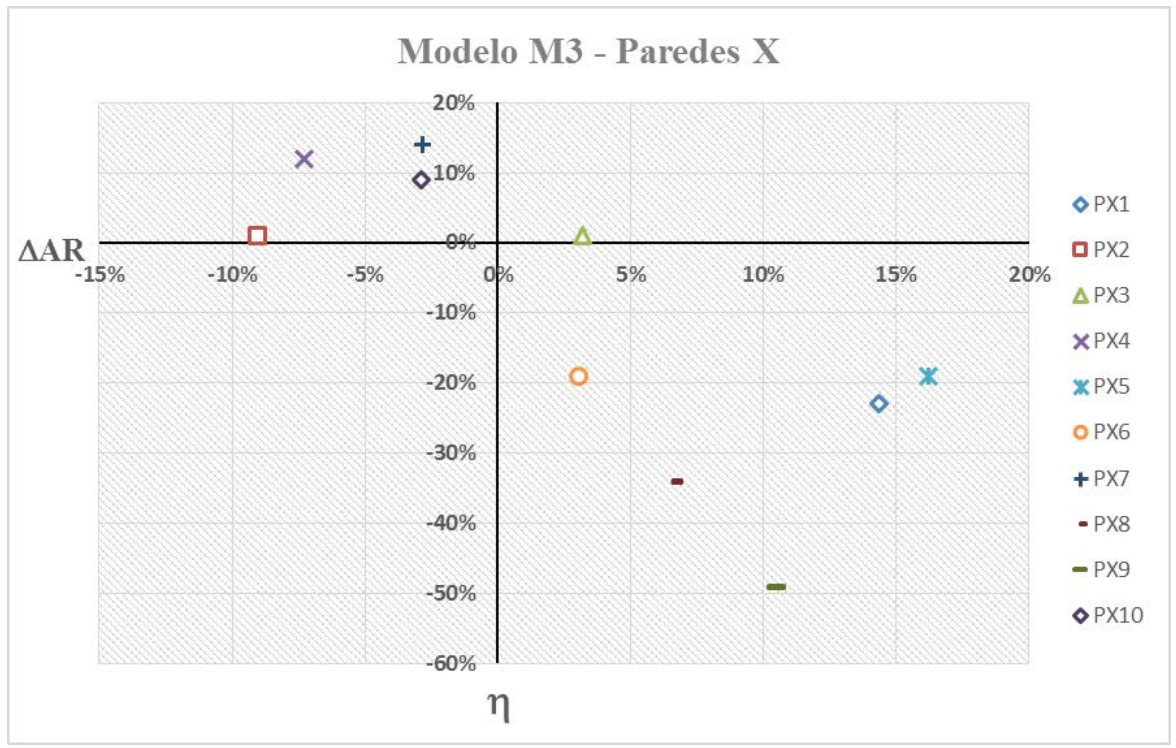

Figura 5.14 - $\triangle$ AR x $\eta$ - Modelo M3 - Paredes Y

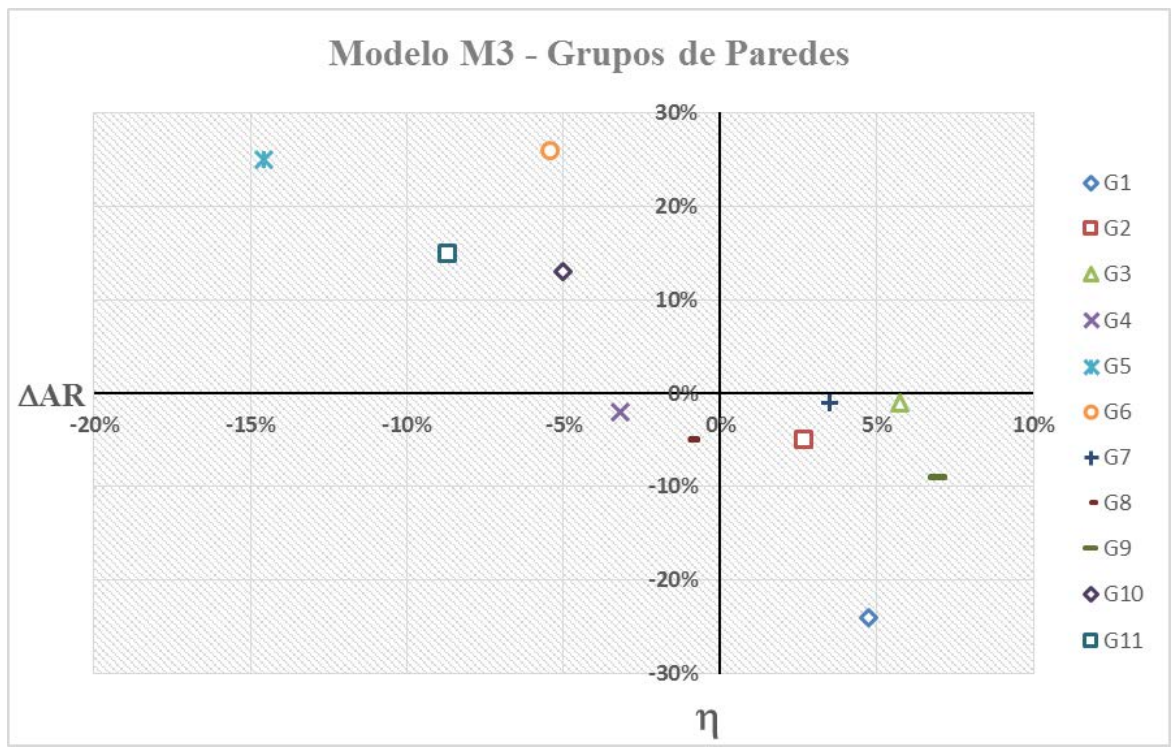

Figura 5.15 - $\triangle \mathrm{AR}$ x $\eta$ - Modelo M3 - Grupos de paredes 
Esses resultados reforçam o comportamento conjunto solo-estrutura. A atenuação dos recalques na base da parede ocorre simultaneamente com o acréscimo dos esforços em decorrência da hiperestaticidade do sistema estrutural. O processo é similar em relação à redução das cargas em conjunto com o aumento dos recalques na base dos elementos. Como ressaltado no capítulo 4, o tratamento separado dos fenômenos (uniformização dos recalques e alterações nas cargas) deve ser evitado. A redistribuição de cargas funciona em conjunto com a homogeneização dos recalques na fundação por consequência da ISE.

\subsection{ANÁLISE DOS ESFORÇOS NA FUNDAÇÃO}

O capítulo 4 mostrou que a incorporação da ISE altera de maneira significativa as cargas nas paredes da estrutura e o fluxo de tensões nesses elementos. Pode-se supor que essas alterações possam acarretar em modificações nos esforços internos na fundação. Os esforços internos solicitantes estudados neste item são os momentos fletores no radier, já que estes são preponderantes no dimensionamento estrutural deste elemento. Os resultados são apresentados por meio de Iso-momentos no radier.

A Figura 5.16 apresenta a primeira análise comparativa dos Iso-Momentos no radier, sendo estes na direção do Eixo-X $\left(m_{x x}\right)$, entre os modelos M1-ISE-EVO e M1-REF-GEO. Os resultados seguem o sistema de eixos global da estrutura. A convenção da direção e sentido dos momentos é a mesma apresentada no capítulo 3. Deste modo, os momentos negativos indicam que a seção do radier está tracionada na região inferior. 


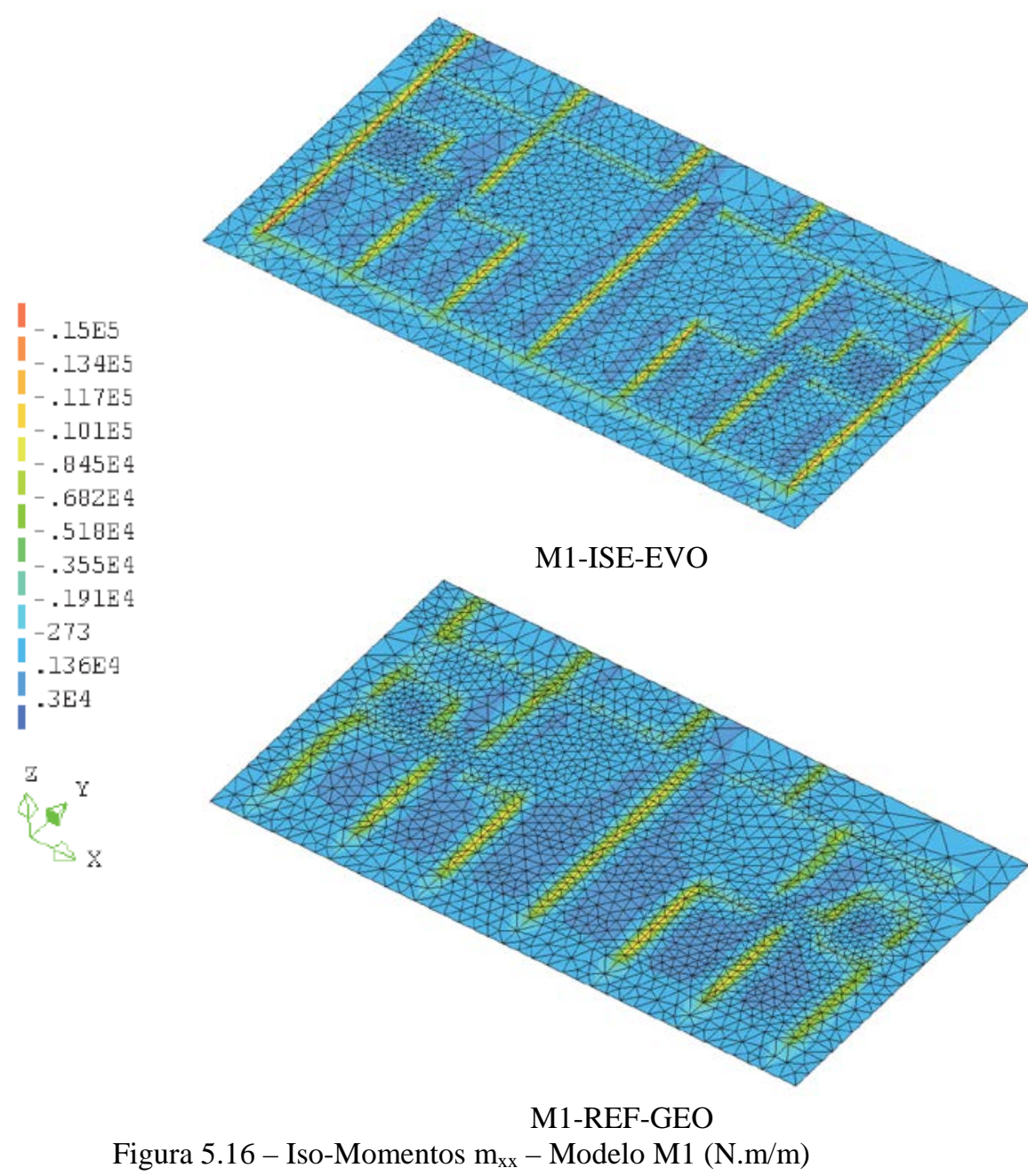

A comparação de resultados dos momentos “ $m_{x x}$ ” apresentada pela Figura 5.16, mostra que a inclusão da rigidez da estrutura proporcionou poucas alterações na distribuição desses esforços. Ambos os modelos apresentam concentração de momentos negativos na projeção das paredes estruturais. Destaca-se que o momento negativo na convenção utilizada proporciona tensões de tração na região inferior do radier. Os momentos positivos ocorrem entre os vãos das paredes com e sem a consideração da ISE. São visíveis pequenas diferenças na intensidade dos valores, mas a distribuição dos esforços permanece semelhante.

A visualização dos Iso-momentos no radier por completo dificulta a interpretação dessa redistribuição. Deste modo, são mostrados alguns resultados localizados em regiões específicas do radier. A Figura 5.17 mostra os resultados de Iso-Momentos “ $m_{x x}$ ” na região das paredes PY1, PY5 e PY7. 

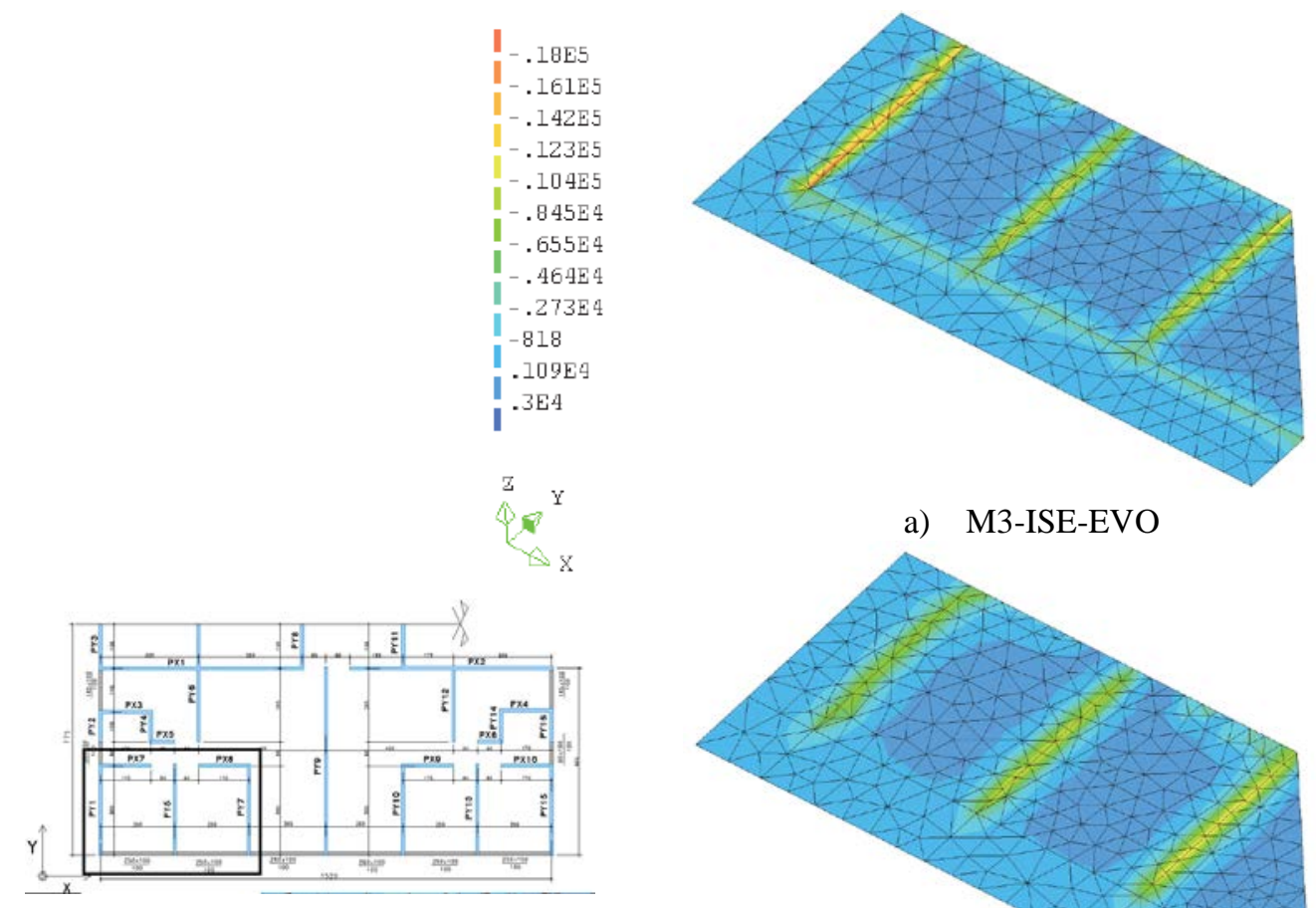

a) M3-ISE-EVO

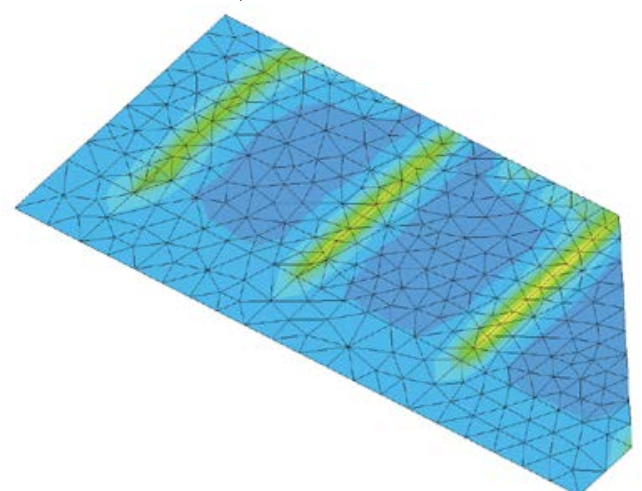

b) M3-REF-GEO

Figura 5.17 - Iso-Momentos $\mathrm{m}_{\mathrm{xx}}$ - Modelo M3 (N.m/m) - Região PY1-PY5-PY7

A análise da Figura 5.17 permite observar que a maior diferença de resultado entres os modelos é na intensidade dos momentos na base da parede PY1. A redistribuição de cargas com a consideração da ISE acarretou em acréscimo de esforços nos elementos da periferia. Neste caso a parede PY1 no modelo com a ISE apresenta cargas atuantes superiores as cargas impostas no modelo de referência. Este fato justifica a diferença dos momentos no radier entre os modelos. A Figura 5.18 mostra os resultados na região da parede PY9, sendo esta uma região localizada mais ao centro da edificação em planta. 


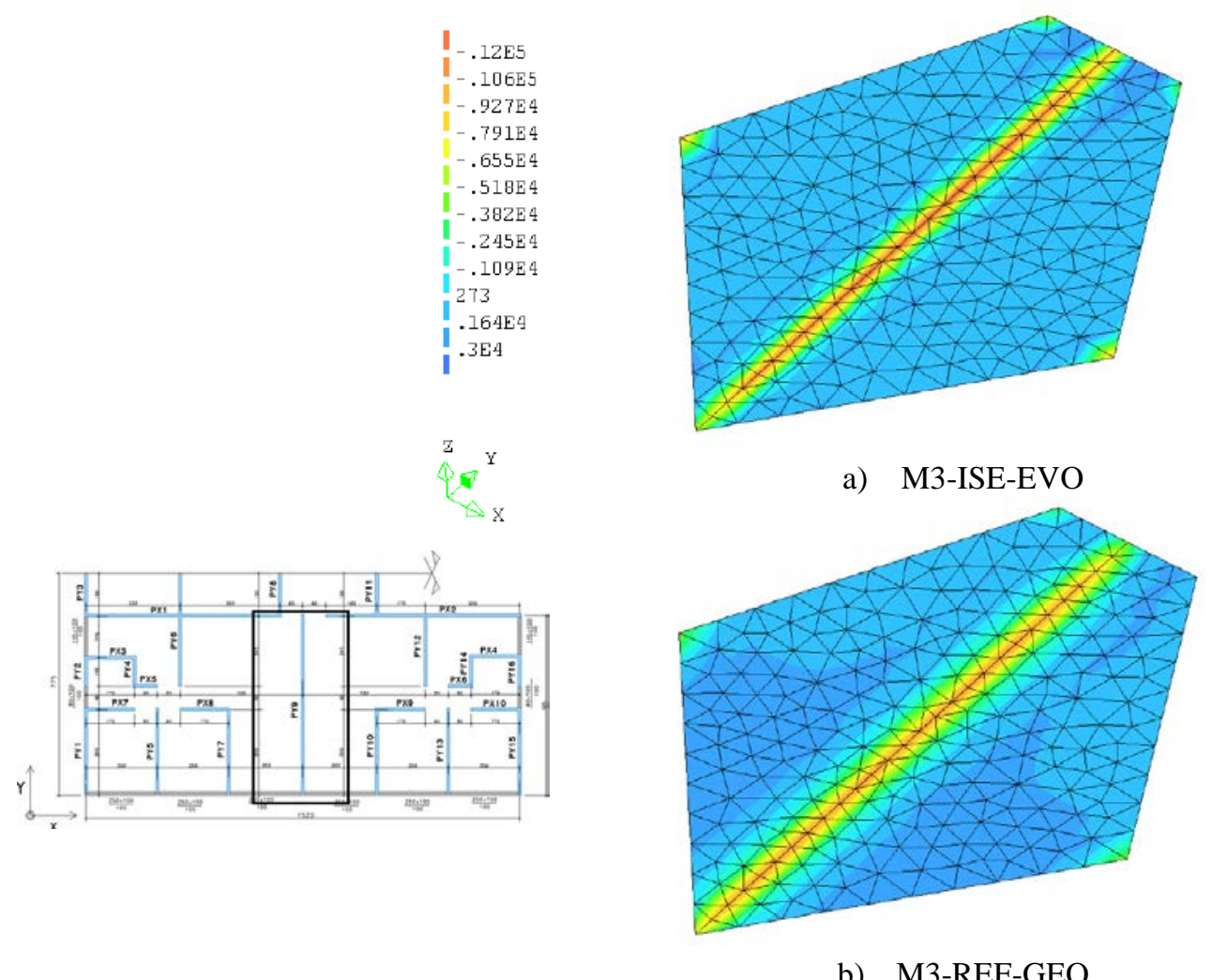

b) M3-REF-GEO

Figura 5.18 - Iso-Momentos $\mathrm{m}_{\mathrm{xx}}$ - Modelo M3 (N.m/m) - Região PY9

Os momentos na base da parede PY9 são similares nos dois modelos. Entretanto o modelo com a desconsideração da contribuição da rigidez da estrutura (M3-REF-GEO) fornece momentos positivos superiores na região fora da projeção da parede PY9.

A redistribuição de cargas nas paredes não é suficientemente alta para que se modifique o comportamento geral do radier. Todavia, ocorrem modificações na intensidade dos momentos, principalmente nas bases das paredes. A ISE proporcionou de uma forma geral um aumento dos momentos na base das paredes e uma redução entre os vãos.

A Figura 5.19 apresenta os Iso-Momentos “ $M_{y y}$ ” com e sem a contemplação da rigidez da estrutura nos modelos M2. 

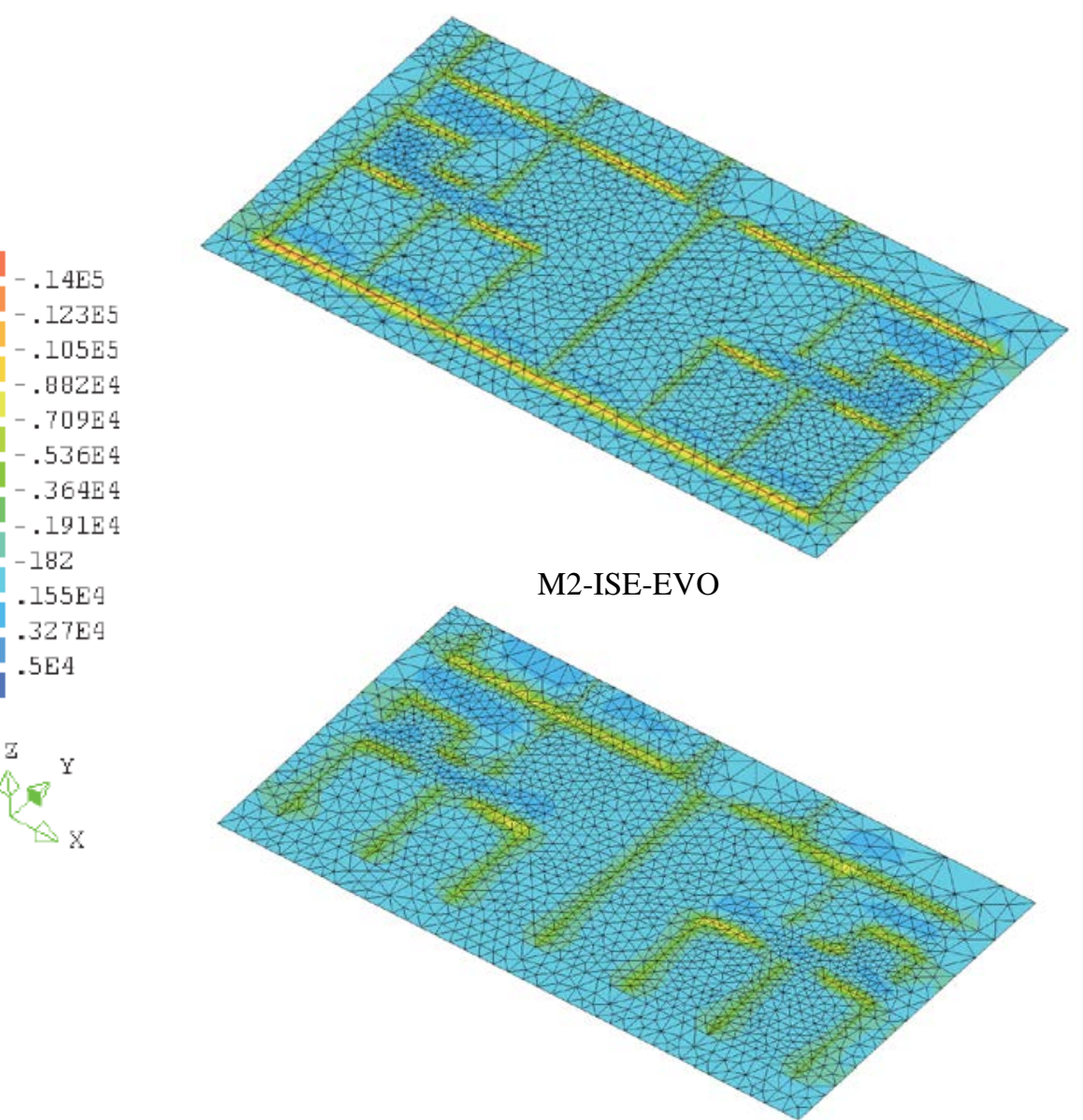

M2-REF-GEO

Figura 5.19 - Iso-Momentos $\mathrm{m}_{\mathrm{yy}}-$ Modelo M2 (N*m/m)

A Figura 5.19 indica semelhança quanto ao comportamento apresentado anteriormente. Esse resultado reforça que a distribuição de esforços no radier com e sem a inserção da ISE são análogos, com variações dos momentos fletores nas proximidades das paredes. Nota-se também a concentração de momentos na base dos linteis do modelo com a consideração, justificado pela interação destes com as paredes. Estes são desprezados no modelo sem a ISE.

A distribuição dos momentos “ $m_{y y}$ ” são sempre superiores na base das paredes com a consideração da ISE. A Figura 5.20 mostra a análise localizada da distribuição dos momentos “ $m_{y y}$ ” na região central da edificação ou do grupo de paredes G1. 

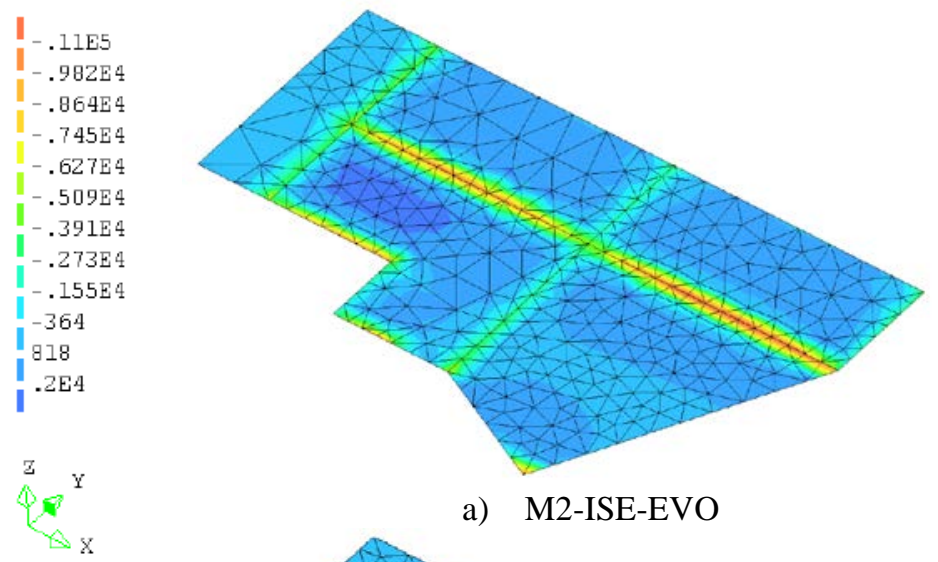

a) M2-ISE-EVO
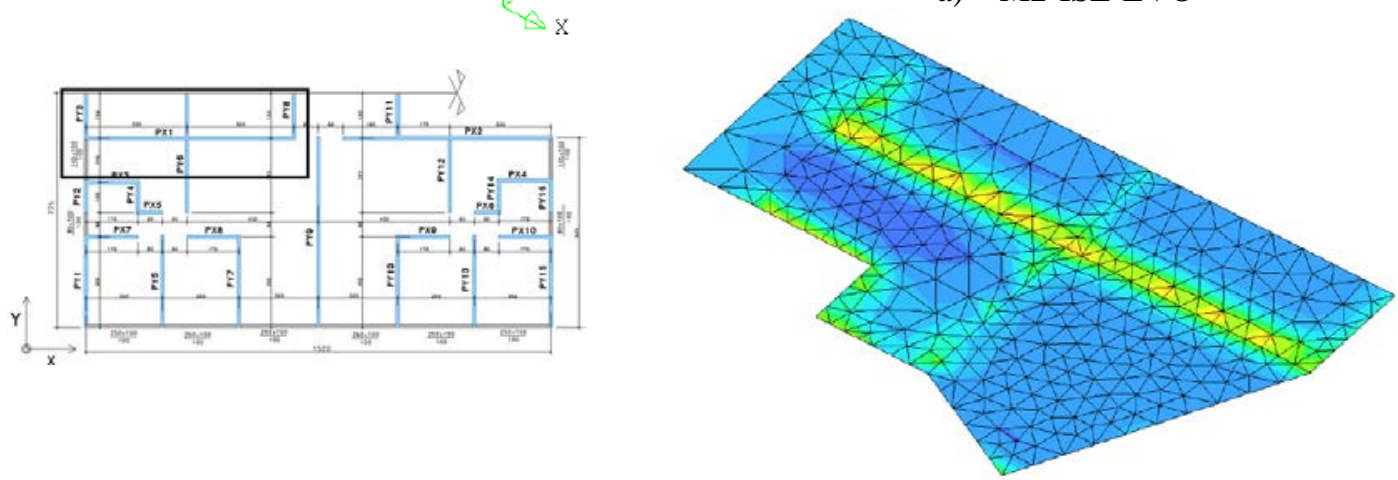

b) M2-REF-GEO

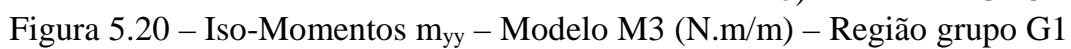

Novamente destaca-se a concentração de momentos negativos na base das paredes. Os momentos negativos, na base das paredes, são superiores nos modelos com a consideração da ISE. Nas regiões localizadas entre as paredes o modelo sem a ISE apresenta momentos positivos superiores ao modelo M2-ISE-EVO. A Figura 5.21 apresenta os Iso-Momentos “ $m_{x y}$ ” do modelo M3, com e sem incorporação da ISE. 

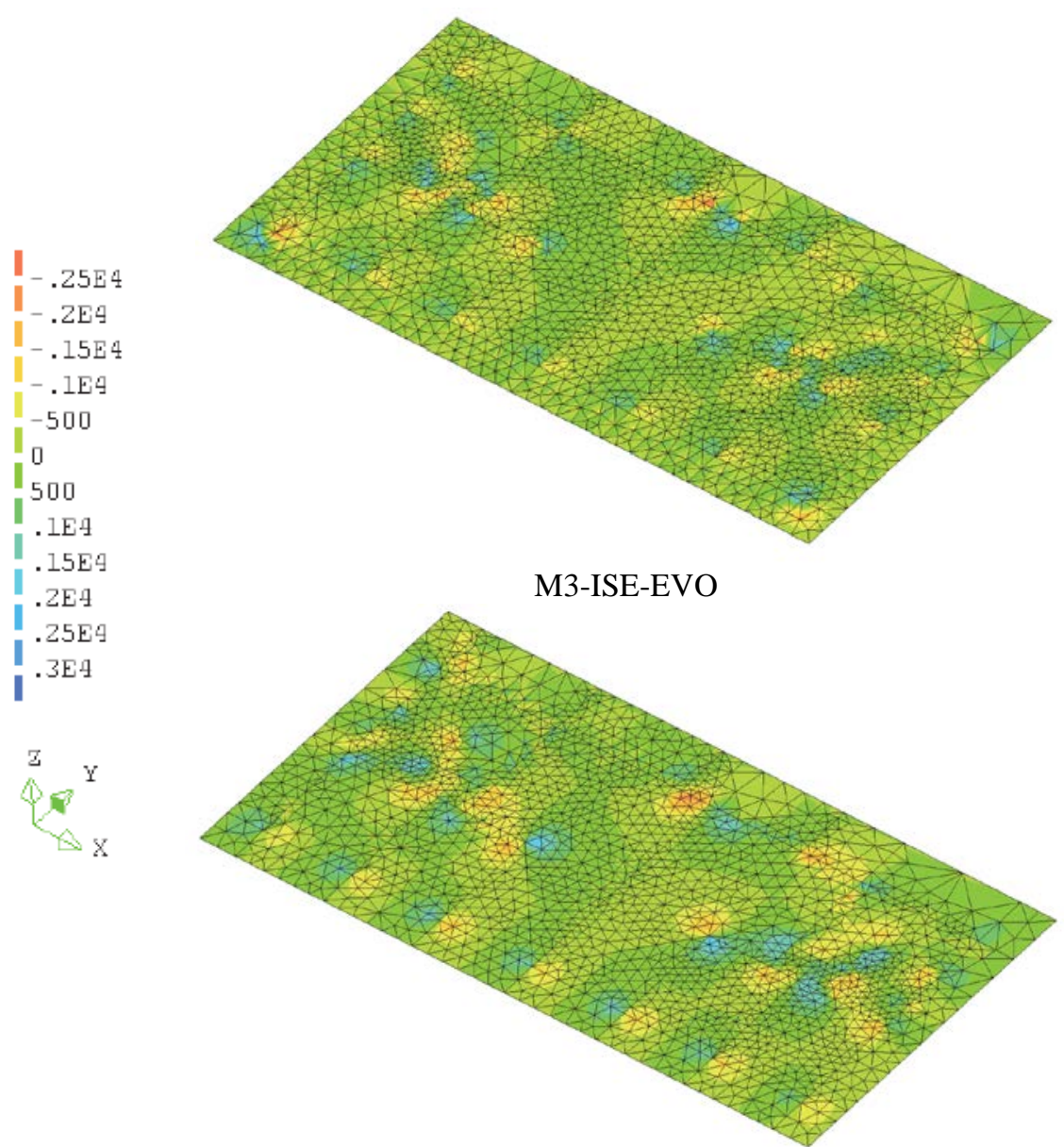

M3-REF-GEO

Figura 5.21 - Iso-Momento $\mathrm{m}_{\mathrm{xy}}-$ Modelo M3 (N.m/m)

A Figura 5.21 indica que a inclusão da rigidez da estrutura (M3-ISE-EVO) reduziu de forma substancial a distribuição dos Momentos “ $m_{x y}$ ” na região central da edificação. Este fato se deu principalmente nas proximidades dos grupos de paredes G3 e G4. A análise localizada da distribuição do momento “ $m_{x y}$ ” na região do grupo G3 é apresentado na Figura 5.22. 


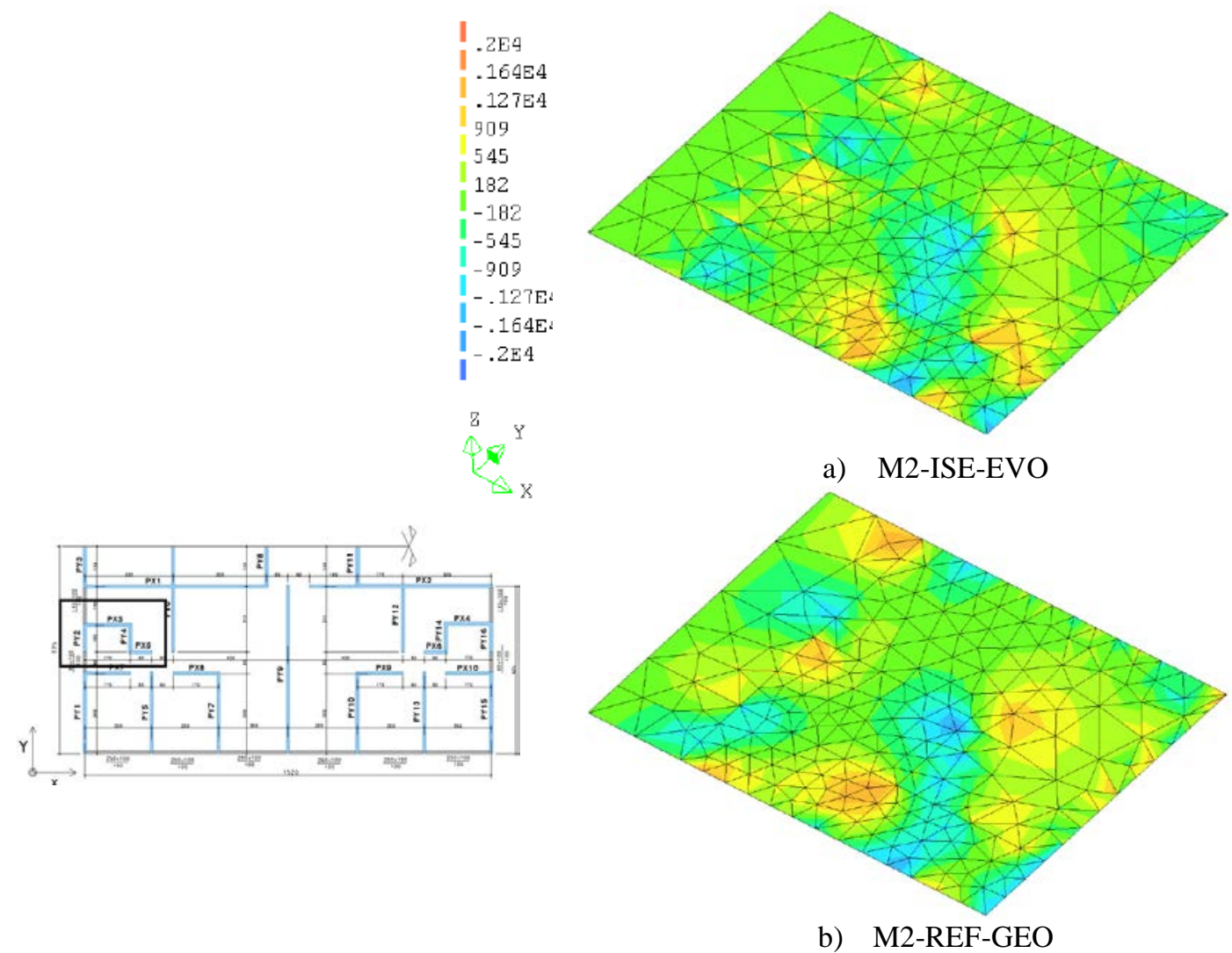

Figura 5.22 - Iso-Momento $\mathrm{M}_{\mathrm{xy}}$ - Modelo M3 (N*m/m) - Região grupo G3

Os momentos “ $m_{x y}$ ” na região do grupo de parede G3 são superiores no modelo de referência. A introdução da rigidez da estrutura reduziu a distribuição deste momento nesta região.

De um modo geral percebe-se o seguinte comportamento na distribuição de esforços do radier quando a ISE é incorporada no modelo:

- Momentos “ $m_{x x}$ ” e “ $m_{y y}$ ” na base das paredes são superiores.

- Momentos “ $m_{x x}$ ” e “ $m_{y y}$ ” distribuídos entre as paredes são inferiores.

- Momentos “ $m_{x y}$ ” são inferiores.

Os resultados expostos são baseados na distribuição dos momentos em três componentes, “ $m_{x x}$ ”, “ $m_{y y}$ ” e “ $m_{x y}$ ”. Do ponto de vista prático do projetista de estruturas o dimensionamento do radier é realizado com base na distribuição dos momentos em duas direções principais perpendiculares. Essas direções corresponde a disposição das armaduras nas lajes. Neste caso, as próprias direções X e Y em planta adotadas do próprio modelo

O procedimento comumente utilizado neste caso é determinar os momentos normais as direções escolhidas, $m_{x x}^{*}$ e $m_{y y}^{*}$, que contemple os esforços “ $m_{x x}$ ”, “ $m_{y y}$ ” e “ $m_{x y}$ ”. Esse procedimento é baseado nas equações de “Wood e Armer” (Wood, 1968). A Equação 5.3 e a 
Equação 5.4 mostra as equações dos momentos fletores equivalentes normais as direções $\mathrm{X}$ e $\mathrm{Y}$ respectivamente.

$$
\begin{aligned}
& M_{x x}^{*}=M_{x x}+\left|M_{x y}\right| \\
& M_{y y}^{*}=M_{y y}+\left|M_{x y}\right|
\end{aligned}
$$

Equação 5.4

As equações acima estão em suas formas simplificadas, nas quais têm como hipótese a contribuição similar dos momentos " $m_{x x}^{*}$ " e “ $m_{y y}^{*}$ " na resistência do momento volvente “ $\mathrm{M}_{\mathrm{xy}}$ ”. Esta simplificação considera que a distribuição das armaduras no radier nas duas direções sejam similares, o que é uma hipótese razoável no problema analisado.

São analisados os momentos equivalentes nas bases e nos trechos entre paredes. São mostrados sempre os valores máximos, pois são estes normalmente utilizados em casos práticos de dimensionamento. Os valores máximos dos momentos $m_{x x}^{*}$ são analisados nas paredes e trechos da direção Y e os momentos $m_{y y}^{*}$ nas paredes e trecho da direção X. Essa análise é realizada nos modelos M2. Os resultados nos modelos M1 e M3 são similares nos demais modelos. A Tabela 5.8 mostra os momentos equivalentes $m_{x x}^{*}$ na base das paredes. A Tabela 5.9 mostra os momentos nos trechos entre as paredes. São apresentados o acréscimo e a redução

\begin{tabular}{|c|c|c|c|}
\hline \multirow{2}{*}{ PAREDE } & \multicolumn{2}{|c|}{$\mathrm{m}_{\mathrm{xx}}^{*}(\mathrm{kN} \cdot \mathrm{m} / \mathrm{m})$} & \multirow{2}{*}{$\begin{array}{c}\text { Acréscimo/redução } \\
\text { percentual com a } \\
\text { inclusão da ISE }\end{array}$} \\
\hline & M2-ISE-EVO & M2-REF-GEO & \\
\hline PY1 & $-16,9$ & $-12,1$ & $40,6 \%$ \\
\hline PY2 & $-13,2$ & $-8,9$ & $49,5 \%$ \\
\hline PY3 & $-14,1$ & $-10,6$ & $32,8 \%$ \\
\hline PY4 & $-9,2$ & $-6,8$ & $35,0 \%$ \\
\hline PY5 & $-12,0$ & $-10,1$ & $18,4 \%$ \\
\hline PY6 & $-10,8$ & $-7,1$ & $52,6 \%$ \\
\hline PY7 & $-13,3$ & $-11,7$ & $13,3 \%$ \\
\hline PY8 & $-10,8$ & $-8,0$ & $34,9 \%$ \\
\hline PY9 & $-13,3$ & $-11,7$ & $13,2 \%$ \\
\hline PY10 & $-11,2$ & $-12,4$ & $-10,0 \%$ \\
\hline PY11 & $-12,0$ & $-8,6$ & $39,0 \%$ \\
\hline PY12 & $-9,5$ & $-6,6$ & $42,5 \%$ \\
\hline PY13 & $-11,2$ & $-11,0$ & $1,6 \%$ \\
\hline PY14 & $-9,2$ & $-6,6$ & $39,4 \%$ \\
\hline PY15 & $-11,2$ & $-8,9$ & $25,1 \%$ \\
\hline PY16 & $-12,0$ & $-8,1$ & $47,8 \%$ \\
\hline \multicolumn{3}{|c|}{ Valor médio } & $29,7 \%$ \\
\hline
\end{tabular}
percentual desses esforços com a inclusão da ISE. 
Tabela 5.9 - Momentos Equivalentes máximos $-\mathrm{m}^{*}{ }_{\mathrm{xx}}-$ Trechos entre Paredes

\begin{tabular}{|c|c|c|c|}
\hline \multirow{2}{*}{ TRECHOS } & \multicolumn{2}{|c|}{$\mathrm{m}^{*}{ }_{\mathrm{xx}}(\mathrm{kN} . \mathrm{m} / \mathrm{m})$} & \multirow{2}{*}{$\begin{array}{c}\text { Acréscimo/redução } \\
\text { percentual com a } \\
\text { inclusão da ISE }\end{array}$} \\
\cline { 2 - 3 } & M2-ISE-EVO & M2-REF-GEO & $-28,4 \%$ \\
\hline PY1/PY5 & 1,3 & 1,8 & $-21,3 \%$ \\
\hline PY5/PY7 & 1,6 & 2,0 & $-17,2 \%$ \\
\hline PY7/PY9 & 1,7 & 2,1 & $-53,8 \%$ \\
\hline PY9/PY10 & 0,1 & 0,3 & $-13,6 \%$ \\
\hline PY10/PY13 & 1,9 & 2,2 & $-11,4 \%$ \\
\hline PY13/PY15 & 1,7 & 1,9 & $-13,3 \%$ \\
\hline PY2/PY4 & 2,1 & 2,4 & $-10,9 \%$ \\
\hline PY4/PY6 & 1,7 & 1,9 & $-28,9 \%$ \\
\hline PY6/PY9 & 1,0 & 1,4 & $-14,4 \%$ \\
\hline PY9/PY12 & 1,9 & 2,2 & $-41,7 \%$ \\
\hline PY12/PY14 & 0,2 & 0,3 & $-15,9 \%$ \\
\hline PY14/PY16 & 1,7 & 2,0 & $-17,0 \%$ \\
\hline PY3/PY6 & 1,6 & 1,9 & $-17,9 \%$ \\
\hline PY6/PY8 & 1,6 & 2,0 & $-12,4 \%$ \\
\hline PY8/PY10 & 2,2 & 2,5 & $-21,2 \%$ \\
\hline & Valor médio & & \\
\hline
\end{tabular}

Os resultados mostram que a inclusão da ISE promove o aumento dos momentos equivalentes na base das paredes. A Tabela 5.8 indica que a ampla maioria dos elementos tiveram seus momentos majorados com a inclusão da ISE, sendo o valor médio de acréscimo percentual de $29,7 \%$. Nos trechos entre as paredes a inclusão da ISE reduziu os momentos, sendo a redução média de 21,2\%. A Tabela 5.10 mostra os momentos equivalentes na direção Y na base das paredes da estrutura. A Tabela 5.11 mostra essa mesma análise, sendo realizada nos trechos entre paredes.

Tabela 5.10 - Momentos Equivalentes máximos $-\mathrm{m}_{\mathrm{yy}}^{*}$ - Base das Paredes

\begin{tabular}{|c|c|c|c|}
\hline \multirow{2}{*}{ PAREDES } & \multicolumn{2}{|c|}{$\mathrm{m}_{\mathrm{yy}}^{*}(\mathrm{kN} . \mathrm{m} / \mathrm{m})$} & \multirow{2}{*}{$\begin{array}{c}\text { Acréscimo/redução } \\
\text { percentual com a } \\
\text { inclusão da ISE }\end{array}$} \\
\cline { 2 - 3 } & M2-ISE-EVO & M2-REF-GEO & $36,8 \%$ \\
\hline PX1 & 12,5 & 9,2 & $28,3 \%$ \\
\hline PX2 & 11,6 & 9,0 & $46,4 \%$ \\
\hline PX3 & 10,5 & 7,2 & $47,3 \%$ \\
\hline PX4 & 8,2 & 5,6 & $40,2 \%$ \\
\hline PX5 & 8,2 & 5,9 & $39,1 \%$ \\
\hline PX6 & 8,5 & 6,1 & $52,7 \%$ \\
\hline PX7 & 10,5 & 6,9 & $42,0 \%$ \\
\hline PX8 & 12,9 & 9,1 & $14,6 \%$ \\
\hline PX9 & 10,8 & 9,4 & $39,8 \%$ \\
\hline PX10 & 10,5 & 7,5 & $38,7 \%$ \\
\hline \multicolumn{3}{|c|}{ Valor médio } & \\
\hline
\end{tabular}


Tabela 5.11 - Momentos Equivalentes máximos - $\mathrm{m}_{\mathrm{yy}}^{*}$ - Trechos entre paredes

\begin{tabular}{|c|c|c|c|}
\hline \multirow{2}{*}{ TRECHOS } & \multicolumn{2}{|c|}{$\mathrm{m}_{\text {yy }}^{*}(\mathrm{kN} . \mathrm{m} / \mathrm{m})$} & \multirow{2}{*}{$\begin{array}{c}\text { Acréscimo/redução } \\
\text { percentual com a } \\
\text { inclusão da ISE }\end{array}$} \\
\cline { 2 - 3 } & M2-ISE-EVO & M2-REF-GEO & $-18,0 \%$ \\
\hline PX1-PX3 & 2,3 & 2,8 & $-18,2 \%$ \\
\hline PX2-PX4 & 2,3 & 2,8 & $-33,6 \%$ \\
\hline PX3-PX7 & 1,3 & 2,0 & $-5,2 \%$ \\
\hline PX4-PX10 & 1,7 & 1,8 & $-18,8 \%$ \\
\hline \multicolumn{3}{|c|}{ Valor médio } \\
\hline
\end{tabular}

Os resultados das análises dos momentos equivalentes “ $m_{y y}^{*}$ ” são similares aos obtidos para os momentos equivalente “ $m_{x x}^{*}$ ". Na base das paredes localizadas na direção x ocorrem acréscimos de até 52,7\%, sendo o valor médio de 38,7\%, com a inclusão da ISE. Nos trechos localizados entre as paredes a redução do momento " $m^{*}{ }_{y y}$ ” apresenta um valor médio de 18,8\%.

As três tipologias estudadas indicam que a alteração dos momentos fletores, quando incorporada a ISE, é mais afetada em trechos próximos às paredes. São modificadas a intensidade desses valores, geralmente apresentando acréscimo de momentos na base da paredes e reduções nos trechos localizados entre os elementos.

A principal diferença entre os modelos REF-GEO e ISE-EVO está na contemplação da rigidez da superestrutura na redistribuição de cargas e uniformização dos recalques. Desta forma, como ressaltado anteriormente, as conclusões observadas não devem ser utilizadas na comparação da influência da ISE em relação aos modelos baseados em molas discretas (tipo Winkler).

\subsection{CONCLUSÕES DO CAPÍTULO}

A partir das análises e levantamentos realizados pode-se chegar às seguintes conclusões do presente capítulo.

- A inserção da superestrutura provoca reduções nos níveis dos recalques máximos e aumento dos recalques mínimos, deste modo promovendo a homogeneização da distribuição dos recalques no radier.

- Os efeitos da inclusão da superestrutura são mais benéficos na redução da distorção angular das paredes. A uniformização dos recalques promove uma forte atenuação dessa variável nas bases desses elementos. 
- A consideração da sequência construtiva em conjunto com a ISE reduz a uniformização dos recalques em comparação com um modelo com a inclusão da ISE e o uso das ações instantâneas.

- A redução do coeficiente de variação dos recalques utilizando as ações evolutivas é progressiva com a construção do edifício, mas não é linear. Os pavimentos superiores contribuem menos na homogeneização dos recalques na fundação. Após a construção do $5^{\circ}$ pavimento no presente estudo, o coeficiente de variação dos recalques já atinge valores muito próximos ao seu final (acima de 99\% de aproximação percentual).

- A inclusão da ISE aumenta os momentos na base das paredes. Nos trechos localizados entre os elementos ocorrem reduções de momentos.

Alguns aspectos abordados e concluídos neste item já haviam sido observados no capítulo 4, como, por exemplo, a menor contribuição da rigidez dos pavimentos superiores. A comparação da variação do fator de recalque absoluto com a redistribuição de esforços evidencia o comportamento conjunto da estrutura com o maciço do solo. Pretendeu-se por meio desse capítulo expor esses aspectos do ponto de vista do maciço do solo, complementando e reforçando essas conclusões.

A aplicação da interação solo-estrutura na avaliação dos recalques é interessante, pois a sua homogeneização pode viabilizar edificações que seriam descartadas sem o uso da ISE. A grande rigidez do edifício de parede promove essa homogeneização.

A alta redução da distorção angular nas paredes causada pela inclusão da ISE é outro aspecto que merece destaque. Os valores irrisórios da distorção angular com a inclusão da ISE indicam que a preocupação com o aparecimento de fissuras devido à ISE é exagerada. Esse aspecto foi comprovado também pela ausência de fissuras nos elementos estruturais exibidos no capítulo 4. Destaca-se aqui que estas conclusões são referentes à rigidez do solo e à solução de fundação aqui utilizada.

O uso das ações evolutivas, ao contrário do que ocorre na superestrutura, não promove benefícios no radier. A distribuição dos recalques é menos homogênea do que com a aplicação das ações instantâneas. 



\section{CAPÍTULO 6 - ANÁLISE PARAMÉTRICA}

Avalia-se neste capitulo diversos parâmetros no comportamento estrutural de edifícios de paredes de concreto sobre o efeito da ISE em conjunto com as ações evolutivas. Alguns desses parâmetros já foram estudados em outras pesquisas, sendo estas aplicadas em estruturas convencionais aporticadas de concreto armado e/ou metálicas. Para o entendimento da ISE em edifícios de paredes de concreto tornam-se necessárias estas avaliações, já que esse sistema apresenta características singulares aos tipos de estruturas avaliadas em trabalhos anteriores.

A principal característica é a alta rigidez dos edifícios de paredes. O comprimento das paredes em relação à sua espessura é outro aspecto que diferencia o sistema estrutural dos demais. Por meio da inclusão da ISE ocorrem mudanças na distribuição das tensões normais ao longo da seção, diferentemente do constatado em edifícios aporticados.

São simulados dezenas de modelos distintos com alterações de parâmetros que são descritos nos itens subsequentes. Todas as análises e resultados neste capítulo são realizadas com o uso das ações evolutivas.

A rigidez relativa estrutura-solo é o principal parâmetro estudado neste capítulo. Inicialmente é proposto um coeficiente para representar a rigidez relativa estrutura-solo. São variadas a rigidez do solo em conjunto com o número de pavimentos da edificação para investigar a interação entre os dois meios.

Posteriormente são estudadas situações com mudanças na profundidade do maciço do solo e com a consideração simplificada da sua heterogeneidade. Por fim, realiza-se uma análise de desempenho estrutural dos elementos dos edifícios de paredes com alterações na altura da edificação e na rigidez do solo.

\subsection{RIGIDEZ RELATIVA ESTRUTURA-SOLO EM EDIFÍCIOS DE PAREDES}

A rigidez solo-estrutura é um dos fatores que governam a ISE. A interação entre os dois meios modifica a transferência de esforços entre os elementos da estrutura e a distribuição de recalques nas fundações.

O comportamento da ISE é governado pela rigidez relativa entre a estrutura e o solo. Uma estrutura pode se comportar como rígida se estiver apoiada sobre um solo mole ou se 
comportar como flexível se estiver apoiada sobre uma base rígida. A homogeneização dos recalques por meio da inclusão da estrutura também depende da rigidez relativa entre os dois meios.

Tendo em vista a importância deste parâmetro, diversos estudos almejaram a definição de um coeficiente que pudesse representar essa relação. A Tabela 6.1 resume algumas formulações de rigidez relativa estrutura-solo. As nomenclaturas são adaptadas para que as expressões possam ser comparadas.

Tabela 6.1 - Rigidez relativa fundação-solo e estrutura-solo

\begin{tabular}{|c|c|}
\hline$K_{f}=\frac{E_{f} I_{f}}{E_{S}^{\prime} B^{3} L}$ & Borowicka (1936) \\
\hline$K_{b}=\frac{E_{f} I_{f}+E_{b} I_{b}}{E_{s}^{\prime} B^{3}}$ & Meyerhof (1953) \\
\hline$K_{f}=\frac{16 * E_{f} * I_{f}\left(1-v_{f}^{2}\right)}{\pi * E_{s}\left(1-v_{s}^{2}\right) * L^{4}}$ & Hain e Lee (1974) \\
\hline$K_{f}=\frac{16 * E_{f} * I_{f}\left(1-v_{s}^{2}\right)}{\pi * E_{S} * L^{4}}$ & Bronw (1975) \\
\hline$K_{b}=\frac{E_{s} l^{4}}{n * E_{b} * I_{b} *\left(1-v_{s}^{2}\right)}$ & Bronw e Yu (1975) \\
\hline$K_{f}=\frac{4 * E_{f}\left(1-v_{f}^{2}\right) h^{3}}{3 * E_{s}\left(1-v_{s}^{2}\right) * B^{3}}$ & Fraser e Wardle (1976) \\
\hline$K_{f}=\frac{5.57 * E_{f}\left(1-v_{f}^{2}\right)}{E_{S}\left(1-v_{S}^{2}\right)} *\left(\frac{B}{L}\right)^{0.5}\left(\frac{h}{L}\right)^{0.5}$ & $\begin{array}{l}\text { Horikoshi e Randolph } \\
\text { (1997) }\end{array}$ \\
\hline$K_{f}=\frac{4 * E_{f}\left(1-v_{s}^{2}\right)}{3 * \pi * E_{s}} *\left(\frac{B}{L}\right)\left(\frac{h}{L}\right)^{3}$ & Hain e Lee (1978) \\
\hline $\begin{array}{l}K_{f}: \text { Rigidez relativa fundação - solo } \\
K_{b}: \text { Rigidez relativa estrutura - solo } \\
E_{f}: \text { Módulo de elasticidade do material do radier } \\
E_{s}: \text { Módulo de elasticidade do maciço solo } \\
E_{b}: \text { Módulo de elasticidade do material da estrut } \\
I_{f}: \text { Momento de Inércia do radier } \\
I_{b}: \text { Momento de Inércia das vigas da estrutura } \\
v_{f}: \text { Coeficiente de poisson do material do radier } \\
v_{s}: \text { Coeficiente de poisson do solo } \\
h: \text { Espessura do radier } \\
B: \text { Comprimento do radier } \\
L: \text { Largura do radier } \\
l: \text { ão das vigas da estrutura } \\
\mathrm{n}: \text { Número de pavimentos }\end{array}$ & \\
\hline
\end{tabular}

Por meio da análise desses trabalhos é possível perceber que não há consenso sobre essa formulação. A maioria das propostas utilizam a relação entre a rigidez à flexão do Radier (numerador) e a suposta rigidez à flexão do maciço de solo (denominador), embora o maciço seja um elemento volumétrico que não apresente rigidez à flexão. Essas formulações foram elaboradas na avaliação de modelos planos e algumas expressões incluem o efeito da diferença do coeficiente de Poisson dos dois materiais. Apenas um módulo de elasticidade é utilizado 
nessas equações para representar o maciço de solo, embora usualmente o maciço do solo seja um meio estratificado com materiais de propriedades distintas. Alguns desses estudos desprezam a influência da superestrutura na rigidez relativa e outros a consideram de maneira simplificada como os realizados por Meyerhof (1953) e Brown e Yu (1975).

A representação de um comportamento complexo por meio de um coeficiente linear apresenta algumas dificuldades, que foram observadas durante o desenvolvimento do presente estudo. São indicados a seguir alguns aspectos relevantes, que usualmente não são incluídos no coeficiente de rigidez relativa estrutura-solo.

- A contribuição da estrutura influencia na homogeneização dos recalques na fundação de modo não-linear. A contribuição dos pavimentos superiores no comportamento conjunto estrutura-solo tem dependência da rigidez do solo.

- A contribuição da rigidez do solo na redistribuição de esforços também é nãolinear.

- O coeficiente não leva em consideração a não-linearidade do material do solo. Esse comportamento altera a distribuição das pressões de contato na fundação.

- O coeficiente não considera a profundidade hipotética do maciço do solo, ou seja, se o nível considerado indeslocável do maciço está próximo ou não da superfície.

Os usos dos coeficientes apresentados anteriormente são impossibilitados no presente estudo. Eles foram desenvolvidos em sua maioria para pórticos planos. Esses coeficientes perderiam a representatividade no modelo aqui apresentado em virtude de suas particularidades. A alta rigidez dos edifícios de paredes de concreto e a complexidade geométrica da disposição dos elementos (Paredes nas duas direções interconectadas) são algumas dessas peculiaridades.

O coeficiente de rigidez estrutura-solo aqui proposto é baseado na sugestão do ACI COMMITTE-336(1988). O coeficiente desenvolvido pela entidade é sugerido para edifícios aporticados apoiados em radiers de concreto e foi baseado no estudo realizado por Meyerhof (1953). A Equação 6.1 mostra esse coeficiente.

$K_{r}=\frac{\left(E c I_{f}+\sum E c I_{b}+\sum E c t h^{3} / 12\right)}{E_{s} B^{3}}$ Equação 6.1

$B$ : Base da fundação perpendicular à direção analisada

$E_{s}$ : Módulo de elasticidade do solo

$E c I_{f}$ : Rigidez à flexão do Radier

$E c I_{b}$ : Rigidez à flexão dos elementos da superestrutura (Vigas)

$E c t h^{3} / 12$ : Rigidez efetiva das paredes perpendiculares à direção analisada 
O coeficiente sugerido pelo ACI possui alguns aspectos que dificultam a implementação em edifícios de paredes. Observa-se que a expressão da Equação 6.1 não é adimensional, o que sugere que a análise seja realizada por unidade de comprimento. As análises realizadas pela entidade fornecem coeficientes que variavam entre 0,5 e 1. A aplicação do mesmo coeficiente nos edifícios de paredes levaria a números muito elevados de rigidez. Outro ponto é que as faixas de recalques diferenciais em estruturas consideradas rígidas, obtidas no estudo do ACI, são inferiores (recalque diferencial inferior a 10\% do recalque máximo) às obtidas nos modelos aqui apresentados.

Buscando a devida adaptação, é proposta a criação de um coeficiente próprio para edifícios de paredes. A Equação 6.2 mostra o coeficiente proposto.

$K_{r \text { Par }}=\frac{E c I_{f}+N\left(\frac{l}{B}\right) E c t h^{3} / 12}{E_{s} L B^{3}}$ Equação 6.2

$K_{\text {rPar }}$ : Rigidez relativa estrutura-solo

$l$ : Vão médio entre as paredes de concreto

$L$ : Largura da fundação (Menor direção)

$B$ : Base da fundação (Maior Direção)

$E_{s}$ : Módulo de elasticidade do solo

$E c I_{f}$ : Rigidez à flexão do Radier

$N$ : Número de pavimentos

$E c t h^{3} / 12$ : Rigidez da parede de um pavimento.

O coeficiente proposto se difere da proposta do ACI (1988), primeiramente, na consideração da largura da fundação na rigidez do maciço do solo, tornando o coeficiente uma grandeza adimensional. A segunda alteração refere-se à parcela que relaciona o vão médio entre as paredes com a largura da fundação. Essa modificação permite considerar a área de influência de cada parede na largura total do radier. A relação do vão médio entre as paredes com a largura do radier permite que o coeficiente possa ser utilizado em comparações de tipologias diferentes de edifícios de paredes de concreto em análises futuras. A diferenciação entre a largura e a base da fundação também permite que sejam avaliadas situações de diferentes relações base/largura da edificação em planta.

Apenas como exemplo ilustrativo calcula-se o coeficiente de rigidez relativa estruturasolo no edifício modelo com a rigidez de solo utilizada nos modelos M2 (Capítulos 3, 4 e 5). A Tabela 6.2 mostra o cálculo do coeficiente “Krpar” para o referido modelo. 
Tabela 6.2 - Cálculo do Krpar - modelo M2

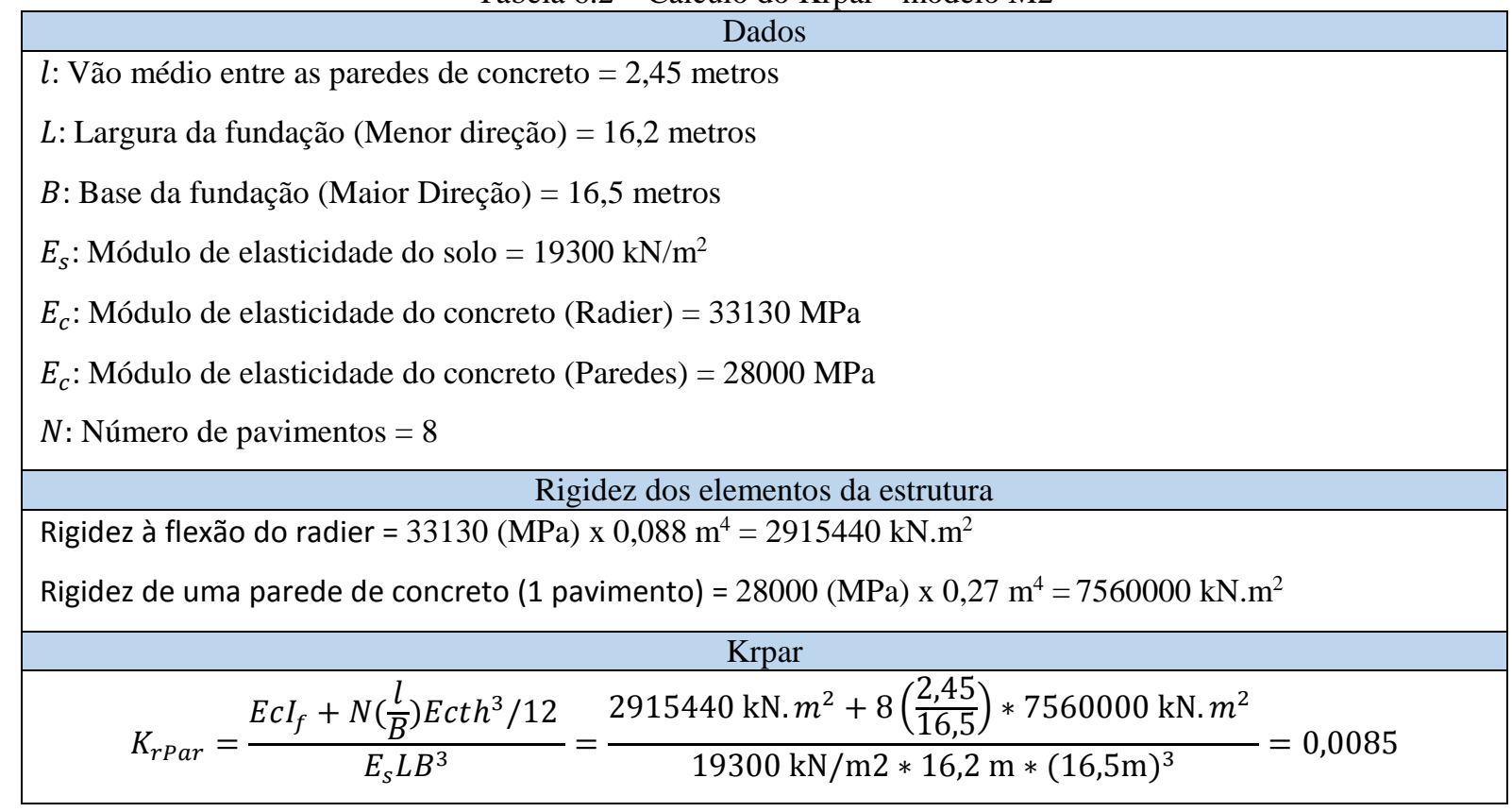

Com a geometria estudada e as propriedades do solo, o coeficiente de rigidez relativa nos exemplos estudados ao longo deste capítulo varia entre $1 \times 10^{-4}$ (Estrutura muito flexível sobre base rígida) e 0,1 (Estrutura rígida sobre base flexível).

A variação da rigidez da estrutura é realizada alterando-se o número de pavimentos contemplados (1 a 20). O módulo de elasticidade do solo também foi variado de 5,4 x $10^{5} \mathrm{~N} / \mathrm{m}^{2}$ a $2,7 \times 10^{10} \mathrm{~N} / \mathrm{m}^{2}$.

Os parâmetros não-lineares do solo foram estimados por meio da equação sugerida por Bowles (1996) que relaciona o NSPT com o módulo de elasticidade. Por meio do NSPT pode-se estimar a coesão e o ângulo de atrito, conforme procedimento apresentado no item 3.3 do capítulo 3.

Deve-se ter em mente todas as simplificações adotadas na presente proposta. Apesar das particularidades que o coeficiente de rigidez relativa estrutura-solo não permite representar, a simplicidade de utilização de um índice linear no estudo da ISE o torna atrativo. Deste modo, a maneira adequada para o uso do coeficiente consiste em sempre fixar algumas das variáveis preponderantes na análise, evitando-se assim erros de interpretação. As variáveis fixadas são sempre o número de pavimentos e a rigidez do solo, tendo em vista a sua influência não-linear nesse parâmetro. 


\subsection{ALTURA DA EDIFICAÇÃO E RIGIDEZ DO SOLO}

\subsubsection{CONSTRUÇÃO DO EDIFÍCIO E LIMITE DE RIGIDEZ}

Pesquisadores em estudos anteriores consideravam uma relação linear da colaboração da superestrutura com o número de pavimentos da edificação. O estudo pioneiro de rigidez relativa estrutura-solo realizado por Meyheroff (1953) por exemplo considera que a rigidez da superestrutura do edifício pode ser obtida pela multiplicação da rigidez individual de um pavimento pelo número total de pavimentos do edifício.

Gusmão Filho e Guimarães (1997) indicaram que o acréscimo de rigidez dos pavimentos na redistribuição de cargas em estruturas convencionais de concreto por meio da ISE não apresenta uma relação linear. Os autores propuseram um limite de rigidez da estrutura a partir do qual o acréscimo de novos pisos na edificação reduz a influência da ISE nesses elementos.

A análise da transferência de esforços em relação à construção de um edifício em fases (pavimento a pavimento) pode indicar detalhes relevantes sobre o limite de rigidez. A Figura 6.1 mostra a transferência de esforços na base das paredes PY1 e PY9 e dos grupos G2 e G4 em relação ao número de pavimentos construídos. O módulo de elasticidade do solo aqui utilizado tem como referência um edifício de porte médio (16 a 20 pavimentos). Esse solo se comporta com significativa rigidez enquanto se têm apenas os pavimentos iniciais da sequência construtiva. O parâmetro utilizado para este estudo foi o coeficiente “ $\eta$ ”.

A Figura 6.1-a indica que com apenas um pavimento construído a percentagem de esforço adicional na parede PY1 é de quase 50\%. Após a construção do primeiro pavimento, ocorrem reduções graduais do valor percentual à medida que os demais pisos são construídos. Este fato indica que com apenas um pavimento construído o limite de rigidez da superestrutura neste elemento é alcançado O mesmo ocorre para o grupo de parede G2 (Figura 6.1-c). 


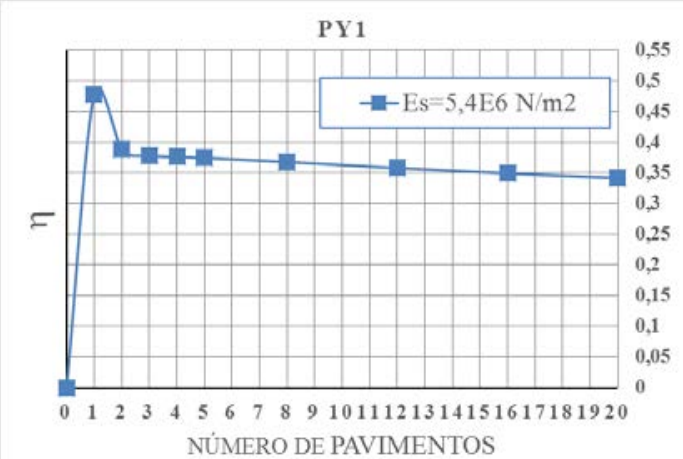

a) Parede PY1

G2

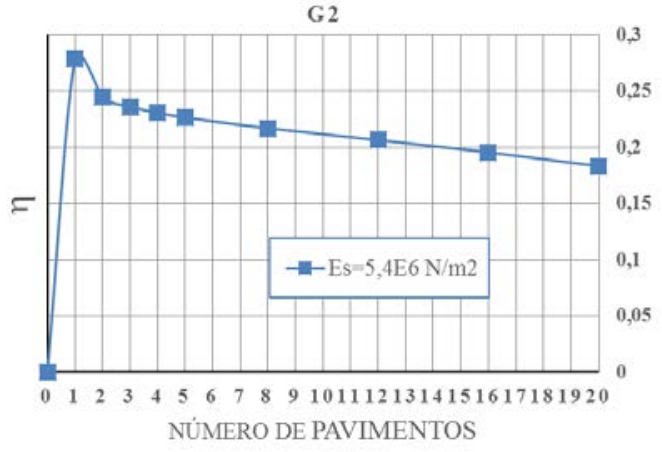

c) Grupo G2

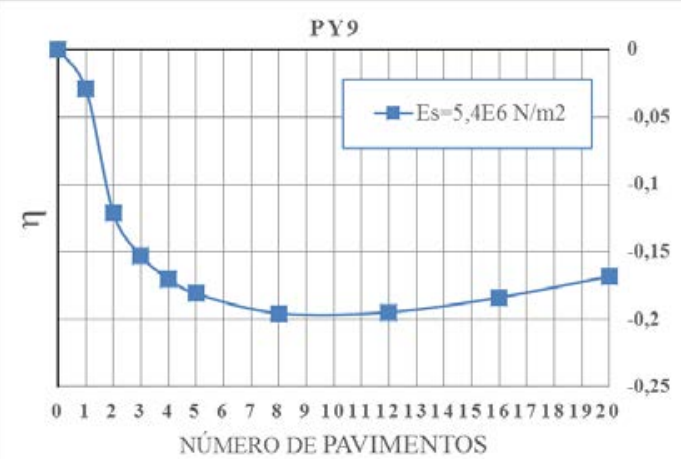

b) Parede PY9

G4

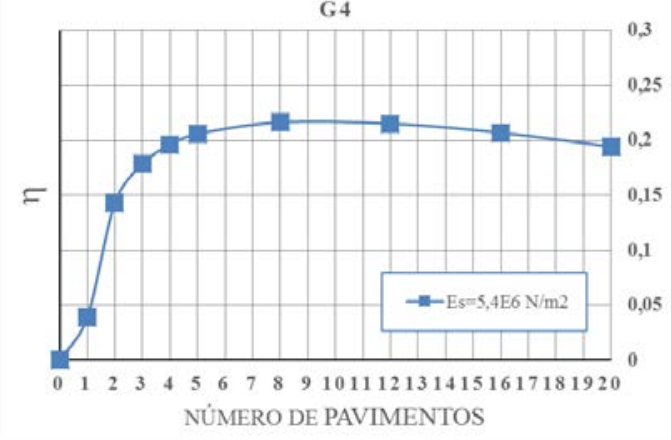

d) Grupo G4

Figura 6.1 - Transferência de esforços x Número de pavimentos - Es $=5,4 \times 10^{6} \mathrm{~N} / \mathrm{m}^{2}$

A quantidade de pavimentos necessários para atingir o denominado limite de rigidez é diferente nos diversos elementos da estrutura, como pode ser observado na Figura 6.1-b e na Figura 6.1-d. O limite de rigidez do grupo de paredes G4 e na parede PY9 ocorre quando a edificação possui 8 pavimentos, diferentemente dos indicados no parágrafo anterior. Embora alguns elementos apresentem reduções na redistribuição de esforços conforme são construídos novos pisos, outros permanecem com a ampliação dessas consequências.

Não foi possível relacionar o limite de rigidez de cada elemento apenas com as suas dimensões. A forma em que se promove a redistribuição de cargas tem relação também com a geometria e a posição dos elementos em planta na estrutura.

Uma hipótese que pode ser formulada é que o limite de rigidez da estrutura é fortemente influenciado pela rigidez do solo. A evidência da contribuição da superestrutura de maneira distinta em relação à rigidez do solo pode ser constatada por meio dos recalques na base. Goshy (1978) propôs a criação do fator de contribuição à uniformização de recalques (“FC”). O coeficiente proposto pelo autor permite avaliar a contribuição percentual de cada pavimento nos recalques diferenciais. O coeficiente foi proposto utilizando-se o $1^{\circ}$ pavimento como referência e desprezando-se sua contribuição. No problema estudado, a contribuição do $1^{\circ}$ pavimento é alta para ser suprimida. A Equação 6.3 exibe o fator de contribuição à uniformização de recalques, adaptado para o problema analisado (vinte pavimentos e 
considerando os recalques iniciais do radier sem a construção da superestrutura como referência).

$F c=\frac{\Delta w_{R}-\Delta w_{n}}{\Delta w_{R}-\Delta w_{20}}$

Equação 6.3

$\Delta w_{R}:$ Recalque diferencial para o radier construído

$\Delta w_{n}$ : Recalque diferencial para $n$ pavimentos construídos

$\Delta w_{20}:$ Recalque diferencial para 20 pavimentos construídos

A Figura 6.2 mostra a avaliação do coeficiente " $F C$ ” no edifício estudado para dois diferentes tipos de solo, sendo um de grande rigidez $\left(E_{\mathrm{s}}=1,5 \times 10^{9} \mathrm{~N} / \mathrm{m}^{2}\right)$ e um de baixa rigidez $\left(E_{\mathrm{s}}=1,5 \times 10^{6} \mathrm{~N} / \mathrm{m}^{2}\right)$.

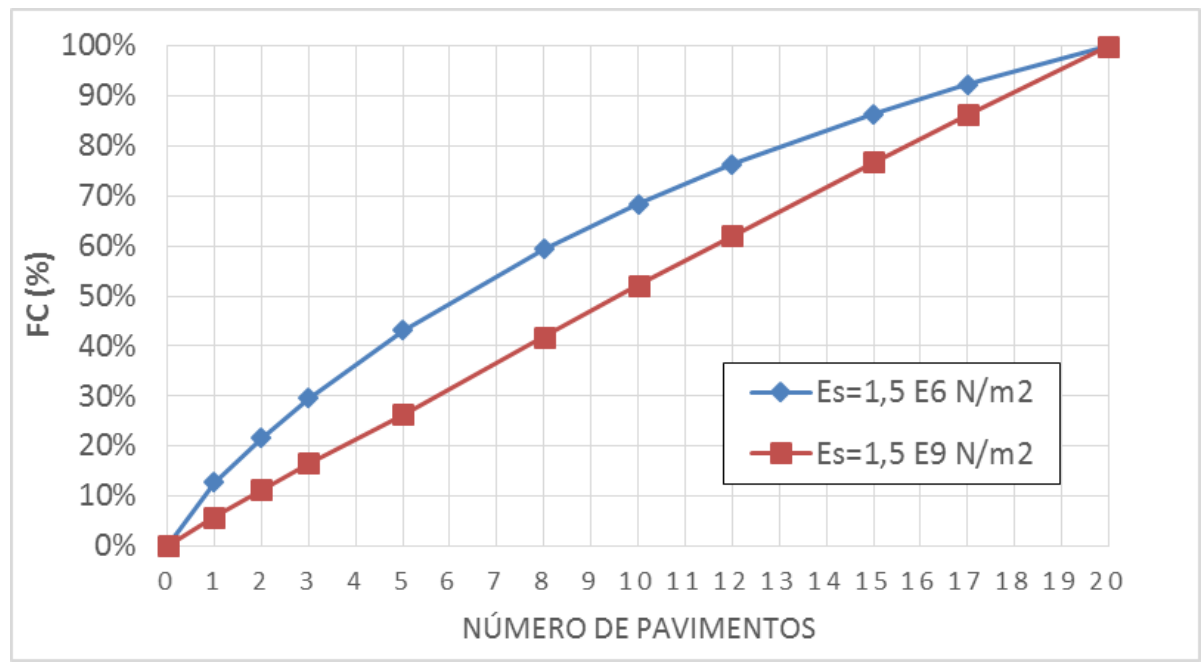

Figura 6.2 - FC - Fator de contribuição à uniformização de recalques

Os resultados indicam que a rigidez do solo tem um papel fundamental no modo que a colaboração da estrutura uniformiza os recalques. Em solos menos rígidos os primeiros pavimentos possuem uma grande parcela de contribuição na uniformização dos recalques. Nesta situação a edificação com 3 pavimentos construídos possui “FC” acima de $30 \%$, sendo um edifício de 20 pavimentos. Com o solo rígido esse valor é de 16,54\%. A estrutura com 10 pavimentos construídos, que seria o equivalente à metade da rigidez estrutural, possui “ $F C$ ” de 68\% quando se considera o solo menos rígido. Esses resultados evidenciam que a contribuição entre os dois meios (uniformização dos recalques e redistribuição dos esforços) não apresenta uma relação linear. 


\subsubsection{PRESSÕES DE CONTATO E RIGIDEZ RELATIVA ESTRUTURA- SOLO}

Goshy (1977) afirmou que a distribuição das pressões de contato na estrutura e a configuração dos recalques dependem da rigidez relativa estrutura-solo. A Figura 6.3 ilustra a hipótese levantada pelo autor.

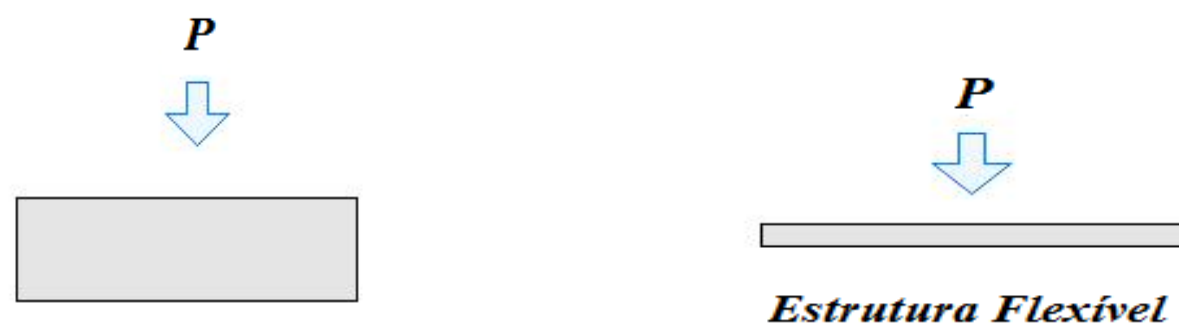

\section{Estrutura Rígida}
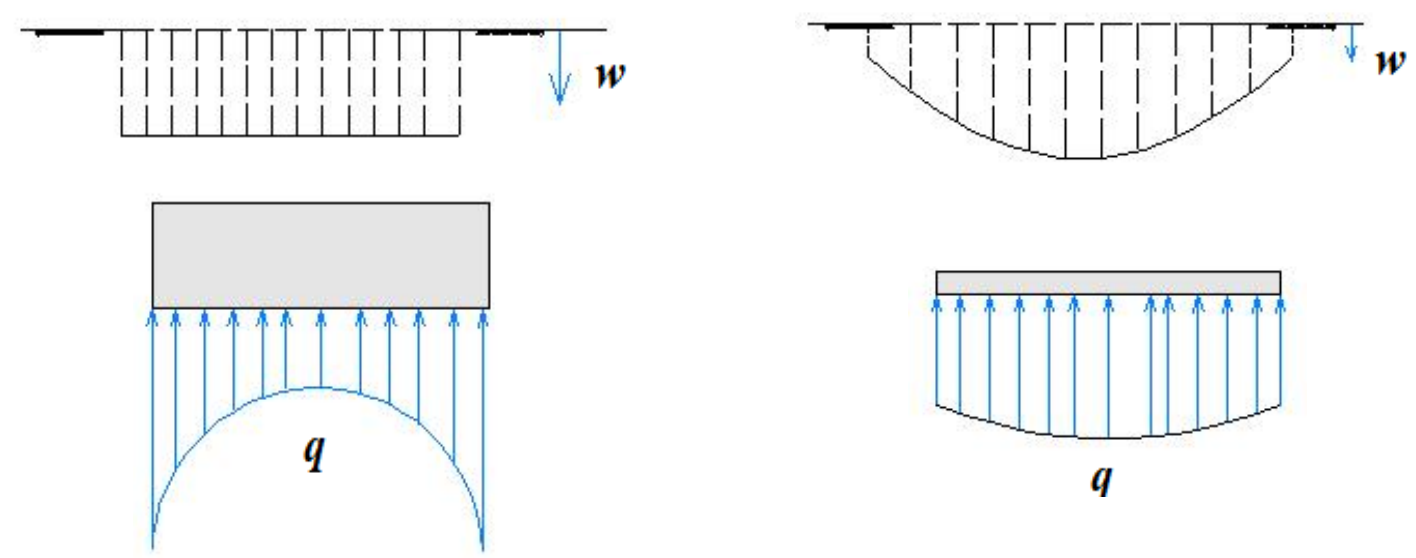

a) Recalques e Pressões de contato - Estrutura Rígida

Figura 6.3 - Pressões de contato e Rigidez relativa estrutura-solo

Os edifícios analisados no capítulo 4 apresentaram um comportamento similar ao de um edifício rígido. Os elementos localizados nas regiões externas sofreram acréscimo de esforços e os localizados nas regiões internas sofreram reduções. Por meio da hipótese dada pelo autor pode-se supor que a redistribuição dos esforços nas paredes pode obter configurações distintas dependendo da rigidez relativa estrutura-solo. Destaca-se que a distribuição das cargas também depende da geometria e da disposição das paredes em planta e que naturalmente os elementos centrais são mais carregados que os externos.

Sobre a distribuição dos recalques, obviamente a configuração totalmente rígida é impossível de ocorrer, sendo mais racional relacionar que a distribuição de recalques assume uma configuração mais homogênea em um edifício de grande rigidez. A Figura 6.4 mostra o deslocamento vertical no radier (recalques) com duas situações distintas da rigidez relativa estrutura-solo. As duas tipologias possuem 8 pavimentos e mesma carga aplicada. 


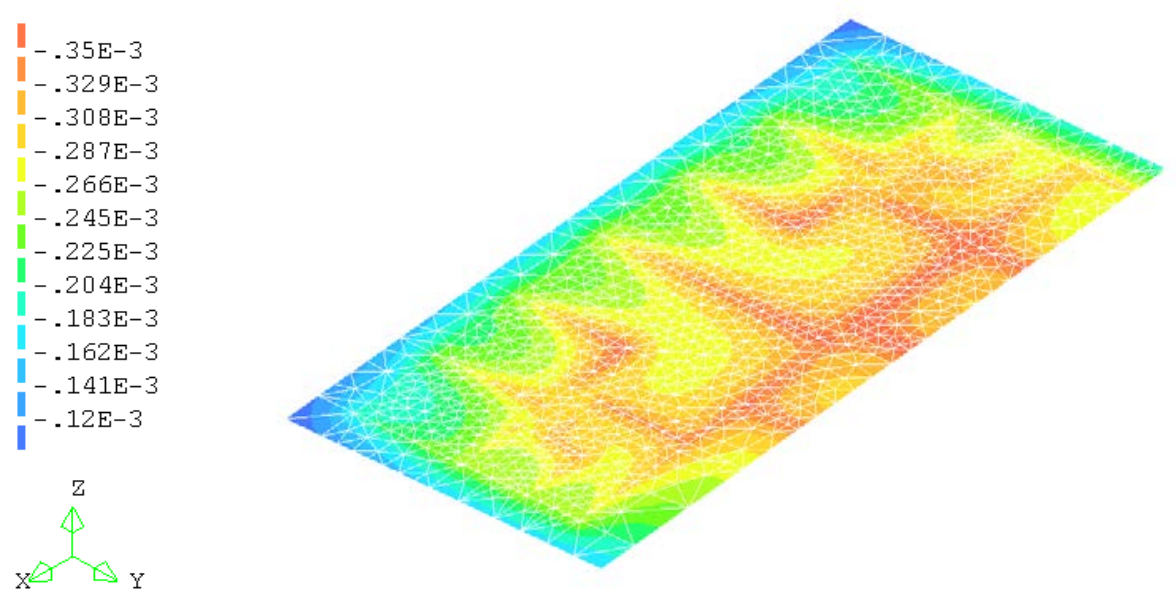

a) $\operatorname{Krpar}=0,0001$
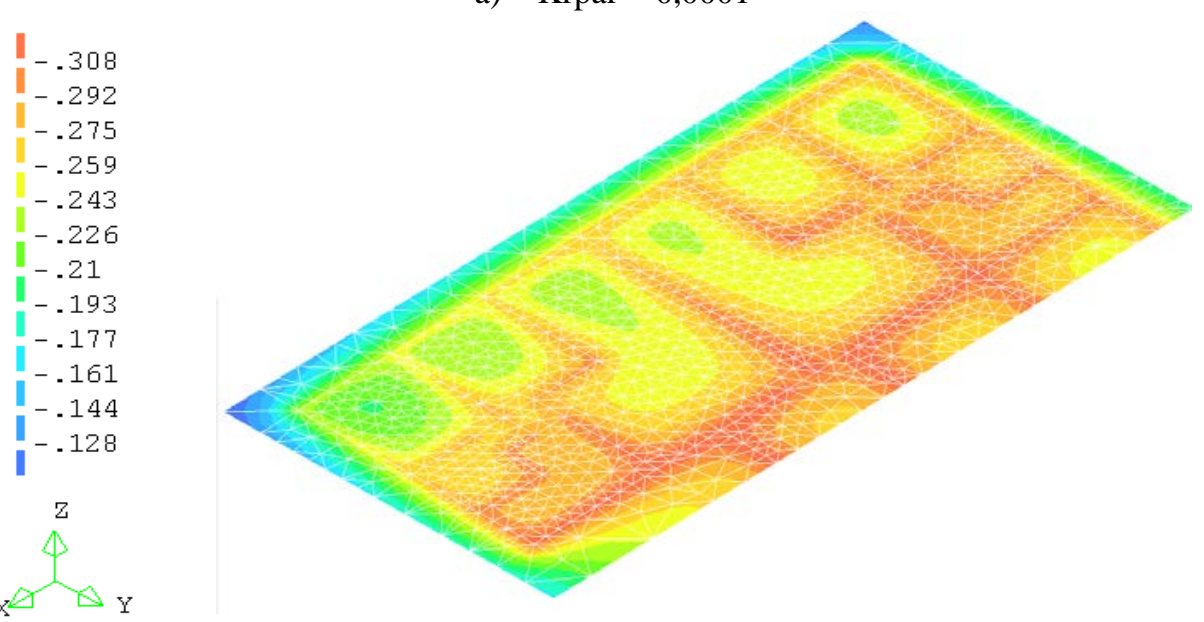

b) $\quad$ Krpar $=0,1$

Figura $6.4-\mathrm{u}_{\mathrm{z}}(\mathrm{m})$ - Recalques - Edifícios - 8 pavimentos

A Figura 6.4 ilustra que a distribuição dos recalques é modificada por meio de alterações na rigidez relativa estrutura-solo. A tipologia de rigidez relativa estrutura-solo muito baixa (Figura 6.4-a) apresenta uma configuração de recalques menos uniformes do que o modelo com maior rigidez relativa estrutura-solo (Figura 6.4-b). No entanto, essa desigualdade não é tão relevante se considerada a diferença deste parâmetro entre as duas tipologias.

\subsubsection{ANÁLISE COMPARATIVA DA VARIAÇÃO DO NÚMERO DE PAVIMENTOS E RIGIDEZ DO SOLO}

A primeira análise realizada relaciona a redistribuição média de esforços na base com a rigidez estrutura-solo e o número de pavimentos da edificação. Inicialmente são definidas 3 alturas diferentes de edifícios (Tabela 6.3), sendo realizada a variação da rigidez estrutura-solo por meio da alteração das propriedades do solo. 
Tabela 6.3 - Nomenclatura - Variação de pavimentos

\begin{tabular}{|c|c|}
\hline Nomenclatura & $\begin{array}{c}\text { Número de } \\
\text { pavimentos }\end{array}$ \\
\hline H5 & 5 \\
\hline H12 & 12 \\
\hline H20 & 20 \\
\hline
\end{tabular}

Embora desta maneira ocorra uma perda de sensibilidade devido à diferença de cargas aplicadas e os diferentes recalques, essa análise permite mostrar a influência da rigidez relativa nos modelos com distintos números de pavimentos e módulos de elasticidade do solo.

A Figura 6.5 mostra a comparação da redistribuição de esforços entre alguns elementos para diferentes coeficientes de rigidez relativa estrutura-solo e número de pavimentos. Isso é feito pelo parâmetro “ $\eta$ ”, como mostrado no capítulo 4. Por causa da disparidade entre os valores da rigidez relativa estrutura-solo utiliza-se a escala logarítmica nos gráficos.

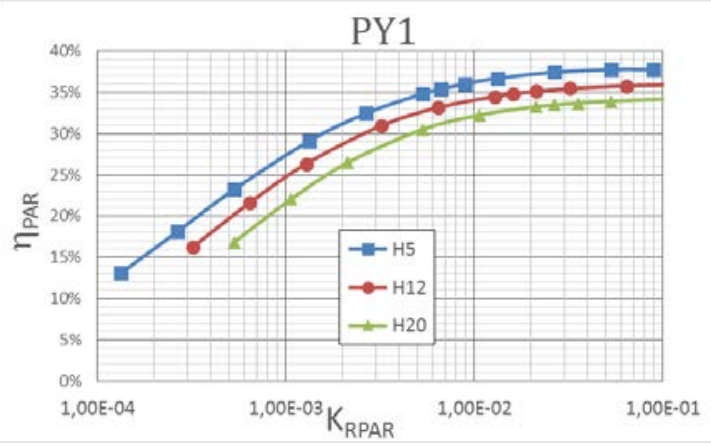

a) Parede Py1

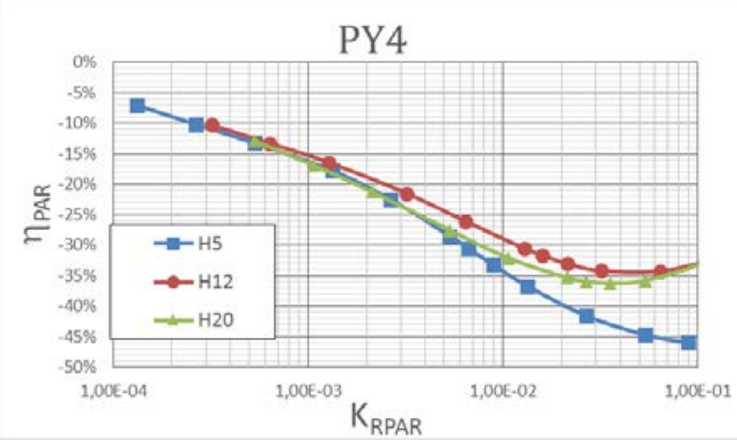

c) Parede Py4

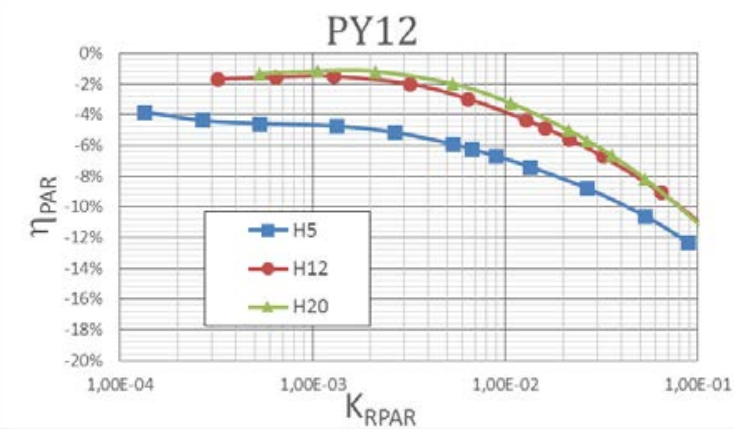

e) Parede Py12

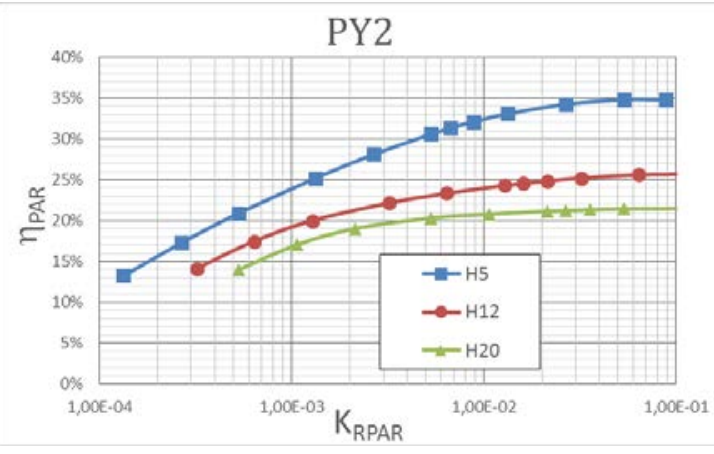

b) Parede Py2

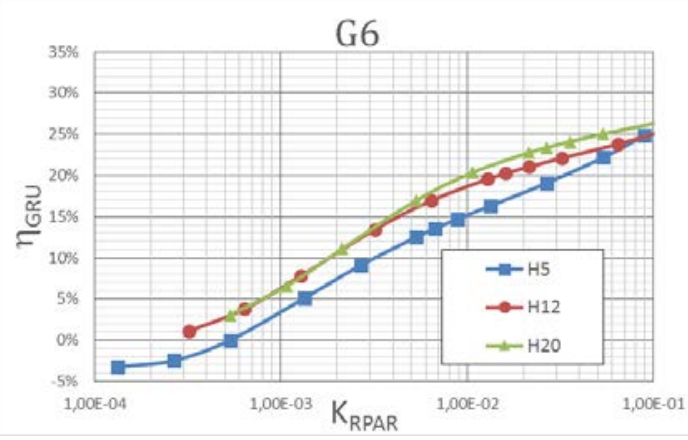

d) Grupo G6

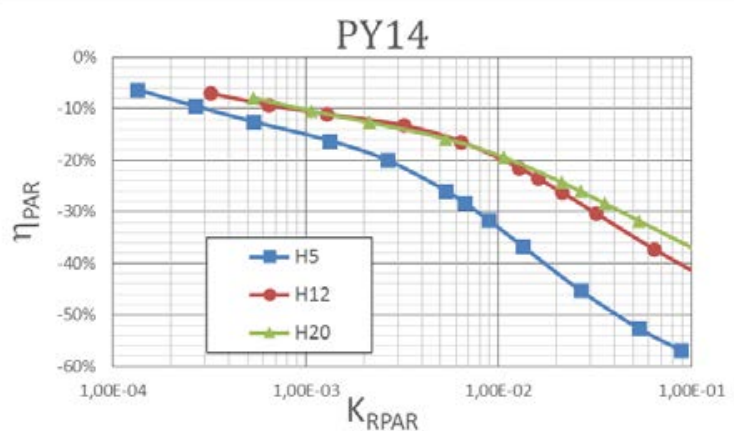

f) Parede Py14

Figura 6.5 - Redistribuição de esforços - Krpar x $\eta$ 
A comparação da redistribuição de esforços entre os modelos H5, H12 e H20 permite observar alguns aspectos sobre o papel da rigidez do solo em conjunto com a da superestrutura. O primeiro aspecto é a semelhança de comportamento entre os modelos com 12 e 20 pavimentos. Poucos elementos apresentaram diferenças significativas e, quando ocorridas, foram apenas em solos de baixa rigidez. Fica evidenciado que a rigidez de um edifício de 12 pavimentos se assemelha à de um edifício com 20 pavimentos no comportamento da ISE. Devese observar que usualmente edifícios com essas alturas não são utilizados em solos de baixa rigidez.

A maioria dos elementos apresentam redução na redistribuição de esforços à medida que se aumenta a rigidez do solo. O resultado é consistente, já que com o aumento da rigidez do solo aproxima-se da hipótese de apoios rígidos. Desta forma, a redistribuição de esforços nos elementos deve tender a zero conforme se aumenta a rigidez do maciço.

No entanto, alguns elementos apresentam comportamento distinto. A redistribuição de esforços conforme se diminui a rigidez relativa estrutura-solo não segue um padrão decrescente nesses elementos. O comportamento é variável conforme se modifica a rigidez relativa estrutura-solo. A Figura 6.6 mostra o comportamento de alguns desses elementos nos edifícios analisados.

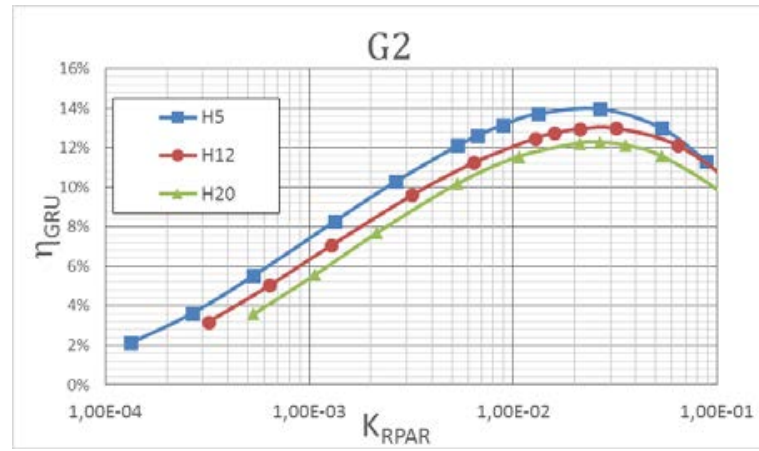

a) Grupo G2

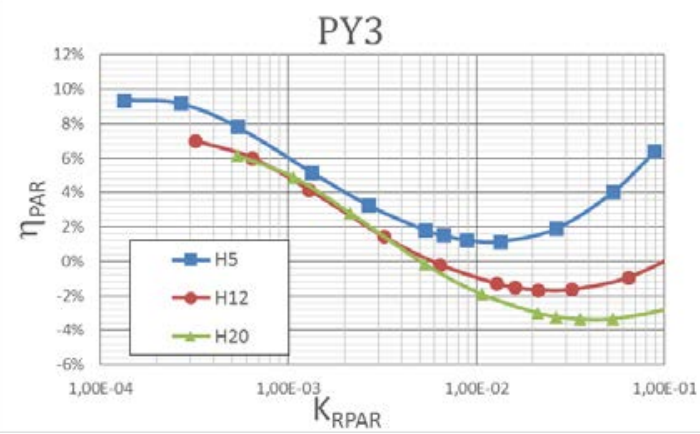

c) Parede Py3

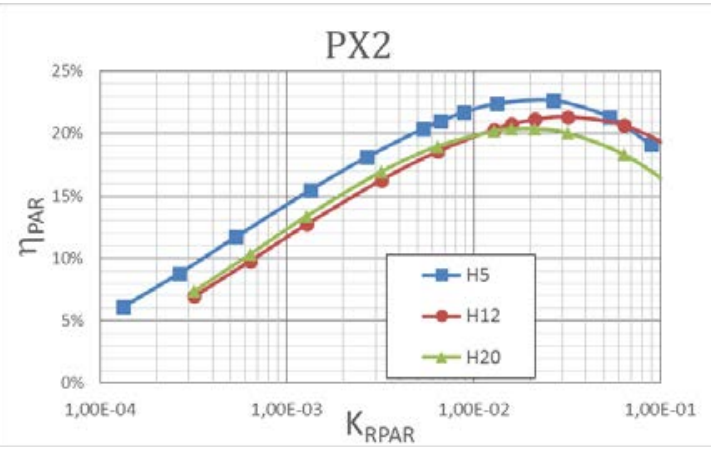

b) Parede Px2

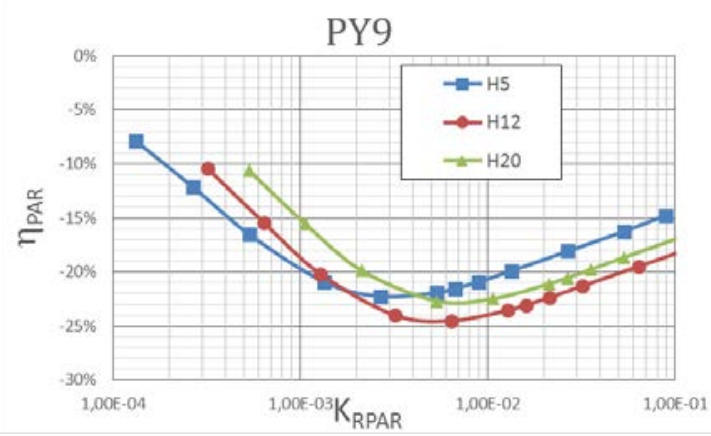

d) Parede Py9

Figura 6.6 - Redistribuição de esforços - Modelos de diferentes números de pavimentos

Os gráficos ilustrados na Figura 6.6 mostram que esses elementos apresentam variações na tendência da redistribuição de esforços conforme se altera a rigidez relativa 
estrutura-solo. Deve-se isto ao fato da distribuição das pressões de contato entre o solo e a estrutura dependerem dessa rigidez, conforme apresentado no item 6.2.2. Por meio das modificações da rigidez estrutura-solo ocorre inversão dos efeitos da ISE nesses elementos. Deve-se lembrar que uma parede, diferentemente de um pilar, pode ter comprimentos grandes em planta, o que leva a trechos de diferentes comportamentos em um mesmo elemento estrutural, por conta dos diferentes recalques ocorridos em sua base. A hipótese perde a validade à medida que o solo começa a apresentar uma grande rigidez, onde neste caso a redistribuição de esforços começa a assumir valores próximos de zero (Apoios rígidos).

A altura da edificação também pode modificar o comportamento da distribuição das pressões de contato na parede. Pode-se levantar a hipótese de que as teorias sugeridas por Gusmão e Guimarães (1977) sobre o limite de rigidez da estrutura e a analogia de viga-parede apresentada por Goschy (1978) se complementam. A analogia de viga-parede de Goshy (1978) pode ser observada no capítulo 4. À medida que os pavimentos superiores são menos suscetíveis aos efeitos da ISE, ocorre uma tendência das consequências finais na base se reduzirem conforme se acrescentam os novos pavimentos.

Assim sendo, quando se reduz a rigidez relativa estrutura-solo ocorrem reduções na redistribuição de esforços na ampla maioria dos elementos. Alguns elementos atingem o seu limite de contribuição, independente da rigidez do solo. Este fato ocorre pela considerável rigidez dos edifícios de parede de concreto. Todavia, outros elementos ainda são influenciados pela rigidez relativa estrutura-solo no seu comportamento, como pode ser observado na Figura 6.7.

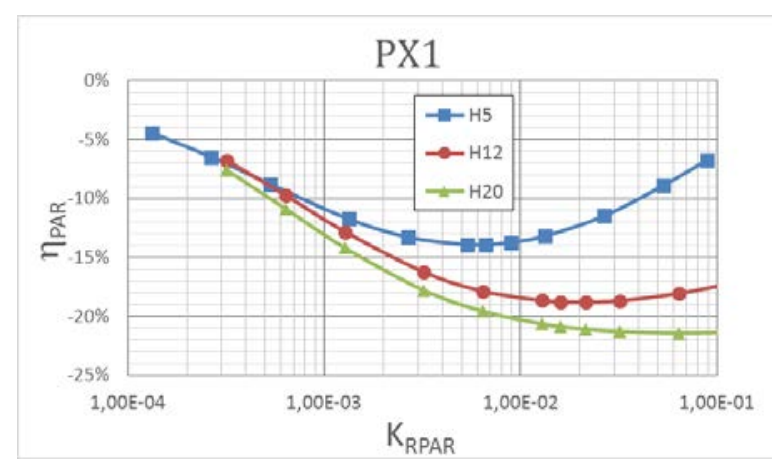

a) Parede Px1

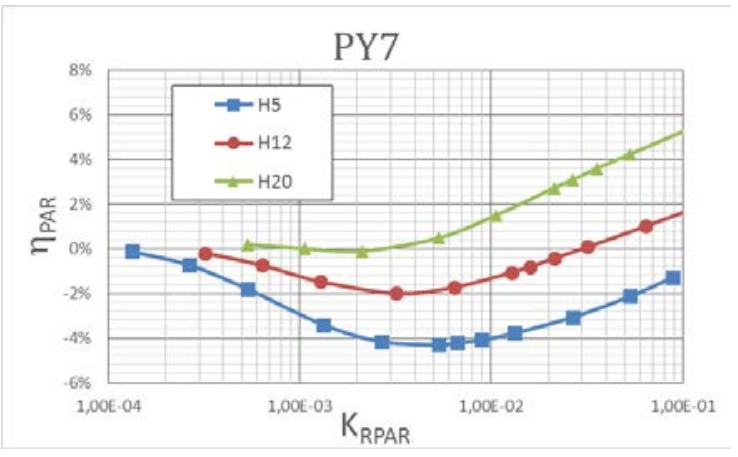

b) Parede Py7

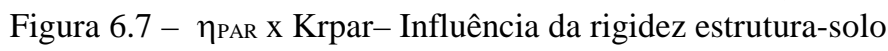

Nos dois elementos mostrados, com apenas 5 pavimentos a tendência na redistribuição de esforços é influenciada pelas mudanças da rigidez relativa estrutura-solo. No entanto, os mesmos apresentam reduções na redistribuição de esforços conforme se diminui a rigidez relativa estrutura-solo nos modelos com 12 e 20 pavimentos. 
Embora ocorram inversões na redistribuição de esforços causadas por modificações da rigidez relativa estrutura-solo nos elementos investigados individualmente, o mesmo não ocorre quando se analisa o pavimento como um todo. A Figura 6.8 mostra a variação do coeficiente de redistribuição de esforços normais médios na base da estrutura em relação ao número de pavimentos e da rigidez relativa estrutura-solo. Nesta análise o número de modelos analisados foi ampliado, com variação agora de 5 a 20 pavimentos.

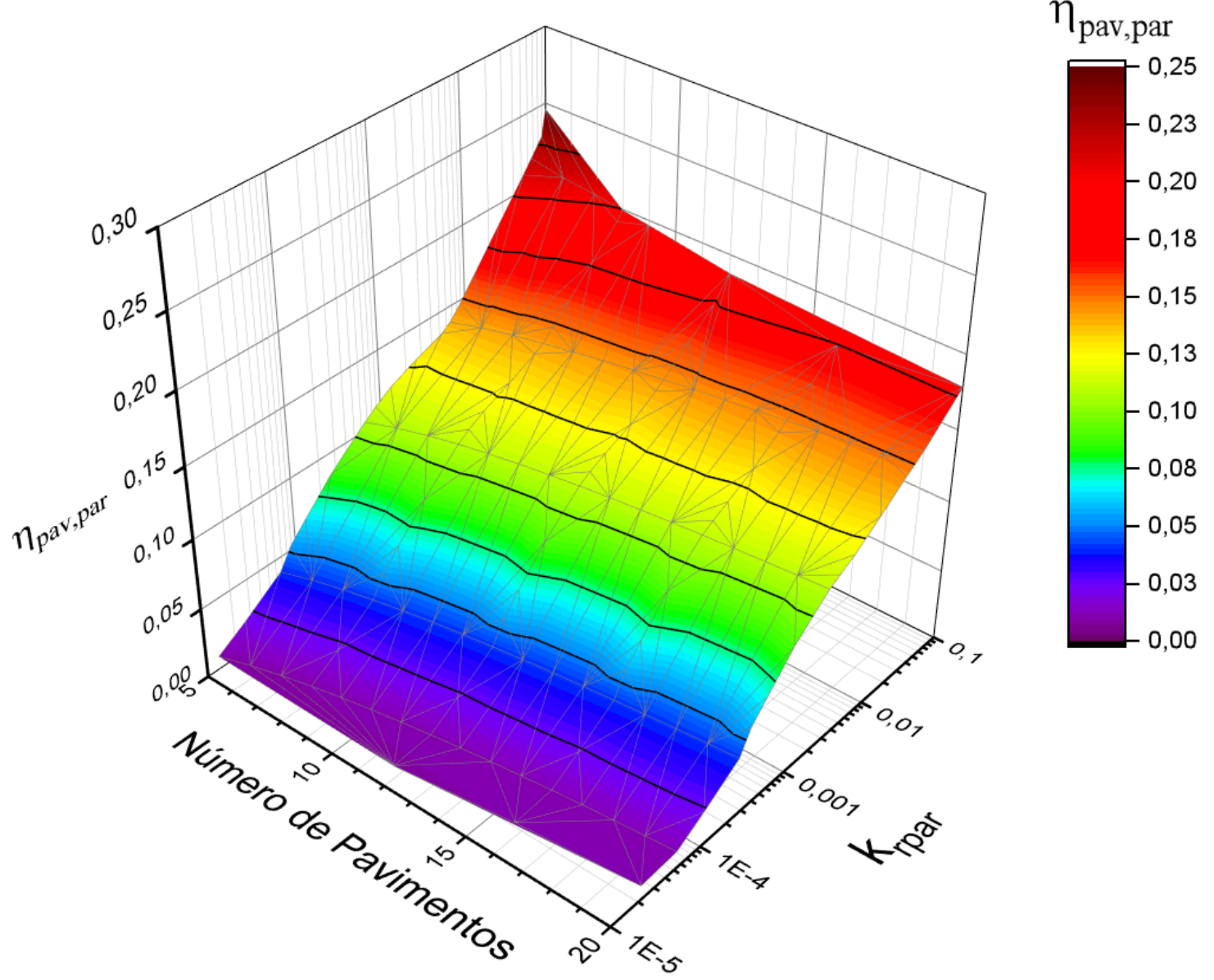

Figura 6.8 - $\eta_{\text {pav,par }} \mathrm{x}$ Krpar x Número de pavimentos

Conforme se aumenta a rigidez estrutura-solo, os efeitos na redistribuição de esforços são maiores, sendo a modificação realizada por meio da redução da rigidez do solo. As tipologias com coeficiente inferior a 0,01 mantiveram a redistribuição de esforços médio abaixo de 10\%, independentemente do número de pisos. Esse aspecto vai contra a exigência da norma que relaciona a necessidade da consideração da ISE com o número de pavimentos da edificação e não com a rigidez do solo.

Os edifícios que possuem poucos pisos são os mais sensíveis quanto às mudanças da rigidez relativa estrutura-solo. As tipologias com 5 pavimentos e grande rigidez estrutura-solo (próximos de 0,1) são as que apresentam maiores efeitos na redistribuição de esforços. Em 
relação às edificações de maior porte, entre 15 e 20 pavimentos, os resultados são similares. Esses edifícios mesmo com uma rigidez estrutura-solo alta apresentaram no máximo 20\% no coeficiente de redistribuição de esforços médios. No entanto deve-se ressaltar que as modificações médias não refletem necessariamente os efeitos localizados de concentração de tensões nas paredes.

Em relação às semelhanças de resultados entre os edifícios com 12 e 20 pavimentos pode ser explicado pela redução da contribuição de rigidez dos pavimentos superiores. Desta forma, a rigidez da estrutura das duas tipologias não apresenta diferenças discrepantes. A avaliação dessa similaridade entre o comportamento dos dois edifícios pode ser também observada na Figura 6.9 que mostra a distribuição do coeficiente de variação de recalques das três tipologias estudadas em relação à rigidez do solo.

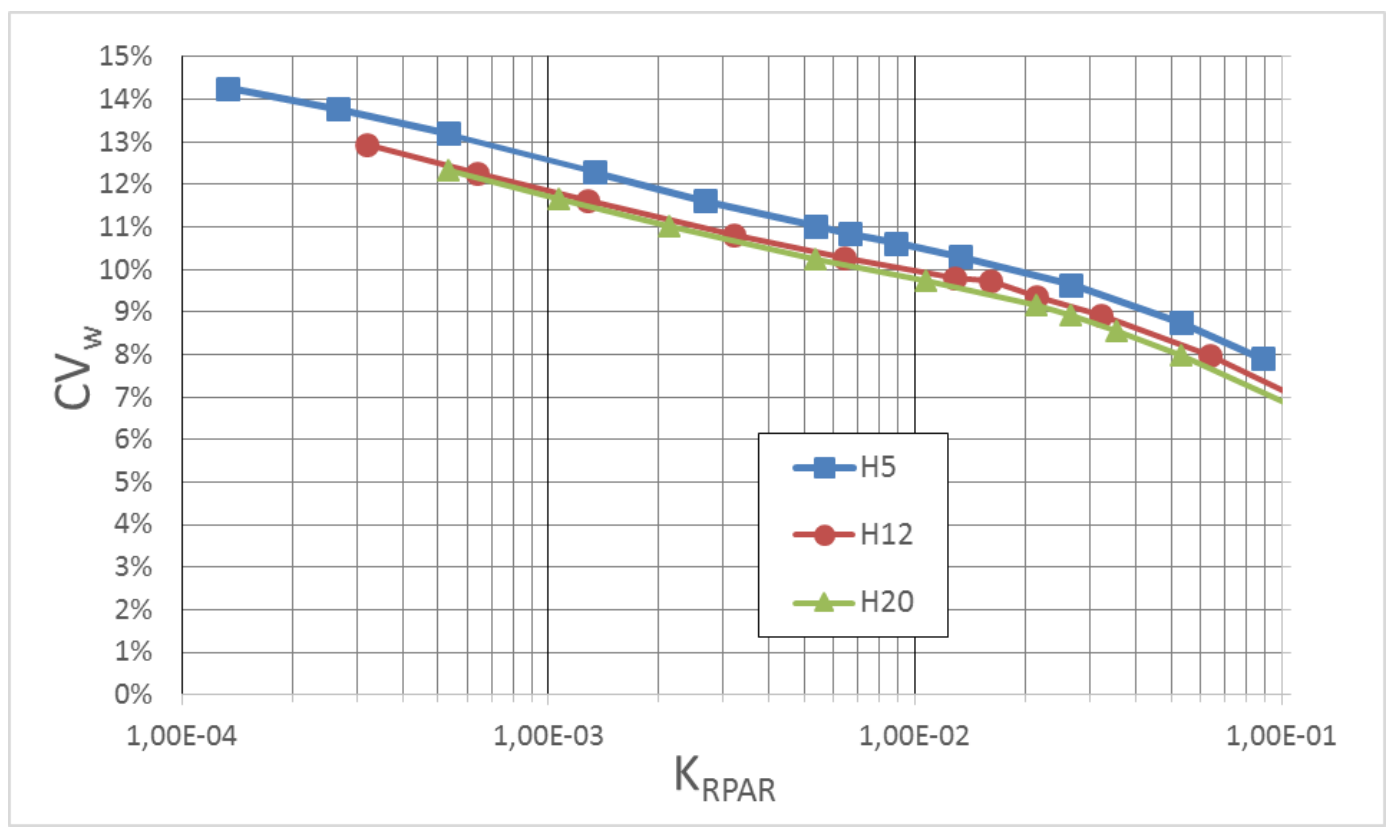

Figura 6.9 - Coeficiente de variação dos recalques

A Figura 6.9 mostra que a contribuição do número de pavimentos na uniformização dos recalques não é linear. Esses resultados permitem observar que a contribuição da rigidez da estrutura nos edifícios com 12 e 20 pavimentos são similares, mesmo que o edifício de 20 pavimentos apresente em teoria uma rigidez muito superior ao de 12.

Pode-se afirmar então que o solo exerce um papel mais relevante na rigidez relativa estrutura-solo do que o número de pavimentos na redistribuição de esforços da estrutura. Sobre a uniformização dos recalques em virtude da inclusão da estrutura, a Figura 6.10 mostra o coeficiente de variação dos recalques na base dos elementos de parede, ampliando-se a análise para tipologias com diferentes números de pavimentos. 


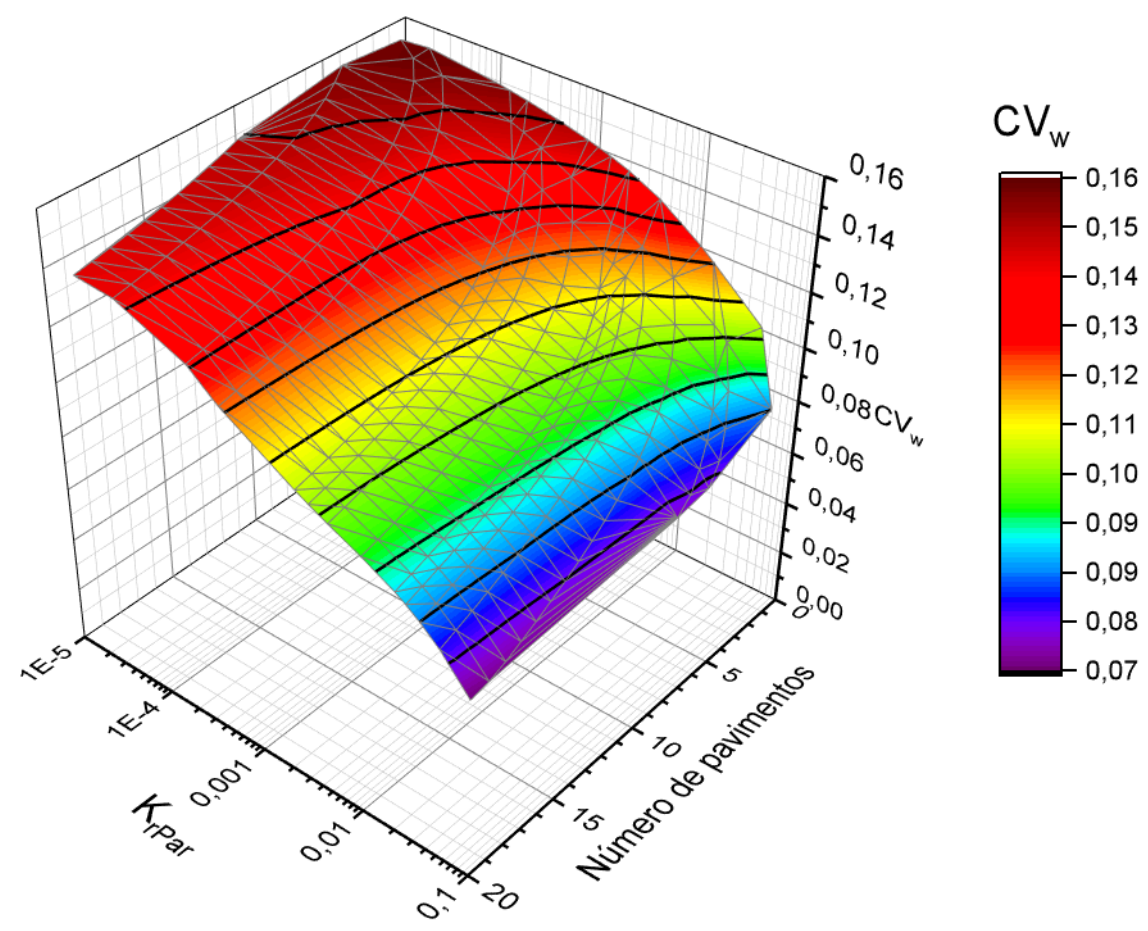

Figura 6.10 - CV x Krpar x Número de pavimentos

Os resultados mostram que existe uma grande dependência do coeficiente de variação dos recalques com a rigidez estrutura-solo. Quanto maior a rigidez estrutura-solo menor é o coeficiente de variação dos recalques. O comportamento rígido da estrutura tende a homogeneizar os recalques na fundação. Observa-se novamente neste caso uma baixa dependência do número de pavimentos da edificação. As tipologias com Krpar maior que 0,01 mantiveram o $\mathrm{CV}_{\mathrm{w}}$ inferior a 9\% sendo estas com 1 ou 20 pavimentos. As tipologias com Krpar muito baixo (inferior a 0,0001) tiveram variações do $\mathrm{CV}_{\mathrm{w}}$ de 0,13 a 0,16.

Pode-se entender que a influência da ISE na uniformização de recalques nesses edifícios tem maior dependência da rigidez do solo do que do número de pavimentos do edifício. Obviamente quanto maior o número de pavimentos, menor o coeficiente de variação de recalques. No entanto, a contribuição dos pavimentos superiores é reduzida, por consequência da rigidez já incluída pelos primeiros pavimentos.

A redistribuição de esforços nos pavimentos superiores nos modelos investigados no capítulo 4 tinha menor intensidade. De um modo geral, no quinto pavimento a maioria dos elementos possuía esforços próximos ao do modelo de referência. A Figura 6.11 mostra a variação do coeficiente “ $\eta$ ” ao longo da altura do edifício em algumas paredes em edifícios de 5, 12 e 20 pavimentos para diferentes situações de rigidez relativa estrutura-solo. 


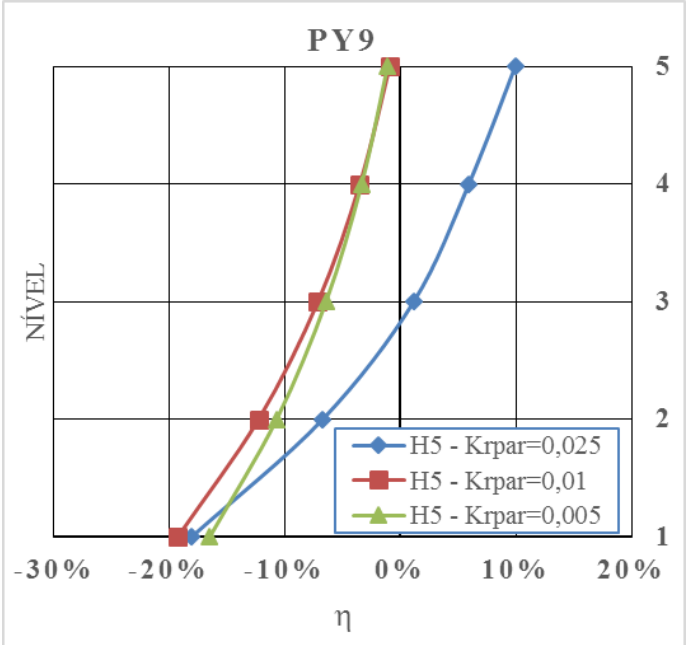

a) Parede PY9 - 5 pavimentos

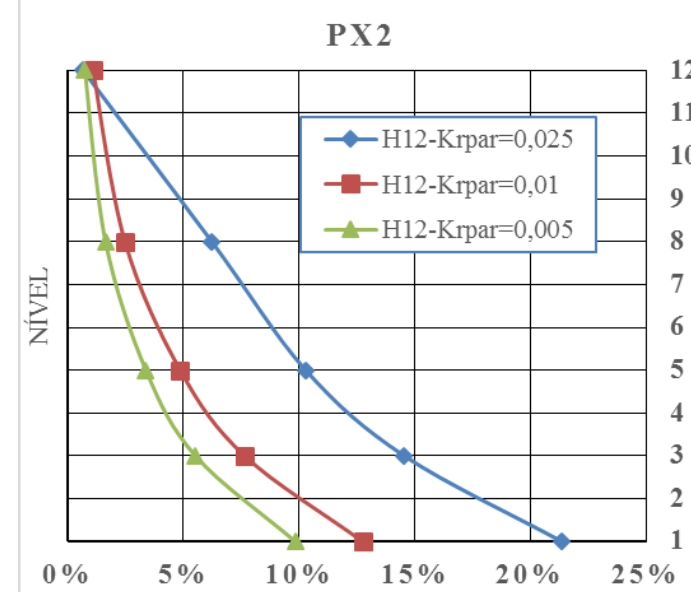

$\eta$

d) Parede PX2 - 12 pavimentos

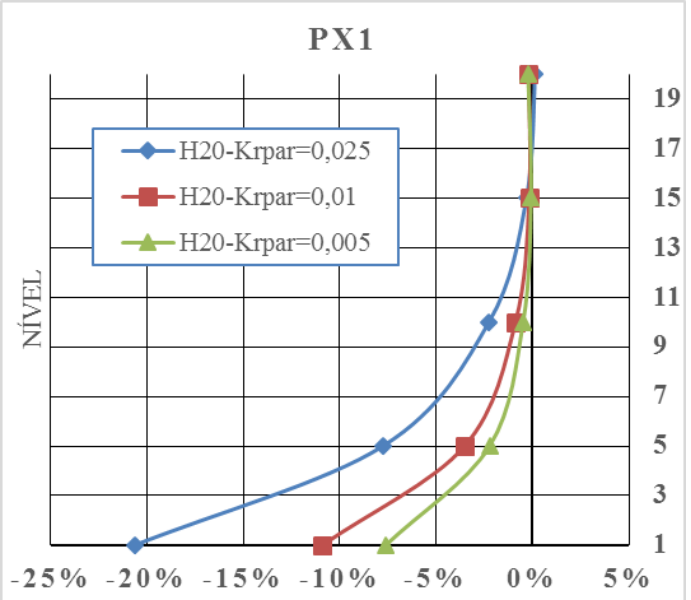

g) Parede PX1 - 20 pavimentos

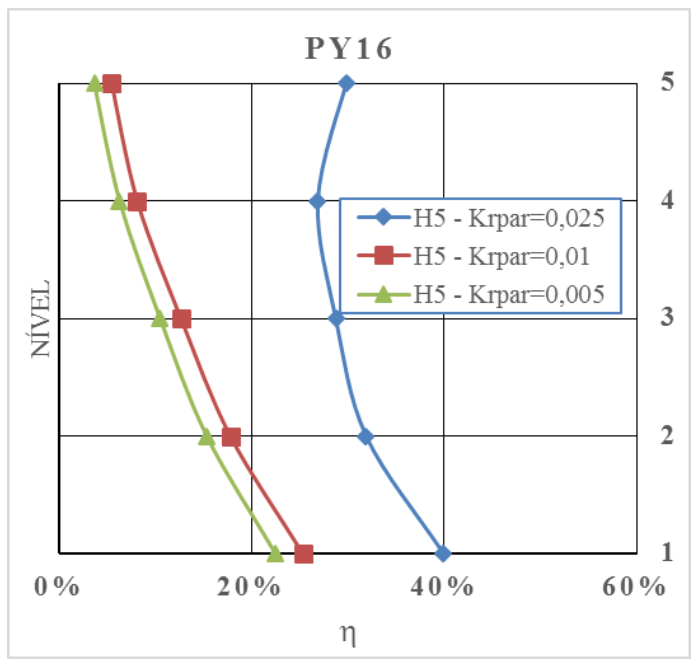

c) Parede PY16 - 5 pavimentos

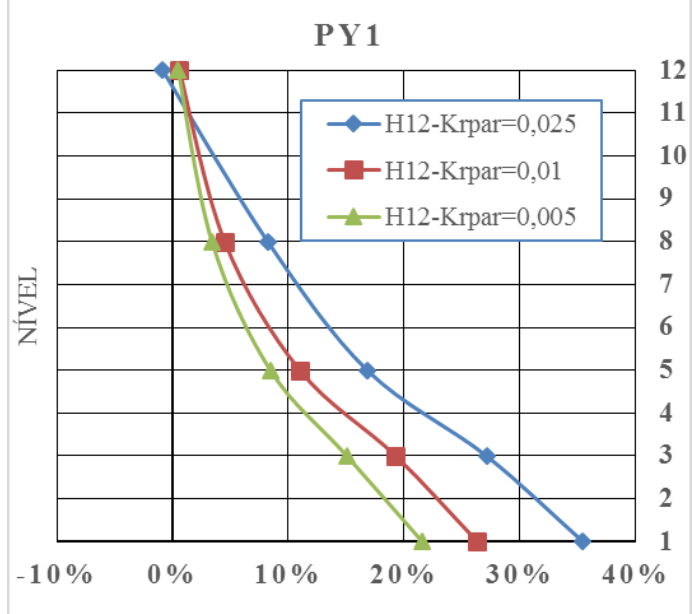

$\eta$

f) Parede PY1 - 12 pavimentos

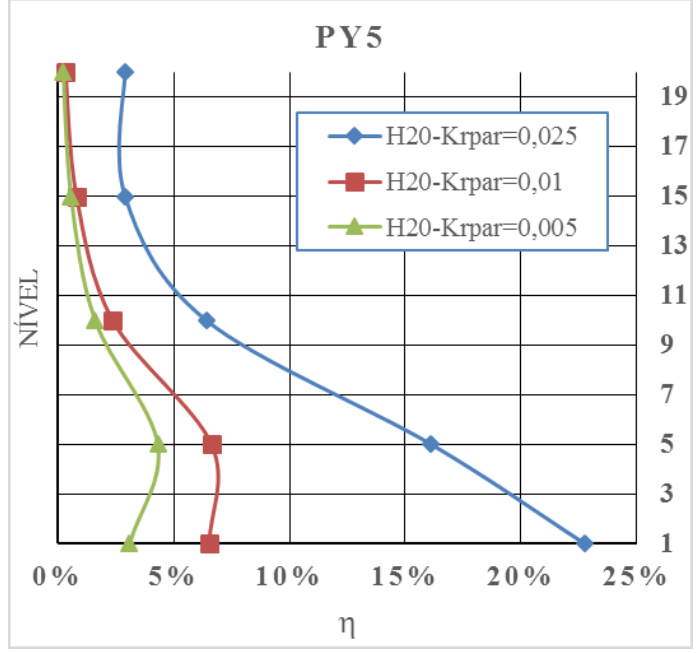

i) Parede PY5 - 20 pavimentos

Figura $6.11-\eta$ - Alturas x Krpar

A Figura 6.11 indica que a redistribuição dos esforços nos pavimentos superiores reduz, mas possui uma dependência da rigidez relativa estrutura-solo. Os edifícios com uma expressiva rigidez relativa estrutura-solo (Krpar=0,025) obtiveram uma menor redução da redistribuição de esforços nos pavimentos superiores. Essa configuração de rigidez fornece 
recalques excessivos na estrutura e os resultados se diferem das outras duas configurações de rigidez relativa investigadas.

As tipologias com média e baixa rigidez relativa estrutura-solo (Krpar=0,01 e Krpa=0,005) mostram similaridades no seu comportamento, principalmente nos pavimentos superiores. Os resultados indicam que em situações com média e grande rigidez do solo os resultados dos pavimentos superiores são parecidos. Nessas tipologias os efeitos da ISE estavam presentes até o oitavo pavimento nas tipologias com 12 pavimentos e até o décimo pavimento nos modelos com 20 pavimentos. A Figura 6.12 realiza comparações similares, sendo agora investigadas tipologias com diferentes alturas e idênticos coeficientes de rigidez relativa estrutura-solo.

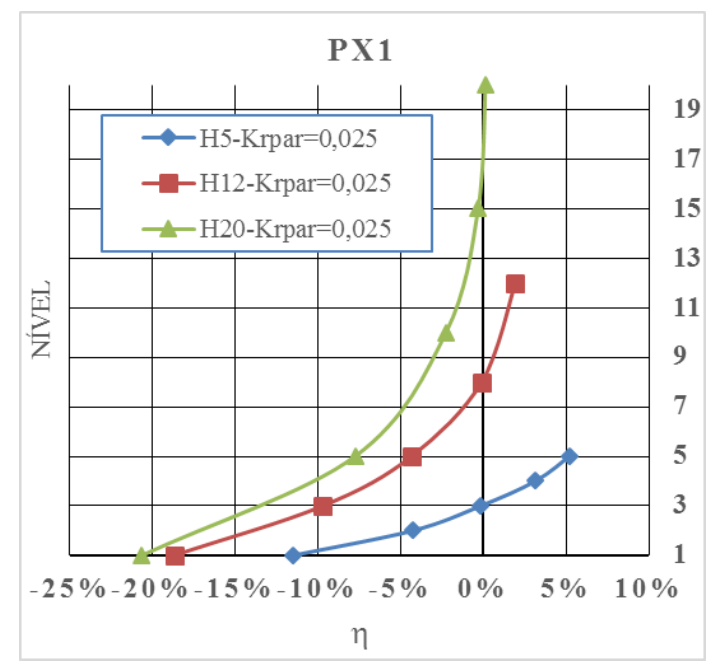

a) $\operatorname{Px} 1-$ Krpar $=0,025$

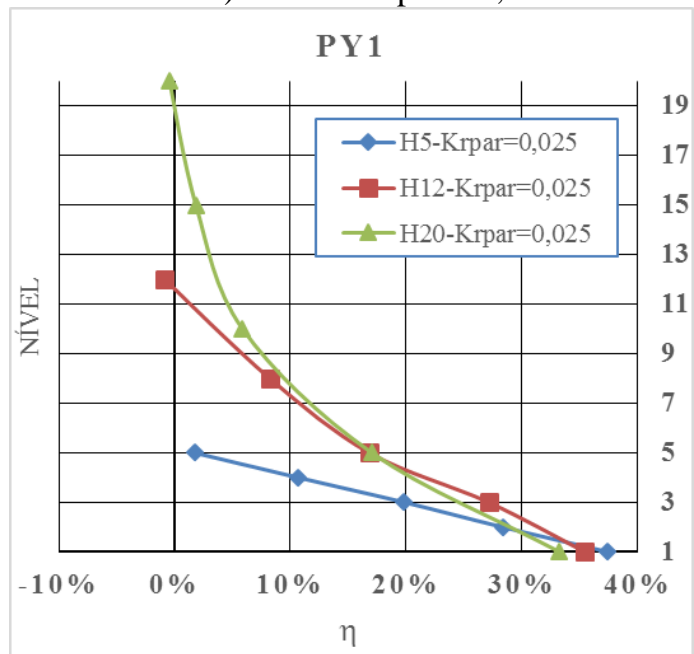

c) PY1 - Krpar $=0,025$

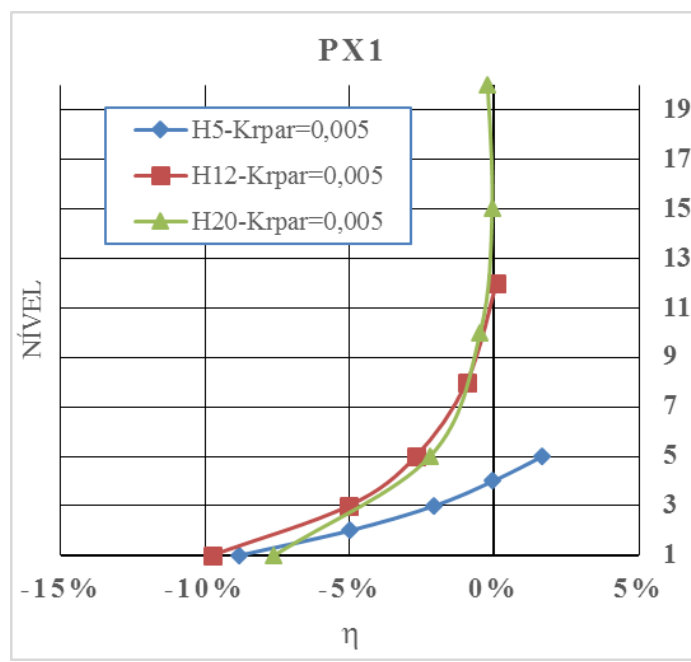

b) Px1 - Krpar $=0,005$

PY 1

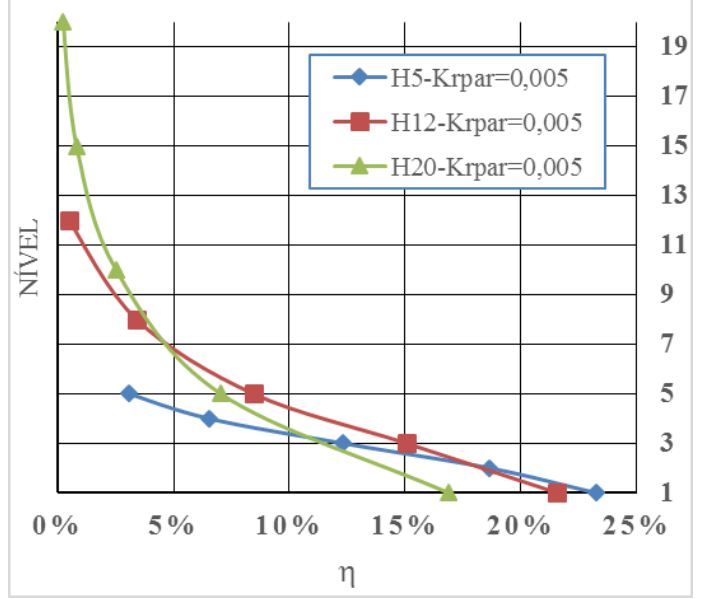

d) PY1 - Krpar =0,005

Figura $6.12-\eta$ - Alturas x Krpar

A confrontação de valores expostos na Figura 6.12-a e na Figura 6.12-b mostra a dependência da rigidez relativa estrutura-solo na distribuição de esforços em todos os 
pavimentos da estrutura. A grande rigidez relativa estrutura-solo $(\mathrm{Krpa}=0,025)$ torna os resultados dos 3 modelos desiguais ao longo de toda a altura, diferentemente de quando a rigidez estrutura-solo tem um valor reduzido. Neste caso (Figura 6.12-b), o comportamento entre os edifícios com 12 e 20 pavimentos são similares. A confrontação de resultados da Figura 6.12-c e Figura 6.12-d propicia conclusões semelhantes, mas nesta última situação os modelos com 12 e 20 pavimentos ainda apresenta pequenas diferenças.

\subsection{MACIÇO DO SOLO}

O estudo da rigidez relativa estrutura-solo mostrou a contribuição reduzida dos pavimentos superiores, tornando a rigidez do solo o fator preponderante no comportamento conjunto da ISE. As alterações no número de pavimentos já foram estudadas amplamente nos itens anteriores.

Neste item são avaliados aspectos relacionados ao maciço do solo. O primeiro aspecto é a perda de homogeneidade do solo. São avaliadas duas situações da ISE com a consideração de solos heterogêneos. A profundidade do maciço é uma variável relevante, pois altera a intensidade e a distribuição dos recalques na fundação. Desta maneira, são avaliadas as consequências das mudanças da espessura do maciço do solo.

\subsubsection{SOLO HETEROGÊNEO}

As análises realizadas ao longo do desenvolvimento da tese consideraram sempre o solo sendo um maciço homogêneo. Essa simplificação em situações práticas pode ou não ser aceitável. As medições de recalques dos edifícios apresentados no capítulo 3 indicaram a presença de heterogeneidade no maciço de solo em um número considerável de exemplares. Duas tipologias são selecionadas para avaliar a ISE com a consideração simplificada da heterogeneidade do maciço. As duas tipologias são selecionadas para que a heterogeneidade acarretasse no desaprumo atuando apenas em uma direção. No caso, foi escolhido o Eixo-X, que possibilita manter o mesmo plano de simetria no modelo utilizado ao longo da tese. A Figura 6.13 mostra o modelo numérico construído para esta avaliação. 


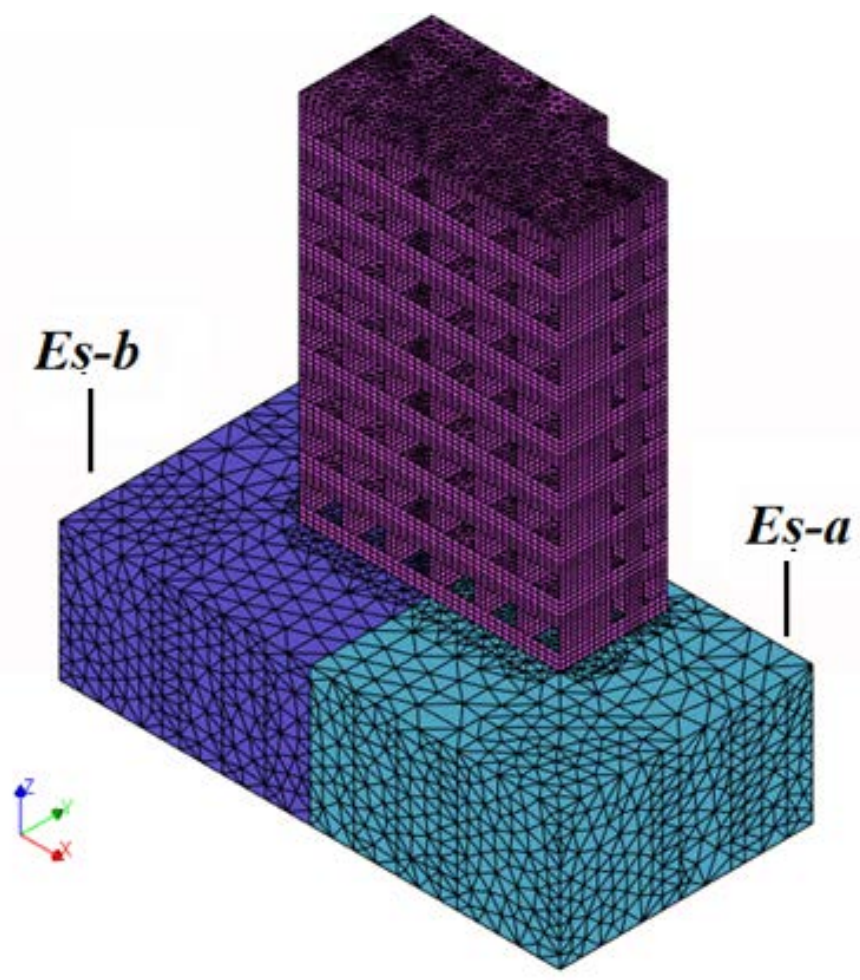

Figura 6.13 - Modelo numérico - Solo heterogêneo

O maciço é definido por duas regiões de propriedades distintas de rigidez do solo, denominadas como Região a e Região b. A simplificação é justificada devido às dificuldades na construção de um modelo com muitas variações nas propriedades do solo. A Tabela 6.4 mostra as propriedades do maciço do solo e a nomenclatura dos dois modelos estudados.

\begin{tabular}{|l|c|c|c|c|c|c|c|}
\multicolumn{7}{c|}{ Tabela 6.4 - Modelos com solo heterogêneo } \\
\cline { 2 - 9 } & H $(\mathrm{m})$ & Es $\left(\mathrm{N} / \mathrm{m}^{2}\right)$ & $\begin{array}{c}\text { Coesão } \\
\left(\mathrm{N} / \mathrm{m}^{2}\right)\end{array}$ & $\begin{array}{c}\text { Ângulo } \\
\text { de } \\
\text { atrito }\end{array}$ & Es $\left(\mathrm{N} / \mathrm{m}^{2}\right)$ & $\begin{array}{c}\text { Coesão } \\
\left(\mathrm{N} / \mathrm{m}^{2}\right)\end{array}$ & $\begin{array}{c}\text { Ângulo } \\
\text { de atrito }\end{array}$ \\
\hline ISE-EVO-HET1 & 8 & $4,1 \times 10^{7}$ & $4,5 \times 10^{5}$ & $42^{0}$ & $1,6 \times 10^{7}$ & $1,7 \times 10^{5}$ & $33^{\circ}$ \\
\hline ISE-EVO-HET2 & 7 & $2,6 \times 10^{7}$ & $7,7 \times 10^{4}$ & $27^{0}$ & $5,2 \times 10^{7}$ & $2,8 \times 10^{5}$ & $38^{0}$ \\
\hline
\end{tabular}

Os dois modelos numéricos permitem avaliar o desaprumo atuando nos dois sentidos do plano formado pelos eixos Y-Z. Os recalques medidos foram comparados com os obtidos numericamente. Os deslocamentos verticais analíticos alcançaram boa aproximação com as medições de recalques. A confrontação desses valores não é exposta e debatidos neste item, já que foram discutidas no capítulo 3 (Para o solo homogêneo) e por este item objetivar especificamente os efeitos da ISE na estrutura. Essas confrontações estão expostas no apêndice D.

A Tabela 6.5 mostra a redistribuição de esforços normais na base das paredes. Os resultados de referência (Ref-Ea e RefEb) correspondem aos modelos que consideram o solo homogêneo, igualando-se a rigidez nas regiões A e B. 
Tabela 6.5 - $\eta_{\text {PAR }}$ - Base das paredes modelos ISE-EVO-HET1 e ISE-EVO-HET2

\begin{tabular}{|c|c|c|c|c|c|c|}
\hline & \multicolumn{6}{|c|}{$\eta_{\text {PAR }}$} \\
\hline & \multicolumn{3}{|c|}{ Análise - ISE-EVO-HET1 } & \multicolumn{3}{|c|}{ Análise - ISE-EVO-HET2 } \\
\hline Paredes & $\begin{array}{c}\text { ISE-EVO- } \\
\text { HET1 }\end{array}$ & REF-Ea & REF-Eb & $\begin{array}{c}\text { ISE-EVO- } \\
\text { HET2 } \\
\end{array}$ & REF-Ea & REF-Ea \\
\hline PX1 & $-32 \%$ & $-18 \%$ & $-21 \%$ & $-9 \%$ & $-20 \%$ & $-14 \%$ \\
\hline PX2 & $16 \%$ & $4 \%$ & $1 \%$ & $-7 \%$ & $2 \%$ & $4 \%$ \\
\hline PX3 & $0 \%$ & $-2 \%$ & $1 \%$ & $-9 \%$ & $0 \%$ & $-2 \%$ \\
\hline PX4 & $-34 \%$ & $9 \%$ & $11 \%$ & $11 \%$ & $10 \%$ & $8 \%$ \\
\hline PX5 & $-3 \%$ & $-17 \%$ & $-17 \%$ & $-12 \%$ & $-17 \%$ & $-14 \%$ \\
\hline PX6 & $-31 \%$ & $-20 \%$ & $-19 \%$ & $-27 \%$ & $-19 \%$ & $-17 \%$ \\
\hline PX7 & $-3 \%$ & $7 \%$ & $13 \%$ & $-8 \%$ & $11 \%$ & $5 \%$ \\
\hline PX8 & $-52 \%$ & $-31 \%$ & $-33 \%$ & $-14 \%$ & $-32 \%$ & $-26 \%$ \\
\hline PX9 & $-8 \%$ & $-43 \%$ & $-49 \%$ & $-58 \%$ & $-47 \%$ & $-36 \%$ \\
\hline PX10 & $-58 \%$ & $3 \%$ & $9 \%$ & $7 \%$ & $7 \%$ & $2 \%$ \\
\hline PY1 & $15 \%$ & $29 \%$ & $32 \%$ & $21 \%$ & $31 \%$ & $25 \%$ \\
\hline PY2 & $15 \%$ & $19 \%$ & $20 \%$ & $7 \%$ & $20 \%$ & $16 \%$ \\
\hline PY3 & $-12 \%$ & $0 \%$ & $-2 \%$ & $-15 \%$ & $-1 \%$ & $0 \%$ \\
\hline PY4 & $-29 \%$ & $-47 \%$ & $-53 \%$ & $-47 \%$ & $-51 \%$ & $-39 \%$ \\
\hline PY5 & $13 \%$ & $23 \%$ & $26 \%$ & $25 \%$ & $25 \%$ & $20 \%$ \\
\hline PY6 & $-33 \%$ & $-33 \%$ & $-42 \%$ & $-23 \%$ & $-39 \%$ & $-27 \%$ \\
\hline PY7 & $-16 \%$ & $8 \%$ & $9 \%$ & $24 \%$ & $9 \%$ & $7 \%$ \\
\hline PY8 & $-61 \%$ & $-25 \%$ & $-35 \%$ & $11 \%$ & $-31 \%$ & $-20 \%$ \\
\hline PY9 & $19 \%$ & $-4 \%$ & $-5 \%$ & $1 \%$ & $-5 \%$ & $-3 \%$ \\
\hline PY10 & $35 \%$ & $2 \%$ & $2 \%$ & $-16 \%$ & $2 \%$ & $2 \%$ \\
\hline PY11 & $24 \%$ & $-11 \%$ & $-16 \%$ & $-30 \%$ & $-14 \%$ & $-9 \%$ \\
\hline PY12 & $2 \%$ & $-14 \%$ & $-18 \%$ & $-24 \%$ & $-16 \%$ & $-11 \%$ \\
\hline PY13 & $12 \%$ & $10 \%$ & $13 \%$ & $7 \%$ & $12 \%$ & $9 \%$ \\
\hline PY14 & $-57 \%$ & $-49 \%$ & $-58 \%$ & $-54 \%$ & $-55 \%$ & $-41 \%$ \\
\hline PY15 & $-44 \%$ & $15 \%$ & $18 \%$ & $19 \%$ & $17 \%$ & $12 \%$ \\
\hline PY16 & $-42 \%$ & $20 \%$ & $21 \%$ & $23 \%$ & $21 \%$ & $17 \%$ \\
\hline$\eta_{\text {pav1,par }}$ & $26 \%$ & $18 \%$ & $21 \%$ & $20 \%$ & $20 \%$ & $15 \%$ \\
\hline
\end{tabular}

Algumas paredes são mais suscetíveis às mudanças de sentido do desaprumo da edificação (PX2, PY10, PY11, PY15 e PY16). Esses elementos apresentam comportamento inverso ao se modificar o sentido do desaprumo, mostrando a dificuldade de se analisar a ISE com solos muito heterogêneos.

Alguns elementos são afetados em uma menor escala com a inclusão da heterogeneidade do solo por possuírem a redistribuição de esforços mais relacionada ao comportamento do solo na direção Y (PX6 e PX8). A distância de alguns elementos das regiões com mudança de propriedades (PY1 e PY14) também é um fator atenuante. A redistribuição de esforços por grupo de paredes pode ser visualizada na Tabela 6.6. 
Tabela 6.6 - $\eta_{\mathrm{GRU}}$ - Base das paredes modelos ISE-EVO-HET1 e ISE-EVO-HET2

\begin{tabular}{|c|c|c|}
\hline Grupo de paredes & $\eta_{\text {GRU }}-$ ISE-MH1 & $\eta_{\text {GRU }}-$ ISE-MH2 \\
\hline G1 & $-33 \%$ & $-11 \%$ \\
\hline G2 & $15 \%$ & $-14 \%$ \\
\hline G3 & $1 \%$ & $-9 \%$ \\
\hline G4 & $-41 \%$ & $-2 \%$ \\
\hline G5 & $9 \%$ & $13 \%$ \\
\hline G6 & $13 \%$ & $25 \%$ \\
\hline G7 & $-25 \%$ & $15 \%$ \\
\hline G8 & $19 \%$ & $1 \%$ \\
\hline G9 & $25 \%$ & $-26 \%$ \\
\hline G10 & $12 \%$ & $7 \%$ \\
\hline G11 & $-49 \%$ & $15 \%$ \\
\hline
\end{tabular}

A redistribuição de esforços segue uma tendência geral em que as paredes e grupos localizados na região mais rígida do maciço tendem a sofrer acréscimo de cargas. Observa-se que essa tendência não pode ser encarada como uma regra. A redistribuição dos esforços em cada parede também tem relação com a rigidez das paredes adjacentes e ocorre nas duas direções em planta (X e Y). Os resultados apresentados evidenciam que o desaprumo na edificação altera a configuração de distribuição de esforços em virtude da ISE. A Figura 6.14 mostra um esquema ilustrativo desses valores nos dois modelos. 


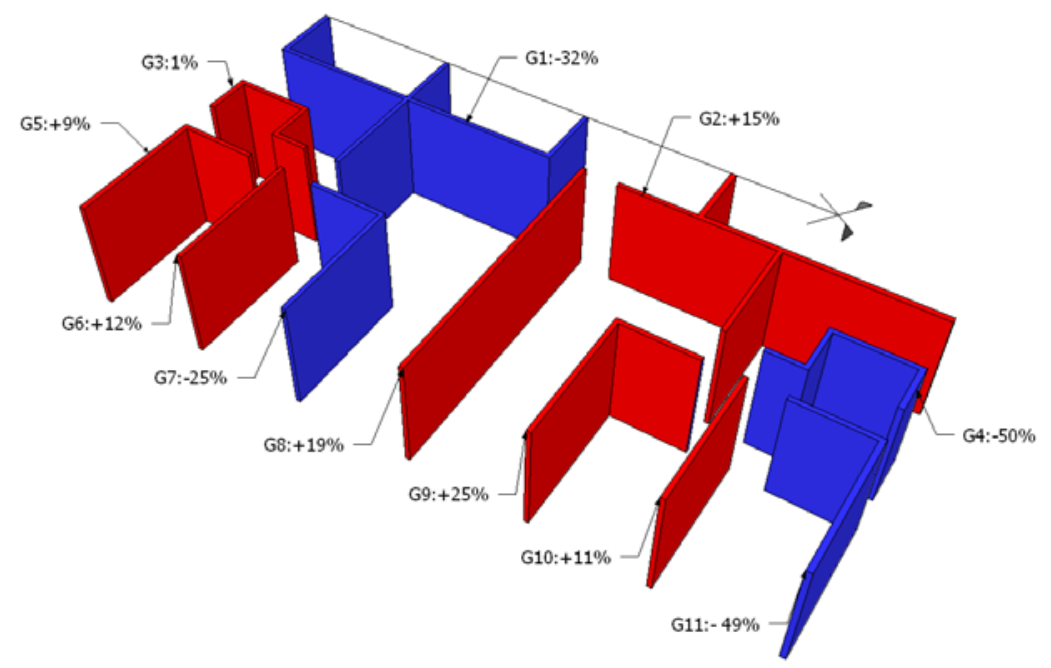

a) Modelo ISE-EVO-HET1

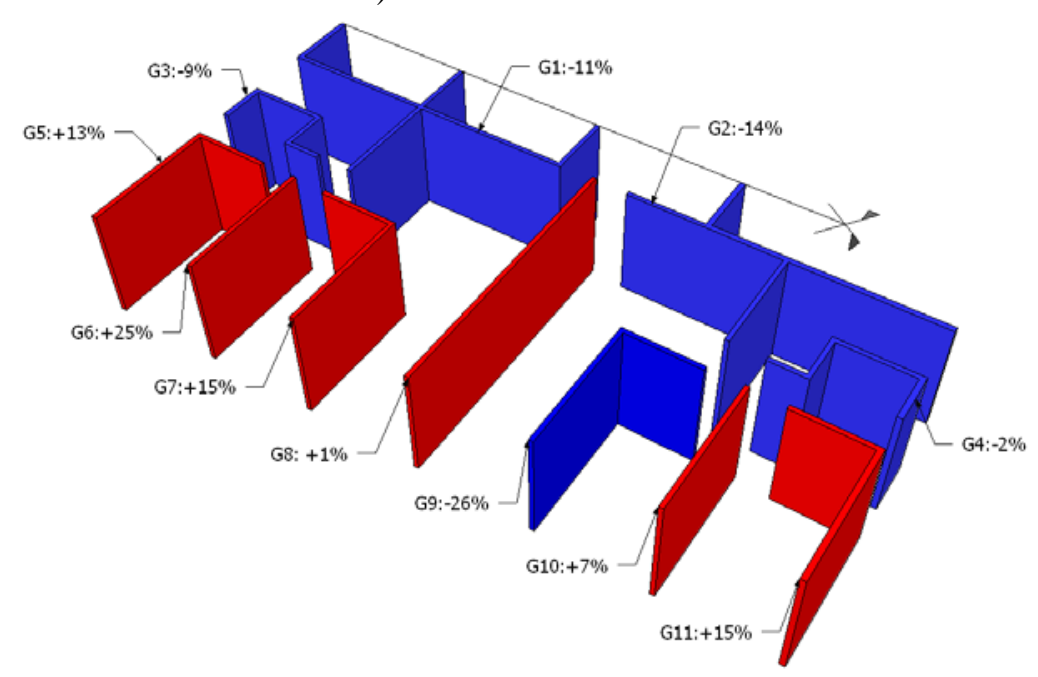

b) Modelo ISE-EVO-HET2

Figura 6.14 - $\eta_{\text {GRU }}$ - Grupos de paredes - Solo heterogêneo

Observa-se que a hipótese da redistribuição de esforços normais estabelecida no capítulo 4 perde a validade (Regiões centrais e mais carregadas sofrem reduções de cargas e regiões periféricas e menos solicitadas sofrem acréscimos de esforços) quando o solo não é homogêneo. A presença do solo heterogêneo rearranja essa configuração que acaba sendo influenciada pela rigidez relativa entre as regiões A e B. A diferença de rigidez entre as camadas promove uma configuração diferenciada na distribuição dos recalques que consequentemente altera a distribuição de esforços (Figura 6.15). 

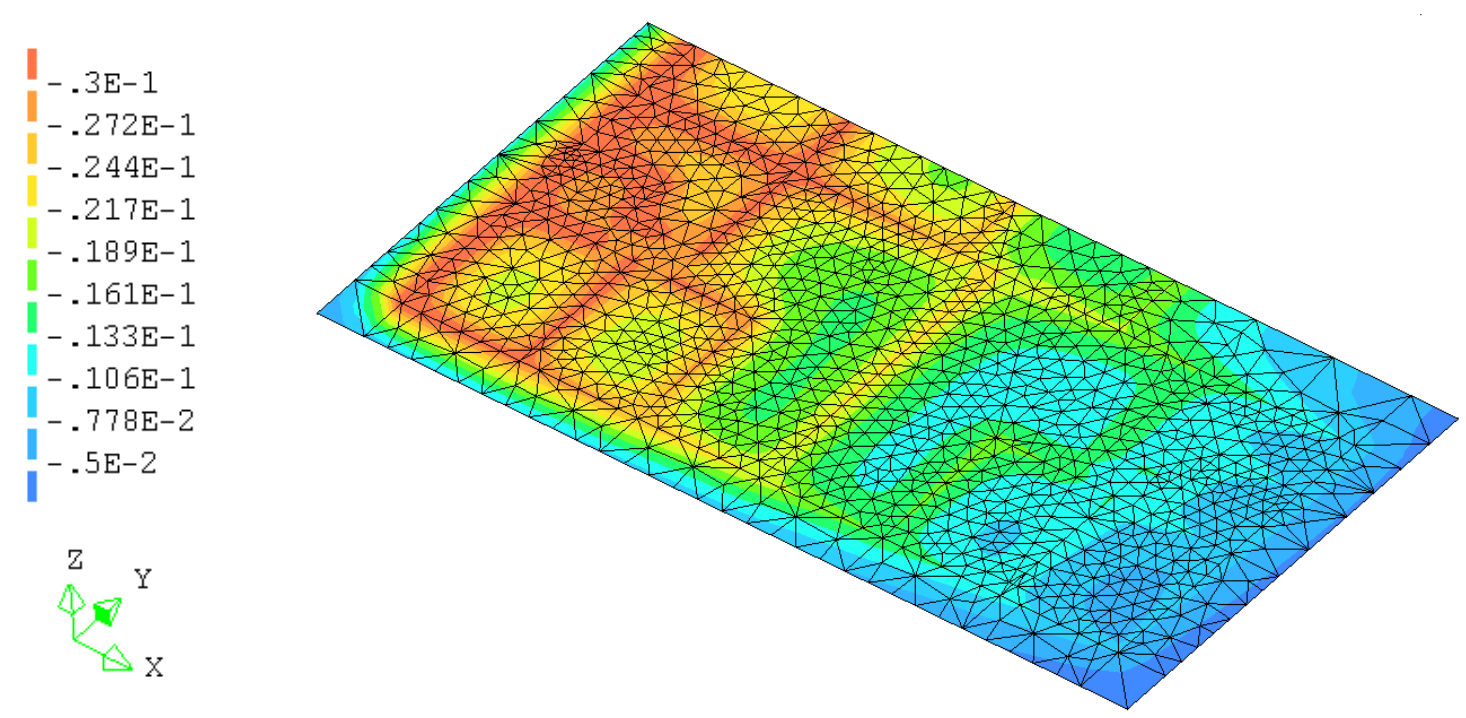

a) $\mathrm{u}_{\mathrm{z}}(\mathrm{m})$ - Recalques ISE-EVO-HET1
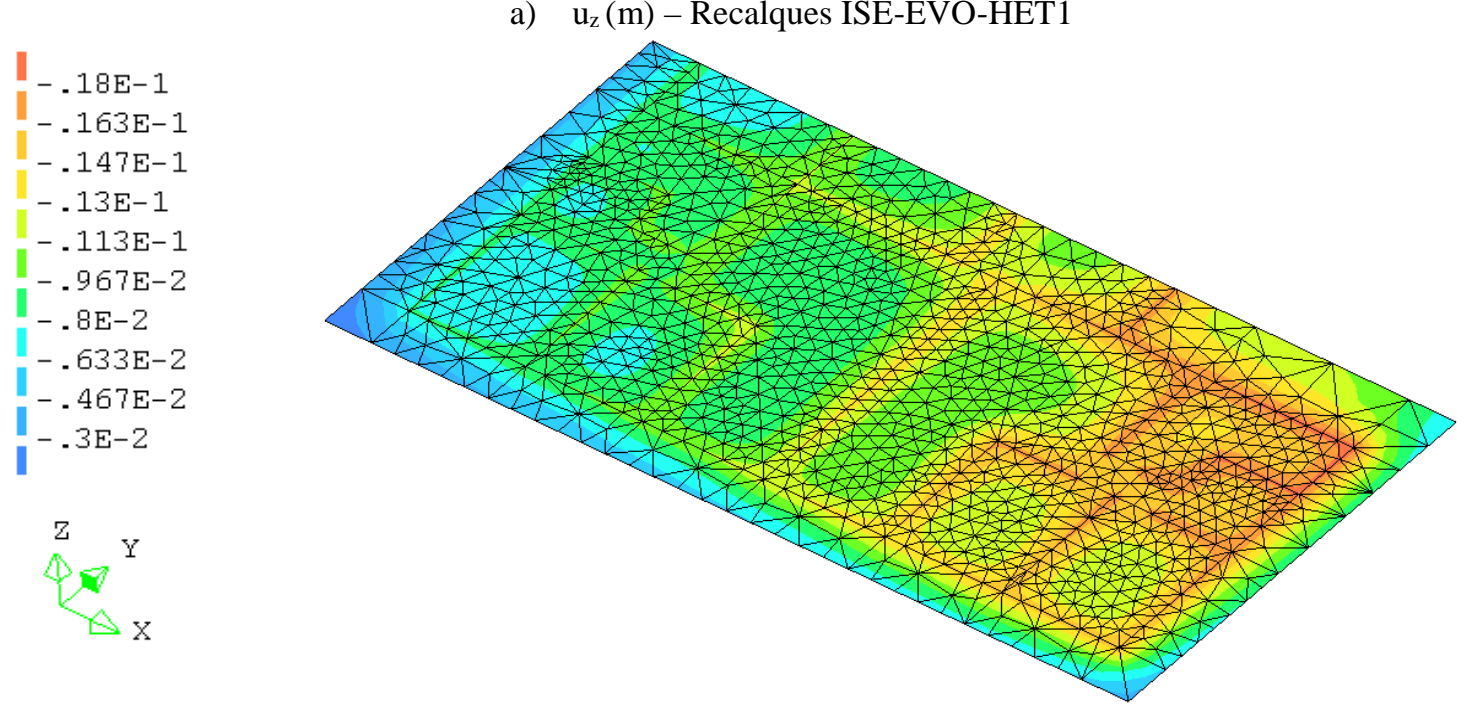

b) $\mathrm{u}_{\mathrm{z}}(\mathrm{m})$ - Recalques ISE-EVO-HET2

Figura 6.15 - Recalques Modelos ISE-EVO-HET1 e ISE-EVO-HET2

A diferença de rigidez entre os maciços promove configurações diferentes dos recalques daqueles apresentados usualmente com o solo homogêneo, conforme pode ser observado na Figura 6.15. Para estudo, foi realizado um levantamento paramétrico com a variação da rigidez relativa entre as camadas de solo consideradas no modelo proposto. Destaca-se que a diferença de rigidez entre os maciços corresponde a resultados medidos experimentalmente, ou seja, pode ocorrer perfeitamente em situações práticas. Procurou-se nesta análise não extrapolar os limites superiores aos observados nas medições de recalques. A Figura 6.16 mostra a comparação da redistribuição média de esforços na base da estrutura com as modificações da rigidez relativa das camadas horizontais do solo. Em ambos os modelos foi fixada a rigidez do maciço da "Região A” e alterada as propriedades da “Região B”.

Os resultados do modelo ISE-EVO-HET1 (Figura 6.16-a) indicam que as reduções na rigidez da região B provocam aumento da redistribuição média de esforços na base da estrutura. 
Deve-se atentar à baixa sensibilidade dos resultados de referência por meio das mudanças na rigidez do solo, desde que ele seja homogêneo. A consideração do solo heterogêneo acarreta em um crescimento significativo da redistribuição dos esforços nos elementos. Os resultados obtidos com a relação de rigidez dos maciços entre 1,5 e 2,5 são similares. Deste modo, não são necessárias grandes diferenças de rigidez entre as camadas para que ocorram modificações relevantes nos esforços dos elementos.

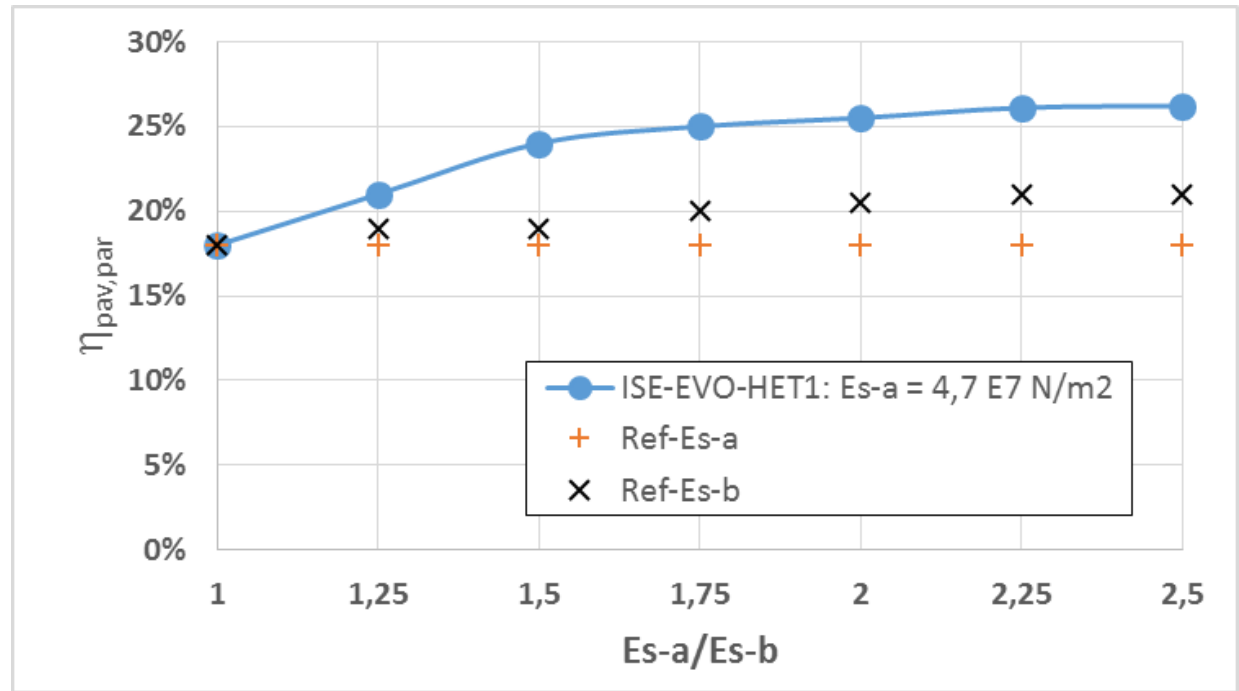

a) Modelo ISE-EVO-HET1

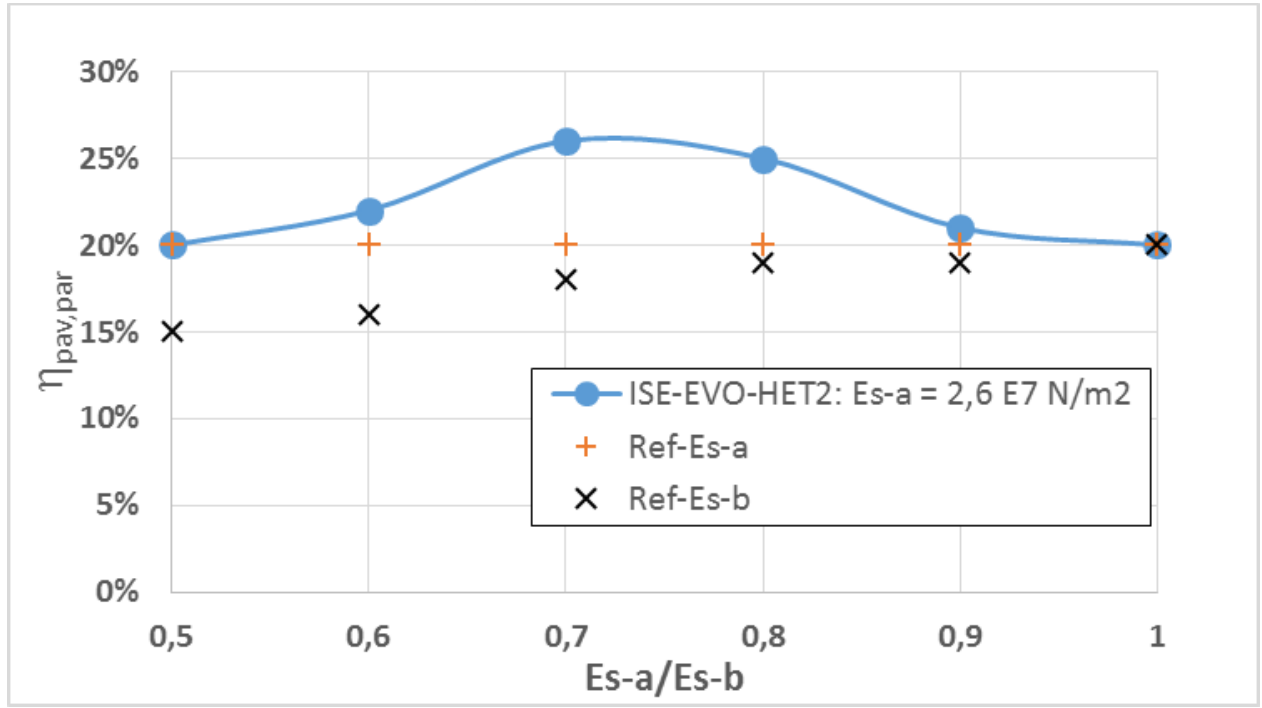

b) Modelo ISE-EVO-HET2

Figura 6.16 - Redistribuição de esforços e variação da rigidez relativa entre os maciços

Entretanto, no modelo ISE-EVO-HET-2 (Figura 6.16-b) o aumento da rigidez do solo da região $B$, provocou acréscimo na redistribuição de esforços apenas até um certo limite (relação Es-a/Es-b de 0,7). Acima desse limite, os resultados se aproximam dos obtidos com o solo menos rígido. Assim sendo, a redistribuição de esforços em um solo heterogêneo não tem 
relação apenas com a rigidez relativa entre as regiões do maciço. A geometria da estrutura também afeta esse comportamento, pois altera a distribuição de cargas de acordo com a rigidez relativa entre os maciços.

\subsubsection{MACIÇO DO SOLO - PROFUNDIDADE DA BASE RÍGIDA}

O maciço do solo é considerado como um meio semi-infinito. Na prática é comum as primeiras camadas do solo da superfície estar sobrejacente a um material de alta rigidez, ou seja, praticamente indeformável. A baixa deformabilidade desse material permite considerar o seu topo indeslocável, e utilizar uma profundidade hipotética do maciço do solo.

As alterações dessa profundidade modificam a intensidade e a distribuição dos recalques na fundação. São realizadas neste item análises dos efeitos da ISE com alterações na profundidade do maciço do solo.

Cintra et. al (2011) compararam recalques de uma sapata quadrada de um maciço de espessura finita com a consideração do meio semi-infinito. O recalque com o maciço de profundidade equivalente a duas vezes a largura da sapata chega a $80 \%$ do recalque com a consideração do meio semi-infinito. Os autores concluíram que a profundidade necessária para que o recalque no maciço finito seja equivalente a $90 \%$ do maciço semi-infinito varia de duas a seis vezes a largura da sapata. Essa profundidade necessária para o desenvolvimento do “bulbo de recalques” (termo definido pelos autores) depende das propriedades de rigidez do solo.

A partir deste conceito, são modificadas as relações entre a profundidade do maciço (H) e comprimento da edificação máxima em planta (L). A relação H/L é variada de 0,33 até 2 . Utiliza-se como referência o comprimento da edificação em planta de 15 metros. Para que a investigação não seja influenciada pela estrutura, são considerados 8 pavimentos da edificação em todos os modelos deste item. Esse valor é maior que o limite mínimo de 5, é significativo quanto às variações que se deseja analisar e não exige um esforço computacional muito elevado. Deste modo, é variada a rigidez do solo com o objetivo de se alterar a rigidez estrutura-solo

Um dos aspectos que se pretende investigar é se em baixas relações $\mathrm{H} / \mathrm{L}$ ocorre desenvolvimento suficiente dos mecanismos da ISE para que esta deva ser considerada. O segundo objetivo é verificar a diferença de resultados entre os casos em que a base rígida se encontra muito abaixo da superfície com as demais situações. A Figura 6.17 mostra a representação dos modelos estudados com a variação da profundidade do maciço do solo. 


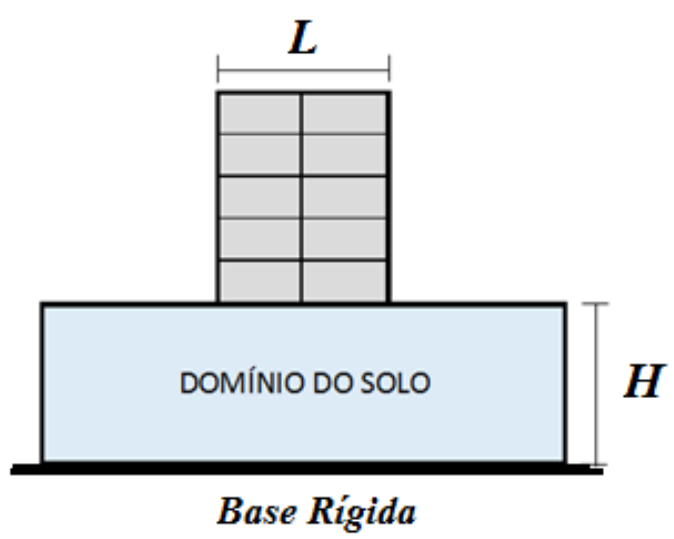

Figura 6.17 - Modelos - Relação H/L

A mudança da espessura do maciço do solo modificou os níveis de recalques. Esse resultado já era previsto, sendo mais importante nessa análise a investigação da distribuição e uniformização dos recalques.

A distribuição dos recalques é afetada pelo conjunto rigidez relativa estrutura-solo com a profundidade do maciço. A Figura 6.18 e a Figura 6.19 ilustram como a profundidade do maciço do solo modifica essa distribuição. Os dois casos apresentam a mesma rigidez estruturasolo calculado por meio do coeficiente Krpar. Deve-se observar que o coeficiente não contempla a espessura do maciço do solo no seu equacionamento.
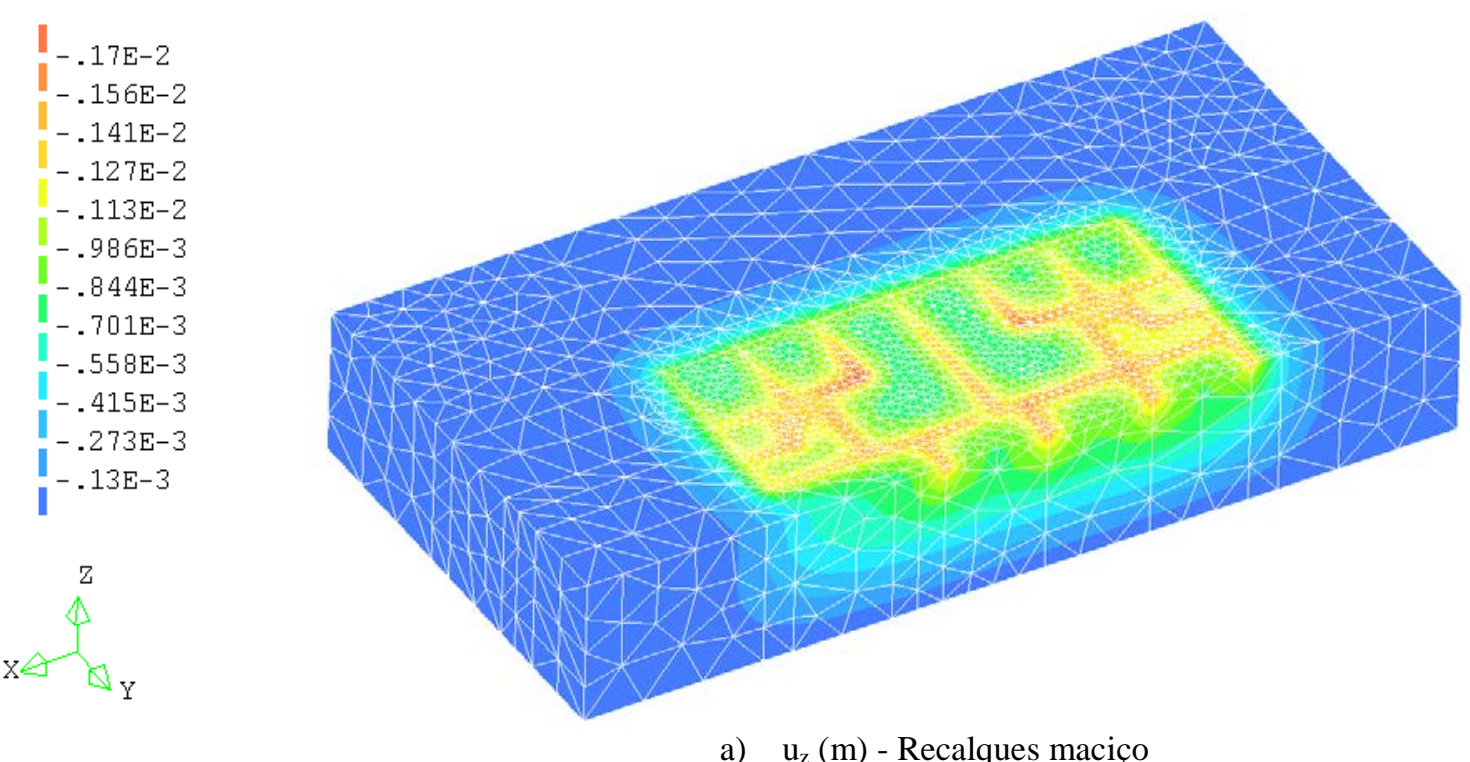

a) $\mathrm{u}_{\mathrm{z}}(\mathrm{m})$ - Recalques maciço 


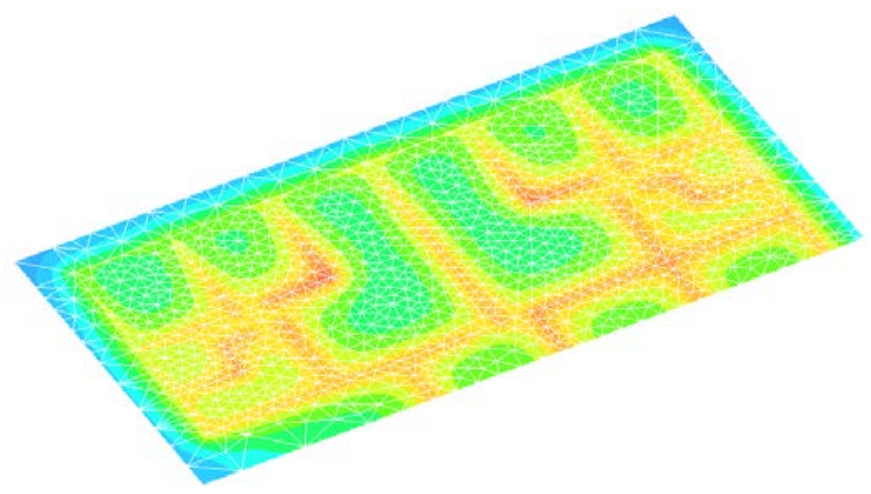

b) $\mathrm{u}_{\mathrm{z}}(\mathrm{m})$ - Recalques radier

Figura $6.18-\mathrm{u}_{\mathrm{z}}(\mathrm{m})$ - Recalques maciço e radier $-\operatorname{Krpar}=0,001=\mathrm{H} / \mathrm{L}=5$
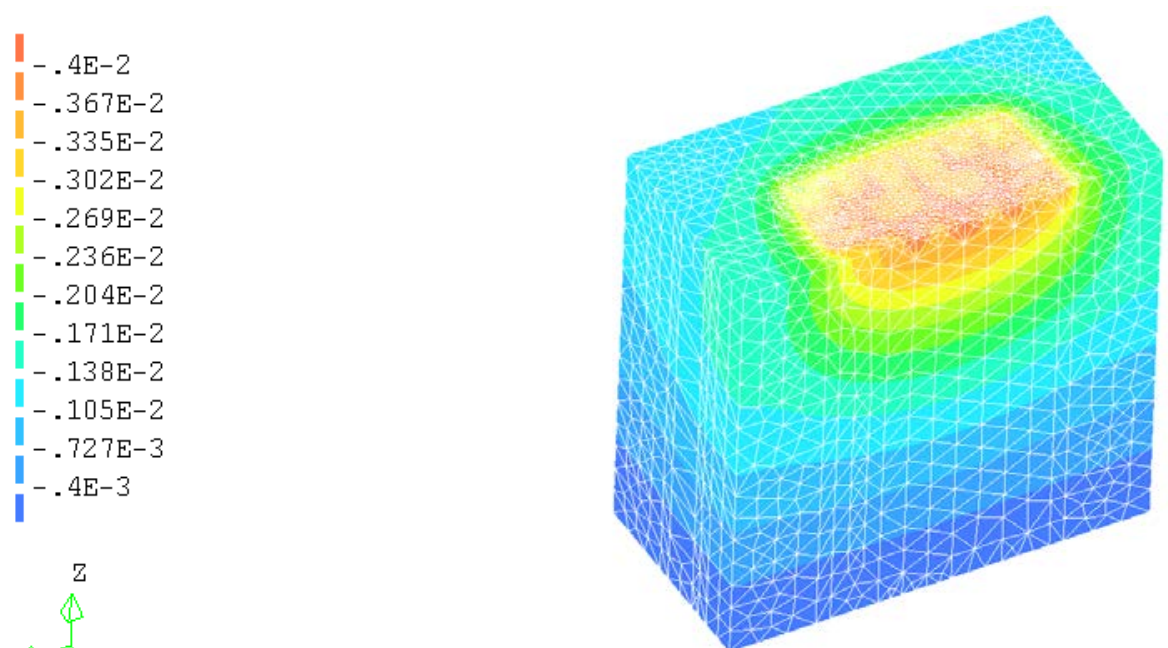

a) $\mathrm{u}_{\mathrm{z}}(\mathrm{m})$ - Recalques maciço

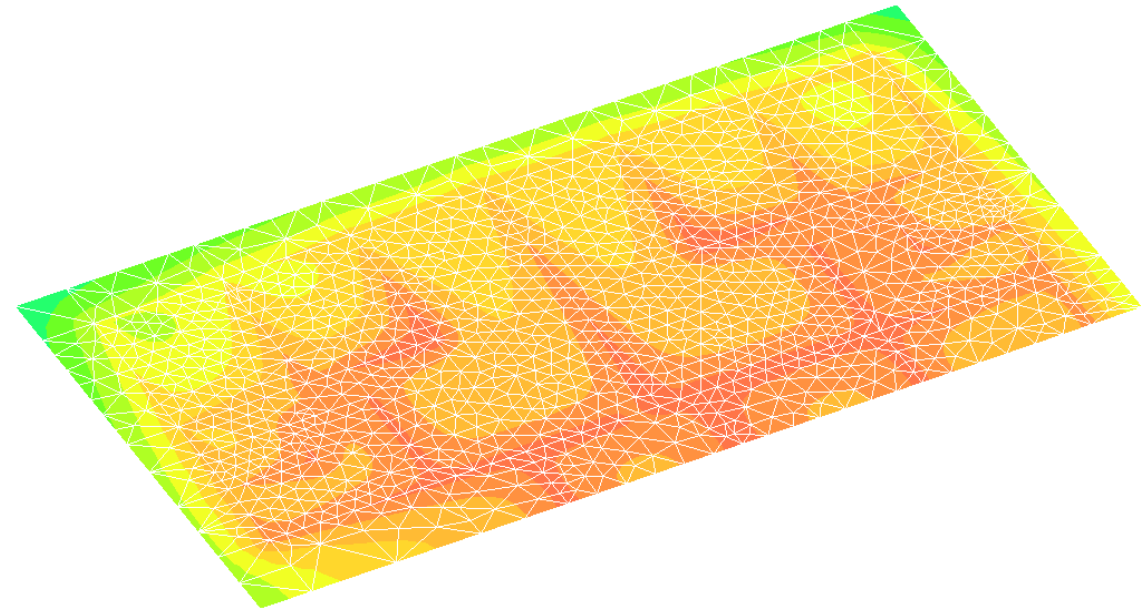

b) $\mathrm{u}_{\mathrm{z}}(\mathrm{m})$ - Recalques radier

Figura $6.19-\mathrm{u}_{\mathrm{z}}(\mathrm{m})$ - Recalques maciço e radier $-\mathrm{Krpar}=0,001=\mathrm{H} / \mathrm{L}=30$

Os resultados apresentados permitem vislumbrar que quanto maior a profundidade do maciço mais uniformes são os recalques. O maciço de pequena espessura (Figura 6.18) não desenvolve um espalhamento desses recalques, estabelecendo-se uma concentração dos mesmos na base das paredes. Nos modelos com espessuras maiores os recalques se desenvolvem ao longo da espessura do maciço, o que consequentemente aumenta a sua 
uniformização no radier. Esses resultados podem ser confirmados pela Figura 6.20 que mostra o coeficiente de variação dos recalques em relação à variação da profundidade do maciço para diversos índices de rigidez estrutura-solo.

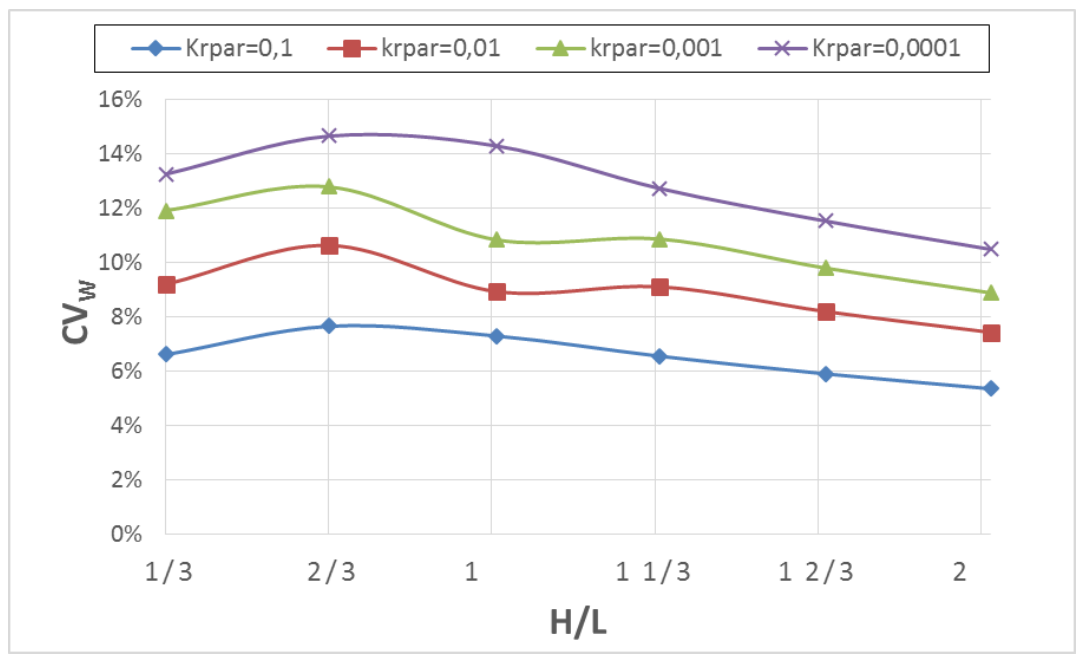

Figura 6.20 - $\mathrm{CV}_{\mathrm{w}}$ - Coefiente de variação dos recalques- H/L e Krpar

A ampliação da espessura do solo age como uma flexibilização da sua rigidez. Essa flexibilização por consequência da espessura do maciço não está sendo considerada no coeficiente proposto (Krpar). Assim sendo, conforme se aumenta a espessura do maciço, ocorre aumento da rigidez relativa estrutura-solo e consequentemente uma maior uniformização dos recalques. No entanto, ocorre aumento do $C_{\mathrm{w}}$ entre a profundidade de 5 a 15 metros, que corresponde a H/L entre 1/3 a 1. Apesar da redução do coeficiente de variação do maciço para espessuras maiores que 15 metros, o recalque diferencial na estrutura não apresentou mudanças relevantes (Figura 6.21).

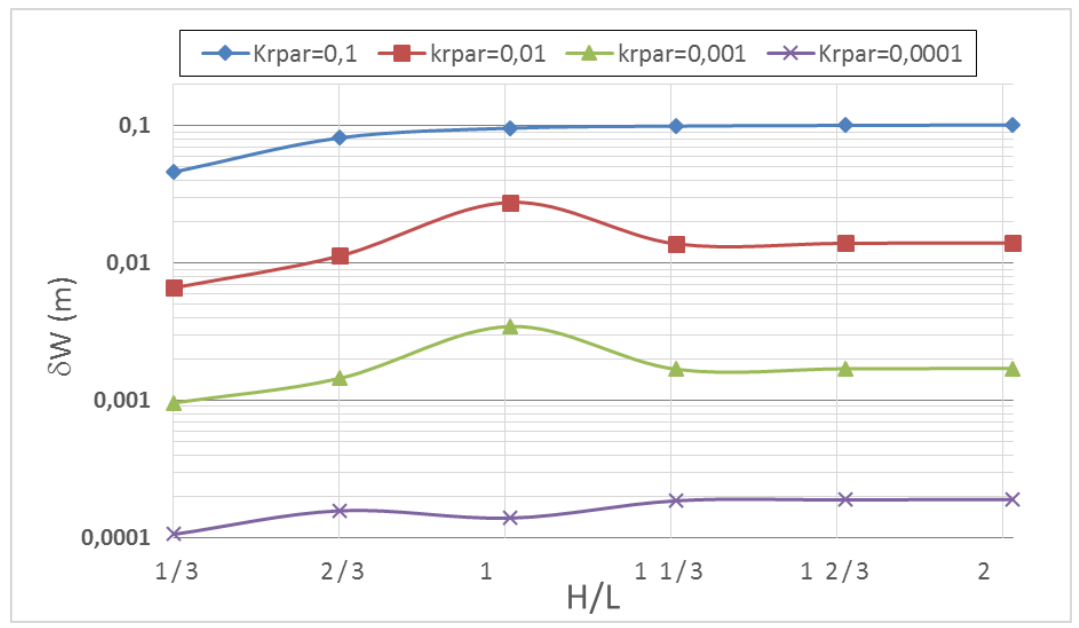

Figura 6.21 - $\delta w(m)$ - Recalque diferencial - H/L e Krpar

Os recalques diferenciais dos modelos com espessura entre 20 e 30 metros de profundidade são semelhantes independentemente da rigidez estrutura-solo. Apresenta-se a 
resposta da estrutura em função da espessura do maciço. A Figura 6.22 mostra a redistribuição de esforços em alguns elementos da estrutura perante a espessura do maciço e a rigidez estrutura-solo.

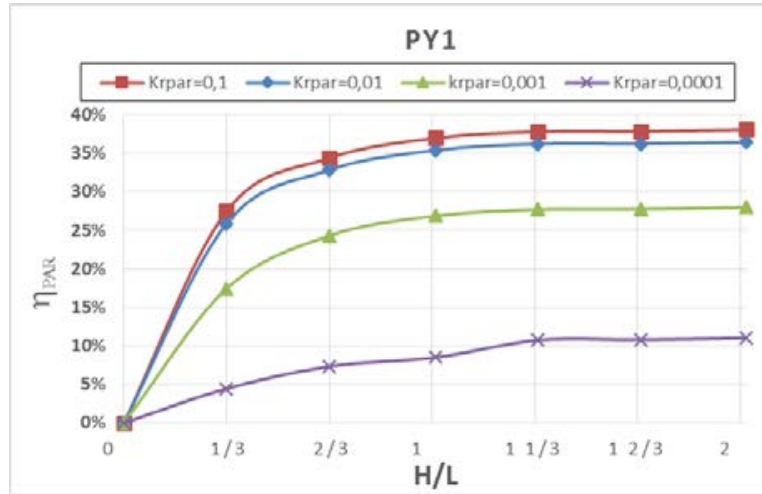

a) PY1 - $\eta_{\text {PAR }}$ X H/L e Krpar

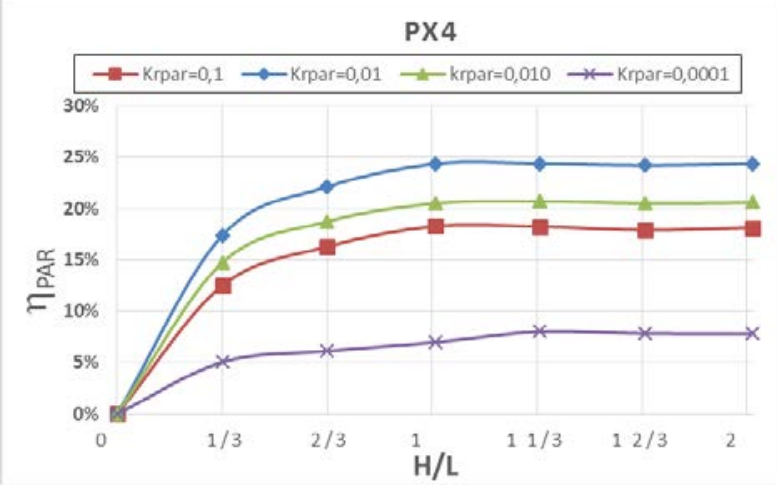

b) PX4 - $\eta_{\text {PAR }}$ X H/L e Krpar

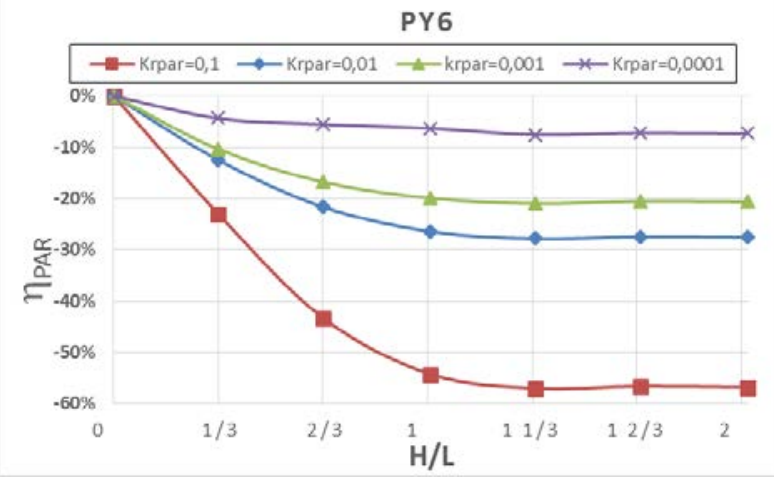

c) PY6 - $\eta_{\text {PAR }}$ X H/L e Krpar

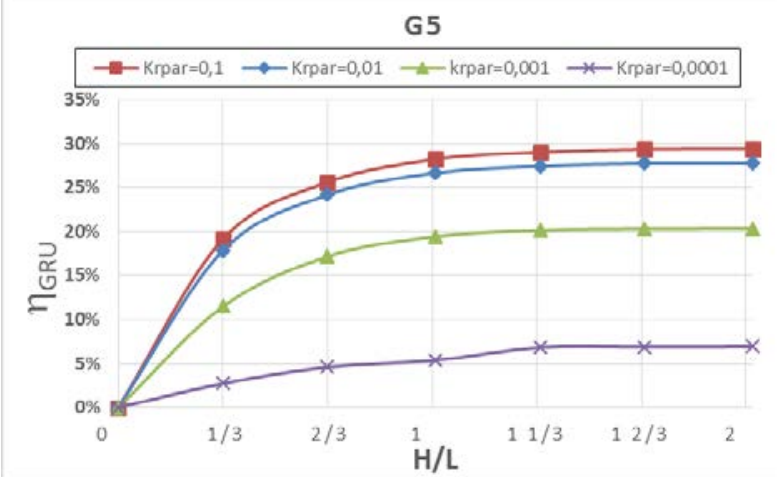

d) PY6 - $\eta_{\text {GRU }} \mathrm{X}$ H/L e Krpar

Figura 6.22 - Redistribuição de esforços/ Espessura do maciço do solo 
Não ocorrem diferenças significativas na redistribuição de esforços quando a espessura do solo assume valores acima de 15 metros. Esse fato mostra que a contribuição do solo no conjunto, para este caso, fica limitado a essa faixa de espessura. Nessa faixa ocorrem modificações nas grandezas relacionadas aos recalques, mas com mudanças irrelevantes nos esforços das paredes. Para a espessura do maciço abaixo de 15 metros ocorrem reduções na redistribuição de esforços. Todavia, a redistribuição de esforços nas paredes ainda foi relevante. A Figura 6.23 mostra a redistribuição média do $1^{\circ}$ pavimento em relação às demais variáveis estudadas neste item.

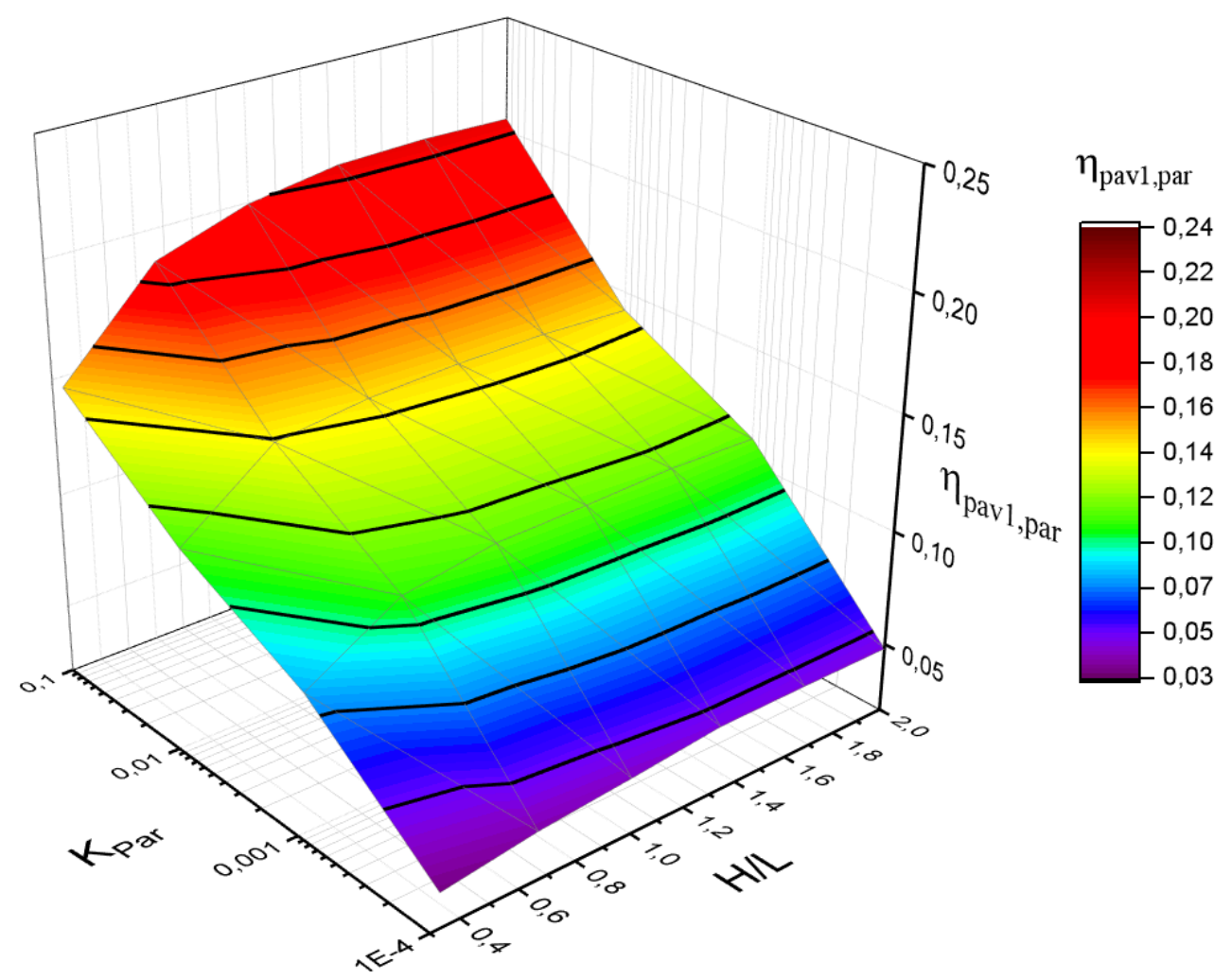

Figura 6.23 - Redistribuição de esforços/Espessura do maciço do solo

A redistribuição média de esforços no $1^{\circ}$ pavimento da estrutura apenas sofre alterações nos trechos de baixa espessura do maciço do solo (H/L de 0,33 a 1). Essas mudanças são maiores nos modelos com média e grande rigidez estrutura-solo (acima de 0,01). Observase que não ocorrem diferenças significativas quando o maciço apresenta a relação H/L acima de 1.

A investigação realizada confirma que a mobilização do maciço ocorre apenas nas camadas superiores. Neste caso, pode-se supor que construir um modelo numérico para este tipo de problema que contemple todo o maciço apenas ampliaria o custo computacional, pois os resultados obtidos na estrutura seriam similares. 
Mesmo em situações nas quais o indeslocável está próximo da superfície, neste caso 5 metros, a interação solo-estrutura ainda teria relevância. Embora as influências sejam menores, elas ainda são relevantes na redistribuição de esforços. Pode-se entender que uma espessura reduzida do maciço apenas aumenta a rigidez do solo, mas a ISE ainda está presente e é governada pela rigidez relativa estrutura-solo.

\subsection{ANÁLISE DO DESEMPENHO ESTRUTURAL - VARIAÇÃO DO NÚMERO DE PAVIMENTOS E RIGIDEZ DO SOLO}

A redistribuição de esforços analisadas nos itens anteriores refere-se percentualmente ao esforço normal total do elemento analisado. Percentualmente os valores da redistribuição de esforços podem ser similares em paredes de edifícios de número de pavimentos distintos, mas os esforços atuantes nesses elementos são diferentes. Outro ponto que deve ser observado é que o fluxo das tensões normais na parede não é uniforme. Deste modo, embora possuam alterações percentuais similares, as consequências estruturais em edifícios de diferentes alturas podem ser desiguais.

Neste item é avaliada a ISE em edifícios com variação do número de pavimentos e rigidez do solo. São estudadas 3 tipologias distintas do edifício modelo, que se diferem pelo número de pavimentos. São definidos edifícios de pequena (5 pavimentos), média (12 pavimentos) e grande altura (20 pavimentos).

Em cada tipologia são variados os parâmetros de rigidez do solo. A definição do módulo de elasticidade foi feita de modo que os recalques assumissem valores excessivos (pior situação) até insignificantes (simulando uma base rígida da qual usualmente a ISE não seria considerada). São utilizados os valores de recalques admissíveis sugeridos por Bowles (1996) para fundações do tipo radier como referência. A Tabela 6.7 mostra os limites de recalques em radier sugeridos por Bowles (1996) os quais foram utilizados como referência para definir a rigidez do solo.

Tabela 6.7 - Recalques admissíveis em Radier - Bowles (1996)

\begin{tabular}{|c|c|}
\hline Recalque máximo $(\mathrm{mm})$ & 50 \\
\hline Recalque diferencial $(\mathrm{mm})$ & 20 \\
\hline
\end{tabular}

Devido à diferença do nível de carga utilizado em cada altura do edifício, os módulos de elasticidade do solo utilizados são distintos, mas será mantida a rigidez estrutura-solo. Esse 
tipo de análise permite vislumbrar os efeitos práticos da ISE em situações dentro e fora dos limites admissíveis dos recalques.

Modelos com rigidez equivalente a uma base rígida foram analisados (Krpar < 0,00001), mas não serão expostos, pois os resultados apresentaram efeitos muito reduzidos na estrutura. Essa conclusão pode ser observada na análise da rigidez estrutura-solo realizada no item 6.2.3. São listados abaixo as três situações aqui investigadas para cada altura da edificação.

- Rigidez relativa estrutura-solo alta (Krpar =0,025): Estes modelos possuem uma baixa rigidez do solo, no qual os limites de recalques admissíveis seriam ultrapassados. Neste caso, pelos métodos convencionais da teoria da elasticidade (sem a ISE), essa tipologia não seria viabilizada. O objetivo é avaliar quais as consequências na estrutura com níveis de recalques excessivos.

- Rigidez relativa estrutura-solo intermediária (Krpar =0,01): Simulando uma situação usual de fundação do tipo radier, no qual os recalques possuem valores dentro dos limites admissíveis.

- Rigidez relativa estrutura-solo baixa (Krpar =0,0005): Modelo com solo bastante rígido e recalques insignificantes. Este modelo procura observar se mesmo em um solo muito rígido a ISE ainda é relevante na análise das estruturas.

Deve-se ter em mente que esses valores são utilizados como referências para a análise paramétrica, pois outros aspectos devem ser investigados na escolha da fundação do tipo radier, não apenas os recalques diferenciais e totais na base. Acredita-se que são raros os edifícios de 20 pavimentos executados com este tipo de fundação. Contudo, a análise pode ser estendida para esses edifícios com objetivo de observar seu comportamento. A Tabela 6.8 mostra as características e nomenclatura dos modelos analisados neste item. Além disso são construídos modelos de referência, com apoios rígidos. 
Tabela 6.8 - Nomenclatura - Variação de pavimentos

\begin{tabular}{|c|c|c|c|}
\hline Altura & Nomenclatura & Krpar & Es (N/m $\left.\mathbf{m}^{2}\right)$ \\
\hline \multirow{3}{*}{5 pavimentos } & H5-KA & 0,025 & $5,5 \times 10^{6}$ \\
\cline { 2 - 4 } & H5-KB & 0,01 & $1,5 \times 10^{7}$ \\
\cline { 2 - 4 } & H5-KC & 0,0005 & $2,5 \times 10^{8}$ \\
\hline \multirow{3}{*}{12 pavimentos } & H12-KA & 0,025 & $1,5 \times 10^{7}$ \\
\cline { 2 - 4 } & H12-KB & 0,01 & $2,5 \times 10^{7}$ \\
\cline { 2 - 4 } & H12-KC & 0,0005 & $5,5 \times 10^{8}$ \\
\hline \multirow{3}{*}{20 pavimentos } & H20-KA & 0,025 & $2,5 \times 10^{7}$ \\
\cline { 2 - 4 } & H20-KB & 0,01 & $5,5 \times 10^{7}$ \\
\cline { 2 - 4 } & H20-KC & 0,0005 & $1,0 \times 10^{9}$ \\
\hline
\end{tabular}

A análise do desempenho neste item é realizada por meio da investigação nos seguintes pontos:

- Resistência de cálculo das paredes sob esforço normal de compressão. A investigação do dimensionamento dos elementos sob esforço normal de compressão é realizada pelo método simplificado da NBR-16055 (ABNT, 2012).

- Resistência de cálculo das paredes devido a concentração de tensões. São comparadas as tensões máximas na base das paredes com as tensões máximas de contato permitida pela NBR 16055 (ABNT, 2012)

- Análise de abertura de fissuras. Os limites de abertura de fissuras da NBR-6118 (2014) são comparados com os valores apresentados nos modelos numéricos.

- Dimensionamento dos elementos pelo procedimento da NBR-6118 (ABNT, 2014). Alguns elementos são analisados utilizando o procedimento da referida norma, onde são inclusos os efeitos das instabilidades locais e localizadas.

\subsubsection{EDIFÍCIO DE 5 PAVIMENTOS}

A escolha do mínimo de 5 pavimentos é baseada na recomendação da NBR-16055 (ABNT, 2012), que indica este número de pavimentos como limitante para a obrigatoriedade de inclusão da ISE em edifícios de paredes de concreto. A Tabela 6.9 mostra uma comparação dos recalques obtidos nos modelos de edifícios de 5 pavimentos. É mostrado, também, o coeficiente de variação dos recalques. 
Tabela 6.9 - Recalques - Edifício de pequena altura

\begin{tabular}{|c|c|c|c|c|c|c|}
\cline { 2 - 7 } \multicolumn{1}{c|}{} & $\bar{w}(\mathrm{~mm})$ & $w_{\text {máx }}(\mathrm{mm})$ & $w_{\text {máx }} / \bar{w}$ & $w_{\min }(\mathrm{mm})$ & $\delta w(\mathrm{~mm})$ & $\mathrm{CV}_{\mathrm{w}}(\%)$ \\
\hline H5-KA & 70,9 & 80,9 & 1,14 & 55,2 & 25,7 & $9,64 \%$ \\
\hline H5-KB & 23,8 & 27,5 & 1,15 & 15,0 & 12,5 & $10,62 \%$ \\
\hline H5-KC & 1,4 & 1,7 & 1,20 & 0,8 & 0,9 & $13,18 \%$ \\
\hline
\end{tabular}

Ressalta-se novamente que uma das tipologias apresenta recalque máximo absoluto acima do limite recomendado. Esta ocorrência foi proposital, com o objetivo de avaliar as influências desses recalques no comportamento estrutural. A diferença entre os coeficientes de variação de recalques entre os modelos H5-KA e H5-KB é bastante baixa. A razão entre os recalques máximos e médio para as duas tipologias são próximos de 1,15.

Embora os dois modelos apresentem as variáveis relacionadas aos recalques diferentes, o comportamento em relação à uniformidade de recalques e a contribuição da rigidez estrutural são equivalentes. É necessário um relevante acréscimo de rigidez no solo para gerar mudanças bruscas no comportamento, conforme observado pelos resultados do modelo H5-KC.

O procedimento utilizado para a verificação do dimensionamento das paredes aos esforços normais de compressão é o mesmo apresentado no capítulo 4. Utiliza-se o equacionamento simplificado da NBR-16055 (ABNT, 2012) para a obtenção do esforço normal por comprimento resistente de cálculo. Os resultados são convertidos em esforço normal resistente de cálculo de acordo com o comprimento de cada parede. Esse resultado é confrontado com o valor total do esforço normal solicitante de cálculo de cada parede, obtidos por meio do modelo numérico. A Tabela 6.10 mostra a comparação dos esforços normais e resistentes de cada parede e a razão entre os dois valores. São mostrados, apenas como complementação, os resultados obtidos por meio do modelo de referência (Apoios rígidos).

O emprego da ISE não impossibilita o dimensionamento de nenhum dos elementos de paredes utilizando o método simplificado da norma NBR-16055 (ABNT, 2012). O dimensionamento é possível, mesmo nas tipologias que possuem recalques absolutos e diferenciais acima dos valores admissíveis. 
Tabela 6.10 - Dimensionamento dos elementos - Edifícios de 5 pavimentos - NBR-16055

\begin{tabular}{|c|c|c|c|c|c|c|c|c|c|}
\hline \multirow[b]{2}{*}{ Parede } & \multirow[b]{2}{*}{$\mathrm{Nd}_{\text {res }}(\mathrm{kN})$} & \multicolumn{2}{|c|}{ REF-AP- H5 } & \multicolumn{2}{|c|}{ H5-KA } & \multicolumn{2}{|c|}{ H5-KB } & \multicolumn{2}{|c|}{ H5-KC } \\
\hline & & $\begin{array}{l}\mathrm{Nd}_{\text {sol }} \\
(\mathrm{kN})\end{array}$ & $\begin{array}{l}\mathrm{Nd}_{\text {sol }} / \\
\mathrm{Nd}_{\text {res }}\end{array}$ & $\mathrm{Nd}_{\mathrm{sol}}(\mathrm{kN})$ & $\begin{array}{c}\mathrm{Nd}_{\text {sol }} / \\
\mathrm{Nd}_{\text {res }}\end{array}$ & $\mathrm{Nd}_{\mathrm{sol}}(\mathrm{kN})$ & $\begin{array}{c}\mathrm{Nd}_{\text {sol }} / \\
\mathrm{Nd}_{\text {res }}\end{array}$ & $\mathrm{Nd}_{\mathrm{sol}}(\mathrm{kN})$ & $\begin{array}{c}\mathrm{Nd}_{\text {sol }} / \\
\mathrm{Nd}_{\text {res }}\end{array}$ \\
\hline PX1 & 4857,1 & 721,7 & $14,9 \%$ & 647,5 & $13,3 \%$ & 634,5 & $13,1 \%$ & 633,6 & $13,0 \%$ \\
\hline PX2 & 4857,1 & 615,6 & $12,7 \%$ & 795,9 & $16,4 \%$ & 786,2 & $16,2 \%$ & 773,7 & $15,9 \%$ \\
\hline PX3 & 1214,3 & 152,6 & $12,6 \%$ & 143,5 & $11,8 \%$ & 149,9 & $12,3 \%$ & 154,3 & $12,7 \%$ \\
\hline $\mathrm{PX} 4$ & 1214,3 & 160,5 & $13,2 \%$ & 202,1 & $16,6 \%$ & 207,1 & $17,1 \%$ & 207,7 & $17,1 \%$ \\
\hline PX5 & 571,4 & 80,4 & $14,1 \%$ & 81,3 & $14,2 \%$ & 85,0 & $14,9 \%$ & 86,9 & $15,2 \%$ \\
\hline PX6 & 571,4 & 82,9 & $14,5 \%$ & 76,5 & $13,4 \%$ & 83,1 & $14,5 \%$ & 86,2 & $15,1 \%$ \\
\hline PX7 & 1214,3 & 180,0 & $14,8 \%$ & 184,4 & $15,2 \%$ & 183,3 & $15,1 \%$ & 183,0 & $15,1 \%$ \\
\hline PX8 & 1214,3 & 204,7 & $16,9 \%$ & 178,2 & $14,7 \%$ & 190,2 & $15,7 \%$ & 197,6 & $16,3 \%$ \\
\hline PX9 & 1214,3 & 213,1 & $17,5 \%$ & 168,6 & $13,9 \%$ & 199,9 & $16,5 \%$ & 215,1 & $17,7 \%$ \\
\hline PX10 & 1214,3 & 178,4 & $14,7 \%$ & 177,7 & $14,6 \%$ & 177,2 & $14,6 \%$ & 176,8 & $14,6 \%$ \\
\hline PY1 & 2142,9 & 303,0 & $14,1 \%$ & 484,4 & $22,6 \%$ & 474,1 & $22,1 \%$ & 464,8 & $21,7 \%$ \\
\hline PY2 & 714,3 & 102,4 & $14,3 \%$ & 155,7 & $21,8 \%$ & 150,9 & $21,1 \%$ & 147,5 & $20,7 \%$ \\
\hline PY3 & 2142,9 & 300,6 & $14,0 \%$ & 306,4 & $14,3 \%$ & 304,5 & $14,2 \%$ & 306,1 & $14,3 \%$ \\
\hline PY4 & 714,3 & 89,2 & $12,5 \%$ & 63,0 & $8,8 \%$ & 66,9 & $9,4 \%$ & 69,4 & $9,7 \%$ \\
\hline PY5 & 2089,3 & 452,3 & $21,6 \%$ & 594,5 & $28,5 \%$ & 572,7 & $27,4 \%$ & 562,1 & $26,9 \%$ \\
\hline PY6 & 5501,7 & 844,8 & $15,4 \%$ & 622,7 & $11,3 \%$ & 674,0 & $12,3 \%$ & 684,0 & $12,4 \%$ \\
\hline PY7 & 2142,9 & 486,1 & $22,7 \%$ & 471,6 & $22,0 \%$ & 467,3 & $21,8 \%$ & 465,8 & $21,7 \%$ \\
\hline PY8 & 2142,9 & 315,8 & $14,7 \%$ & 214,7 & $10,0 \%$ & 240,1 & $11,2 \%$ & 251,9 & $11,8 \%$ \\
\hline PY9 & 4352,6 & 920,3 & $21,1 \%$ & 779,4 & $17,9 \%$ & 760,8 & $17,5 \%$ & 755,2 & $17,4 \%$ \\
\hline PY10 & 2142,9 & 489,2 & $22,8 \%$ & 415,5 & $19,4 \%$ & 431,2 & $20,1 \%$ & 442,4 & $20,6 \%$ \\
\hline PY11 & 2142,9 & 270,3 & $12,6 \%$ & 284,7 & $13,3 \%$ & 273,5 & $12,8 \%$ & 268,2 & $12,5 \%$ \\
\hline PY12 & 1750,0 & 269,0 & $15,4 \%$ & 247,2 & $14,1 \%$ & 252,1 & $14,4 \%$ & 254,0 & $14,5 \%$ \\
\hline PY13 & 2089,3 & 455,6 & $21,8 \%$ & 424,2 & $20,3 \%$ & 411,8 & $19,7 \%$ & 408,8 & $19,6 \%$ \\
\hline PY14 & 714,3 & 95,3 & $13,3 \%$ & 65,6 & $9,2 \%$ & 72,4 & $10,1 \%$ & 75,7 & $10,6 \%$ \\
\hline PY15 & 2142,9 & 308,0 & $14,4 \%$ & 331,0 & $15,4 \%$ & 314,1 & $14,7 \%$ & 307,7 & $14,4 \%$ \\
\hline PY16 & 714,3 & 97,5 & $13,7 \%$ & 162,4 & $22,7 \%$ & 154,0 & $21,6 \%$ & 149,0 & $20,9 \%$ \\
\hline
\end{tabular}

- Observa-se que as razões entre os esforços solicitantes de cálculo e o esforço resistente estão sempre abaixo de 30\%. Embora ocorram alterações relevantes nos níveis de cargas das paredes, a obrigatoriedade do uso de dimensões mínimas nesses elementos garante capacidade resistente suficiente para o dimensionamento. A Tabela 6.11 mostra a análise comparativa das tensões máximas nos elementos com a tensão máxima de contato permitida pela NBR-16055 (ABNT, 2012) nos edifícios com 5 pavimentos. 
Tabela 6.11 - Dimensionamento dos elementos - Edifícios de 5 pavimentos - NBR-16055

\begin{tabular}{|c|c|c|c|c|c|c|}
\hline \multirow[b]{3}{*}{ Parede } & \multicolumn{6}{|c|}{$\sigma_{\text {cont }, d} \leq 12,64 \mathrm{MPa}$} \\
\hline & \multicolumn{2}{|c|}{ H5-KA } & \multicolumn{2}{|c|}{ H5-KB } & \multicolumn{2}{|c|}{ H5-KC } \\
\hline & $\begin{array}{l}\sigma_{\text {cont }, d} \\
(\mathrm{MPa})\end{array}$ & $\frac{\sigma_{\text {cont }, d}}{0,85 * f c d}$ & $\begin{array}{r}\sigma_{\text {cont }, d} \\
(\mathrm{MPa})\end{array}$ & $\frac{\sigma_{c o n t, d}}{0,85 * f c d}$ & $\begin{array}{l}\sigma_{\text {cont }, d} \\
(\mathrm{MPa})\end{array}$ & $\frac{\sigma_{c o n t, d}}{0,85 * f c d}$ \\
\hline PX1 & 1,65 & $13,1 \%$ & 1,61 & $12,7 \%$ & 1,56 & $12,3 \%$ \\
\hline PX2 & 2,32 & $18,4 \%$ & 2,20 & $17,4 \%$ & 2,12 & $16,8 \%$ \\
\hline PX3 & 0,78 & $6,1 \%$ & 0,80 & $6,3 \%$ & 0,81 & $6,4 \%$ \\
\hline PX4 & 1,44 & $11,4 \%$ & 1,42 & $11,3 \%$ & 1,40 & $11,0 \%$ \\
\hline PX5 & 1,13 & $9,0 \%$ & 1,18 & $9,4 \%$ & 1,21 & $9,6 \%$ \\
\hline PX6 & 1,02 & $8,1 \%$ & 1,13 & $8,9 \%$ & 1,17 & $9,3 \%$ \\
\hline PX7 & 1,09 & $8,6 \%$ & 1,08 & $8,5 \%$ & 1,07 & $8,5 \%$ \\
\hline PX8 & 1,33 & $10,5 \%$ & 1,37 & $10,8 \%$ & 1,38 & $10,9 \%$ \\
\hline PX9 & 1,23 & $9,7 \%$ & 1,37 & $10,8 \%$ & 1,42 & $11,3 \%$ \\
\hline PX10 & 0,94 & $7,4 \%$ & 0,98 & $7,7 \%$ & 0,99 & $7,8 \%$ \\
\hline PY1 & 2,99 & $23,6 \%$ & 2,90 & $22,9 \%$ & 2,79 & $22,1 \%$ \\
\hline PY2 & 2,46 & $19,5 \%$ & 2,32 & $18,4 \%$ & 2,17 & $17,2 \%$ \\
\hline PY3 & 1,59 & $12,6 \%$ & 1,56 & $12,3 \%$ & 1,50 & $11,9 \%$ \\
\hline PY4 & 0,60 & $4,8 \%$ & 0,64 & $5,1 \%$ & 0,67 & $5,3 \%$ \\
\hline PY5 & 4,98 & $39,4 \%$ & 4,62 & $36,5 \%$ & 4,43 & $35,0 \%$ \\
\hline PY6 & 0,90 & $7,1 \%$ & 0,81 & $6,4 \%$ & 0,81 & $6,4 \%$ \\
\hline PY7 & 3,81 & $30,2 \%$ & 3,58 & $28,3 \%$ & 3,45 & $27,3 \%$ \\
\hline PY8 & 0,79 & $6,3 \%$ & 0,77 & $6,1 \%$ & 0,77 & $6,1 \%$ \\
\hline PY9 & 3,79 & $30,0 \%$ & 3,57 & $28,2 \%$ & 3,49 & $27,6 \%$ \\
\hline PY10 & 3,21 & $25,4 \%$ & 3,02 & $23,9 \%$ & 2,94 & $23,2 \%$ \\
\hline PY11 & 0,80 & $6,3 \%$ & 0,78 & $6,2 \%$ & 0,77 & $6,1 \%$ \\
\hline PY12 & 0,94 & $7,5 \%$ & 0,92 & $7,2 \%$ & 0,93 & $7,3 \%$ \\
\hline PY13 & 3,55 & $28,1 \%$ & 3,27 & $25,9 \%$ & 3,17 & $25,1 \%$ \\
\hline PY14 & 0,61 & $4,8 \%$ & 0,68 & $5,4 \%$ & 0,72 & $5,7 \%$ \\
\hline PY15 & 1,60 & $12,7 \%$ & 1,53 & $12,1 \%$ & 1,50 & $11,9 \%$ \\
\hline PY16 & 1,54 & $12,2 \%$ & 1,52 & $12,0 \%$ & 1,49 & $11,8 \%$ \\
\hline
\end{tabular}

As tensões de compressão atuantes são irrisórias perante as tensões resistentes, não ocorrendo problemas quanto ao dimensionamento das tensões de contato e ao esmagamento do concreto. A parede PY5 é a que apresenta maior concentração de tensões de compressão, com 4,98 MPa, mesmo muito abaixo do limite imposto pela referida norma.

Os modelos com a consideração de 5 pavimentos não apresentam o aparecimento de fissuras no modelo numérico. Deste modo esta análise não é realizada neste item.

\subsubsection{EDIFÍCIO DE 12 PAVIMENTOS}

A mesma tipologia, agora com 12 pavimentos será avaliada. As grandezas dos recalques nos modelos investigados são expostas na Tabela 6.9. 
Tabela 6.12 - Recalques - Edifício de 12 pavimentos

\begin{tabular}{|c|c|c|c|c|c|c|}
\cline { 2 - 7 } \multicolumn{1}{c|}{} & $\bar{w}(\mathrm{~mm})$ & $w_{\text {máx }}(\mathrm{mm})$ & $w_{\operatorname{máx}} / \bar{w}$ & $w_{\min }(\mathrm{mm})$ & $\delta w(\mathrm{~mm})$ & $\mathrm{CV}_{\mathrm{w}}(\%)$ \\
\hline H12-KA & 50,9 & 57,2 & 1,12 & 33,4 & 28,1 & $9,36 \%$ \\
\hline H12-KB & 30,7 & 34,5 & 1,12 & 19,6 & 14,9 & $9,78 \%$ \\
\hline H12-KC & 1,59 & 1,91 & 1,20 & 0,92 & 0,98 & $12,27 \%$ \\
\hline
\end{tabular}

O coeficiente de variação de recalques no modelo H12-KA é menor que o do modelo H5-KB (ambos com mesmas propriedades do solo), indicando o acréscimo da contribuição de rigidez no edifício com um número maior de pisos construídos. Destaca-se que esse crescimento não é tão efetivo já que ocorreu apenas um ganho de cerca de 15\% no coeficiente de variação de recalques com um aumento de sete pavimentos na estrutura (vide Tabela 6.9). A Tabela 6.13 mostra o dimensionamento das paredes por meio do método simplificado da NBR-16055 (ABNT, 2012).

Tabela 6.13 - Dimensionamento dos elementos - Edifícios de 12 pavimentos - Método simplificado NBR16055 (2012)

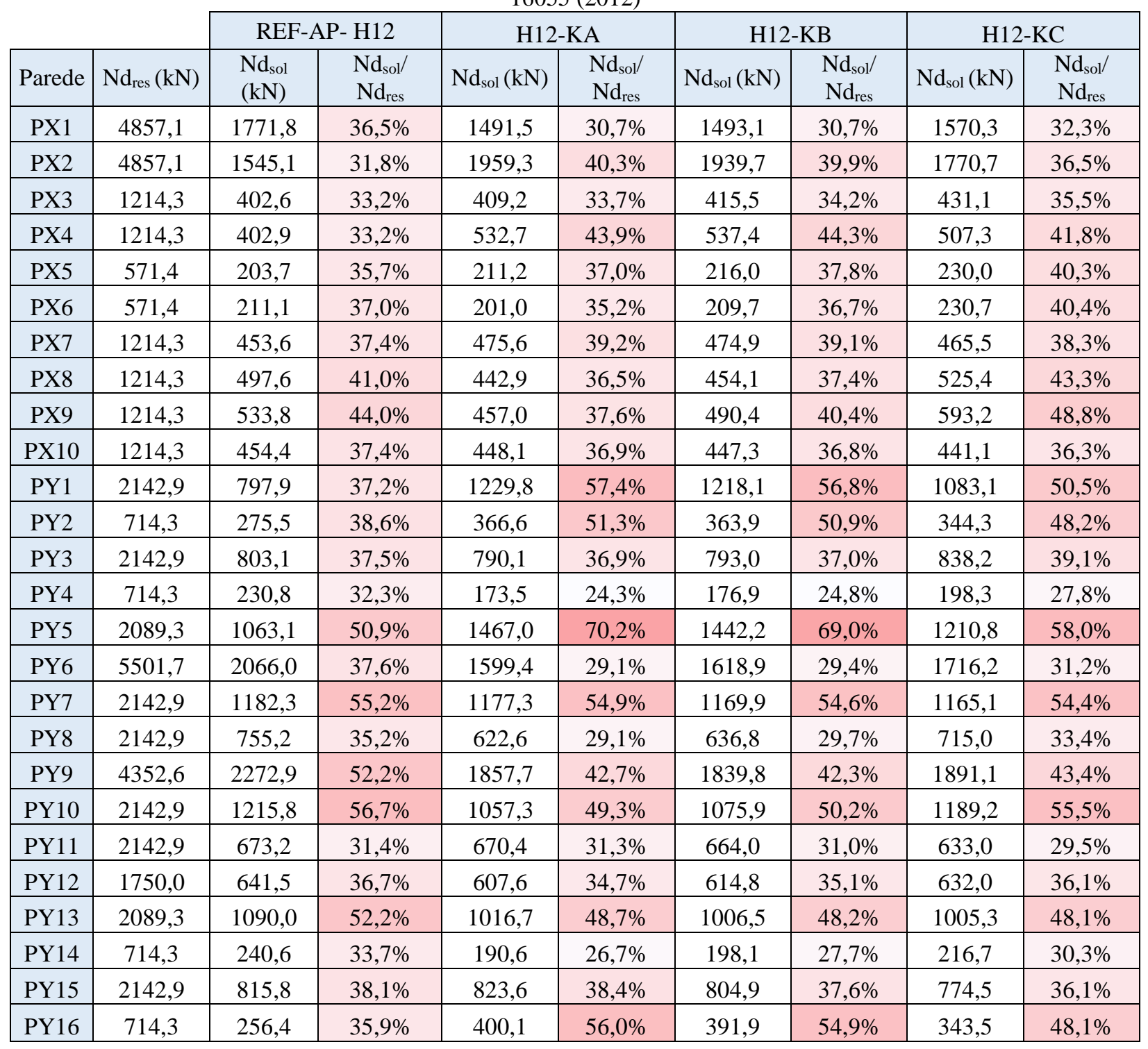


Os resultados apresentados na Tabela 6.13 mostram que todos os elementos atendem aos requisitos de dimensionados pelo método simplificado da NBR-16055 (ABNT, 2012) quando inclusa a ISE. Destaca-se que mesmo para um solo muito flexível (Modelo H12-KA) e que apresenta um recalque diferencial alto $(28,1 \mathrm{~mm})$ os elementos não apresentem problemas de dimensionamento. A parede PY5, por exemplo, apresenta relação do esforço de cálculo solicitante com o esforço de cálculo resistente de 70,2\%.

A Tabela 6.14 apresenta as tensões máximas localizadas entre a base das paredes estruturais e o radier. Apresenta-se, também, a comparação percentual com a tensão de contato resistente de cálculo.

Tabela 6.14 - Tensões de contato máxima base Parede/Radier (MPa) - Edificio de 12 pavimentos

\begin{tabular}{|c|c|c|c|c|c|c|}
\hline \multirow{4}{*}{ Parede } & \multicolumn{6}{|c|}{$\sigma_{\text {cont }, d} \leq 12,64 \mathrm{MPa}$} \\
\hline & \multicolumn{2}{|c|}{ H12-KA } & \multicolumn{2}{|c|}{ H12-KB } & \multicolumn{2}{|c|}{ H12-KC } \\
\hline & $\sigma_{\text {cont }, d}$ & $\sigma_{\text {cont }, d}$ & $\sigma_{\text {cont }, d}$ & $\sigma_{\text {cont }, d}$ & $\sigma_{\text {cont }, d}$ & $\sigma_{\text {cont }, d}$ \\
\hline & (MPa) & $0,85 * f c d$ & (MPa) & $0,85 * f c d$ & (MPa) & $0,85 * f c d$ \\
\hline PX1 & 3,54 & $28,0 \%$ & 3,49 & $27,6 \%$ & 3,00 & $23,7 \%$ \\
\hline PX2 & 5,69 & $45,0 \%$ & 5,57 & $44,0 \%$ & 4,46 & $35,2 \%$ \\
\hline PX3 & 2,33 & $18,4 \%$ & 2,37 & $18,7 \%$ & 2,47 & $19,5 \%$ \\
\hline PX4 & 3,74 & $29,6 \%$ & 3,69 & $29,2 \%$ & 3,21 & $25,3 \%$ \\
\hline PX5 & 2,85 & $22,6 \%$ & 2,93 & $23,2 \%$ & 3,04 & $24,0 \%$ \\
\hline PX6 & 2,61 & $20,6 \%$ & 2,75 & $21,7 \%$ & 3,02 & $23,9 \%$ \\
\hline PX7 & 2,63 & $20,8 \%$ & 2,61 & $20,6 \%$ & 2,50 & $19,7 \%$ \\
\hline PX8 & 3,25 & $25,7 \%$ & 3,26 & $25,8 \%$ & 3,14 & $24,8 \%$ \\
\hline PX9 & 3,16 & $25,0 \%$ & 3,28 & $26,0 \%$ & 3,40 & $26,8 \%$ \\
\hline PX10 & 2,41 & $19,1 \%$ & 2,44 & $19,3 \%$ & 2,44 & $19,3 \%$ \\
\hline PY1 & 7,38 & $58,4 \%$ & 7,23 & $57,2 \%$ & 5,60 & $44,3 \%$ \\
\hline PY2 & 4,44 & $35,2 \%$ & 4,31 & $34,1 \%$ & 3,46 & $27,3 \%$ \\
\hline PY3 & 3,46 & $27,4 \%$ & 3,42 & $27,0 \%$ & 3,03 & $24,0 \%$ \\
\hline PY4 & 1,58 & $12,5 \%$ & 1,62 & $12,8 \%$ & 1,78 & $14,0 \%$ \\
\hline PY5 & 11,83 & $93,6 \%$ & 11,45 & $90,6 \%$ & 8,35 & $66,0 \%$ \\
\hline PY6 & 1,90 & $15,0 \%$ & 2,03 & $16,1 \%$ & 2,22 & $17,5 \%$ \\
\hline PY7 & 9,30 & $73,6 \%$ & 9,02 & $71,4 \%$ & 7,31 & $57,8 \%$ \\
\hline PY8 & 1,83 & $14,5 \%$ & 1,84 & $14,6 \%$ & 2,02 & $15,9 \%$ \\
\hline PY9 & 8,89 & $70,3 \%$ & 8,67 & $68,6 \%$ & 7,72 & $61,0 \%$ \\
\hline PY10 & 7,66 & $60,6 \%$ & 7,44 & $58,9 \%$ & 6,74 & $53,3 \%$ \\
\hline PY11 & 1,94 & $15,4 \%$ & 1,93 & $15,3 \%$ & 1,85 & $14,6 \%$ \\
\hline PY12 & 2,26 & $17,8 \%$ & 2,37 & $18,8 \%$ & 2,70 & $21,3 \%$ \\
\hline PY13 & 8,09 & $64,0 \%$ & 7,80 & $61,7 \%$ & 6,62 & $52,4 \%$ \\
\hline PY14 & 1,75 & $13,8 \%$ & 1,84 & $14,6 \%$ & 2,01 & $15,7 \%$ \\
\hline PY15 & 4,12 & $32,6 \%$ & 4,00 & $31,7 \%$ & 3,64 & $28,8 \%$ \\
\hline PY16 & 4,00 & $31,7 \%$ & 3,94 & $31,2 \%$ & 3,39 & $26,8 \%$ \\
\hline
\end{tabular}


Em relação às tensões máximas de contato, todos os elementos atendem ao requisito da NBR-16055 (ABNT, 2012). No entanto, alguns elementos apresentaram valores de tensões máximas próximas do valor limite, como a parede PY5 nos modelos H12-KA e H12-KB. Observa-se que os elementos do modelo H12-KC apresentam tensões máximas distantes dos valores limites. Embora o edifício possua 12 pavimentos os efeitos da ISE não foram relevantes nesse modelo. Este resultado indica novamente que os efeitos da ISE possuem uma conexão maior com a rigidez do solo, ou rigidez relativa estrutura-solo, e não com o número de pavimentos.

O modelo numérico H12-KA apresentou um panorama de fissuração nas bases de algumas paredes. A Figura 6.24 mostra as aberturas de fissuras na direção Y das paredes PY13 do modelo H12-KA.
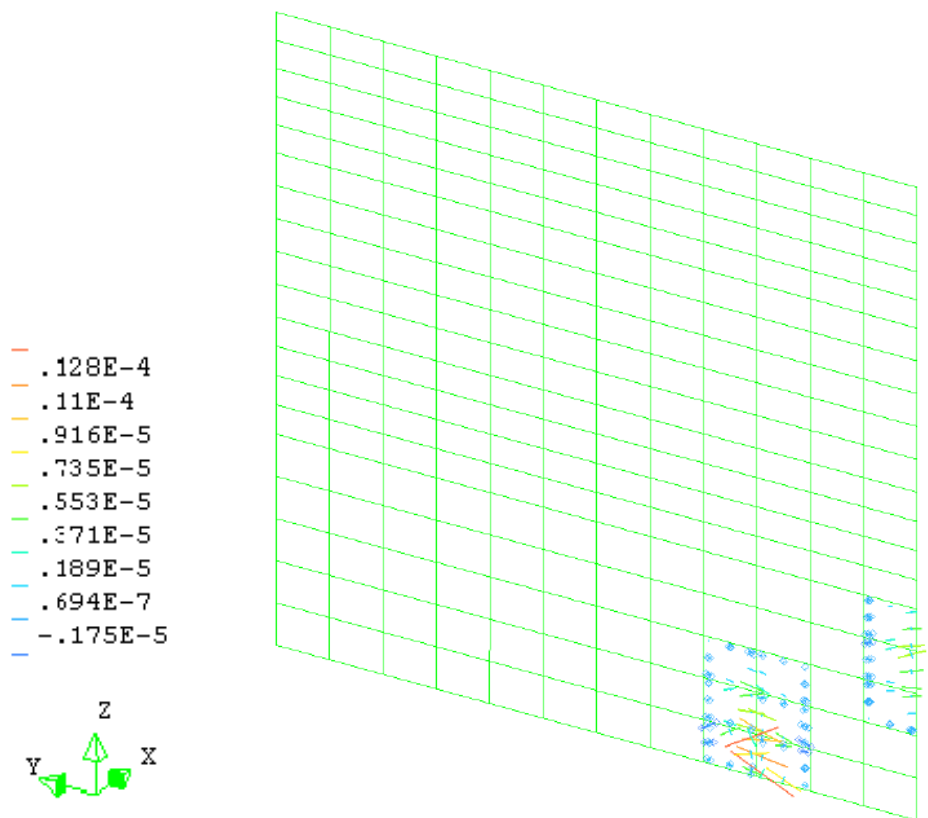

Figura 6.24 - Abertura de fissuras (m) - Modelo H12-KA - PY13

As paredes possuem uma baixa distoração angular, similar aos resultados apresentados nos modelos do capitúlo 5. Apesar disso as tensões de tração foram superiores à resistência de tração do concreto.

Além dos recalques diferenciais nas paredes, esses elementos também sofrem um deslocamento diferencial horizontal devido aos recalques. Entende-se que o deslocamento diferencial horizontal devido aos recalques contribuiu, em conjunto com o recalque diferencial, para o surgimento dessas tensões (Figura 6.25). 

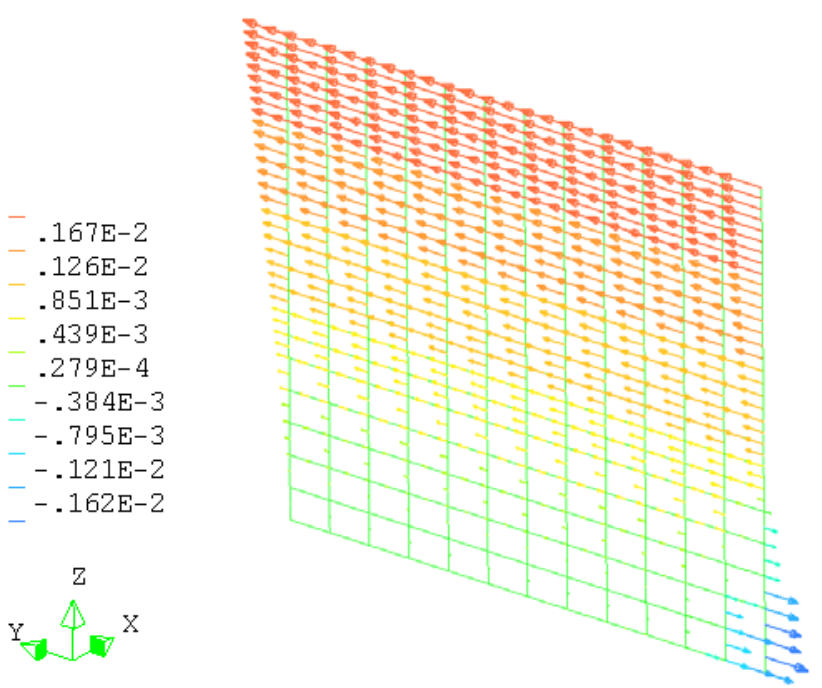

Figura 6.25 - uy $(\mathrm{m})$ - Parede Py5 - Modelo H12-KA

Observa-se com a análise conjunta do deslocameno horizontal e o surgimento das tensões de tração na base das paredes, a semelhança de comportamento desses elementos com a analogia de viga-parede apresentada por Goshy (1978) no capítulo 4. Esse comportamento foi observado tambem na análise dos modelos do capítulo 4. A Tabela 6.15 mostra as aberturas de fissuras apresentadas e os respectivos elementos.

Tabela 6.15 - Fissuras - Modelo H12-KA

\begin{tabular}{|c|c|}
\hline Parede & Abertura de fissuras (mm) \\
\hline PY3 & 0,009 \\
\hline PY9 & 0,011 \\
\hline PY13 & 0,012 \\
\hline PY5 & 0,096 \\
\hline
\end{tabular}

Os valores não excedem os limites impostos pela NBR-6118 (ABNT, 2014), apresentados no capítulo 4, independentemente da classe de agressividade do ambiente. Embora ocorram tensões de tração na base de algunas elementos, as aberturas de fissuras assumem valores insignificantes.

\subsubsection{EDIFÍCIO DE 20 PAVIMENTOS}

Por fim, define-se um edifício com 20 pavimentos. A comparação dos recalques em função da rigidez pode ser observada na Tabela 6.16.

Tabela 6.16 - Recalques - Edifício 20 pavimentos

\begin{tabular}{|c|c|c|c|c|c|c|}
\cline { 2 - 7 } \multicolumn{1}{c|}{} & $\bar{w}(\mathrm{~mm})$ & $w_{\text {máx }}(\mathrm{mm})$ & $w_{\operatorname{máx}} / \bar{w}$ & $w_{\min }(\mathrm{mm})$ & $\delta w(\mathrm{~mm})$ & $\mathrm{CV}_{\mathrm{w}}(\%)$ \\
\hline H20-KA & 49,2 & 55,2 & 1,12 & 32,6 & 27,1 & $9,15 \%$ \\
\hline H20-KB & 24,8 & 27,7 & 1,11 & 15,9 & 11,8 & $9,73 \%$ \\
\hline H20-KC & 1,30 & 1,54 & 1,18 & 0,75 & 0,78 & $12,33 \%$ \\
\hline
\end{tabular}


Deve-se ressaltar que em relação ao comportamento estrutural foi verificada a contribuição reduzida dos pavimentos superiores na ISE. Em relação à uniformização dos recalques, os pavimentos superiores ainda contribuem, embora não de maneira linear. Sobre o dimensionamento dos elementos, o edifício de 12 pavimentos apresenta paredes que são atendidas pelo procedimento da NBR-16055 (ABNT, 2012), mas com valores próximos aos limites de resistentes de cálculo. No entanto, a mesma análise é realizada na tipologia com 20, para efeito de comparação (Tabela 6.17).

Tabela 6.17 - Dimensionamento dos elementos - Edifícios de 20 pavimentos - Método simplificado NBR16055 (2012)

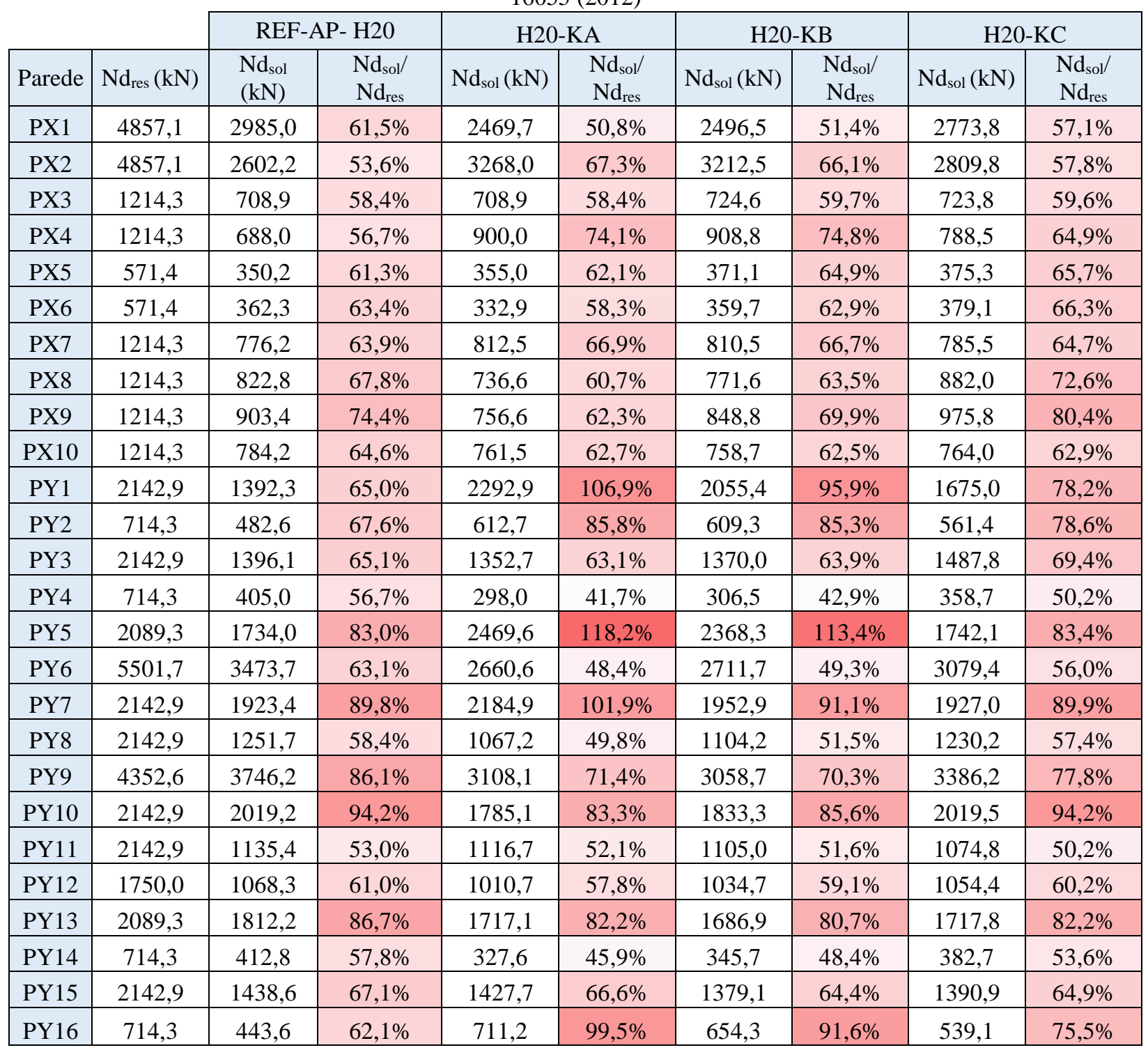

Alguns elementos não atendem ao critério de dimensionamento da NBR-16055 om a inclusão da ISE, devido ao nível maior de cargas nestas tipologias com 20 pavimentos. Os elementos PY1, PY5 e PY7 são os elementos que apresentam os problemas de 
dimensionamento pelo método simplificado no modelo H20-KA. No modelo H20-KB apenas a parede PY5 apresenta o esforço normal solicitante superior ao resistente de cálculo.

Destaca-se que em um edifício desse porte provavelmente são utilizados concretos de maiores resistências e maiores espessuras de paredes, em virtude também da inclusão de ações devidas ao vento. No entanto, em relação às ações verticais levantadas, as espessuras e resistências inicialmente adotadas são suficientes para o dimensionamento dos elementos, sem o uso da ISE, conforme a Tabela 6.17. A Tabela 6.18 mostra as tensões de contato máximas nas paredes para o edifício com 20 pavimentos.

\begin{tabular}{|c|c|c|c|c|c|c|}
\hline \multirow{3}{*}{ arede } & \multicolumn{6}{|c|}{$\sigma_{\text {cont }, d} \leq 12,64 \mathrm{MPa}$} \\
\hline & \multicolumn{2}{|c|}{ H20-KA } & \multicolumn{2}{|c|}{ H20-KB } & \multicolumn{2}{|c|}{ H20-KC } \\
\hline & $\sigma_{\text {cont }, d}$ & $\sigma_{\text {cont }, d}$ & $\sigma_{\text {cont }, d}$ & $\sigma_{\text {cont }, d}$ & $\sigma_{\text {cont }, d}$ & $\sigma_{\text {cont }, d}$ \\
\hline datue & $(\mathrm{MPa})$ & $0,85 * f c d$ & $(\mathrm{MPa})$ & $0,85 * f c d$ & $(\mathrm{MPa})$ & $0,85 * f c d$ \\
\hline PX1 & 5,67 & $44,85 \%$ & 5,53 & $43,72 \%$ & 4,73 & $37,46 \%$ \\
\hline PX2 & 9,51 & $75,26 \%$ & 9,12 & $72,16 \%$ & 6,12 & $48,43 \%$ \\
\hline PX3 & 4,27 & $33,78 \%$ & 4,34 & $34,32 \%$ & 4,20 & $33,26 \%$ \\
\hline PX4 & 6,36 & $50,29 \%$ & 6,19 & $49,00 \%$ & 4,75 & $37,61 \%$ \\
\hline PX5 & 4,72 & $37,33 \%$ & 4,99 & $39,49 \%$ & 4,60 & $36,41 \%$ \\
\hline PX6 & 4,22 & $33,38 \%$ & 4,67 & $36,98 \%$ & 4,63 & $36,61 \%$ \\
\hline PX7 & 4,39 & $34,75 \%$ & 4,33 & $34,28 \%$ & 4,08 & $32,30 \%$ \\
\hline PX8 & 5,40 & $42,69 \%$ & 5,38 & $42,59 \%$ & 4,74 & $37,53 \%$ \\
\hline PX9 & 5,22 & $41,28 \%$ & 5,51 & $43,59 \%$ & 5,12 & $40,52 \%$ \\
\hline PX10 & 4,07 & $32,19 \%$ & 4,11 & $32,55 \%$ & 4,07 & $32,20 \%$ \\
\hline PY1 & 12,44 & $98,41 \%$ & 11,89 & $94,04 \%$ & 7,46 & $59,04 \%$ \\
\hline PY2 & 6,75 & $53,41 \%$ & 6,48 & $51,26 \%$ & 5,18 & $41,01 \%$ \\
\hline PY3 & 5,58 & $44,15 \%$ & 5,47 & $43,30 \%$ & 4,88 & $38,59 \%$ \\
\hline PY4 & 2,66 & $21,05 \%$ & 2,77 & $21,91 \%$ & 3,03 & $23,94 \%$ \\
\hline PY5 & 19,80 & $156,67 \%$ & 18,41 & $145,63 \%$ & 10,32 & $81,64 \%$ \\
\hline PY6 & 3,38 & $26,76 \%$ & 3,57 & $28,22 \%$ & 3,79 & $30,02 \%$ \\
\hline PY7 & 15,68 & $124,08 \%$ & 14,66 & $116,02 \%$ & 10,30 & $81,47 \%$ \\
\hline PY8 & 3,04 & $24,03 \%$ & 3,11 & $24,59 \%$ & 3,48 & $27,56 \%$ \\
\hline PY9 & 14,92 & $118,03 \%$ & 14,14 & $111,88 \%$ & 11,33 & $89,61 \%$ \\
\hline PY10 & 12,98 & $102,72 \%$ & 12,26 & $96,98 \%$ & 10,12 & $80,05 \%$ \\
\hline PY11 & 3,25 & $25,70 \%$ & 3,22 & $25,50 \%$ & 3,11 & $24,64 \%$ \\
\hline PY12 & 3,91 & $30,95 \%$ & 4,20 & $33,19 \%$ & 4,42 & $34,96 \%$ \\
\hline PY13 & 13,64 & $107,95 \%$ & 12,70 & $100,50 \%$ & 9,47 & $74,88 \%$ \\
\hline PY14 & 2,95 & $23,34 \%$ & 3,19 & $25,27 \%$ & 3,32 & $26,25 \%$ \\
\hline PY15 & 7,26 & $57,46 \%$ & 6,89 & $54,47 \%$ & 5,93 & $46,88 \%$ \\
\hline PY16 & 6,82 & $53,94 \%$ & 6,61 & $52,29 \%$ & 5,03 & $39,77 \%$ \\
\hline
\end{tabular}

As tensões de contato de cálculo nos edifícios de 20 pavimentos com o emprego da ISE ultrapassam os limites de resistências em duas tipologias. A análise das tensões máximas 
apresenta um panorama de dimensionamento mais agravante que a análise anterior, que verifica o dimensionamento ao esforço normal de compressão. A parede PY5, por exemplo, apresenta tensões solicitantes superior (razão de 156,7\%) à tensão resistente de cálculo indicada pela norma. Novamente, destaca-se que os efeitos da ISE não têm relação com o número de pavimentos já que na tipologia de solo mais rígido os critérios de dimensionamento são atendidos.

Embora as tensões de contato nas extremidades desses elementos assumam valores expressivos, não ocorre esmagamento de concreto nos modelos numéricos. As tensões normais de compressão nesses modelos alcançaram valores consideráveis. Entretanto o dimensionamento impõe a majoração das ações e a redução da resistência do concreto.

Os modelos H20-KA e H20-KB também apresentaram panorama de fissuração na base de algumas paredes, semelhante ao ocorrido no modelo H12-KA. O surgimento das tensões de tração segue o padrão apresentado pelo modelo H12-KA. O modelo H20-KC não apresentou fissuras nos elementos. A Figura 6.26 mostra o panorama de fissuração da parede PY5. A Tabela 6.19 apresenta um resumo das aberturas de fissuras em ambos os modelos.
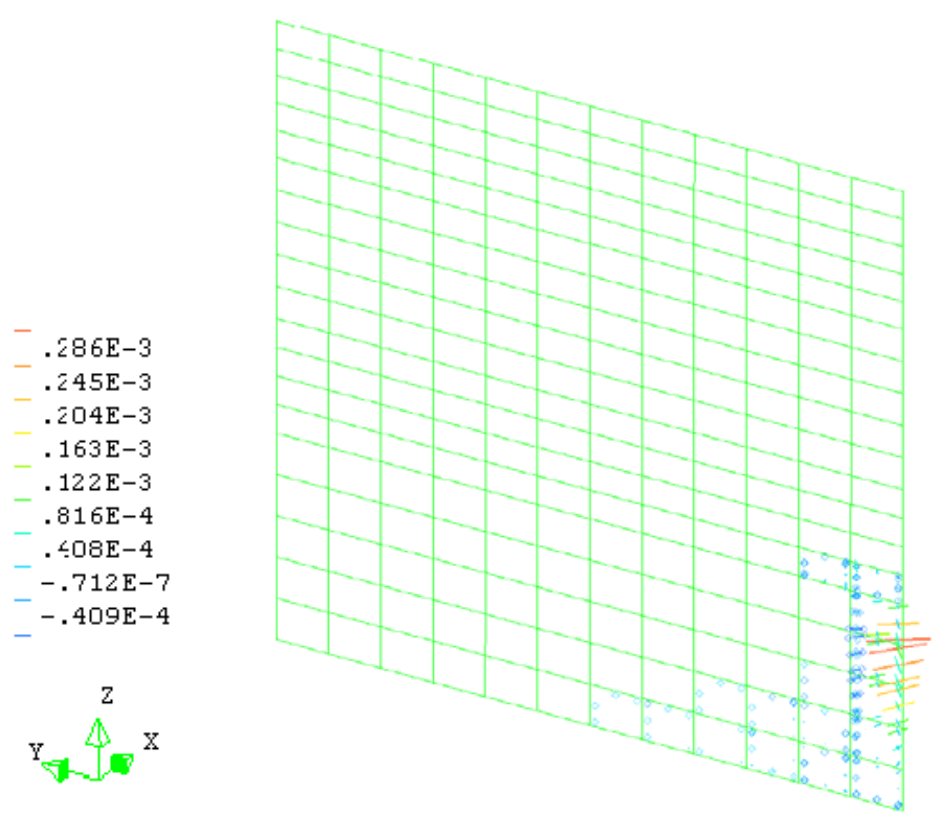

Figura 6.26 - Abertura de fissuras (m) - Parede Py5 - Modelo H20-KB 
Tabela 6.19 - Fissuras - Modelo H20-KA e Modelo H20-KB

\begin{tabular}{|c|c|c|}
\hline Modelo & Parede & Abertura de fissuras (mm) \\
\hline \multirow{4}{*}{ H20-KA } & PY3 & 0,022 \\
\cline { 2 - 3 } & PY10 & 0,002 \\
\cline { 2 - 3 } & PY9 & 0,022 \\
\cline { 2 - 3 } & PY7 & 0,007 \\
\cline { 2 - 3 } & PY13 & 0,041 \\
\hline \multirow{5}{*}{ H20-KB } & PY5 & 0,286 \\
\cline { 2 - 3 } & PY3 & 0,019 \\
\cline { 2 - 3 } & PY10 & 0,002 \\
\cline { 2 - 3 } & PY9 & 0,016 \\
\cline { 2 - 3 } & PY7 & 0,006 \\
\cline { 2 - 3 } & PY13 & 0,026 \\
\cline { 2 - 3 } & PY5 & 0,196 \\
\hline
\end{tabular}

No modelo H20-KA a parede PY5 apresenta fissuras maiores que 0,2 mm, extrapolando um dos limites da NBR 6118 (ABNT, 2014). Neste caso, essa abertura de fissura apenas é relevante na classe de agressividade de ambiente CAA-IV. Os demais elementos apresentaram aberturas de fissuras irrelevantes.

Entretanto, o surgimento de fissuras nas tipologias com 20 pavimentos não seria o fator mais grave. As alterações do fluxo de tensões ocasionam concentrações de tensões localizadas nas extremidades das paredes que provocam aumentos nas tensões de contato entre a superestrutura e o radier. Assim sendo, a solução de fundação do tipo radier para um edifício desse porte só seria viável em solos rígidos. Um solo de grande rigidez aumentaria a uniformidade das tensões, podendo viabilizar tal solução. $\mathrm{O}$ aumento da resistência do concreto e da espessura das paredes são outras possibilidades que seriam naturalmente utilizadas em um edifício com este número de pavimentos.

\subsubsection{DIMENSIONAMENTO DAS PAREDES PELA NBR:6118 (2014)}

As tipologias com 20 pavimentos apresentaram resultados em alguns elementos nos quais os critérios de dimensionamento da norma NBR-16055 (ABNT, 2012) não foram atendidos. O equacionamento proposto pela NBR-16055 inclui de forma aproximada os efeitos da instabilidade localizada nos elementos com as excentricidades mínimas previstas pela mesma norma. A capacidade resistente da parede é limitada em $40 \%$ da resistência à compressão de cálculo do concreto, independentemente das dimensões das paredes e tomandose o coeficiente de ponderação igual a 1,68.

A redução da capacidade resistente considerada pela NBR-16055 tem coerência, já que as paredes de concreto possuem pequena espessura. Essa reduzida capacidade resistente 
pela inclusão desses efeitos pode ser observada também em trabalhos experimentais conforme já exposto no capítulo 2. Deve-se ressaltar que as normas internacionais de referência (ACI318, BS810 e AS3600) também apresentam equacionamentos similares, sendo até mais rigorosos em alguns casos, como mostrado nas comparações realizadas por Braguim (2013).

Deste modo, se propõe investigar os efeitos da instabilidade local e localizada nessas paredes utilizando o procedimento da NBR-6118 (ABNT, 2014). Deve-se destacar que os princípios na norma de paredes de concreto NBR 16055 são baseados em elementos de concreto simples. Todavia, essa norma faz menção à NBR-6118 (ABNT, 2014) nas considerações sobre as instabilidades locais e localizadas. Alguns pontos da aplicação desse dimensionamento devem ser destacados.

- A NBR-6118 (ABNT, 2014) não permite pilares com espessura menor que 14 cm. A versão anterior da NBR-6118 (ABNT, 2009) permitia essa espessura de parede e considerava um coeficiente adicional de ponderação para essa espessura de 1,35.

- As armaduras da seção são as mesmas prescritas no capítulo 4. Deve-se atentar que a taxa de armadura é menor do que as prescrições da NBR-6118 (ABNT, 2014).

- Os elementos analisados possuem índice de esbeltez menor que 90 (capítulo 4). Assim sendo, a instabilidade local de segunda ordem será contemplada pelo método aproximado do pilar-padrão com rigidez secante aproximada (NBR6118: ABNT, 2014).

- Os elementos investigados possuem índice de esbeltez maior que 35 (capítulo 4). Deste modo, a instabilidade localizada deve ser contemplada (NBR-6118: ABNT, 2014).

- A instabilidade localizada é considerada pelo processo aproximado. Esse processo considera a decomposição do pilar-parede em faixas verticais. A Figura 6.27 ilustra o processo aproximado da NBR-6118. 


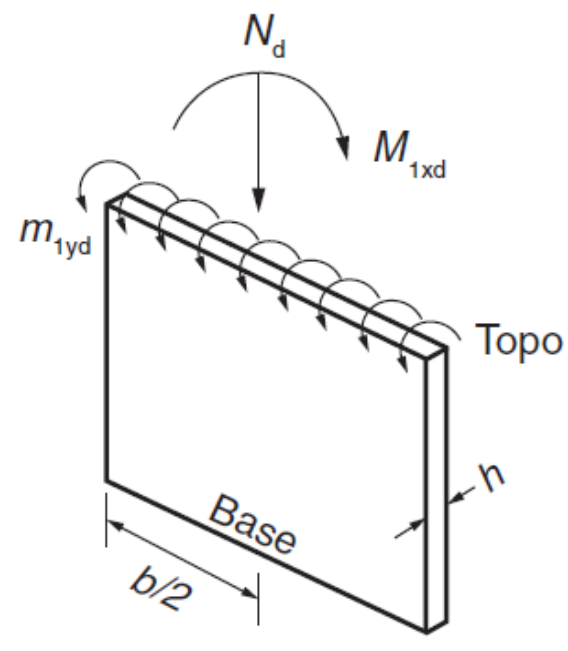

a) Pilar Parede

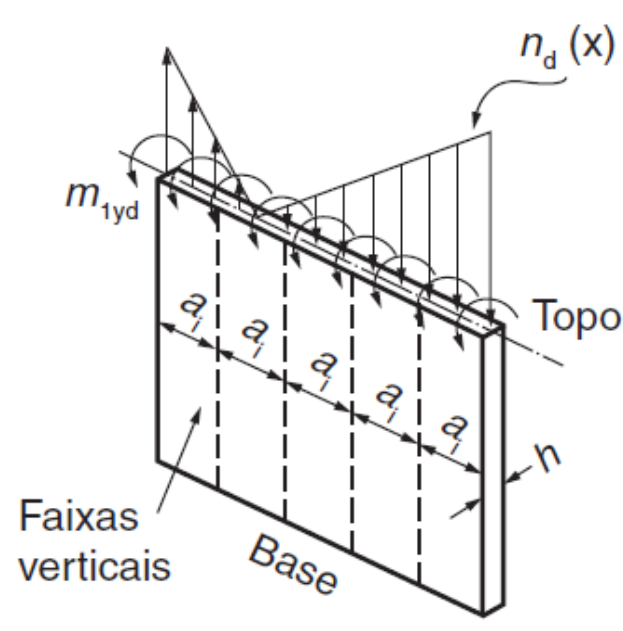

$$
\begin{aligned}
& a_{\mathrm{i}}=3 h \leq 100 \mathrm{~cm} \\
& M_{\text {yid }}=m_{1 \text { yd }} a_{\mathrm{i}}
\end{aligned}
$$

b) Processo de subdivisão em faixas Figura 6.27 - Processo aproximado - Instabilidade localizada - Adaptado da NBR-6118 (2014)

O processo consiste em dividir o pilar-parede em trechos, convertendo-se a distribuição de esforço normal e os momentos aplicados em esforços distribuídos por faixas. No presente estudo os esforços normais já estão distribuídos de maneira desuniforme. O uso do processo aproximado permite investigar a instabilidade localizada nos trechos que possuem concentração de tensões normais, diferentemente do procedimento da NBR-16055 (2012).

Os momentos de primeira ordem atuantes nas paredes são provenientes das imperfeições geométricas locais. O procedimento normativo destaca que a consideração apenas da falta de retilineidade no lance do pilar é suficiente para incorporar as imperfeições geométricas (Figura 6.28). Deve-se destacar que o mesmo código normativo não impõe a obrigatoriedade de considerar a excentricidade mínima caso sejam consideradas as imperfeições geométricas da peça. O procedimento simplificado da norma de parede de concreto considera a excentricidade mínima, e consequentemente o momento mínimo.

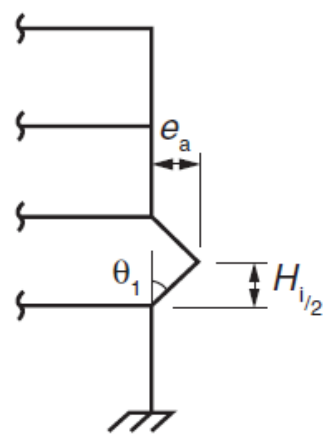

$$
\begin{aligned}
& \theta_{1 \min }=1 / 300 \text { para estruturas reticuladas e imperfeições locais; } \\
& \theta_{1 \text { máx }}=1 / 200 ; \\
& H \text { é a altura total da edificação, expressa em metros }(\mathrm{m}) ; \\
& n \text { é o número de prumadas de pilares no pórtico plano. } \\
& \theta_{1}=\frac{1}{100 \sqrt{H}}
\end{aligned}
$$

Figura 6.28 - Excentricidade - Imperfeições locais - NBR-6118 (ABNT, 2014) 
$\mathrm{Na}$ análise da instabilidade local, o carregamento desuniforme é convertido em um carregamento uniforme e um momento aplicado na seção. São analisadas as paredes PY1, PY5 e PY7 do modelo H20-KA, sendo estes os elementos que apresentaram deficiência no dimensionamento pelo procedimento simplificado da NBR-16055 (ABNT, 2012).

A convenção de sinais de esforços utilizados neste caso é diferente do utilizado ao longo da tese, que considera o eixo global da estrutura. A análise deste item utiliza a convenção de momentos da Figura 6.27. Neste caso, o momento $\mathrm{M}_{\mathrm{yd}}$ é o atuante no eixo de menor inércia do elemento estrutural.

A Figura 6.29 mostra a envoltória dos momentos solicitantes e resistentes da parede PY5 do modelo H20-KA. Os resultados dessas figuras são expostos em formas de envoltórias solicitantes $\left(S_{d}\right)$ e envoltórias resistentes $\left(R_{d}\right)$ da seção. A construção das envoltórias foi realizada conforme o procedimento simplificado permitido pela NBR-6118 (ABNT, 2014). A envoltória solicitante já inclui os momentos de segunda ordem. A Tabela 6.20 mostra os momentos solicitantes e resistentes nas paredes analisadas com a inclusão dos efeitos da instabilidade local.

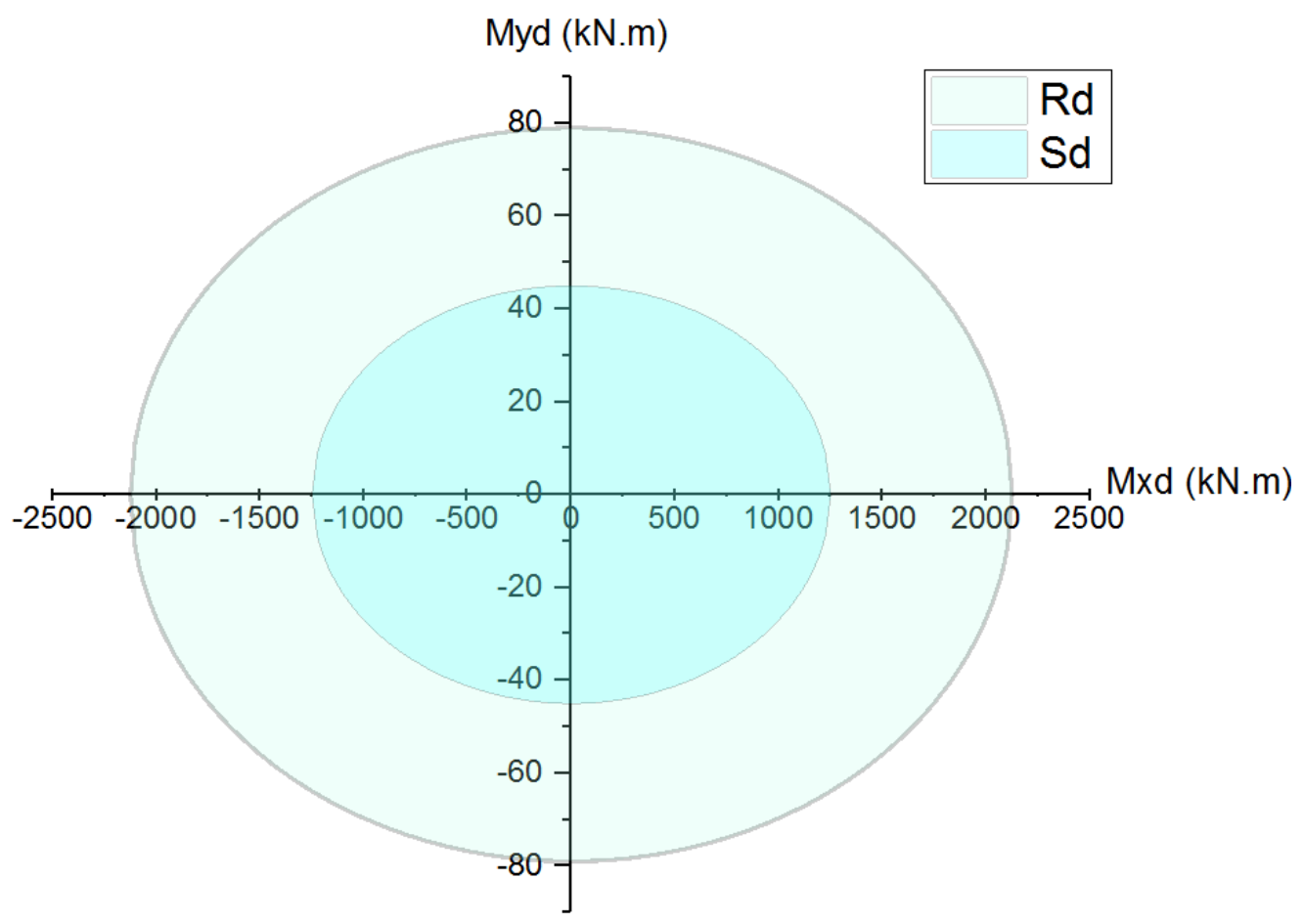

Figura 6.29 - Envoltória momentos resistentes Nd =2469 kN - Instabilidade Local - Parede Py5 
Tabela 6.20 - Análise da instabilidade local

\begin{tabular}{|c|c|c|c|c|c|c|c|}
\cline { 2 - 8 } \multicolumn{1}{c|}{} & $\mathrm{Nd}_{\text {sol }}(\mathrm{kN})$ & $\begin{array}{c}\mathrm{Mxd}_{\text {res }} \\
(\mathrm{kN.m})\end{array}$ & $\begin{array}{c}\text { Mxd } \\
(\mathrm{kN} . \mathrm{m})\end{array}$ & $\begin{array}{c}\text { Mxd } \\
\mathrm{Mxd}_{\text {res }} /\end{array}$ & $\begin{array}{c}\mathrm{Myd}_{\text {res }} \\
(\mathrm{kN} . \mathrm{m})\end{array}$ & $\begin{array}{c}\mathrm{Myd}_{\text {res }} \\
(\mathrm{kN.m})\end{array}$ & $\begin{array}{c}\mathrm{Myd}_{\text {sol }} / \\
\mathrm{Myd}_{\text {res }}\end{array}$ \\
\hline PY5 & 2469 & 2125 & 1250 & $58,8 \%$ & 79 & 45 & $57,0 \%$ \\
\hline PY1 & 2293 & 2097 & 1131 & $53,9 \%$ & 78 & 42 & $53,8 \%$ \\
\hline PY7 & 2185 & 2081 & 1120 & $53,8 \%$ & 77 & 38 & $49,4 \%$ \\
\hline
\end{tabular}

Os resultados mostram que não ocorreram problemas de dimensionamento em nenhuma das paredes analisadas quanto aos esforços provenientes da consideração da instabilidade local. A capacidade resistente da seção aos momentos solicitantes na direção x é alta, devido obviamente ao comprimento da seção. Destaca-se que as ações devidas ao vento não estão inclusas. Em relação aos momentos na direção de menor inercia, embora se tenha uma menor resistência, os momentos solicitantes também permaneceram abaixo dos resistentes.

A análise da instabilidade localizada é realizada na faixa vertical mais solicitada das paredes. A Figura 6.30 mostra a envoltória da faixa vertical mais solicitada da parede PY5 utilizando o processo aproximado na consideração da instabilidade localizada. Ressalte-se que, a favor da segurança, foi introduzido o momento Mxd na faixa, considerando a variação da tensão normal, o que nem precisaria ser realizado de acordo com a NBR6118 (ABNT, 2014). A Tabela 6.21 mostra um resumo dos esforços resistentes e atuantes nas faixas verticais mais solicitadas das paredes que não haviam atendido aos critérios de dimensionamento da NBR16055 (ABNT, 2012).

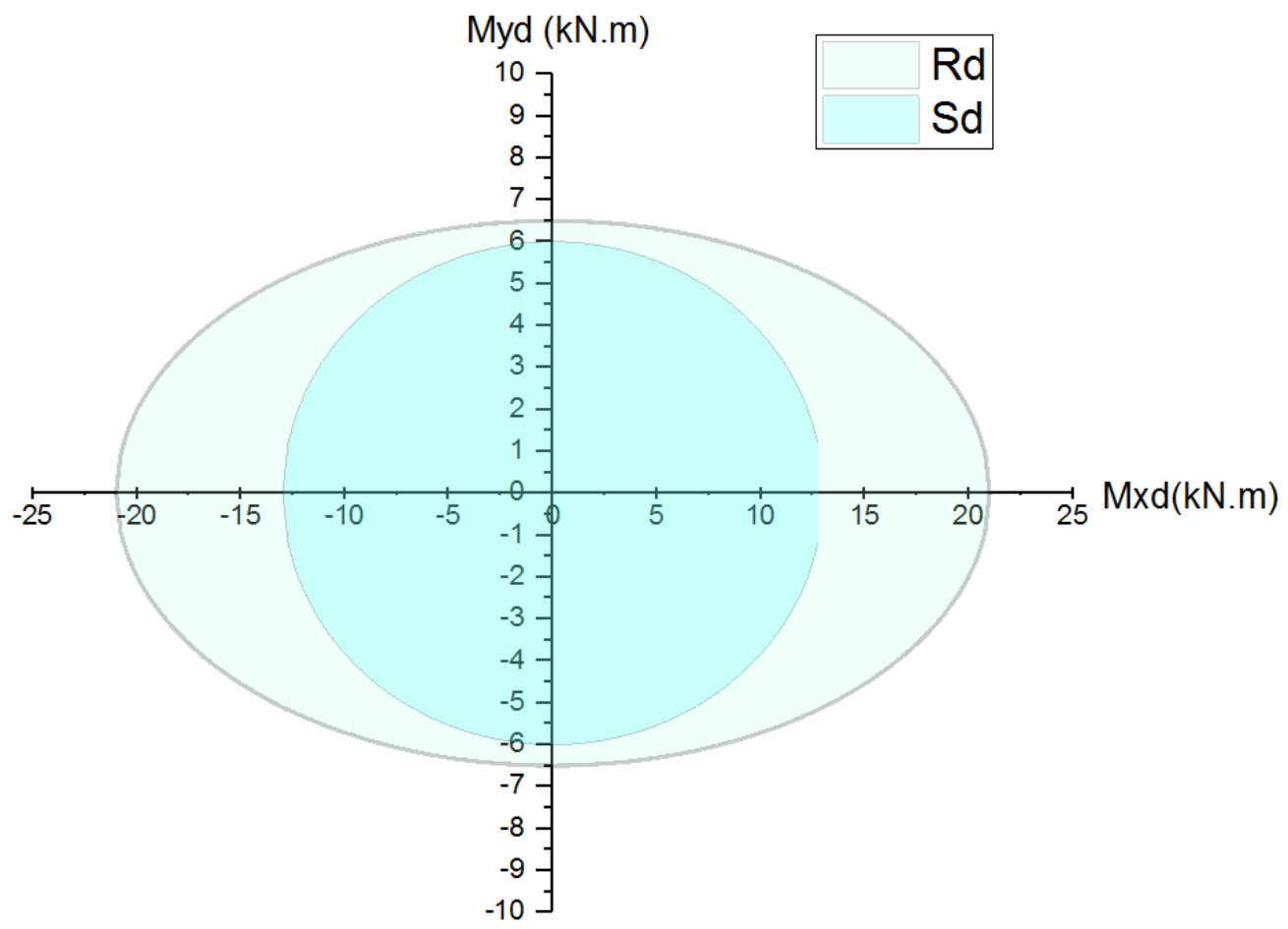

Figura 6.30 - Envoltória momentos resistentes - Nd = 490 kN - Instabilidade localizada - Parede Py5 
Tabela 6.21 - Momentos Myd,res x Myd,sol - Instabilidade localizada

\begin{tabular}{|c|c|c|c|c|c|c|c|}
\hline & $\mathrm{Nd}_{\text {sol }}(\mathrm{kN})$ & $\begin{array}{l}\text { Mxd }_{\text {res }} \\
\text { (kN.m) }\end{array}$ & $\begin{array}{l}\text { Mxd }_{\text {sol }} \\
\text { (kN.m) }\end{array}$ & $\begin{array}{l}\text { Mxd }_{\text {sol }} / \\
\text { Mxd }_{\text {res }}\end{array}$ & $\begin{array}{l}\text { Myd }_{\text {res }} \\
\text { (kN.m) }\end{array}$ & $\begin{array}{l}\text { Mydres }_{\text {rem) }} \\
\text { (kN.m) }\end{array}$ & $\begin{array}{l}\text { Myd }_{\text {sol }} \\
\text { Myd }_{\text {res }} \\
\end{array}$ \\
\hline PY5 & 490 & 22,2 & 12,5 & $56,3 \%$ & 6,6 & 5,9 & $89,4 \%$ \\
\hline PY1 & 401 & 19,2 & 11,2 & $58,3 \%$ & 6,1 & 5,7 & $93,4 \%$ \\
\hline PY7 & 425 & 21,2 & 11,8 & $55,7 \%$ & 6,3 & 4,3 & $68,3 \%$ \\
\hline
\end{tabular}

Sobre a análise dos esforços provenientes da instabilidade localizada, os momentos

resistentes $M_{x d}$ se mantiveram com diferenças significativas em relação aos momentos solicitantes nesta direção. Os momentos atuantes segundo o eixo de menor inércia ( $\left.\mathrm{M}_{\mathrm{yd}}\right)$ ficaram próximos do momento resistente da faixa analisada, conforme pode ser observado pela envoltória da Figura 6.30. No entanto, os elementos atendem ao critério de dimensionamento.

A Tabela 6.21 mostra que todos os elementos investigados apresentaram capacidade resistente suficiente quanto aos momentos atuantes na menor direção em razão da instabilidade localizada. Esses não atenderiam a capacidade resistente da seção pelo dimensionamento simplificado da norma específica de parede de concreto. A taxa de armadura considerada nessa análise é a mínima e está centralizada na parede. Todavia, foi suficiente para o seu dimensionamento.

Esta análise não considera a ação do vento na edificação. Neste caso seria usual em edifícios desse porte a ocorrência de paredes de maior espessura e com a presença de tela dupla nesses elementos, o que aumentaria a sua capacidade resistente.

\subsection{ASPECTOS CONCLUSIVOS SOBRE O DIMENSIONAMENTO DOS EDIFÍCIOS DE PAREDES DE CONCRETO COM A ISE}

As análises realizadas neste capítulo indicam que a rigidez estrutura-solo governa os efeitos da ISE, sendo a rigidez do solo mais importante que o número de pavimentos da edificação neste comportamento.

O uso do procedimento simplificado permite o dimensionamento destes na ampla maioria dos casos analisados. Apenas situações extremas com alta rigidez estrutura-solo alguns dos elementos não atende o equacionamento. A verificação das tensões máximas apresentou comportamento similar, mas este dimensionamento é mais sensível as mudanças da rigidez estrutura-solo. Obviamente esta ocorrência tem relação com a distribuição desuniforme das tensões de compressão na parede. Realiza-se um levantamento do dimensionamento dos elementos com a variação da rigidez relativa estrutura-solo em conjunto com o número de pavimentos. É avaliado o limite de rigidez relativa estrutura-solo para o não atendimento aos critérios de dimensionamento das paredes. Neste caso, a definição do limite é obtida quando 
um dos elementos da estrutura não atende aos critérios estipulados anteriormente (resistência aos esforços normais e ultrapassagem das tensões máximas de contato). São considerados sempre os esforços resistentes e solicitantes de cálculo. A Figura 6.31 mostra a análise realizada para os esforços normais solicitantes e resistentes de cálculo (NBR-16055, 2012). São delimitadas duas regiões, destacando a faixa de rigidez relativa estrutura-solo na qual os critérios de dimensionamento não são atendidos.

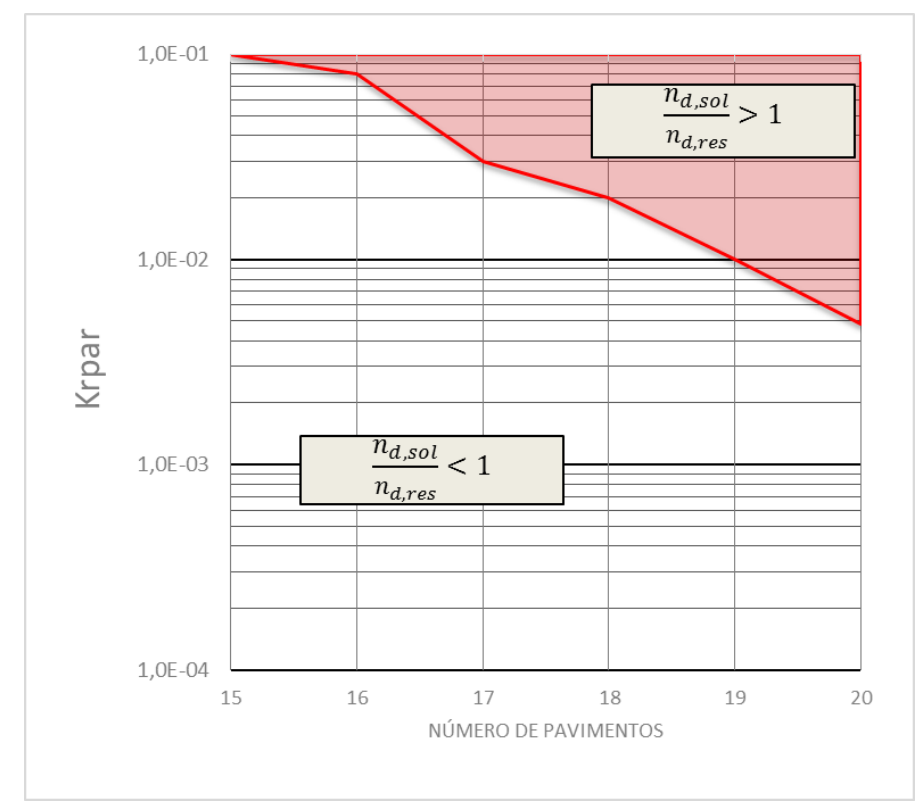

Figura 6.31 - Análise dos esforços normais solicitante e resistentes de cálculo

As análises realizadas indicam que edifícios com menos 15 pavimentos não obtiveram problemas de dimensionamentos quanto aos esforços normais de compressão nas paredes. Destaca-se que todos os edifícios com rigidez relativa estrutura-solo (“Krpar”) menor que 0,003 atendem ao critério de dimensionamento estipulado. A Figura 6.32 mostra a análise comparativa das tensões máximas com as tensões máximas de contato permitida pela NBR 16055 (ABNT, 2012). Similarmente os resultados são separados em duas regiões destacando a faixa de rigidez que o edifício não atende a este critério de dimensionamento. 


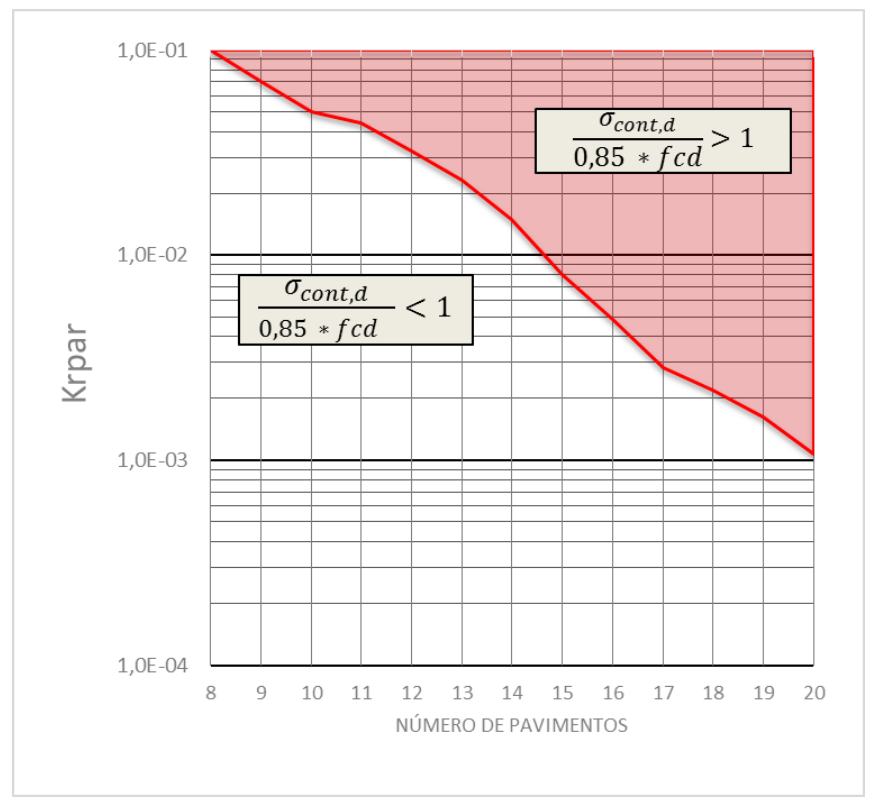

Figura 6.32 - Análise das tensões máximas atuantes (tensões de contato)

Os resultados desta análise mostram que os edifícios com rigidez relativa estruturasolo menor que 0,001 possuem tensões máximas de cálculo nas paredes menores que a tensão resistente estipulada pela NBR-16055 (ABNT, 2012). Observa-se que a consideração da ISE torna este critério de dimensionamento mais rigoroso que o anteriormente mostrado. Algumas tipologias não possuem problemas de dimensionamento quanto à resistência das paredes ao esforço normal, mas não atendem ao critério das tensões máximas de contato na base.

Esses resultados evidenciam que o atendimento aos critérios de dimensionamento tem relação maior com a rigidez estrutura-solo, e não exatamente com o número de pavimentos. Edifícios com 20 pavimentos não possuem problemas quanto ao dimensionamento quando sua rigidez relativa estrutura-solo possui valores adequados com o porte do edifício. Edifícios com um número maior de pavimentos exigem solos com melhor qualidade para a viabilidade da fundação do tipo radier, deste modo naturalmente existe uma adequação da rigidez relativa estrutura-solo devido ao uso de um solo mais rígido.

A Figura 6.8 indica que a redistribuição de esforços nos edifícios tem maior relação com a rigidez relativa estrutura-solo do que com o número de pavimentos. Esses resultados podem ser rearranjados em curvas, conforme exposto na Figura 6.33. 


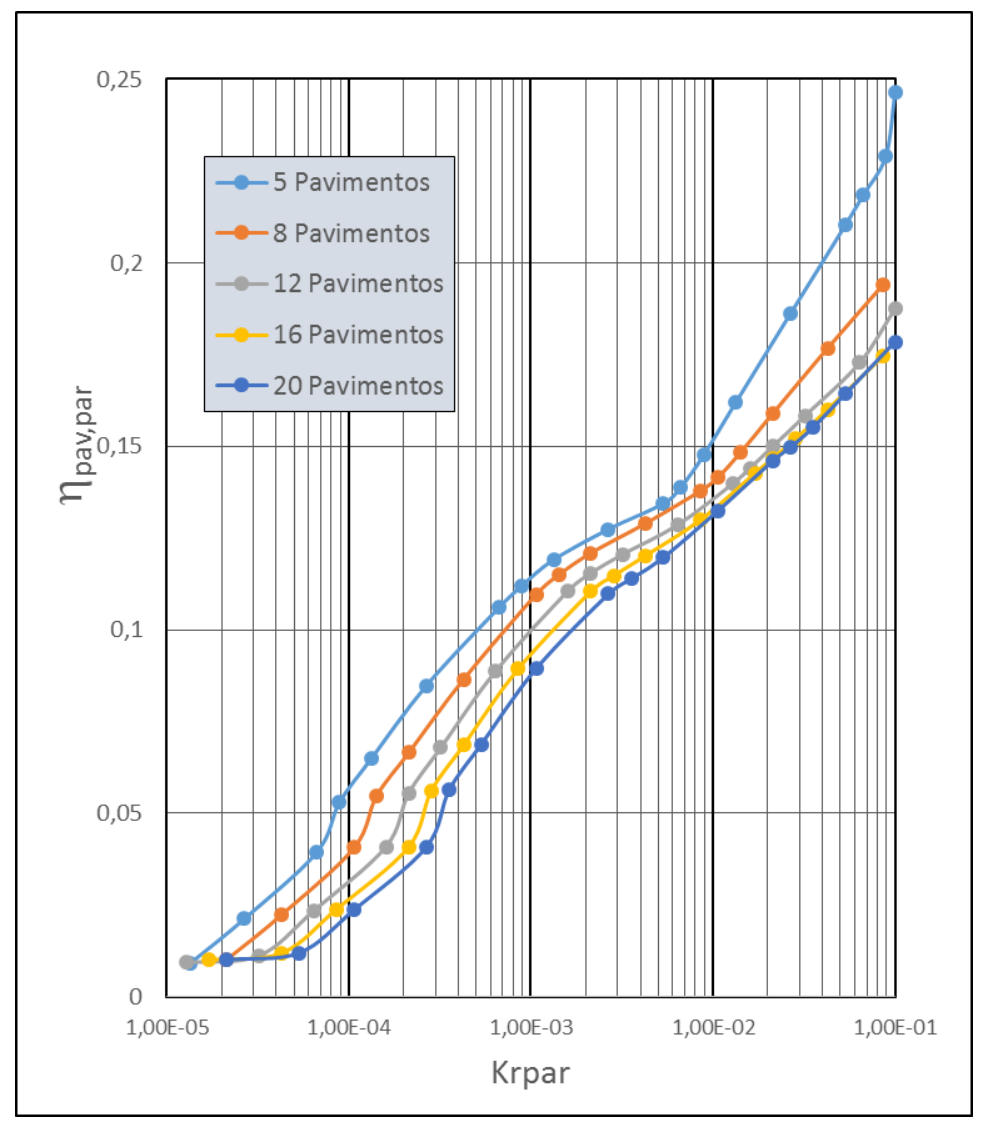

Figura 6.33 - Krpar x $\eta_{\text {pav,par }}$

Os resultados da Figura 6.33 mostram que não existe grandes diferenças entre as curvas exibidas, evidenciando que o coeficiente " $\eta_{\text {pav,par }}$ ” depende mais da rigidez relativa estrutura-solo do que o número de pavimentos. Como não existe grandes diferenças nos valores dos coeficientes entre edifícios com diferentes números de pavimentos, utilizar a curva que apresenta os máximos valores como representativa para as demais tipologias (curva construída para o edifício de 5 pavimentos) é admissível, sendo a favor da segurança para edifícios com mais de 5 pavimentos. Deste modo, pode-se inferir que a alteração média de esforços depende exclusivamente da rigidez estrutura-solo de acordo com os valores apresentados pela Tabela 6.22 .

Tabela $6.22-\eta_{\text {pav,par }}$ e rigidez relativa estrutura-solo

\begin{tabular}{|c|c|}
\hline Krpar & $\eta$ pav,par \\
\hline 0,1 & $25 \%$ \\
\hline 0,05 & $22 \%$ \\
\hline 0,01 & $15 \%$ \\
\hline 0,005 & $14 \%$ \\
\hline 0,001 & $12 \%$ \\
\hline 0,0005 & $10 \%$ \\
\hline 0,0001 & $6 \%$ \\
\hline 0,00005 & $3 \%$ \\
\hline
\end{tabular}


O uso do coeficiente “ $\eta_{\text {pav,par }}$ ” como parâmetro para estimar a redistribuição de esforços nas paredes é razoável, pois expressa, embora sendo um valor médio, a redistribuição dos esforços nos elementos da base. Os coeficientes apresentados pela Tabela 6.22 são valores médios, mas para edifícios de maior porte estão a favor da segurança. O uso desses valores como estimativa da redistribuição de esforços pode ser um procedimento interessante para estimar os efeitos da ISE em modelos usuais (apoios rígidos).

\subsection{CONCLUSÕES DO CAPÍTULO}

Neste capítulo foi avaliado o comportamento da ISE com modificações da rigidez relativa estrutura-solo. Foi proposto um coeficiente de rigidez relativa com o objetivo de estudar a influência da ISE na estrutura e no solo. O seu uso permitiu investigar a influência das variações de rigidez tanto da estrutura como do solo. Abaixo são listadas algumas conclusões obtidas.

- A contribuição da rigidez da estrutura não varia linearmente com o número de pavimentos. Os pavimentos superiores contribuem menos que os inferiores no comportamento estrutural com ISE.

- A redistribuição de esforços tem influência da rigidez relativa estrutura-solo. Edifícios com menores números de pavimentos são mais influenciados pela rigidez relativa estrutura-solo. Edifícios de médio e grande porte têm comportamentos proporcionalmente similares.

- A influência da rigidez do solo é mais relevante do que a da estrutura no comportamento com ISE. Entende-se que a alta rigidez dos edifícios de paredes faz com que edifícios de poucos pavimentos já apresentem um comportamento rígido da superestrutura. Deste modo, a rigidez do solo adquire maior relevância na ISE como um todo.

- A consideração da heterogeneidade do solo ampliou os efeitos da ISE na redistribuição dos esforços. A heterogeneidade do solo precisa ser investigada em trabalhos futuros, pois suas consequências sobre a estrutura tendem a ser mais acentuadas.

- A profundidade do maciço do solo promove mudanças nos efeitos da ISE até atingir valores da ordem das dimensões em planta da edificação $(H / L=1)$. Nas tipologias estudadas os resultados da redistribuição de esforços com a 
consideração de 15 até 30 metros de espessura são similares. A consideração da profundidade do maciço reduzida (5 metros) diminnui a redistribuição de esforços, embora com valores ainda relevantes. Em relação à uniformização dos recalques, a profundidade do maciço aumentou a influência da rigidez da estrutura sobre essa uniformização.

- A influência da ISE é superior em edifícios com poucos pavimentos. No entanto, o uso de espessuras mínimas nas paredes acarreta uma boa capacidade resistente da edificação. Todos os elementos estruturais puderam ser dimensionados pelo procedimento simplificado da NBR-16055 nos edifícios com poucos pavimentos, independentemente do nível de rigidez do solo.

- Os efeitos da ISE percentualmente são similares em edifícios de médio e grande porte. No entanto, o nível de carga atuante impossibilita o dimensionamento dos edifícios de 20 pavimentos, mantidas as espessuras das paredes. Nesta situação tais edificações não poderiam ser utilizadas, sem a devida adaptação do projeto.

- Algumas paredes dos modelos com 12 e 20 pavimentos apresentaram um panorama de fissuração em sua base. O surgimento das tensões de tração nas paredes se assemelha ao da analogia de viga-parede apresentada por Goshy (1978). No entanto, as aberturas de fissuras presentes nos modelos foram na ampla maioria dos casos inferiores aos limites da NBR-6118 (ABNT, 2014).

- O uso do procedimento da NBR-6118 (ABNT, 2014) possibilita o dimensionamento de elementos não atendidos pelo procedimento simplificado da NBR-16055 (ABNT, 2012) nos edifícios com 20 pavimentos. Observa-se que a consideração simplificada dos efeitos das instabilidades locais e localizadas nas paredes não impossibilita o dimensionamento.

O estudo da rigidez relativa estrutura-solo indica a preponderância da rigidez do solo no comportamento estrutural com ISE. Os edifícios de parede de concreto possuem uma expressiva rigidez mesmo com poucos pavimentos. A influência da ISE na redistribuição de esforços ocorre independentemente do número de pavimentos da edificação. Tal fato deverá ser observado em uma futura revisão da NBR 16055.

Os edifícios com poucos pavimentos possuem uma reserva de resistência por decorrência das espessuras mínimas exigidas para as paredes, possibilitando que os efeitos da 
ISE não sejam relevantes no dimensionamento. Edifícios com maior porte, apesar da redução percentual dos efeitos da ISE, podem apresentar problemas de dimensionamento. Esta dificuldade está atrelada à distribuição desuniforme das tensões nas paredes, devido à inclusão da ISE. 


\section{CAPÍTULO 7 - CONCLUSÃO}

Neste capítulo são apresentadas as conclusões e reflexões obtidas ao longo do desenvolvimento da tese. Os aspectos conclusivos são divididos em itens específicos. Em cada item são apresentados os objetivos alcançados e as contribuições realizadas. Ao final do capítulo, são apresentadas sugestões para o desenvolvimento de trabalhos futuros.

\subsection{MODELO NUMÉRICO}

O modelo numérico desenvolvido mostrou-se adequado. A confrontação entre os recalques medidos em obra com os obtidos numericamente apresentaram uma boa aproximação. Destaca-se que as diferenças ocorreram em virtude da heterogeneidade do solo quando esta não foi contemplada no modelo numérico.

A estratégia utilizada na definição das propriedades do maciço do solo foi simplista e a boa aproximação dos recalques medidos indicou a sua eficiência. Deve-se ter em mente as dificuldades impostas na definição das propriedades constitutivas do maciço do solo, já que nenhum material foi coletado in loco para aferir essas propriedades em laboratório.

O uso de elementos planos nas paredes possibilitou analisar a distribuição desuniforme das tensões. O emprego de um modelo simplificado, baseado em elementos de barras, não permitiria analisar tais ocorrências, a menos que se fizesse uma analogia de pórtico (ou treliça) para simulação de cada parede. O autor deste trabalho acredita que o emprego de elementos planos seria um avanço natural nas análises estruturais corriqueiras em edifícios de paredes.

Tendo em vista a possibilidade de considerar o solo como um meio contínuo, o emprego de elementos sólidos mostrou-se uma escolha acertada, por ser de fato um modelo mais refinado que o uso de molas discretas. O custo computacional apresentado foi relevante, quando consideradas as não-linearidades do solo e as ações evolutivas. Entretanto, esta dificuldade inerente ao modelo era esperada e foi aceita, devido ao caráter acadêmico e de longo prazo no desenvolvimento da tese.

Em análises usuais realizadas em escritórios de projetos, a modelagem do maciço do solo via MEF pode inserir dificuldades relacionadas ao custo computacional e a construção da geometria do modelo. A consideração do solo heterogêneo é outro fator agravante, pois inclui dificuldades na construção da geometria do maciço via MEF. 
A consideração das ações evolutivas é o procedimento mais correto a ser adotado em uma análise estrutural. Os resultados mostraram que ocorrem mudanças de comportamento na estrutura e no solo. A sua incorporação nos modelos numéricos não é muito complexa. Alguns softwares de análise estrutural permitem incluir a sequência construtiva. Cabe ao engenheiro de estruturas dominar a ferramenta numérica e a conceituação teórica para a sua aplicação.

Os resultados obtidos mostram que uso de modelos constitutivos não-lineares (estrutura e maciço do solo) não é necessário para o estudo da ISE neste tipo de problema. Os elementos da estrutura apresentaram poucos casos com fissuras, sendo estas com valores irrisórios. Usualmente esses elementos são submetidos a um nível baixo de tensões de compressão. Deste modo pode-se afirmar que o uso de um modelo elástico linear pode fornecer resultados suficientemente precisos para analisar a ISE nos edifícios de paredes de concreto.

\subsection{ISE EM EDIFÍCIOS DE PAREDES}

\subsubsection{SUPERESTRUTURA}

O comportamento da estrutura dos edifícios de paredes com o emprego da ISE foi investigado ao longo da tese. A redistribuição de esforços relaciona-se com a rigidez relativa estrutura-solo, os níveis de cargas nos elementos e a geometria em planta da edificação.

Normalmente os elementos menos suscetíveis aos recalques na base absorveram uma parcela dos esforços dos elementos adjacentes mais suscetíveis a tais recalques. Os elementos localizados nas regiões centrais dos edifícios naturalmente tenderam a ter alívio de esforços, por serem usualmente os mais carregados. O mesmo raciocínio aplica-se aos elementos das periferias, que usualmente são os menos carregados e absorvem parte dos esforços dos elementos centrais. Essa redistribuição ocorreu no edifício analisado por causa da semelhança entre os valores das tensões normais de compressão nas paredes por influência da regularidade da geometria da estrutura. Em uma situação com uma geometria irregular e com níveis de solicitação muito diferentes entre os elementos, a redistribuição de esforços pode assumir um comportamento diferente do apresentado.

As paredes com a inclusão da ISE apresentaram uma distribuição de tensões normais na seção sem uniformidade, devido aos recalques da base. Usualmente as tensões normais foram mais intensas nas extremidades das paredes nas quais o seu recalque apresentava seu menor valor. Essa configuração não se repetiu em todos os elementos. Elementos com pequeno 
comprimento mantiveram a distribuição uniforme e elementos interconectados foram influenciados pelas paredes vinculadas, na formação de grupos.

A análise do comportamento estrutural das paredes nos pavimentos superiores indicou a redução dos efeitos da ISE nesses pavimentos. Tais efeitos reduziram conforme a análise evoluiu para os pavimentos superiores. Nos últimos pavimentos, os elementos apresentaram comportamento semelhante à de um modelo de referência com a consideração do edifício sobre apoios rígidos.

A redução dos efeitos da ISE nos pavimentos superiores ocorreu tanto em relação aos esforços normais totais nas paredes como com a distribuição das tensões, que se apresentou mais homogênea nesses pavimentos.

A inclusão das ações evolutivas reduziu as decorrências da ISE. Essa redução ocorreu tanto na base da estrutura como ao longo da altura da edificação.

A rigidez relativa estrutura-solo é um dos parâmetros que controla a ISE. Por este motivo, foi proposto um coeficiente de rigidez relativa estrutura-solo especifico para edifícios de paredes de concreto. As análises realizadas evidenciaram que a rigidez do solo foi preponderante sobre a estrutura, deve-se isto a grande rigidez da estrutura até com poucos pavimentos. As mudanças da tendência da redistribuição de esforços da estrutura conforme se modificam a rigidez relativa estrutura-solo pôde ser observada em edifícios baixos (5 pavimentos). Edifícios com 12 a 20 pavimentos mantiveram um comportamento similar. As análises evidenciaram que esses edifícios possuíram uma contribuição de rigidez equivalentes.

A inclusão da ISE não foi significativa na redistribuição de momentos no radier. Os resultados indicaram que a ISE propiciou um aumento dos momentos localizados na projeção das paredes e reduções nos vãos localizados entre esses elementos.

\subsubsection{MACIÇO DO SOLO}

A inclusão da superestrutura favoreceu a uniformização dos recalques na fundação. A grande rigidez da estrutura dos edifícios de paredes propiciou essa uniformização, mantendo uma distribuição de recalques mais homogênea na fundação.

A aplicação das ações evolutivas reduziu a contribuição da rigidez da estrutura na uniformização dos recalques. A desconsideração da sequência construtiva pode levar a uma configuração de recalques mais uniforme do que quando esta é incluída na análise.

O maior benefício da inserção da estrutura na análise dos recalques foi a redução da distorção angular na base das paredes. Os modelos que não consideravam a estrutura apresentaram distorções angulares relevantes (valores próximos a 1/200). A inclusão da 
estrutura no modelo reduziu expressivamente esses valores. Neste caso, a ampla maioria dos elementos apresentaram recalques desuniformes sem distorção.

O estudo da rigidez relativa estrutura-solo indicou que o acréscimo de novos pavimentos na estrutura reduziu o coeficiente de variação de recalques na fundação. Entretanto, essa redução não é linear. Os pavimentos superiores contribuem menos efetivamente na homogeneização dos recalques.

O solo teve papel preponderante na rigidez relativa estrutura-solo. A grande rigidez dos edifícios de paredes, mesmo com poucos pavimentos, fez com que o desempenho do conjunto estrutura-solo tivesse uma maior relação com a rigidez do solo.

Do mesmo modo que a contribuição da rigidez dos pavimentos superiores da estrutura é reduzida, foi evidenciado que a dos trechos inferiores do maciço do solo pouco modificou a resposta na estrutura. O comportamento estrutural com maciços com relação profundidade do maciço e comprimento da edificação em planta (H/L) entre 1 e 2 foi semelhante.

A consideração da heterogeneidade do solo aumentou expressivamente os efeitos da ISE na redistribuição de esforços na estrutura.

\subsection{CONSIDERAÇÕES SOBRE A ISE EM EDIFÍCIOS DE PAREDES DE CONCRETO}

A inclusão da ISE quando realizada de forma inadequada pode distorcer o comportamento real da estrutura. A desconsideração da heterogeneidade do solo no modelo teórico pode levar a resultados divergentes da estrutura real. As mesmas consequências podem aparecer caso seja desprezada a influência de edificações vizinhas. Deste modo, a aplicação da ISE deve ser realizada de modo cuidadoso e por meio de um modelo representativo que considere o maciço do solo de acordo com as condições mais próximas dos reais. Deste modo, está apenas deveria ser imposta em situações de caráter especial, como a presença de heterogeneidade do solo ou em solos com baixa rigidez.

O desenvolvimento da tese permitiu observar que a redistribuição de esforços nos edifícios de paredes com o uso da ISE é relevante. A grande rigidez da estrutura é a responsável por essas implicações. No entanto, a contribuição da rigidez ocorre já com poucos pavimentos. A análise da rigidez relativa estrutura-solo indicou que a redistribuição de esforços tem uma dependência maior da rigidez do solo do que o número de pavimentos da edificação.

A redistribuição de esforços nos edifícios analisados de 5 a 8 pavimentos foi facilmente absorvida pelos elementos. Estas paredes possuem uma grande seção resistente, por consequência das espessuras mínimas impostas pela norma de parede de concreto (NBR-16055, 
2012). Edifícios de maior porte podem ter problemas no dimensionamento dos elementos, induzidos pela introdução dos efeitos da ISE. Deve-se deixar explícito que, neste caso, o emprego de fundações superficiais seria limitado a solos com boa capacidade. Edifícios maiores também utilizariam maiores espessuras nas paredes e uma maior resistência do concreto.

A deficiência no dimensionamento dos elementos nos modelos com a incorporação da ISE pela norma NBR-16055 (ABNT, 2012), quando ocorrida, foi causada pela presença de tensões desuniformes. Neste caso, as concentrações de tensões nas paredes ultrapassavam os limites das tensões de contato de cálculo permitida pela referida norma.

A NBR-16055 (ABNT, 2012) age inadequadamente ao impor que a ISE deva ser obrigatoriamente considerada em edifícios com mais de 5 pavimentos. Utilizar apenas a rigidez do solo como parâmetro para a ISE também não é apropriado. A influência da rigidez do solo na ISE está atrelada ao nível de carga aplicada e a rigidez da estrutura. Os elementos que não atenderam aos critérios de dimensionamento possuíam alta rigidez relativa estrutura-solo (Krpar), conforme mostrado no capítulo 6. No mesmo capítulo também fica explícito que quanto maior a rigidez relativa estrutura-solo, maior é a redistribuição de esforços entre os elementos. Deste modo o processo mais lógico a ser realizado é vincular a necessidade da inclusão da ISE com a rigidez relativa estrutura-solo.

Um modo simplificado, que pode ser sugerido, para a incorporação indireta da ISE no dimensionamento dos elementos é a majoração dos esforços de cálculo, sendo estes obtidos por meio de uma análise convencional (apoios rígidos). A NBR-6118 (ABNT, 2014) emprega um procedimento similar ao utilizar o coeficiente “ $\gamma_{n}$ ” para majorar esforços de cálculo em pilares e pilares-paredes com dimensões menores de $19 \mathrm{~cm}$. A mencionada norma também utiliza o mesmo processo para majorar esforços de lajes em balanço.

Por meio da análise da Figura 6.33 e utilizando os valores da Tabela 6.22 pode-se verificar percentualmente a redistribuição média de esforços nas paredes na base do $1^{\circ}$ pavimento ( $\left.\eta_{\text {pav,par}}\right)$, sendo este o mais afetado pela ISE. Deste modo, por meio desses resultados é possível estimar o coeficiente adicional de majoração de esforços necessário para cobrir a redistribuição média de cargas devida à inclusão da ISE de acordo com a variação do “Krpar”. Utilizar o próprio coeficiente médio de redistribuição de esforços, “ $\eta_{\text {pav,par }}$, como indicativo para a ponderação desses esforços é razoável, já que representa um valor percentual médio de esforços normais redistribuídos nos elementos do pavimento. A Tabela 7.1 mostra a sugestão do coeficiente adicional majorador de esforços devido à ISE de acordo com os limites do coeficiente de rigidez relativa estrutura-solo. 
Tabela $7.1-\gamma_{\mathrm{n}}$ - Coeficiente adicional majorador de esforços devido a ISE em edifícios de paredes de concreto sobre radier

\begin{tabular}{|c|c|c|c|c|}
\hline Krpar $\leq$ & 0,1 & 0,01 & 0,001 & 0,0001 \\
\hline$\gamma_{\mathrm{n}}$ & 1,25 & 1,20 & 1,15 & 1,10 \\
\hline
\end{tabular}

- O coeficiente “ $\gamma_{n}$ ” pode ser utilizado para majorar os esforços quando o engenheiro estrutural não tem os recursos necessários para analisar corretamente a ISE. Deste modo, quando este majorador é utilizado se dispensaria a inclusão explícita da interação solo-estrutura no modelo estrutural.

- O coeficiente “ $\gamma_{n}$ ” deve ser utilizado para majorar os esforços finais de cálculo, ou seja, esforços já ponderados pelo coeficiente “ $\gamma f ”$.

- Para "Krpar” menor que 0,0001 a interação solo-estrutura pode ser desprezada no dimensionamento dos elementos

\subsection{RECOMENDAÇÕES PARA A NBR-16055 (ABNT, 2012)}

Por meio de todos as análises realizadas no desenvolvimento da tese alguns aspectos podem ser sugeridos como contribuição para a revisão da norma de paredes de concreto NBR16055 (ABNT, 2012):

- A associação do número de pavimentos da estrutura na obrigatoriedade da aplicação da ISE deve ser revista. Fundamentar a obrigatoriedade do uso da ISE por algum critério baseado na rigidez relativa estrutura-solo.

- Obrigatoriedade da inclusão na ISE atrelada à possibilidade do surgimento de recalques diferenciais relevantes na fundação, principalmente em casos com a presença de solos heterogêneos. Esta possibilidade pode ser avaliada por um engenheiro geotécnico. A referida norma já atribui a definição dos parâmetros geotécnicos do modelo estrutural a um especialista em mecânica dos solos.

- Quando considerada, a aplicação da ISE deve ser realizada por um modelo que considere o solo como um meio contínuo. Caso seja utilizado um modelo com molas discretas, deve-se incluir a interação entre elas. Neste caso, pode ser utilizado um modelo com molas de rigidez atualizáveis, em processo de cálculo iterativo. 
O coeficiente proposto é uma variável simples que permite estimar a relação de rigidez entre os dois meios e pode servir de parâmetro para análise da ISE. Neste caso, as contribuições sugeridas para a NBR 16055 (ABNT, 20120) em relação ao coeficiente de rigidez relativa estrutura-solo para edifícios de fundação do tipo radier são:

- Não obrigatoriedade da inclusão da ISE em edifícios com rigidez relativa estrutura-solo menor que 0,0001 .

- O uso do coeficiente “ $\gamma_{n}$ ” como procedimento indireto para incluir os efeitos da ISE na análise estrutural. Neste caso, se dispensaria a inclusão da ISE na análise estrutural.

\subsection{SUGESTÕES PARA TRABALHOS FUTUROS}

São listadas algumas sugestões para o desenvolvimento de trabalhos sobre a ISE em edifícios de paredes de concreto.

- Realizar um estudo paramétrico com mudanças geométricas nos edifícios de paredes. Analisar a influência da rigidez relativa estrutura-solo com alterações de tipologia, vãos entres os elementos e diferentes relações largura/comprimento em planta da edificação.

- Aprofundamento do parâmetro “ $\gamma_{n}$ ” como procedimento indireto para a consideração da ISE em tipologias distintas da analisada.

- Continuidade das análises realizadas considerando fundação do tipo profunda. Análises do parâmetro "Krpar” e do coeficiente “ $\gamma_{n}$ ” nesse tipo de solução de fundação.

- Estudo da modelagem numérica da ISE em edifícios de paredes de concreto (Elementos de membrana) com o uso de molas de rigidez atualizáveis.

- Estudo da ISE com a consideração do solo heterogêneo e/ou influência de fundações vizinhas. Além do desaprumo devido à heterogeneidade do solo, podem ser analisadas as consequências das rotações nessas edificações.

- Estudo experimental das paredes e painéis de concreto sobre o efeito de recalques diferenciais. 
- Estudo numérico das instabilidades local e localizadas em paredes e painéis de concreto com distribuição de tensões normais desuniformes na seção 


\section{REFERÊNCIAS BIBLIOGRÁFICAS}

AOKI, N. Aspectos geotécnicos da interação estrutura-maciço de solos. In. XXVIII Jornadas sul-americanas de Engenharia Estrutural - Escola de Engenharia de São Carlos, Universidade de São Paulo. Vol 1, p vii. São Carlos, Brasil. 1997.

AOKI, N.; LOPES, F.R. Estimating Stresses and settlements due to deep foundtions by theory of elasticity. In. 5th PAN AMERICAN CONFERENCE ON SOIL MECHANICS AND FOUNDATION ENGINEERING, Proceedings Buenos Aires. 1975

AMERICAN CONCRETE INSTITUTE. ACI 318: Building Code Requirements for Reinforced concrete. Farmigton Hills, 2011

AMERICAN CONCRETE INSTITUTE: ACI COMMITTEE 336. Suggested Analysis and Design Procuderes for Combined Footings and Mats. 1988

ASSAN, A. E. Método dos Elementos Finitos. Editora da Unicamp, Campinas. 1999

ASSOCIAÇÃO BRASILEIRA DE CIMENTO PORTLAND (ABCP). Parede de Concreto: Coletânea de ativos. São Paulo, 2008.

ASSOCIAÇÃO BRASILEIRA DE NORMAS TÉCNICAS (ABNT). NBR 6118: Projeto de estruturas de concreto - Procedimento. Rio de Janeiro, 2014.

, NBR 6120: Cargas para o cálculo de estruturas de edificações. Rio de Janeiro, 1980.

, NBR 8681: Ações e seguranças nas estruturas. Rio de Janeiro, 2004.

NBR 16055: Parede de concreto moldada no local para a construção de edificações - Requisitos e procedimentos. Rio de Janeiro, 2012.

BADIE, S. S; SALMON, D. C.; BESHARA, A. W., Analysis of shear wall structures on elastic foundations. Computers and structures, vol. 65, No 2, pp 213-224. 1997. 
BATHE, K. J. Finite Element Procedures in Engineering Analysis. New Jersey, Prentice Hall. 1982

BORGES, A. C. L. Metodologia para avaliação do comportamento estrutural de edifícios altos em concreto armado com a consideração da interação solo-estrutura. Tese (Doutorado) - Universidade Federal de Pernambuco. Pernambuco. 2009.

BOWLES, E. J. Foundation analysis and desing. New York: McGraw-Hill, 1997

BRAGUIM, T. C. Utilização de modelos de cálculo para projeto de edifícios de paredes de concreto armado moldadas no local. Dissertação (mestrado) - Escola Politécnica da Universidade de São Paulo. São Paulo. 2013.

BRAGUIM ,T,C.; BITTENCOURT,T.N.; Design of reinforced concrete walls cast in place for the maximum normal stress of compression. RIEM, Ibracon Structures and Materials Journal. 18:498-533. 2014

BRITISH STANDARDS INSTITUTION: BS8110-1997. Structural Use of Concrete, Part I - Code of practice for Design and Construction. LONDON, 1997

BROWN, P.T., Strip footing with concentrated loads on deep elastic foundations. Geotchenic Eng. 6 1-13. 1975

BROWN, P. T; YU, K. R., Load sequence and structure-foundation interaction. Journal of Structural Engineering. March, Vol. 112, No. 3 p481-489. 1986.

BURLAND, J.B; WROTH, C.P., Settlement of buildings and associated damage. State-ofthe-Art review. Proceedings, Conference on Settlement of structures, Cambridge, Pentech Press, Londres. 1974.

BURLAND, J.B; BROMS, B.B; DE MELLO, V. F. B., Behavior of foundations and structures. Proceedings, 9th International Conference on Soil Mechanics and Foundation Engineering. 1977. 
CAPUTO, P.H. Mecânica dos solos e suas aplicações. Vol. 1. $6^{\text {a }}$ edição. Editora LTC. Rio de Janeiror. 1988

CEB/FIP - CÓMITE EURO-INTERNATIONAL DU BÉTON, CEB-FIP Model Code London, Thomas Telford. 1990.

CHAMECKI, S., Consideração da rigidez da estrutura no cálculo dos recalques da fundação. $1^{\circ}$ Congresso Brasileiro de Mecânica dos Solos e Engenharia de fundações, Porto Alegre Vol. 1, pp. 35-80. 1954.

CHAMECKI, S. Structural rigidity in calculating settlements. Journal of Soil Mechanics and Foundation Division, ASCE, v.82,n.SM-1, p1-19, 1956.

CINTRA, J. C. A; AOKI, N.; ALBIERO, J. H., Tensão admissível em fundações diretas. Oficina de textos, São Carlos. SP. 2003

COLOTTI, V. Shear Behavior of RC Structural Walls. Journal of Structural Engineering, ASCE, v. 119, No 3, March 1993.

CORRÊA, M. R. S., Fluxo de forças em edifícios de alvenaria estrutural. Tese (Livredocência)- Escola de Engenharia de São Carlos, Universidade de São Paulo, 2003.

DOH, J. H. Experimental and theoretical studies of normal and high strength concrete wall panels. Thesis (Docstor of philosophy), Griffhit University.2002.

FRAGOMENI, S. Design of normal and High Strength reinforced concrete walls. Ph.d Thesis, University of Melbourne, Australia. 1995.

FRASER, R. A, WARDLE, L. J. Numerical analysis of rectangular rafts on layered foundations. Géotechinique, 26. No 4, 613-630. 1976.

GOSHY, A. D. Soil-foundation-structure interaction. Journal of the Structural Division, ASCE. Vol. 104, p. 749-761, 1978. 
GUSMÃO, A. D., Estudo da interação solo-estrutura e sua influência em recalques de edificações. Dissertação (Mestrado) - Universidade Federal do Rio de janeiro. Rio de janeiro. 1990.

GUSMÃO, A. D., Aspectos relevantes da interação solo-estrutura em edificações. Solos e Rochas, v. 17, n.1, p. 47-55, 1994.

GRUNDY, P; KABAILA, A. Construction loads on slabs with shored formwork in multistory Buildings. Journal of the american concrete institute. V 60, N. 12. December pp 1729-1738. 1963.

GUSMÃO FILHO, J. A; GUIMARÃES, L.J.N., Limit Stiffness in soil structure interaction of buildings. Proc. 14th int. conf. on soil mechs and found. Eng. Hamburg 2: 807-808. 1997.

HAIN, S. J, LEE, I. K. Analysis of flexibe raft-pile Systems. Géotechinique, 28. No 1, 65-83. 1978

HARR, M. E. Foundations of theoretical soil mechanics. New York: MacGraw-Hill Book Co. 1966

HENDRY, A.W.. Structural Brickwork. London, Macmillan Press .1981.

HORIKOSHI, K., RANDOLPH, M. F. On the definition of raft-soil stiffess ratio for rectangular rafts. Géotechinique, 47. No 5, 1055-1061. 1997

IWAMOTO, R. K., Alguns aspectos dos efeitos da interação solo-estrutura em edifícios de múltiplos andares com fundação profunda. Dissertação (Mestrado). Escola de Engenharia de São Carlos, Universidade de São Paulo. São Carlos, Brasil. 2000.

KRIPKA, M; Análise incremental construtiva de edificações. Tese (Doutorado). Universidade Federal do Rio de Janeiro, COPPE. 1990.

LOURENÇO, P. B., Computational strategies for masonry structures. Delft University Press: The Netherlands. 1996. 
LIU, G.R; QUEK, S.S. The Finite Element Method. A Practical Course. Elsevier, Oxford. 2016

MEYERHOF, G. F., The settlement analysis of building frames. The journal of structural engineers. August, pp 368-401. 1947.

MEYERHOF, G. F. , Some Recent Foundation research and its application to design. The journal of institution of structural engineers. Vol 31. pp 151-167. 1953.

MINDLIN, R. D, Force at a point in the interior of a semi-infinite solid. Physics, v.7, p.195-202, 1936.

MONGE, R.; MAYOR, A. V; SILVA, J. B., A construção de um sistema de sucesso. Concreto e construções, v.90, p.42-46, Abr-Jun 2018.

NASCIMENTO NETO, J. A. (2003). Estudo de painéis com abertura, constituídos em alvenaria estrutural de blocos. Tese (Doutorado) - Escola de Engenharia de São Carlos, Universidade de São Paulo. (2003)

NUNES, V. Q. G. Análise estrutural de edifícios de paredes de concreto armado. $150 \mathrm{f}$. Dissertação (Mestrado) - Escola de Engenharia de São Carlos, Universidade de São Paulo, São Carlos. 2011.

POULOS, H. G, Settlement Analysis of structural foundation systems. Proceedings, 4th Southeast Asian Conference on Soil. Kuala Lumpur, Malaysia. 1975

POULOS, H. G., Foundation settlement analysis - Practice versus research. 8th Spencer Lecture, November. 2000.

PRADO, J. F. M. A; CORRÊA, M. R. S; RAMALHO, M. A., A new procedure for the analysis of construction loads in multstory reinforced concrete structures. The structural design of tall and special buildings. 12. Pp 293-315. 2000 
PRADO, J. F. M. A. Estruturas de edifícios em concreto armado submetidas a ações de construções. 1999. 201f. Tese (Doutorado) - Escola de Engenharia de São Carlos da Universidade de São Paulo, São Carlos, 1999

SAHEB, S.M.; DESAYI, P. Ultimate Strength of R.C. Wall Panels in One-way In-Plane Action. Journal of Structural Engineering, ASCE, v. 115, No 10, p. 2617-2630, October 1989.

SAHEB, S.M.; DESAYI, P. Ultimate Strength of R.C. Wall Panels in Two-way In-Plane Action. Journal of Structural Engineering, ASCE, v. 116, No 5, p. 1384-1402, October 1990.

SANTOS, M. G. C., Análise Estrutural dos Efeitos dos Deslocamentos dos Apoios de Edifícios de Paredes de Concreto Moldadas no Local. 273f. Disseração (mestrado) - Escola de Engenharia de São Carlos, Universidade de São Paulo, São Carlos. 2016.

SANTOS, P. V. S., Ações Evolutivas em Edifícios de Paredes de Concreto e de Alvenaria, considerando a ação do solo. 176f. Dissertação (mestrado) - Escola de Engenharia de São Carlos, Universidade de São Paulo, São Carlos. 2016.

SELVARAJ, S.; SHARMA, S. P. Influence of construction sequence on the stresses in tal buildings frames. Regional conference on tal building, Bangkok, pp 197-211. 1974.

SILVA, M. F. A. S.; Desenvolvimento de um modelo analítico para determinação da resistência ao cisalhamento de nós de pórtico externos de concreto armado. 168f. Dissertação (mestrado) - Escola de Engenharia de São Carlos, Universidade de São Paulo, São Carlos. 2016.

STANDARDS AUSTRALIA. AS 3600: Concrete Structures. North Sydney, NSW, Australua, 2009

STAVRIDIS, L. T., Simplified analysis of layered soil-structure interation. Journal of Structural Engineering. Vol. 128, Nº 2, pp 222-230. February. 2002.

TA, L.D; SMALL, J.C. An approximation for analysis of raft and pilled raft foundations. Computers and Geotechnics. Vol. 20, Issue 2, pp 105-123. 1997 
TESTONI, E., Análise estrutural de edifícios de paredes de concreto por meio de pórtico tridimensional sobre apoios elásticos. 219f. Dissertação (mestrado) - Escola de Engenharia de São Carlos, Universidade de São Paulo, São Carlos. 2013.

VELLOSO, D. A; LOPES, F. R., Fundações. Oficina de textos. São Paulo. 2000.

VESIC, A. S. Beams on elastic subgrade and the Winkler's hypothesis. Proceedings, 5th International Conference on Soil Mechanics and Foundation Engineering Vol. 1, pp 845-850. 1961.

YAGUI, T. Análise de estruturas de edifícios constituídas de núcleo de concreto armado e pilares e pendurais de aço (carregamento crítico de instabilidade). Tese (livre-docência) Universidade Estadual de Campinas, 1978.

ZHANG, B. Q., SMALL, J. C. Finite layer analysis of the behaviour of a raft on a consolidating soil. Internacional Journal for Numerical and Analytical Methods in Geomechanics. V 18. Issue 4. Pg 237-251. 1994 



\section{APÊNDICE A - ANÁLISES PRELIMINARES}

Este item apresenta análises preliminares realizadas para o desenvolvimento do modelo numérico. São analisados dois estudos. Objetiva-se, por meio dessas análises, reduzir o custo computacional do modelo numérico, sem que ocorra a perda na precisão dos resultados.

Os modelos analisados são similares ao edifício apresentado no capítulo 3, tendo sido considerado para este item apenas um pavimento do mesmo. As ações verticais são aplicadas em sua totalidade de maneira instantânea, nas presentes avaliações.

Apenas uma camada de solo é considerada, para a representação do maciço, com comportamento elástico-linear. O módulo de elasticidade utilizado é de $1 \mathrm{x} 10^{6} \mathrm{~N} / \mathrm{m}^{2}$, valor este similar aos utilizados nos modelos estudados no capítulo 3, 4 e 5.

\section{A.1 EXTENSÃO DO DOMÍNIO LATERAL DO MACIÇO DO SOLO}

Foi concebido domínio finito para representar o maciço do solo. É avaliado se a extensão lateral considerada para o domínio do solo pode alterar os resultados referentes aos recalques da superestrutura.

Define-se a extensão do domínio lateral do maciço por meio do conceito de bulbo de recalques de acordo com Cintra et al. (2000). Desta maneira, é estabelecida a extensão como a metade da maior dimensão em planta da edificação.

São criados cinco modelos numéricos, com variações na extensão do domínio lateral, com o objetivo de validar a estratégia adotada. A Figura A.1 em conjunto com a Tabela A.1, ilustram os limites adotados e os modelos criados para a validação do domínio do solo.

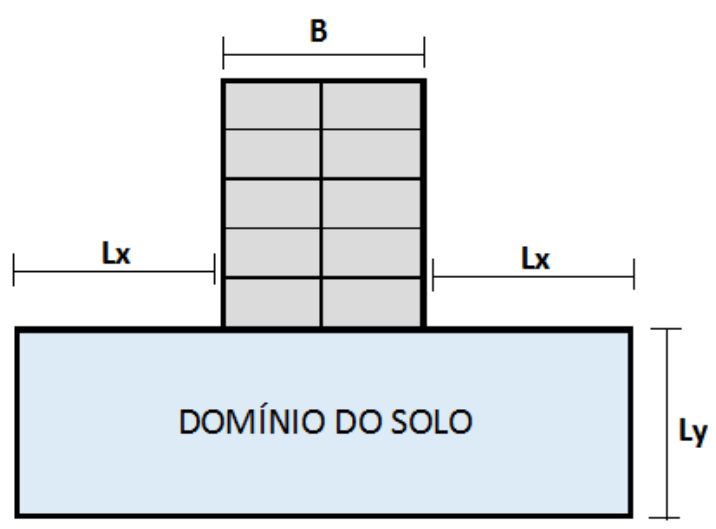

Figura A1. - Domínio do maciço do solo 
Tabela A.1- Modelos para análise do domínio lateral do maciço do solo

\begin{tabular}{|c|c|c|}
\hline Modelo & Lx $(\mathrm{m})$ & Ly $(\mathrm{m})$ \\
\hline A1-1 & $0,3 \mathrm{~B}=4,5$ & $3 \mathrm{~B}=45$ \\
\hline A1-2 & $0,5 \mathrm{~B}=7,5$ & $3 \mathrm{~B}=45$ \\
\hline A1-3 & $\mathrm{B}=15$ & $3 \mathrm{~B}=45$ \\
\hline A1-4 & $1,5 \mathrm{~B}=22,5$ & $3 \mathrm{~B}=45$ \\
\hline A1-5 & $2 \mathrm{~B}=30$ & $3 \mathrm{~B}=45$ \\
\hline
\end{tabular}

A profundidade do maciço do solo é fixada em 15 metros. As análises realizadas no capítulo 6 indicam que valores acima desta profundidade pouco modifica o comportamento da estrutura. Realiza-se comparações dos recalques no radier e na base de algumas paredes. A Tabela A.2 aponta os valores referentes aos recalques máximos, mínimos e diferenciais no radier, enquanto a Tabela A.3, os recalques diferenciais nas bases de algumas paredes da superestrutura.

Tabela A.2- Recalques no radier

\begin{tabular}{|c|c|c|c|}
\hline Modelo & Recalque máximo $(\mathrm{mm})$ & Recalque mínimo $(\mathrm{mm})$ & Recalque diferencial (mm) \\
\hline A1-1 & 9,11 & 1,47 & 7,64 \\
\hline A1-2 & 9,54 & 1,53 & 8,01 \\
\hline A1-3 & 9,54 & 1,53 & 8,01 \\
\hline A1-4 & 9,54 & 1,53 & 8,01 \\
\hline A1-5 & 9,54 & 1,54 & 8,00 \\
\hline
\end{tabular}

Tabela A.3- Recalque diferencial (mm) nas bases das paredes

\begin{tabular}{|c|c|c|c|c|c|c|}
\hline \multirow{2}{*}{ Modelo } & \multicolumn{7}{|c|}{ Recalque diferencial (mm) } \\
\cline { 2 - 7 } & PY1 & PY5 & PY9 & PX7 & PX8 & PY13 \\
\hline A1-1 & 0,31 & 0,91 & 2,54 & 0,49 & 0,51 & 1,11 \\
\hline A1-2 & 0,33 & 0,94 & 2,66 & 0,54 & 0,54 & 1,33 \\
\hline A1-3 & 0,33 & 0,95 & 2,66 & 0,55 & 0,54 & 1,37 \\
\hline A1-4 & 0,33 & 0,95 & 2,66 & 0,55 & 0,54 & 1,37 \\
\hline A1-5 & 0,33 & 0,95 & 2,66 & 0,55 & 0,54 & 1,37 \\
\hline
\end{tabular}

Observa-se de acordo com as tabelas A.2 e A.3 que o aumento no domínio lateral para valores acima do proposto, não modificou de forma significativa os resultados. A diferença percentual máxima nos recalques diferenciais nas bases das paredes, entre os modelos analisados, ficou abaixo de $1 \%$. A comparação do deslocamento vertical do $1^{\circ}$ pavimento entre os modelos A1-2 e A1-3 pode ser visualizada na figura A.2 


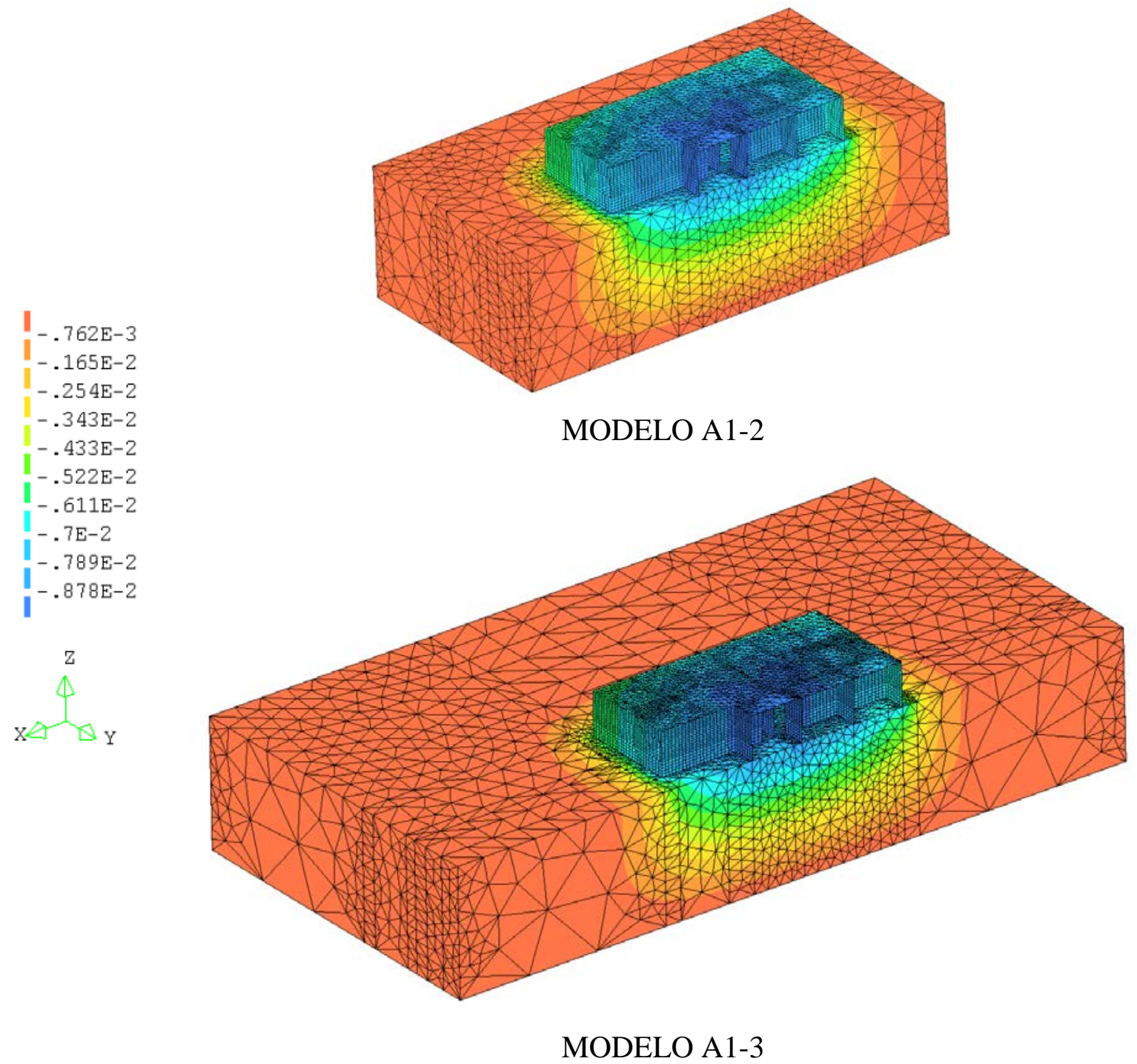

Figura A2. - $\mathrm{u}_{\mathrm{z}}(\mathrm{m})$ - Deslocamento vertical - Análise do domínio lateral do maciço do solo

Observa-se pela figura A.2 que os modelos A1-2 e A1-3 apresentam a mesma configuração do deslocamento do conjunto estrutura/maciço do solo. A modificação da extensão lateral entre os dois modelos não alterou os resultados. Os resultados indicam que o valor proposto para a extensão do domínio lateral do maciço, para o presente modelo numérico, é satisfatório, pois não acarreta prejuízos nos resultados, além de possibilitar um menor custo computacional em comparação com os demais modelos.

\section{A.2 - DENSIDADE DA MALHA DE ELEMENTOS FINITOS}

São analisadas a adequação da densidade da malha utilizada nas paredes da superestrutura. Almeja-se avaliar se a densidade de malha nas paredes utilizada, que apresentou um adequado custo computacional, pode prejudicar a qualidade dos resultados finais obtidos. O aumento da densidade da malha nas paredes acarreta na ampliação do custo computacional 
do modelo, principalmente devido ao acréscimo de nós no maciço do solo, devido a sua conexão com a superestrutura. São desenvolvidos 5 modelos com diferentes densidades de malha nas paredes e, consequentemente, no maciço do solo. A Tabela A.3 apresenta uma descrição dos modelos avaliados. O modelo utilizado no desenvolvimento da tese apresenta uma densidade similar ao do modelo A2-2. A figura A.3 mostra o deslocamento vertical do $1^{\circ}$ pavimento nos modelos A2-2 e A2-4. A Tabela A.4 aponta os recalques no radier.

Tabela A.3 - Modelos para análise da redução da malha nas paredes

\begin{tabular}{|c|c|c|}
\hline Modelo & Número de nós & Número de elementos \\
\hline A2-1 & 75954 & 47321 \\
\hline A2-2 & 99904 & 64200 \\
\hline A2-3 & 142862 & 87954 \\
\hline A2-4 & 189425 & 108861 \\
\hline A2-5 & 251425 & 121564 \\
\hline
\end{tabular}
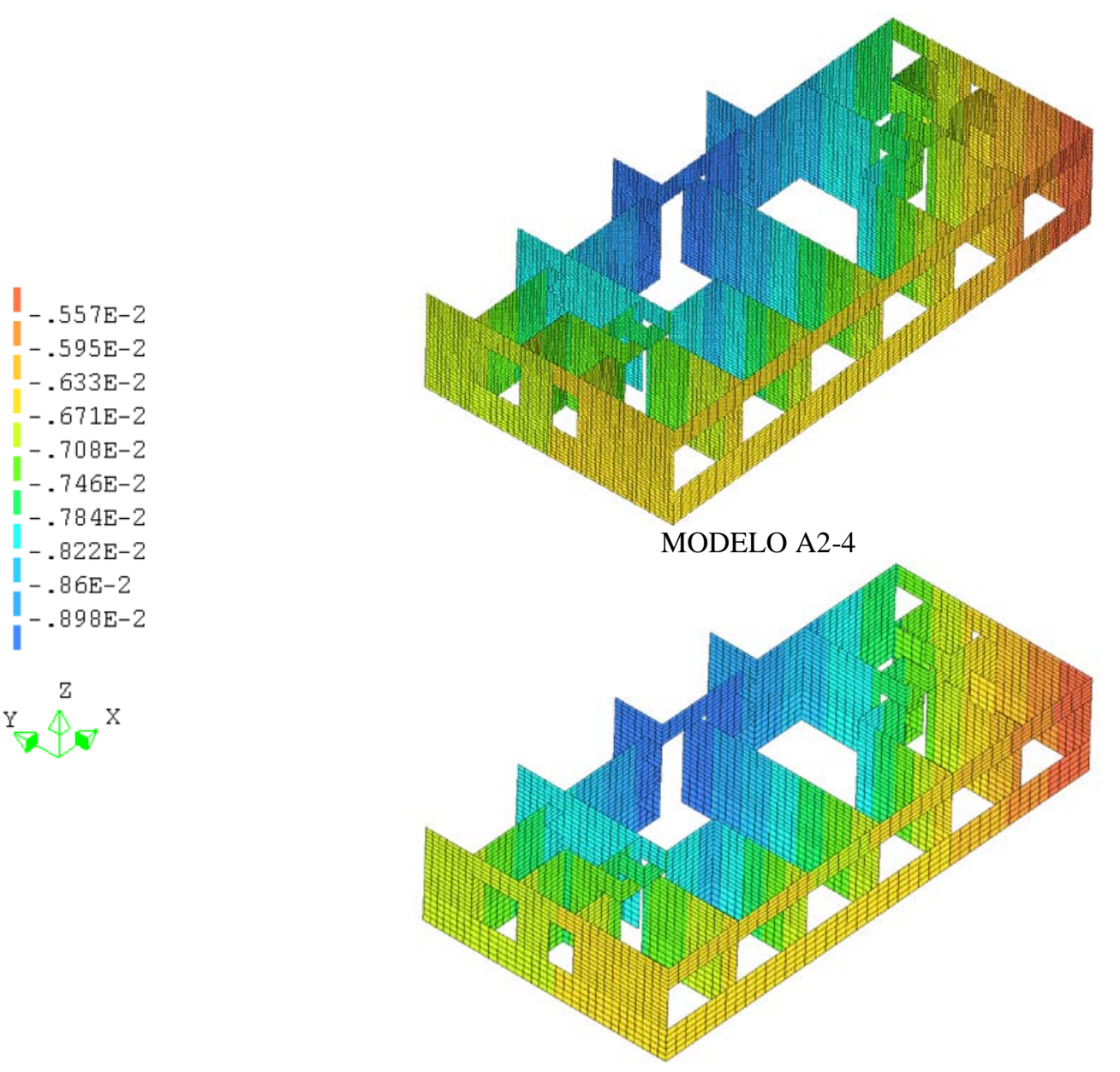

MODELO A2-2

Figura A3. - $\mathrm{u}_{\mathrm{z}}(\mathrm{m})$ - Deslocamento vertical - Modelos A2-2 e A2-4 
Tabela A.4 - Recalques máximos e mínimos no radier

\begin{tabular}{|c|c|c|c|}
\hline Modelo & Recalque máximo $(\mathrm{mm})$ & Recalque mínimo $(\mathrm{mm})$ & Recalque diferencial $(\mathrm{mm})$ \\
\hline A2-1 & 9,54 & 1,53 & 8,01 \\
\hline A2-2 & 9,54 & 1,53 & 8,01 \\
\hline A2-3 & 9,55 & 1,55 & 8,00 \\
\hline A2-4 & 9,55 & 1,55 & 8,00 \\
\hline A2-5 & 9,56 & 1,57 & 7.99 \\
\hline
\end{tabular}

Essas análises indicam que a densidade da malha utilizada não altera significativamente os resultados de deslocamentos no modelo numérico, conforme mostra a tabela A.4 e a comparação do deslocamento no $1^{\circ}$ pavimento na Figura A.3.

Entretanto, torna-se necessário avaliar as possíveis alterações no fluxo de tensões nas paredes. A Figura A.4 ilustra o fluxo da distribuição do esforço normal $\left(\mathrm{N}_{\mathrm{xx}}\right)$ na direção z (eixo global) em alguns elementos da superestrutura nos modelos A2-2 e A2-4.
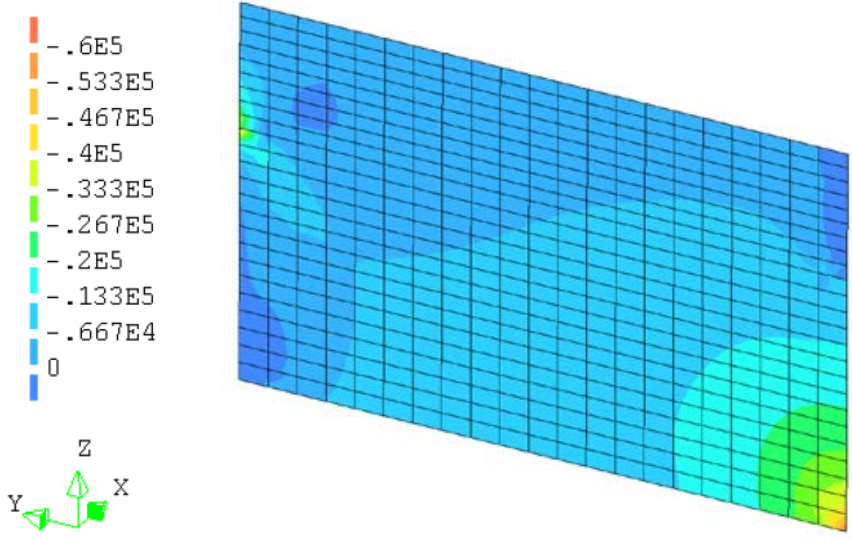

a) Parede Py1

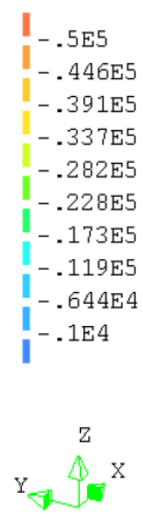

MODELO A2-4

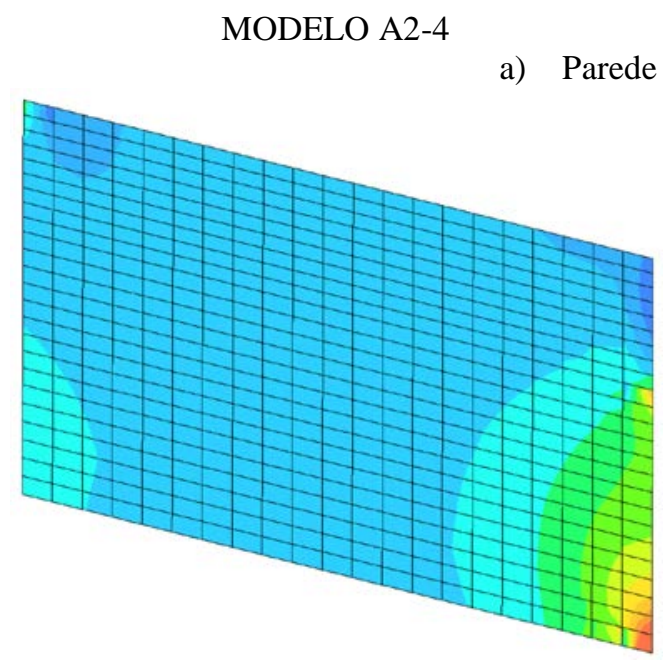

MODELO A2-4

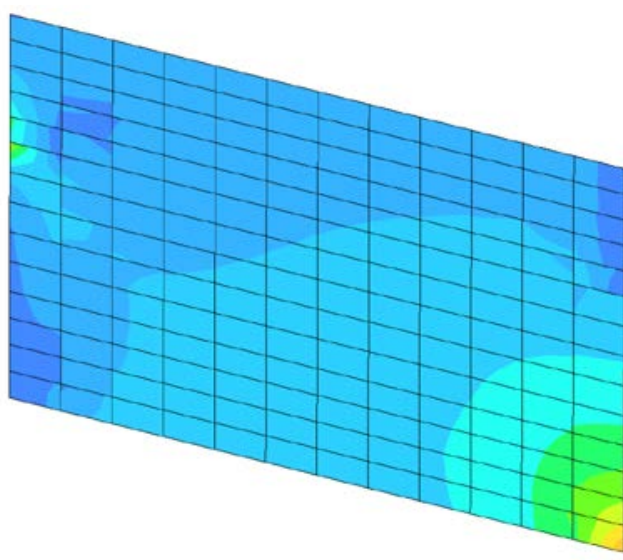

MODELO A2-2

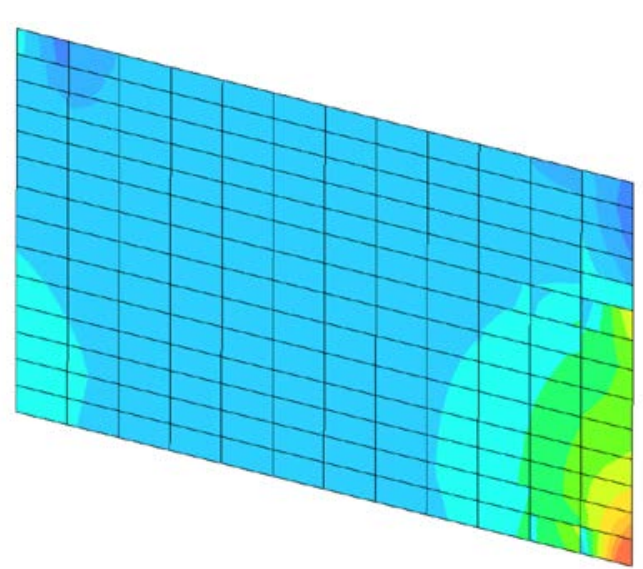

MODELO A2-2

b) Parede Py5 


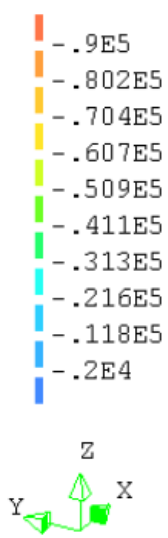

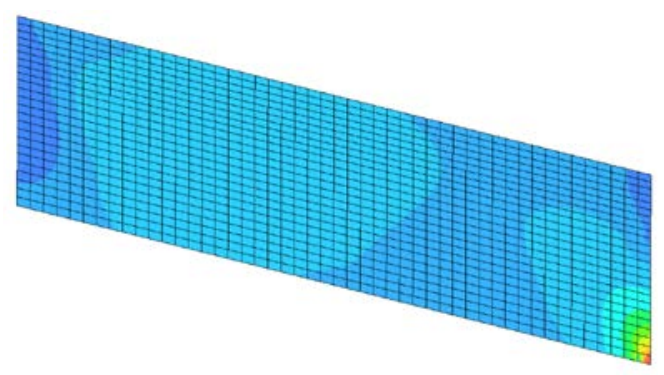

MODELO A2-4

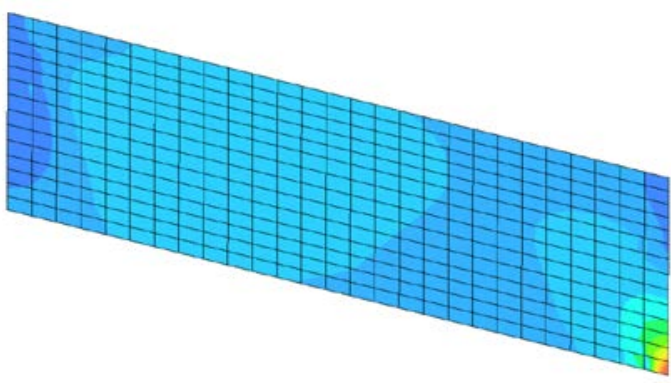

MODELO A2-2

c) Parede Py9

Figura A.4 - $\mathrm{N}_{\mathrm{xx}}(\mathrm{N} / \mathrm{m})$ - Esforço normal distribuído - Modelo A2-4 e A2-2

O fluxo de esforço normal distribuído nas paredes da superestrutura entre os modelos A2-2 e A2-4 são similares. Deve-se ficar atento que os modelos analisados nos capítulos 3, 4 e 5 possuem 8 pavimentos e a consideração das ações evolutivas se faz necessário diversas análises para que se obtenha o resultado final. Deste modo, embora o modelo A2-4 apresente uma melhor visualização gráfica, o seu elevado custo computacional inviabiliza utilizar esta densidade de malha para o desenvolvimento do estudo. Assim sendo, foi utilizada uma malha de densidade similar ao do modelo A2-2, que apresenta resultados finais idênticos ao dos demais modelos analisados. 


\section{APÊNDICE B - RESULTADOS COMPLEMENTARES: CAPÍTULO 4}

No desenvolvimento do capítulo 4 foi apresentada a análise dos resultados mais importantes dos modelos estudados. Este item apresenta os demais resultados de redistribuição de esforços “ $\eta$ ” e do coeficiente de variação das tensões, “CV $V_{\sigma}$ ”, dos modelos ISE-EVO-M1, ISE-EVO-M2 e ISE-EVO-M3. As análises e conclusões referentes a esses resultados estão expostas no capítulo 4.

\section{B.1 “ $\eta ”$ - REDISTRIBUIÇÃO DE ESFORÇOS NOS PAVIMENTOS}

Tabela B.1 - $\eta_{\text {PAR }}-$ Modelo M1-ISE-EVO

\begin{tabular}{|c|c|c|c|c|c|c|c|c|}
\hline \multirow{3}{*}{ PAREDE } & \multirow{2}{*}{\multicolumn{8}{|c|}{ Pavimento }} \\
\hline & & & & & & & & \\
\hline & 1 & 2 & 3 & 4 & 5 & 6 & 7 & 8 \\
\hline PX1 & $-17 \%$ & $-15 \%$ & $-12 \%$ & $-9 \%$ & $-7 \%$ & $-5 \%$ & $-3 \%$ & $-2 \%$ \\
\hline $\mathrm{PX} 2$ & $5 \%$ & $0 \%$ & $-3 \%$ & $-4 \%$ & $-3 \%$ & $-3 \%$ & $-1 \%$ & $-1 \%$ \\
\hline PX3 & $-2 \%$ & $-8 \%$ & $-8 \%$ & $-5 \%$ & $-2 \%$ & $0 \%$ & $0 \%$ & $0 \%$ \\
\hline $\mathrm{PX} 4$ & $9 \%$ & $-1 \%$ & $-4 \%$ & $-4 \%$ & $-3 \%$ & $-2 \%$ & $-1 \%$ & $0 \%$ \\
\hline PX5 & $-17 \%$ & $-19 \%$ & $-8 \%$ & $-2 \%$ & $0 \%$ & $1 \%$ & $1 \%$ & $0 \%$ \\
\hline PX6 & $-20 \%$ & $-17 \%$ & $-8 \%$ & $-3 \%$ & $-1 \%$ & $-1 \%$ & $-1 \%$ & $-1 \%$ \\
\hline PX7 & $6 \%$ & $1 \%$ & $2 \%$ & $4 \%$ & $5 \%$ & $4 \%$ & $3 \%$ & $2 \%$ \\
\hline PX8 & $-31 \%$ & $-43 \%$ & $-28 \%$ & $-14 \%$ & $-6 \%$ & $-1 \%$ & $1 \%$ & $2 \%$ \\
\hline PX9 & $-42 \%$ & $-48 \%$ & $-31 \%$ & $-17 \%$ & $-9 \%$ & $-4 \%$ & $-1 \%$ & $0 \%$ \\
\hline PX10 & $2 \%$ & $0 \%$ & $3 \%$ & $5 \%$ & $6 \%$ & $5 \%$ & $4 \%$ & $3 \%$ \\
\hline PY1 & $29 \%$ & $25 \%$ & $19 \%$ & $12 \%$ & $7 \%$ & $4 \%$ & $2 \%$ & $1 \%$ \\
\hline PY2 & $19 \%$ & $9 \%$ & $8 \%$ & $7 \%$ & $5 \%$ & $3 \%$ & $2 \%$ & $1 \%$ \\
\hline PY3 & $0 \%$ & $2 \%$ & $0 \%$ & $-2 \%$ & $-2 \%$ & $-2 \%$ & $-1 \%$ & $1 \%$ \\
\hline PY4 & $-46 \%$ & $-11 \%$ & $-6 \%$ & $-4 \%$ & $-2 \%$ & $-1 \%$ & $0 \%$ & $-1 \%$ \\
\hline PY5 & $23 \%$ & $23 \%$ & $18 \%$ & $13 \%$ & $9 \%$ & $6 \%$ & $3 \%$ & $1 \%$ \\
\hline PY6 & $-32 \%$ & $-19 \%$ & $-14 \%$ & $-10 \%$ & $-7 \%$ & $-5 \%$ & $-4 \%$ & $-2 \%$ \\
\hline PY7 & $8 \%$ & $9 \%$ & $7 \%$ & $5 \%$ & $3 \%$ & $2 \%$ & $1 \%$ & $1 \%$ \\
\hline PY8 & $-23 \%$ & $-27 \%$ & $-21 \%$ & $-14 \%$ & $-9 \%$ & $-5 \%$ & $-3 \%$ & $0 \%$ \\
\hline PY9 & $-4 \%$ & $-1 \%$ & $1 \%$ & $2 \%$ & $2 \%$ & $2 \%$ & $1 \%$ & $1 \%$ \\
\hline PY10 & $2 \%$ & $3 \%$ & $4 \%$ & $3 \%$ & $2 \%$ & $1 \%$ & $1 \%$ & $1 \%$ \\
\hline PY11 & $-10 \%$ & $-11 \%$ & $-10 \%$ & $-8 \%$ & $-5 \%$ & $-3 \%$ & $-2 \%$ & $0 \%$ \\
\hline PY12 & $-13 \%$ & $-6 \%$ & $-5 \%$ & $-4 \%$ & $-4 \%$ & $-4 \%$ & $-3 \%$ & $-2 \%$ \\
\hline PY13 & $10 \%$ & $14 \%$ & $11 \%$ & $8 \%$ & $5 \%$ & $3 \%$ & $2 \%$ & $1 \%$ \\
\hline PY14 & $-48 \%$ & $-16 \%$ & $-9 \%$ & $-7 \%$ & $-5 \%$ & $-5 \%$ & $-4 \%$ & $-4 \%$ \\
\hline PY15 & $14 \%$ & $14 \%$ & $11 \%$ & $8 \%$ & $5 \%$ & $3 \%$ & $1 \%$ & $1 \%$ \\
\hline PY16 & $20 \%$ & $9 \%$ & $5 \%$ & $2 \%$ & $1 \%$ & $0 \%$ & $0 \%$ & $0 \%$ \\
\hline
\end{tabular}


Tabela B.2 - $\eta_{\mathrm{GRU}}$ - Modelo M1-ISE-EVO

\begin{tabular}{|c|c|c|c|c|c|c|c|c|}
\cline { 2 - 9 } \multicolumn{1}{c|}{} & \multicolumn{9}{c|}{ Pavimento } \\
\hline GRUPO & 1 & 2 & 3 & 4 & 5 & 6 & 7 & 8 \\
\hline G1 & $-19 \%$ & $-15 \%$ & $-12 \%$ & $-9 \%$ & $-7 \%$ & $-5 \%$ & $-3 \%$ & $-1 \%$ \\
\hline G2 & $-1 \%$ & $-3 \%$ & $-4 \%$ & $-5 \%$ & $-4 \%$ & $-3 \%$ & $-2 \%$ & $-1 \%$ \\
\hline G3 & $-2 \%$ & $-4 \%$ & $-1 \%$ & $0 \%$ & $1 \%$ & $1 \%$ & $1 \%$ & $0 \%$ \\
\hline G4 & $-2 \%$ & $-4 \%$ & $-3 \%$ & $-3 \%$ & $-2 \%$ & $-2 \%$ & $-1 \%$ & $-2 \%$ \\
\hline G5 & $22 \%$ & $18 \%$ & $13 \%$ & $10 \%$ & $6 \%$ & $4 \%$ & $2 \%$ & $1 \%$ \\
\hline G6 & $23 \%$ & $23 \%$ & $18 \%$ & $13 \%$ & $9 \%$ & $6 \%$ & $3 \%$ & $1 \%$ \\
\hline G7 & $-1 \%$ & $-3 \%$ & $-1 \%$ & $0 \%$ & $1 \%$ & $1 \%$ & $1 \%$ & $1 \%$ \\
\hline G8 & $-4 \%$ & $-1 \%$ & $1 \%$ & $2 \%$ & $2 \%$ & $2 \%$ & $1 \%$ & $1 \%$ \\
\hline G9 & $-9 \%$ & $-8 \%$ & $-5 \%$ & $-3 \%$ & $-1 \%$ & $0 \%$ & $0 \%$ & $0 \%$ \\
\hline G10 & $10 \%$ & $14 \%$ & $11 \%$ & $8 \%$ & $5 \%$ & $3 \%$ & $2 \%$ & $1 \%$ \\
\hline G11 & $10 \%$ & $9 \%$ & $8 \%$ & $7 \%$ & $5 \%$ & $4 \%$ & $3 \%$ & $2 \%$ \\
\hline
\end{tabular}

Tabela B.3 - $\eta_{\text {PAR }}$ - Modelo M2-ISE-EVO

\begin{tabular}{|c|c|c|c|c|c|c|c|c|}
\hline \multirow{3}{*}{ PAREDE } & \\
\hline & \multicolumn{8}{|c|}{ Pavimento } \\
\hline & 1 & 2 & 3 & 4 & 5 & 6 & 7 & 8 \\
\hline PX1 & $-21 \%$ & $-17 \%$ & $-14 \%$ & $-10 \%$ & $-7 \%$ & $-5 \%$ & $-3 \%$ & $-2 \%$ \\
\hline PX2 & $1 \%$ & $-4 \%$ & $-6 \%$ & $-6 \%$ & $-5 \%$ & $-3 \%$ & $-2 \%$ & $-1 \%$ \\
\hline PX3 & $1 \%$ & $-6 \%$ & $-6 \%$ & $-3 \%$ & $-1 \%$ & $0 \%$ & $1 \%$ & $0 \%$ \\
\hline PX4 & $11 \%$ & $-1 \%$ & $-4 \%$ & $-4 \%$ & $-3 \%$ & $-2 \%$ & $-1 \%$ & $0 \%$ \\
\hline PX5 & $-17 \%$ & $-18 \%$ & $-4 \%$ & $1 \%$ & $3 \%$ & $3 \%$ & $2 \%$ & $2 \%$ \\
\hline PX6 & $-19 \%$ & $-14 \%$ & $-5 \%$ & $0 \%$ & $1 \%$ & $1 \%$ & $0 \%$ & $0 \%$ \\
\hline PX7 & $13 \%$ & $6 \%$ & $5 \%$ & $6 \%$ & $6 \%$ & $5 \%$ & $3 \%$ & $2 \%$ \\
\hline PX8 & $-33 \%$ & $-44 \%$ & $-27 \%$ & $-13 \%$ & $-4 \%$ & $0 \%$ & $2 \%$ & $2 \%$ \\
\hline РX9 & $-49 \%$ & $-50 \%$ & $-31 \%$ & $-16 \%$ & $-8 \%$ & $-3 \%$ & $-1 \%$ & $0 \%$ \\
\hline PX10 & $9 \%$ & $5 \%$ & $6 \%$ & $7 \%$ & $7 \%$ & $6 \%$ & $5 \%$ & $4 \%$ \\
\hline PY1 & $32 \%$ & $26 \%$ & $19 \%$ & $13 \%$ & $7 \%$ & $4 \%$ & $2 \%$ & $0 \%$ \\
\hline PY2 & $20 \%$ & $8 \%$ & $7 \%$ & $6 \%$ & $4 \%$ & $3 \%$ & $2 \%$ & $1 \%$ \\
\hline PY3 & $-2 \%$ & $0 \%$ & $-2 \%$ & $-3 \%$ & $-3 \%$ & $-3 \%$ & $-1 \%$ & $0 \%$ \\
\hline PY4 & $-53 \%$ & $-7 \%$ & $-2 \%$ & $-2 \%$ & $-1 \%$ & $0 \%$ & $0 \%$ & $-1 \%$ \\
\hline PY5 & $26 \%$ & $25 \%$ & $19 \%$ & $14 \%$ & $9 \%$ & $6 \%$ & $3 \%$ & $1 \%$ \\
\hline PY6 & $-42 \%$ & $-23 \%$ & $-17 \%$ & $-12 \%$ & $-8 \%$ & $-6 \%$ & $-4 \%$ & $-3 \%$ \\
\hline PY7 & $9 \%$ & $9 \%$ & $8 \%$ & $5 \%$ & $4 \%$ & $2 \%$ & $1 \%$ & $1 \%$ \\
\hline PY8 & $-35 \%$ & $-34 \%$ & $-23 \%$ & $-15 \%$ & $-9 \%$ & $-5 \%$ & $-2 \%$ & $0 \%$ \\
\hline PY9 & $-5 \%$ & $-2 \%$ & $1 \%$ & $1 \%$ & $1 \%$ & $1 \%$ & $1 \%$ & $1 \%$ \\
\hline PY10 & $2 \%$ & $4 \%$ & $4 \%$ & $3 \%$ & $3 \%$ & $2 \%$ & $1 \%$ & $1 \%$ \\
\hline PY11 & $-16 \%$ & $-15 \%$ & $-13 \%$ & $-10 \%$ & $-6 \%$ & $-4 \%$ & $-2 \%$ & $0 \%$ \\
\hline PY12 & $-18 \%$ & $-8 \%$ & $-6 \%$ & $-6 \%$ & $-5 \%$ & $-5 \%$ & $-4 \%$ & $-3 \%$ \\
\hline PY13 & $13 \%$ & $16 \%$ & $13 \%$ & $9 \%$ & $6 \%$ & $4 \%$ & $2 \%$ & $1 \%$ \\
\hline PY14 & $-58 \%$ & $-14 \%$ & $-7 \%$ & $-6 \%$ & $-5 \%$ & $-4 \%$ & $-4 \%$ & $-5 \%$ \\
\hline PY15 & $18 \%$ & $16 \%$ & $13 \%$ & $9 \%$ & $6 \%$ & $3 \%$ & $1 \%$ & $1 \%$ \\
\hline PY16 & $21 \%$ & $7 \%$ & $3 \%$ & $1 \%$ & $-1 \%$ & $-1 \%$ & $-1 \%$ & $0 \%$ \\
\hline
\end{tabular}


Tabela B.4 - $\eta_{\mathrm{GRU}}$ - Modelo M2-ISE-EVO

\begin{tabular}{|c|c|c|c|c|c|c|c|c|}
\cline { 2 - 9 } \multicolumn{1}{c|}{} & \multicolumn{7}{c|}{ Pavimento } \\
\hline GRUPO & 1 & 2 & 3 & 4 & 5 & 6 & 7 & 8 \\
\hline G1 & $-25 \%$ & $-18 \%$ & $-14 \%$ & $-11 \%$ & $-8 \%$ & $-5 \%$ & $-3 \%$ & $-2 \%$ \\
\hline G2 & $-5 \%$ & $-7 \%$ & $-7 \%$ & $-7 \%$ & $-5 \%$ & $-4 \%$ & $-2 \%$ & $-1 \%$ \\
\hline G3 & $-1 \%$ & $-3 \%$ & $0 \%$ & $1 \%$ & $1 \%$ & $1 \%$ & $1 \%$ & $0 \%$ \\
\hline G4 & $-2 \%$ & $-4 \%$ & $-3 \%$ & $-2 \%$ & $-2 \%$ & $-2 \%$ & $-1 \%$ & $-1 \%$ \\
\hline G5 & $26 \%$ & $20 \%$ & $15 \%$ & $10 \%$ & $7 \%$ & $4 \%$ & $2 \%$ & $1 \%$ \\
\hline G6 & $26 \%$ & $25 \%$ & $19 \%$ & $14 \%$ & $9 \%$ & $6 \%$ & $3 \%$ & $1 \%$ \\
\hline G7 & $-1 \%$ & $-3 \%$ & $-1 \%$ & $0 \%$ & $1 \%$ & $1 \%$ & $1 \%$ & $1 \%$ \\
\hline G8 & $-5 \%$ & $-2 \%$ & $1 \%$ & $1 \%$ & $1 \%$ & $1 \%$ & $1 \%$ & $1 \%$ \\
\hline G9 & $-9 \%$ & $-8 \%$ & $-5 \%$ & $-2 \%$ & $0 \%$ & $0 \%$ & $1 \%$ & $1 \%$ \\
\hline G10 & $13 \%$ & $16 \%$ & $13 \%$ & $9 \%$ & $6 \%$ & $4 \%$ & $2 \%$ & $1 \%$ \\
\hline G11 & $15 \%$ & $13 \%$ & $11 \%$ & $8 \%$ & $6 \%$ & $4 \%$ & $3 \%$ & $2 \%$ \\
\hline
\end{tabular}

Tabela B.4 - $\eta_{\text {PAR }}-$ Modelo M3-ISE-EVO

\begin{tabular}{|c|c|c|c|c|c|c|c|c|}
\hline & \multicolumn{8}{|c|}{ Pavimento } \\
\hline PAREDE & 1 & 2 & 3 & 4 & 5 & 6 & 7 & 8 \\
\hline PX1 & $-23 \%$ & $-17 \%$ & $-13 \%$ & $-10 \%$ & $-7 \%$ & $-5 \%$ & $-3 \%$ & $-2 \%$ \\
\hline PX2 & $1 \%$ & $-4 \%$ & $-6 \%$ & $-6 \%$ & $-5 \%$ & $-3 \%$ & $-2 \%$ & $-1 \%$ \\
\hline PX3 & $1 \%$ & $-7 \%$ & $-7 \%$ & $-4 \%$ & $-2 \%$ & $0 \%$ & $1 \%$ & $0 \%$ \\
\hline PX4 & $12 \%$ & $-2 \%$ & $-6 \%$ & $-5 \%$ & $-3 \%$ & $-2 \%$ & $-1 \%$ & $0 \%$ \\
\hline PX5 & $-19 \%$ & $-20 \%$ & $-6 \%$ & $0 \%$ & $2 \%$ & $2 \%$ & $2 \%$ & $1 \%$ \\
\hline PX6 & $-19 \%$ & $-15 \%$ & $-6 \%$ & $-2 \%$ & $0 \%$ & $0 \%$ & $0 \%$ & $-1 \%$ \\
\hline PX7 & $14 \%$ & $4 \%$ & $4 \%$ & $6 \%$ & $6 \%$ & $4 \%$ & $3 \%$ & $2 \%$ \\
\hline PX8 & $-34 \%$ & $-45 \%$ & $-28 \%$ & $-13 \%$ & $-5 \%$ & $0 \%$ & $1 \%$ & $2 \%$ \\
\hline PX9 & $-49 \%$ & $-50 \%$ & $-31 \%$ & $-16 \%$ & $-8 \%$ & $-3 \%$ & $-1 \%$ & $0 \%$ \\
\hline PX10 & $9 \%$ & $4 \%$ & $5 \%$ & $7 \%$ & $7 \%$ & $6 \%$ & $5 \%$ & $4 \%$ \\
\hline PY1 & $33 \%$ & $26 \%$ & $19 \%$ & $13 \%$ & $7 \%$ & $4 \%$ & $2 \%$ & $1 \%$ \\
\hline PY2 & $19 \%$ & $8 \%$ & $8 \%$ & $6 \%$ & $4 \%$ & $3 \%$ & $2 \%$ & $1 \%$ \\
\hline PY3 & $-2 \%$ & $2 \%$ & $-1 \%$ & $-3 \%$ & $-3 \%$ & $-2 \%$ & $-1 \%$ & $0 \%$ \\
\hline PY4 & $-54 \%$ & $-8 \%$ & $-4 \%$ & $-3 \%$ & $-1 \%$ & $-1 \%$ & $0 \%$ & $-1 \%$ \\
\hline PY5 & $28 \%$ & $25 \%$ & $20 \%$ & $14 \%$ & $10 \%$ & $6 \%$ & $3 \%$ & $2 \%$ \\
\hline PY6 & $-43 \%$ & $-23 \%$ & $-16 \%$ & $-12 \%$ & $-8 \%$ & $-6 \%$ & $-4 \%$ & $-3 \%$ \\
\hline PY7 & $10 \%$ & $10 \%$ & $8 \%$ & $6 \%$ & $4 \%$ & $2 \%$ & $1 \%$ & $1 \%$ \\
\hline PY8 & $-37 \%$ & $-34 \%$ & $-24 \%$ & $-16 \%$ & $-10 \%$ & $-5 \%$ & $-2 \%$ & $0 \%$ \\
\hline PY9 & $-5 \%$ & $-2 \%$ & $1 \%$ & $2 \%$ & $2 \%$ & $1 \%$ & $1 \%$ & $1 \%$ \\
\hline PY10 & $4 \%$ & $4 \%$ & $4 \%$ & $3 \%$ & $3 \%$ & $2 \%$ & $1 \%$ & $1 \%$ \\
\hline PY11 & $-16 \%$ & $-14 \%$ & $-13 \%$ & $-10 \%$ & $-6 \%$ & $-4 \%$ & $-2 \%$ & $0 \%$ \\
\hline PY12 & $-20 \%$ & $-9 \%$ & $-6 \%$ & $-6 \%$ & $-5 \%$ & $-5 \%$ & $-4 \%$ & $-3 \%$ \\
\hline PY13 & $14 \%$ & $17 \%$ & $13 \%$ & $9 \%$ & $6 \%$ & $4 \%$ & $2 \%$ & $1 \%$ \\
\hline PY14 & $-60 \%$ & $-15 \%$ & $-9 \%$ & $-7 \%$ & $-6 \%$ & $-5 \%$ & $-5 \%$ & $-5 \%$ \\
\hline PY15 & $19 \%$ & $17 \%$ & $14 \%$ & $10 \%$ & $6 \%$ & $3 \%$ & $2 \%$ & $1 \%$ \\
\hline PY16 & $21 \%$ & $7 \%$ & $3 \%$ & $1 \%$ & $0 \%$ & $-1 \%$ & $0 \%$ & $0 \%$ \\
\hline
\end{tabular}


Tabela B.6 - $\eta_{\text {GRU }}$ - Modelo M3-ISE-EVO

\begin{tabular}{|c|c|c|c|c|c|c|c|c|}
\cline { 2 - 9 } \multicolumn{1}{c|}{} & \multicolumn{7}{c|}{ Pavimento } \\
\hline GRUPO & 1 & 2 & 3 & 4 & 5 & 6 & 7 & 8 \\
\hline G1 & $-25 \%$ & $-18 \%$ & $-14 \%$ & $-10 \%$ & $-7 \%$ & $-5 \%$ & $-3 \%$ & $-2 \%$ \\
\hline G2 & $-5 \%$ & $-6 \%$ & $-7 \%$ & $-7 \%$ & $-5 \%$ & $-4 \%$ & $-2 \%$ & $-1 \%$ \\
\hline G3 & $-2 \%$ & $-3 \%$ & $-1 \%$ & $1 \%$ & $1 \%$ & $1 \%$ & $1 \%$ & $0 \%$ \\
\hline G4 & $-3 \%$ & $-5 \%$ & $-4 \%$ & $-3 \%$ & $-2 \%$ & $-2 \%$ & $-2 \%$ & $-2 \%$ \\
\hline G5 & $26 \%$ & $19 \%$ & $14 \%$ & $10 \%$ & $7 \%$ & $4 \%$ & $2 \%$ & $1 \%$ \\
\hline G6 & $26 \%$ & $25 \%$ & $20 \%$ & $14 \%$ & $10 \%$ & $6 \%$ & $3 \%$ & $2 \%$ \\
\hline G7 & $-1 \%$ & $-3 \%$ & $-1 \%$ & $1 \%$ & $1 \%$ & $1 \%$ & $1 \%$ & $1 \%$ \\
\hline G8 & $-5 \%$ & $-2 \%$ & $1 \%$ & $2 \%$ & $2 \%$ & $1 \%$ & $1 \%$ & $1 \%$ \\
\hline G9 & $-9 \%$ & $-8 \%$ & $-5 \%$ & $-2 \%$ & $0 \%$ & $0 \%$ & $1 \%$ & $1 \%$ \\
\hline G10 & $14 \%$ & $17 \%$ & $13 \%$ & $9 \%$ & $6 \%$ & $4 \%$ & $2 \%$ & $1 \%$ \\
\hline G11 & $15 \%$ & $12 \%$ & $11 \%$ & $9 \%$ & $6 \%$ & $5 \%$ & $3 \%$ & $2 \%$ \\
\hline
\end{tabular}

\section{B.2 - “CV ${ }_{\sigma}$ " COEFICIENTE DE VARIAÇÃO DAS TENSÕES}

Tabela B.7 - CV $\sigma$ - Modelo M1-ISE-EVO

\begin{tabular}{|c|c|c|c|c|c|c|c|c|}
\cline { 2 - 9 } \multicolumn{1}{c|}{} & \multicolumn{7}{c|}{ Pavimento } \\
\hline PAREDE & 1 & 2 & 3 & 4 & 5 & 6 & 7 & 8 \\
\hline PX1 & $19,6 \%$ & $6,7 \%$ & $3,8 \%$ & $3,5 \%$ & $4,5 \%$ & $6,0 \%$ & $8,4 \%$ & $14,5 \%$ \\
\hline PX2 & $34,4 \%$ & $12,5 \%$ & $5,4 \%$ & $7,9 \%$ & $12,3 \%$ & $16,8 \%$ & $23,1 \%$ & $39,1 \%$ \\
\hline PX3 & $12,4 \%$ & $2,1 \%$ & $1,8 \%$ & $1,3 \%$ & $1,6 \%$ & $1,9 \%$ & $2,5 \%$ & $6,2 \%$ \\
\hline PX4 & $26,5 \%$ & $8,2 \%$ & $3,2 \%$ & $1,6 \%$ & $2,2 \%$ & $3,0 \%$ & $3,9 \%$ & $8,1 \%$ \\
\hline PX5 & $27,1 \%$ & $0,8 \%$ & $2,9 \%$ & $6,1 \%$ & $7,7 \%$ & $8,7 \%$ & $10,2 \%$ & $14,2 \%$ \\
\hline PX6 & $22,8 \%$ & $3,6 \%$ & $5,1 \%$ & $8,6 \%$ & $10,6 \%$ & $12,0 \%$ & $14,0 \%$ & $18,7 \%$ \\
\hline PX7 & $13,0 \%$ & $8,7 \%$ & $3,7 \%$ & $5,7 \%$ & $8,2 \%$ & $10,7 \%$ & $14,6 \%$ & $24,0 \%$ \\
\hline PX8 & $24,1 \%$ & $13,9 \%$ & $2,5 \%$ & $5,4 \%$ & $6,3 \%$ & $7,3 \%$ & $9,0 \%$ & $14,3 \%$ \\
\hline PX9 & $19,5 \%$ & $13,1 \%$ & $3,8 \%$ & $7,2 \%$ & $8,0 \%$ & $8,6 \%$ & $9,8 \%$ & $14,8 \%$ \\
\hline PX10 & $12,6 \%$ & $6,5 \%$ & $4,8 \%$ & $7,9 \%$ & $10,8 \%$ & $13,4 \%$ & $17,2 \%$ & $26,9 \%$ \\
\hline PY1 & $50,3 \%$ & $21,0 \%$ & $10,1 \%$ & $7,1 \%$ & $6,9 \%$ & $7,8 \%$ & $10,2 \%$ & $14,6 \%$ \\
\hline PY2 & $16,1 \%$ & $22,5 \%$ & $19,9 \%$ & $16,1 \%$ & $13,2 \%$ & $11,2 \%$ & $10,1 \%$ & $11,8 \%$ \\
\hline PY3 & $23,1 \%$ & $8,5 \%$ & $7,7 \%$ & $7,6 \%$ & $7,5 \%$ & $7,3 \%$ & $7,0 \%$ & $5,8 \%$ \\
\hline PY4 & $12,8 \%$ & $0,2 \%$ & $2,2 \%$ & $1,6 \%$ & $0,9 \%$ & $0,5 \%$ & $0,3 \%$ & $1,7 \%$ \\
\hline PY5 & $82,5 \%$ & $39,2 \%$ & $25,5 \%$ & $19,7 \%$ & $18,2 \%$ & $19,4 \%$ & $22,0 \%$ & $22,3 \%$ \\
\hline PY6 & $7,8 \%$ & $3,3 \%$ & $2,5 \%$ & $2,3 \%$ & $3,1 \%$ & $4,9 \%$ & $8,2 \%$ & $17,9 \%$ \\
\hline PY7 & $76,9 \%$ & $45,1 \%$ & $31,6 \%$ & $24,3 \%$ & $20,0 \%$ & $17,6 \%$ & $16,1 \%$ & $14,0 \%$ \\
\hline PY8 & $4,8 \%$ & $3,9 \%$ & $3,8 \%$ & $3,0 \%$ & $2,4 \%$ & $2,1 \%$ & $2,2 \%$ & $3,9 \%$ \\
\hline PY9 & $68,1 \%$ & $38,5 \%$ & $30,3 \%$ & $25,1 \%$ & $21,4 \%$ & $18,8 \%$ & $16,7 \%$ & $12,5 \%$ \\
\hline PY10 & $75,7 \%$ & $44,4 \%$ & $30,6 \%$ & $23,2 \%$ & $19,1 \%$ & $16,9 \%$ & $15,5 \%$ & $13,6 \%$ \\
\hline PY11 & $3,0 \%$ & $0,8 \%$ & $1,4 \%$ & $1,9 \%$ & $2,4 \%$ & $3,3 \%$ & $5,4 \%$ & $14,3 \%$ \\
\hline PY12 & $13,7 \%$ & $11,1 \%$ & $11,2 \%$ & $12,2 \%$ & $13,2 \%$ & $14,7 \%$ & $17,4 \%$ & $24,2 \%$ \\
\hline PY13 & $81,5 \%$ & $37,7 \%$ & $25,7 \%$ & $21,0 \%$ & $19,8 \%$ & $20,6 \%$ & $22,4 \%$ & $22,1 \%$ \\
\hline PY14 & $7,2 \%$ & $2,4 \%$ & $2,9 \%$ & $1,5 \%$ & $0,2 \%$ & $1,3 \%$ & $3,3 \%$ & $8,2 \%$ \\
\hline
\end{tabular}




\begin{tabular}{|l|c|c|c|c|c|c|c|c|}
\hline PY15 & $46,2 \%$ & $18,0 \%$ & $12,4 \%$ & $11,7 \%$ & $11,7 \%$ & $11,9 \%$ & $13,0 \%$ & $16,4 \%$ \\
\hline PY16 & $19,0 \%$ & $5,3 \%$ & $10,4 \%$ & $10,9 \%$ & $10,7 \%$ & $10,3 \%$ & $9,8 \%$ & $10,0 \%$ \\
\hline
\end{tabular}

Tabela B.8 - CV $\sigma$ - Modelo M2-ISE-EVO

\begin{tabular}{|c|c|c|c|c|c|c|c|c|}
\cline { 2 - 10 } \multicolumn{1}{c|}{} & \multicolumn{7}{c|}{ Pavimento } \\
\hline PAREDE & 1 & 2 & 3 & 4 & 5 & 6 & 7 & 8 \\
\hline PX1 & $21,5 \%$ & $4,0 \%$ & $3,6 \%$ & $3,6 \%$ & $4,6 \%$ & $6,1 \%$ & $8,4 \%$ & $14,5 \%$ \\
\hline PX2 & $35,3 \%$ & $5,1 \%$ & $8,5 \%$ & $8,5 \%$ & $12,8 \%$ & $17,0 \%$ & $23,1 \%$ & $39,0 \%$ \\
\hline PX3 & $6,0 \%$ & $4,9 \%$ & $3,3 \%$ & $3,3 \%$ & $2,8 \%$ & $2,6 \%$ & $2,8 \%$ & $6,3 \%$ \\
\hline PX4 & $23,1 \%$ & $1,8 \%$ & $2,5 \%$ & $2,5 \%$ & $3,2 \%$ & $3,7 \%$ & $4,3 \%$ & $8,2 \%$ \\
\hline PX5 & $41,3 \%$ & $5,8 \%$ & $8,7 \%$ & $8,7 \%$ & $9,7 \%$ & $10,3 \%$ & $11,6 \%$ & $15,5 \%$ \\
\hline PX6 & $35,4 \%$ & $8,4 \%$ & $11,4 \%$ & $11,4 \%$ & $12,8 \%$ & $13,7 \%$ & $15,4 \%$ & $20,0 \%$ \\
\hline PX7 & $19,8 \%$ & $6,1 \%$ & $7,3 \%$ & $7,3 \%$ & $9,5 \%$ & $11,7 \%$ & $15,2 \%$ & $24,4 \%$ \\
\hline PX8 & $25,7 \%$ & $4,5 \%$ & $7,0 \%$ & $7,0 \%$ & $7,3 \%$ & $7,9 \%$ & $9,2 \%$ & $14,3 \%$ \\
\hline PX9 & $19,8 \%$ & $5,9 \%$ & $8,9 \%$ & $8,9 \%$ & $9,2 \%$ & $9,4 \%$ & $10,2 \%$ & $15,0 \%$ \\
\hline PX10 & $17,7 \%$ & $7,3 \%$ & $10,0 \%$ & $10,0 \%$ & $12,5 \%$ & $14,6 \%$ & $18,0 \%$ & $27,5 \%$ \\
\hline PY1 & $52,2 \%$ & $10,5 \%$ & $7,2 \%$ & $7,2 \%$ & $6,9 \%$ & $7,9 \%$ & $10,3 \%$ & $14,8 \%$ \\
\hline PY2 & $20,7 \%$ & $20,8 \%$ & $16,5 \%$ & $16,5 \%$ & $13,3 \%$ & $11,1 \%$ & $9,9 \%$ & $11,5 \%$ \\
\hline PY3 & $23,2 \%$ & $7,6 \%$ & $7,6 \%$ & $7,6 \%$ & $7,5 \%$ & $7,3 \%$ & $7,0 \%$ & $5,9 \%$ \\
\hline PY4 & $30,0 \%$ & $0,6 \%$ & $0,4 \%$ & $0,4 \%$ & $0,5 \%$ & $0,5 \%$ & $0,8 \%$ & $2,3 \%$ \\
\hline PY5 & $83,2 \%$ & $24,3 \%$ & $18,6 \%$ & $18,6 \%$ & $17,5 \%$ & $18,9 \%$ & $21,7 \%$ & $22,2 \%$ \\
\hline PY6 & $7,9 \%$ & $3,8 \%$ & $2,7 \%$ & $2,7 \%$ & $2,8 \%$ & $4,3 \%$ & $7,7 \%$ & $17,2 \%$ \\
\hline PY7 & $79,4 \%$ & $30,7 \%$ & $23,1 \%$ & $23,1 \%$ & $19,0 \%$ & $16,8 \%$ & $15,6 \%$ & $13,8 \%$ \\
\hline PY8 & $9,4 \%$ & $4,9 \%$ & $3,7 \%$ & $3,7 \%$ & $2,9 \%$ & $2,4 \%$ & $2,4 \%$ & $4,1 \%$ \\
\hline PY9 & $71,8 \%$ & $30,8 \%$ & $25,0 \%$ & $25,0 \%$ & $21,1 \%$ & $18,5 \%$ & $16,6 \%$ & $12,5 \%$ \\
\hline PY10 & $78,0 \%$ & $29,7 \%$ & $22,0 \%$ & $22,0 \%$ & $18,1 \%$ & $16,1 \%$ & $15,1 \%$ & $13,5 \%$ \\
\hline PY11 & $2,7 \%$ & $1,5 \%$ & $2,0 \%$ & $2,0 \%$ & $2,5 \%$ & $3,4 \%$ & $5,5 \%$ & $14,3 \%$ \\
\hline PY12 & $12,0 \%$ & $11,5 \%$ & $11,9 \%$ & $11,9 \%$ & $12,5 \%$ & $13,8 \%$ & $16,5 \%$ & $23,4 \%$ \\
\hline PY13 & $83,8 \%$ & $24,8 \%$ & $20,2 \%$ & $20,2 \%$ & $19,2 \%$ & $20,1 \%$ & $22,1 \%$ & $21,9 \%$ \\
\hline PY14 & $20,6 \%$ & $0,7 \%$ & $0,3 \%$ & $0,3 \%$ & $1,1 \%$ & $2,1 \%$ & $4,0 \%$ & $8,9 \%$ \\
\hline PY15 & $46,4 \%$ & $13,5 \%$ & $12,5 \%$ & $12,5 \%$ & $12,2 \%$ & $12,3 \%$ & $13,2 \%$ & $16,6 \%$ \\
\hline PY16 & $17,4 \%$ & $12,1 \%$ & $11,9 \%$ & $11,9 \%$ & $11,2 \%$ & $10,5 \%$ & $9,8 \%$ & $9,8 \%$ \\
\hline
\end{tabular}

Tabela B.9 - CV $\sigma$ - Modelo M3-ISE-EVO

\begin{tabular}{|c|c|c|c|c|c|c|c|c|}
\cline { 2 - 10 } \multicolumn{1}{c|}{} & \multicolumn{7}{c|}{ Pavimento } \\
\hline PAREDE & 1 & 2 & 3 & 4 & 5 & 6 & 7 & 8 \\
\hline PX1 & $21,3 \%$ & $7,7 \%$ & $4,1 \%$ & $3,5 \%$ & $4,4 \%$ & $6,0 \%$ & $8,3 \%$ & $14,5 \%$ \\
\hline PX2 & $34,9 \%$ & $12,7 \%$ & $5,1 \%$ & $8,1 \%$ & $12,5 \%$ & $16,8 \%$ & $22,9 \%$ & $38,8 \%$ \\
\hline PX3 & $7,8 \%$ & $4,3 \%$ & $3,1 \%$ & $2,2 \%$ & $2,3 \%$ & $2,4 \%$ & $2,8 \%$ & $6,3 \%$ \\
\hline PX4 & $22,7 \%$ & $5,3 \%$ & $1,8 \%$ & $2,0 \%$ & $2,8 \%$ & $3,4 \%$ & $4,1 \%$ & $8,2 \%$ \\
\hline PX5 & $37,3 \%$ & $0,8 \%$ & $4,6 \%$ & $8,0 \%$ & $9,2 \%$ & $10,0 \%$ & $11,3 \%$ & $15,2 \%$ \\
\hline PX6 & $36,4 \%$ & $6,7 \%$ & $7,7 \%$ & $10,9 \%$ & $12,4 \%$ & $13,5 \%$ & $15,3 \%$ & $20,0 \%$ \\
\hline PX7 & $19,5 \%$ & $12,1 \%$ & $5,2 \%$ & $6,7 \%$ & $8,9 \%$ & $11,3 \%$ & $15,0 \%$ & $24,2 \%$ \\
\hline PX8 & $24,2 \%$ & $13,4 \%$ & $4,1 \%$ & $6,5 \%$ & $6,9 \%$ & $7,6 \%$ & $9,1 \%$ & $14,2 \%$ \\
\hline PX9 & $20,7 \%$ & $13,9 \%$ & $5,1 \%$ & $8,5 \%$ & $8,9 \%$ & $9,2 \%$ & $10,2 \%$ & $15,0 \%$ \\
\hline PX10 & $17,5 \%$ & $9,4 \%$ & $6,6 \%$ & $9,5 \%$ & $12,1 \%$ & $14,4 \%$ & $17,9 \%$ & $27,5 \%$ \\
\hline
\end{tabular}




\begin{tabular}{|c|c|c|c|c|c|c|c|c|}
\hline PY1 & $52,6 \%$ & $22,1 \%$ & $10,4 \%$ & $7,1 \%$ & $6,9 \%$ & $7,9 \%$ & $10,2 \%$ & $14,7 \%$ \\
\hline PY2 & $20,0 \%$ & $23,2 \%$ & $20,1 \%$ & $16,1 \%$ & $13,1 \%$ & $11,1 \%$ & $9,9 \%$ & $11,6 \%$ \\
\hline PY3 & $22,6 \%$ & $8,1 \%$ & $7,5 \%$ & $7,5 \%$ & $7,4 \%$ & $7,2 \%$ & $7,0 \%$ & $5,8 \%$ \\
\hline PY4 & $25,3 \%$ & $1,7 \%$ & $0,8 \%$ & $0,6 \%$ & $0,3 \%$ & $0,4 \%$ & $0,8 \%$ & $2,3 \%$ \\
\hline PY5 & $85,0 \%$ & $40,1 \%$ & $25,3 \%$ & $19,2 \%$ & $17,7 \%$ & $19,0 \%$ & $21,7 \%$ & $22,2 \%$ \\
\hline PY6 & $8,5 \%$ & $4,7 \%$ & $4,0 \%$ & $2,8 \%$ & $2,7 \%$ & $4,2 \%$ & $7,5 \%$ & $17,0 \%$ \\
\hline PY7 & $79,1 \%$ & $46,0 \%$ & $31,4 \%$ & $23,7 \%$ & $19,4 \%$ & $17,1 \%$ & $15,8 \%$ & $13,9 \%$ \\
\hline PY8 & $10,0 \%$ & $5,9 \%$ & $4,8 \%$ & $3,7 \%$ & $2,9 \%$ & $2,5 \%$ & $2,5 \%$ & $4,2 \%$ \\
\hline PY9 & $71,8 \%$ & $40,6 \%$ & $31,4 \%$ & $25,5 \%$ & $21,5 \%$ & $18,7 \%$ & $16,7 \%$ & $12,5 \%$ \\
\hline PY10 & $78,6 \%$ & $45,7 \%$ & $30,4 \%$ & $22,6 \%$ & $18,5 \%$ & $16,3 \%$ & $15,2 \%$ & $13,5 \%$ \\
\hline PY11 & $2,5 \%$ & $0,6 \%$ & $1,4 \%$ & $1,9 \%$ & $2,5 \%$ & $3,4 \%$ & $5,5 \%$ & $14,3 \%$ \\
\hline PY12 & $10,4 \%$ & $11,0 \%$ & $11,2 \%$ & $11,9 \%$ & $12,6 \%$ & $13,8 \%$ & $16,6 \%$ & $23,4 \%$ \\
\hline PY13 & $84,1 \%$ & $37,5 \%$ & $25,1 \%$ & $20,5 \%$ & $19,3 \%$ & $20,2 \%$ & $22,0 \%$ & $21,8 \%$ \\
\hline PY14 & $21,3 \%$ & $0,1 \%$ & $1,4 \%$ & $0,3 \%$ & $1,0 \%$ & $2,1 \%$ & $4,0 \%$ & $9,0 \%$ \\
\hline PY15 & $48,5 \%$ & $20,1 \%$ & $13,6 \%$ & $12,5 \%$ & $12,2 \%$ & $12,2 \%$ & $13,2 \%$ & $16,6 \%$ \\
\hline PY16 & $17,6 \%$ & $7,5 \%$ & $12,1 \%$ & $11,9 \%$ & $11,3 \%$ & $10,6 \%$ & $9,9 \%$ & $9,9 \%$ \\
\hline
\end{tabular}




\section{APÊNDICE C - RESULTADOS COMPLEMENTARES: CAPÍTULO 5}

No capítulo 5 foi relacionado a variação dos recalques nas paredes com a redistribuição de esforços nos elementos. Neste item são apresentadas a relação do coeficiente “ $\Delta \mathrm{AR}$ ” com os coeficientes “ $\eta$ ” nas paredes e grupos de paredes dos modelos M1-ISE-EVO e M2-ISE-EVO. Esses resultados são expostos por meio dos gráficos nas figuras C.1 a C.6. Os resultados referentes ao modelo M3-ISE-EVO estão expostos no item 5.4 do Capítulo 5. As conclusões e levantamentos sobre essa reação foram realizadas no item 5.4 do referido capítulo.

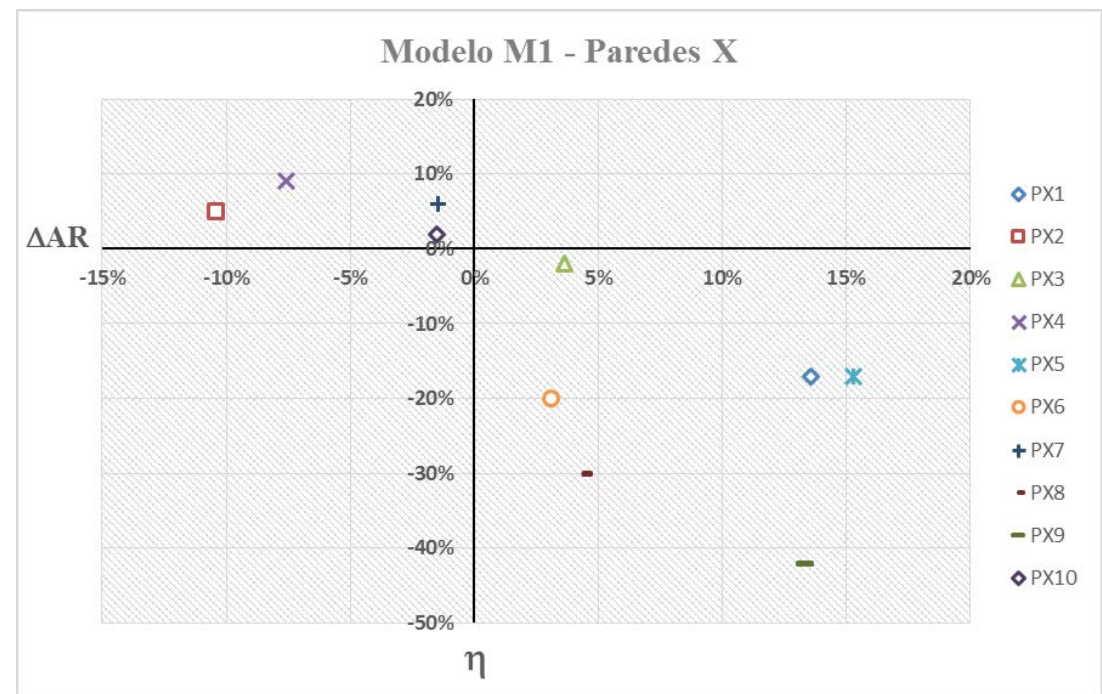

Figura C.1 - $\eta$ x $\Delta \mathrm{AR}$ - Modelo M1 - Paredes-X

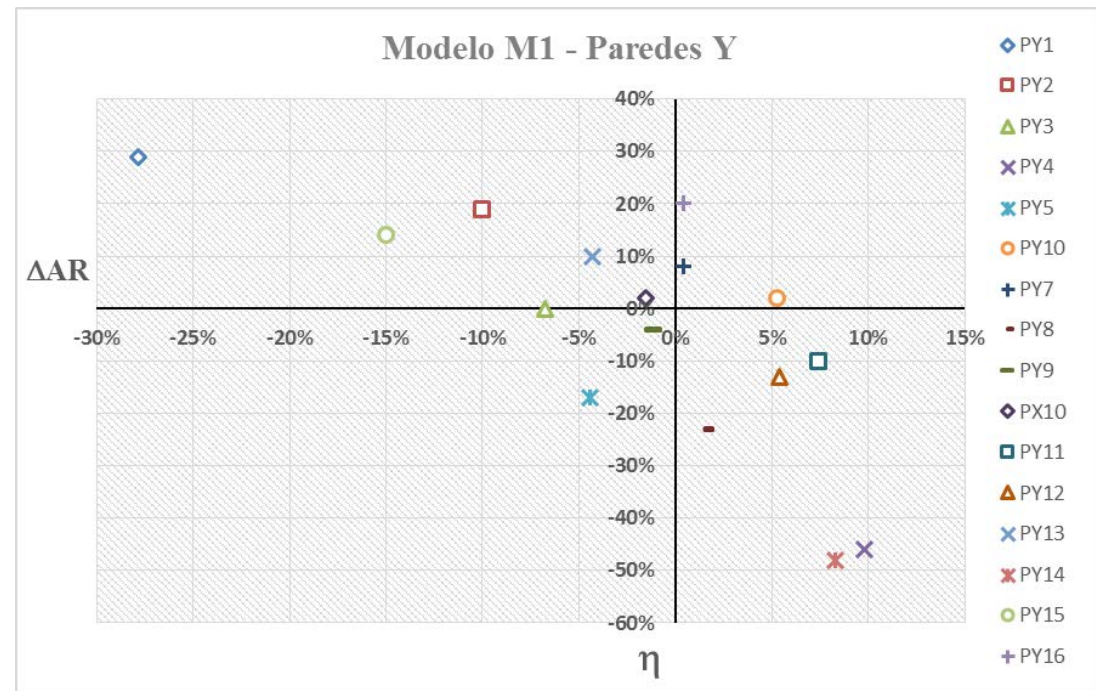

Figura C.2 - $\eta$ x $\Delta \mathrm{AR}$ - Modelo M1 - Paredes-Y 


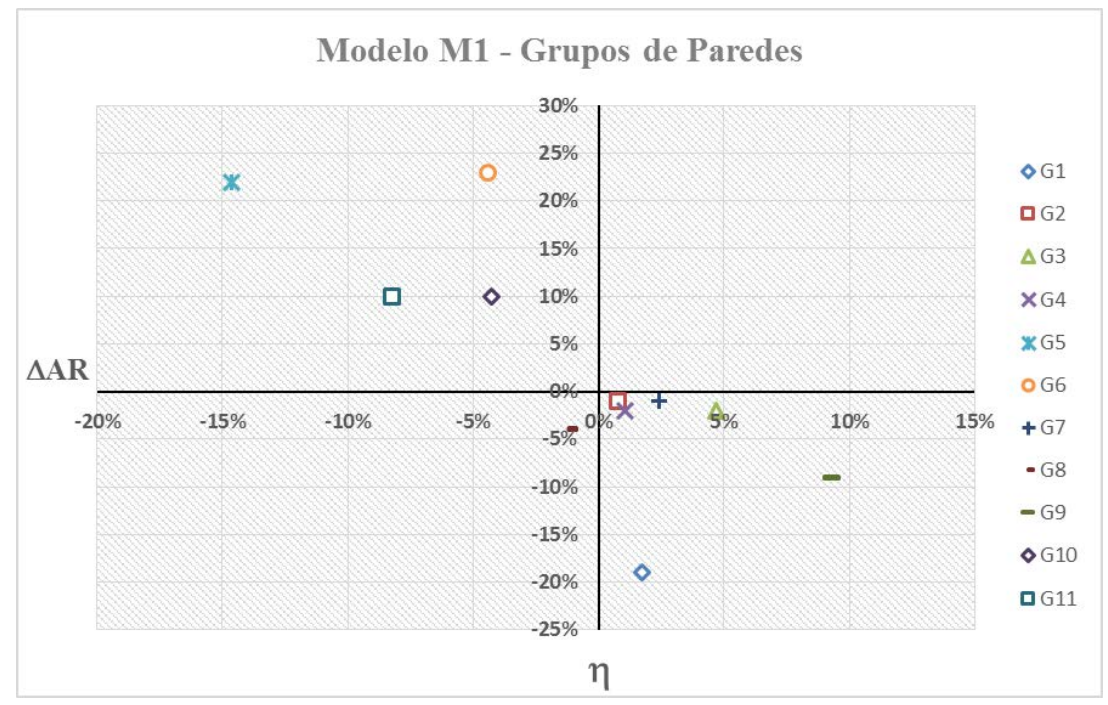

Figura C.3 - $\eta$ x $\Delta \mathrm{AR}$ - Modelo M1 - Grupo de paredes

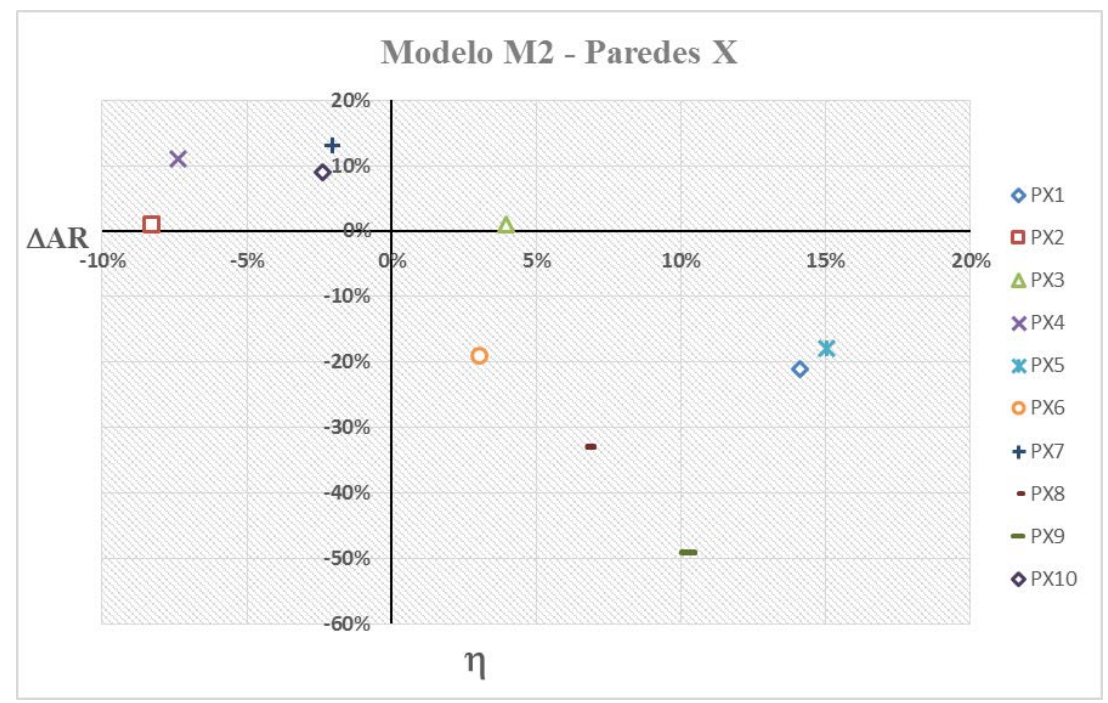

Figura C.4 - $\eta$ x $\Delta \mathrm{AR}$ - Modelo M2 - Paredes X

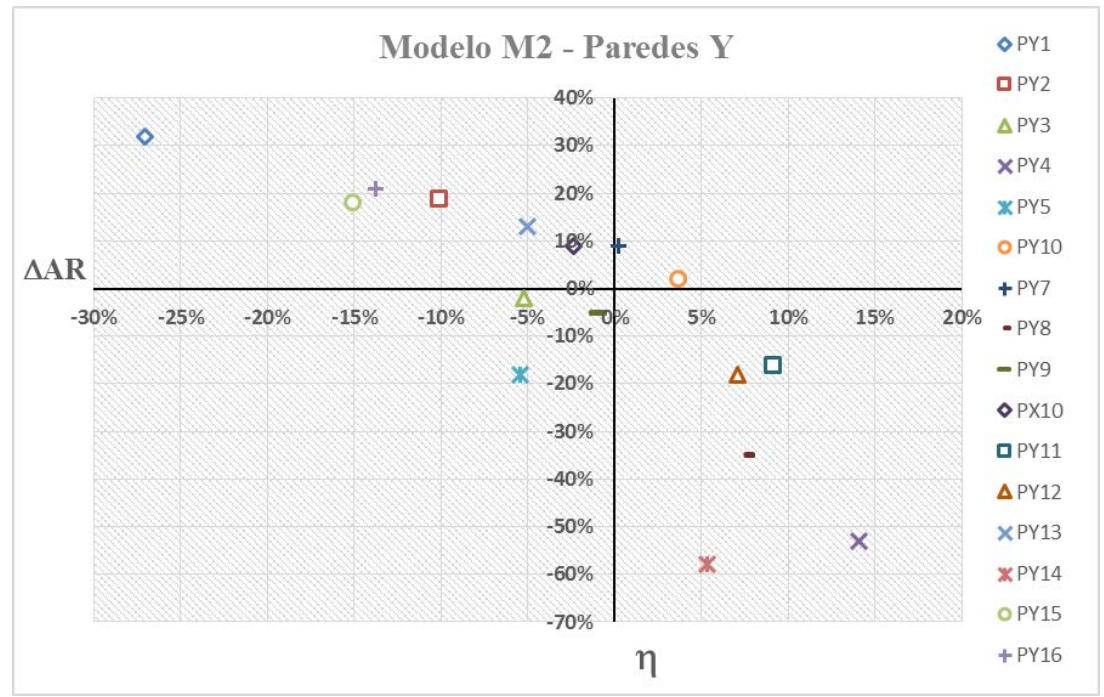

Figura C.5 - $\eta$ x $\Delta$ AR - Modelo M2 - Paredes - Y 


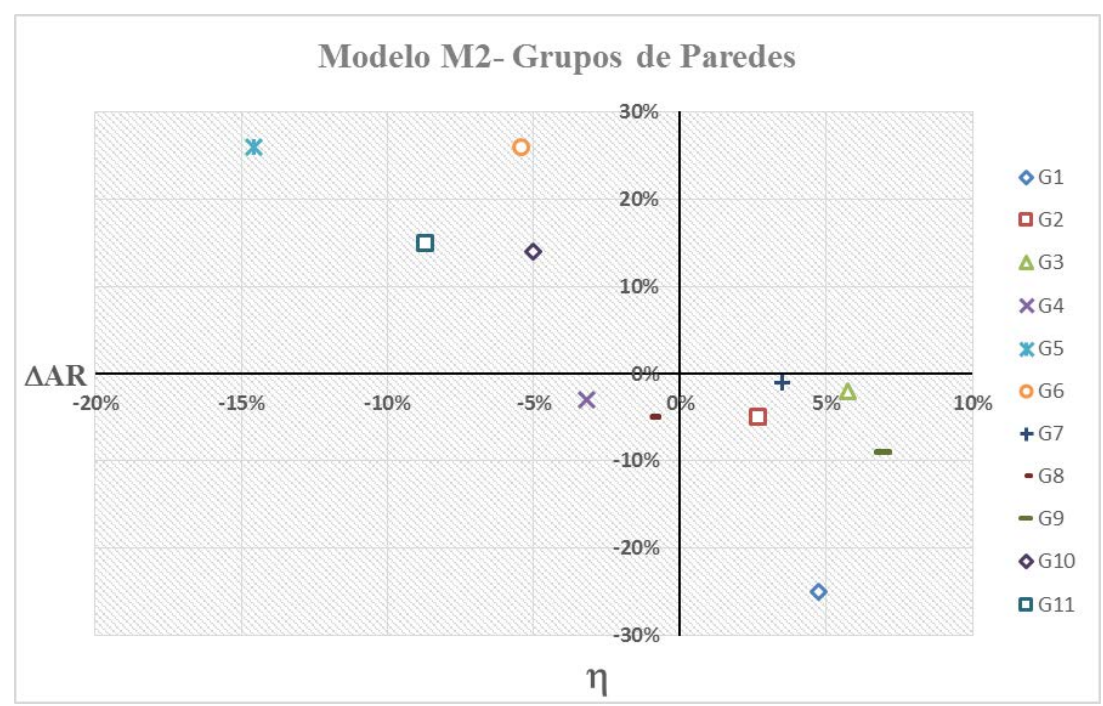

Figura C.6 - $\eta \mathrm{x} \Delta \mathrm{AR}$ - Modelo M2 - Grupo de paredes - Y 



\section{APÊNDICE D - RESULTADOS COMPLEMENTARES: CAPÍTULO 6}

Os modelos ISE-EVO-HET1 e ISE-EVO-HET2, que foram discutidos no item 6.3.1 do capítulo 6, foram baseados em estruturas reais nas quais os resultados numéricos foram comparados com as medições experimentais realizadas em obra. A confrontação dos resultados experimentais com os numéricos não foi mostrada no capítulo 6. Este item apresenta a confrontação dos resultados numéricos experimentais dos dois modelos com a consideração simplificada da presença do solo heterogêneo. O procedimento realizado é o mesmo disposto no capítulo 2. A posição dos pinos de medição são os mesmos apresentados no referido capítulo que são mostrados novamente na Figura D-1. A Figura D.2 mostra a confrontação dos resultados no modelo ISE-EVO-HET1 e a Figura D.3 mostra a mesma comparação no modelo ISE-EVO-HET2.

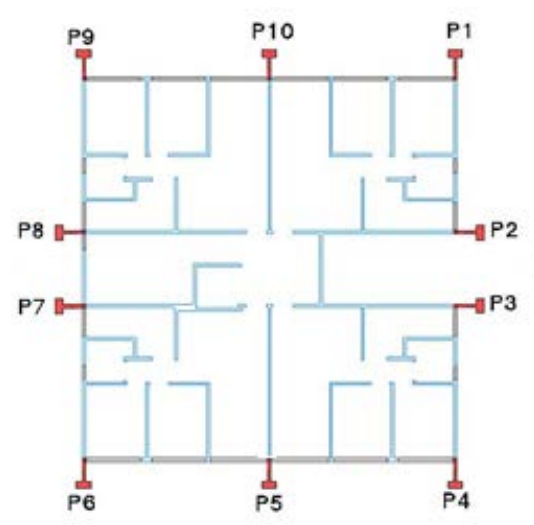

Figura D.1 -Modelo ISE-EVO-HET1

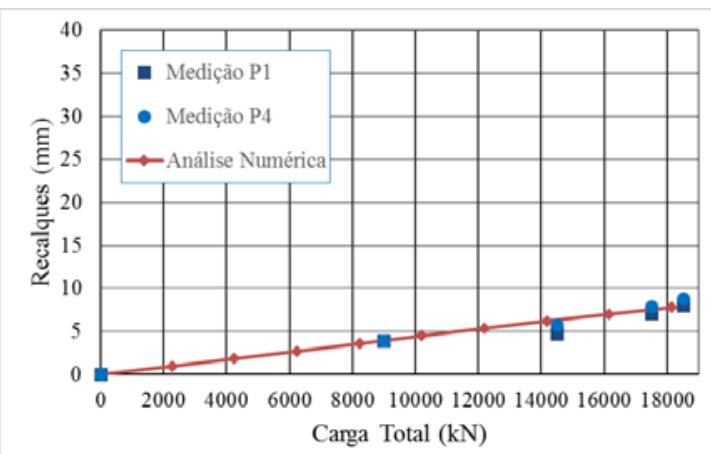

a) Pinos P1 e P4

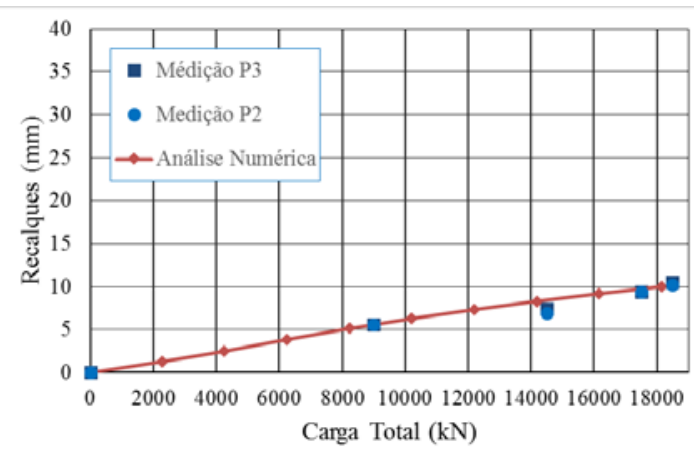

b) Pinos P3 e P2 


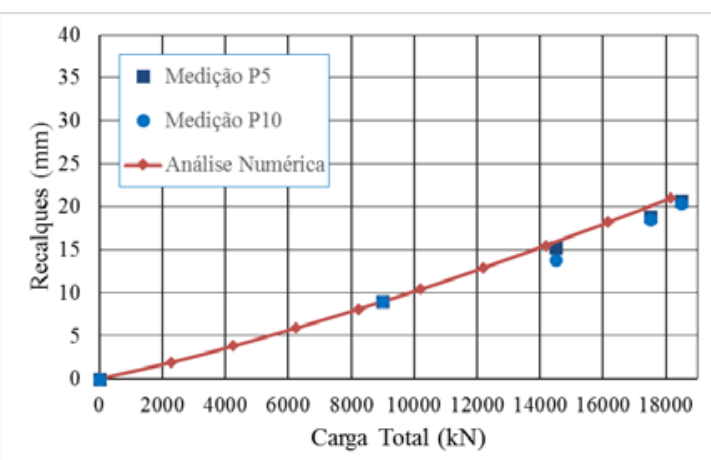

c)

Pinos P5 e P10

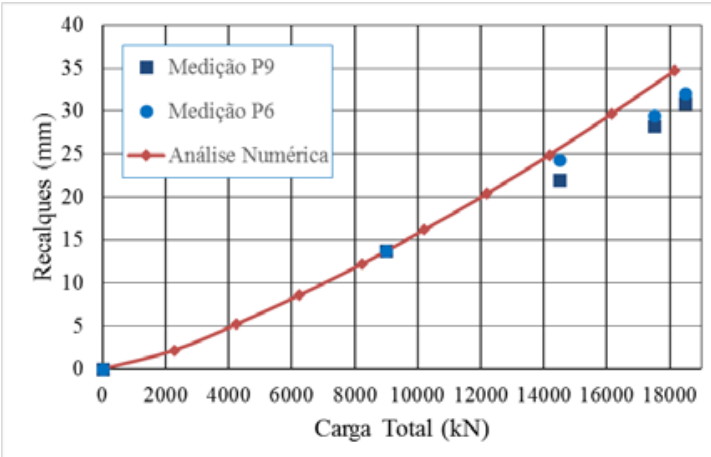

d) Pinos P9 e P6

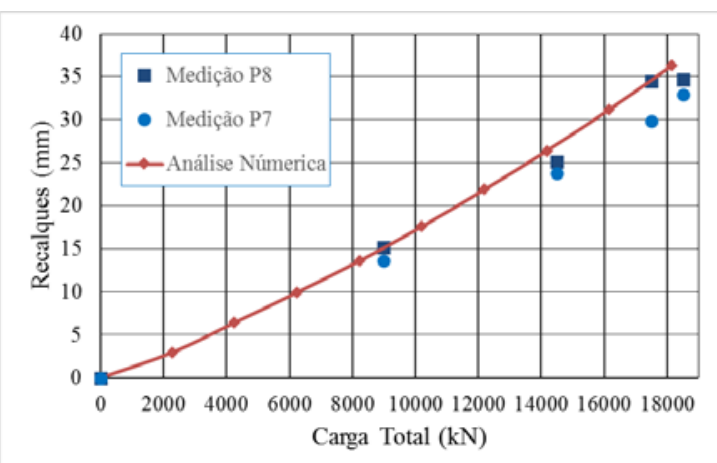

e) Pinos $\mathrm{P} 8$ e $\mathrm{P} 7$

Figura D.2 -Modelo ISE-EVO-HET1

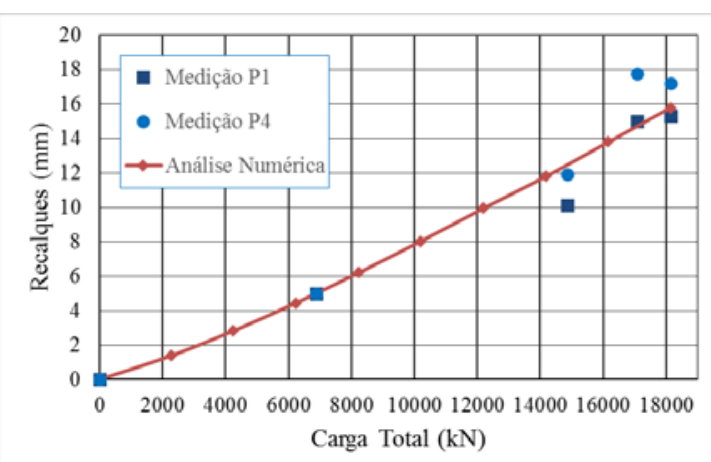

a) Pinos P1 e P4

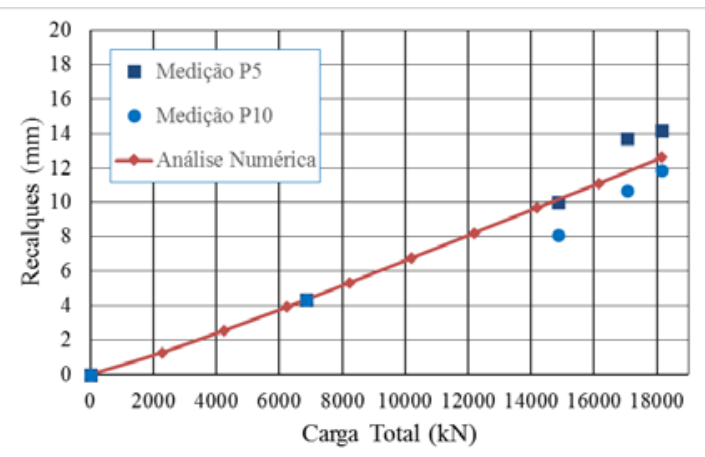

c)

Pinos P5 e P10

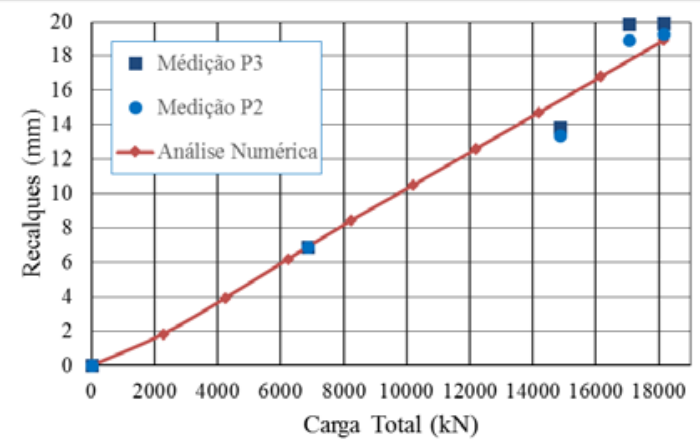

b) Pinos P3 e P2

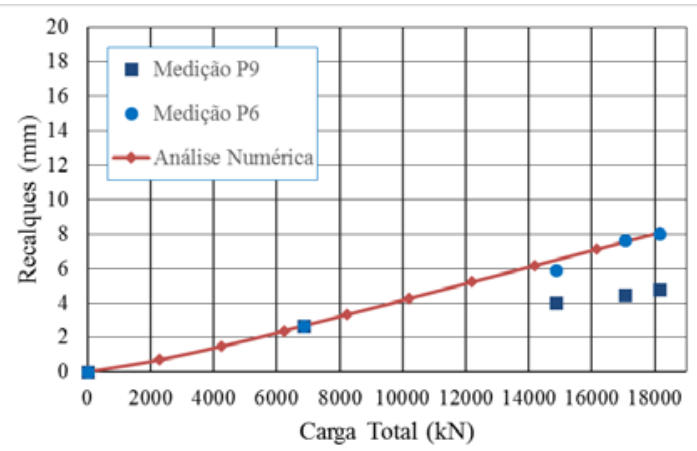

d) Pinos P9 e P6 


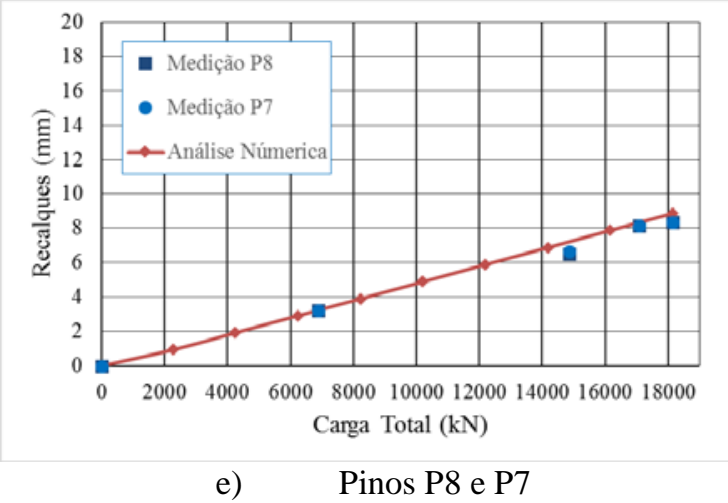

Figura D.3 -Modelo ISE-EVO-HET2

As Figuras D.2 e D3 mostram que apesar da simplificação do modelo na consideração da heterogeneidade do solo os resultados numéricos ficaram próximos dos valores medidos em obra. Devido a estes resultados o modelo, dentro de suas simplificações, pode ser utilizado para as análises comparativas realizadas no capítulo 6. 